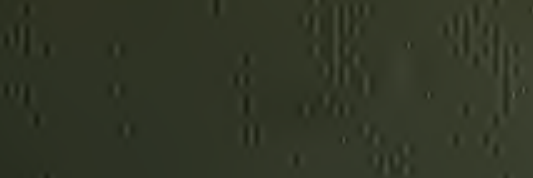

$0 \quad$ igio

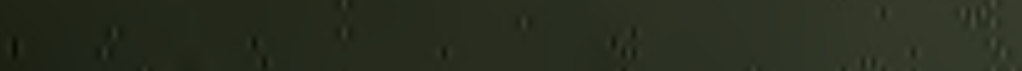

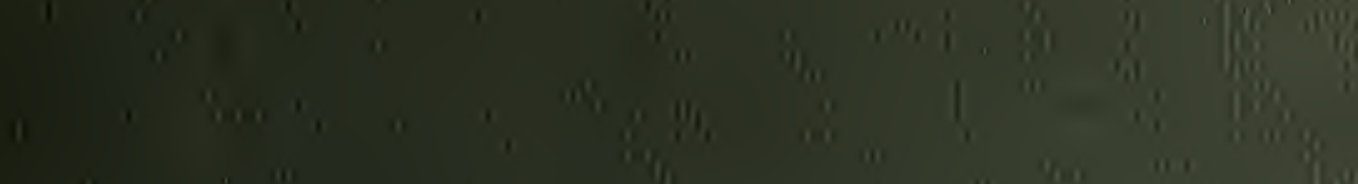

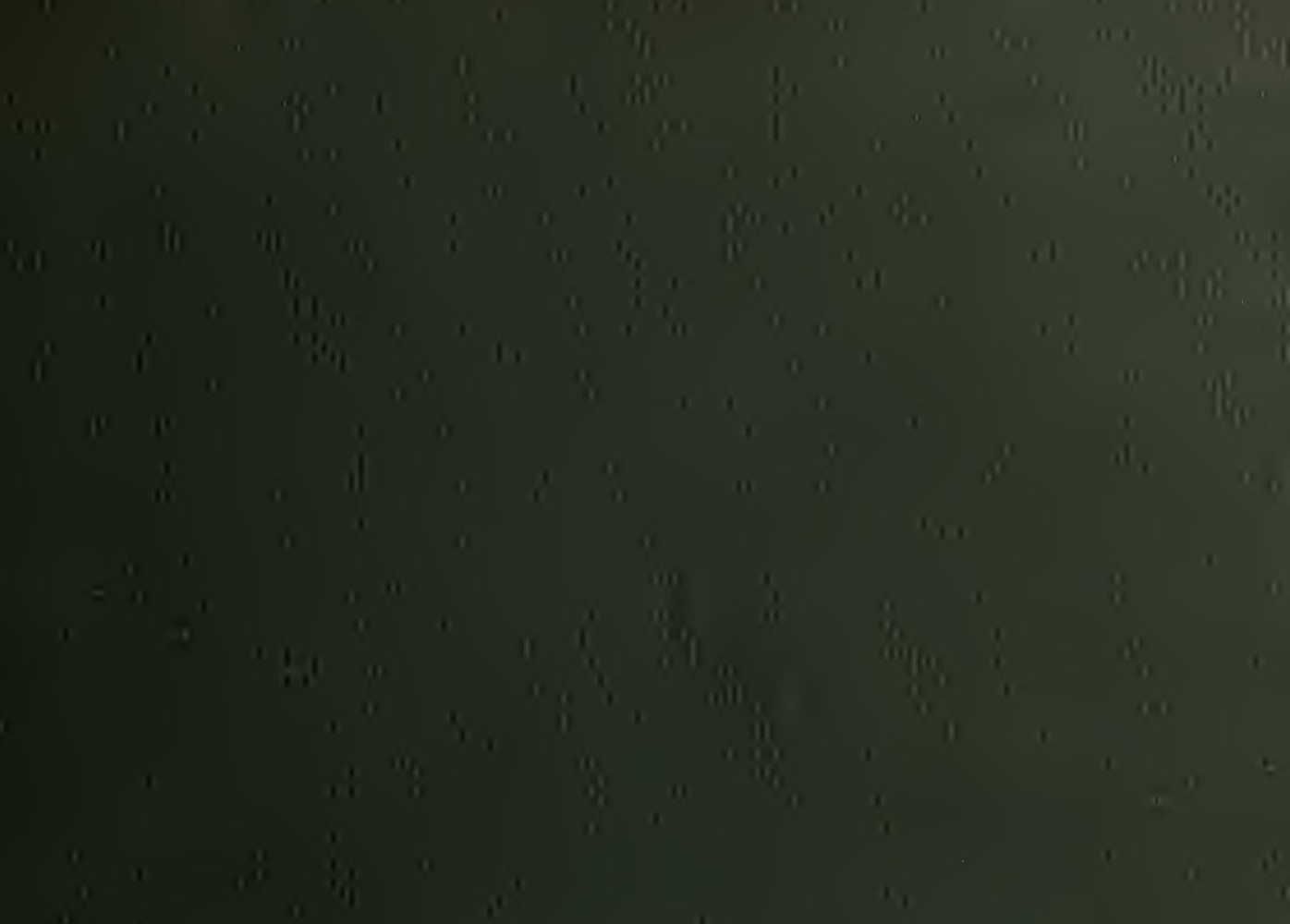

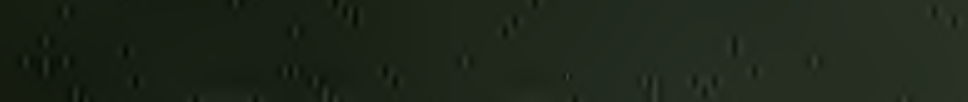

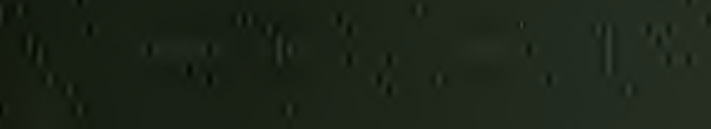

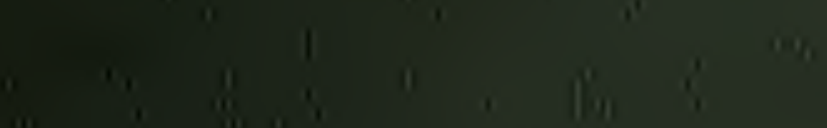

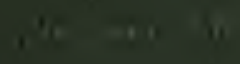
: 11 "ix

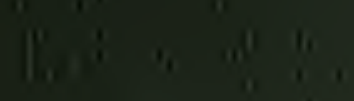
$\left\{\begin{array}{l}1 \\ 1 \\ 1\end{array}\right.$$$
\text { (T) }
$$

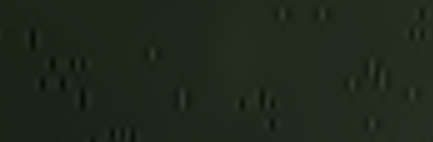

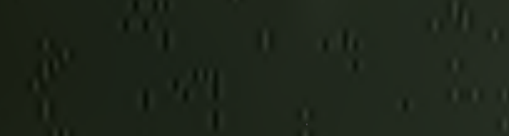

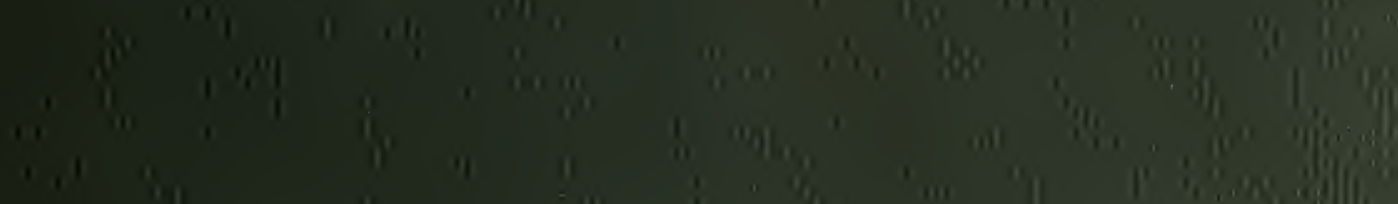

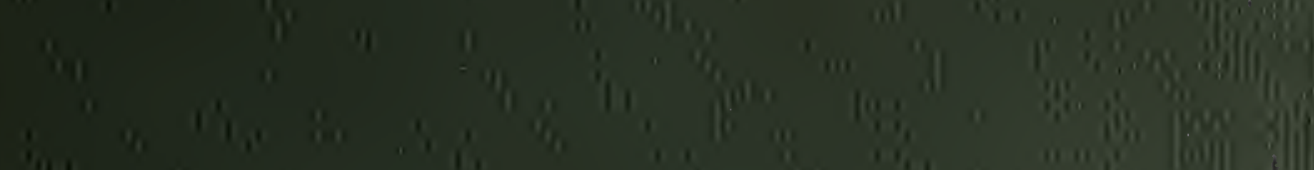









\title{
ABHANDLUNGEN
}

ZOOL.BO'IAN. GESELLSCHAF'T IN WIEN.

\author{
BAND XIII. HEFT I.
}

HERAUSGEGEBEN MTT UNTERSTÜTZUNG DES BUNDESMINISTERIUMS FÜR INNERES UND UNTERRICHT.

\section{DIP'TEROLOGISCHE STUDIEN}

YON

\author{
'T'H. BECKER
}

\section{DOLTCHOPODIDAE}

\section{B. NEARKTISCHE UNI) NEOTROPISCHE REGION}

MIT 147 FIGUREN IM TEXT

WIEN, 1921

VERLAG DER ZOOL.BOTAN. GESELLSCHAFT 


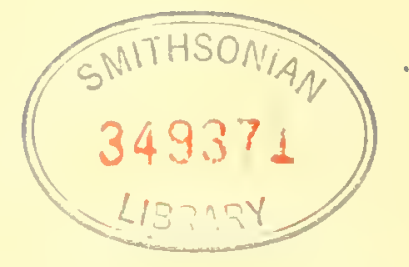

Druck von Adolf Holzhausen in Wien. 


\section{Dolichopodidae.}

\section{B. Nearktische und neotropische Region.}

\section{Einleitung.}

Es erschien mir ersprießlich, diesc beiden Regionen mit ihrer Fauna nicht getrennt zu behandeln, sondern sie zusammenzufassen, da beide unmerklich ineinander ibergehen und ungefïh die Hälfte ihrer Gattungen gemeinsam rorkommen.

Was den Umfang der Regionen und ihre Begrenzung anlangt, so bin ich hier auch der sonst zum Ausdruck gebrachten iiblichen Auordnung gefolgt, nach der zur neotropischen Zone außer Siid-Amerika und dem westindischen Archipel anch noch Mexiko gerechnet wird.

Die verwandtschaftlichen Beziehungen zur paliiarktischen Fanna sind selbstverstilndlich innerhalb der nearktischen Region erlueblich größer als bei der neotropischen. Aus der Zusammenstellung der Gattungen ergibt sich folgendes Bild:

Paläarktische Region mit 66 Gattungen,

Nearktische und neotropische Region mit 62 Gattungen, von denen 18 gemeinschaftlich anftreten.

Europa hat ferner mit Nord-Amerika 27 Gattungen gemeinsam, mit Stid-Amerika nur 18.

Meine nachstehenden Untersuchungen stitzen sich einerseits auf die Arbeiten von Loew ïher nordamerikanisehe Dolichopodiden sowie auf die der neueren amerikanischen Dipterologen, unter denen sich in erster Linie Aldricl, Wheeler, Helander, Brues und Coquillett durch besonders eingehende Studien auszeichnen, anderseits auf mir zur Verfiigung gestelltes Sammelmaterial aus den Museen von Berlin, Stettin, Wien, Budapest; ferner konnte ich die im Dresdner Museum aufbewahrte Schnusesche Sammlung ans Sud-Amerika benutzen. Aldrich und Melander untersttitzten mich durch Uberlassung von Typen. Dr. W. Lundbeek in Kopenhagen gab mir wert- 
volle Aufschliisse iber Wiedemanusche Arten. Es ist mir eine angenehme Pflicht, allen Museumsvorstinden und Frennden auch an dieser Stelle für ihre Hilfe meinen verbindlichsten Dank ausznsprechen.

Liegnitz, 19. September 1917.

Th. B e eker.

Anmerknng. Wie ich erst vor kurzem durch Mitteilnng von J. M, Aldrich aus Washington und M. C. Van Duzee aus Buffalo erfahren habe, sind willurend des Krieges, hauptsäellich aber in den beiden letzten Jahren verschiedene wertvolle Abhandlungen iber nordamerikanisehe Gattungen der Dolichopodiden aus der Feder von M. C. Vau Duzee in folgenden Zeitschriften erschienen:

Annals of Entomol. Soc. of Amerika (Nemrogona).

Psyche (Thrypticus, Diaplıorus, Asyndetus).

The Cauadian Entomologist.

Entomological News (Sympyenus, Sciopus).

Proccedings of Californian Acarlemy of Sciences (Medeterus).

Bulletin of the Buffalo Soc. of Nat. Sciences (Diaphorus).

Washington University Studies.

Die Verhältnisse fiigen sich insoweit günstig, als es mir möglich geworden ist, meine bereits im Jalne 1917 fertig vorliegende Abuanding jetzt, nach Verlauf ron fast 4 Jahren, zu veröfentlichen. Nun ist es mir aber nicht mehr möglich, die rorhin erwïhnten amerikinischen Arbeiten für diese meine Abhandlung noch zu verwerten; es wiirde dies einer fast vollständigen Umarbeitung gleichkommen und dadurch die Drucklegung nicht nur verzögert, sondern wahrscheintich ganz in F'rage gestellt werden. Man möge also die neneren amerikanischen Arbeiten als Ergänzungen zu der meinen ansehen und bewerten.

liegnitz, 10. Februar 1921.

Th. Be cker. 


\section{Ëbersichtstahelle iiber die Giruppen und Gattnngen.}

\section{Dolichopodinae.}

Dolichomes Latl.

Hygrocelcuthus Lw.. . . . . . 10

Hercostomus Lw. . . . . . . 39

Practius Big. . . . . . . .

I'elastoncurus Lw. ...... 35

Sarcionus Aldr......... 3

Stenopygium n. genus .... 1

Tachytrcchus Walk ....... 12

Polymedon 0. S. ........ T

Macellocerus Mik. ....... 5

Psilichium n. genus ..... 1

Sybistroma Meig. . . . . . . 1

Leptocorypha Aldr. . . . . . . 1

Gonioneurum n. gents .... 1

Arten . . 249

\section{Plasjionenrinae.}

Plagioncurus Lw......... 1

Arten .. 1

\section{IIydrophorinde.}

Hydrophorus Fall. ....... 28

Scellus Lw. .......... 7

Liancalus Lw. ........ 5

Thinophilus Walk ....... 2

Diostracus Lw. .......... 2

Hypocharassus llik. ...... 2

Syntomoneurum n. genus .. 1

Phylarchus Aldr......... 1

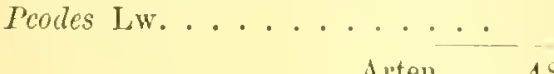

IV. Aphrosylinate.

Paraphrosylus n. subg..... 3

Arten .. 3

T. Medeterinae.

Artion Medetera Fisch. . . . . . . 26

Thrypticus Gerst. . . . . . . 7

Arten . . 33

\section{Rhaphimar.}

Thaphium Meig. ....... 1

Porphyrops Meig. . . . . . . 9

Tiphandrium Lr. . . . . . . 1

Syntormon Lw. . . . . . . 13

Eutarsus [,w. . . . . . . 1

Achalcus Lw. ......... 2

Peloropcodes Wheel. ....... 1

Syslenus Lw. . . . . . . . . 1

Arten . . 29

VII. Neurogoninae.

Neurogona Rond ........ 11

Arten . . 11

\section{Diaphorinae.}

Diaphorus Meig. ....... 22

Lyroneurus Lw. ....... 10

Chrysotus Meig. ........ 38

Cocloglutus Aldr......... 1

Asyndetus Iw........ 6

Argyra Meig. ........ 8

Leucostola Lw. ......... 2

Achradocera u. genus..... 3

Symbolia n. genus ....... 1

Fanthina Aldr......... 1

Arten . . 92

IX. Stolidosominae.

Stolidosoma n. gemus ..... 4

Arten .. 4 
X. Campicuemince.

\section{Carten}

6 Condylostylus Big. ........ 161

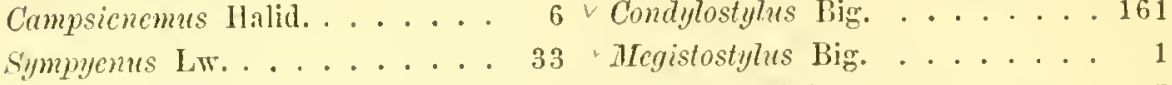

Subsympycnus n. genus ... 1 v Mesorhaga Schin........ 7

Hyptiochaeta 11. genus .... 1 teptorketum Aldr. ...... 1

Calyrochactus Big. ....... 6 . . . . . . . . 22

Chrysotimus Lw. ....... 3

Tanthochlorus Lw. ....... 1

Ancpsiomyia Bezzi ....... 1

Tenchophorus Lw. ...... 1 Anchineura Thoms....... 1

1. Dolichopodinae....... Arten 247

II. Plagioneurinae .... ${ }_{n} 1$

III. Hydrophorinae...... , 48

IV. Aplrosylinae....... , 3

V. Jedetcrinae ...... " " 33

VI. Thaphiinat....... „ 29

VII. Neurogoninac ......

VIII. Dirphorinae ........,$\quad 92$

IX. Stolidosominae.... n 4

X. Campsicneminae .....,, 53

XI. Chrysosomatinae ..... , 192

XII. Genus incertae sedis. . $\frac{\pi}{\text { Arten } 714}$ 


\section{Gruppe I.}

\section{Dolichopodinae.}

Der Charakter dieser Gruppe in der nearktisehen sowie in der neotropischen Region ist fast ebenso einheitlich wie in der paläarktisehen; nur bei einer siddamerikanisehen neuen Gattung Psilichium finden wir eine Ansnahme von der allgemeinen Regel, nach der das erste Fühlerglied oberseits behaart ist. Das Fehlen dieser Haare findet aber seine natiirliche Erklärung darin, daß auch am ganzen Förper, namentlich am Thorax, Kopf und an den Hiiften alle Borsten und Haare bis anf geringe Teile ganz geschwunten sind. Daß bei dieser allgemeinen Riickbildung auch die Härehen anf dem ersten Fühlergliede verloren gegangen, ist also ein ganz natirlieher Vorgang und kamn daher dieser Umstand bei der allgemeinen Bewertung der Form nicht so ins Gewieht fallen. (Siehe das Nähere bei Psilichium.)

Wenn wir in dieser Gruppe innerbalb der paläarktischen Region 11 Gattungen aufzählen konnten, so sind es für die nearktische Zone deren nur 8, für die neotropische 10 Gattungen; es sind die folgenden:

$$
\text { Nearktische Region. Neotropisebe Region. }
$$

Dolichopus Latr. . . . . . . . . . . . .

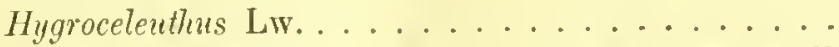

Tachytrechus Walk ........Tachytrechus Walk:

Hercostomus Lw. . . . . . . . . . . . . . . .

Paraclius Lw. . . . . . . . Paraclius Lw.

Pelastoneurus Lw. . . . . . . Pelastoneurus Lw.

Polymedon O.S. . ........ Polymedon O.S.

Macellocerus Dik.

Sybistroma Meig.

Sarcionus Aldr.

Leptocoryphia Aldr.

Stenopygium n. gen.

Gonioneurum 1. gen.

Psilichium n. gen.

Unsere paliarktische Region hat demnach mit der nearktisehen die vier Gattnngen Dolichopus, Iyygroceleuthus, Tachytrechus nnd Hercostomus gemeinsam, mit der neotropischen Region hingegen nur die beiden Sybi- 
stroma und Tachytrechus. In Nord- und Südamerika sind gemeinsame Gattungen: Paraclius, P'elastonewns, Tachytrechus und I'olymedon.

\section{Bestimmungstabelle fiir die Gattungen der Dolichopodinae} der nearktischen und neotropischen Region.

1 Hintermetatarsus beborstet . . . . . . . . . . . . 2

- Hintermetatarsus ohue längere Borsten . . . . . . . . . . 3

2 Erstes Fuihlerglied verlängert und an der inneren Spitze mit rorspringender Eeke. Untergesicht bis unter die Augen hinabreichend (ठ)

Iygroceleuthus Lw.

- Erstes Fühlerglied cinfaeh, nielıt verlïngert. Untergesieht nieht bis unter die dugen reichend. . . . . . . Dolichomus Latr.

3 Fuihlerborste gefiedert . . . . . . . . . . . . . . . . 4

- Fühlerborste nicht gefiedert, naekt oder pubeszent . . . . . . 5

4 Gesicht breit, oben eingedriickt, unten etwas gewölbt rortretend. Thoraxriieken mit schwarz sammetartigen Fleeken Pelastoncurus Lw.

- Gesicht schmal, gerade herabgehend. . . . . Sarcioms Aldr.

5 Untergesieht bandförmig bis unter den Angenrand linals rellängert. Erstes Fühlerglied ron gewöhnlieher Länge und Form. Sehiippchen, namentlich beim männliehen Geschleeht fïeher- oder besenförmig zusammengefaltet, mit langen Wimpern . . . . . . . 6

- Untergesieht bis zur nnteren Augeneeke himabreiehend. ( $\sigma^{7}$ ) Fliigeladern auf der oberen Fligelhälfte etwas zusammengedringt. Kopf hochgestellt . . . . . . . . . . Tuchytrechus Walk.

- Untergesielıt nicht bis zum unteren Augenrand reiehend . . . 7

6 Dritte Laingsader gerade oder nur wenig in gleicher Riehtung wie die Vorderrandader gebogen. Vierte Längsader an der Flügelbeule mit sanfter Bieguug und gleichartiger Kriimmung parallel zur dritten an der Flügelspitze endigend; hintere Querader senkrecht zur vierten Längsader . . . . . . . . . . . Polymedon O. S.

Dritte Lïngsader stark nach alufwärts gebogen. Vierte Längsader stumpfwinkelig aufbiegend und am Eude parallel zur dritten Längsader weit rol der Fliggelspitze endigend; hintere Querader gebogen und fast parallel zum Fligellinterrande Gonioneurum n. ڤ..

7 Fiihlerborste verlängert $\left(\sigma^{\top}\right)$, an Ende und mitunter auch auf der Mitte blattaltig rerbreitert . . . . . . . . . . . S

- Fühlerborste nicht verlängert und rerbreitert. . . . . . . . 9

8 Erstes Fiihlerglied $\left(\sigma^{7}\right)$ verlaingert, etwas verdickt und deutlieh behart; zweites Glied rerkiimmert, das dritte knrz; Fiihlerborste dorsal, zweiteilig. . . . . . . . Macellocerus Mik.

- Erstes Fihlerglied kurz, unten spitz rorgezogen, naekt, das zweite Fiihlerglied dentlich, das dritte kurz mit subapikaler zweiteiliger Borste

Psilichium n. g. 
Erstes Fiihlerglied etwas verdickt, aber kurz und behaart, das zweite deutlich, das dritte kurz bis lang mit dorsaler eingliedriger ( $\left.\sigma^{\top}\right)$ Borste; beim q zweighiedrig . . . . . . Sybistroma Meig.

9 Drittes Fiihlerglied zugespitzt, mit einer Einkerbung anf der Unterseite. Hypopyginm lang und schmal mit aufallend grofen langen äußeren Analauhïngen . . . . . . . . Stenopygium n. g. Drittes Fiihlerglied groß, verlängert, auf der Oberseite konkav, erstes Glied an der Spitze der Innenseite mit kegelförmigem Ansatz

Leptocorypha Aldr.

— Drittes Füblerglied ron gewöbnhicher Form . . . . . . . 10

10 Letzter Abschnitt der vierten lïngsader von der Querader aus auf der ersten Hiilfte gerale, dinn etwas knieförmig, in einem dem Fliigelvorderrande parallel lanfenden Bogen der dritten Längsader sich nälıernd. Hinterschenkel breit. Gesicht sehr selımal Puraclius Lw.

- Letzter Abschnitt der vierten Längsader ohne Kinick, mehr oder weniger in einer kontinuierlichen Kurre der dritten sich niihelnd, oder beide Queradern gleichzeitig konvergicrend oder parallel lanfend . . . . . . . . . . . Mercostomus Lw.

\section{Dolichopus.}

Latr., J'recis. caract. gen. Ins. 159. XYI (1790).

Iphis Meig., Nouvelle classif. 27. 46. (1800).

Rageneura Big., Ann. Suc. Ent. Fr. sẻr. G. X 269. (1890).

Ragheneura Rond., Dipt. Ital. P'roulr. I 144. 13. (1856).

Satyru Meig.. in lllig. Hagaz. f. Ins. II 272. 67. (1803).

Spathictira Big., Ann. Soc. Ent. Fr. sér. 6. X 278. 292 (1820).

Dolichopus scheint eine Gattung zu sein, die lediglich unsere nördliche Hemisphäre bewohnt; in der paläarktischen und nearktischen Region ist sie heimisch und stark vertreten; je meiter man aber nach Siiden kommt, desto geringer wird die Artenzulıl; in Afrika begegnen wir der Gattung nur noch im Norden der Sahara. Loew giht in seiner Fauna von Sud-Afrika an, daß die wenigen Arten, die als Dotichopus beschrieben seien, keinen Dorn auf dem Hintermetatursus zeigten und wahrscheinlich alle als zu Tachytrechus gebürig zu deuten wïren; auf den Kanarischen Inseln und anf Madeira fand ich dic Gattung nicht. In der orientalischen Region werden wir sie nur ganz vereinzelt antreffen. In Amerika kommt sie schon in Westindien nicht mehr vor. Aldriel in seiner Bearbeitung der Dipteren ron St. Vincent p. 309 (1896) und in der ron der Insel Grenada, Kansas Unir. 22 (1902) hat keinen Vertreter der Gattung genannt; er berichtet auch des weiteren, daß er in rerschicdenen gröberen Sammlungen aus Siid-Amerilia nichts daron gesehen babe; auch in Selunuses Samnlung - dem Sammelresultat von 5-6 Jahren - befindet sieh kein Dolichopus. Anf Grund der bis heute bekannten Fundergebnisse wird man im allgemeinen also wohl 
sagen könuen, daß der Wendekreis des Krebses fïr diese Gattung die siidlichste Grenze bildet. Wir haben es daher nur mit Arten der nearktischen Region zu tun.

Von älteren Schriftstellern sind hauptsächlich zu nennen: Walker und Philippi; von neneren außer Loew die amerikanischen Dipterologen Aldrich, Wheeler, Mclander, Brues und Coquillett; letztere, namentlich aber Aldrich, haben uns durch intensive Studien, vortreffliche Beschreibungen und bildliche Darstellung die nordamerikanischen Arten nahe gebracht, so dab wir uns rou dem Vorkommen und den Besonderheiten der dortigen Arten ein gutes Bild entwerfen können. Der Charakter der Gattung hat sicl gegeniiber unseren palïarktischen Arten nicht verändert; wir können nur feststellen, daß die Arten mit hellen Schenkeln und Fïhlern dort gegenïber den schwarzbeinigen noch mehr das Ubergewicht besitzen als bei uns.

Philippi hat in den Verh. zool.-bot. Ges. Wien XV p. 775-779 (1865) folgende elf Arten ans Chile neu beschrieben:

Dolichonus horticola $0^{7}$, kann der Beschreihung nach kein Dolichopodine sein.

Dolichopus lamprostethus $\rho$, unkenntlich.

Dotichopus dubiosus , unkenntlich.

Dolichopus nemoralis ơ, unkenntlich.

Dolichopus concolor, ist der Beschreibung nach keine Dolichopodine, da die Brast deutlich beborstet ist (ohne Geschlechtsangabe).

Dolichopus flavifrons, ist der Beschreibung und Figur nach keine Dolichopodine (ohne Geschlechtsangabe).

Dolichome exilis (ohne Geschlcchtsangabe), unkenntlich.

Dolichopus longipes ơ, keine Dolichopodine.

Dolichopus inormatus o, unkenntlich.

Dolichopus punctiger, ist der Beschreibung nach keine Dolichopodinc. (olne Geschlechtsangabe).

Dotichopus collimus (obne Geschlechtsangabe), unkenntlich.

Bei fiinf dieser Beschreibungen vermissen wir die Angabe des Geschlechts, drei derselben sind nur nach Weibchen gefertigt; bei den meisten Beschreibungen erkennt man sofort, daß nicht nur kein Dolichomus, sondern iiberhaupt kein Vertreter der Dolichopodidae vorgelegen hat, vichmehr ein 'Tier eincr anderen Familic, vielleicht einer Muscine. Philippi hat allerdings, um quasi seine Unkenntnis zu entschuldigen, vor jele Beschreibung und Namen ein Fragezeichen rorgesetzt; es wäre unter diesen Verbiltnissen besser gewesen, die Beschreibung zu nutcrlassen, anstatt iiberflussigen Ballast zu schaffen. Wir können einen Autor, der im Zweifel ist, ob er einen Dotichopus oder cine Ifuscine oder Tachine ror sich hat, nicht erust nehwen und miissen diese elf nenen Arten streichen. Dic Typen sind uns nicht zugiinglich, wahrscheinlich befinden sie sich in Chile.

Walker beschreibt in List of dipt. British Mus. p. 659-666 (1849) folgende 15 Arten: 
Dolichopus adjacens, affinis, ciliatus, coercens, confuis, contcrminus, contiguus, discessus, distractus, cxclusus, finitus, lamellipes, remolus, separatus, soccatus; ferner in den Ins. Saunders Dipt. I 213-215 (18566) folgende funf Arten: consors, contingens, hebes, ineptus, pulcher.

Von diesen 20 Arten sind 11 olne Gescblechtsangabe oder nur als Weibchen beschrieben; aber aucl die iibrigen sind oberflachlich eharakterisiert, alle unkenntlieh; Aldrich hat Walker vollständig bei Seite gelegt, auch wir wollen uns mit ihm nicht weiter besclüiftigen.

An Bestimmungstabellen fiir die nordamerikanischen Arten besitzen wir folgende drei, die alle gleich gnt brauchbar sind:

Loew, N. Beitr. VIII $9(1861)$. . . . . . . . 28 Arten

Loew, Monogr. Dipt. N. Amer. II 25 (1864) . . . . . 42 Arten

Aldrieh, Kansas Univers. Quart. Il No. 1 Juli (1893) . . S2 Arten ferner noeh Zusiatze und Abiinderungen zu Aldriehs Tabelle ron:

Nelander et Brues, Biolog. Bull. I No. 3 p. 145 (1900).

Mehrere Arten bat die nearktisehe Fauna mit der paläarktisehen Region gemein: es sind dies folgende: ammlipes Zett., brevipemis Meig., nigricomis Meig., groenlandicus Zett., plumipes Scop., plumitarsis Fall., remipes Wahlb., rupestris Halid., und ungulatus L.

In dem Material der Museumsammlungen von Berlin, Berlin-Dahlem, Wien, Budapest, Dresden, das mir für meine Arbeit zur Verfiigung stand, habe ich neue Arten nicht entdeeken können.

\section{$\ddot{y}$ Terzeichnis der Artell.
abdominalis Sag. Journ. Aead. Nat. Sc. Philadelphia VI 170 (1820).
Ist sicher, wie Loew schon vermutet, gar kein Dolichopus. Aldrich
in seinem Katalog 1905 vermutet darunter eine Argyra.}

1 acuminatus Lw. O, N. Beitr. VIII 12.4 (1861) et Monogr. Dipt. N. Amer.

II 34. 7 (1864). Vergleiche Loew's Beschreibung u. Bestimmungstabelle.

adustus Wied., Außereurop. zweifl. Ins. II 231.3 (1830) . . Urugnay

Ist der Beschreibung nach kein Dolichopus. Loew, der die Type im

Berliner Museum gesehen haben muß, gibt an, dab achstus zur

Gattung Lyroneurus gehöre, s. Monogr. Dipt. N. Amer. II 170 (1864).

Tclı habe die Type nicht mehr finden können.

agilis Aldr. = coloradensis Aldr.

2 agronomus Meland. et Brues , Biolog. Bull. I 140. fig. 17 (1900); s. 1. c. Beschreibung und Tabelle.

3 albiciliatus Lw. \&, Berlin. Ent. Zeitschr. VI 211.59(1862) et Monogr. Dipt. N. Amer. II 31. 4 (1864). Wheeler, Psyele V. No. 169, Mai 338 (1890). $\sigma^{7}$.

Loew beselırieb nur das Weibehen, Wheeler gibt auch die Besehreibung des Männchens.

4 allicoxa Aldr. O', Kansas Univ. Quart. II. 10. tab. I fig. 13 (1893). 
5 amphericus Meland. et Brues ơ , Biolog. Bull. 1 146. fig. 22 a - d (1900).

6 angustatus Aldr. O', Kansas Univ. Quart. 11 15. tab. 1 fig. 4 (1893).

7 ammulipes Zett. O’ , Ins. Lappon. Dipt. 710.12 (1838).

StenhammariZett., Dipt. Scand. $\left.11621.18(1843)^{1}\right)$ aus Labrador, Alaska.

8 apheles Melant. et Brues ơ, Biolog. Bull. 1144 fig. 221 (1900).

9 aurifacies Aldr. $\sigma^{7}$, Kansas Univ. Quart. II 20 (1893).

10 barycnemus Coquill. J" Proeed. Washington Acad. Se. II 4.24 (1900) Alaska

11 batillifer Lw. $\sigma^{7}$ o, N. Beitr. VIll 15.10 (1861) et Monogr. Dipt. N. A mer.

1145.17 (1864). 1 Exempla of von den White mountains (ron Mik bestimmt) in der Sammlnng des Wiener Hofmuseums.

12 bifractus Lw. o , N. Beitr. VIII 1:. 17 (1861) et IIonogr. Dipt. N. Amer. II 53. 24 (1864). $2 \sigma^{7}$ in der Sammlnng des Berliner \%ool. Mus. bipunctutus Maen. ơ f, Dipt. exot. II 2. 126.4. tab. XXII fig. 2 (1842)

Chile

Macquarts Beschreibuns, namentlich anch seine Zeichnung, schließen einen Dolichopus aus; letztere mit der Fliigeladerung und den beiden sehwärzlichen Fleeken auf der hinteren Querader und der Fliigelbeule weist ziemlich deutlieh darauf hin, daf seine Art zur Gattung Tachytrechus gehört.

13 hrevimanus Lw. O", N. Beitr. VIII 14.8 (1861) et Monogr. Dipt. N. Amer. II $29.12(1864)$.

socius Lw., Berlin. Entom. Zeitsehr. VI 211.60 (1862).

Aldrieh lat in seiner Bestimmungstabelle beide Arten noeh getrennt aufgefalit, unterscheidet sie aber nur durch etwas abweichende Fïrbung der Vordertarsen.

14 breripennis Meig. o', S. Besehr. IV 89. 27 (1824). Lw., Monogr. Dipt. N. Amer. II 37. 10 (1864).

15 bruncus Aldr. O, Kansas Univ. Quart. II 14 (1593). Nur als Weibehen bekannt und besehrieben.

16 calainus Meland. et Brues ơ, Biolog. Bull. I 138. fig. 15 (1900).

17 calcuratus Aldr. O', Kansas Univ. Quart. II 8 (1893).

18 canalirulatus Thoms. ơ, Eugenies Resa, Dipt. 512. 115 (1869).

O. Sack. o Mestern Diptera, Bull. Unit, Stat. Geolog. Survey 315. 3 (1877).

19 chrysostomus Lw. O’, N. Beitr. VIII 23.24(1861) et Monogr. Dipt. N. Amer. II 67.35 (1864).

20 coloradensis Aldr. ơ , Kansas Univ. Quart II 26 (1893). agilis Aldr. (nec Meig.), Kansas Unir. Quart. Il 16 (1893). 1 б aus

Colorado in der Sammlung des Wiener Hofmuseums. 50 , 4 ans Colorado in Loew's Sammlung.

21 comatus Lw., N. Beitr. VIII 23.25(1861) et Monogr. Dipt. N. Amer. 1169. 37 (1864). 207, 2 in der zoolog. Sammluug des Wiener Hofmuseums.

3) Alurich hat in seinem Kaltalog (1905) den Namen Stcnkammari wieder eingeführt, indem er behauptet, der Nane annulipes sei priokkupiert; mir ist nichts daron bekannt. 
22 convergens Aldr. ơ, Kansas Univ. Quart. II 9 (1893).

23 Coquilletti Aldr. O', Kansas Unir. Quart. II 19. tab. I fig. 17 (1893).

24 corax 0. Sack. o \&, Bull. Unit. St. Geolog. Sur. III 314. 1 (1877). cupreus Say = cuprinus Wied.

25 cuprinus Wied. ơ, Außereurop. zweitt. Ins. II 230.1 (1830).

cupreus Say, Journ. Acad. Nat. Sc. Philadclphia III 86.6 (1823) et Compl. Writ. II 76. 6 (1559).

cuprinus Lw. (nee Wied.) Aldr., Kansas Univ. Quart. II. 4 (1893).

Aldrich, der 1. e. p. 12 die Art cuprimus Wied. erwihnt und karakterisiert, hat p. 7 dieselbe ebenfalls in seine Bestimmungstabelle aufgenommen, gleiehfalls aher auf p. 4 eine Art cuprinus Lw. genannt, ohnc eine Erklairng dieser Doppclstellung zu geben. Geht man in dieser Tabelle den trennenden Eigensehaftsmerkmalen nach, so ergibt sich, daß bei cuprinus Lw. (nce Wied.) die vierte Längsader gebrochen, bei cuprinus Wied. nicht gebrochen ist; andere Unterschiede sind nicht gemannt und auch wohl nicht vorhanden. Ich glaube auch nicht, daß Aldrich hier zwci verschiedene Arten hat beschreiben wollen, daß hier vielmehr nur ein Druckfehler des Antornamens vorliegt und daß Aldrich diese doppelte Erwähnng der Art cuprimus Wied. absichtlich gewählt hat, weil der Bruch in der vierten Lingsader, wie ich dies auch bei Exemplaren der Wiener Sammlung babe feststellen können, nicht immer sehr dentlich ausgepriigt ist und man dalıer iiber die Bedentung dieses Mcrkmals hin und wieder in Zreifel geraten kann.

$1 \sigma^{\pi}, 2$ in der zoolog. Samml. des Wiener Hofmuseums.

$120 \%$ in der Sammlung des zoolog. Jus. in Berlin.

26 dakotensis Aldr. $0^{7}$, Kansas Univ. Quart. II. 11. tab. I fig. 1 (1893).

27 detersus Lw. O7 o, Berlin. Ent. Zeitschrift. X 44. 79 (1866).

discifer Stann. = nigricomis Meig.

28 dorycerus Lw. ơ, Berlin. Ent. Zeitschr. VIII 93. 85 (1861) et Monogr.

Dipt. N. Amer. II $326.43(1864)$.

29 duplicatus Aldr. 07 Kansas Univ. Quart. II 18. tab. I f. 21 (1893).

edactylus Aldr. = eudactylus Lw.

30 enigma Meland. et Brues 07, Biolog. Bull. I 139 fig. 16 (1900).

31 eudactylus Lw. o 9 , N. Beiti. VIII16.11(1S61) et Monogr. Dipt. N. Amer.

II $46.18(1864)$.

edactylus Aldr. Kansas Unir. Quart. II 16 (1893) laysus.

tonsus Lw. var. N. Beitr. VIII 16. 12 (1861) - 18 inder Loewschen

Sammlnng.

festinans Coquill. = rupestris Halid.

32 flagellitenens Wheel. o', Psyche V. 239 (1890).

33 fulvipes Lw. O, Berlin. Ent. Zeitschr. VI 212.61 (1861) et Monogr. Dipt.

N. Amer. I] 61.30 (1864). 
34 funlitor Lw. ơ, N. Beitr. VIII 22. 23 (1861) et Monogr. Dipt. N. Amer. II 66. 34. tab. IIl fig. 2 (1864). $2 \sigma^{7}$ aus Georgien in der alten Samml. des Wiener Hofunseums. $2 \sigma^{\lambda}$ (als cuprinus Wied. bezeichnet) in der Samml. des zoolog. Mnseums in Berlin. Type $\left(\sigma^{7}\right)$ ebenfalls in der Loewselien Sammlung.

35 germanus Wheel. ợ, Psyehe V 341 (1890).

36 gracilis Aldr. $\sigma^{7}$, Kansas Unir. Quart. 1115 (1893).

37 grandis Aldr. $\sigma^{7}$, Kansas Univ. Quart. II 21. tab. I fig. 22 (1893).

$1 \sigma^{7}$ aus Kalifornien in der Samml. des Wiener Hofmuseums.

38 groenlandicus Zett. ठౌ of N. Amer. Dipt. Washington 301 (1905)

39 hastatus Lw. o7 , Monogr. Dipt. N. Amer. II 59. 28(1864). 2 o', 1 q in der Sammlung des zoolog. Mus. Berlin.

Henshawi Wheel. = mugil Lw.

Heyden Wied. ․, AnBereurop. zweifl. Zus. II 230. 2(1830) . Brasilien. Ein Weibchen mit abgebrochenen Fühlern und mit gelben dreieckigen Seitenflecken am Hinterleibe ist jedenfalls kein Dolichopus. 40 incisuralis Lw. ठㅇ, N. Beitr. VIII 25. 28. (186I) et Monogr. Dipt. N. Amer. II 74. 42. (1864).

platyprosopus Lw., Berlin. Ent. Zeitschr. X 44.80 (1866), 1 o in der Sammung des Wiener Hofmuseums. $2 \sigma^{7}$ in der Sammlung des zoolog. Mus. Berlin.

41 incongruus Wheel. ơ, Psyehe V. 338 (1890).

42 intentus Neland. et Brues o7, Biolog. Bull. I 137 f. 14 (1900).

43 Johnsoni Aldr. O', Kansas Univ. Quart. II 7 (1893).

44 Kansensis Aldr. O", Kansas Univ. Quart. II 8 (1893).

45 laticornis Lw. ơ, N. Beitr. VIII 12. 2 (1861) et Monogr. Dipt. N. Amer. II 29.2 (1864).

46 lobatus Lw. ơ, N. Beitr. VIII 24. 27 (1861) et Monogr. Dipt. N. Amer. II 72. 40 (1864).

47 longimanus Lw. ơ, N. Beitr. VIII. 14. 7 (1861) et Monogr. Dipt. N. Amer. II 38. 11 (1864). $3 \sigma^{\pi}$ aus N.-York in der Berliner Sammlung (als cruprinus Wied. bestimmt).

Loew's Beschreibung ron sarotes paßt ebenso g'ut auf diese Exemplare. Aldrich unterseheidet in seiner Tabelle (1893) nach der Fligelform $\left(\sigma^{7}\right)-$ ("narrow at base and not narrow"). In seinem Katalog 1905 kommt er bei der Art sarotes noelımals darauf zu sprechen und gibt als Untersehied an: bei sarotes sei das dritte Tarsenglied viel größer, breiter und weißer.

47 a longipennis Lw. Oౌo, N. Beitr. VIII 21. 20 (1861) - 11 Exemplare in der Loewsehen Sammlung.

48 luteipennis Lw. ठ7, N. Beitr. VIII 18. 15 (1861) et Monogr. Dipt. N. Amer. II 51. 22 (1864).

49 marginatus Aldr. $\sigma^{7}$, Kansas Univ. Quart. II 17. (1893). 
50 melanocerus Lw. ठౌ , Berlin. Ent. Zeitschr. VIII93. 86 (1864) et Monogr. Dipt. N. Amer. II 330. 46 (1864).

51 Melandri Beck. n. n. 0 \% misellus Meland. (nec Bohem.) Canad. Entomol. XXXII 130. 2. fig. II (1900). misellus Meland. (nec Bohem.) = Melaudri Beck.

52 myosota O. Sack. ơ, Biolog. Centr. Amer. I 213.1 1887) . . Mexico

53 nigricornis Meig. ơ, S. Beschr. IV. 82. 14 (1824).

tamyus Lw., N. Beitr. VIII 24. 26 (1861).

discifer Stann, Isis I. 57. 10 (1831). Coquill, Proceed. Washington Acad. Sc. II 423 (1900).

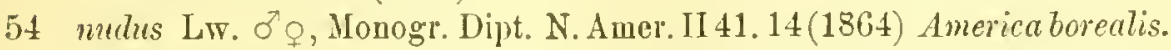
55 obcordatus Aldr. ơf, Kansas Univ. Quart. II 14 tab. I fig. 24 (1893).

1 o aus S. Colorado in der Samml. des Wiener Hofmuseums.

56 orcidentalis Aldr. ơ, Kansas Univ. Quart. II 19. tab. I fig. 18 (1893).

57 oratus Lw. ठ", N. Beitr. VIII 13. 5 (1861) et Monogr. Dipt. N. Amer. II 3ว. 8. (1864).

58 pachycuemus Lw. ơ , N. Beitr. VIII 13.6 (1861) et Monogr. Dipt. N.

N. Amer. II 35. 9 (1864). - 1 ठ in der Loewschen Sammlung.

59 palcestricus Lw. o", Berl. Ent. Zeitschr. VIII 92. 84 (186t) et Monogr.

Dipt. N. Amer. II 328. 45 (1864).

60 paluster Meland. et Brues ơ , Biolog. Bull. I 136. fig. 13 (1900).

61 pantomimus Meland. et Brues o*, Biolog. Bull. I 142. fig. 19 (1900).

62 partitus Meland. et Brues ơ, Biolog. Bull. I 135. fig. 12 (1900).

63 pernix Meland. et Brues ö, Biolog. Bull. I 141. fig. 18 (1900).

platyprosopus $\mathrm{Lw} .=$ incisuralis $\mathrm{Lw}$.

64 plumipes Scop. ఫ, Entom. Carniol. 334. 895 [Musca] (1763). Aldr.,

Kansas Univ. Qnart. II 13. (1893). $10^{7}$ aus Colorado in der Samml.

des Wiener Hofmusenms.

65 plumitarsis Fall. ơ, Dipt. Suec. Dolichop. 10. 4 (1823). Coquill.,

Proceed. Washington Acad. Sc. II. 425 (1900).

66 plumosus Aldr. \%', Kansas Univ. Quart. II. 18. tib. I fig. 16 (1893).

67 pollex 0. Sack. of, Bull. Unit. Stat. Geolog. Surv. III 314. 2 (1877).

68 praeustus Lw. б', Berlin. Entom. Zeitschr. VI 212.62 (1862) et Monogr.

Dipt. N. Amer. II 68. 36 (1864).

69 mgit Lw. o7, Berlin. Entom. Zeitsclur. X 43.77 (1866).

Henshawi Wheel., Psyche V. 340 (1890).

melchrimana Big. O', Ann. Soc. Ent. Fr. série 6. VI]I Bull. XXX [Spatichira] (1888) et sér. 6. X 292. [Spathichira] (1890).

Aldrich in Kansas Univ. Quart. II 23. (1893) weist darauf hin, daß Bigot l. c. zwei verschiedene Beschreibungen von einer und derselben Art gegeben hat. Es ist in der 'Tat so: seine erste Beschreibung 1888 und seine zreite Diagnose nebst Beschreibung 1890 decken sich nicht in Bezug auf die Erweiterung und Färbung der vorderen Tarsenglieder; da er sich in seiner zweiten Beschreibung 
anf die erste beruft und sie zitiert, so hat er nicht etwa zwei verschiedene Arten unter demselben Namen, sondern dieselbe Art versehieden besehrieben. Wir streichen deshilb seine Art.

70 quadrilamellatus Liv. o7 , Berlin. Ent. Zeitsehr. VIII 92. 83 (1864) et Monogr. Dipt. N. Aner. Il 331. 47 (1864).

71 ramifer Lw. Oै?, N. Beitr. VIII 19.16 (186i) et Monogr. Dipt. N. Amer. II 52. 23 (1864). 1 б̋ ans Nebraska, Samml. des Wiener Hofmuseums.

72 reflectus Alkr. Q, Kansas Unir. Quart. I1.12(1893). Nur als Weibehen bekinnt nnd beschrieben.

73 remipes Wallb. ơ, liongl. Vet. Akad. Handl. 13.6(1838). Aldr., Catal.

N. Amer. Dipt. 304 (1905).

74 renidescens Meland. et Brues ơ o, Biolog. Bnll. I. 143 fig. 20 (1900).

75 ruficomis Lw. O’, N. Beitr. VIII $21.21(1861)$ et Monogr. Dipt. N. Amer.

II 63. 32 (1864). $10^{\text {T }}$ in der Samml. des Wiener Hofmusenms.

76 mpestris Halid. ơ, Entom. Mag. I 164 (1833).

festinans, Coquill, Proceed. Washington Aead. Se. II 424 (1900).

77 sarotes Lw. ơ, Berlin. Entom. Zeitschr. X 44.81 (1866). $10^{7}$ ans Chicago in der Samml. des Wiener Hofmuseums.

78 scumlaris Lw $\sigma^{7}$, N. Beitr. VIII 22, 22(1861) et Mlonogr. Dipt. N. Amer.

II 64. 33 (1864). $1 \sigma^{7}, 1$ in der Samml. des Berliner zoolog. Museums.

79 scoparius Lw. ठ7, Monogr. Dipt. N. Amer. Il 70.38 (1864). 1 07, 1 in der Samml. des Berliner zoolog. Museums.

so setifer Lw. ठ', N. Beitr. VIlI 1.2. 3े (1861) et Monogr. Dipt. N. Amer. II 30.3 (1864).

81 setosus Lw. ơ, Berlin. Ent. Zeitschr. VI213.63 (1861) et Monogr. Dipt.

N. Amer. II 73. 41 (1861).

82 sexarticulatus Lw. J $\sigma_{f}$, Monogr. Dipt. N. Amer. Il 62. 31 (186t).

20,2 q ans Texas in der Samml. des zoolog. Mus. Berlin.

83 sincerus Meland. o", Canat. Entom. XXXI1. 136. 1. fig. 9-10 (1900). socius Lw. = brevimanus $\mathrm{Lw}$.

$\$ 4$ sphaeristes Brues. O’, Entom. News Philadelphia XJI 44 fig. (1901).

splendidulus Lw. = splendidus Lw.

85 splendidus Lw. Оフ, N. Beschr. VIII. 14. 9.(1861) et Monogr. Dipt. N. Amer.

II 44.16 (1564).

splendidulus Lw., Berlin. Ent. Zeitsehr. V1II 9I. 82 (1864).

86 subcilintus Lw. ơ, Monogr. Dipt. N. Aner. II 42.15 (1864). tamypus Lw. = nigricornis Ileig.

87 tener Lw. O', N. Beitr. VIll 17. 13 (1861) et Monogr Dipt. N. Amer. II 49. $20(1864)$.

S8 temipes Aldr. O, Kansas Unir. Quart. 11155 (1894).

89 terminalis Lw. O", Berlin. Ent. Zeitsel. X. 43. 78 (1866). 1 o aus

Washington in der Summl. des Wiener Ilofmuseums.

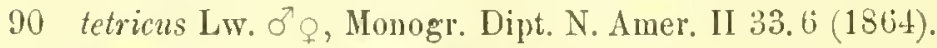
tonsus Lw. = eudactylus Lw. 
91 ungulatus L. Ơ o, Syst. Nat. Edit. X 598. 76 [Musca] (1758).

92 cariabilis Lw. O . N. Beitr. YIII 17. $14(1 \times 61)$ et Jonogr. Dipt. N.

Amer. II 50. 20 (1864). Type (5) in Loews Sammlung.

93 rarijes Coquill. $\Im$, Proceed. Washington Acad. Sc. II 425 (1900).

94 rigilans Aldu. Of?, Kansas Univ. Quart. II 13. talo. 1 fig. 15 (1893).

95 vittatus Lw. О7, N. Beitr. VIll 20. 18 (1861) et Monogr. Dipt. N. Amer. II 55.25 (1864).

96 Irillistoni Aldr. Ko, Kausas Univ. Quart. II 22. tab. I tig. 23 (I893).

97 ianthocnemus Lw. Of, Monogr. Dipt. N. Amer. II 31.5 (1864).

\section{Bestimmmgstabelle fïr die Arten der Gattmig Dolichopus.}

Die Tabelle, welche ich hier gebe, fuBt auf derjenigen, welche Aldrich im Kansas Univers. Quart. II Nr. 1. Juli 1893 herausgegeben hat und die einige achtzig Arten enthiilt. lch füge dieser Tabelle alle diejenigen Arten hinzu, die s]äter noch veröffentlicht wurden, hauptsächlich von Nelander und Brues in dem Biolug. Bulletin 1 (1200); letztere Autoren baben anch einige Umändernngen und Ergänzungen zur Aldrichschen Tabelle gegeben; letztere ist in ihrer Kiirze ausgezeichnet und sehr praktiscb eingerichtet, gibt aber doch häufig zur Erkenunng und Unterscheidung ciner Art rou ähnlichen und wahestehenden nur eiu einziges Merkmal an, so daß man, um sicher zn gehen, hänfig die Beschreibung zur Vergleichung zu Hilfe nehmen mub. - Um nun diese erweiterte Tabelle fiur die Bestimnung miglichst selbständig zu machen, habe ich sie durch Hinzufügung einiger anderer charakteristischer Merkmale häufig etwas weiter ausgebant und verrollstïndigt. lch kenne zwar nur den kleineren Teil der lier behandelteu Arten aus cigener Anschanung, jedoch ingesichts der ansgezeichneten, zuverlissigen Beschreibungen von Aldrich, Melander, Brues, Wheeler, Coquillet und Loew, kann man hier wohl anf das fehlende Anschaungsuaterial verzichten, ohne befirchten zu miissen, cine falsche oder zu ungenaue Charakteristik in dieser solcherweise erweiterten Tabelle zu geben. Auf eine besondere Darstellung der Weibchen habe ich mich aus obigen Griuden aber nicht speziell einlassen können, um so weniger, als selbst Aldrich nur büchst selten Weibchen erwähnt. Die Tabelle schließt die Weibchen nicht ganz aus, ist aber doch in erster Linie auf die Erkenuungsmerkmale des männlichen Geschlechtes zugeschnitten.

1 Schenkel gauz oder iberwiegend schwarz. Fiibler schwarz . . . 2

- Schenkel gelb, höchstens die Spitze derHinterschenkel schwarz gefleckt 24

2 Hinterkoufborsten auch unten schwarz. . . . . . . . . . 3

Hinterkopfborsten unten blaligelb oder weiß. . . . . . . . 13

3 Fligel gefleckt. Vorderschiene und deren Metatarsus bis auf die Spitze gell,

- Fliigel nicht gefleckt . . . . . . . . . . . . . . . 5

4 Fliigel zn $\%$ ihrer Fläche an der Spitze gchriunt. Anallanellen weiß mit bramem Rande. $3 \mathrm{~mm}$ lang

Jolnsoni Aldr. 
Flïgel zwischen Randader und der vierten Lïngsader anf der Spitzenhiilfte gebriunt; anch die hintere Querader ist gefleckt. Randader an Ende der ersten Liingsader mit linglicher Verdirkung (0). Anallamellen gell, mit schwarem liande, 5-5.5 mm lang .

prevtitus Meland.

5) Alle Schienen sehwarz, Hinterschienen etwas rerdickt . . . . 6

- Nicht alle Schienen schwarz . . . . . . . . . . . . 7

(i) Vordertarsen am letzten Gliede stark rerbreitert $\left(\sigma^{\top}\right)$, sclnwar\% und an der Sjitze kur\% sehwar\% gebartet. Gesieht gelb. 5-6 mm lang .

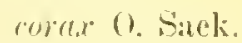

- Tordertarsen einfach. Ilinterschenkel auf der Spitzenhälfte der UThterseite schwarz behart. Gesicht gelbbraun. 5-5\% $\mathrm{mm}$ liug. .

paluster Mel., Brues.

7 Die vier Vorderschienen gelh

- Sehienen sehwar, die Mittelschienen auf der Mitte mit weiblichem Ringe. Gesicht schmutzig weiß. liandader am knde der ersten Liings ader verdickt. $6 \mathrm{~mm}$ lang. . . . . . . . . (mmulipes Zett.

8 Schiippehen selwarz hewimpert . . . . . . . . . . . . 9

- Sehijpphen weiß hewimpert . . . . . . . . . . . . . 12

9Hinterschienen ganz schwarz . . . . . . . . calcaratus Mldr.

- Hinterschienen gelh, an der Spitze schwarz . . . . . . . 10

10 Hinterschenkel anf der Unterseite lang und schwarz hehart. Spitzenhälfte dej Ilinterschienen schwar. Gesicht ockerbräinlich. Raudader von der ersten Liingsader an verdickt. $6 \mathrm{~mm}$ lang gratus L.w.

IIntersebenkel anf der Unterseite nackt, nur $1 / 5$ oder $1 / 6$ der Hinterschienenspitze schwarz . . . . . . . . . . . . 11

11 Drittes Fibherglied ein wenig linger als breit, etwa $1 \frac{1}{4}$ mal lainger mit dorsaler Borste. Gesicht elunkelbram. $6 \mathrm{~mm}$ lang. groenlandirus Zett.

- Drittes Fithlerglied reichlich doppelt so laug wie breit, mit subapilaler Burste. Gesicht silberweiß. $4 \mathrm{~mm}$ lang . . . intentus Meland., Br.

12 Drittes Fihhlerglied grof, breit, eiförmig, Borste in zweiten Drittel einsetzend. Gesicht silberweiß. Ilinterschienen gelb, an des Spitze sehwarz, nieht verdickt. Riundader an der Miindung der ersten Lïingsader katum resdickt. 4.5-5 mm lang. . . . . . luticomis Lw.

Drittes Fiihlerglied sroß, Borste anf der Mitte des Oberrandes einsetzend. Gesicht schmal, silberweib. Vorder- und Hintersehenkel zu \%: ron der Wurzel an schwilz. ITinterschenkel unten ohne llare. $5 \mathrm{~nm}$ langr. . . . . . . . . . . incongrums Wheel.

13 Mittelsehienen schwar\% . . . . . . . . . . . . . . . 14

- Mittelschienen gell . . . . . . . . . . . . . 21

14 Beine schwarz, $1 / 3$ aller Schenkel an ler Spitze gelb. Ilinterschenkel unten ohne Behaarung; letztes Glied der Vordertarsen lappig erweitert. Gesicht gelbgrau. Analamellen weißlich, elliptiseh. 4-5 mm lang . . . . . . . . . . . . . tetricus Lw. 
Beine schwarz, höchstens die Kiniee gell. 'T'arsen der Vorderbeine einfinch . . . . . . . . . . 15

15 Hinterschenkel der o ant der Unterseite behalat . . . . . . 16

Hinterschenkel unterseits mackt . . . . . . . . . . . . 17

16. Hintersehenkel ling sehwar\% behaart. Gesicht schmal, weiß. Fliigelrorderant an der Mündung der ersten Läingsader verdiekt. 5 mm lang . . . . . . . . . . . detersus Lw.

Hintersehenkel kur sehwarz behart. Gesicht hreit, geelblich. Vorderrandader etwas diek. $4-45 \mathrm{~mm}$ ling . . . . Kansensis Aldr.

17 Beine ganz sehwal\%. . . . . . . . . . . . . 18

Beine selıwar, Vorderschienen gelbbraum . . . . . . . . . 19

18 Gesieht silberweiß. Anallamellen weißlich. Fligelrandader ohne Ansehrellung. 4 mm lang . . . . . . . . . . myosota tr. 0.S.

Gesicbt graugelb. Anallamellen braun. Fliigehandader mit Anschwellung am Ende der ersten Lïngsader. 5 mm lang. calainus Meland., Brues

19) Fliggelrandarler ohne Ansehwellung . . . . . . . . . . . 0

Fliigelrandader mit kurzer aber deutlieher Verdieknng am Ende der ersten Liingsader. Flitgel vorne und an den Liingsadern etwas bräiunlich. Gesicht silherweil;, breit. Anallamellen sehmutzig weiß, durehscheinend von fast viereckiger Form. $4 \mathrm{~mm}$ lang. enigma Del., Brues

20 Anallumellen zugespitzt

actminatus Lw.

Aualiamellen rundlich

oretus Lw.

$\because 1$ Erstes Glied der Hintertarsen ungewöhnlich stark beborstet. Hinterschenkel unterseits lang schwar" behaart. Flitgelrandater an Ende der ersten Langsader kaum etwas gesehwollen. 45-5 mm lang.

setifer Lw.,

Erstes Glied der Hintertarsen wit den ibliehen wenigen Borsten . 23

2.) Hintersehenkel des o nnterseits behart. . . . . . . . . . . 23

Hinterschenkel unten nackt. Gesicht silherweiß. Anallamellen weililich. Fliggelrandader obne Anschwellung; dritte und vierte Längsadern ungewiblnlieh stark konvergierend. 4 mu lang . . convergens Aldr.

23 Hinterschenkel unter sehr lang weil; behart. Hintersehienen an del Spitze in geringer Ausdehnung schwar\% mit scharfer Begrenzung. Fliggelvorderrand an Ende der ersten Lïngsader mit Anseluwellung. 35 mm lang . . . . . . . . . . . . xanthocnemus Lw.

Hintersehenkel unterseits sehr lang sehwar'z behart. Hintersehienen lis zir 1/3 an der Spitze schwarz, aber ohne scharfe Begrenzung. Anschwellung am Ende der ersten Lïngsader vorhanden. $55-6 \mathrm{~mm}$ lang:

albiciliatus Lw.

Hinterschenkel unten nnr kurz sehwarz behaart. Iinterschienen schwal', nur die iulerste Wurzel gelb. Fligelrandader wit kium bemerkbarer Anschwellnng am Ende der ersten Längsader. $35 \mathrm{~mm}$ lang. ugronomus Mel, Br. 
- Hinterkopframaborsten unten weiß . . . . . . . . . . . 31

25) Sehiippehen schwar\% ljewimpert . . . . . . . . . 26

26 Hintersehenkel nnten olne lïngere Beharung . . . . . . . 27 Hinterschenkel muten lang behart . . . . . . . . . . . 99

27 Fihhler schwar\%, erstes und zweites Glied gelb, Fihlerborste an der Spitze mit einer Verbreiterung. Vorderhiiften gelb; dic 4 letzten Glieder der Vordertarsen verbreitert und schwirz. Fligelrandader nur mit geringer Anscluwellung an Ende der ersten Lingsader. $55-6 \mathrm{~mm}$ lang . . . . . . . . . . . . . Morycerus Lw.

- Fihler ganz schwarz, Fiihlerborste einfach. Vorderhiften sehwarzgrau. Vordertarsen einfach. Fliigelrandader am Ende der ersten Lingsader verdiekt

Gesicht silberweili, schmal. Iintersehenkel auf der Oberseite dunkler. $4 \% \mathrm{~mm}$ lang . . . . . . . . . . . . . sincerus Mel.

- Gesicht grau. Hinterschenkel an der Spitze schwarz. 5 mm lang rupestris Halid.

29 Vorderhiiften grausehwarz: Hinterschenkel unten lang sehwarz behart 30

- Vorderhiuften gell. Ilintersehenkel unten lang gelb hehaart: das vierte und fiinfte Glied der Vordertarsen verbreitert und scliwarz. FligelJ'tndaler mit dentlicher Verdicknng' am Ende der ersten Läingsader. 6-7 mm lang. . . . . . . . . . . brevipennis Meig.

30 Hinterschenkel mit mehreren l'riapikalborsten. Vordertarsen einfach. Fligelrandader nit schwacher Verdiekung an Ende der ersten liangsader. 6-65 mu lang . . . . . . . . . ungulatus L.

llinterschenkel mit nur einer Pröiapikalen. Dis erste und zweite Glied der Vordertarsen sowie die Wrurzel des rritten gelb, die iibrigen sehwarz, dis vierte etwas rerbreitert und cinseitig bebartet, das fiinfte oval verlureitert. Fligelrandader ohne Verdickung. $6-6.5$ mu lang . . . . . . . . . . . . . . pachyenemus Lw.

:3 Schippchen mit hellen Winpesn . . . . . . . . . . . 32

- Schiippchen mit schwamen IImpern. . . . . . . . . . . 43

32 Filhler scliwarz, mitunter clas erste Glied unten etwas rotgelb. . 33

- Fiihler ganz orler fast granz l'otgell, . . . . . . . . . . . 41

33 Vurderhiiften zum groben Teil sehwargrau; llinterschenkel unterseits gell, behart; Hinterschicnen gelb, Hintertarsen schwarz; funftes Glied der Tordertarsen stark verlneitert. Gesicht hellgell. 6.5-7 mm lang. . . . . . . . . . Tongimanus Lw.

- Vorderhiiten gelh . . . . . . . . . . . . . . . . 34

34 Spitze der Hinterschienen bis zn $1 / 4$ ihrer Lainge dentlich schwar 35

- Spitze der Hinterschienen gar nicht oder nur sehr geringfiigig geschwirzt. . . . . . . . . . . . 36

35 Viertes und finttes Glied der Vordertarsen ( $\left.\delta^{\star}\right)$ etwas verbreitert und schwilrz. Hintersehenkel unterseits olne llaare. $5 \mathrm{~mm}$ lang.

albicora Aldr. 
Vordertarsen ganz einfach. Hinterschenkel unterseits kurz schwarz hehaart. 45-5 mm lang. . . . . . . . . . lrevimanes Lw.

36 Hintertarsen ganz schwarz . . . . . . . . . . . . . . 37

IIintertarsen zum großen Teil gelb . . . . . . . . . . . 40

37 Hinterschenkel unterseits nackt. Gesicht ockergelb. 5 mm laug

nudus Lw.

Hinterschenkel unterseits behart. . . . . . . . . . . 38

38 Das verbreiterte letzte schwarze Vordertarsenglied ( $\sigma^{-7}$ ) zeigt an der Außenseite weiben Schimmer. Hinterschenkel unten sparsam gelb behaut. Gesicht hell oekergelh. $5 \mathrm{~mm}$ lang. . . pulaestricus Lw.

Das verbreiterte letzte Vordertarsenglied ohwe weifen Schimmer . 89

39 Hintersehenkel unterscits stark grelb bchart; Hinterschieuen ganz gelb. Gesicht hellgelb. ว̃ $\mathrm{mm}$ lang . . . . . . . . . sulendidus Lw.

Hinterschenkel unterseits mu seh" sparsim behart; Hintersehienen all der Spitze etwas gebrëunt. Gesicht gelbgran. $4.50-5 \mathrm{~mm}$ lang subcitiatus Lw.

$40 \mathrm{Nur}$ das letzte Glied der Vordertarsen $\left(\sigma^{-7}\right)$ rerlureitert. Hinterschenke] unterseits nackt. Gesicht schmal, hellgelb, 5.5-6 $\mathrm{mmm}$ lang batillifer $\mathrm{Lr}$.

Die beiden letzten Glieder der Vordertarsen verbreitert, das vierte weiß, das fiufte schwarz. Hintersehenkel nnterseits behart. Gesicht schmal, ockergelb. $505-6 \mathrm{~mm}$ laug . . . . . euductylus Lw.

Die drei letzten Glicher der Tordertarsen allmählich verbreitert, die beiden ersten weib, das letzte schwarz. Hinterschenkel nnten zart weiß behaart. Gesieht schmal, gelb. $55 \mathrm{~mm}$ lang dakotensis Aldr.

41 Letztes Vordertursenglied rerbreitert, schwarz. 35 $-4 \mathrm{~mm}$ lang tener Lw. Vordertarsen einfach . . . . . . . . . . . . . . 42

42 Fligel in asehgraner Färbung . . . . . . . . variabilis Lw.

- Fligel in gelblicher Färbung . . . . . . . . latipemis Lw.

43 Vicrte Läingsader gebrochen . . . . . . . . . . . . 44

— Vierte Längsader nicht gebrochen . . . . . . . . . . 50

44 Fühler schwarz . . . . . . . . . . . . . . 45

— Fiihler rotgell . . . . . . . . . . . . . . . 46

45 Torderbüften grausehwarz; Hintersehenkel lang gelbirann behaart; ricrtes und fiuftes Glied der Vordertarsen verbreitert. Gesicht melb. Flïgelrandader mit dertlicher linglicher Schwellung. $4 \mathrm{~mm}$ lang obcorlutus Aldr.

- Torderhiuften gelb; Iinterschenkel unten mit weißgelben Haaren; Vordertarsen cinfach. Gesicht weiß. Fliigelrandader mit sehr schmaler Schwellung. 3-35 um lang. . . . . . . . . ramifer Lw.

46 Thoraxrïcken gell, hestïubt, matt. Gesicht weißlich. Ilintertarsen und die Spitze der Hinterschienen schwarz. Hinterschenkel unterseits olne längere Haare. Vordertarsen am vierten und fiinften Gliede etwas verbreitert und schwarz. Fliigelrandader ohne Schwellung. $5 \mathrm{~mm}$ lang . . . . . . . . . . . . bifractus Lw. 
Thoraxrieken elzgriin, etwas glinzend .

47 Hintertarsen nud die Spitze der Hintersehienen schwar. 5 mm lang rellectus Aldr.

Hintertarsen zum Teil und Ilinterschienen ganz gelb.

48 Hinterschenkel unterseits lang goelb behart. Erstes und zweites Glied der Vordertarsen ( $\overrightarrow{3}^{3}$ ) und die lliblfte des dritten gelh, diune, die iibrigen sehwallz und nicht rerdickt. das dritte anf einer Seite stark schwarz bebartet, das vicrte Glied etwas schwicher behartet. Mrittes Fiilulerglied an der Spitze bräinnlich. Fligelvorderrand ohne nennenswerte Verdickung. 5\%)-6 mm lang . . . . . cuprims Wied.

- Hintersehenkel unterseits ohne lingere Haare . . . . . . . 49

49 Vordertarsen einfach. Fligelvindader mit denticher schwelhung. $55-6 m m$ lang . . . . . . . . . . . . . vittatus Lw.

- Listes and zweites Vordertarsenglied lang und gelb, drittes anch gell, au Ende schwarz und etwas breiter, oberseits seliwarz behiart, das vierte und finfte Glied schwarz und verbreitert, das vierte anch anf cincr Seite schwar bebartet. Fliggetrandader nur mit ciner sehr schmalen Schwellung. $6-6.5 \mathrm{~mm}$ lang . . longivennis Lw.

50 Fiihlerborste $\left(\sigma^{3}\right.$ an der Spitze pfleilspitzenihnlich verbreitert. Die drei letzten Glieder der Hitteltarsen etwas verbeitert; Mittelschienen mit sebwarzer Spitze. 5 $55 \mathrm{~mm}$ lang . . . . . hastatus Lw. Fiihlerborste cinfach . . . . . . . . . . . . . 51

51 Mliteltarsen ganz sehwarz, das erste Glied beim Manmehen beiderseits geliedert. . . . . . . . . . . plumipes sicop.

- Mitteltarsen mehr oder weniger gelb, nicht gefierlert. . . . . 52

52 llinterschienen an der Spitze dentlich sehwarz, scharf begrenzt . 5.,

- Hinterselienen gar nicht oder kamm etwas an der Spritze gebriunt, nicht scharf begrenzt . . . . . . . . . . . . . . . . . . .

53 Fiihler schwark, des erste Glied mitunter anf der Unterseite gelb 56 Das erste Fühlerglied ganz getb . . . . . . . . . . 5t

5f Fiihler getb, Spitzenbälfte des dritten Gliedes schwarz. . . . .55

- Das zweite Fihlerghlied anf der Oberseite und das dritte Glied schwarz. Die ersten vicr Glieler der Vordertarsen gelb, das fiunfte schwarz; drittes und vicrtes Glied schr km\%, das fintte grolb, fast kreisförmig $5 \mathrm{~mm}$ lang . . . . . . . . . . . . Magellitenens Wheel.

55 Vorderschienen $\left(0^{\pi}\right)$ an der Spitze rerdickt und selıwarz. $5-555$ mu lang mujit Lw.

- Vordersehienen nicht verdickt und nieht schwar an der Spitze; drittes, viertes und fibuftes Vordertal'senglied etwas verbreitert mud schwar. 5 jum langr. . . . . . . . . . . . vigitans Aldr.

56 Mitteltarsen des $\sigma^{*}$ an ersten Gliede mit $9-10$ langen IIasuen. $4-45 \mathrm{~mm}$ lang . . . . . . . . . . . . comatus liw.

Mitteltarsen des confacl . . . . . . . . . . . . . . . 57

57 Vorderlitiften gelb . . . . . . . . . . . . 58 
Vorderhiiften schwärzlich graul .

as Kleine dunkel bronzefurbige Art von $3 \mathrm{~mm}$ Läinge . brumens Aldr.

- Grißere mehr oder weniger erygrine Arten . . . . . . . . 59

59 Fiihler ganz schwarz . . . . . . . . . . . . . . . 60

- Fiiller sehwarz, das erste Glied unten gelb . . . . . . . . 64

60 Vordertarsen einfach. Hinterschenkel (O) unten behaart. . . .61

- Vordertarsen verziert; viertes und fünftes Crlied selwarz, etwas ver-

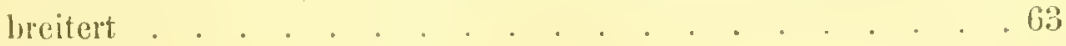

(il Vorderhiiften schwarz belaart . . . . . . . . . . . . . 62

_ Vorderhiffen hell behalart. Viesicht schmal, hellbrann; drittes Fïllerglied verlingert, zweimal so lang wie breit $4 \mathrm{~mm}$ lang pantomimus thetr. Meland.

62 Gesicht sehmal, goldgelb; Stime griiu. $4.5-5 \mathrm{~mm}$ lang melanocerus Lw.

- Gesicht breit, hellbram; Stime violett. $4.5-5 \mathrm{~mm}$ lang

renidescens $\mathrm{Mel}$., Br.

(i3 llinterschenkel unten sparsam behant. Fesicht weißgelb. Fliigehandader ohne Schwellung. 55-6 mm lang $\quad$ hlumitursis Fall.

Hinterschenkel muten nackt. Gesicht silberweiß. Fliggehandader am Ende der crsten Längsader verdiclit. 45-5 mm lang. pernix Mel., Br.

64 Hinterschenkel schwallz, unten nackt. Vordertarsen einfach. Mitteltarsen am vierten nnd fünften Glierle etwas verbreitert und behant. $5 \mathrm{~mm} \operatorname{lang}$. . . . . . . . . . . . . . ravipes Coquill.

llintersehenkel gelb, Mitteltarsen einfach . . . . . . . . . 65

(5) Vordertarsen einfach . . . . . . . . . . . . . . $66^{\circ}$

Vordertarsen verziert . . . . . . . . . . . . . . 69

66 llinterschenkel unterseits lang gelb behaart, Hinterschienen mit seh" liugen Borsten. Fligelrandader mit dentlicher Verdickung: 5-6 1 mm $\operatorname{lang}$. . . . . . . . . . . . . . . setosus Lw.

Hintersehenkel unterseits nicht lang lehaart, Hinterschienen mit normalen Borsten . . . . . . . . . . . . . . . 67

67 Hinterschenkel an der Spitze oberseits schwarz. Flïgelrandader ohne Verdickung. $5 \mathrm{~mm}$ lang . . . . . . . . . apheles Mel., Br.

Hinterschenkel olne scliwaze Spitzen . . . . . . . . . 68

68 Gesicht gelhreilj. Fliggelrandader ohne dentliche Ansehwellung. 5 nm lang . . . . . . . . . . . . . . Melendrin.n. Gesicht weiß. Fliigelrandarler mit dentlicher Anschwellung. 4 mm lang incisuralis Lw.

69 Gesicht silberweiß. Das fünfte Vordertarsenglied heit mut schwar\%. Hinterschenkel unten nackt. Flïgelrandader krïftig ohne besomlere Yerdickmng. $55 \mathrm{~mm}$ lang. . . . . . . . . nigriconnis Meig.

Gesicht graugelb. Das vierte und fiinfte Vordertarsenglied schwarz und ein wenig rerbreitert. Hinterschenkel an der Spitze schwarz, unten lang schwarz behart. Fligelvorderand mit einer lainglichen, allmaihlich abnehmenden Verdickung. $6 \mathrm{~mm}$ lang brachycnomus Coquill. 
70 Vordertarsen einfach. Hintersehenkel unten fast nackt. Fliigelspitze gesehwålzt, Randader ohne deutliche Schwellung. 45-5 $11 m$ lang: maeustus $\mathrm{L}$ w.

- Vordertarsen verziert

71 Die ersten drei Glieder der Vordertarsen weißlich mit schwarzer Spitze, viertes und funftes Glied verbreitert, sehwarz. Hintersehenkel unterseits an der Spitze mit einigen schwarzen Borsten. Fligelrand. atler nur mit seluwacher Selıwellung. 5-0 $\mathrm{mm}$ lang pollex O. Sack.

- Das vierte und fünfte Vorlertarsenglied schwarz, das fünfte mit lappenfömigem Anlang. Hinterschenkel unten mit langen bramen Haren. Flïgelrandader nit langer und starker Anschwellung. $4 \mathrm{~mm}$ lang: obcordatus Aldr.*;)

72) Hintertarsen ganz schwar, Vorderhiiften gell, . . . . . . . 73 Hintertarsen zun grolien Teil an der $W^{\top}$ urzel gelb. . . . . . so

73 Fiihler ganz rotgelb. Gesicht schmal, gelbgrau. Vordertarsen einlach. Hintersehenkel unten lang gelb behaart. 4 num lang. . gracilis Aldr.

- Drittes Fiblerglied ganz oder wenigstens zur Ilälfte schwirz . 74

74 Hintersehenkel unterseits nicht behart. Hinterschienen gelb . . 75

- Hintersehenkel unterseits lang sehwarz behaart, llinterschienen an der Spitze sehwach gebriunt. . . . . . . . . . . . . . 79

75 Vordertarsen nicht verziert; llintersehienen auf del Oberseite nit einem weiben geschwollenen lecken. Gesicht goldgelb; Fuhler rotgelb, drittes Glied an der Spitze sehwarz. $505-6 \mathrm{~mm}$ lang. fulvipes Lw.

- Vordertarsen verziert . . . . . . . . . . . . 76

76 Drittes Glied der Fiiller verlingert nnd zugespitzt. Fithler schwarz, erstes Glied unten gelb; Gesicht gelhgrau. Die 4 ersten Glieder der Vordertarsen gelb, das funfte schwarz, verbreitert, so lang wie das dritte Glied, las vierte ein wenig breiter und kirzer als las funfte. $5 \mathrm{~mm}$ lang . . . . . . . . . . . . . angustatus Aldr.

- Drittes Fiihlerglied von gewïhnlicher Form, nieht verlingert. . 77

77 Fiihler sehwarz, erstes Glied rotgell . . . . . . . . . . 78

- Fuihler schwarz, das erste Glied ganz und das zweite unterseits rotgelb. Gesieht goldgrelb. Die ersten beiden Vordertarsenglieder gelb, das dritte an der Spitze sehwar, viertes und fiinftes sehwarz; las vicrte liur, etwas dreieckig crweitert, las funfte oval und rerbueitert. 6.5-7 mm lang. . . . . . . . . amphorins Mel., Br.

78 Das erste Glich der Tortertarsen gelb mit sehwal'zer Spitze, dic iibrigen Glierler sehwarz; das vierte sehr kurz nnd an der Spitze erweitert. das fünfte sehr grob und deutlich schwarz bewimpert. Gesicht blab. gelb. Hintersehienen namentlich auf der Mitte verdickt. Hinterer Fliigelwinkel des o nit zwei lappigen Ausbauchungen. $55-6 \mathrm{~mm}$ lang . . . . . . . . . . . . loluatus Lw.

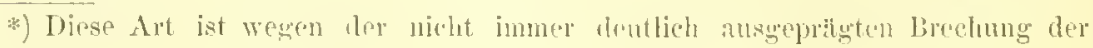
vierten Liingsador an ther stelle ller Flitgelbeule amch an diestr stelle grenimnt. 
Die drei ersten Glieder der Vordertarsen gelb, das vierte kurz, etwas breiter als lang, das fiinfte oral, seliwarz, so lang wie das zweite Glied. Hinterschienen einfach, liligelhinterrand desgleichen. $5 \mathrm{~mm}$ lang. . . . . . . . . . . . . coloradensis Aldr.

79 Fiihler rotgelb, drittes Glied an der Șitzenhälfte sehwarz. Die ersten drei Glieder der Tordertarsen gelb, das vierte an der Spitze sehwarz und etwas verbreitert, das fuinfte sehwar', oral, stark verbreitert. Gesicht selımal, ockergell, 5-55 nm lang . . . . mugil Lw: Fibler rotgell, drittes Glied ganz sehwarzhraun. Tordertarsen nieht verbreitert, das finfte Glied hat nur einen zahnartigen Vorsprung: Gesicht weißlich. Lamellen des Hypopygiums mit vielen langen sehwar. zen Randborsten. 5.5-6 mm lang . . . . maryinatus Aldr.

so Fiihler ganz schrarz. Voldertursen einfaeh. Gesieht goldgelb. Hinterschenkel unterseits mit kumen Hatren, nieht wie gewöhnlieh lang behaart. $4 \mathrm{~mm}$ lang. . . . . . . . . . chrysostomus LW.

Fijhler nicht ganz schwarz . . . . . . . . . . . . 81

\$1 Fihler schwarz, erstes filied unterseits gelbrot . . . . . . . 82

- Fiihler sehwar $\%$ erstes Glied ganz gelbrot . . . . . . . . 83

- Fühler rotgelb, drittes Glierl wanz sebrarz . . . . . . . . 84

Fiihler ganz rotgelb, höehstens das dritte Glied an der Spitze bräun-

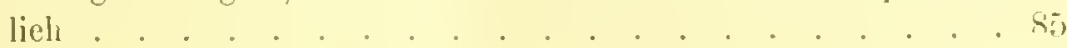

82 Die ersten drei Tordertusenglieder gelb, das dritte an der Spitze schwarz, anch das rierte und fünfte Glied sehwarz und etwas verbreitert, beiderseits kul'z getiedert. 5-5.j mm lang. scoparius Lw.

- Die ersien drei Vordertarsenglieder gelb, das vierte und funfte verbreitert, sehwarz und schwarz behart. Anallamellen dunkelgelb, scheinbar aus zwei Lamellen bestehend. $6 \mathrm{~mm} 1$. quatrilamellatus $\mathrm{Lw}$.

83 Erstes und zweites Glied der Vordertarsen gell, ibre Spitzen schwarz; die drei letzten Glieder auch schwarz. Viertes nod fiintes sehwaeh rerdiekt und einseitig behant. 5.2. $\mathrm{mm}$ lang. . . Corpilletti Aldr.

Die elsten drei Glieder der Tordertarsen gelh, viertes nud fünftes schwarz, das vierte kurz, das fiunfte sehr groß, oral. 5\% min I. occidentalis Aldr.

s4 Anallamellen gelb, groß, durch einen Einsehnitt in zwei Teile gespalten. Fligellandader ohne Anschwellung. Erstes und zweites Glied der Vordertarsen gelb, drittes Glied brann, viertes und fiinftes sehwarz; das rierte kurz, einseitig etwas behart, das funfte groh, oral. $6 \mathrm{~mm}$ $\operatorname{lang}$. . . . . . . . . . . duplicutus Ald1.

Anallamellen hellgelb, linglich rund ohne Einsehnitt. Erstes nnd zweites Glied der Yoldertursen gelb; drittes, riertes und fünftes schwarz: das dritte und vierte kurz, beide etwas schrige abgeschnitten; das ftunte mäßig groß, nicht oval. Fligelrandader mit dentlieber Anschwellung am Ende der ersten Längsader. $4.5 \mathrm{~mm}$ lang. . . plumosus Aldr.

*) Wegen der etwas unbestimuten Bräunng ler Hinterschienenspitze int llies. Art anch an dieser stelle aufgefiihrt. 
85 Sehulterbeulen gelb . . . . . . . . . . . . 86

- Sehulterbenlen ron der Fanbe les Thoraxrickens . . . . . . 47

86 liihler ganz rotgelb. Vordertarsen einfach. Hintersehenkel unten mit lïngerer heller Belaarung. 50 $-6 \mathrm{~mm}$ lang . . . scamlaris lw.

- Drittes Fiblerghied an der Spitze schwarzbran. Die drei ersten Glieder der Vordertarsen (o) gelb; das vierte sehwar", etwas rerbreitert nud anf einer Seite behart; das fünfte Glied oval, weib, rerbreitert. Unterseite der Hinterseluenkel lang gelb belıart. 55-6 mm lang

fumtitor Lw.

87 Vurdeltarsen dles of einfach 83

- Vordertarsen verziert . . . . . . . . . . . . . . 90

S5 Fliigelrandader an Ende der ersten Lïugsader stark verdickt. Gesicht weiß. Hinterschenkel unterseits nieht lang behaart. $5 \%-6 \mathrm{~mm}$ lang. . . . . . . . . . . . . . . viltatus Lw.

- Fliigelrandader nicht so rerdielit . . . . . . . . . . 84

8. Gesicht goldgell) . . . . . . . anrifucies Aldr:

- Gesicht silberweib . . . . . . . . . . . germans Wheel.

90 Hinterschenkel des of unten mit gelben Haaren . . . . . . 91

- llimterschenkel unten nackt. . . . . . . . . . . . . . 99

91 Dals zweite Vurdertarsenglied ist linger als das erste, gelb, beiderseits sehr fein bewimpert, die drei letzten Glieder selnwar, ungeführ gleich lang und gleichmißig etwas verbreitert. Hintersehenkel unten kurz welb behaart. liligelraudider anf längerer Streeke rerdiekt. $6.5-7$ mm lang. . . . . . . . . . . . . gramlis Aldr.

- Die Voudertarsenglieder in abnehmender liinge aneinander gereiht !12

92 Die ersten vier Tordertarsenglieder (ठَ) gelb, diune, das fiunfte schwar", etwas verbreitert. Drittes Fiihlerglied ganz rotgell. $4-4.5 \mathrm{~mm}$ lang

- Erstes und zweites Glied der Vordertarsen und die luälfte des dritten gelb, diinne, die iilnigen selıwarz und nicht verdiekt; das dritte anf einer Seite stark sehwarz bebartet, das vierte Glied etwas schwiicher. l)ittes Fiblerglied an der Spitze brïnnlich. 55-6 mm lang .

cunimus Wied.;

Die ersten drei Vordertarsenglieder gelb, lang. annähernd gleich lang, das vierte weiligelb aber kntz, das fünfte Glied sehwarz, groh, kreisfurmigr. Gesiebt silberweif; drittes Fiilılerglied an der spitze breit schwarbbrann. $7 \mathrm{~mm}$ lang. . . . . . . . cunuliculatus Thous.

(\%) letztes Vordertarsenglied mit einem lappenförmigen Anhang . 94

- Letztes Vordertarsenglied nicht so gebildet . . . . . . . 95

94 Hie ersten drei Vordertansenglieder lang und gelb, diun, das vierte sehwarz, kul', etwas dreieckig verhreitert, das fünfte grïher, Spitze

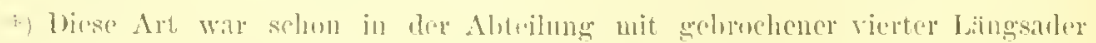

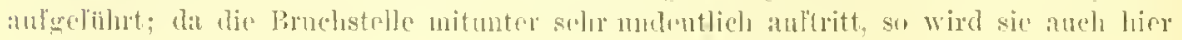
nuchnals cingestellt. 
des fünften Crliedes und Spitze des lappenfömigen Anluanges sclmeeweif. Hintersehienen anf der Wrurzelhälfte stark verdickt. $5-55 \mathrm{~mm}$ $\operatorname{lan} g$ sexarticulutus Lw.

Erstes und zweites Tordertarsenglied gelb, dimn, das dritte gelb, an der Spitze etras breiter; das vierte Glied schwarz mit gelber Spitze, einseitig schwarz behaart: das finfte schwarz mit weißer Spitze, einseitig schwarz hehaart; der lappenförmige Anbang schwar'z ohne weiße Spitze. Hinterschienen nicht rerdickt. $55-6 \mathrm{~mm}$ lang . . .

Ilillistoni Aldr.

95 Gesicht ockergelb. Hintersebienen $\left(0^{\top}\right)$ stark verdickt . . . . 96

Gesicht weih. Hinterschienen nicht rerdickt . . . . . . . . 97

96 Erstes, zweites und drittes Vordertarsenglied gelb, viertes mul fiuftes schwarz, gleichlang nit schneeweißem großen Empodium. li mim lang . . . . . . . . . . . . . - spliacristes Br.

$97 \mathrm{Nu}$ das letzte Torlertarsenglied dureh geringe Verbreiterung etwas ansgezeichnet. $5-55 \mathrm{~mm}$ lang . . . . . . . terminalis $\mathrm{Lw}$.

Vordertarsen anders rerziert . . . . . . . . . . 98

98 Der minnliche Fligel an der Wrurzel versehniblert. Erstes und zweites Vordertarsenglied lang und gelb; drites gell, etwas verbreitert nud am Ende schwarz, oberseits schwarz bebaart; riertes und fünftes schwarz, verbreitert, das vierte anf einer Seite schwarz behart.

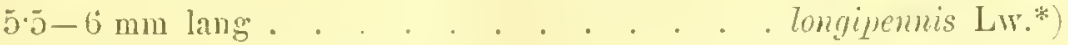

Der männliche Flügel an der Wurzel nicht verschmillert. Die ersten drei Tordertarsengliedel gelb, das dritte zur Hälfte selıwarz; viertes nnd fünftes schwarz, kmr, olerseits schwarz bebartet. $5 \overline{0}-6 \mathrm{~mm}$ $\operatorname{lang}$. . . . . . . . . . . . . saroles Lw.

\section{H!groceleuthus.}

(Subgenus ron Dotichopus.)

latew, X. beitr. I. 10 (1857).

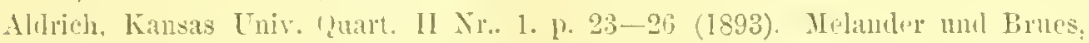
lioloug. Bull. II Xr. 3. 123 (1900).

leh batte diese Gattung in meinen Ausfijlunugen itber die Dolichopodiden der paläarktischen Region als ein Subgenus rou Iolichopus Latr. bezeichnet. Aldrich in seinem Kálalog der N. Anerikanischen Dipteren 1 (4) stellt sie als Synonym von Dolichopus hin, nachdem el sie in den líansas Unir. Quart. 1. c. noch als besondere Gattung gefiuhrt hatte. Melander und Br'nes haben in dem Biolog. Bnll. 1 (1900) eine kleine Abhandhug ither diese Gattung geschrieben; in dieser wird ihr eine gewisse Selbstandigkeit nicht abgesprochen, jedoch mit dem Hinzufiigen, dalf sie der Gattung I) olichopus sehr nahe verwandt sei und daf die unterscheidenden Merkmale lediglich im männliehen Geschlechte vorhanden wïren. Länge des Gesiehts,

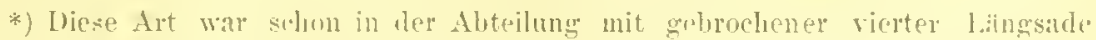

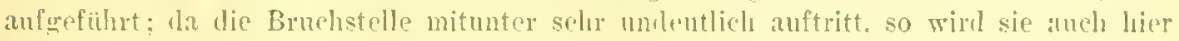
wieder eingestellt. 
Verliingerung der Fiihler, namentlich des ersten Gliedes, das an der inneren Seite lappenförmig verlingert ist, Verdicknng der Randader und Einbuehtung des Fliigelhinterrandes an der Mtindung der füuften Laingsader sind die charakteristischen Gattungsmerkmale, von denen aber das eine oder andere Herkmal bei dieser oder jener Art nicht voll ausgepright ist. lelı glaube, die Amerikanischen Kollegen werden danit einverstanden sein, wenn ich diese Gattung anch hier als Subgenus bezeichue und behandle.

Die Nordamerikanisehe Fauma ist reieher an Arten als unsere paliiarktische. Ans Sidamerika ist keine Art bekannt geworden und wird anch wohl keine, ebenso wie bei der Gattung Dolichoms, dort gefunden werden. Helander und Brues haben l. c. aus Nordamerika neun Arten und zwei Varianten behandelt mit Bestinmungstabellen und Beschreibungen. Unter diesen belindet sieh aneh Dotichomus plumines Senp., diese Art laben sie hier mit eingestellt einmal wegen des etwas verlängerten Gesichts ( $\left.\sigma^{7}\right)$, dann aber auch, weil bei plumipes lie Mitteltarsen verziert sind; unter den amerikanischen IIygrocelenthus-Arten giht es nämlich drei Arten, welche ebenfalls verzierte, und eine Art, welche ahnlich so verzierte Mitteltarsen hat wie plumipes Scop. Melander und Brues glauben nun, daß die Mittelbein-Verzierung eine besondere ligenschaft der Gattung Hygroceleuthus im Gegensatz zu Dolichopus sei, bei der solche Verzierungen nicht vorkimen, und daß es deshalh gereehtfertigt sei, die Art phmipes zur Gattung IIygroceleuthus zu rechnen. Hierzn möchte ich nur bemerken, daß es aueh einen Amerikanischen Dolirhopus sibt, nimlich comatus Lw, dessen Mittelmetatarsus durch eine anffillige lborstenreihe verziert ist, nnd dab wir in unserer paläartischen Fanna eine ganze lieihe solcher Arten besitzen wie planitarsis liall., Whahlhergi Zett., pectinitarsis Stenh., pemnahus Veig., pomularis Wied., aemulus Lw., trgmrotarsis Wablb., signatus Meig., urlomus Meig. Ws kann daher die Mitteltarsen.Verzierung woln nicht als lrivileginm der Gattung Ilygrocdeuthes angesehen werden; ich lasse daher anch die Art phumines scop. bei rolichopus.

\section{Alteggister.}

1 afflirtus O. Sack. O" , Bull. Unit. Stat. Geolog. Surv. III. 313 (1877). America sept.

2 Allrichi Wheel. so, l'roeced. Califurn. Acad. Sc. ser. 3. Zoolog. II. 3. 5. tab. 1 tig. $1-3(1899)$. . . . . . . . . Ameriea sept.

3 amnicola Meland.11. Brues. , Biolog. Bull.1.130 fig.6 (1900) America sept.

4 citialus Aldr. O’o, Liansas Univ. Quart. Il 25. tab. I fig. 28 (1893)

Awerica sept.

5 comsengumens Wheel. ơ 9 , Proced. ralifurn. Acad. Sie. ser. 3 Zool. 11.

5. 6. tab. I fig. 5-7 (189!) America sept. var. mopimpuns tleland. und l'rues, Biolog. Bull. I 132 (1900).

6 crenatus O. Sack. Su, Bult. Unit. Stat. Geolog. Surv. III 312 (1877)

Ameriea sept. 
7 idahoünsis Aldr. o7, Kansas [Tniv. Quart. 11 154 (1893) Ameriea sept. 8 lamellicomis Thoms. ;, Engenies Resa, Dipt. 511. 114. [Dolichopus] (1869)

Anerica sept.

Ist nur als ITeibchen besehrieben und als Art nieht erkemubar, seheint aber der Filhlerform naeh zu dieser Gattung zu gelıören. O. Sacken nahm an, dali es das Weibehen ron afflictus sei, was sich aber nach Wheelers Ansführngen nicht zu bestätigen seheint. 9 latipes Lw. O’o, N. Beitr. VIll 5. 1 (1861). . . . Ameriea sept. 10 Wheeleri Meland. '11. Brnes O , Biolog. Bnll. I 126. tig. 2. a-ce (1900)

Anerica sept.

Von vorhandenen Bestimmungstabellen der Arten siud die beiden nachstehenden zn nemuen:

1. Aldrich, Kansas Univ. Quart. Il Nr. 1. pag. 24 (1893), mit 4 Arten.

2. Melander 1. Brues, Biolog. Bull. 1 Nr. 3. pag. $125(1900)$, nit 8 Arten.

Der nachfolgenden 'Tabelle habe ich obige Veröttentlichung von Melander und Brues zu Grunde gelegt unter Ausschlnß der Art phomipes Scop. und unter Hinzufügung anderer charakteristiseher Merkmale, so daß bei Benutzung derselben eine Vergleichung der Beschreibungen sich ertibrigen wird; hinsiehtlich der letzteren verweise ieh anf oljige Arbeiten von Aldrich, Melander, Brues, O. Sacken, Wheeler, Loew. Was die Tabelle der Weibehen hetrifft, so war es mir mangels typischer Exemplare nicht möglich, eine eigene aul'zustellen; der' Vollstiindigkeit halber' habe ich dalser' die 'Tabelle ron Melander und Brnes in der Übersetzung wiedergegeben.

\section{Bestimmmngstabelle tiïr die Arten der liattung Hygroceleuthus.}

\section{l) iı uchen:}

1 Mitteltarsen verziert. Postokularzilien unten hell . . . . . . 2

- Nitteltarsen cinfach. Postuknlarzilien ebenfalls hell . . . . . 4

2 Fiilıler sehwarz, erstes und zweites Glied unten gelb. Beine mit Vorderhiiften gelb; das zweite, dritte mnd vierte Glied der Mlitteltarsen schw:1\%, etwas zusammengedriickt und auf einer Seite schwarz gebartet. Hintersehienen etwas verdickt. Fliigel im Analwinkel mit 2 Ausbauchungen. $4-5 \mathrm{~mm}$ lang . . . . . . . Aldrichi Wheel.

Fiihler rotgell, Spitze des dritten Gliedes sclıwarz . . . . . . 3

3 Die vier letzten Tarsenglieder der Mittelbeine sebrvarz, verbreitert und anf einer Seite scliwarz bebartet. Flügel am Ende der elsten Läingsader mit deutlieher Verdiekung der Costa. Mittelsehiene nieht doppelt so lang wie der Selienkel. 5-7 mm lang . . . . . latipes Lw. Das erste Glied der Mitteltarsen beiderseits gefiedert, sehwar wie die iibrigen Glieder. Mittelsehienen sehr lang, annähernd doppelt so lang* wie der Schenkel. Analwinkel der Fligel mit deutlich lappenförmigem Vorsprung. $5 \mathrm{~mm}$ lang. . . . . . . . IJ7epleri Aldr. 
4 Soluippehen gell, bewimpert . . . . . . . . . . . 5

- Schijplehen selwwarz bewimpert . . . . . . . . . . . . T

5) Kweiter Ilinterleibsring an jeder Seite nit einen gelben Harschopt. Gesicht silherwoib. licine mit Vorderhiilten gell, Tarsen rom linde des ersten (ilieles an sehwar. IIntersehienen etwas verdickt. Fligel mit Stigma an Ende der ersten liingsader, Hinterrand am Ende der fiinften Lïngsader mit dentlichen linsehnit. $6-7 \mathrm{~mm}$ lang . . "rflictus: O. Sack.

- Zweiter Hinterleibsring une gelben Ilaarsehnip . . . . . . ti

6 Gesielıt gelhweiß. Inallamellen gehh. Fligel mit deutlichem stigma am Fucle der erstun liangsader; Hinterand der Fligel mit tiefen Ein. schnitt an der Mündung del fiunften Längsader. (i-7 mm lang. .

renatus 0 . Sack.

- Resicht silberweiß. Anallamellen weili. Fliigel mit lingliehem Stimma, Einsehnift am Ende der tiunften Längsader nur selu schwaeh ansgebildet. 6-7 mm lang . . . . . . . cillumönsis Aldr.

7 Fiihlerborste naekt. Fihler s'hwar, erstes Glied an der imeren Seite gell). Gesieht gelbweili. Vorderliiften gelb, anf ier Hinterseite selıwarz. llintersehienen an der Spitze schwarz. Fligel mit selı schwahem Stigma und Einsehnitt. $4 \mathrm{~mm}$ lang . . . . . . ciliutus Aldr. Fiihlerborste pulseszent. Fiihler schwarz, erstes und zweites Glied teilweise gelb. Gesieht ockergeh. Vorderlüften gelb. Hintersehienen etwas verdiekt. Flitgelstigna dentlieh. $5.5-6.5 \mathrm{~mm}$ lang

consomaniners Wheel.

Weibehen.

1 Erstes Fihlerglied gelb

Erstes Fiihlerglied zum grolien 'Teil schwarz. . . . . . . . 4

2 Arten von (i mm Lituge. Erstes Glied der Mitteltarsen an der Wurzel gelb.

3 Hinterschienen ganz gelb; Scheitel griin . . . . . latipes Lw.

Hinterschienen an der Spitze schwarz. Scheitel violett. latipes var. cognutus

4 Spritze der llintersehienen schwarz, oder, wenn gelb, damn die Fliigel schmal

- Ilinterschienen ganz gell,

5) Vordersehenkel zn $\% / ;$ an ker Wurzel gebrännt. amnicolu Mel. $11 \mathrm{Br}$.

- Vorderschenkel ganz gell, . . . . . . . . Aldrirlii Wheel.

6 Fiihlerborste etwas jubeszent. Flïgel gewöhnlich mit einem Aderanhmg an der Biegung der vierten lingsader . . . . . . . . . 7

Fïhlerborste nackt . . . . . . . . . . . . . . 8 8

7 Zweites Glied Rer Hintertarsen an der Wurzel gelb. Beine gelb; kleine Art rrenutus $U$. Sack.

- Zweites Glied der Hintertursen schwarz. beine dunkler; größere Art. consunguineus Wheel. 
S Wimpern der Sehüppehen ganz sehwar\%, etwas stark, viliatus Alur. Wimpern der Selriippehen an den Seiten gell . . . . . . . 9

9 Fliigel vorne gelblieh. Iliften gell, Fliigel wasserklar, lliiften dnukler "ffliches 0. Silek. illahoünsis Aldr.

\section{Ilelerestom 11.5.}

Lonw, X. Beitr. Y. $9(185 \pi)$.

Gymnopternus Lw., X. Beitr. V. 10 (1857) et Aut. Parrgymnoptermus Big., Ann. sue. Eut. Fr. Nèr. 6. X. $281(1590)$.

Die Gattung Ilercostomus mit Einschluli der als Grymopternus bezeichneten Arten ist in Nord-Amerika gut vertreten; vereinzelt kommen noch Arten in Mexiko und Westindien ror: dariilser himans und in ganz SiidAnerikal seheint die Gattung nielit mehl heimiseh zu sein.

Die amerikaniselien Entomologen haben die von Loew angebahnte 'Trennung zwisehen Herostomus und rymmonterms angenommen nud antrecht erhalten, namentlich auch die letatere Gattumg, wihlrend Ilercostomus rou ilnen als ein mixtum compositun angesehen wirl. Es lïßt sich auch nicht leugnen, daß die Grymoptemus-Arten (seusu Lw.) in Nord-Amerik: weit zahlleicher vertreten sind als die von Ifropostomus und dalf diese Gruppe einen etwas geschlosseneren, einheitlicheren Eindruck gewäilut; alle Arten haben fast mur eine mittlere. wenig roneinander abweichende Grölje; inre Unterseliede sind geringfiigig, da grölere plastische Untersehiede fehlen; anch das Hypopyg mit seinen Anhängen hat bei der Mehrzalıl der Arten einen iibereinstimmenden Ban; es fehlt aber ebensowenig wie bei den Arten der paliarktisehen \%one nicht an Übergingen nach Mercostomus hin. Die hauptsäichlichsten Untersehiede zwischen beiden Gattungen, welche Loew fiu Crymmoplerms angibt, sind die parallele Lage der dritten and vierten Lïugradern, die Kitrze des dritten Fühlergliedes und die geringe, wenig ron einandel abweichende kntwieklung der Anallamellen. Unter den bekannten Grymoptemus.Arten haben nou despicatus Lw. micomis Aldr. und pulitus Lir. mehr oder weniger deutlieh konvergente Längsadern; a uf der anderen Seite besitzen die nordamejikanischen Hercostomus-Arten metatarsalis Thoms, vetitus Meland. und impudirus Wheel. eine so wenig ausgebildete Konvergenz der Adern, daß man sie regen dieser Eigensehaft nieht von crymnoptermus zu trennen brauchte. Das dritte Fiihlerglied ist verlängert bei den Arten Gymuoptermus scotius Lw. und subulatus Lw.

Ich habe naehstehend nur eine Gattung Iercostomus angenommen; die Grinde, die mich dazu veranlassen, habe ich bei Behandnng derselben Materie in der paläarktisehen Region weitliufig entwiekelt.

Die hier magebende Literatur ist aus dem nachfolgenden Artver\%eichnis ersiehtlich. An Bestimmungstabellen fiir die Arten sind folgende zu nennen:

Loew, N. Beitraige VIII 26-36 (I\&61); . . 'Tiublle mit 22 Arten 
Loew, Monogr. Dipt N. Amer. II 77 (1S64); Tabelle mit 23 Arteu und ebendort im Nachtrag p. 332 eine andere mit 24 Arten Whe heler, l'roceed. Californ. Acad. Sc. Ser. 3 \%oolog. IT s' (1899).

Taluelle iiber 4 IIerostomms-Arten

Melander, Canat. Entomol. XXX̄ll 138 (1900).

'T'abelle iiber 7 IIcrostomus-Arten

Von Hercostomus-Arten sind sowohl im Katalog Kertész VI als im Latalog Aldrich (1905) \& Arten nambaft gemaeht, von denen die eine, latipes Aldr. vielleieht nieht hierher gehört; siehe hieriber lie Bemerkungen bei dieser Art.

Als Gymnopterms sint in beillen Katalogen 33 drten genannt. In der Loewsehen Bestimunngstabelle fehlen die spaiter bekanut gewordenen Adten mirificus Meland., pluflophome Lw. und ruficomis Aldr.

\section{Artregister fiil dir Nord-Amerikanischen Vertretel von Hercostomus und Gymnopternus.}

1 albiceps Lw. N. Beitr. VIII 30. 7 [rmmoyterms] (1861).

2 anomostus Meland. O", (anal. Entomol. XXXII 139. 5. fis. ¿̀ (1900).

3 umifer Thums. Ho, lugenies hesa 512. 117 [Jholirhopms] (1869).

Diese Art ist ohne Vergleichnng der Typen, ledighich nach der Besehreilung nicht zu erkennen, ist aneh hisher von kemem der Antoren gerlentet worien.

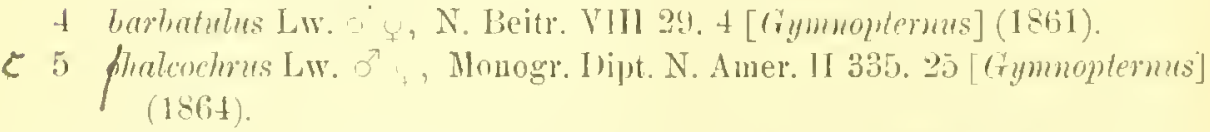

6 ro.ralis Lw. O', Berl. Ent. '/seitsehr. VIII 94. 87 [Gymupternus] (186t).

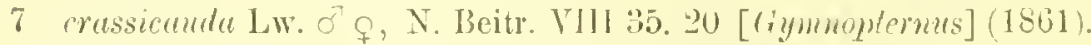

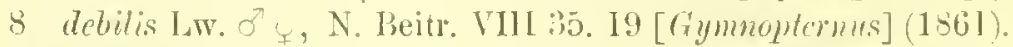

9 despicalus Lw. O, N. Beitr. VIII 33. 13 [Gymontermes] (1861).

10 difficitis Lw. N. Beitr. VIII 3.. 14 [Gymnoptermus] (1861).

11 exigurs lw. O, M[onogr. Dipt. N. Amer. 11 337. 29 [(rymoplerums] (1864).

12 exilis Lw. ${ }^{7}, \mathrm{~N}$. Ireitr. VIII 30.5 [trymopterms] (1861).

13 fimlriatus Lw. o, N. Beitr. V11I 32. 12 [Crymuoptermus] (1861).

14 flacipes Aldr. 5, Biolog. Centr. Amer. Dipt. I 336. 1 tab. VI fig. 17

(1901) . . . . . . . . . . . . . Mexieo

Der Name liollidiert zwal mit der Art Hercostomes fluvipes v. Röd., soll aljer vorlainfig ron mir belassen werden, da letztere Art naeh Bekanntwerden des Miunchens doeh wahrscheinlich einer neuen Gattung wirl zngeteilt werden müssen.

15 flavus Lw. o \&, N. Beitr. VI11 28. 1 [ (rymmopterms] (1861).

16 frequens Lw. $\sigma_{+}$, N. Beitr. VIIt 32. 10 [(tymmoptems] (1S61).

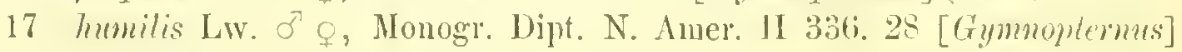
$(1864)$.

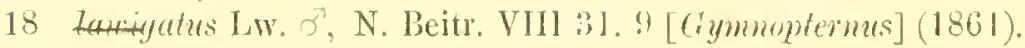
Lavis 
19 lutipes Aldr. $\sigma^{-}$, Trans. Entom. Soe. London 311. 1. tab. XII fig. 111 (1896)

Westindien

Anmerkung: leh labe grobe Zweifel, wh diese Art lierher gehört und nicht vielleieht weit besser $z$ ulen Paraclins-Arten zu stellen ist; die Aldrichselıe Besehreibung gibt eine licilu sum luhaltejmkte fir meine Vermntung: das kupferfarbige Schildehen: dic sillucwciß bestiuhten Flceken anf dem Thoraxrieken an den bezeichnetun stellon kummen somst nur bej der trattung Paraclius vor; anch die rote Fitrbung der Fühler spricht eher dafïr als elagegen; die Fliggraderung komut in geringen Abweiehungen vom Normaltypus ebentills vor; das sehr schmale Gesicht und die kurzen Vordertarsen sind der Gattung Parachius ebenfills eigen. Am niichsten steht dieser Art wohl Paraclius vicinus Ahr. Ieh

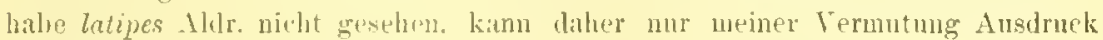
gueben.

20 lunifer Lw. O', N. Beitr. VIIl :3. 11 [Gymnontermus] (1861).

21 meniscus Lw. ơ \&, Berlin. Entom. Zeitschr. VIII 94. 88 [Gymnopternus] (1.861).

2.) metatarsalis Thoms. j7, Eugenies Resa Dipt. 512. 116 [Dolichopus] (1869).

procerus Wheel., Proceed. Californ. Acad. Sc. ser. 3. Zoolog. II 8. 8 tal). I fig. 9-10 (1899).

¿3 minutus Lw. O', N. Beitr. VIII 35, 21 [Gymmonterms] (1861).

¿4 mirificus Meland. ơ. Camad. Eutomol. XXXII 137. 3 fig. 13 [Gymnopternus] (1900).

25 nigribarbus Lw. 5, N. Beitr. VIII 33. 15 [Gymnopternus] (1861).

26 olscurus Say , Jou'n. Acad. Nat. Se. Philadel]nia III 85, 4 [Dolichomus] (1820).

Ist nur als Weibehen und unerkennbar besehrieben, konnte bisher noeli nicht gedeutet werden.

27 opacns Lw. N. Beitr. VIII 34. 17 [Gymonterms] (1S61).

25 particomis Lw. O, N. Beitr. VII1 34. 16 [Gymmoptermus] (1861).

29 phyllophorus Lw. б, Berlin. Entom. Zeitsehr. X 4ว. 82 [Gymnoptcrms] (1861).

poenitens Wheel. = unirolor Lw.

:0) politus Lw. Q, N. Beitr. V1I1 34. 18 [Gymnonternus] (1861).

mocerus Wheel. = metataralis Thoms.

31 pusillus Lw. Monogr. Dipt. A. Amer. Il 334. 24 [Crymoptemus] (1464).

32 ruficumis Alds. ? Trans. Entom. Soc. London 309. 1 [Gymontermus] (1896).

33 scotius Lw. 7 9, N. Beitr. V111 99. 3 [Gymmontermus] (1861).

it spcctabilis Lw., N. I3eitr. V'I1I 30.6 [Gymmoptermus] (1861).

35 subdilatatus Lw. 5 , X. Beitr. VIII 31. S [Gymmoptermus] (1861).

$\$ 6$ subulatus Lw. 3, N. Beitr. V111 29. 2 [Gymontermes] (1861).

37 tristis Lw. - o, Monogr. Dipt. N. Amer. II \$3.5 [Gymnoptermus] (1S64).

38 unicolor Lw. o, Monogr. Dipt. N. Amer. II 117. 1 tab. IlI fig. 9 [(iymnopterns] (1564).

pocnitens Wheel., Psyche V 3505 [Gymuptemus] (1890).

Abhandl. d. zool.-botan. Ges. Bd. IIII, Heft I 
39 veutrulis Lw. O, N. Beitr. V11 :36. 22 [Gymontemus] (1861).

40 retitus Meland. O, C'anad. Entomol. XXXI1 138. 4 fig. 1, 2 (1900).

\section{Bestimmmostabelle tiir die Arten der Gathmg Hercostomus.}

1 Dritte und rierte Längsader parallel oder nur schwach konvergierend ב

- Dritte und vierte laingsaler deutlieh konvergierend. . . . . 33

2 Arten von metallischer Firbung . . . . . . . . . . . . 3

- Thorax gelb; Schildehen kahl. Gesicht weib, Fïhler gelb, drittes Glied mit schwarzer Spitze. Stirne gelb bestäubt. Ininterknfloorsten unten hellgelb. beine l,aßgelb. Wimpern der tegulae gelb. Fliigel gran. gelblich. $25-3 \mathrm{~mm}$ ling . . . . . . . . Jlamens Lw. $\sigma^{7}$

3 Beine ibberwiegend sehwarz; Hiiften und Sehenkel sthwarz; Kunee: Sehienen und Wurzel der rorderen Tarsen gelh. Fïhler ganm schwarz . . . . . . . . . . . . . . . . . 4

— Beine iiherwiegend gelb. Fihler schwarz nnd rotgelb . . . . . 7

4 Metallisch hellgrime Art. Stirne gran bestiubt. Gesicht weili. Fligel

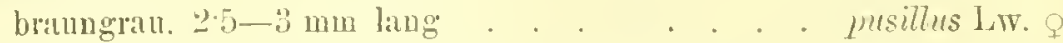

Metallisch schwallggrin gefirbte Arten . . . . . . . . . 5

5 Drittes Fiihleralied linglich oral, zugespitzt, dentlieh pubeszent. Sehildchen nackt. Stirn mnd Gesicht gran. Hinterschienen auf der Oberseite $\left(\sigma^{\top}\right)$ dicht heh:art. Analiamellen klein, schwarz. Flïgel grauschwïrzlich, am Vorlerrande dunkler. 35-4 mu lang . . . scotias lsw.

- Drittes Fiillerglied kurz, abgerundet mit lianm bemerkbarer Pubeszens. Selildehen zart behart . . . . . . . . . . . . 6

6 Gesicht weiforau, zart schwarz hehaart $\left(0^{\circ}\right)$. Anallamelien klein, braun. Fliigel grau. 3-35 mm lang . . . . . . burlatulus Lw. ơ o

- Gesicht schwarz $\left(0^{7}\right)$, sehwarzman $(q)$, beim $q$ etwas behart. Anallamellen schwarzhan in Form einer Mondsichel. Fligel schwiirzlich. 3-35 num lang. . . . . . . . . tristis Lw. Oo

7 Fïhler ganz schwarz

Fiiller ganz oder teilweise rotgelb his rotbrann . . . . . . 19

8 letztes Vordertarsenglied etwas verbreitert, schwarz $\left(\sigma^{7}\right)$. Vorderhiiften bis zur Mitte schwarz. Anallanellen braungelb bis braunschwarz, nierenfürmig gehogen und deutlich beborstet. $35-4$ mm lang.

subdilatatus Lw. O

- Tarsenglieder alle einfacl . . . . . . . . . . . . . . . 9

9 Vorderlinften schwillz . . . . . . . . . . . . 10

- Vorderhiiften gelh oder hiochstens an der Wurzel schwarggran . 12

10 Thosax dunkel reilelıenblan. Gesicht silberwejb. Schildehen anf der Oberfliche etwas behant. 45-5 mulang . . . spectabitis Lw. G

Thorax schwarzeriin. Schildchen nackt . . . . . . . . . 11

11 Gesicht des o ockergeib, des o weiligrau. Anallamellen schwarz. $35-4 \mathrm{~mm}$ lang . . . . . . . chatrochrus Lw. o + 
11 Gesicht des ơ weif. Anallamellen gelb. $3-35 \mathrm{~mm} \operatorname{lang}$ curalis Lw ó

12 Anallamellen gelb bis weilgelb . . . . . . . . . . . $1: 3$

Anallamellen bran bis schwarz. . . . . . . . . . . 18

13 Vorderhiiften an der Wurel schwargrau. Gesicht weiß. $355-4 \mathrm{~mm}$ lang.

meniscus Lw. ơ

Vorderhiiften ganz geth.

14 Gesicht des o ockergelh. $25-3 \mathrm{~mm}$ lang . . . . exigums Lw. 0

15 Hinterschienen an der Styitze schwarz, Hiutertarseu ganz schwarz.

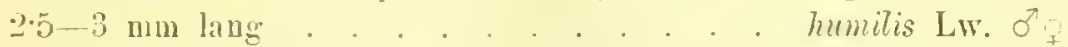

Hinterschienen ganz gelb. 'l'arsen erst ron der Spitze des ersten Gliedes an schwarz oder braun

16 Die inneren Analanhänge sind lang pinselförmig gestaltet und lang behaart. $25-3$ mun lang . . . . . . . fumbriatus Lw. o

Die inneren Anatanhinge sind ron anderer Form nnd unbedentend 17

17 Hinterschieven anf der Oberseite und Spitzenbailfte lang und dicht behart. Dritte und rierte Längsadern deutlich konvergierend.

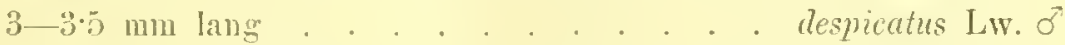

Hinterschienen auf der Oberseite und spitzenhälfte kurz und weniger dicht belaart. Dritte und riertc Längsadern parallel. 3-3.5 mu lang difficitis $\mathrm{Lw}$. 0

18 Anallamellen braun his braungell, nierenformig. Beine dunkelgelb, Hinter schenkel oben an der nitze etwas brann. $35-4 \mathrm{~mm} \mathrm{laug.} \mathrm{lunifer} \mathrm{Lw.} \mathrm{of}$ Anallamellen schwar, abgerundet. Beine gelb, Ilintersehenkel an der Spitze nieht hrann. 3-35 mm lang. . . frequens $\mathrm{Lw} .09$

19 Spitze der Hinterschenkel gesehwilzt. Fiihler braunselwarz, zweites Glied und die Wurel des dritten rot. Sehildchenoberfläche kaum etwas behaart. Anallamellen gelb, klein, nierenförmig, selıwarz bebaart. $3 \mathrm{~mm}$ lang . . . . . . . . . . exilis Lw. ơ

Spitze der llintersehenkel nicht gesehwïrzt. . . . . . . . 20

20 Fiiblerborste au der Spitze rerlneitert. Fiiller rotgelb, drittes Glied an der Spitze braun . . . . . . . . . . . 21

Fithlerborste nicht verbreitert . . . . . . . . . . . 22

21 Fiihlerborste an der Spifze mit einer sehwarzen Lamelle, die so groß ist wie das dritte Fiihlerglied. Gesicht duskel ockergell. Hypopygium groß, Lanellen gelblich, halbmondförmig. $350-4 \mathrm{~mm}$ lang: pheyllophorus Lw. O’

liihlerborste an der Spitze nur schwach verbreitert. Gesicht graugelb. Hypopyg klein, nur ${ }^{1 / 3}$ so lang wie bei der vorigen Art. 35 mu lang . . . . . . . . . mirificus Meland. o

22 Drittes Fiiblerglied sehr lang, zugespitzt und dentlich behaart. Fiiller dunkelbrann, zweites Glied rot, Fiihlerborste im zwciten Drittel des Oberrandes einsetzend. Ilypopygium ziemlich diek, Lamellen klein, gelb. 35̃-4 mm lang . . . . . . . . subulutus Lw. O 
- Drittes fiihlerglied vicht verlingert . . . . . . . . . 23

23 Weibchen . . . . . . . . . . . 24

- Minnchen . . . . . . . . . . . . . . . . 26

¿4 Die weibliche Legeröhe mit dem gewöhmliehen Dornenkranz :m Ende . . . . . . . . . . . . . . . . . . . 20ั

-- Die weibliche legerölue olme Dornenkranz. Gesieht unten behaart. Fligel braungrau. Dritte nnd vierte Lingsader schwach konvergierend . . . . . . . . . . . pulitus Lw.

25) Fiiluler rotgelb, drittes Glied an der Spitze bran. Thoraxideken dunkel veilcheublau. Gesicht schneeweib. 4.5 mm lang . albireps Lw.

- Fihler schwawbrann, zweites Glied und die Wurzel des dritten Gliedes rotbrann. Gesicht weiBgran, unten gewölht und behaart. Thoraxriicken schwarkgriin. 25 mu lang . . . . nigribarbus Lw.

26 Hintertarsen von der Spitze des ersten Gliedes an deutlieh sehwarz. Fiihler schwarz, zweites Glied und die Wurzel des dritten Gliedes rot. Gesieht weiß. Anallamellen weißgelb. halbmondförmig. $3 \mathrm{~mm}$ lang . . . . . . . . . . . . . laevigertus Lw.

Hintertarsen gegen das Ende etwas veriunkelt, löchstens braun, nicht schwarz . . . . . . . . . . . . . . 27

27 Mittel- und Hinterbiffen an der Wurzel dentlich gesebwiirt. . 28

- Nittel- und Hinterhiiften gelb, an der Wurzel kann etwas gran 29

28 Fibler klein, Fliggel schwarzgran. $3 \mathrm{~mm}$ lang. parvicomis Lw. of

- Fiihler groß, Fligel schwach grangelb. 35 mm lang . opacus Lw. o

(9) Banch und hinterer liand des brustseiten nicht gelb. Fïller rotgelb, drittes Glied an der Spitze lraun . . . . . . . . . . 30

- Banch and hinterer Rand der brustseiten gelb . . . . . . 31

30 Gesicht weiß, Fliigel wasserklar, dritte und vierte Liingsadern konvergierend. Anallamellew gelb, serundet und mit gelben Borsten am Rande. $16 \mathrm{~mm}$ langr. . . . . . . vuficomis Aldr. of Gesicht grau. Fligel schwach gelbgrau, dritte und viente Läingsadern fast parallel. Anallamellen klein, l)labgelb, scbwarz gewimpert. $3 \mathrm{~mm}$ lang . . . . . . . . . . debilis Lw. O

:3) Hypopyginu ungewöhnlich dick und gloß. Gesicht weiß, beim + unten behart. 3-35 mm lang . . . . . . crassicauda Lw. O7O

Hypopygium rou der gewöhnlichen Größe . . . . . . . . 32

:32 Filler rotbraun, sehr klein, das iritte Glied am Ende dunkler. Torderhiften nu weiß behant. $205 \mathrm{~mm}$ lang . . . . minutus Lw. o

- Filhler braunsot, ron mittlerer Gröbe. Vorderhiuften aneh schwarz be haart. $35-4 m m$ lang . . . . . . . ventralis Lw. $\sigma^{7}$

33 Beine liberwiegend gelb . . . . . . . . . . . . 34

- Beine iiberwiegend schwar . . . . . . . . . . . . . 37

34 Iinterkopfborsten unten selwarz . . . . . . . . . . . 35

- Hinterkopfhorsten nnter weißlich . . . . . . . . . . . 36

35 Gesicht ockergelb. Schildehen auf der Oberflache unbehart. Vorder- 
büften gelb, an der Wnrzel schwarz. Hinterschenkelspitze schwarz. Dritte nud vierte Lïngsadern schwach konvergierend. $45-5 \mathrm{~mm}$ lang . . . . . . . . . . metatarsalis Thoms. or

Gesicht braun. Schildehenfläche behart. Vorderhïften schwärzlich grau. Hinterschenkel ohne schwarze Spitze. Dritte mud vierte Längsadern selu schrach konvergierend. $4.5 \mathrm{~mm}$ lang vetitus Meland. O" 36 Fiubler rotgelb, drittes Glied braun, nicht linger als breit. Flijgel fast wasserklar; dritte und vierte Liingsadern dentlich konvergierend. Vordertarsen etwas verbreitert. $3-35 \mathrm{~mm}$ lang . latipes Aldr. ő Fiibler lang, schwarz, drittes Glied zweimal so lang wie breit. Fliigel schwärzlich, dritte und rierte Längsaderı sehwach konvergierend. Vordertarsen einfach. $3 \mathrm{~mm}$ lang . . . . impudicus Wheel. óf

Fỉhler kurz schwarz. Flïgel fast wasserklar, die vierte Längsader zur dritten dentlich anfbiegend. $3 \mathrm{~mm}$ lang. . . flavipes Aldr. O

.77 Beine ganz pechsehwar. Anallamellen oral, schwärzlich. Fliigel grau ohne Verdickung am Ende der ersten Längsader. 2־5-3 mm lang unicolor Lw. o

Beine rotgelh, Obersejte aller Schenkel schwarzbraun, Spitze der Hinterschjenen, die Hintertarsen, Voldep- und Mitteltarsen rom Ende des ersten Glicles an schwar. Anallamellen braun, halbmondförmig. Fligel wasserklal nit Verdickung am Ende der ersten Längsader. $3 \cdot \overline{6}$ mu lang. unumustus Meland.

\section{Proreliels.}

Bignt. Ann. Sur. Entom. Fr. 215 [T'aracleines] (1859).

Loew, Monugr. Dipt. N. Aurr. II 97 (1864).

'Type: Dotichopus heteroneurus Macr. Q. Dipt. exot. suppl. IV 128 tah. XII Fig. 10. [Dolichopus] (1849).

Loew hat 1. c. p. I9 dic Bigotsehe Gattung Paracleius mit der Type heteroneurus Macq. nicht anerkannt; er sagt, er könne sich mit Bigot's Definition und Unterscheidung von Gymnopternus nicht einverstanden er. klären. Es mag zugegreben werden, daß Bigot's Erkliarnng ron der Form des dritten Fïblergliedes und der Biegung der vierten Längsader nur eine unvollkommene ist und daß die Gattung erst dureh Loew's Gegeniberstellung auch mit Pelastoneurus nnd Gymuopternus leucospilus Lw. besser und vollkommener hat erklairt und hegriondet werden können, aber immerlin ist die Gattung P'rraclius doch da nod ron der typischen Art heteroncurus sagt Loew selbst, man miisse nach Macquart's Beschreibung und Zeichunng zu der Ansicht kommen, daß diese Art zu Paruclius gehire. Loew hat damit keinen Beweis aufgestellt, daß Bigot's Gattung zu Unreelit bestehe, vielmehr ihn Recht gegeben. Jan håtte Loew's Erklärung, daß er für sich die Bigotsehe Gattung nicht beachten könne, vielleicht mit Stillsehweigen iibergehen könuen; weun er nun aber in demselben Atem- 
zuge ankiundigt, daß er eine neue Gattung nit Bigot's Namen Paratius aufstellen mitsse, so sind wir genötigt zu erklären. daf wir Loew aul diesem Wege nieht folgen kömen, vielmehr ihm die Berechtigun absprechen miissen, den bereits vergebenen Gattungsnamen weiter als den seinigen zu gebraueben; die Notwendigkeit, eine nene Gattung zu begriuden, lag ja iberbampt nicht vor, da Joew's Gattung sich mit rer von Bigot deekt.

Aldrich hat in seinem Katalog der Norlanerikanischen Dipteren p.301 (1905) bei L'aractius in einer Note zwar seine Ansicht dahin alusgesuroehen, daß die Gattung Paractcius Big. nicht dieselbe sei wie Paractins Iw.: leider aber hat Aldrich seine Ansicht nieht begrindet. Ich vermag mich ans den oben anfgefiibrten Griinden nicht Aldrich's Meinung anzuschlielien, balte mich vielmehr fiir verpflichtet, die Bigotsche Gattnng Paractius anfrechtzulalten und loew's sogenannte neue Gattung Paractios synonym dazu zu stellen.

\section{liattureshegrill.}

Ieh nehme die Gattung so an, wie sie Aldrich in dem Kansas Unir. Se. Bull. XI, 77 (1902) im Vergleich mit P'elastonenns und Surroms hingestellt laat. Die Angen sind lang nnd hoch; das Gesicht ist meist sehr schmal, selten breiter als das dritte Fiihlerglied und geht nicht iiher den unteren Angenrand hinab; es ist nicht wie bei J'elustonenns im oberen Teile eingesenkt und in unteren Teile buckelig rorstehend, somdern es fiillt fast ganz gerade obne dentliche Querteilung ab. Fiiluler kur\%; das erste Glied ist oben zart behaut, das dritte ist kum allgernudet oder in eine kurze stumpfe Spitze endigend, selten etwas linger als brat nnd dann anf der oberen Seite suhwel konkals; die Fïhlerborste ist nulkroskopisch pubeszent bis deutlich pubeszent, aber niemals gefiedert. Liussel und 'Taster sind beide sebwach entrickelt; eine sammetschwarze Fleckenzeichnung des 'Thoraxritekens wie bei Pelustoncmus kommt meines WTissens nur bei einer Art quutrinotutus Aldr. vor. Die Notoplentaldepression ist bei allen Arten stark weif bestiulot; auljerdem sieht man, was fiir die Gattung eharakteristisch ist, in versehiedenen Stellen des 'Thoraxrickens: an der Sehulterbenle, vor dem Schildelen und in der Sutura bei einer Reibe ron Arten scharfbegrenzte selneeweiße Flecken. Die Schiippelren sind stets schwarz gewimpert, die Hinterkoptrandborsten sind hei allen bekannten Arten weiß, so daß diese Firbugsverluiltuisse in der neotropischen Region als Gattungsmerkmale mit genannt werden kiuneu, was bei Pelastoncurs nur mit Bezug and die Wimpern der Sehippehen fiiltigkeit hatte. Die Form des Hypopygs ist annihernd die gleiche; die Hintersehenkel sind vielfach stark verlyreitert, bei allen Arten steht aluer die Priajikalborste weit entfernt ron der Spitze, nngelahl im zweiten Drittel oder dritten Viertel der Schenkellänge, fast ebenso wie bei Pelastoncums, weiter entfernt als bei den ibrigen verwaudten Gattungen wie Ifroostomms, Poscilo bolhrus usw. In Verlaufe der vierten Läingsader ist die erste Hiilfte des 
letzten Abschnittes gerade, während die zweite Hälfte mehr oder weniger dentlich knieförmig abzweigt nnd sich der dritten Längsader in einem dem Fligelvorderrande parallel gerichteten Bogen stark nïhert.

Von den $22 \mathrm{im} \mathrm{Katalog} \mathrm{Kertész} \mathrm{VI} \mathrm{anfgefüluten} \mathrm{Arten} \mathrm{unBten} \mathrm{wir}$ zunachst jusillus Mac. und praedicuns Walk. als ungeniigend charakterisiert beiseitelassen und konuten sie in unsercl T'abelle nicht beriicksichtigen, auf der anderen Seite konnten wir die ron Loew bei Pelastoneurus anfgeführte Art lencospitus hier mit einstellen. Die Arten arcuatus und alternans Lw. sind nur als Weibchen beschrieben, Fon denen ich arcuratus mit aufnehmen kunnte. Tu den somit vorhandenen 21 Arten konnte ich noch 16 neue Arten, hauptsächlich aus Siidamerika hinzufijgen, so daß nnsere leutige Artkenntnis bereits anf 37 Arten angewachsen ist, die in meiner Bestimmungstabelle einander gegentibergestellt werden konnten.

Bisber anfgestellte Bestimmungtabellen.

1. Loew, ILonogr. Dipt. N.-Amer. II 101 (1S0t) . . . . 2 Arten

2. Wheeler, Proc. Calif. Acad. Sc. 3. S. II 18 (1599) . . 6 Arten

3. Aldrich, Kansas Univ. Se. Bull. X1 3.77 (1902) • . 11 Arten

4. Aldrich, Trans. Amer. Ent. Soc. XXX 273 (1904) . . 17 Arten

letztere in Vereinigung mit den Arten der beiden Gattungen Pelastoncums und Sarcionns.

\section{liestimmmngstabelle fïir die Arten der Gattung Paraclius liig.}

Nearlitische und neotropische Region.

1 Schenkel schwarz bis dunkelbrann, löchstens an der änljersten Wrurzel oder Spitze gell,

Schenkel schwal'z und gelb gezeichnet . . . . . . . . 7

Schenkel gelb oder höchstens auf der Oberseite cin wenig verdunkelt 8

2 Vorderrandader am Ende der crsten Liingsader mit einer großen schwarzen Schwielc (ठ). Fliigel schwarzbrïunlich. Hiiften und Schenkel nebst Tarsen schwarz, Iiiftgelenke und Schienen mit Ausnahme deren Spitze gelb. $5 \mathrm{~mm}$ lang . . callosus n. sp. of.

Vorderrandader an den heiden ersten Abschnitten stark und lang rerdickt $\left(\sigma^{7}\right)$. Spitze der Schenkel, Hiuftgelenke und die Schienen gelb; beim $q$ ist die Randader noch merklich, wenn anch schwächer verdickt als beim . 4-5 mm lang . . abominalis Aldr. of

Vorderrandader auf der Mitte des ersten Randaderabschnittes schwielig rerdickt. Fliigel schwach gebrïunt. Beine ganz schwarz. $5 \mathrm{~mm}$ lang

mysticus n. sp. 万

Forderrandader mur im ersten Abschnitte verdickt. Schcnkel und

Schienen ganz schwarz. 4-4.5 $\mathrm{mm}$ lang. . . albonotatus Lw. jo

Torderrandader nicht verdickt 
3 Fiiller ganz sehwarz

.. Fiiller braun bis dunkelbraun. Gesicht sebmal schneeweil. Stime hellbraun bestiubt. Hypopygium groß und dick, Lamellen kur\%, bram. Hiften sehwar\%; Sclıenkel dunkelbann; Hiiftgelenke, Kniec und Schienen gelh, Tarsen sehwarz. 35-4 mm lang . . fuscicomis Aldr. Oे

4 Sehienen und Beine ganz schwar. Gesicht weilb, etwas breiter als gewöhlieh, Stirne grau bestiubt. Hypolyg groß, Lameklen klein, brann, rudimentiir. $35-4 \mathrm{~mm}$ lang . . . migripes Aldr. jo

- Sehienen gell, nur die Hintersehienen an der Spitze scbwarz . 5

5 Thoraxriteken mit drei kupferfarbenen Längsstreifen. Spitze der Schenkel gelb. Gesicht schnal, weiß, Stime silberweiß. Fligel brïunlieh gran mit blasser 'schwielenartiger Verdieknng am Ende der Subeostalader. $45 \mathrm{~mm}$ lang . . . . . tylophones Sehin. o?

- Thoraxilicken olue solche Läingsstreifen .

6 Vordersehenkel an der Wurel gelbliels, Hiftgelenke desgleichen. Ilypopygriunı sehl lang; Lamellen klein, oval, bellbram, an der Spitze dunkler. Fligel fast glashell. 3 um lang . . Jumilio Lw.

- Vordersehenkel ganz schwal\%, nu die Hỉtgelenke gelh. Hypopygium kur\%, dick, Lamelken selı klein und bramugelb. Raudadel sehwach verdiekt, Fliggelfiiehe au den Adern gebrimut. $4 \% 3 \mathrm{~mm}$ lang

\section{humeralis Aldr.}

7 Vordersehenkel an der Spitzenhilfte, Mittelsehenkel am Spitzendrittel, Hinterschenkel an der Spitze gell, Sehienen und vordere Tarsenglieder desgleichen. Fihler sebwar, Stime und das schmale Gesieht weiß bereift. Hypopyg groß, diek und selowar mit runden, fast ganz kahlen gebluaumen Lamelleu mit schwarem Rande. Fltigel zart gelbbräinlich getribt ohne besomdere Nerkmale. 45 mm lang . . . . . . femoralis u. sp. o

- Vordersehenkel gelb, Mittelschenkel an Spitzendrittel, Hinterschenkel an der Spitzenhälfte schwarz; Schienen gelb, Hintersehienen an der Spitze selwwarz; Ilintertarsen ganz schwarz. IJypopygium kilein; Lamellen klein, oval, gelb, spitze dunkler. $2 \cdot 6 \mathrm{~mm}$ lang

femoratus Aldr. ơ

- Volder- und Mittelschenkel anf der Oberscite briumlich, Hinterschenkel last auf der ganzen Eudbällte ziemlich deutlicb gebriiunt. Stirne und das sehmale Gesicht reiß. lihgel schwiirzlieh mit fast winkelförmiger Aufbiegung des letzten Absehnittes der vierten Liingsadel. $35-4 \mathrm{~mm}$ lang . . . . . . . . . . arcuatus Lw. ㅇ

8 Fliigelrandader in ihren beiden ersten Absehnitten fist der ganzen Länge naeh verdiekt. Stime und das schmale Gesicht weiß bestäubt. Fibler schwarz, drittes Glied kur, mitunter rotbraun mit nackter Borste. Schienen und Endhälfte der Vorderliiften rotgelb. Hypopyg groß, selıwar' mit loamen kurz behaarten runden Lamellen. $4 \mathrm{nmm}$ lang. rostalis $11 . \mathrm{s}$ l. : 
Fliigelrandader nicht rerdickt . . . . . . . . . . 9 9

9 Fiihler schwarz . . . . . . . . . . . . . . 10

Fiiller ganz oder zum 'l'eil rotgelb bis rotbraun . . . . . . 14

10 Hinterschienen an den Wurzelpunliten der Borsten braun gefleckit. Stirne und Gesicht weiß bestiubt, letzteres so breit wie das dritte Fiihlerglied, Fiilılerborste kur\% belaart; das dritte Fiilılerglied reichlich so lang wie breit, dreieckig zugespitzt. Hypopyg klein, gelh, an der Wurcel selıwar\% mit gelben ovalen zngespitzten, schwach beharten Lamellen. 4 mn lang. . . . pictipes n. sp. ợ Hinterschienen nicht so gefleclst . . . . . . . . . . . 11

11 Gesicht wie gewöhnlich schr selınal . . . . . . . . . . 12 Gesicht breit, etwa $1 \frac{1}{2}$ mal so breit wie das dritte Fiihlerglied. Hypopyg gelbbraun, an der Wurzel sehwarz, mit runden gelben sehwarz gesiumten Lamellen. $4 \mathrm{~mm}$ lang. . . . facialis n. sp. of

12 Fïhlerborste nackt oder fast nackt . . . . . . . . . 13

- Fiillerborste puleszent oder kur behaurt. Thoraxricken mit einigen weißen Flecken. Hypopy gehlank, an der Basis schwart, an der Spitze gelb. Lamellen weilgelb, klein, schmal, schwar, gesiumt und an der Spitze zart behart. 5n mu lang. . lencospitus Lw. o

Fiihlerborste deutlich probeszent. Thoraxriucken olne weilie Flecken. Hypopyg oval, dentlich gestielt, schwarz. Lamellen tellerfömig, ganz weißgelb, ohne dunkleren Rand, letzterer unbehaart. $4.5 \mathrm{~mm}$ lang. . . . . . . . . . . . peruun n. sp. o

I3 Hypopygium klein, schwar,; Lamellen grol und breit, abgerundet viereckig, gelbbraun mit lunklem Rande, kurz, liell behaart. Flïgel fast glashell. $35 \mathrm{~mm}$ lang. . . . . Subpubescens n. sp. o7

- Hypopygium mittelgroh, schwarz; Lamellen groh oval, dreieckig, schaufelförmig, selwarzbram mit gelher Wurzel, Ränder schwarz behaart. $4 \mathrm{~mm} \operatorname{lang}$. . . . . . . . . . albinus 1. sp. o+

14 Fiblerborste lang und diinu, an der Wurzel diek, so lang wie die Vorderschenkel mit einer kteinen oralen Lamelle an der Spitze. $3 \mathrm{~mm}$ lang . . . . . . . . . . discifer Aldr. C’

Fühlerborste von gewöhnlicher Form und Läinge, $2 / 3$ so lang wie der Vorderschenkel, an der Spitze etwas verdickt. $3 \mathrm{~mm}$ lang claviculatus Lw. O

- Fiihlerborste an der Spitze weder verdickt noch verbreitert. . 15

15 Stirne glänzend, griin oder blan . . . . . . . . . . 16

- Stirne matt bestäubt, weiß, grau bis goldbraun . . . . . . 18

16 Sehenkel gelb, Hinterschenkel anf der Oberseite etwis verdunkelt; Hinterschienen an der Spitze, Iintertarsen ganz schwarz. Hypopygimu kurz, Lamellen oval, lurt, in eine lange behaute Spitze auslaufend. $2.8-3.3 \mathrm{~mm}$ lang. . . . . . . . moprinque Wheel. of Schenkel und Sehienen ganz gelb . . . . . . . . . . 17

17 Drittes Fiihlerglied etwas gröfer als gewïhnlich, Fijlıler rotgelb. Gesicht 
ziemlich hreit, matthrau. Hypolygium klein, Lamellen klein, schwar, rundlich, an der Spitze lang behaart. 3 num lang. . ricimus Aldr. O

- Drittes Fijlilerglied vou der gewöhnlichen Gröe, Fiihler rotgelb. Gesicht nicht ganz so breit wie das dritte Fiblerglied, weifgran. Hypopyg grol, scluwar, mgestielt mit kleinen bramen kurz behaarten Anal. lamellen. 3-4 mm lang . . . . . . diflicilis n. sp. of f

brittes Fiblerglied von der gewölnhichen Größe. Fihler schwarz, drittes Clied rotbrann. Gesicht silberweif, so breit wie das dritte Fiiblerglied. Hypopygim schwar, lang, lang gestielt mit kreisrnuden braunen kaum etwas beharten Anallamellen. - Viertes mod fiinftes Vordertarsenglied lappig erweitert. Krallen gezälut. 4 ım lang. . . . . . . . . . . Oedipus n. sp.

- Drittes Fühlerglied von gewöhnlicher Größse. Fiihler schwar, drittes Glied rot mit dunklerer Spitze. Gesicht weili, vou der Breite des dritten Fiiblergliedes. Hypopyg ziemlich groß, schlank, deutlich lang und diinn gestielt mit großen braunen tellerföruigen äußeren Anlïngen, die am Außenrande lang beborstet sind; rierte Lïngsader im letzten Abschnitt schlank Sloirmig anfliegend. $4 \mathrm{~mm}$ lang. . . stylatus n. sp. O

18 Stirne mattweit?

Stirne anders gefiubt . . . . . . . . . . . . . . 21

19 Torderschienen des of llach spindelförmig, auf der Oberseite sehneeweil. Gesicht schmal gellweiß. Hypopyg grof, rostbraun, an der Spitze gelb; Lamellen breit und kurz, abgerumdet, gelb, fast unlebaart. $4 \mathrm{~mm}$ lang . . . . . . fusiform is n. sp. o ?

Vorderschienen des $\sigma^{3}$ vorme ansgehiohlt, schneeweib. Mittelschienen des of an' der Ober- mod Unterseite mit langen Borsten kammartig besetzt. Gesieht schmal, weißgrau. Ilypopyg wroh, rostgelb; Lamellen viereckig, abgerundet, rostgelb, am Anfenrande dunkler, kaum behart. $3.8 \mathrm{~mm}$ lang. . . . . . . . . ciliferus n. sp. o7

Vorderschienen einfach gebildet . . . . . . . . . . 20

20 Fiihlerlonste deutlich pulseszent. Anallamellen gelbbraun, rorne zngespitzt und zart beborstet. $35 \mathrm{~mm}$ lang. . . . . fitifer Allir. o fiiblerborste nackt. Anallanelleı gelb, rund, obne Borsten. $45 \mathrm{~mm}$ lang.

21 Drittes Fithlerglied dentlich liinger als breit . . . . . . . 2.2

- Drittes Fiihlerglied nieht lïnger als breit . . . . . . . . 23

23 Gesicht verhältnismäßig breit, goldgran, Stirne matt goldig bestänbt. Hypopyg kaum gestielt; Lamellen klein dreieckig, lechbraun, an der" Wurzel heller. Hinterschenkel ant" der Unterseite wit einer Reihe kurzer Borsten. $4 \mathrm{~mm}$ lang . . . . Tybridus Meland. ơ o

- Gesicht schmal, silberweif, drittes Fiihlerglied dreieclsig, Stirne dunkelgriin. Hypopygim klein, Lawellen grol oval, gelb mit dunklen Kanten. 2-3 mm laug. . . . . . . . . vcrustus Aldr. of

¿3 Ilypopygium grof, schwarz, liim gestielt; Anallanuellen grof, oral, 
gelbbrann mit dunklen, lang beborsteten Rïndern. Drittes Fihlerglied rotbraun mit stumpfer Spitze. Gesicht weißgrau, reichlich so breit wic das dritte Fühlerglied. liliggel brïunliehgran; rierte Liingsader in schlankem Bogen bis dicht an die Fliigelspitze verlaufend. $4 \mathrm{~mm}$ lang: latifaries n. sp. $0^{7} \mathrm{e}$

Hypopygium grob, schwarz: Anallamellen sehr klein, gelb, die Spitze bis $2 u^{1 / 3}$ schwar\%. Flïgelfliche etwas gelblich gefïrbt. $3 \cdot 1-3 \cdot 6 \mathrm{~mm}$ lang .

liellus Aldr. of

Hypolyginm schwarz, ron mäBigel Größe: Anallamellen gelb, rund, schaufelförmig nit bramen schwach behaarten Rändern. Gesicht weiligrau, sehr breit. Flïgel sehwach graulich, vierte Längsader im letzten Abschnitt auf ler llitte schlank gebogen. 2- $3 \mathrm{~mm}$ lang

$$
\text { laeris n. sp. }
$$

Hypopygium sehwarz, von mïßiger Gröfe. Anallamellen klein, schwarz, dreieckig. Fliigelfiiche briuntich getriabt; letzter Abschnitt der ricrten Längsader jenseits seinel Vitte gebogen. $25 \mathrm{~mm}$ lang quatrimotatus Aldr. 5+

\section{Artrerzeichnis, Beschreibmugen.}

1 abrominalis Aldr. C'c, Kansas Univ. Soc. Bull. I, 78 (1902)

America centr. et merid.

Adrich beschrieb diese Art von Grenada, Westindien, Schuse fand sie in Sijd-Amerika.

3 ठ, 2 o ans Bolivia-Mapiri 16. I. nnd 8. III. (1903) - aus Peru, Laristhal 800 -2000 m boeh 16. VIII. 1903) [Sehnuse] in der Samml. des Dresdner zool. Mus.

2 albinus n. sp. $\sigma^{\top}$ f; s. Figur. 1 Hypopyg . . . . America merid.

ơ. - Thoraxriicken metalliseh blaugriin, vorne bräunlich bereift; Schildchen kupferfarbig, die reiße Bestaubung in der Notoplenraldeprression deutlich. - Kopf: Gesicht schr sebmal, weiß, Stirn im ganzen schneeweil, kein Doppelfeck, Hinterkopf oben anch weiß bestäubt. Fiihler schwarz, das drittc Glied kur\%, rotbram mit zart pubeszenter Borste. - Hinterleib hlausehwarz, die purpurfarbenen Vorderrandbinden sind sehr undentlich. Hypopyg von mittlerer Größe, schwarz; äußere Lamellen schmarzbraun, grob, oval mit vorspringender Ecke oder kreissegmentiibnlich, die Riinder schwarz beharrt und beborstet, Wurzel rostgelb. Die Penisscheide ist hier ganz einfuch stabformig; ron inneren Organen sehe ich nur je ein schmales bandförmiges, in zwei Spitzen auslanfendes Gebilde (s. Figur). - Beinc gelb; Hüften schwarzgrau mit gelber Spitze; Hintertarsen sehwarzbraun, Witteltarsen ron der Mitte des ersten Gliedes an. Vordertarsen von der Spitze des ersten Gliedes an braun. Dic Vordersehienen sind cin wenig geschwollen, ibre Oberseite ist unbehart und hier mit 
weiliem lieif iiberzogen; anch die Mittelsehienen sind rorne etwas weif hereift; lijgel brïunlich: die vierte Längsader biegt in ihrem letzien Abschnitt efwas hinter ihrer Mitte stumpfwinklig nach oben (mit ungefiilur 15: Grad).

. Das Gesicht ist ein wenig breiter; Vorder- und Mittelschienen sind sebwächer weili gezeichnet, sonst dem ơ gleich. $3 \cdot 5-4 \mathrm{~mm}$ lang.

6 б, 4 aus Bolivia Mapiri, Saranpioni $700 \mathrm{~m}$ hoch III, IV, XI (190:3) [Schnuse]. Samml. des Dreshner zool. Mns.

$\therefore$ allonotatus Lw., of Monogr. Dipt. N. Amer. Il 102. 2. tab. IlI fig. 7

Ameriea sept. et centr.

Dureh ganz sehwarze Beine nnd dnreh die Verdickung des ersten Abschnittes der Fligelrandader ausgezeichnet.

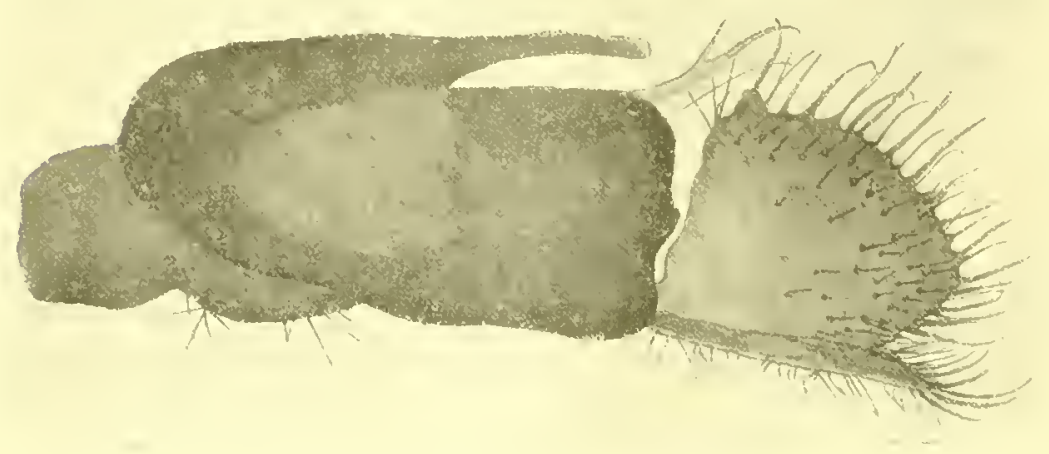

Fip. 1. Hyponyer von Tracactius albinus n. sp.

4 altermans Lw. q, Berlin. Entom. Zeitsebr. VIII 95. 91 [Pelastoneums]

(1864) et Monogr. Dipt. N. Amer. I1 339.8 (1864). America sept.

Nur als Weibehen beschrieben. In meiner Bestimmungstabelle wiirde sie neben propinums. Wheel, vicims Aldr. und difficilis m. stehen missen; waluseheinlich ist sie mit einer dieser drei Arten identiselı.

5 armatus Lw. N. N. Beitr. VIII 39. 4 [Pelastoneums] (1861) et Mono-

gripl. Dipt. N. Aner. II 101. 1. tal. III f. $7 \mathrm{a}-\mathrm{c}$ (1864). Ameriea centr.

Anch nur als Weibehen besehrieben. Loew bat in den Monogr. I. c. tab. III, fig. 7 ein Nännchen abgebildet, lat aber keine Bcsebreibung dazu gegeben, die Zeiehnung scheint also wohl nur ans Versehen dahin geraten zu sein. Aldrich hat das Männehen anch nicht besebrieben, hat dasselbe aber mit in seine Tabelle, Trans. Amer. Ent. Soe. XXX 375 (1904) anfgenommen, allerdings meist nur mit negativen Merkmalen eharakterisiert, so daf man ein vollstaindiges Bild nicht erhilt. Ob seine Art aber mit der Loew'schen ibereinstimmt, erscheint mir frag. lich, di: er iiber die besondere, heim Weibehen anffillige Sehenkelfarbun nichts sagt als daß die Sebenkel nm an der Spitze oder 
gar nicht verdunkelt seien. Ich habe in der Schnuseschen Sammlung eine Art gefunden, die aus Bolivia herstammt und der Aldrichschen Definition entspricht. Ich hatte sie ursprünglich als arcuatus Lw. O angesehen, bin aber heute nieht mehr ron der Riehtigrkeit iiberzengt.

6 bellus Aldr. ơ, Kansas Univ. Sc. Bull. I S1 (1902) America centr.

Siebe die Besebreibung bei Aldrich und die Charakterisierung in meiner Tabelle.

7 callosus n. sp. s?

America merid.

Eine durch starke Fiïgelsehwiele ansgezeiehnete Art.

$\sigma^{7}$. - Thoraxrijeken glïnzend sehwarzgriin, die weilje Bestiubung. in der Notopleuraldepression sowie an den Brustseiten sehr deutlieh. Schwinger and Schippehen gelb, letztere schwar' bewimpert. Kopf: Stirne und Gesicht dieht weil bestaiubt; letzteres selu schmal, selminler als die Breite des halben dritten Fiihlergliedes. Fiihler sehwarz, das dritte Glied alggerundet, nicht länger als breit, mit ganz nackter Borste. Hinterkopfrandborsten unten weiß. - Hinterleib schwarzgriin, an den Seiten dentlicl weiß gefleckt. Hypopygium auftallend groß, fast so grol, wie del Hinterleib selbst mit grofen viereckig abgerundeten selwwarzbraunen außeren Anhängen, deren Ränder lang luehart sind. Der Baueh zeigt eine bemerkenswerte Bildung: der zweite und dritte Sternit hängen lang herab und bilden so einen starken Absatz gegeniber dem folgenden Abschnitte; lier ist eine vollstiudige Tasche, die wohl den Zweck hat, dem Spitzenteil des llypopygiums Sebut\% zu gewïhren, wie dies bei einem Exemplare lentlich zu sehen ist, bei dem das Hypopyg wie in ein lintteral hineingesehoben ist. - Beine: Hiiften und Schenkel schwarz, Hiil'tgelenke gelb; Schienen mit Ausnalme der Hinterschienenspitze gelb. Vorler- und Hitteltarsen zum Teil, Hintertarsen ganz schwarz. Fligel stark rauchgran gefirlot, am Minterrande ein wenig schwächer; am Ende der ersten Läingsader liegt eine große schwarze Schwiele, die beinahe lis an die zweite Langsader helanreicht; der letzte Abschnitt der vierten längsader biegt anf der llitte seiner Läinge etwas zur dritten Längsader hinauf und verlauft sehwach konvergierend bis in die Nihe dersellen; hintere Querader senkrecht zur vierten. $5 \mathrm{~mm}$ lang.

f. - Mit nur wenig breiterem Gesiebt, ohne Flïgelrandmal und mit etwas schwicheren Beinborsten.

50,3 a a s Pern, Callanga. Samml. des Ungar. Nat. Mus.

$1 \sigma^{7}$ aus Venezuela [Lindig] (1864). Samml. des Wiener zool. Hofmuseums, von Sehiner als leucospilus Lw. bestimmt.

8 ciliferus n. su. ơ 1 Figur . . . . . . . . . Ameriea merid.

o. - Thoraxricken schwarzgriin mit blauen Reflexen wie das Schildehen, vorne etras brïunlich bereift; die weiße Bestäubung der Notopleuralgrube ist sehr dentlich. - Kopf: Gesicht schmal weiB, ant der Stirne zirei in der llitte geteilte weiße Flecken. Fihhler rotgell. 
alle drei Glieder auf der Oberseite breit bram, so daf eigentlielı nur das dritte Glied auf der Unterseite dentlich rotgelb ist; Fiihlerborste fast nackt. - Hinterleil, kupferig griin mit undentlichen purpurschwarzen Binden, aber mit dentichen weißen Seitenflecken. Hypopygium grol), rostgell; Lamellen rostgelb, vicreckig mit alggerundeten Eeken, an den Räudern dunkler, kaum etwas behaart. - Beine gelb; lliften schwarzgrau, Spitzen gelb. Hintertarsen ganz bramn, die iibrigen nur an der Spitze. Dic Mittelschicnen tragen sowohl anf der Vorderwie Ilinterseite der ganzen Liinge nach eine Reihe von 15-17 langen schwarzen Borsten; anch das erste Tarsenglied, das reichlich $1_{1 / 2}^{1 / 2}$ mal so lang ist wie das zweite, zeigt anf der Oberscite sciner Wurzelläilfte $4-5$ lïngere Borsten. Die Vordersehienen zeigen einen weilien Streifen längs der Vorder- oder Oberseite, aber diese Vorderscite bildet leine Flache wie bei der Art fusiformis, sie ist vielmehr fast halbkreisfümig ansgebölt. - Fliigel deutlich braunschwarz, an Hinterrande etwas heller unit der gewöhuliehon Aderung. is $\mathrm{mm}$ lang.

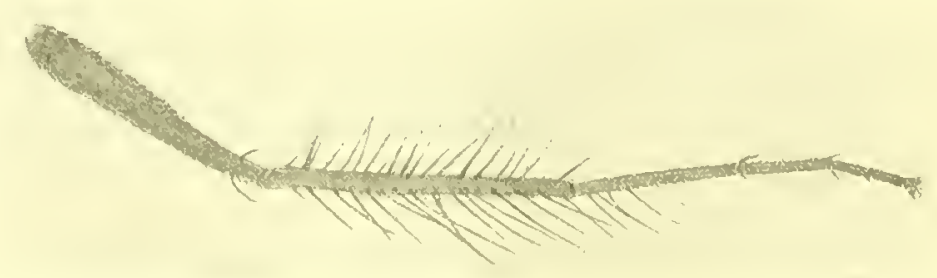

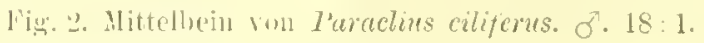

Drei Exemplare aus Peru-Urubambati, Umahuankilia 16. IX. (1903) [Schnuse]. Sauml. des Drestner zool. Mlus.

9 claciculatus Lw. 57, Berlin. Entom. Zeitsebr. X 45. $\$ 3$ (1 itib)

America sept. et centr:

Mit gelben schenkeln, ruten Fühleru, einfachen Fliigeln, aber mit einer Fiulerborste, die an der Spitze etwas recdickt ist. costalis n. sp. . . . . . . . . . . America merid.

Wegen Verdickung der Vorderrandader rerwandt nit ublominalis Aldr., abtreichenil durch helle beine.

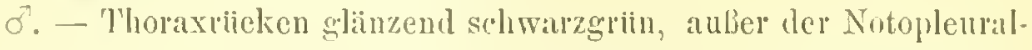
grube sind anch die schulterbenlen weiß gefleckt, ferwer sicht man je einen Flecken lintel der Fligelwrizel neben dem Sehildehen. Brustseiten schwargerau mit weif sehillernden Flecken. Sehwinger gelb, Schippehen desgleichen, schwar\% bewimpert. - Kopf: Stim und Gesicht dicht reil bestaiubt, letzteres sehr schmal, nnter den Fiihlern sind die Augen nur fast linienförmig roneinander getrennt. Taster und Fiihler sebwarz, das dritte Glied kurz, abgerundet und 
nicht ganz sehwar\%, vieluchr meist rotbrann mit nackter Borste. Hinterleil, sehwargriun, fast bronzefarbig, die Seiten (der linge weib gefleckt. IIypopygium sehwar\%, nicht gestielt, groß mit dunkelbraunen ovalen, kurz behauten äulieren Anhingen. Beine: Hüften schwar"gran, die Vorderhiiften an der Spitzenlialfte rostgelb. Die breiten Schenkel rostgelb, meist ist die obere Finte lang gestriemt. Sebienen rot; die Vorlerschienen anf der Oberseite mit einem schmalen harlosen Streilen, der weib bereift ist und anch noch auf die ersten drei etwas breit sedrickten Tasenglieder iibergreift; anch die Hintersehienen zeigen auf ihrer Oberseite weiben Schimmer. Hintertarsen schwarz, die vorderen sind dies nur an den Endgliedern. Die Selienenbeborstung besteht auf der Oberseite der Vorderschienen aus drei bis vier kiirmeren Bürstchen und ein bis zwei solchen an der Anfenseite; an den Mittelschienen stehen stälkere Borsten in zwei Reihen ziemlich ausgichig und auf der l'nterseite nocl ein his zwei Borsten. - Fliigel schwar\%gran, am Hinterlaude etwas weniger stark gefärbt; der erste nnd zweite Abschnitt der Randader sind mit einer langestreckten schwielenartigen Verdickung verselien; der letzte Abschnitt der vierten Längsader biegt anf seinel Mitte unter einem Winkel ron 135 Grad mit starker Krimmung zur dritten liingsader anf. 4 mm lang.

Die Fliigel sind heller, die Verdickung am Fligelvorderrande ist schwicher.

40,1 aus Parnguay, S. Bernardino, 2. IV. (1906) [Balarezy und l'iebrig]. Samml, des Ungar. Nat. Mus.

$5 \sigma^{7}, 1$ o aus Palaguay [Fiebrig]. Samml. des Wiener zool. 1Iofmus.

Anerica merid.

0. - Thoraxricken bronzegrün mit zwei blanen Längslinien zwisehen Akrostikal- und Dorsozentralborsten; in der Quernaht und iiber der Fliigelwurzel wird auch eine mattschwarze Bestäubung sichtbar. Brustseiten schwarzgrau. Schwinger und Schiippchen gelb, letztere schwarz berrimpert. - Kopf: Stirne glïnzend blau, unbestäubt; Gesiclit weifgrau bestiubt, kaum so breit wie das dritte Fihlerglied. Fiihler rotgelb, das dritte Glied kn, zugespitzt mit pubeszenter Rickenborste. Hinterkopfrandborsten unten weißlich. - Hinterleib kurz und breit, g] inzend griin mit mattschwarmen Binden an den liandern mnd weiß. licher Bereifung der linge. Hylopygimu schwarz, grof, ungestielt mit kleinen braunen, kurz bebauten Anallamellen. - Beine und alle Hiiften rotgelb; lliutertarsen mit Ausnalume der Wurzel des ersten Gliedes braun, an den ibrigen Beinen sind nur die Endglieder der 'l'arsen gelniunt; das zweite Glied der Hintertarsen ist $1 \frac{1}{2}$ mal so lang wie das erste. - Flïgel sehwach braungrau getribt; an dem letzten Absehnitt der vierten Iüngsader ist deren erster grader Teil erheblich länger als der folgende, er maeht dann nach aufwirts eine 
knieformige biegnng ron etwa 135 Grad und verlinft dieht ror dem Ende der dritten Liingsaler. 3-4 mm lang.

Gesicht etwas breiter, elwa 1\%/2mal so breit wie das dritte Fiublerglied.

60,1 a a sus Trinidad, Port of Spain und aus Columbia, s. Maria (1912) [Ujhelyi]. Samml. des Ungar. Nat. Mus.

12 discifer Aldr. Kansas Univ. Se. Bull. I 80 (1902) America centr.

In männlichen Geseblecht ist diese Art leicht kenntlielı dureh rlie lange diunne Fühlerborste, die an der Spitze uit einer kleinen paleftenfömigen Verbreiterung rersehen ist.*)

13 facialis n. sp. . . . . . . . . . . . . . Brasilia.

o. - Thoraxriicken glinzend erzgriin, die Notoplenraldepression und ein Fleck iiber der Fliigelwurzel weiß bestiubt. Schwinger und Schiippchen gelb. - Kopf: Stim und Gesicht seidenartig weiß, letzteres bleiter als gewöhulieh, reichlieh $1 \frac{1}{2}$ mal so breit wie das dritte l'iblerglied. Taster und Fibler schwarz, letztere etwas rerlängert, das dritte Glied ein wenig linger als breit, deutlich dreieekig zuge. spitzt und auf del Oberseite ein wenig koukav. Hinterkopfraudborsten unten weil. - Hinterleib erzgriin mit weißen seitliehen Vorderrandflecken. Hypopyginm an der Wurzel sehwar, im iibrigen gelbbraun mit lunden gelben, schwarz gesiumten Lamelten. - Beine nehst. Vorderhiiften rosigelb, nur die Hintertarsen sind an den Endgliederu braun; Hintersebienen anBer der Beborstnng aneh strupjig behart. Fliigel etwas brïunlich; der letzte Absebnitt der vierten Läingsader ist a ul $2 / 3$ seiner Länge ganz grade und biegt dann ziemlich seharf etwa in Winkel von 125 Grad zur dritten lingsader hinanf; die hintere Qnerader sleht rechtwinklig zur vierten Längsader. 4 mm lang.

Ein Exemplar ans Brasilien von der Expedition Wettstein. Young Igulye, in der Samml. des Wiener zool. Ilofmus.

14 femoralis n. sp. o . . . . . . . . . . . . Brasilia.

э. -- Thoraxrieken glïnzend erzgriu; rome am llalse stehen anflallend viele Humeralbürstchen; die Notopleuralgrube ist weiß bestitubt. Sehiijpehen gelb, scluwar\% berimpert. - Kopf: Stime metalliseh blau, in selurïger Riehtnng beselren, weiß schimmernd. Gesicht schmal,

*) Ich luege die Wohl nicht g:mz unbegrimete Termutumg, daß die Alt diseifor

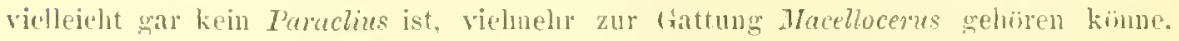
Alterdings lat sich Aldrich iiber die Fibhlerform nicht weiter ansgelassen, als alaf or

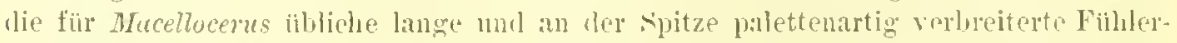

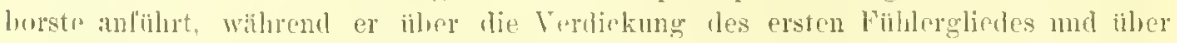
das Verschwinden des zweiten Gliedes nichts sagt; letateres kïnnte aber fibersuen sein. Was in Aldrins Beschreibuno weiterhin noch an einen Drucellocerus oder Tachy-

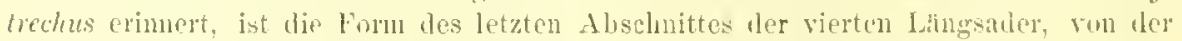

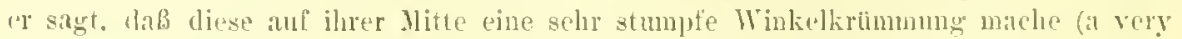
(btuse angle), wie dies jnicht bri Paructius, wohl aber bei Tachytrechus lie lingel ist. Vielleicht ist diese meine Vermutung du AnlaB zu genaneren T'utersuchung. 
weilj. Fiihler schwar, das dritte Glied kurz, abgerundet. - Hiuterleib er'zgriin mit kreideweißen Seitenfleeken. Hypopygium schwarz, groß und dick mit zwei sehmutzig gelbbraunen, lunden, schwarz umrandeten, fast nackten äulieren Lamellen. - Beine: Hiiften alle schwarz; Sebenkel sehwarz, jedoch sind die Vorderschenkel an der Spitzenhälfte, Mittelsehenkel im letzten Drittel und die Hinterschenkel an der Spitze gelb. Sehienen gelb; die Mittel- nnd Vorderschienen zeigen auf ihrer Oberseite einen auch bei anderen Arten melırfach beobachteten weißen Längsstreifen. Tarsen rustgelb, Hintertarsen schwarzbraun; Vorderschienen mit 3-4 Bursten anf der Oberseite und einer Borste anf der Aufenseite. Mittelschienen mit einigen starken Borsten auf der Oberund Außenseite und mit wwei solchen der Unterseite. Hintersehenkel oberseits mit zwei etwas divergierenden Reihen von $1-5$ Borstenparen und nit einer ron der Selıenkelspitze ziemlich entfernt stehenden Präapikalborste. - Flïgel zart gelbbraun mit der gewöhulichen Aderung; die Vorderrandader lat keine selwielenartige Verdiekung, ist aber anf ihrer ganzen Läuge ron ziemlieher Stärke. $4 \cdot 5 \mathrm{~mm}$ lang.

Ein Exemplar ans Brasilien [Lhotzky] Nr. 3147 in der Berliner zool. Museumssammlung.

15 femoratus Aldr. ơ $q$, Biolog. Centr. Amer. Dipt. I 340, 2(1901). Mexieo.

Der Charakter der Beinfiirbung ist derselbe wie bei meiner Art femoralis, nur etwas heller; die Art ist aber erheblich kleiner und die Analanhinge sind wesentlicl abweichend; siehe meine Bestimmungstabelle.

16 filifer Aldr. o, Transact. Entom. Soc. London 314, 1 tab. Xl, fig. 102. [fliferus] (1896)

- Ameriea sept. et centr.

1 o, 1 a a Paraguay [Fiebrig]. Samml. des Wiener Hofmuseums.

17 fuscicornis Aldr. of , Kansas Univ. Se. Bull. I 79. (1902). America centr.

15 fusiformis n. sp. $\sigma^{\prime}$, zwei Figuren. . . . . Ameriea merid.

o. - Thoraxlicken metalliseh griin bis blau, dureb dentliehe braune Bestäubung etwas matt, hinten gliinzend; Sehildehen kupferfarbig; Notopleuralgrube intensiv weif. - Kopf: Gesicht schmal weib, Stirne im gauzen ebenfalls weiß, welche Firbung kaum noeb etwas auf den Hinterkopf übergreift. Fühler ganz rotgelb, drittes Glied klein abgerundet, Borste fast nackt. - Hinterleib sehwarggriin bis blau olne deutliche Bindenzeichnung aber mit dentlichen kreideweiljen Seitenflecken. Hypopygium grof, rostbrun, an der Spitze gelb; iußere Lanellen breiter als lang, viereckig, abgerundet, nur an der Aufenseite der Ränder stiurker, sonst ïuljerst fein behaart, olıne Borsteu. Die Penisscheide zeigt sieh in Form von zwei dicht nebeneinande. liegenden stabfirmigen Haken; von inneren Organen sehe ich drei sehmale farblose Bandstreifen in gehogener Form und zugespitzt. Beine rotgelb; Hiiften schiefergran mit gelber Spitze; Tarsen mit Abbandl, der zool.-botan. Ges. Bd. SlII, Heft 1. 
Ansmahme der crston Glieder bran un Hinterscheukel breit. Vorderschienen im ganzen fist spindelfölnig verbreitert, etwas platt šedriick1, die vordere breite Fliche schneeweiß unl ganz haulos (s. Kign 3); erstes Tarsenglied der IInterbeine dentlich kiirzer als das zweite. - Fligel braun mit der gewöhnlichen Aderung. 4 mm lang. S. Figur 4.

O. Die Weilochen haben einfache Vorderschienen.

8 o a 3 ans Pern-Urubaubati, Unahnankilia, 11.-17. IX. (1903) [Sehnuse]. Samml. des Dresdner zool. Mus.

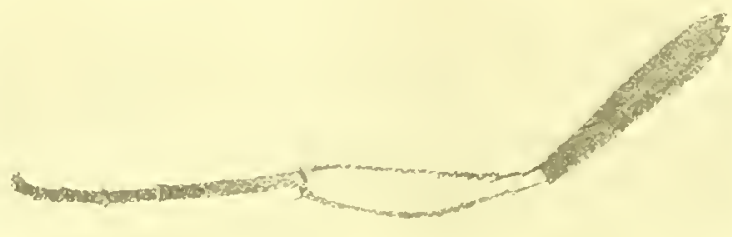

Fin. :3. Vorrlorlein von l'unclus fusiformis. 0 . 18:1.

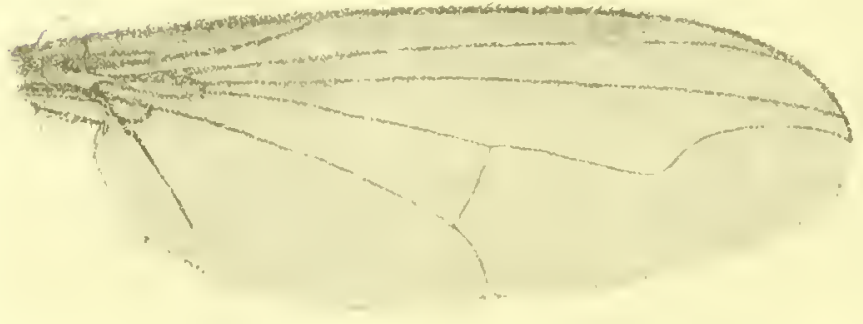

Fign. 4. Fingel ron I'uractius fusiformis. 18:1.

19 heteronerus Maer. +, Dipt. exot suppl. IV 128. 5 tab XII fig. 10 [Molichoms] $(1849)$. . . . . . . . . Anericat sept.

Diese Ant ist die Type zu unserer Gattung Paraclins. Es ist wahrscheinlich, daß bigot eine Matrquartsche Type besaf, als cr seine Gattmug anfstelle; abel anch wenn eine solehe Type nicht vorbanden sein sollte und wir die Art in minnlichen Gesehlecht mit Sicherheit nicht mehr sollten feststellen können, wird die Gattung Puraclius doch durch Macquat's Besehreibung und Figuren gekemueichnet sein und von Pelastoneurus ausreichend abgegrent crscheinen; siehe hieriber meine Bemerkungen in der Finkitung zu Peraclius. In die Tabelle habe ich dies Weiljehen nicht anfgenommen.

20) Thmeralis Aldr. of , Biolog. Centr. Amer. Uipt. I 340. :3 tab. V1 tig. 10 (1901). 
21 legbridus Melaud. $\sigma_{+}$, Cunad. Entom. XXXII 141. 7 fig. 4, 5 (1900)

America sept.

2.2 laevis n. sp. $\sigma_{x}$

America meriá.

7. - 'Thoraxriicken schwarzyriin, etwats glänzend; Brustsciten weifgrati. Schwinger und Schiippehen gach, letztere mit schwarzen Wimpern. - Kopl": Stime matt blaugriun, kaum etwas glänzend, nicht weiß hereift. Gesicht weif, rerhilmismäig lueit, fast doppelt so breit wie das dritte Fihlerghied. Fiblled rotgelb, das dritte Glied oben schwärzlich verdunkelt, ku1z mit stumpfer Spitze nud pubeszenter borste. Hinterkopfrandhorsten unten weils. - Hinterleib schwarzarin mit weißen Seitenflecken. Hypopyg von mittlerer Größe, sclwan's mit gelben, runden, schaufelförmigen Anlaingen, deren Ränder nur wenig gebriunt und behaut sind. - Beine mit allen Hiiften gelh, Hinterfarsen schwalzbran, vordere T'arsen nur an den letzten Gliedern gebräiunt. Dic Beborstung der Schienen ist der der anderen Arten entsprechend, jedoch sehr kriiftig. - l'litgel sehwach graulich getribt; der letzte Abschuitt der vierten Läugsader ist nngefïlo anf seiner Mitte schlank bogenfirmig anfgebugen, hintere Qnerader schwach nach aufen gebogen, aber senklecht zur vierten Liingsader. 2.5 -3 mu lang. 2. - Gesicht kamm etwas breiter als beim ${ }^{\pi}$.

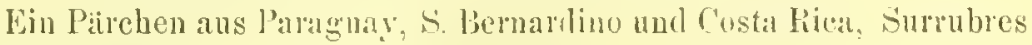
[Babaczy]. Samml. des Ingar. Nat. Ilus.

$2:$ latifacies n. s]). $\mathrm{O}^{7}$;

Anericar merid.

б:. - Thoraxricken schwarggriin, schwach glänzend, olne weiße Thoraxflecken, nur dic Notoplenrafdejuression zeigt sich, ron oben besehen, schneeweib. Schwinger und Schippehen selb, letztere schwarz bewimpert. - Kopf: Stime metallisch grin bis blat, matt; das Gesicht ist dicht weib bestiubt, etwas breiter als gewihnlich, $1 \frac{1}{2}$, mal so breit wic das dritte Fiihlerglied. Fiihler schwal\%, das dritte Glied rotbraun, kur" mit stumpfer Spitze nnd dentlich pubeszenter Borste. Tister schwärzlich, oberseits weilj bereift Ilinterkopfrandhorsten unten weib. - Ilinterleib lronzegriin, in den Seiten der linge weiß gefleckt. Hypopygim mit diunem Stiel, grob und schwars; die äußeren Lamellen zicmlicb groß, gelbblaun, oval mit dunkelbrannen lang belorsteten Riandern. - Beine mit Vorderhiilten und allen Sehenkelgliedern hellgell, Hintertarsen schwarz; alle schienen haben anf ibrer Oberseite cine weißliche Farbung. Die Yorierschienen trigen anfer ter kuren lieborstung noch zwei lingere Einzeluorsten anf der Ober-oder Vorderseite; dic Mittelschienen anßer den Endborsten noch fünl Einzelborsten der Oberseite in zweilicilien, anberdem noch zwei anf der Unterseite; die Hinterschienen anl der Ober- und Aubenseite sieben Einzelborsten. Das erste Glied der Hintertarsen ist etwas kiirzer als das zweite. Fligel bräunlichgran. an der vorderen llaifte etwas stäker als hinten: der letzte Absehnitt del vierten Laingsader macht keinen Kiniek, sondem 
verlïuft in sehlanken Bogen bis zum Fliigelrande in der Nihe der dritten Laingsader vor der Fligelspitze. $4 \mathrm{~mm}$ lang:

* - Gesicht breiter, etwa vom vierten Teil der ganzen Kopfbreite, sonst dem or gleieh.

Ein or, sieben o aus Peru, Callanga. - aus Paraguay, S. Bermardino [Fiebrig, Babarczy] (1908). Samml. des Ungar. Nat. Mns.

24 lcucospilus Lw. ơ , Wien. Entom. Monatssebr. 1, 41 tab. I fig. 14, 15 [Gymnoptermus] (1857) et N. Beitr. VIII 36. 2 [I'elastoncurus] (1861). . . . . . . . . . Anerica merid.

5. - Stirne und das sehr sehmale Gesicht weils. Hinterkopfrandborsten weib. Fihler ganz schwarz, das dritte Glied kmz nit kmrz behartel oder dentlich pubeszenter Fiululerborste. Wenn Loew hierfir den Ausdruck ,plumata" gebraucht, so entspricht das nicht unserer Auftassung, anch die Loewsehe Zeichnung sprielit dagegen; derartige dentlich pubeszente Fiinlerborsten lommen bei der Gattung I'aractius mehrfach ror; gegen die Gattung l'elastonem spricht aber ameh entsehieden das sehr sehmale Gesieht. - Thoraxrieken dunkel olivengrin, schwach bräunlich hereift; die Notopleuralgrube ist dentlich weil bereift, anßerdem sieht man weiße Flecke ïher der Fliigelwurzel und rol der Quernaht. Brustsciten weiß. Hinterleib nit bindenformigen weiß bestaiubten Flecken auf jedem Ringe. - Hiiften, Schenkel und Scbienen gelb, Tarsenendglieder braun. Fligel branngrau; der letzte Abschuitt der vierten Längsader ist fast anf $2 / 3$ seiner Länge grade und biegt dam stmmpfwinkelig und bogenförmig anf, parallel mit dem Vorderrande. 5 mol lang.

Aus Surinam, Loewsche Samml, ans Venezuela in der Schinersehen Samml.

25 mysticus 11. sp.

America sept.

б. - Thoraxriicken er'zgr'iñn, etwas glïnzend und schwach gell,grau bereift; die Notopleuralgrube ist weil) bestäubt. Schwinger gelb, Schiippehen sehwarzbraun, schwarz bewimpert. - Kopf: Stime und Untergesicht verbältnisuaißig loreit, weiß bestäubt, reichlich $1^{1} / 2$ mal so breit wie das dritte Fiillerglied. Fiihler ganz sehwarz, das dritte Glied kurz mit stumpfer Spitze. Taster schwarz, Hinterkopfrandborsten unten weiß. - Hinterleih erzgriin nuit seitlichen weiß bestaubten Vorderrandflecken. IIypopyginm diek, groß und sehwarz mit runden schwarzen, an Rande nur selwwach beborsteten und bebarten äßeren Lamellen. - Beine nebst Hijften ganz schwarz, sebwach behart aber dentlich beborstet. Flïgel namentlich anf der Torderrandhälfte dentlich gebräunt; auf ler Mitte des elsten Randalerabsehnittes liegt eine breite schware Sehwiele; der letzte Abschnitt der vierten Längsaler verlïuft zuniehst grade und hiegt erst hinter der Mitte seiner Länge stumpfwinklig zur dritten Liingsader auf; die lintere Querader ist nach anben hin 
etwas gebogen, steht im ibrigen rechtwinklig zur vierten Liangsider. $4.5 \mathrm{~mm}$ lang.

․ - dem Männchen gIcich, jedoch die Schwinger sind hellbrann, das Gesicht ist etwa doppelt so breit wie das dritte Fiihlerglied; die Schwiele an der Fliigelwurzel ist deutlich wahruehmbar, aber erheblich schwiicher als beim o

Ein Päichen aus Georgia [Pöppig] Nr. 3085 in der Berliner zool. Musenmssammlung.

26 nigripes Aldr. Ơ $^{7}$, Kians. Univ. Se. Bull. I, 78 (1902). Americacentr. et merid.

Aldrich beschrieh diese Art ans Grenada, Westindien, ich fand sic in der Schnuseschen Sammlung:

1 a aus Peru-Urahambati, Umahuankilia, 16. IX. (1903) [Schunse]. Samml. des Dresdner zool. Nus. $-1 \sigma^{\prime}$ in de Loewschen Samml.

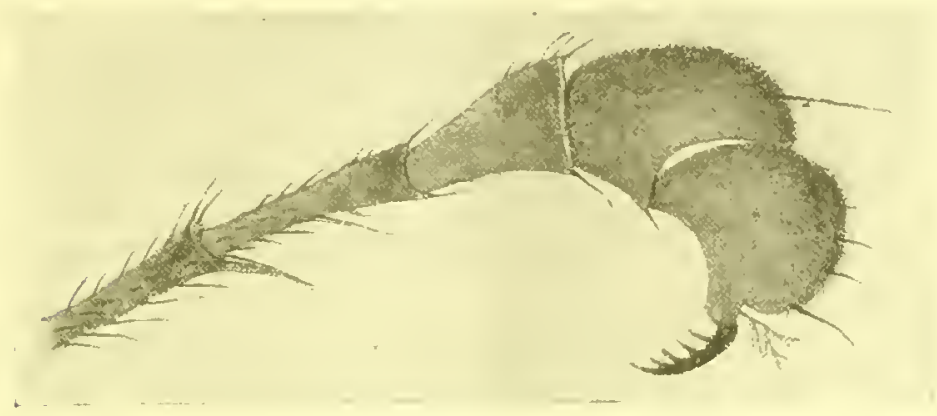

Fig. 5. T'uraclius, Oedimus n. sp'. ठ’. Vordertarsen. I!I : 1 .

27 Oedipus n. sp. $\sigma^{7}$.

Brasilia

$\sigma^{7}$. - Thoraxriicken glinzend sehwarzgriin, die Notopleuralvertiefung ist deutlich weiß bestiubt, die Brustseiten sind im Anschluß daran ebenfalls durch weiße Bestäubung grau. Schwinger und Schiippehen hellgelb, letztere schwal'z bewimpert. - Kopf: Gesicht fast silberfarbig. weil, so breit wie das dritte Fiihlerglied. Stime metallisch blaugriin, glinzend. Taster schwarz. Fiibler schwarz, das dritte Glied rotbraun mit stumpfer Spitze und etwas pubeszenter Borste. Hinterkopfborsten unten weiß. - Hinterleib erzgrïn glainzend mit weißen Seitenflecken. Hypopygium schwarz, lang und schual mit langem Stiel und runden braunen Lamellen, bis zum ersten Banchring reichend; der Rand der Lamellen ist kanm etwas dunkler und nur oben mit einigen längeren zarten Haaren besetzt; sonst nackt. - Beine nebst Vorderhiiften rotgelb; die binteren Hiiften sind an der Spitze gelb, Hintertarsen braun, Vorderschienen etwas dicker als gewöhulich, mit einigen muregelmäßig gestellten Borsten anf der Vorier- oder Oberseite. Vordertarsen ganz zelb; das erste und zweite Glied sind dinne, das dritte ist an der Spitze dreieckig verbreitert, das vierte und fiufte nach oben hin lappig 
erweitert, abgermulet und am Rande etwas dunkier; am vierten steht eine Einzelborste, an finften cinige wenige Jaare; die Klamen sind lammartig gezihnt (s Fig.5). Mittel- und Hinterbeine ohne Besnnderheiten. - Fliigel zart gelbbriunlich; die vierte Längsader ist in letzten Alschuit ohne anfallenden Knick, mehr in schlanker Kurve zur dritien anfhiegend. $4 \mathrm{~mm}$ lang.

Ein Exemplar aus Bhunenau, Brasilien [IJetsehko s?] in der Sammlung des Wiener Jlofunsemms.

:b peruanus $11 . \mathrm{sp}$.

America merid.

o. -.- Glingend sehwatgriun; Thoraxritcken nur rorne in del Niahe der Schnterheule grau bestäubt. Schwinger und Schippehen gell, letztere schwarz bewimpert. - Kopf: Stirne metallisch griin, aber ziemlich dicht grau bestäint, matt. Gesicht nicht breiter als das dritte Fiblherglied. Fiihler schwarblonn, drittes Ghed oval, fast $1 \%$ mal so lang wie lreit nit stumpfer Spitze und pubeszenter Borste auf der Mitte des Oberranles. Taster grelb. Hinterkoptzilien nnten weili. - llinterleil, erygrin, an den Seiten weif gefleckt, kur und zngespitzt mit groleu, dentlich mol lang gestichten sehwarzen Hypopyr; die inneren Organe sind gelb, handförnig, die äuberen tellerlirmig, ganz weißgelb, kimm etwas hehallt, ohne dunkleren Rand. - Beine mit allen lliiften gell, nur die hinteren Hiiften an der Wurel etwas grau; hintere Tarsen bran, das erste Glied kiirzer als das zweite. Flïgel zalt gelbhräunlich getriblit; der letzte Abschnitt der rierten Liingsader weniger winkelfömig als bogig konvergierend, aluf der Mitte kaum etwas geknickt. $4.5 \mathrm{~m}$ m lang.

1 aus l'eru, Callanga, Samml. des Ung. Sat. Mnseuns.

o. - Thoraxricken schwalrgrin, ziemlich matt mit kreideweifer Fleckung: won oben hetrachtet sielit man aulier der scharf einsehneidenden Fleckung der Notopleuralgrube je einen ovalen bis kreisrunden Flecken nnmittelbar itber der Fliggelwurzel und noch je einen dicht dahinter neben der Basis les Schildchens; eine weitere weilie Flecknng haben die mattbrannen Brustseiten, auch die Hiiften sind weißgefleckt. Schwinger gelb, Schippehen schwarz bewimpert. - Kopf: die griine Grundfarbe von Stirn und Gesiobt ist durch dichte weiße Bestäubung verdeckt, letzteres ist ungefälu so breit wie das dritte Fïhlerglied. Fiihler sehwarz, das dritte Glied reichlich so lang wie hreit und dreieckig zugespitzt, Fihlerhorste deuthich puleszent. Taster und liissel versehwindend klein, Hinterkopframdborsten weiß. - IJinterleil glinzend schwargriin, schwarz hehaart und helorstet mit seharf begrenzten kreideweißen Seitenflecken. Hypopg rerhïltnismäißig klein, an der Wurzel schwarz, sonst gauz gelb mit gelben, ovalen, blattfömig zugespitzten :inlieren Lamellen, deren Riinder schwach gelı:innt und behatart sind. - Beine nehst Vorderhiiften gelb, Hintertarsen hann: 
Selicnen stark beborstet. Vorderschienen fehlen. Mittelschienen anßel den vier bis füf Endborsten noch mit aclit meist starken Borsten, von denen zwei auf del Unterseite stehen. Ilinterschienen auf der Oberseite in zwei Reihen mit vier Par Borsten, deren Wmzelpunkte auf der Schiene bram gefleckt sind, so dab dadurch eine besondere Zeichnung hervorgernfen wirk. Die Hintersehenkel sind breit und haben zwei Präapikalborsten, jedoch stehen diese nieht wie gewöhnieh lintereinander, sondern ibereinander. Fliigel gleichmäßiø blaburaun gefübt; der letzte Abschnitt der vierten Lïngsiuler ist :uf seiner ersten Strecke grade, die mogefuhl $11 \%$ mal so lang ist wie die zweite, die deutlich kniefirmig und stark konvergiesend nach oben abbiegt, 4 inm lang.

$10^{T}$ a us Paraguay, S. Bernardino 2. III. 1906 [Babarezy]. Samml. des Ung. Nat. Mus.

30 mopinguns Wheel, of, I'reed. Californ. Acad. Se. serie 3. Zool. II 18. 19 tab. I fig. $22-24$ (1999) . . . . . Aneriea sept. et meril.

1 a as Peru-Urubambafi, Unahuankilia. 13. IX. (1903) [Schnuse]. Samml. des Dresdner zool. Mus.

¿ ans Paragnay, S. Bernarlino [Fiebrig]. Samml. des Wiener Hofmuseums.

:1) prmilio Lw. O, Berlin. Entom. Zeitsehr. XVI (10.63 (1872)

America sept. et inerid.

Von Loew aus Nordanerika besehrieben; ich fand anch ein Exemplar, o, aus Paragnay. S. Bernardino. 2. IV. (1906) [Babarczy] in der Samml. des Ung. Nat. Mus.

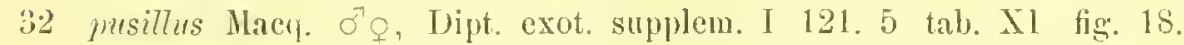

[Iotichopus] (1845)

Biasilia

In Schiners Sammlung befindet sich ein o als msillus Macq. bestimmt. Die aligemeimen Färbungsverhiltnisse entsprechen der Maequartsehen Besehreibung, es ist daher die Mögliehkeit rorhanden, daf das Exemplar die Art meillus darstellt. Da es sich abe1 $1311^{\circ}$ mm eiı Weibehen handelt, das Exemplal auch noch dazu sehlecht erhalten ist, so kommen wil anch mit Hilfe dieses Exemplares dem riehtigen Erkennen der Art keinen Sehritt niiher und so wird es auch in Zuknuft wohl bleiben.

3:) quatrinotatus Aldr. Of , Kansas Univ. Se. Bull. I 81 (1902)

Ameriea centr.

:4 robustus $\mathrm{n} . \mathrm{sp} . \mathrm{o}^{7} \mathrm{q}$

Amelica merid.

э. - Thoraxrieken glinzend sehwarggrin, vorne etwas brann bestiubt; Notoplenralgrube dentlich weiß; Schildehen kupferfarbig; Sehulterbenten ganz weißlich bestiubt. - Kopf: Gexicht sehr sehmal, weili, Stime von metallischer Grundfarbe, der obere Teil zu $2 / 3$ weil hestiulut. Fiihler rotgelb, zweites und drittes Glied obenanf und an der Spitze brann. Borste nackt. - Ilinterleib netalliseh schwarzgriu 
unit dunkel purpurfarligen Eimsehniten. Hypouyg groß, sehwarz; Lamellen von mittlerer Größe, rmud, ganz gelb, zart hell behaart. Beine rotgelb, Vorderhiiften desgleichen, Nittel und Hinterbiiften an der Wurzelhälfte schwargrau; Tarsen sehwarz mit Ausnahme eines 'Teils der ersten Glieder beider elsten Vorderbeine: Vordersehienen anf' (ter Spitzenhälfte der Oberseite mit schneeweißem Liugsstrieh. liligel sehwarzbrïunlich. $45 \mathrm{~mm}$ lang.

f. - mit einfachen Vorderschienen, sonst kein Untersebied.

30,1 q ans Bolivia-Mlapiri, Sarampioni $700 \mathrm{~m}$ hoeh. 1 und 131 (1903). [Sehnuse]. Samml. des Dresdner zool. Mus.

ว’. - 'Thoraxriieken gliinzend schwarzgriin bis blan, Brinstseiten asehgrau. Schwinger und Sehiippehen hellgelb, letztere sehwarz bewimpert. - Kopf: Stirne blau, ziemlich g]inzend; Gesieht silberweiß schimmernd, so breit wie das dritte Fiihlerglied. Fühler sehwarz, drittes Glied rot, an der Spitze schwarzbrann, Borste pulseszent; Taster gelblich; Hinterkopfilien weiß. - Hinterleib sehwargrinn, der sechste Ring ist sehr dïn; Iypopyg ziemlich grol, lang und dentlieh gestielt, anf der oberen Seite rostgelb; iunere Organe hellgelb; die inßeren sind tellerförmig, schwarzgratu, anf der Hitte heller, britun, die eine Seite mit langen sehwarzen Borstenharen besetzt. - Beine uebst Vorlerhiiften gelb. Die Vordersehienen zeigen auf ihrer Vorder-oder Oberseite drei his vier Borsten, an ihrer Spitze steht eine kiirzere dieke, gekrimmte, dornartige Borste, der Hetatarsus ist an der Basis seiner Unterseite mit einer senkleeht abstehenden Borste bewehrt, zweites und drittes Tarsenglied sind unterseits auf ibrer Endhïlfte behaart; die iibrigen Schienen und Tarsen baben ihre gewöhnliche Bildung und Beborstung. - Flïgel zart graubrïunlich getriibt; der letzte Abselnniti der vierten Lïngsader liuft sehlank S fömign grebogen bis zum Fltigelraude. 4 ınıl lang.

$10^{+}$ans Pern, Callanga. Samml. des IJngar. Nat. Mus.

$\sigma^{-7}$. - Thoraxricken von oben besehen metalliseh glimzend, griin bis blan, ron der Seite besehen mit matt bronzefarbiger Bestainbung anf der vorderen llailte; Sehildehen kupferfarbig; die weiße Bestiubung in der Notoplenuldepression ist dentlich, anch der vordere Rand der Schulterbenle ist weil\} bereift. - Kopf: Gesieht sehr sehual, weißgelb mit mehr oder weniger braunen Reflexen; anf der Stirne liegen zwei weiß bestäubte, in der Mitte etwas getrennte Flecken, denen an llinterkopfe an Seheitel zwei ähnliche Fleeken entspreehen. Fiihler sebwarz, das dritte Glied selu kur, rötlieh briun, kamm mehr als halbkreisförmig vortretend mit zurt pubeszenter Borste; Taster klein, anl der Oberseite gran bestiubt. - Hinterleib metalliseh griu mit schmalen purpurselıwaten Vorderandsbinden nud etwas breiteren an 
Ilinterrande, die Mitte der Seite ist Hecken- bis bindenförmig weili. Hypopygium klein, schwarz; die änßeren Lamellen sind breiter als lang, viereckig abgerundet, gelbbraun mit schwarzem Saum, kurz behaart, nieht eigentlich beborstet; die Penisscheide stellit sich dar als eine starke Pfeilspitze, die noch von zwei Baindern gebalten wird (s. Figur). - Beine rotgelb; die Vorderhiuften sind bis zur Hälfte, die librigen fast bis zur Spitze sehwarzgrau; Hinter- und Mitfeltarsen ganz bis fast ganz sehwarzbraun, die Vordertarsen von der Spitze des ersten Gliedes an. Hinterschenkel breit ; die Vorderschienen liaben an der Oberseite eine glatte unbeharte Fliche, welehe schneeweib ist, daneben stehen nach vorne gerichtet vier schwarze Borsten. — Fliigel bräunlich; der erste Vorderrandabsehnitt ist ein wenig dieker als die ibrigen

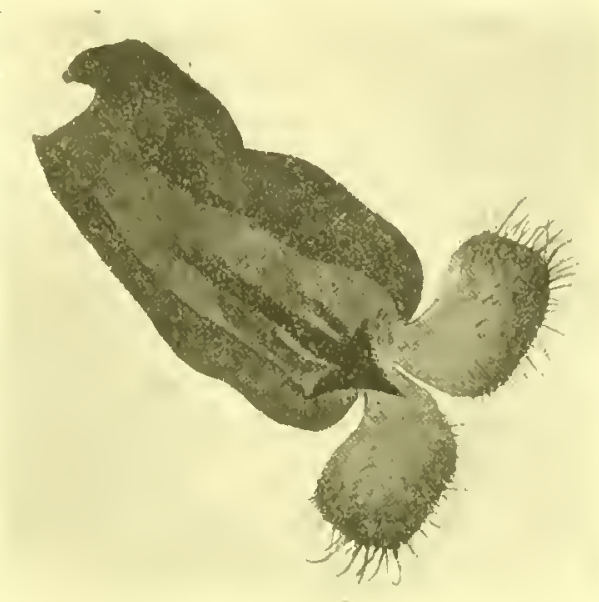

Fig. 6. Paraclius subpulescens B. Hypopgium von unten gesehen. Teile; die Biegung des letzten

Abschnittes der vierten Liingsader liegt anf oder etwas hinter der Mitte desselben. $3.5 \mathrm{~mm}$ lang.

6 o 3 q ans Bolivia-Mapiri, Sarampioni $700 \mathrm{~m}$ boch. II und III 1903 [Schnuse]. Samml. des Dresdner zool. Mus.

37 tylophorus Schin. ơ, Novara Reise Dipt. 219.25(1868) America mericl. 38 venustus Aldr. \%, Biolog. Centr. Amer. Dipt. I 340. 4 tab. VI fig. 11 (1901) . . . . . . . . America centr. et merid.

1 Exemplar aus Pern, Pichis Weg 4. I. I904 [Schnuse]. Sanml. des Dresdner zool. Mus.

39 vicims Aldr. $\sigma^{\top}$, Trans. Amer. Entom. Soc. Philadelphia XXX 274 et 277. (1904) . . . . . . . . . . . Anerica sept.

\section{Pelastonemus.}

Loew, N. Beitr. VIII 1, 36 (1861).

Metapelastoneurus Aldr., Kansas Iniv. Quart. II 152 (1893).

Loew trennte gewisse Arten von Gymnopternus und nenut als muterscheidende Merkmale der neuen Gattung: 1. die gefiederte Fiiblerborste, 2. die erheblich größere Mundöfłnung und den anderen Riisselban, 3. die Konvergenz der vierten Laingsaler zur dritten, 4. das lange freie, meist gestielte Hypolyginm mit schaufelfirmiger Gestalt seiner inßeren Anhïnge. 
Zn diesen allgemeinen keunzeichen lißht sich noeh Folgendes als Erginzung linzutiigen: Das Gesicht ist breit in beiden Geschlechtern, kiirzer als die Augen; die obere Ilïfte, dureh eine Querlinie von der unteren getremnt, ist efwas eingedrickt, dic untere höcker-oder beulenfömig vorstehend; der Rissel tritt sackartig etwas vor, rome ron deu riemlich breiten Tastern bedeckt. Der Thoraxriicken ist rome meist etwas hestainbt, hinten aber stets glänzend mit scharf hegrenzten, weißhestiinbten Flecken an den Seitenrinderu; so zeiehuet sich anch die Notoplenraldepression Aureh helle Bestiubung ans; ferner sicht man eine sammetschware, fleckenartige Binde iiber der Fliigelwu\%el, die mitunter aneh die Seitenecken des Sehildehens in gleicher Weise färbt; die Wimpern der Schiippehen sind durehweg sehwarz. Der letzte Absehnitt der vierten Lïngsader ist bald im ganzen schlank bogenförmig konvergierend (s. Figur v. unguiculatus Aldr.) ofler in der Niale der Nitte nael oben abbiegend (s. Loew, Monogr. Dipt. of N. Amer. Pl. Il[ fig. $5[196 \%]$ ). Ieh bin mit Aldrich, s. Kansas Univers. Soc. Bull. Yol. I Nr. 3 p. 77 (1902), der hier die drei nahestehenden Gattungen P'elastonenus, Peraclius und Sarronus miteinander vergleicht, der Ansicht, daß diese etwas verschiertenen Biegungen der vierten Läingsader nicht das entseheidende Merkmal sind. Ich halte die Kopfform und Form des Hypopygims tiu die wesentlichsten Gattungsmerkmale.

lis likt sich nicht leugnen, dak man bei dieser Gattnng an Poccilobothms Mik eriunent wird; die gefiederte Fiihlerborste, die Konvergenz der dritten mnd vienten Längsaler und die purpurseluwaren Fleeken an der Dorsopleuraluaht sind ähuliche Erseheinungen; so haben Bigot anch seine Art $I$ '. mexicrunes und Aldrich $P$. unguiculutus als cinen P'occitobothrus beschrieben, aber abweiehend sind die Kopform und die Form des Hypoprginms mit seinen eharakteristischen dreicekigen inberen An hängen bei Poecitubothrus.

Von Bestimmungstahellen fiul die amerikaniselıen Arten sind folgende zil nennen:

Loew, Monogr. N. Amer. Dipt. Il Sappl. p. 337 (TS64) . . . . S Arten. W. M. Wheeler, J'roe. ('alif. Aead. Se. S. 3. vol. II N. 1. p. 11 (1899)

17 Aiten.

I. Il. Aldrich, Biolog. Centr. Amer. 1). 337 (1901) rerlunden mit den Gattungen Pavelius nnd Sorromms . . . . . . . . . 14 Arten.

1. AI. Aldrich, Trans. Amer. Ent. Soc. Philarlelphia XXX 273 (1904) rer. bunden mit den Gatfungen J'fruclius und Sarioms . . . 29 Arten.

Im Katalog Kertés. VI finden wir 32 Arten anfecührt; hiervon sind bifrons Walk, heteronemus Mace, maculipes Walk. und meglectus Wheeler lediglich nach weiblichen Exemplaren beschrieben, wobei ru bemerken b]eibt, daß hetroneurns Macy. als Paraclius ansscheidet. Bei der großen Sehwierigkeit, welehe die meisten Arten für die sichere Unterscheirnng bieten, ist es ausichtslos, solche beschreibungen verwerten zn kinnen, 
falls die Weibchen nicht etwa an besonderen Merkmalen der Männchen teilnelımen, wie dies bei einigen Arten in der Fliggelzeichnung allerdings der Fall ist. Wir können daher von diesen drei Arten nur neglectus Wheel. beriicksichtigen. Ferner ist Bigot's Beschreibung semer Art mexicamus zu wenig charakteristisch. Was $P$. flrvipes Schin. darstellt, liißt sich ohme weiteres auch nicht sagen; viclleicht ist sic identisch mit fasciatus $\mathrm{v}$. liöler oder argentiferus Aldr.; auch pilosicomis WTalk. ist eine ganz zweifelhatte Art. Nach Abzug diescr sechs Arten bleiben noch 26 iibrig, denen ich noch acht neue hinzugesellen kann, für die ich nachstehende Bestimmungstabelle aufstellte. Zn dieser Tabelle möchte ich bemerken, daf ich die größere Anzahl der Arten nielıt geselıen habe; ich habe die Tabelle hauptsächlich nach den vorhandenen guten Beschreibungen, in Anschlıf und untel Benutzuug der Aldı’ichschen Tabellen aufgestellt; fiir die Männchen war diese Methode wohl möglich und anwendbar, nicht aber für alle Weibchen; zudem ist auch erst der kleinere Teil der Weibchen bekannt: einige Weibchen lassen sich aber anch ohne Vergleichng von Typen aurch ihre besonderen Merkmale erkennen, so daß ich eine Fieihe von Weibchen habe mit einstellen köunen.

Diese Gattung kommt in Nord- und Siid-Amerika ror.

bestimmmngstabelle fiil die Arten ler Giattmmg Pelastoneurus Lw.

1 Zilien des nnteren Angenrandes weiß bis gelb . . . . . . 2

Zilien des unteren Angenrandes schwarz. . . . . . . . 14

2 Fliigel deutlich gefleekt, auch beide Qucradern . . . . . . :

- liigel gran bis bräunlich, nngefleckt, böchstens die hintere Querader etwas dunkler.

3 An der Fligelspitze eine grißere rauchsehwarze fleckenartige Trübung. Thoraxriicken mit schwarzen Flceken an den Borstenwuryelu. Fiiller klein, gelb, drittes Glied an der Spitze braun, Fiihlerborste lang gefiedert. Beine mit Vorderbiften gelh. 5 mm lang

ligeminatus Aldr. of

Beide Queradern ron dentlichen braumen lecken umgeben. Fühler ganz rotgelb. Borste lang gefiedert. Beine rotgelb, Kniee der Hintersehenkel, Spitze der Hinterschienen und die Hintertarsen schwarz. $4 \mathrm{~mm}$ lang. . . . . . . biguttatus n. sp. o

Beide Queradern und die Fligelbenle hraun gefleckt. Fiiller schwarzbraun, unten rot. Borste kur\% gefierlert. Beine und Vorderlinften rotgelb, Hinterschienen an den Wurzelpunkten der Borsten bramu gefleckt. 35 mu lang . . . . . . umbripustus n. s]).

Außer zwei braunen Flecken anf den Queradern noch ungefiihr 25 braune runde bis lingliche Fleeken aul den Fliigeln, ron denen siehen am Vorderrande liegen. Thoraxricken mit je zwei grofen runden getrennten sammetschwarzen Seitenflecken; anch am Sehildehen sind die 
Seitenecken schwarz. Beine hell rotgelh, Spitze der llinterschienen, des Metatarsus und die letzteu Glieder aller Tarseu gebriiunt. $3 \mathrm{~mm}$ lang

turliblus u. sp. or

4 Sehenkel und Beine iiberwiegend schwarz, nur die Kniee und Sehenkelglieder gell; letztes Tarsenglied der Vorderbeine des $\sigma^{7}$ mit hakenförmiger lílaue. 5-6 mm lang . . . . . . hamalus Aldr. o

- Selienkel rotgelb

5 Eister Vorderandsabschuitt des Flïgels beim ó deutlich etwas verdickt, beim noch stairker. Letztes 'Tarsenglied der Vorderheine beim ơ mit einer inneren lık knförmigen Ǩlaue. Fiihler sehwarzlırann, unten etwas rot. $4-45 \mathrm{~mm}$ lang . . . . . unguiculatus Ahlr.

- Erster Fligelandabschnitt nicht verdickt; letztes 'T'arsenglied der Vorderbeine bein of einfach . . . . . . . . . . 6

(j) Fiihlerborste besonders lang; Fiilılel gelb, drittes Glied nit Spitze. Vorderhinften ganz gelb, Mittel- und Hinterhiuften anf der Spitzenbailfte gelb, Beine desgleichen. $4 \mathrm{~mm}$ lang. . neglectus Wheel f

Fihlerborste lang; Fühler gelb, drittes Glied sehwarzbraun. Beine mit allen IItiften gelb. Mittel- und IIinterhüften an der äufersten Wurzel sehwilzlich. $3 \mathrm{~mm}$ lang. . . . . semiplumatus n. sp. 5

- Fiblerborste ron gewöhnlicher Länge . . . . . . . . . 7

7 Vordechiiften ganz gell)

- Vorderhiffen sebwargran, höhstens die Spitze gelb . . . . 12

8 Fiihler rot bis gelb, drittes Glied höehstens an der Spitze dunkler 9

- Fïhler schwar\%, ler untere liand der Glieder etwas rot. Fïhlerborste knrz gefielert. Hypopygium grol, ohne deutlichen Stiel, Lamellen sehwarz, lang anfgebogen und beborstet. Beine mit Vorderhiiften getb. Kniee etwas dunkler. $35 \mathrm{~mm}$ lang. . argentiferus Aldr. of

9) Fithlerborste lang gefiedert . . . . . . . . . . . . . 10

- Fiilılerborste kur\% gefiedert . . . . . . . . . . . . 11

10 Thoraxoiicken schwarzgrín lois bronzefarbig, Mittelstreifen und Wurzelu der Rỉckenborsten gränzenl sehwarz, die weiße Bestänbung in der Notopleuralgrube nur klein, fleckenartig. Hypopygium dick, bis zum Ende des zweiten Ringes reichend, mit schwaren, länglieh schanfelfürmigen, unten deutlich beborsteten Lamellen. Vierte Laingsader im letzten Abschnitt bis zur Mitte sehwach, hernach stäker bogenlörmig. 3-t mm lang . . . . . . . . . cognatus Lw. бo

- 'Thoraxrieken glinzend schwarzgriin. Fiihler ganz rot. Hypopyginm groß und lang, stumpf kegelförmig verlaufend mit schwarzen beilförmigen stark behaarten iulieren Anlü̈ngen. $3.5 \mathrm{~mm}$ lang

asciacformis n. sp. o $^{n}$

'Thoraxrieken sehwarzgriin, gelbgran bereift, zu beiden Seiten der Akrostikalbörstchen eine jurpurfarbene Läingslinie. Stirne gelbbraun hestioubt. Iyporgygim sclulank, Anallamellen klein, rund, gelb. $3.7 \mathrm{~mm} \mathrm{lang}$

Wheeleri Neland. 
Thoraxricken schwarzgriin, zart gelbgran bereift. Stirn dunkelbraun. Hypopyginm lang und schlank, deutlich gestielt; äußere Anhänge schmutzig gelb in Form eines breiten spitzen Blattes, das an seiner oberen liante einen fingerïlnlichen, an der Spitze lang belainten Anhang zeigt. $4 \mathrm{~mm}$ lang . . . . . . rigitulus 11. sp. ơ

11 Thoraxricken bronzefarbig, linten violett. Stime metallisclı violett gläzzend. Hypopyginm dick, so lang wie der Hinterleib; Anallanellen dreieckig, schwarz, an der basis gelb und an den Enden lang hehaart. $35-4 \mathrm{~mm}$ lang . . . . . . . . floridamus Wheel. o"

- Thoraxrïcken glänzend schwarggriun. Stirne schwarzblau matt, Gesicht weifgrau. Hypopyg groß, schwarz, bis zum zweiten Bauchringe reichend mit zwei fast eben so langen braunen, schmal bandförmigen, ann Rande behaarten äuBeren Anhängen. $2.5 \mathrm{~mm}$ lang

treniatus n. spl. o

Thoraxrïcken dunkelgriin, ziemlich glänzend. Stirne glänzend violett. Hypopygium sehr lang, am Ende getblich. $2 \cdot 3 \mathrm{~mm}$ lang

fasciatus Rod. $\sigma^{7}$

Thoraxrïcken erzgriin. Stirne braun, Gesicht oben schwar, unten grau. Drittes Füblerglied breit und kur\%. Hypopygium groß, so lang wie der Hinterleils. Anallamellen klein und bräunlich. $4.5 \mathrm{~mm}$ lang

flavipes Schin. ơ

12 Fibler schwarzbram, unten rot bis gelb.

- Fiilner rotgell, drittes Glied schwarzbrann. Stine nattbraun bestäuht. Finhlerborste lang getiedert. Beine bräunlich gelb. Thoraxricken griin mit zwei violetten Längslinien, Ecken des Schildehens sammetschwarz. Hinterleib schlank. Hypolygium lang, duinn gesticlt. Anallamellen lang and schmal, schwarz. 1.8-2 mm lang

vagans Lw. O)

13 Stirne glinzend violett; Fihlerborste mit mittellangen Fiederu. Hypopygium lang und schlank, Lamellen lang und spitz, Jeborstet. beine gelb. 3 nm lang. . . . . . . occidentalis Wheel. O Stirne matt griinblan; lühlerborste mïßig lang gefiedert. Thoraxricken sclıwarzgriun, mäßig glinzend, zart gelhgrau bereift. Gesicht Lreit, aschgratn. Schenkel rotgelb; Schienen rotbraun, Tarsen schwarzbraun. llypopygium groß, bis zum zweiten Bauching reichend; Anallamellen lang trapezformig, schwar, an der Spitze "und.unten beborstet. $4 \mathrm{~mm}$ lang. . . . . . . . . trapezoilles n. sp. o7

14 Fligel braun bis schwarz gefleckt . . . . . . . . . . . 15

Fliigel gleichmälig gebrïunt otler grau, ohne lilecken . . . 16

15 Flïgel mit etwa 20 runden brannen Flecken, von denen fiun am Vorderrande liegen. Fiihler grol, schwarz mit kurz gefiederter Borste. Stirne mattbraun. Thoraxilicken mit unterbrochenen grauen Liingsinien. Hypolyg klein, kurz und schwar' mit gelter Spitze; Lamellen klein, spitz und gelb. Schenkel gelb. $4 \mathrm{~mm}$ lang . . punctipennis Say. ơ 
15 Kliggel mit gesehwiratem Vorderande und mit diesem verbunden vier schwäzliche aus Fleken zusimmengesetzte Querbinden. Wibler gelb, drittes Glied an der Spitze gebrimut mit dieht gefiederter Borste. Hypopygium knrz, diek, so lang wie der knrze Hinterleib; Lamellen klein, rumb, sehwarz und schwar\% hehaart. Sehenkel gelbluram mit verdnnkelten Oberseiten. $3 \mathrm{~mm}$ ling . . . pictipemis Wheel. $\sigma^{\pi}$;

16 Sehenkel ganz schwarz. . . . . . . . . . . . . . 17

Schenkel gelb und sehwaz gezeichnet, oder gelb mit scluwarzer spitze ler llintersehenkel . . . . . . . . . . . . . 1 s

Schenkel ganz gelb, Fibhler rotgelb, drittes Glied an der Spitze

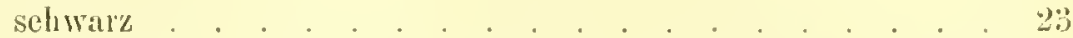

17 Fiihler schwärzlich, jedoch alle Glieder an der Wurzel ein wenig gell. Fïhlerborste miißig gefiedert. Hrpopyginm groß, schwarz, Anallamellen sehmal, schwallz. IIiilten sehwar, Schienen mol 'Tarsen bramn. Fliigel gleichmäig brann. "̈ mm lang. . . . scututus Aldr. of

1 Ilinterselienkel gelb, an der spitze gefleekt . . . . . . . 19

- Schenkel in :nderer Weise gezeichnet . . . . . . . . . 22

19 Schildchen mit sammetschwarzen Mittelstreilen und Seitenecken. Fïhler schwarzluaun, unten etwas rot. Hypopygrium sehr lang; Anallamellen klein, brannsehwarz. 4 nm lange . Congicaudu Lw. G

- Selildehen nieht so gefiribt . . . . . . . . . . . . . 20

20 Finller rot, drittes Glied an der Spitze schwarz . . . . . . 21

- Fiihler schwarz, an der Unterseite etwas gello. llypopygium $2 / 3$ so lang wie der Hinterleih. Anallamellen sehr klein, dreieckig, schwar\% behaart. Hiiften sehwar\% mit gelber Spitze; Schienen gelb. Vorderund Mittelschienen an der Spitze schwarz; Vordertarsen mit Ansuahme des Metatarsus schwar, zweites und drittes Glied unten weiß betilzt. $350-45$ mm lang . . . . . . eyaneus Wheel.

¿1 Wülulerborste kurz gefiedert. llypolyogallamellen sehr klein, schwarz, fist sichelförnig, schwarz hehart. Alle Hïften sehwarz, Vorderschenkel mit.

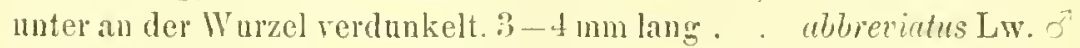

Fithlerborste lang gefiedert. Ilypopygiallamellen schwarz, kurz, nach der spitze hin breiter werdend. Vorderhiiften nur an der Wurzel sehwarz; Sehienen gelb, Spitze der Mittel und Hintersehienen gebräiunt. ; mm lang. . . . . . . . . lamellahus Lw, O

$\because 2$ Finhler sehwarz, erstes Glied unten gelb. Stine metallisch blan. Hypo. lygium so lang wie der Hinterleib; Anallamellen selswar, dreieckicr. Hiiften schwarz. Vordersehenkel sehwar, Mittelschenkel mit gellyer Spitzenhïlfte, llintersehenkel gelb mit schwarzer Binde und Spitze. Vorder- und Hintersehienen sehwarz, Mittelsehienen gelb; Vordertarsen anf der Unterseite licht weib befilat. $4.5 \mathrm{~mm}$ lang

dissimilis Wheel. of:

- Fiihler rotbram, drittes Crlied an der Spitze hrannschwarz. Stime matt schwarzbram. Hypopyginu dick, balb so lang wie der Hinterleib; 
Anallamellen rand schwar, schwarz behatart. Sehildehen mit mitt. schwarzen Seitenecken. Vorderhiiften braungelb; Sehenkel gellbraun, Vordersehenkel obenatu, Ilintersehenkel an der Spitze schwar\%, Schienen schwarzbraun. $9.3 \mathrm{~mm}$ lang . . . lugubris Lw. $0^{T}$

23 Drittes Fiilılerglied etwas verlingert, linger als breit . . . 24

- Drittes Fiihlerglied nicht rerkingert . . . . . . . . . . .5

24 Ftihlerborste kur\% gefiedert. Gesicht schneewcif, Stirne violett, whinzend. Sehildelıen an den Seiten tiefschwarz. Beine nebst Vurderhiiften gelb. Flügel brungrau. :3 1 m lang. . . . . . . letehs Lw. ot Fiilaterborste lang gefiedert. Gusicht b]ïulich weiß; Stirne matt braungrau. Schildehen ohne selhware Seitenecken. Flitgel tast farblos. $3 \mathrm{~mm} \operatorname{lang}$

Fiilulerborste mäifg langुg getiedert. Gesicht brinulieh; Stime an den Seiten stahlblau. Fiihler rotgell, drittes Glied groß, Spritze dunkler. Schihehen olne mattschwarze Seitenecken. Hypopyginn lang,

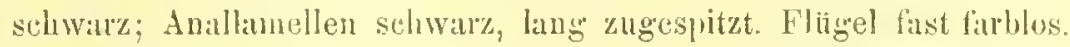
$3 \mathrm{~mm}$ lang . . . . . . . . . . . proximus Aldr. o’

25 Fibler sehmutzigrot, drittes Glied an der Spitze sthwill". Gesicht und stirne braun bestiubt. Ilypopygium stark verlingert; Anallanellen grob und sehwarz, gegabelt. Fliigel sehwiirzlich. 45 mm langr

fircifur LW.

Fïhler rotgelb, drittes Glied obenauf sehwairzlich. Gesicht weiblich. Iypopygium dick umd lang, grau bestiubt. Anallamellen schwarz, zugespitzt. Fliigel gebräunt. 3 mu lang . . . frulcutus Aldr. o

- Fiblier grelb, drittes Glied au der Spitze grobritunt. Gesicht silberweif. Stirue violett bronzefulbig. Anallamellen schlank, braun. Flitgel deutlich gebriiunt. 3-t mun lang . . . . liansensis Aldr. ő

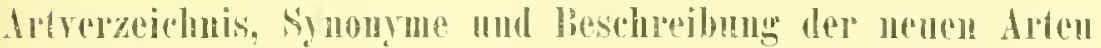
der nearktischen und ncotropischen Region.

1 rbbreciatus Lw. o, Berlin. Entom. Zeitschr. VIII 94. 89 (1864) et Monograpls. Dipt. N. Amer. II 338.7 (196it) . . . . . America supt.

$\because$ aryentiferus Aldr. \%, Transact. Ent. Soe. London 313. 2 (1896)

America centr.

3 asciaeformis n. sp. o . . . . . . . . America sept.

ऊ. - Thoraxrielen glänzend schwarzgrin; die mattschwarze lieckenbinde an den Flibgelwirzeln und die Seitenfleeken am Sohildchen dentlich. Schwinger bram, Schiijpclien gelb, schwar hewimpert. Stirne schwälzlich, seidenartig schimmernd. Gesicht ganz grau. Fiihler ganz rot, Fiblerborste von gewöhnlicher läinge, lang gefiedert. Hinterleib el'zgriin, Seiten grau hestäubt. IIypopygium mit selı kurem Stiel, dick und grof, fist lis zum ersten linge reichend, zylindrisch, stumpf kegelig mit kibrcren schwaren beilförmigen nud stark beharten 
außeren Lamellen. Beine nelost Vorderhiiften gelb, Spitze der Mittelund Hinterhiiften auch gelb, Hintertarsen braum. Flïgel sehr wenig getriibt; vierte Liingsader an der Fliigelbeule mit bogenförmiger Abbiegung. $3.5 \mathrm{~mm}$ lang.

Ein Exemplar aus Georgia [Morrison] Nr. 7961 der Sammlung des Bertiner zoolog. Mus.

Anmerkung. Diese Art hat gruße Ähnlichkeit uit cognatus Lw. mul muß in der Tahelle neben derselben stehrn; sic unterselıeidet sich aber wesentlich durch die Form der Analanhinge.

— bifions Walk. Q, Ins. Samnders. Dipt. I. 212. [Dolichopus] (1852)

Ameriea sept.

Bei dem Fehlen von charakteristisehen Merkmalen in der Besehreibung ist diese Art als Weibehen alleine nicht zu denten.

4 bigeminatus Aldr. OT, Biolog. Centr. Amer. Dipt. I 338. 6. tab. VI fig. 13 (1901)

. Mexico

Charakterisiert dureh die fleckenartige ranebsehwarze Triibung am Vorderande der Fligelspitze.

5 Pelastoneurus biguttatus 1. Sp. O’ 0,1 Figur. . Ameriea merid.

Thol:ax metalliseh dunkelgriin bis stablblau von Grundfarbe, dureh Bestaubung fast ganz matt; auf der Mitte der Akrostikalbörstehenreilien liegt eine matt bronzegrine Läingslinie, die sich naelı dem Sehildehen lin verbreitert, in iibrigen ist die Bestaubung weiblich. Deutlich weiße Flecken sieht man je zwei an vorderen und hinteren Ende des cullus postularis und einen fiinften an der Spitze des Sehildehens. Die Notopleuralgrube ist nieht bestiubt, zeigt vielmehr metallisehen Glanz; die sammetseluwarzen Fleekenbinden iiber der Fliigelwurzel sind stark entwiekelt, anch das Sebildehen hat an den Seitenecken diese Firbung. Brustseiten, Sehïppehen, Sehwinger wie bei allen tibrigen Arten.

Kopf: Stirne und Hinterkopf dunkelrotbrann, die Augenränder sind weilj bestiubt und findet diese Bestiubung ihre Verlingerung an Hinterkopf in zwei nach dem Halsansatze hin konvergierenden weißen Streifen, neben denen in geringer Entfernung noeh zwei gleiche Streifen stehen; die untere Hinterkopfhälfte ist gralu bestïubt, so daß die obere Hiilfte dureh die rorhin erwähnten vier schmalen weißen Streifen mit fünf selhwarzen Fleeken versehen zu sein scheint. Gesicht grangrïn, Augenrinder weiß; 'Taster obenauf griinlieh, die inneren Seitenkanten silberweiß bestiiıbt. Fiihler rotgelb, drittes Glied klein, abgerundet, Borste lang gefiedert.

Hinterleib schwarzgrü mit blïuliehen und kupferfarbigen Reflexen und purpursehwarzen Vorderrandbinden; die Seiten und die Spitze des seelssten Ringes sind selneeweif gefleekt. Hypopyginm sehr klein, nicht iiber das Ende des vierten Ringes vorstehend. Ich habe das Hypopygium in seiner Lionstruktion bei dem einzigen vorhandenen 
Mäunchen nicht näher untersuchen können; die üußeren Lámellen sind schwarz und zeigen eine dentliche vordere Spitze mit beborsteten Seitenräindern.

Beine mit Vorderhiuften gelb, Spitze der Hinterschenkel, der Hintersehienen und alle Hintertarsenglieder schwarz, die ibrigen Tarsen kanm am Ende gebriunt.

Fliggel dentlich ge. briiunt, am Vorderrande gesiittigter; beide Queradern sind deutlich gefleekt, auch die Flitgelbenle zeigt eimen leisen Anflug von Verdunkelung, s. Figur 7.

ZweiExemplare von

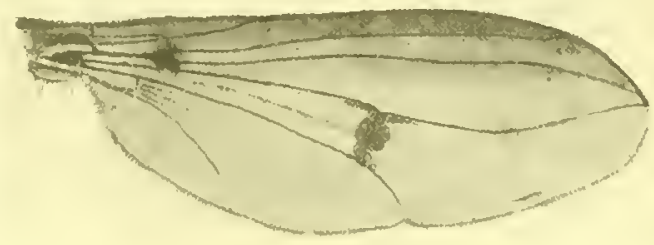

Fig. 7. Fliigel. Pelastoneurus biguttatus Brek. 18:1. Bolivia-Mampiri, Sampioni I, II 1903 [Schnuse]. Sammlung des Dresduer zoolog. Mnseums.

cognatus Lw. ợ, N. Beitr. VIII 39. 4 (1861) et Monogr. Dipt. N. Amer. II 109.5 (1864) . . . . . . . America sept. et eentr.

Loew kaunte und beschrieb nur das Weibehen. Aldrich hat in der Biolog. Centr. Amer. Dipt. I 339 (1901) das Männchen sehr ausfihlrlich und gut besehrieben. Die mil hier vorliegenden Exemplare entspreelen mit Ausnahme eines einzigen Merkmales der Besehreibnng so rollkommen, daß eine andere Art meiner Ansicht nach kaum gedacht werden kann. Aldrieh legt großen Wert auf die Bestäubung in der Suturalgrube und nennt dies eins der besten Erkennungsmerkmale. Nun soll bei cognatus Lw. nach Aldrich nieht die ganze Grube, sondern nur ein Teil derselben, von oben beschen, weiß erscheinen, während bei den hier vorliegenden Exemplaren die ganze Fliiehe gleichmäßig weiß ist. Ob diese Abweichung in der Ausdehnung del Bestäubung nur

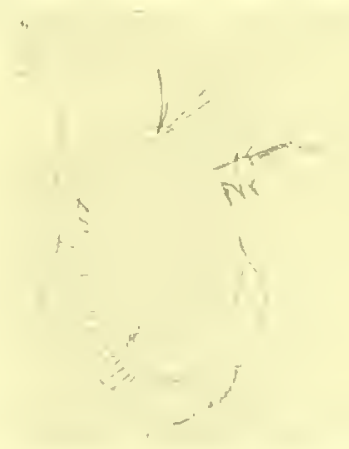

Fig. 8. Pelastoneurus cognatus Loew. $9.18: 1$. Kopf von der Seite. individueller Natur ist, vermag ich nicht zu entscheiden, jerlen. fulls kann ich hierin nieht allein das Kriterium einer anderen Art erblicken. Ich habe zur Vergleiehung das Hypopygium gezeichnet, s. figur 9; dasselbe ist sehwarz, diek, an der Wurzel grau bestiubt, fist bis zum zweiten linge reichend, mit zwei eckig vorstehenden seitliehen Verlingerungen; die äußeren Lamellen sind länglich oval, schaufelformig, schwal'z, an der Spitze und der unteren Kiante lang Abbandl. d. zoul..bot. Ges. Bd. XuI, Hett 1. 
beburstet, auch anf der Oherseite behatat; die imeren Organe bestehen ans $6-7$ dieht zusinmenstehenden kurzen stabartigg gehogenen Teilen. $3-1$ min lang.

5 5, 5 o aus Peru-losalina, Urulambafi V1ll 1903. - chamelua mayo I 1914. - Pachita Hiindung XI 1903 [Schnuse]. Samml. Il. Dreseluer zool. Mus.

7 cyneus Wheel. of, Proceed. Califern. Acal. Se. serie 3 Zool. II 17.

18. tab. 1. lig. 16-18(1899) . . . . . . Ameriea sept. \& digitulus n. sp. $\sigma^{7} \rho$. . . . . . . . . . . America meril.

Dureh die Form der Analanhrünge besonders ansgezeichnet.

o. - 'Thoraxilicken schwarggriin, ziemlich glinzend mit zartem gelhgrauen Reife. Schildchen mit mattseluwaren Seitenecken, Schwinger

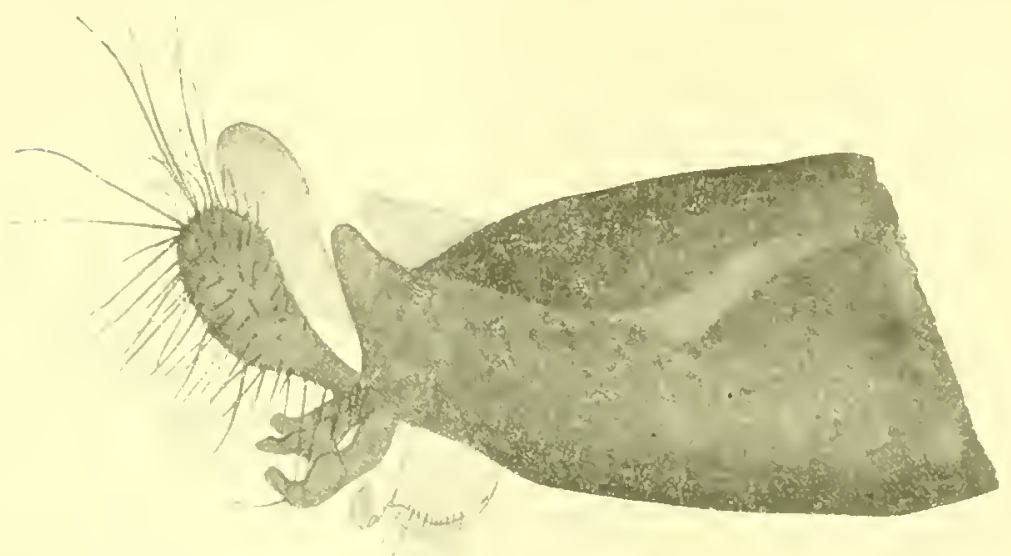

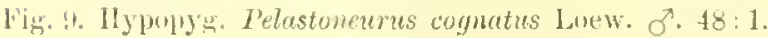

und Sehiifpehen gell, letztere sehwarz bewimpert. - Kopf: llinterkoppilien unten weif; Stirne matt dunkelbraun, Gesicht unten weiljgran, Taster gran bestäut. Fibler rot mit verdunkeltem Endgliede, borste lang getiedert. Hintelleib seluwarzgriu bis lronzefarbig, an den Seiten Aleckig weib bestaiubt. Hypupygium lang nnd selumal mit dentlichem Stiel nud mehreren fadenfömigen iuneren Orgmen, so laug wie der Hinterleib; auträllig sind die äußeren Lamellen, sie surd hreit blatförmig mit stumpfer Spitze, an ilurer oberen Kante mit einer fingeroder löffelförmigen Verlängung, deren abgerundetes Ende mit lingren feinen borstenharen besetzt ist; die Farbe dieser Anhänge ist schmutzig gelb. - Beine nebst Vorderhiiften rotgelb, Endglieder der Tarsen gebräunt. - Fliigel fast wasserklar, der letzte Abschnitt der vierten Längsader geht in sehlankem Bogen bis zum Flïgelrande. 4 mun lang.

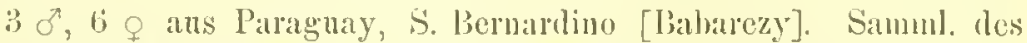
Ungar. Nationalmusenus. -1 o aus Paraguay, S. liemarlino [liebrig]. Sammul, des Wiener zoolog. llofmus. 


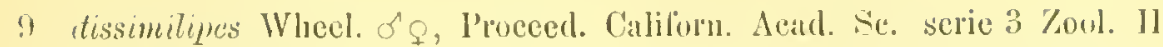
16. $17(1899)$. . . . . . . . . . Americal sejt. nigrescens Wheel., l'roceed. Californ. Acarl. sc. serie :3 Zool. 11 21. $27(1899)$.

10 fulcutus Aldr. of, T'ransact. Amer. Ent. Soc. Philadelphia XXX $27 t$ et $277(1904)$. . . . . . . . . . . Americal sept.

11 fasciatus Röder $\sigma^{7}$, Stett. Ent. Zeitg. XLVI 341 (1885) America centr.

Diese Art ist ungenigend beschrieben, wamentlich mit bezug aul die Form der Analanhinge; ich fuilue sie in der Tabelle nur mit gewissem Vorbehalt auf.

12 flavipes Schin. Oo, Novara lieise Dipt. $219.26(1868)$. . Brasilia

Die Beschreibung, welche Sehiner giebt, ist etwas oberflächlich, mamentlich in Bezug auf die Form der Analanhänge, die bei vielen Arten fast das einzige Unterselieidungsmerkmal abgeben; die Art steht dicht neben fusciatus v. Riider, von der sie sich dureh dunkle, nicht gelbe Anallamellen unterscheidet.

Schiner spricht von 2 on und 1, ; in schiners simmlung fand ich zwal nur zwei schlecht erlualtene Weibchen jedoeh

20,1 a a Brasilien. Sammlung des Wiener zoolog. Hofmuseuns.

13 floridunus Wheel. ơ 9 , Proceed. Californ. Acad. Sc. serie 3 Zool. 1113.

13. tab. 11, fig. 26 (1899). . . . . . . . . America sept.

14 fureifer Lw. o', Berlin. Ent. Zeitsehr. XVI 91.64 (1872) Ameriea sept.

15 hematus Aldr. O', Biolog. Centr. Amer. Dipt. I 335. 5. tab. V1, fig. 12,

$12^{3}(1901)$

Mexico

hetcroncurus Macy. Dipt. exot. suppl. IV 128. 5. tab. XII s. 10

[Dutichopus] (1849) . . . . . . . . . . America sept.

Diese Art ist sicher kein Pclastonerrus, gehört vichmehr zur Gattung Puraclius. Die Zeichnung, welche Macquart gegeben: nackte Fiihlerborste und der scharfe Knick in der Biegung des letzten Alsschnittes der vierten Längsader, spreehen nicht für Pelastoneurus, sonderu liür Paruclius; siehe das weitere bei dieser Gattung.

irrasus Walk. 5, List. Dipt. Brit. Hns. III 667 [Dolichopus] (1849)

America centr.

$1 \mathrm{~m}$ Katalog Kertész VI 231 (1909) ist diese Alt als zweifelladies Synunym von lactus Lw. behandelt. Liest und vergleicht man beide Beschreibungen, so kamn nam, meine icl, nicht in Zweifel dariber sein, daß beide Arten nicht zusammen gehören. Wenn anch Walker mur das Weibchen beschrjeben und nur allgemeine Angaben gemacht lat, so ist doch alleine schon die Fiblerfïrbung entscheidend. Ein Nämmehen mit roten Fühlern (lactus) und ein Weibchen nit selwwarzen Fiahlern grehen nienals zusammen; die Walkersehe Art kann aber nicht gerleutet werden.

17 liansensis Mldr. O', Tnivers. Quart. II 153 [Mctapelustonemms] (1893)

Aneriea sept. 
18 lectus Lw. O', N. Beitr. VIl1 3\$. 3 (1861) et Monogr. Dipt. N. Aner. Il 106.3 $3(1864)$. . . . . . . . . . . America sept.

19 lamellatus Lw. O', Berlin. Entom. Zeitsehr. VIII 95. 90 (1864) et Monogr. Dipt. N. Amer. II 338.6 (IS64) . . . . . . . Ameriea sept.

20 lonjicauda Lw. o, N. Beitr. VIII 37. 1 (186i) et Monogr. Dipt. N. Amer. I1 104. 1 (1864) . . . . . . . . . Americal sept.

21 luyubris Lw. , N. Beitr. VIII 38. 2 (1861) et Monogr. Dipt. N. Amer. II 105. 2(1864). . . . . . . . . Ameriea sejt. et centr.

Wheel. or, Proced. Calilorn. Aeal. Se. serie 3. Zool. II 15. 16. tab. II, fig. 28 (1899).

- maculipes Walk. Q, Ins. Saunders. Dipt. 1214 [Dolichopus] (18522)

Ameriea sept.

Ungenügend charakterisiert; vielleieht wiirde die Beinfärlumg geeignet sein, die Art anch im männliehen Gesehleeht daran zu erkennen, falls man sicher wiilite, daf die Art zu Pelastoneurus gehört. In the Tabelle habe ich sie nicht anfnehmen können.

mexicums Big. ơ, Ann. Soc. Ent. Fr. serie 6. VIII. Bulletin XXX

[Y'oecilobothrus] (188s) . . . . . . . . . . . . . Mexieo

Die Art muf wegen ungen ïgender Charakterisiermng vernachläi werken.

2.2 neylectus Wheel. f, Proeed. Californ. Aead. Se. serie 3. Zool. II 12. 10. tah. I, lig. 14 (1899) . . . . . . . . America sept.

Siehe meine Ammerkung bei der Art semiplumatus

- nigresecus Wheel. = dissimilines Wheel.

23 oceidentulis Wheel. $\sigma^{7}$ s, Proeed. Californ. Aead. Se. serie 3. Zuol. 11

13. 12. tab. 1, fig. $20(1899)$. . . . . . . . America sept.

24 parmes Aldr. O', 'Transact. Amer. Ent. Soe. Philadelphia XXX 274 et

$276(1904)$. . . . . . . . . . . America sept.

25 pictipemis Wheel. ơ

14. 14. tab. 1, fig. 19. tab. II, fig. 25 (1899). . . . Ameriea sept. ?varius Walk., Ins. Sannders. Dipt. I 215 [Dolichopus] (1852).

Ls ist nieht unmoglieh, daß diese Synonymie riehtig ist; etwas Sicheres laift sich aber anf Walker's Besehreilung allein hin nicht ansspreehen.

pilosicornis Walk, List Dipt. Brit. Mus, III 653. [Porphyrops] (1849) Ameriea borealis

Daf diese Art zur Gattung Pelastonewns gehirt, geht aus Walkers Besehreibung keineswegs hervor, iilserhaupt lifit sich keinerlei einigermalien sichere Vermutung iber Gattmng und Art daraus schöpfen. Diese Art ist ganz zweifellaft.

26 moximus Aldr. ఠ", Transaet. Amer. Ent. Soe. Philadelphia XXX 274 et 278 (1904) 
27 munctipennis Say $\sigma^{\pi}$, Journ. Aead. Nat. Sc. Philadelphia VI 170. 2 [Medeterus] (1829). . . . . . . . . . . . . . Mexieo variegatus Aldr., Biolog. Centr. Amer. Dipt. I tab. VI, fig. 14 (1901) 28 smetatus Aldr. o", Transact. Amer. Entom. Soe. Philadelphia XXX

273 [Paraclius] et 276 (1904) . . . . . . Amcrica sept. 20 semiplumatus n. sp. ơ, 3 Fignren . . . . . . . . Amerika б. -- Thoraxriikkengliinzend schwarzgriin mit fiunf Dorsozentralborsten, anden Seiten uud hinter der Queruaht ein sammetschwarzer Längsstreifen. Schwinger und Schtippchen gelb, letztere schwarz be. wimpert. - Kopf: Stime metalliseh griin ; Untergesicht etwas konvex nach unten gebogen, unverhältnismäßigbreit, fast den dritten Teil des Kopfes einnehmend, seidenartig weißgran schimmerud. Fiihler rot, das dritte Glied schwarzbrann, kurz mit stumpfer Spitze und einer langen Borste; diese ist anf ihrer Wurzelhälfte durch anliegende Behaarung etwas dick, mikiroskopisch prbeszent, auf ihrer Spitzenhälfte deutlich kurz gefiedert. Tastel hell, weiß bereift. Hinterkopfzilien unten

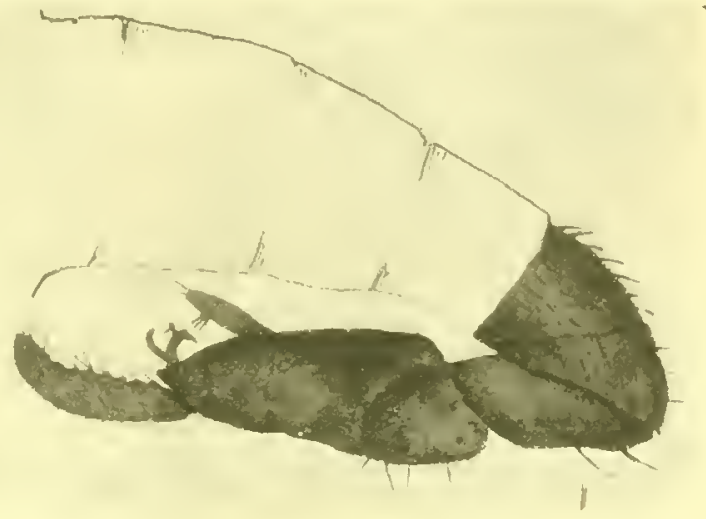

Fig. 10. Ilypopyg. Pelastoneurus semiplumatus lieck. के. $24: 1$.

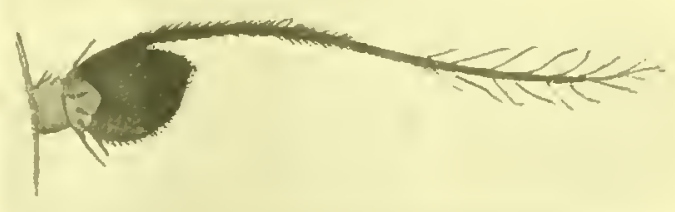

Fig. 11. Fïlller. Pelastoneurus semiplumatus Beck. O?. $48: 1$.

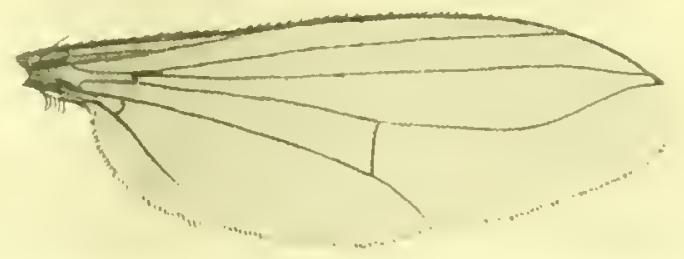

Fig. 12. Nlïgel. P'elastonenns semiplumatus Beck. ơ.12:1. weiß. - Hinterleib glänzend griiuschwarz, schwarz behart. Hypopyg deutlich gestielt, unter den Banch geschlagen, so laug wie der Hinterleib mit langen blatt- bis schanfelförmigen schwarzen äußeren Anhäugen, deren Riander zart behaut sind; die inneren Organe bestehen mindestens 
ans drei Parren, von denen das eine lanzettförmig gehildet ist; as trigt an scinel Spitze zwei zalrte Bürstehen und anf seiner Unterseite eine Warze mit kurzen sehwarzen bïrstehen; die anderen beiden Organe lassen sich nur teilweise erkemnen. Beine nebst Vorlerhiften gelb: diese schwal" behaart mit einzelnen schwarzen Borsten. Sehenkel alle ohne besondere Beborstumg und Beharung. Hintersehenkel mit einer Priiapikalen; Vordersehienen anf der Obersejte mit mehreren kurzen und einer längeren Borste; Mittelsehienen anf der Unterseite mit einer Borste: IInterschienen desgleichen. - Fliigel ungefleckt, fast glashell; dritte Lïngsadier fast grade, vierte von der Fliigelbeule an in schlankem liogen znr dritten konvergierend und v or der Fliigelspitze miundend. 3 mm lang.

1 Exemplar atus Ameriki in der Sammlung Lielntwardt, Berlin.

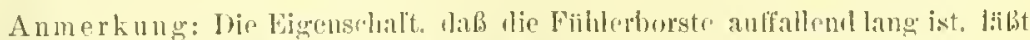

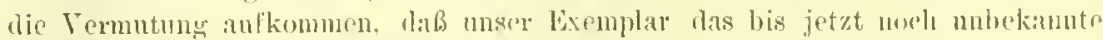

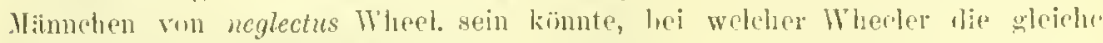

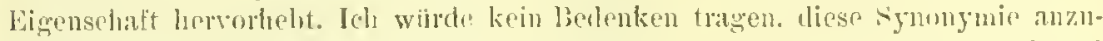

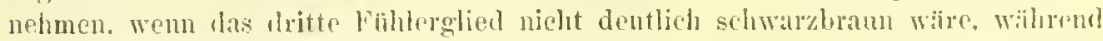
hei neglectus of die Fibler als gatuz gelb geschildert werlen. Immertin lubiht

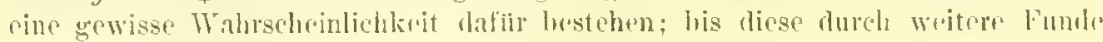
oder" Vergleich" lestgestellt oder widferlegt worden. mag dir Art als suleh" bestehen bleibrin.

taeniatus n. sp. o . . . . . . . . . Ameriea centr.

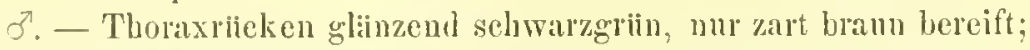
die sammetschwarze Seitenbinde in der Quernaht und iiber der Fliigelwnrzel ist vorhanden, aber nicht seln ausgedehnt; die Notopleuraldepression ist weil\} bestiulut, von oben besehen sieht man einen seharf hegrenzten ovalen silherweißen Flecken. Die Seiteneeken des Sehildeheus, seheinen von der mattschwarzen Bestïubung kaum beriilnt zu sein, dabingegen liegt auf dem Sehildehen selbst ein breiter mattsehwarmer Lïngsstreifen. Schwinger und Schiippehen gelb, letztere sehwarz bewimpert. - Kopf: Stirue metalliseh sehwarzhlan, aber matt, ohne bemerkenswerten Glanz; das Gesicht ist weißgran bestäubt. Ftihler rot, das dritte Glied an der Spitzenhälfte verdunkelt, die Borste ist nm knrz gefiedert; Hinterkopfrandborsten unten weiß. - - Hinterleil, glïnzend ermgriun mit kreideweilien Seitenflecken. Jypopyg groß, sehwarz, etwa his zom zweiten Bauchringe reichend; die änßeren Anhänge bestehen aus zwei schwarzbraunen handfömnigen, an den Bindern behaarten Lamellen, die fast ebenso laug sind wie das Hypopygiun selbst. Beine und alle Hiiften gelh, jedoch sind die Mittel- und Finterhiiften auf ilırer Wurzelluälfte schwar\%graul. Die Beborstung der Sehienen hat den gleiehen Charakter wie bei allen iibrigen Arten. - Fliigel kaum etwas gelbbrimulieh getriilst mit brauner normaler Aderung olme Aderverdickung oler likeckenzeichnung. $2.5 \mathrm{~mm}$ lang.

1 Exemplar von der Insel St. Jean. Westindien $\mathrm{Nr} .3089$ in der Samml. des berliner zool. Mus. 
31 trapezoides 11. sp. $\sigma^{7}$.

Americal merid.

Nach Aldriehs Tabellen stioßt man anf occidcutalis Wheel.; es stimmt aber nicht die Aushildung des Hypopygos, seiner Lamellen und dic Beinfïrbung.

6. - Thoraxrïcken sehwarzgriin, kaum etwas glïnzend, ron der Seite gesehen zart gelhglan bereift: der Thoraxiicken zeigt anßer der mattsehwarzen Fleckung iiber der Fliigelwurzel eine entsehiedene weiße Firbung der Notopleuralgrube, ferner je einen weißen Flecken iiber der Flïgelwurzel und eine grauc dreieekige Bereifungsstelle vor dem Scliildehen. Brustseiten und Haiften weiß bereift. Schwinger und Sehiippehen hellgelb, letztere sehwarz hewimpert. - Kopf: Stirne matt griinblan, Gesicht breit, aschgran; Fihler schwarz; erstes und zweites Glied nuten ront, such an dritten zeigt sich an der Wurzel ein roter Fleck; dic Filhlerborste hat mittellange Hiedern. Hinterkopfzilien weiligelb. - Hinterleib schwarz bis bronzegriin, die Ringe namentlich an den Seiten breit weißgrau bereift, sodaß nur die Einsehnitte unbestäbt und lnnkel erscheinen; der sechste Ring ist am Hinterrande breit weif und auch das schwarze Hypopygium ist weiß bestiiubt; letzteres liegt breit unter dem Banche bis zum Ende des zueiten Ringes; die äßeren sichtbaren Anhïnge sind schwarz, selumal trapezförmig, an der Spitze mit einer feinen Endborste, auf der Unterseite mit einer Reihe stiirkerer Borsten. - Beine rotgelb bis brann; Hiiften aschgran, die vorderen an der Spitzenlailfte, die hinteren wur an der Spitze gelb. Schenkel rotgelb, Sehienen rothranu, an der Spitze dunkler, Tarsen schwarzbran, an den Hinterbeinen am dunkelsten. Klawen einfach. - Fliigel nur schwach graulieh getriibt; der letzte Abschnitt der vierten Liingsáder ist olne besonderen Knick im ganzen schlank bogenförmig bis in dic Nihe der dritten Liingsader gefiilurt. 4 mm lang.

1 o a Pas Paguay Aßnneion, Villa Morra [Vezényi] Sammlung des Ungar. Nat. MIus.

32) turbidus 1. sp. Q, 1 Figur . . . . . . . . . America merid.

Q. - Thorax selwwargriin, kanu etwas glïnzend mit feiner, etwas bläulieh weißer Bereifung, namentlieh vorne; die mittlere Liingslinic zwischen den Akrostikalbürstehen ist nieht bestänbt, bildet vielmelı' einen dunkleren Mittelstreifen, wiihrend die seitlichen Dorsozentralborsten auf je einem breiten granen Streifen stehen; je ein weililicher Fleek liegt neben der Borste auf dem callus postalaris, wiilurend dic Notopleuraldepression, von oben betrachtet, nicht als weiß erseheint. Der mattschwarze Seitenstreifen iuber der Flïgelwurzel hat sich in zwei isoliert stehende kreisrunde Fleeken anfgelöft neben der Dorsupleuralnaht und hinter der Fliigelwurzel; anch die äußersten Seiteuecken des Schildehens werden davon noeh beriihrt, auf dem sehildchen sieht man ferner noeh eine grane Hittellinie. Brustseiten, Schiiplohen, Sehwinger wie gewïhnlich. - Kopf: Stime dunkelnot his hranu, 
sammetartig, welche Färbung als vertikale Strieme iber den lIinterkopf bis zum Halsansatze länft; die scitlichen Orbitalräuler sind weiß bestiubt. Gesiclit auf der Mitte matt bronzefarbig, die Seitenrinder weib. Taster branu, obenanf grau bereift. Hinterkopfzilien unten gelblich. Fiihler rotgelh, das dritte Glied klein rundlich mit kaum merkbarer Spitze und am obersten Rande etwas braun; Borste schwarz, deutlich gefiedert. - Hinterleib dunkelgriin, die Einschnite zart purpurfarbig, die Seiten weiß gefleckt. Beine hell rotgelb. Vorderhiiften ganz gelb, Mittel- und Hinterhiffte schwarzgrau, Spitzen gelb. Vordertarsen, Spitze der Mittel- und Hinterschienen sowie die letzten Tarsenglieder bräunlich; die hintere oder obere Seite der Ilinternnd Mittelsehienen ist zwischen den Borsten weiß gestreift. - Die rligel haben eine schwach graubrimnliche Grondfurbe mit ausgrieliger brauner Fleekenzeichnnng; am Vurderrande zihlt man sieben Flecken. S. Figur 13. $3 \mathrm{~mm}$ lang.

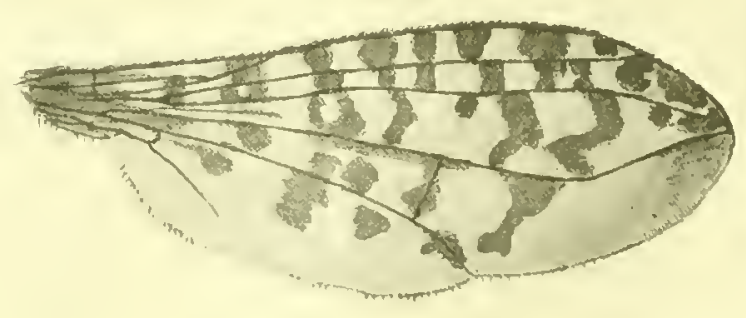

Fig. 13. Fliggel. Pelustonererus turbidus Beek. 18:1.

2 Exemplare ans Bolivia, Hampiri. Chimate $650 \mathrm{~m}$ hoeh. 18. I. 1903 und ans Sarmpioni $700 \mathrm{~m}$ hoch 14. 11I. 1903 [Schnnse] Samml. des Dresdner zoolog. Mus. $-1 \delta^{7}, 1$ a aus Bolivia, Cillutineara, Deutsch. Entomol. Museum Berliu-Dahlem.

$\Lambda$ nuerknng. 1) ir elarakteristische Flïgelzeichnng sichert mweigerlich die Erkemmung des zugehrïigen Mïnnchens.

maniculatus Aldr. ऽ; Transact. Ent. Soc. London 310. 1. tab. XI, fig. 101. tab. XIII, fig. 116. [Poecilobothrus] (1896)

Ameriea eentr. et melid.

Die Art ist von Aldrich ausreichend gekennzeichnet. Ich gebe eine Abbildung des Ilypopygs, des Fliigels und des letzten Tarsengliedes der Vorderbeine; die Art scheint gemein zu sein. 57 \%, 53 q ans Bolivia-Mapiri, Lorenzopata $2000 \mathrm{~m}$ hoch, IV., V. (1903). - alls Sau Carhos $800 \mathrm{~m}$ hoch, 1. (1903) - aus Sampioni $700 \mathrm{~m}$ hoch II. (1903) - ans Chile, Arica X1. (1902) - ans Peru-Lima, liaraneo, 1. (1904) [Sclnnuse] Simmul. des Dresdner zool. Mus. 


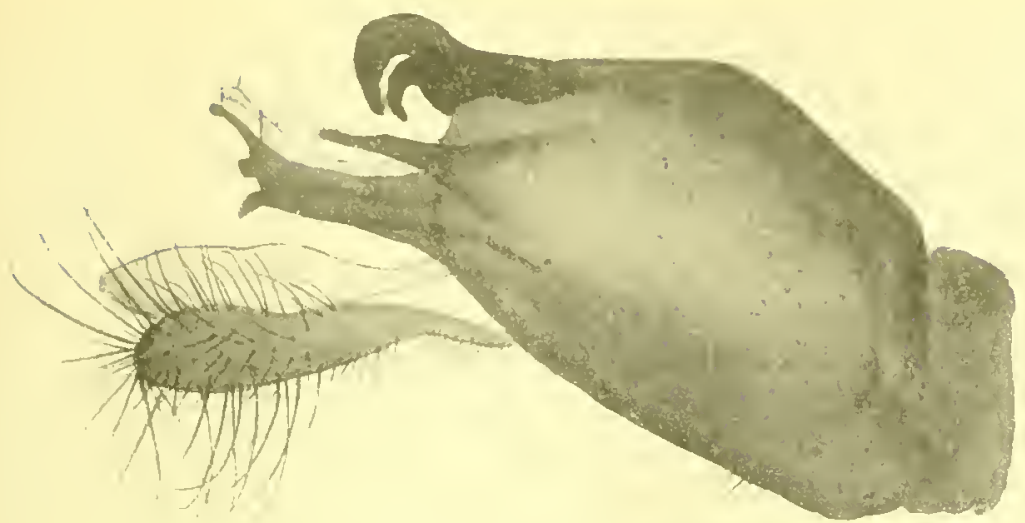

Fig. 14. Ilypopyg. Pelestoneurus unguiculatus Mlix. ठ. 48: 1.

ragans Lw. ơ $\sigma^{7}$, N. Beitr.

VIII 39 (1881) et Monogr.

Dipt. N. Amer II 107 (1864)

Ameriea sept et centr. vagrans Snodgr. Proceed. Calif. Ae. Se. s. 3 Zool. III 278, taf. XXX1, fig. 2, 4, $6(1904)$ [lapsus]. - 11 Exemplare in der Loewschen Sammlung. ragrans Snodgr. $=$ vagrons Lw. variegatus Aldr: = muctipennis Say.

varius Walk. = pictipennis Wheel.

umbripictus n. sp.q. Am. sept.

Diese neue Art ist 7war nur als Weibchen bekannt, ist aber doeh so charakteristiseh

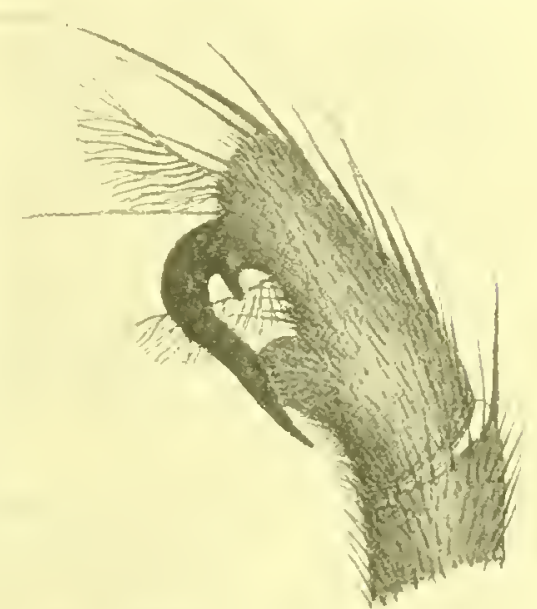

Fig. 15. Letztes Vordertarsenglied C. Pelastoneurus unguiculetus Aldr. 96 : I. gezeiehnet, da $B$ das zngehörige Miiunehen nnsehwer wird erkannt werden. . - Thoraxriieken glänzend griinschwarz mit etwas dunklerer Mittellinie iber den Zirten Akro stikal - Börstehen

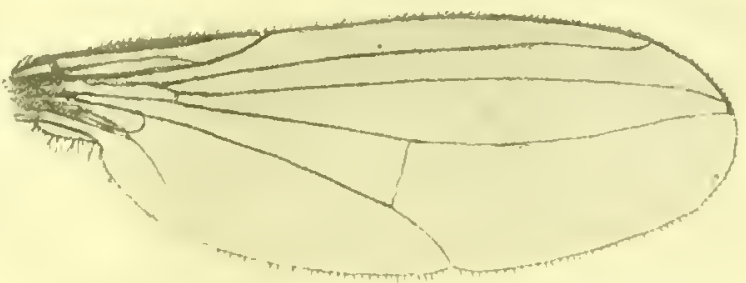

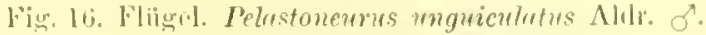


nul nit zwej blanen Jängshinien anf den Aufenseiten der Dorsozentralborsten. Die Wmrelpunkte der liorsten sind sammetscliwarz gefleckt; iiber den Sehnlterbenlen liegt ein dreieekiger sammetsehwarzer Fleck; die mattseluware Laingsstrieme an den Seiten ist groß und seln deutlieh, sie besteht eigentlicl aus zwei griblieren seliwarzen Flccken an der Quernaht und hinter der Fliigelwurel, die an der auferen Seitennabt noch mit ein. ander in Verbindung stehen; dieht vor der Quernaht, mitten im schwarzen Flecken, macht sich ein stark glänzender silberweiber Fleck benerkluar; einen zweiten weißen Flecken sieht man an Ende der schwarzen Striene vol dem Schildehen; die Seitenecken des Schildchens sind ebenfalls schwarz gezeichnet, das Sehildehen selbst hat einen zart flanmartigen weiBlichen Rand. Sehiippehen gelb, selıwarz hewimpert. - linpf: Stime mattbraun, das vorspringende Gesieht yran bestiiubt. Fibluler schwarbraun, unten mebr oder weniger rot gefleckt, das dritte Glied ist kurz, abgerundet, die Borste nur kur\% gefiedert. Taster scluwar\%. llinterkopfrumborsten nnten weib. linterleib erzgrin, sehr knrz. - Beine nebst Vorderhiiften rotgelb. Mittel- und Hintertarsen mit Ansnabme der Wurzellailfte des ersten Glicdes braun; an den Hintersebienen, fast ebenso dentlich ancl an den Mittelschienen, sind die Wurzelpunkte der Borsten braun gefleckt. - Fligel, namentlich im Vorderraude zart gehriunt; außerdem simd die heiden Quel'tdern sowie die Fliigelbeule dureh Briiuntung dentlich fleckenartig gezeichnet; die vierte Längsader läuft von der hinteren Querader an mit schlankem Bogen zum Fliigelrande. $35 \mathrm{~mm}$ lang.

1 Exemplar ans Carolina [Zimmermann] Nr. 3086 mod 1 zweites Exemplitr aus Baúanquilla, Bogotá Nr. 7269 in der Sammlung des lierl. zool. Mns.

\section{Sereionus}

subgenus von I'elastoneums $\mathrm{L}$ w.

Aldr., Biolug. Contr. Amer. Dipt. I 841 (1901).

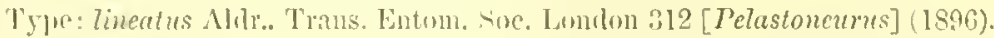

Diese Gattung ist wolıl num als Sulogemus von T'elastonemms anfanfassen. Aldrich gibt als cinzigen Untersehied an die Form des Gesichtes; letateres ist olyen nicht eingeldiickt und unten rortretend wic bei Pelastoneurus, sondern grade heralygehend, es ist anch weit schmiler. Das Gesieht (o') ist in ller Witte an sclumälsten, oben und muten breiter, so daß die Angenlinie eine geschwungene Form annimut, s. hei flaricoxa Aldr. tab. IV, fig. $15^{\mathrm{a}}$.

bie beiden bisher bekammten Arten lassen sich leicht wie folgt unterseheiden:

\section{Artell.}

flamicoxa Aldr. ơ 0 , Biolugr. ('cutr. Aner. Dipt. I 341. 2. tal, VI, fig. 15 [Pecilobothrus] (1!) Mexien 


\section{Bestimmitingstalielle.}

1 Fibler rot. Stirne weiß bestäubt. Hypopyg sehwar\%. 4 mm lang:

limeatus Aldr. $\sigma_{i}$

Fiihler dunkelgelb, drittes Glied hraimulich. Stirne gliinzend violett. Iy popyge lramn. $4 \mathrm{~mm}$ lang . . . . . flavicora Alelr. ớ

\section{Stenop!grimm}

novum genus Dotichopodinarum

Die Gattungsform, welehe dureh die machstehend besehriebene Art dasgestellt wird, lat noch am meisten Verwandtschaft mit Pelastonemus Lw. Das Gesieht ist etwas sehmäler, lat aber inı ganzen eine ähuliehe Form mol die Fliigel sind mit ihrer Aderung ganz im Churakter der Pelastonemrus-Arten gebalten. Abweichend ist aber die Form des dritten Fiihlergliedes, die mur julseszente, nieht gefiederte Fiihlerborste, das vollständige Fehlen der sammetsehwarzen Fleekenloinde ither der litgelwurzel und die ansmehmend sehlanke Form des Hinterleibes, des Hypopygiuns und ler äußeren Anbänge.

Kopf so hoch wie breit. Augen hoehgestellt, puheszent. Seheitel kanm etwas eingesenkt. Untergesicht in zwei Teile geteilt, wenn auch nielıt dureh eine nentliche Querfalte; der obere Teil ist vou dunkler Crundfurbe mit sehrigen Furehen, kaum etwas eingedriekt, der untere Teil ein wenig volspringend, aber weit weniger als bei Pelastoneurus, weiß bestiult. liïssel mebr oder weniger suekartig herunterhängend mit ziemlieh großen aufliegenden Tastern. Fiiller hoch oben an Kopfe stehend, das erste Glied oben behaart, das dritte Glied etwas verlingert, zugespitzt, der untere Rand mit seichtem Ansselmitt. Riickenhorste lang und pubeszent. Thorax mit den gewöhnlieuen Borsten, Sehildehen mit zwei Borsten. Hinterleil, stark verjingt mit langem sehr schunalen Hypopygium, das nit ebeufalls langen, ain Rande zart und späirlich hehaarten äußeren Lamellen versehen ist (s. Figur 17). Penisscheide oben lang und deutlich. Beine gewöhnlieh mit späilieber Beborstnng wie bei Pelcstonentres und Paraclius; ller IJintermetatarsus ist deutlieh kiurzer als das zweite Glied. Fliigel ziemlieh ganß; dic dritte und vierte Längsader konvergieren zu einander mit logcufürmiger Neigung älnlieb wie bei Pelustoneums.

1 nubeculum n. sp. $\delta$ q. Zwei Fignen. . . . . . Ameriea merid.

o'. - Thorax ron metallisel griner Grundfarbe, von branner

liestäubung ziemlich matt; die rordere Halspartie und Selunterbeule sind graugelb bestiubt, auberdem sicht man noel an fast allen IJanutborsten des Thoraxitickens neben den Wurzeln graugelbe lilecken. Die Notoplenraliepression ist nur undentlieh grau bestaiubt, ïber der Fliigelwurzel felılt die mattsehware Fleekenbinle. Seliippehen und Selıwinger geib, erstere schwarz bewimpert. Gesicht wic obeu be-

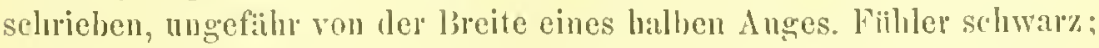
untere Hinterkopfzilien schwar. - Hinterleil metalliseh griin. Hy]u- 
pyginm wic oben besehrieben, ¡uliere Lamellen sehwarzbrann. Beine mit Vorderluiften rotgelb, ITintertarsen ganz schwarzbrum. die Mittel- nnd Vordertarsen vom Ende des ersten Gliedes an ebenso. Fliigel rou hellbräunlicher Färbung mit undentlich begrenzten, verwaschenen, briunlichen, wolkenartigen Fleeken. $4-45 \mathrm{~mm}$ lang.

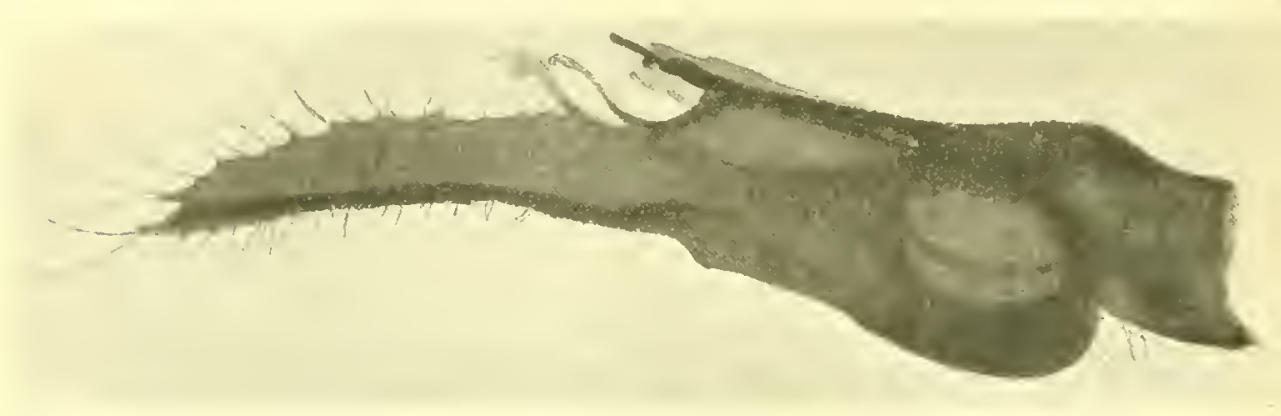

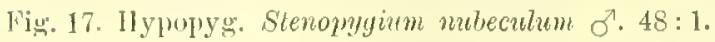

૧.-- Das Gesicht ist kanm etwas breiter als beim ơ; das dritte Fiihlerglied ist nicht verlingert, nit etwas stumpfer Spitze, ant der Unterseite nicht ansgekerht.

$8 \sigma^{7}, 2$ a a BoliviaMappiri. Lorenzopata $2000 \mathrm{~m}$ hoch. 11. V. (1903) - aus Peru, Pichis-Weg. 4.I. (1904) [Sclmnse]. Samminng des Dresdner zool. Hnsemms.

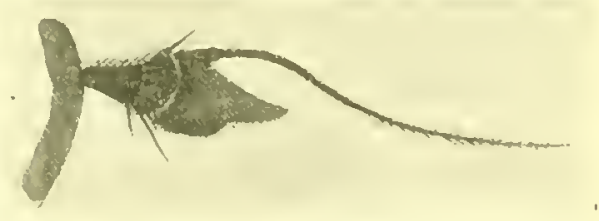

Fig. 18. Fühler. Stenopygizm mbeculum 18:1 $1 \zeta^{7}$ aus Peru, Callanga. Samml. des Ungar. Nat. Mus.

\section{Truch!jtiechus.}

Wralk. Ins. Liritamn. Dipt. I 173. (1)s. (1851).

Ammobates Stann., lsis I 33. 2. (1831) prapoce. Latr. IIymen. (1909).

IIammobates Limul., Nipteral. It:l. Proilr. I 143 (1857).

Stomia Rond. Dipterol. Ital. I'rodl. II 14 (IS57).

Diese in der paliarktischen Region gut vertretene Gattung ist aueh in Nord- und Siidamerika heimiseb, olne ihren Charakter wesentlich ab. znindern. Kopf, Thorax und Hinterleib sind anmïhernd gleich gebildet. An den Beinen sind die Sehenkel an der Wurzel, wenigstens die vorderen, ebenfalls etwas verdickt. Die Tarsen, welehe bei unseren paliarktisehen

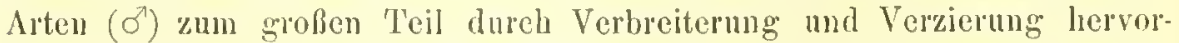
treten, sind hier wesentlich einfacher gehalten. Die Hintersebenkel haben nieht die Reihe der Priapuikallorsten. welche wir als Gattungscharakter anzusehen gewohnt waren; meistens ist nur eine im letzten Drittel oder 
Viertel stehende Borste sichthar, denen sich vereinzelt bei einigen Arten cine zweite und dritte binzugesellt; dies Merkmal ist hier also schwankend und kann nieht als Gattnngszeichen rerwertet werden. Die Fliigelfeekung an der Spitze, die bei nus nu in einer Art Koutr $\approx i$ Hik anftritt, hat hiev cine größere Verbreitnug gefunden. Die Längsalern sind anch hier anf die Vorderhälfte der Fliigelflaiche zusammengedräingt und die vierte läugsader îhnlich aufgebogen.

Ebenso wie in Aldrichs Katalog 1. c. p. 307 ist anch in Katalog Kertész die Gattung Macellocerus Mik wieder mit Taclyytrechus rereinigt worden. Dall ieh diese Ansicht nicht teile, viclmeln Macellocerus als besondere Gattung behandle und ans welchen Grinden dies geschehen, wolle man ebenfalls bei dieser Gattung einselicn.

\section{Bestimmungstabelle fïr die Arten der Gattmmg Tachytrechus.}

\section{M :in nehen.}

1 Fiilıler ganz sehwarz . . . . . . . . . . . . . . . 2

Fiilıler sehwarz, das erste Glied ganz oder teilweise rotgell . . 5 Fiihler rotgelb, das dritte Glied ganz schwarz oder nur an der spitze verdunkelt

2 Ilinterschenkel mit nur einer Priapikalborste. Flïgel ohne grïßeren dentliehen Flecken an der Spitze; Randader im ersten Abschnitte auf der Mitte verdickt

- Hintersehenkel anfer der Priapikalborste noch mit 2-3 anderen Borsten. Fliigel mit dentlichem gramen bis schwarzen Fleck an der Spitze . 4

3 Beine gan' sehwarz. Gesiebt blaß ockergelb . angustipennis Lw. ठ

- Beine schwarz, Kniee und äußerste Sehieneuwurzeln gelb. Vordertursen ein wenig verbreitert, letztes Glied silberweiß. Gesicht seidenartig weifgrau, Stirne nattbraun. Hypopygium dick, Lamellen scluwar'zbraun, viereckig abgerundet nit geringer Behaarung. 4 mm lang.

$$
\text { argyropus n. sp. }
$$

Beine schwarz und gelb gezeichnet: Hiiften und Schenkel selrwirz, Kniee und Sehienen rostgelb. Gesicht ockergelb, Stirne mattbraun. Hypopygium groß; Lamellen selıwarzbram, abgerundet mit zipfelfirmiger Endigung. 4.5-5 mm lang . . intermedius n. sp.

4 Der Spitzenfleck ist groß dreieekig, schwärzlich grau und liegt unterhalb der vierten Lïngsarler, Fliigelspitze breit weiß; Randader im ersten Alsschnitt rerdickt. Untergesicht blaßgelb. $6 \mathrm{~mm}$ lang:

rorax Lw. ot

- Der Spitzenfleck ist fast lireisrund, sehwarz und liegt ganz oder fast ganz unter der vierten Längsader; er fuillt die Spitze des Fliigels aus uhne einen weißen Flecken. Hintere Qnerader wrade, aber schräge gestellt. Gesicht weib. $5 \mathrm{~mm}$ lang. . . florillensis Aldr. $\sigma^{7}$ 
- Der Spitzenlleck ist lingglich oval nul liegt gleichzeitig iiber den Endpunkten der vierten nud dritten Lïngsaderu; die Spitze des Fligels wirl von einem kleinen weilien Flecken ausgefïllt; hinterc Querad el wenig selırige. Gesiclıt veliergelb. $5.5 \mathrm{~mm}$ lang

volitans Meland.

5 Das erste rote fiallerglied ist an der Wurzel deutlich sehwarz. Die vier letaten vorderen 'T'ul'senglieder nebst der Spitze des ersten Gliedes dentlich verbreitert und sehwarz. Fliggel obne Spitzenflecken; hintere Querader grade, schwach gebriunt. 5 mu laug.

latitarsis 11. sp. 0

- Das erste Fiilulerglied ganz rotgell, Vordertarsen von der Spuitze des erstea Gliedes an seluwarz und nieht verbreitert. Flitgelspitze zwischen der dritten und vierten Liingsader und namentlich nnterhalb der letzteren schwarzgrau gefleckt; lintere Querader S förmig und sehräge gestcllt buit schwacher bräumung. $5-5.5$ mm laug

obtectus n. sp. 万

6 Hiilıler rotgelb, das dritte Glied an der Spitze sehwarz . . . 7

Fiihler rotgelb, das dritte Glied ganz seluwarz. Beine dunkel rostgeh, Iliften und Schenkelwureln sehwarz. Vorderschienen anf der Mitte jlattgedriekt; Hintertausen in versehiedener Weise verzient; hiutere Querader und die Fliigcheule dentlich gefirbt. 6 mm lang

pleropodlus Sehin.

7 Vordertarsen schwarz, einfach, erstes Glied zum großen Teil gelt): Vurdersehienen verdickt, schwarz, an der Spitze weiß. beine üherwiegend sehwarz gefiurbt. Hypupygimm schwarz; Lamellen sehwarz breiter als lang. $5 \mathrm{~mm}$ lang . . . . . . . junctus Coquill. ठ

Vordertarsen ganz scluwar\%, etwas breit gedrickt; Vorderschienen verdiekt, an der Vorderseile gelb. Beine iiberwiegend selıwarz geliurlst. Hypopygium loram; Latmellen braun, vicreckign, an der Wurzel gedb. $4.5-5.5$ mm laug. . . . . . . . . protervus Meland. ठ

Weibchen:

1 Fiihler g'anz schwalrz . . . . . . . . . . . . . . . ב

- Fiihler gelh und seliwarz gezeichnet . . . . . . . . . . 6

2 beine ganz schwarz. . . . . . . . . munstipennis Lw.

- beine nieht ganz schwarz . . . . . . . . . . . . . . 3

3 Sehenkel sehwar, Knice und šchienen gelb . . . . . . . 4

- Sulenkel nur ca. $2 / 3$ sehwarz . . . . . . . . . . . . . 5

4 Gesicht blabgelb . . . . . . . . . . vorex liv.

- Gesicht grau; hintere Querader und die Fligelbeule etwas gefitibt intermedius n. sp.

5 Ilinterschenkel ganz sehwarz. . . . . . . rolitons Meland.

- Hinterschenkel um zum Teil schwarz. . . . flonintensis Aldr.

6 Sehenkel gauz oder bis zu $2 / 3$ oter $3 / 1$ von der Wurel an schwar 7 
7 Sehenkel ganz schwarz, uur die Knice und $2 / 3$ del Mittel- und lliuterselienen zelb. Fiihler gelb, drittes Glied an der Spitze schwarz. Gesicht ockergelb . . . . . . . . . . proterus Mland. ?

Sehenkel zn $2 / 3$ oder $3 / 4$ ron der Wurzel an sehwarz; Sehenkelspitzen, Selhienen und, Wurzelhillfte der vorderen Tarsen gelb . . . 8

\& Vordertarsen wenig, alyer doch dentlich etwas verbreitert. Fiiluler schwarz, erstes Glied mit Ausnahme der inßersten Basis rotgelb. Hintere Querader grade verlaufend und nicht schrige gestellt. Ramdader in ersten Abschnitt auf der Mitte verdickt

latitersis n. sp. ?

Vordertarsen einfach, nicht verhreitert. Fïlıler selıwarz, das erste Gilied ganz rotgelb. Ilintere Querader S-fömig und etwas sehrige gestellt. liandader in ersten Abschnitt nicht rerdickt . obtectus n. sp. Q

Anmerkung. Die Weibchen der. Arten junctus Coiquill, pteropodus schin. und argyropus beek. sind noch nicht hekannt.

\section{Verzeichnis mul Beschreibung der Tachytrechus-drten.}

Nearktische und neotropische Region.

1 angustipennis Lw. ớ, Berlin. Lnt. Zeitschr. VI 213. 64 (1862) et

Monogr. Dipt. N.-Amer. Il 113. 3. (1864) Ameriea sept. et merid.

Die Art war bislang nur aus Nord-Amerika bekannt, ieh fand melrere Exemplare beiderlei Geschlechts in der Sehnusesehen Sammlung aus Siid-Amerika, die der Loewsehen Beschreibung durehaus entspreehen, immerhin sind kleine Abweichungen rorhanden: so vermag ich die bräunnng der Randzelle an ihrer Spitze nicht deutlieh zu erkennen, von der Loew spricht, aueh gibt letzterer an, dab an den llinter. schienen drei plattgedriickte Borsten stiunden, während jei nur zwei zihlen kann; diese geringen Unterschiede sind indessen nieht geeignet. dic Grundlagen fiu cine andere oder neue Art zu bilden.

$3 \sigma^{7}, 5$ o ans Chile, Arica, X 1902 nud ans Peru-Lima, Baranca, l 1904 [Sehnuse]. Samml. des Dresdner zool. Mus.

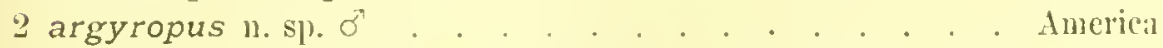

б. - Thoraxrỉeken seliwarzgriun, etwats glainzend, nanentlich rorne grangelb bestainbt; auf der Hitte macht sieh vom Halse ausgehend ein nubestäubter und dalıel dunklerer llittelstreifen bemerkbar. Sehiippchen und Sehwinger gelb, erstere schwarz bewimpert. - Kopl: Stirne matt erzlorann; Gesicht scidenartig weifgrun. Fuihler sehwarz; an der Spitze des ersten Gliedes zeigt sich ein sehr kleiner roter Fleck, den man seined geringen Ansdehnnng wegen aber aueh vernachlissigen kam. Ilinterkopfrandborsten unten weif. - Hinterleib dunkel errgrin, an den Seiten etwas weißlich bestäubt. Hypopyg dick, nngestielt, mit seluwarabramen, vieseekig alogerundeten Lamellen mit geringer hand- 
behaarung. - Beine nelst allen IIiliten schwarz, nur die Knice und die außersten Schienenwurzeln gelb. Die Vordertursen sind nach der inneren Seite hin ein wenig verbreitert, die ersten vier Glieder endigen an der Spitze mit einer kurzen Borste; das letzte Glied ist nielıt so rerbreitert, sondern einfach und dicht silberweiß behast. - Fligel schwach gran getriibt mit der gewöhnlichen Aderung; die hintere Querader und die Fligelbenle sind leieht rauchgran gefleckt; die Costa ist am ersten Abschnitte dentlich etwas verdickt. $4 \mathrm{~mm}$ lang.

Ein Exemplar in der Wiener Sammlung (colleet. Winthem); als Vaterland ist nur cinfach Amerika angegeben. Eine Zettelnotiz von Loew's Hand bezeichnet das Tier als eine unbeschriebene Spezies.

3 bipunctatus Maeq. oto,

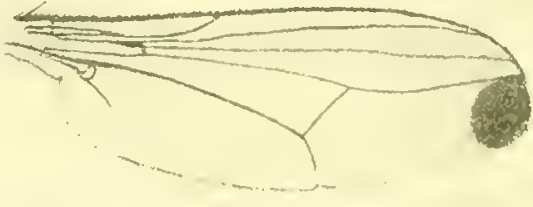

Fig. 19. Fligel. 'Tachytrechus floridensis Aldr. o. $12: 1$. Dipt. exot. II 2, 126 tab. XXII fig. $2[$ Dolichomus] (1842).

Chile

4 floridensis Aldr. Oto, Transact. Amer. Entom. Soc. Philadelphia XXIII 82 (1896).

Die Art ist gekennzeich. net durch ganz scluwarze Fithler, nicht ganz selıwarze Sehenkel und durch einen kreisrunden sehwarzen Fliigelfleek au ler Spitze unterhalb der vierten Längsader. intermedius $11 . \mathrm{sp}$. $\sigma^{7} \mathrm{c}$

Americá merid.

б. - Thoraxriieken metallisch grin, mit braungrauer Bestiubung dicht belleckt; die Akrostikalbörstehen sind dureh zwei feine braune Linien eiugefalit, deren Farbe vielfacl zusammenfließt, so daß auf dem liiicken ein breiter brauner Längsstreifen entsteht; weiß bestiubte Flecken sind nicht sichtbar, auch die Notopleuralgrube ist nicht so bestiubt. - Kopf: Hinterkopf brann und grau bestiubt; Stirne matt braun; Untergesicht ockergelb, bis zum Augenunterande reichend. Taster dunkel gefirlut, kaum sichtbar. Fiihler schwarz, drittes Glied alogerundet; das erste Glied ist an dem nach innen gerichteten kleinen Zipfel auf dessen Oberseite weil. - Hinterleib metallisch griin, glänzend, schwach weiß bereift. Hypopygium groß, schwar, kurz gestielt, Wurzelhalfte grau bestiubt; äußere Lamellen sehwarzbran, abgerundet, behaart, an der äuferen Ecke zipfelförmig verlïngert (in der beifolgenden Figur ist dieser Ziptel wegen Verseliebung des Objektes nicht mit dargestellt); die Penisseheide ist kriffig, sehwarz, auf der Unterseite mit einer dreieekig vortretenden Spitze und cinem Einschnitt: innere Organe gritłelförmig. - Beine: Hüften und Schenkel schwargriin, Knice und Schienen mit Ansnahme ilrer Spitze rotgelh. Hintersehenkel nur mit einer Prapikalen in $3 / 1$ der Sehenkelliuge. Hintersehienen in der inneren Reilse der beiden hinteren Borstenreiben 
mit zwei plattgedriekten Borsten anf der Endhälfte. Tarsen sebwark, dis erste Glied der Mitteltarsen vou der Wurzel an größtenteils rotgelb. Vordertarsen kaum etwas dick, ungefïhr so dick wie die Sehiene. - Flïgel etwas graubrïunlieh getriibt; Randader iu ersten Abselnnitt anf der Mitte verdiekt; hintere Querader gerade, mit der Fliimelbenle deutlich etwas gebriiunt. $4 \cdot 5-5 \mathrm{~mm}$ lang.

f. Untergcsicht gran, sonst keine Untersehiede.

Diese Art scheint sehr gemein zn sein.

130 Exemplare aus Chile, Ariea X. 1902; aus Pern, Arequipla XI. 1902; ans Bolivia, Titienca-See VI. 1903; aus Pern, Sieuani VI. 1903; aus Peru, Calea VHI. 1903; ans Pern, Cuzeo V'lli. 1903. 5700 -4000 m hoch; aus Pern, Ulabiumba, $3000 \mathrm{~m}$ hoch, V1. 1903; aus Peru, Laristal VIII. 1903, 3000-4000 m hoch; aus Peru, Uroya I.

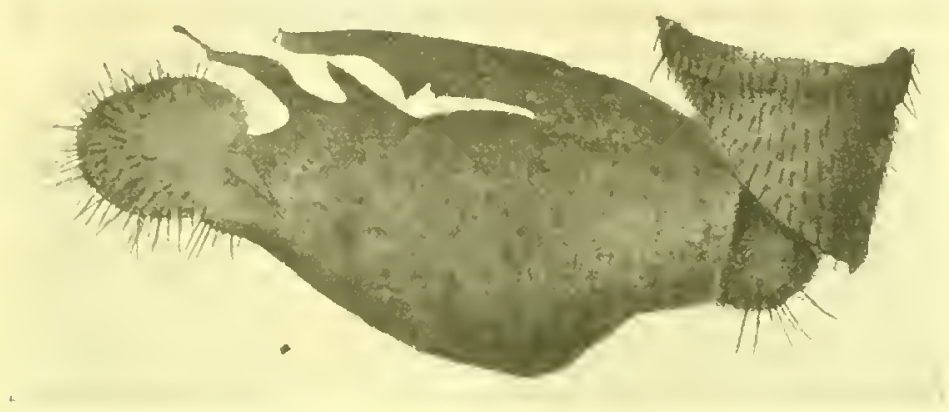

Fig. 20. Hypopyg. Tachytrechus intermedins Beck. o'. 36:1.

1904; aus Peru, Tarma I. 1904; aus Chile, Tacna X. 1902, Patlea X. 1902; aus Chile, Quillota IX. 1902; aus Chile, Valparaiso IX. 1902 [Schunse]. Samml. des Dresdner zool. Mus.

$1 \delta^{7}$ aus Portorico [Moritz] Nr. 7688. Sammlung des Berliner zoolog. Mus.

6 junctus Coquill. o7, Procecd. Ent. Soc. Washington XII 125 (1910)

Amerieat sept.

63. - Fühler rotgelb, das dritte Glied an der Spitze sehwarz. Vordersehienen schwarz, verdickt und an der Spitze wciß; dies sind die charaliteristisehen Merkmale. 5 mm lang.

7 latitarsis n. sp. $\sigma^{7}$. . . . . . . . Ameriea merid.

Ђౌ. - Thoraxrieken mit dichter gelbgrauer Bestäuhung bedeckt, mii deutliehen Purpurfleeken an den Wurzeln der Borsten nehst zwei feinen Längslinien zu beiden Seiteu der Akrostikalbörstehen; die Notopleuraldepression ist ohne hesondere Färbung. - Kopf: Stirne und Hinterkopf matt braun; Gesicht gelbgrau, bis zum Augenunterlande reiehent. Fibhler sehwar, das erste Glied rotgelb, jedoch ist tlie ainßerste Wnuel sehwar\%. - Hinterleih metalliseh grin mit weiß- 
licher Bestähbung, namentlich an den Seiten. Iypoprginu diek, schwarz, kur gestielt, an der Wurchbilfte grau; äufere Lamellen schwar\%braun, viereckig ahgerundet olne Zipfelendigungen mit feiner knrzer Behaturug; die Penisscheide hat nngefahlı die halle Linge des Hypopygs und ist an der Wurzel verhältnismïßig diek; die inneren Organe sind zart mit linienförmiger Endigung. - Beine: Hiiften und Selıenliel, letztere bis zn $2 / 3$ oder $\%$ ihrer Länge sehwar. Spitze ler Sehenkel und die Sehienen gelb; Spitze der Hintersehienen nebst den Ilintertarsen schwar; an len Vorder- und Mitteltarsen ist das erste Glied zum gröbten 'Teil rotgelh, die iibrigen sehwarz. Hintersehenkel nur mit einer Prialukalen, Hintersehienen mit den gewöhuliehen beiden plattgedriickten Borsten. Die Vordermetatarsen sind an der Spitze nebst den vier folgenden Gliedern verbreitert. - Fligel selwwach sranlich; die hintere Querader hat einen geraden Verlanf und ist ein wenig gebrinut; der erste Randaderabschnit ist auf der Mitte rerbreitert. $5 \mathrm{~mm}$ lang:

Q. Gesicht weißgram; Vordertarsen einfach, aber doch ein wenig breiter als gewöhnlich.

Elf Exemplare ans Chile, Palka X. 1902 [Selunse]. Samml. des Dresther zoolog. Jus.

Ein Exemplar in der Coll. Winthem. Wiener zool. Holmus.

\& obtectus n. sp. ठో . . . . . . . . . . . . Ameriea merid.

ठึ. - Der 'Jhorax hat die gewöhnliche metallisehgrine Grund-

farbe, ist aber anf den Rijeken durch braungrane Bestiubung ganz matt; die Akrostikalhörstehen sind dureh zwei feine brane Linien eingefaßt nnd die Wurzelpunkte aller Borsten machen sich als braune. Fleeken bemerklaa; die Notopleuraldepression hat keine besondere Fitbung. Sehippehen und Sehwinger gelb, erstere sehwalz bewimpert. - Kopf höher als hreit; Stirne und Gesicht dicht gelbgrau hestiabt, der untere Gesiehtsrand zum Teil schneeweiß. Fühler schwarz, das erste Glied jedoch rotgelb, es zeigt auf der inneren Soite eise dreieckig zipfelförmige Verlängernng. Taster kaum bemerkbar; die nuteren Iliuterkopfrandborsten sind weiß; Hinterkopf grangelb. - Hinterleit, kupferfarbig mit weiß bereiften Vorderrandsbinden, die an den Seiten breiter sind als auf der Mitte: Hinterricken metalliseh glänend. Das Hypopyg und mamentlich der Stiel sind gran bereift, es reicht mit

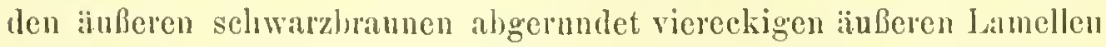
lois zum Ende des zweiten Kinges. - Beine: Hiften und $2 / 3$ der Selıenkel sehwargrin; das letate Drittel und die Sehienen rotgelb; spitze der Hintersehienen nnd deren Tarsen sehwarz; anf der hinteren Seite der Hinterschienen stehen zwei Reihen Borsten, die innere dieser beiden Reilen hat finf loorsten, von denen die beiden rorletzten an der Spitze etwas breitgehliiekt sind, wie dies bei last allen Theluybechus-Arten (-5) der Fiall ist. Die Vordersehienen haben an der 
Spitze der Vorderseite eine flaehe Stelle, welche sillorweif bestiiubt ist. Vorder-und Mitteltarsen mit Ansnalnue des ersten Gliedes sehwarz und ganz einfach. - Fligel schwach gran gefirbt mit starker

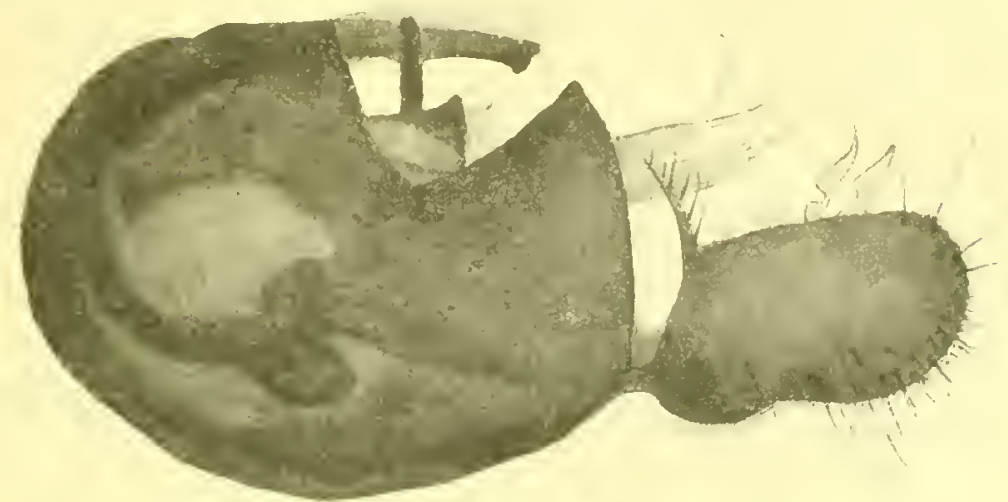

Fig. 21. Iyponyen. Tachytrechus obtectus Brek. r. $36: 1$.

Randader; die iußjere Querader ist etwas S-fürmig gebogen, in schräger Stellung und sehwach seliwar\% grim gefleckt; im der Spitze des Fliigels baluptsichlich unter-

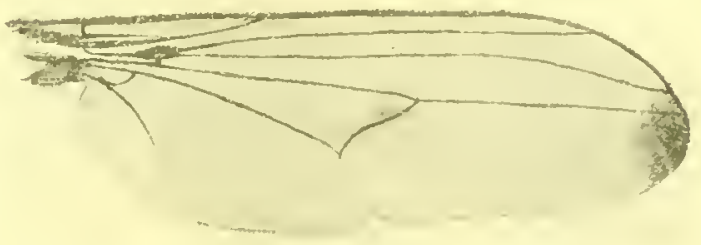

Fig. 22. Flitgrel. Tuchytrechus obtcetus. 18: 1.

Fig. 2324

Kinpl von vorne

1110

Fon llar sirite.

Tuchylrechus

olvectus

Brek. ठ․ $16: 1$.

und
Fon der sinite.
Tachylrechus
obtectus

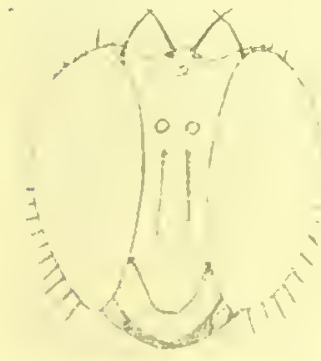

halb der rierten Längsader liegt ein größerer sehwarzgraner Fleek, der bis an die dritte Lüingsader heranreicht (s. Fignr 22).

7. - Das Gesicht ist gran und luat ungefilu 1/5 der Kopf breite. Fliignel ohne Spitzenlleck. Beine ohne die plattgedrickten llinterschicnenborsten und olme die reibhestiulste Spitze der Vordersehienen.

420 , 48 a aus Chile, Ariea X. 1902 [Schnuse]. Samml. des Dresiner zonlig. Mus. 
9 protmens Meland. Oº, Canad. Entumol. XXXII 143. 10. tig. 6, 7 (1900)

America sept

Ieh kenne diese Art nicht ron Ansehannng; sie ist aber ihnlich wie junctus Corpill. dureh verdiekte Vurdersehienen ansgezeiehnet, weicht aher al dureh etwas verbreiterte Vordertarsen und andere Hypopygialanhïinge.

10 pteroportus Selin. ¿" Zwei Fignren.

Brasilia

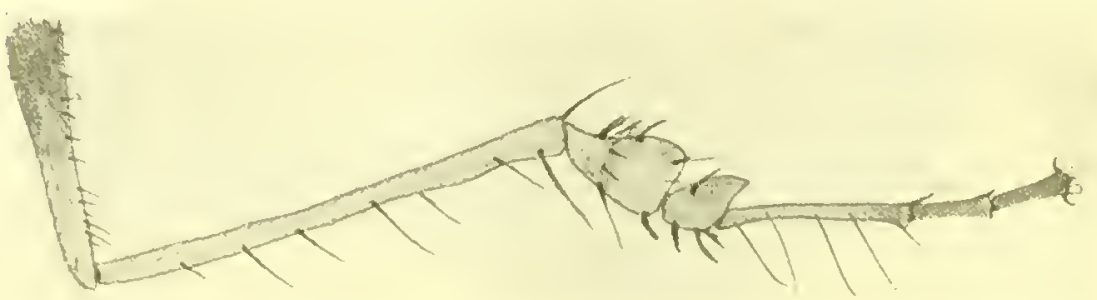

Fig. 25. Mittelhoin. Tiechytrechus pteropodus Sichin. of. 12:1.

万. - Von der gewölnlielıen Thoraxfirbnng und Beborstung. Kopf: Stirne metallisehgriun, von der Seite besehen weißlieh bereift; Gesicht weiligran. Fiilıler rotgelb, das dritte Glied selıw:ır. - Hinterleib an den Seiten weiß gefleekt. Hypopygium groß, diek; Anallamellen seliwarzbrann, vorne abgerundet, halbkreisförmig, naclı tler einen Seite hin sichel. lïmig verliingert und auf der andern Seite mit langen Borstenhataren (Sehiner sagt, die Anhänge seien schneckenförmig ausgezogen). - Beine gelb, jedoelı die Hiiften nnd $\% / 3$ der Sehenkel selıwarz. Vordersehienen auf der Mitte spindelformig verbreitert und verdunkelt. Mitteltarsen (Scliner spriclıt von Hintertarsen) mit lippig verbreiterten zwei

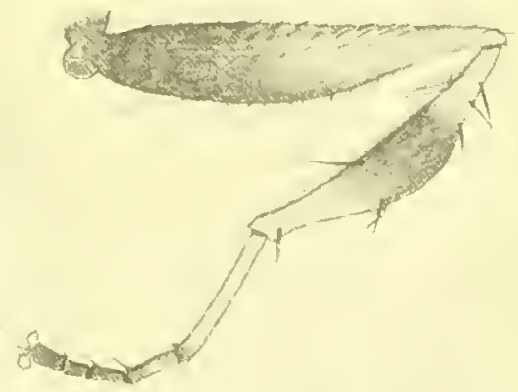

Fig. 2t. Vonderbein, Tachytrechus pteropodus sinkit. O'. $12: 1$.

Sirin.

ersten Tarsengliedern und lanw beborstetem diinnen dritten Gliede (s. Figuren 25, 26). - Fliggel granbrann mit verdicktem ersten lianladerabsehnitt; hintere Querader nebst Fliigelbenle gebriunt. $6 \mathrm{~mm}$ lang.

Ein Exemplar (Type) in der Sehinerselen Sammlung. Wiener llofunseum.

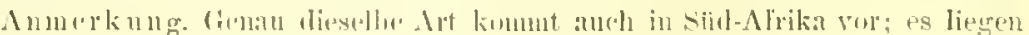

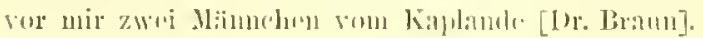


11 volitans Meland. ơ, Canad. Entomol. XXXII 143. 9 f. \$ (1900)

Anerica sejt.

Eine dureh ilren Fligelspitzenflecken bestimmt gekennzeichnete Art; ich gebe beifolgend eine Zeichnung des Fliigels.

Ein Exemplar aus Texas in der zoologischen Sammlung rles Wiener IIofmuseums.

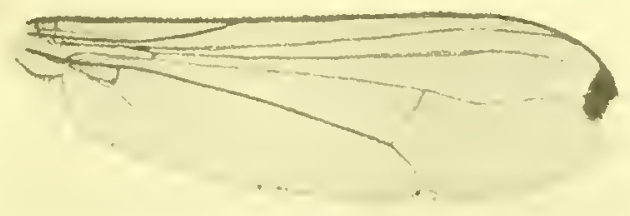

Fig. 27. Flügel. Tachytrechus rolitans Meland.

$$
\text { ก. } 12: 1 \text {. }
$$

$12 \operatorname{arax}$ Lw. ơ $q$, N. Beitr. VIII 41. 2 (1861) et Monogr. Dipt. N. Aner. II 112. 2. tab. III fig. 6 a, e, e (1864). . . . America sept. et merir. Im männlichen Geschlecht ebenfalls durch die hesondere Fliigelzeichnung charakterisiert (s. Figur 27).

Sieben Exemplare ans Peru-Cnzeo $9400 \mathrm{~m}$ hoch, V. 1905. — aus Peru-Calca, VIII, 1903. - aus Peru-Uiubamba, $3000 \mathrm{~m}$ hoel II. 1906 [Schnnse]. Samml. des Dresiner zool. Mus.

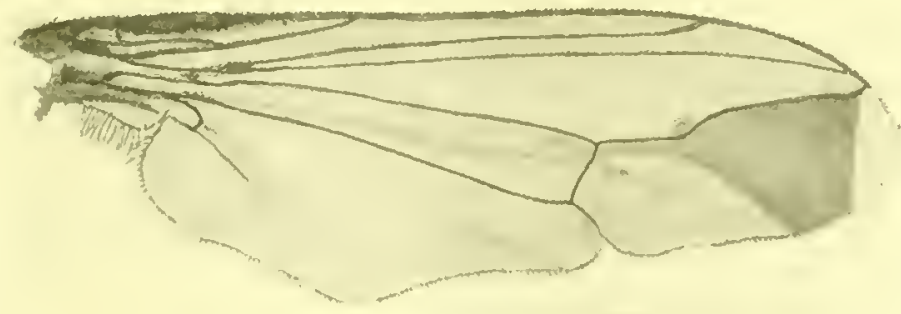

Fig. 28. Flitgel. Tachytrechus vorax 1,w. ఠ. 18:1.

Finf Exemplare aus 'Texas. Sammlung des Wiener Hofmuseuns.

\section{Polymerlon.}

Subgenus von Tuchiftrchus Walk.

0. Sack., Bull. Lnit. Stat. ('eulug. Surv. 111317 (1877).

Type: flabllifer O. S.

Die heiden IIanpteigenschatten, auf welche Osten-Sacken l. c seine Gattung begruindet hat, sind: 
1. das weit iber den Unterand der Jugen hinaus bandintig verlingerte Gesicht mud

9. die licherförmige Gestalt der wit langen Zilien versehenen Schiip]elien, die beim $\sigma^{7}$ sehr dentich, beim, weniger dentlich in die $\mathrm{Er}^{-}$ scheinung treten.

Beim Weihchen reicht das Gesicht gewöhnlich nn' bis zur Unterkantc Ier Augen, bei zwei der hekannten Arten allerdings anch dentlich weiter nnd die Schiippehen sind ganz oder fist ganz normal. Letztere Eigenschaft rer Sehijplueh ist aber anch nur einem Teil der bisher nnter Polynedon genanaten Arten $\left(\sigma^{7}\right)$ eigen, dem Aldrich gibt in den Biolog. Centr. Amer. I :33: (1901) an, daß von den ihm bekaunten finf Arten zwei sich durch hesondere Entwicklung der Schiippehen anszeichnen, gleichzeitig aber aluch noch dureh eine grolie sehwarze Sehwiele am Fliggelvorderrande, welehe fist die ganze Wurzelzelle ausfiillt; die iibrigen drei Arten zeigen nur diss verliugerte Gesicht und enthehren der anderen beiden Merkmale ganz oder last ganz und siud, wie Aldrich dies selbst ausspricht, im iibrigen ron der Gattung Tachytrechus nieht zu trennen.

Die Versuchung, diese drei Arten als Subgenus abzutrennen, liegt nahe, jedoeh möchte ich nicht dazn laten; sehr leicht kinnte eine nene Art entrleckt werden, bei der eins der fehlenden Merkmale vierler vorkime und man miißte dam ron nenem schematisieren. Der Anregnng von Alrich folgend, diese drei Arten zu Tachytrechus zu stellen, whirde anch weniger passend sein, denn dadurch wiirde der soust so einheitliche Chalakter der Gattung zerstört werden. leh lasse daher diese Arten hei Polymedon; allerdings wird dadureh das unterseheidende Gattnngsmerkmal beschrankt bleihen anf das nach muten hin verlingerte silberweiße Gesicht. Man wirr aljer hier nieht sagen können, daß diese Gattung lediglich anf ein männliches Geschleehtsmerkmal anfgebant sei, denn wir kemen schon zwei Weibehen, bei denen das Gesicht ebenfalls erhehlich his nuter die Angen verlingert ist (castus Wheel. und nimins Aldr.). Zwei Weibchen sind iiberhaupt noch nubekannt. Immerhin kam diese Gattung nur als Sulggenus von Tachylrechus Walls. hewertet werilen.

Die bis jetat bekannten Alten stammen ans Nord-Amerika, Mexico, Zentral-Amerika nnd Siid-Amerika.

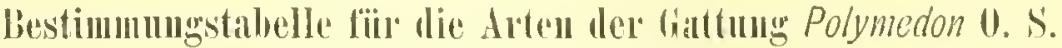

1 Schenliel schwarz.

schenkel gelb

2 Fithler schwarz, auf ler Tnterseite rotgelb. Beine bis anf die linice der vorderen Schenkel ganz schwarz. Anallamellen sehwarzbram, sichelförmig. Erster Randarleral,schnitt mit breitem sehwarzen Stigna. $4 \cdot 5-5 \mathrm{~mm}$ limg

flabellifer $0 . \mathrm{S}$. of 
Fiiller gan\% schwa\%, Hiiften unl sichenkel sehwarz; Krnice, Sedienen mul ein Teil der vorderen 'Tarsen gelb. Anallamellen weißlich, von dreicekigrer Form. Der erste Randaderabsehnitt nur sehr wenig geseluwollen. $5 \mathrm{~mm}$ lang . . . . . . . . aryentatus Aldr.

Fiiluer ganz schwar\%. Hiiften und Sehenkel scluwarz; Kniee nud die Suhienen bis anf deren Spitze rostgelb. Tarsen ganz schwarz; Vordertarsen schwach verbreitert. Erster Abschnitt der Vorderrandader auf der Mitte verdickt. 4 mu lang. . . . longifacies 11. sp. of

3 Das Mämnchen mit starker Verlickung in ersten Ramdaderabschnitt.

Beine mit einem Teil đler ersten Tarsenglieder gelb. Anallamellen gelb, verlaingert, zweiteilig, an der Spitze brann; das mit spit\% verlïingerten Gesicht. $5.5 \mathrm{~mm}$ linğ. . . . . nimins Aldr. O'o Fliigel ohne nennenswerte Verdickung an der Vordermalader . 4

4 Füller gelb, Spitze des dritten Gliedes branı . . . . . . . 5

- Fiiller schwarz, erstes nnd zweites Glied unten gelb. Beine fast gauz gell, Hiiften anf der Vorderseite silberweiß bestaubt. Gesicht his mutel den Angenrand hinaus verlingort. $5 \mathrm{~mm}$ lang . custus Wheel.

5 Anallamellen gelb. Klein, dreicekig. $5.2 \mathrm{~mm}$ lang triangularis Aldr.

Allallamellen sehwarz, grok, rantenförmig. 4-5 mm lang . superbus Aldr. ó

\section{Artrerzeichnis mul Beselureilumg.}

1 flubellifer O. S. OT, linllet. Unit. Stat. Geolog. Snrv. III 317 (Western Diptera) 1877. . . . . . . . Aueriua sept.

ふ๋. - Thoraxricken schwarggriin, anf der Mitte zwisehen den Dorsozentralborsten eine silberweiße striemenförmige Bereifung, die allerdings nur in gewisser Richtung wahrnehmbar ist; Akrostikalbürstehen fehlen ganz. Selwinger und Sehijppehen seluwarzhrann, letztere mit laugen schwarzen liesen-

förmig zusammengeschlos senen Borsten. - Kopf: Stirne rerhiltnismäßig schmal mitSilberschimmer; Gesicht silberweil), glcich breit, so breit wie ein halbes Ange, stark nach unten bandfölmig' verlängert. Fiibler schwarz, anf der Unterseite rotgelly.

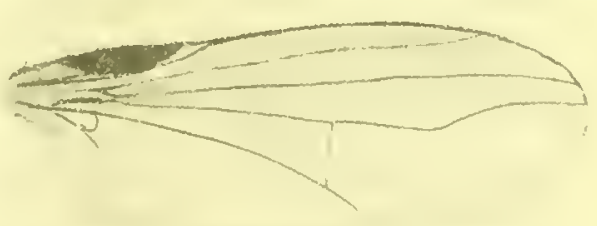

Fig. 29. Fingel. Tolymedon flubellifer 1). Sack. ก. $12: 1$.

llinterleil, selwarzgrian; llypolyg dick, ungestielt mit sehwarzhaunen, sichelfümig abgerundeten schwach behataten Anallamellen. - Beine sehwar", Knice der vorderen Beine gelb; Vordertarsen ein wenig ver. breitert; Behorstung der Selsicnen mäßig. - Fliigel granlich; die vierte Lïngsalder konvergiert nicht erheblich mit der dritten, dic hintere 
Qnerader steht sehr steil; in der Vorderandzelle liegt eine große sehwarze Schwiele. $4-5$ mum lang.

Akrostikalbörstehen sind rorhanden. Gesicht gran, 1 Exemplar in der Samml. des Dentseh. Entom. Mus. (Type von Osten-Sacken). $1 \sigma^{7}$ desgleichen aus Kalifornien in der Sammlung des lierliner zoologisclien Museums.

2 nimius Aldr. ठ7f, Biolog. Centr. Amer. Dijt. 1 334. 3. Tah. VI, fig. S, Sa-c et 9 (1901) . . . . . . Mexico, Ameriea merid.

§. - Thoraxrïeken metalliseh griin mit Akrostikalbörstchen und einem schwachen violetten Mittelstreifen. Schwinger und Schiiplpehen gelb, letatere mit hraunem Rande und starken besenformig zusammengesehlossenen Borsten. - Kopf: Gesieht silberweiß, um dic doppelte eigene Breite nach nnten hin ibber den Angewand verlingert. IIinterleib erzgriin; das Hypopygium groß, etwas gestielt; Anallamellen gelb, an der Spitze braun, verlingert und in zwei Teile gespalten, von denen der eine mit einer Reihe lingerer Haare besetzt ist. - Beine und Hüften fast ganz gelb, 'Tarsen mit Ansnahme eines Teils der ersten Glieder schwarz; mittlere Tarsenglieder etwas gebogen, mit einem krallenförmigen Organ. - Fligel sehr lang und schmal, selıwach gebrä unt; in der Vorderrandzelle eine lange schwarze Schwiele; hintere Querader fast senkrecht zur vierten Laingsader. $5.5 \mathrm{~mm}$ laug.

o Das Gesicht ist weifgrau und endigt in eine Spitze etwas unterhallı der Augen.

2 a as Columbia, Sierra s. Lorenzo [Ujbelyi] Samml. des Ungar. Nat. Mus.

$\therefore$ cryentatus Aldr. $\sigma^{7}$, Biolng. Centr. Amer. Dipt. I 334. 2. (1901) Mexico

ð. - Thoraxriicken dunkelgriin. Schiijppehen gelb, dunkel gerandet mit schwarzen, an den Seiteneeken weilien Zilien. Untergesielit silherweiß, fast um das Maß der Breite unter den Angenrand verlingert. Fiihler ganz sehwarz. Hinterkopfzilien (?). Auallamellen sehmutzig weif an der Wnmel, schwarz am Rande. Beine und alle Hiiften schwarz; Ḱniee, Sehienen und die Wnrzel der Vorder- sowie der Mitteltarsen gelb. Die Vorderrandader ist im ersten Absehnitt nul wenig verdickt. etwas stiilker an der Miindung der ersten Liingsader, von wo ans sic allmäblich an Dicke abnimmt. $5 \mathrm{~mm}$ lang.

4 triangularis Aldr. O7, Biolog. Centr. Amer. Dipt. I 335. 4. (1901) Nexieo

$\sigma^{7}$. - Toraxriicken griin. Sehüppehen gelb, Zilien braun. Untergesieht nm mehr als seine groilite Breite unter den Augenrand hinab verlängert. Fühlel gelb, drittes Glied an der Spitze bram; Hinterkopfzilien weif. Anallamellen klein, gelb, dreieekig, sehwarz gerandet, an einer Seite mit einem runden Ausschnitt. Beine und Vorderhiften gelb; Metatarsen der Vorder- nud Mittelbeine ron der Spitze an und die Hintertarsen schwarz; an zweiten und dritten Gliede der Mlitteltarsen eine kriimmung und ein krallenfiirmiges Organ; älmlieh aber kleiner 
als bei nimius Alur. Die Fliigel sind lïngs der Adern etwas gebrïunt, olne nenneuswerte Verlickung. $5.2 \mathrm{~mm}$ lang.

5 superbus Aldr. $\sigma^{7}$, Trans. Ent. Soc. Loudon 111318 (1896) Westindien

ơ Der Art triangularis ihnlieh, abweichend durch andere Anallamellen; siehe die ausfiuhrliche Beschreibung bei Aldrich l. c.

(f) castus Wheel. Procecd. Caliform. Acad. Sc. S. Francisco 3. ser.

Zoolog. 1. Nr. 4 S. 6, 7 (1897) . . . . . . . America sept.

૧. - Thoraxriicken griin mit weißer Bereifung. Zilien der teynlce schwarz. Fühler schwarz, erstes und zweites Glicd unten gell); das breite silberweiße Gesicht reicht fist um dic Gesichtshreite unter den Angenrand hiuab. Beine und Vorderlitiften gelb; silberweils bereift. Fligel ohne Verdickung. $5 \mathrm{~mm}$ laug.

7 longifacies $11 . \mathrm{sp} .07$.

America merid.

o. - Auf dem Toraxriicken wird dic metallische Grundfarbe durch eine dichte graugelbe Bestiubung verdeckt; die beiden dunklen Mittellinien sind wenig deutlieh; iiber der Fliigelwurzel kommt dic Grundfarbe zum Vorschein, anch die beiten Seiteneeken des Schildehens sind weniger bestäubt, so dali sic braun erscheinen. - Kopf: Hinterkopf nnd Stirn braun bestäubt; Gesicht oben schmutzig weiß, unten mehr rein weiß und nach unten ïber dic Augenecke und den Riissel hinans noch fast um die Gesichtsbreite verlingert. Fïhler ganz schwarz. - Hinterleib glänzend kupfergriin, an den Seiten weiß bereift. Hypupyginm schwarz, dick, anf der Wurzelhälfte grau bereift; iußere Lamellen sehwarzbramn, etwas dreieckig bchaart. Pennisseheide gebogen ohne Zaeken. - Beine: Hiiften und Schenkel sehwarz, Kiniee und Schicnen bis auf deren Spitze rotgelb; Hintersehenkel nur mit einer l'räapikalen; Hinterschienen auf cler Mitte der Hinterseite mit zwei flachgedriickten Borsten. Tarsen schwarz, das erste Glied der Mitteltarsen an der Wnrzel rostgelb. Vordertarsen schwach verbreitert, nicht breiter als die Sehiene. - Fligel sehwach braungran gefirbt; bintere Querader grade, kaum etwas gebräunt, auch dic Fliigelbeule ist kaum merklich dunkler. Randader im ersten Abschnitte auf der Mitte rerdickt. $4 \mathrm{~mm}$ lang.

1 Exemplar aus Chile, Palpa. 15. X. 1902 [Schnnse] Samml. des Dresdncl zoolog. Mus.

\section{Mrecellocerus.}

Mik, Dipterol. Unter'such. 5. 1111. (1878).

Tachytrcchus \%. ‥ Auct.

Mik errichtete diese Gattung anf' T'achytrechus mocchus Lw. aus Nord Amerika und gab als Unterschiede von Tachytrechus an:

1. dic Fiiblerbildung: erstes Glied vergrößert, zweites schr verkleincrt, rudimentair, drittes klein mit langer zarter Fiiblerborste, die an der Spitze schanfelförmig verbreitert ist. 
z. die nur mil einer Priapiliallhorste versehenen llintersehulkel. Im iibrigen sei llabitus und Gesichtshildung wie hei Trachylrechus.

ron diesen heiden Merkmalen ist das zweite nicht stichlualtig. Mik hate die palaearktisehen Arten im Auge, als el die etwas alweichende l'ripikallhorstenbildung erwïhnte; el wulite nieht, dab die meisten amerikanisehen Tachytrechus-Arten nur eine Priapikalborste liesitzen und dali dies daher kein unterseheidendes Gattungsmerkmal bei Hucellocemus sein kann. Es bleibt daher als Unterschied nur die Fiihlerhildung bestehen, clie aber meiner Ansieht naeh aueh ausreichend ist, un die Aufstellung der Gattung zu begriinden, selhst wemn man sie nur als Untergattung bewerten will.

bei Tachylrechus ist das erste Fiihlerglied von g'ewöhlieher Grißße, auf der inneren Seite zipfelfömign verlingert, im ganzen umgekelnt kegelförmig, an Rande nit ein paar Börstehen und auch auf der Oberseite sehwaeh behatart oder heborstet; bei Macellocens ist das erste Glied verlingert, walzenfirmig verdickt und anf der Oberseite meist kappenförung vortretencl, auch fast auf allen Seiten kräiftig beborstet, es ist also wesentlich anders geformt als bei Tachylrechus. Das zweite Fijhlerglied ist bei beiden Gattungen zwar ron gleieher oder ähnlicher Form, bei Macellocerus aber so zusammengesehrumpft, dali es fist verschwindet und liäufig nul noch dureh zarte Randbörstehen am dritten Gliede sich bemerkhar macht. Das dritte Fiiblerglied hat ebenfalls bei beiden Gattungen eine runde Folm, mituntel etwis nierenförmign unl herabuäingend. Die Filhlerborste hat hei beilen Gattungen zwei Glieder, ein kiil'zeres dickes Wurzelglied nud ein lingeres Endglicd; bei Maccllocems ist letuteres anferordentlieh rerliugert und an der Spitze verbreitert; es ist nuter dem Mlikroskop keine 'Teilung dieses Endlıorstenteiles von der Endlamelle zu sehen, selbst bei der Art binodudus, welche zwei Lamellen anfzeigt, besteht die Fiiblerborste mit beiden Lamellen nur aus e inem ungeteilten Stiick. Diese Gattungsuntersehiede bei der Fihlerbildnug setzen sich meiner Ansicht nach aus zwei Teilen zusammen: einmal in der wesentlich anderen Form des ersten Fiillergliedes nebst starker Beborstung und zweitens in der anderen Fiilulerborstenendigung.

Die Kopfbildung ist in ibligen wie bei Thelutiechus. Das Hypopyg hat bei allen Arten eine einheitliehe Bildung; es ist grof, dentlich gestielt und hat annihernd kreisförmige iinßere Analanbinge mit schwaeher Randbeborstung. Die Beine sind kriftig, alle Sehienen stark beborstet. Die Fiugel sind durehaus in Charakter ron Tachylrechus.

Mdrieh hatte im Jahre 1896 in den Transact. Amer. Ent. Soc. XX111 81 Nik's Gattung NTucellocerus anerkannt. Melander in The Canadian Entomol. XXXIl 144. 1900 glaubt, daß kein verninftiger Grund zu einer Tremung von Tueluylrechus vorbamlen sei, und Aldrieh hat dann später 1905 in seinem Katalog, wahrseheinlich ron Melander heeinfluft, die Gattung Mucllocerus als Synonym von Tuchulrechus anfireführt. Melander spricbt 
1. c. nur von cincm einzigen Unterscheidungsmerkmal, in dem er Fühler form und liorstenendignngals cin Merkmal zusammenfaft; daun argumentiert er su, daß man keine Gattmo mur auf e in mämnliches Geschlechtsmerkmal anfrichten solle.

lel bin nicht abgeneigt, dieser Anflassung Melander's im allgemeinen zuzustimmen, aber da es lieine Regel ohne Ausnalme gibt, sielıe Polymedon O. s. u. a., so wird es auch hier der Fall sein; die amerikinischen lintomologen sind von dieser liegel wenigstens mehrfach abgewielıen, icls will nur erinnern an die amerikaniseben Gattungen Leptorhchm, Leptocorypha und Sarciones Aldr. In dem mir voriegenden Falle handelt us sich aber nicht um ein einziges Merkual, sondern, wic ich glanbe nachgewiesen zu haben, um deren zrvei und da diese beiden Untersehiede bei allen bekannten fünf Arten auftreten, so halte ich die von Mlik vollzogene Abtremung fiir gerechtfertigt, mag man die Gattung un als cine vollberechtigte oder um als Untergattung ausehen.

\section{liestimnnugstabelle fïr die Arten der tiattung Macellocerus Vik.}

\section{Il ailunchen:}

1 Zilien des Hinterkopfrandes unten gelb . . . . . . . . . 2

Zilien des Hinterkopfrandes schwarz. Fïlıler gelbrot; Endlunelle der Fiihlerborste oval, sehwarz, die äußerste Wurzel derselhen weif. lieine gelb, Hintersehenkel an der Wurzel sehwarz. Vordersehienen auf der Vorder- und Außenseite mit einer Borstenreibe. Fliigel furblos; hintere Querader schrige gestellt und grade. 5-6 mm lang

sanus 0.5 .07

2 Fiihlerborste nur an der Spitze mit ciner flachen Endlanclle . 3

- Fiilılerborste auber der Endlamelle noeh mit einer oralen sehwarzen Jamelle auf der Mitte. Fỉhler rostgelb. Gesicht gelbweiß. Hypopygium mit zwei schwarzbratuen runden Lamellen. Beine gelb; Torderschenkel kriftig; Vorder- und Mitteltarsen seln kul\%, ron nur $2 / \%$ der Lïnge ihrer Sehienen, Ilintertarsen so lang wie die Sehiene. Flïgel gell, Jrïunlich, hintere Querader stark nach einwïts gebogen. 7 mm lang limodatus Lw. o

3 Beine gelb; Vordertarsen etwas tlachgedriiekt, zaut weif bereift. Fiiller gelb, drittes Glied an der Spitze braun. Gesicht mattgell): Endlamelle der Fiblerborste selowarz, an der äußersten Wurzel weiß. Hypopygium sehwarz, Anallamellen gelb, schwarz behaart. Fliggel pratulich. $6 \mathrm{~mm}$ lang. . . . . . . . . . mocchus Lw. O

lieine gelb; Vorderschenkel an der Wurzel stark verdickt, mit einem großen sehwarzen Flecken anf der Aulenseite, Tarsen schwarz. Vordcrund Mitteltarsen kïrzer als ihre Schiene. Fuilıler rotgelb, drittes Glied oherseits sclwarz mit weilier Borste; Endlamelle ganz schwarz. Gesicht mattgelb. Hypopygium schwar, gesticlt, Anallamellen blalfgecelb, 
rmulich mit zartel Behaarung. Fligel yraulich; hintere Querarier selwwach S-förmig gebilklet und etwas angeräinchert. 6-7 mm lany (Mympiac Aldr. of

- Beine gelh mit goldgelber Bereifung; Vorlerschicne und Vordertarsen glejeh lang, heide etwas gesehwollen. Fühler rotgelb, drittes Glied braun, sehr klein. Gesicht matt goldgelb, his unter den untersten Augen. raud efwas verlingert; Fiihlerborste schwarz, dieht vor der Endlamelle reif, Endlamelle fast dreieckig, ganz seluwarz. Hypopygium schwarz, Allallamellen kreisförmig, hellgelh, schwach behatrt. Fliigel fast farblos; hintere Queraler wenig schrige, grade. $4 \mathrm{~mm}$ lang

\section{Weibehen.}

auratus Aldr. o

1 Hinterkopl'zilien weißgelblich . . . . . . . . . . . 2

Hinterkopfzilien schwar\%. Gesieht weil. Miiften und die Sehenkel an der Wurzel bis nahe zur Spitze gesehwärzt; Schienenendhälffe nud Tarsen desgleichen. Flijgel farblos; hintere Querader etwas selnaige, grade und ohne Brïnnung. . . . . . . . . sams O. S. ठ

2 Fiihler rot, drittes Glied mehr oder weniger braun. Gesicht lell gelb. gran. Fliigel granlich. . . . . . . . . . . . . 3

3 IIiiften und die Sehenkel bis $z{ }^{2 / 3}$ sehwiirzlieh. Vordertarsen von $2 / 3$ der Sehienenlänge. Vorderhiiften und Sehienen vorne weißlich bereift; hintere Qnerader stark nach einwïrts gehogen. binodutus Lw. 우

- Hüften und die Schenkel an der Wurzel geschwärzt. Hintersehienen an der Spitzenhälfte und alle Tarsen schwarz; hintere Querader etwas selurige, S-förmig und selwwirzlich gefleckt . . Olympiue Aldr. f

Hiiften und die Sehenlicl bis nahe zur Spitze sehwarzgrau bis schwarz. Vorderschienen gelbbraun, die hinteren Schienen und alle Tarsen schwarz: hintere Qnerader grale und nicht schrige gestellt . mocchss Lw. f

Das Weihchen auratus Aldr. ist noch mbekannt. Bemerkenswert ist lee diesen viel Weibehen, dab sie alle namentlich in der Beinfürbung dunkler gefiubt sind als die Minnchen. Da eine solche Verdunkeluma gegen die sonst ïbliche Regel verstöht, so kann man bierin vielleicht auch ein sekundiires Gattungsmerkmal erblicken. Die Art moechus Lw. habe ich nicht gesehen, die anderen Arten konnte ich dank der Liebenswiirdigkeit vou Melander vergleichen. Die Weibehen sind an der Farbe der Ilinterkopfzilien nud an der Stellung der hinteren Querader leicht zu unterscheiden.

\section{Altremeichnis.}

1 auratus Aldr. O', Trans. Amer. Enton. Soc. Philadelphia XX111 83 (1896)

America sept.

-) binodatus Lw. כ 5 , Berlin. Entom. Zeitsehr. X 46. 84 [Tachytrechus] (1866)

Ameriea sept. 
3 moechus Lw. O̊o, N. Beitr. VIll 40.1 (1861) et Monogr. Dipt. N. Amer.

II 110. 1. tab. III tig. 6. b, d. [Tachytrechus] (1864). America sept.

4 olympire Aldr. ơ 9 , Trans. Amer. Entom. Soc. Philarlelphia XXI1l 83 (1896) . . . . . . . . . . . . America sept.

5 samus O. Saek. ơ , Bullet. Unit. Stat. Geolog. Surr. III 316. 2 ['Tachytrechus] (1877) . . . . . . . . . . . America sejt.

DaB ich die Art $P$ 'araclins riscifer Aldr. in Verdacht habe, ein Macellocenss zu sein, habe ich bereits bei dieser Gattung hervorgeloben.

Beideransführlichen behandlung der Arten und iluer Figensehaften in der Bestimmungstabelle und angesichts der vorhandenen guten beschreibungen eribrigt sich ein spezielleres Eingehen auf

Fig. so. Kingl' von vorne. Macellocerus olymping Aldr. $\sigma^{7} \cdot 18: 1$.

die Eigenschaften dieser Arten an dieser Stelle.

Macellocerus scheint nurin Nordamerika vor\%ukommen, wenigostens ist noch keine Art ans Siidamerika luekimnt geworden. Sollte Puraclins discifer hierher gehiren. so wire die Verbreitung der Gattung bis nach Zentralamerika gesichert.

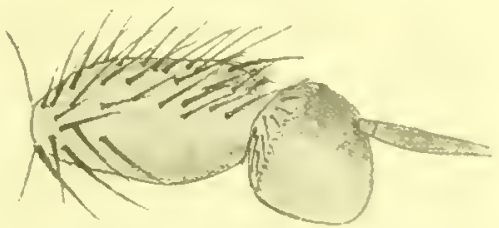

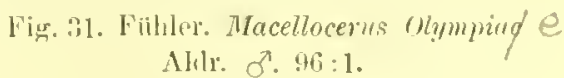

\section{Psilischium.}

Novum Geuns Dolichopotinarum.

Fim wexón mackt nund isyiov Hiilte.

Diese Gattung hat ganz das Aussehen einer Dolichopodine. Hinterleib und Ilypopyginm erinneru an T'achytrechms und l'avachins, der liopf an Macellocerus; die Mittelschienen zeigen deutlich den Borstenkranz ron fiinf Borsten; die Fihler sind jedoch auch am ersten Gliede ganz naekt, am Kopfe und an Thoraxriicken fehlen die gewöhnlichen Borsten nud die Hinterhiiften sind borsten- und harlos. Trotzdem kann diese Gattung nur bei den Dolichopodinen eingestellt werden, wenn man nicht eine besondere Gruppe dafiir errichten will, wozu meiner Ausicht nach jedoeh geniigender Anlaß nicht vorliegt. Befrendend anf den ersten Blick ist nur die Kahllueit des ersten Fühlerglierles. Gerade das behalatsein dieses ersten Glierles war von nus bisher nul imnerhalb del paläarktisehen Zone mit voll- 
kommenen liechte als ein IIanptkriterinm fiir die Abteilung der Dolichofudince angeselien worden. Wem dies Merkmal uns nn im vorliegenden Falle in Stieh liißt, so ist meiner Ansleht nach das Felılen der kuren bïrstelien hier nicht in der iiblichen Weise zu bewerten und als ausschliggebend anzusehen, weil anch der ganze Thorax, Hinterleib und Kopf so iiberans liall sind; die sonst stets vorhandenen Borsten sind hier $7 \mathrm{~mm}$ Teil bis auf kurze bürstehen oder Hïrehen, dic man mit der Lupe erst snehen mnB, verkïmmert; anch auf lem Kopfe sind die beiden Borsten des Punktaugenhöckers sehr selwach und die Scheitelborsten fehlen beiu ร ganz. Hinterleils und Hypopygium sind ganz im Charakter der Dolichopodinae, ebenso die Beinbehorstung und die Fligeladermg. Mehrfach zeigh sich uns, daß die fiir unsere paliiarktischen Gattungen aufgestellten und siiltigen Merkmale in den anderen Regionen nieht die gleiche Giiltigkeit und denselben Wert besitzen, daß sie vielmelu in dem einen oder anderen Punkte alsweichen, olne daß es moiglich wäle, für diese Fornen eine nene Gattung oder Gruppe anfstellen zu kïnnen. So ist es anch hier; wil unissen diese Gattung trotz des Zuriickgehens der Behaurung anf dem ersten Fiilılergliede bei den Dolichopodinen belassen.

\section{Giattullgsbegritt.}

Kopf flach, hoch, aber breiter als hoch mit ganz glattem, bis zum Augenunterande herabreichendem Gesichte, das, unten abgerundet, fist ron halloer Angenbreite ist. Der Seheitel ist ein wenig vertieft und der Punktangenhïeker bis zur Augenhöhe erhoben, dieser mit zwei sehr selwwachen liorsten; es felılen die Seheitelborsten beim $\sigma^{\top}$, wihlend sie beim deutliclı ansgebildet sind. Die Eïhlel sitzen ganz oben an der Stirn, diclit rol' dem P'mktiugenhöeker, so hoeh wie bei keiner anderen Gattmg; alle drei Glierler sind ganz nackt; das erste Glied ist sehr unseheinbar, zeigt aher nach unten hin eine sehlanke zipfelfömige Verlingerung; das zweite ist deutlich becherformig; das dritte erscheint von der Seite :ms besehen, fast kreisförmig, ron rolne und von unten birnförnign nit langer diunner in eine ovale Lamelle endigender subapikaler Borste. 'Taster und liiissel gau\% unbedentend und wenig vortretend. Augen pubeszent.

Thoras: Akrostikalbörstchen sind zweizeilig vorhanden, jedoch sehr kurz. Dorsozentralborsten sind nieht ausgebildet; man sieht nur das hinterste l'alar, sunst in der Reilıe nur zarte Hïrehen. Zwei dentliche Sehildborsten. Minterleih und hypopygium ganz so wie bei Tachytrochers und Paractius, aber auffallend durch fehleule oder nur sehr kurze Beborstung wie der Thoraxriieken.

Beine: Ilinterhiffen ganz nackt, bei einzelnen Weibehen kimn man noch eine anberordentlich zarte Borste wahmelmen. Mittelschienen am Ende mit Borstenkianz von fiinf Borsten, im ibrigen ist die Beborstung ber Selienen weit schwaicher als bei Tachytrochus nud P'arachins. Bemerkenswert scheint mir eine Einzelhorste an der basis der Unterseite 
des Hintermetatarsus: die Hinterschenkel sind stark behaart. - Die liliigid sind nur sehmal, die vierte laingsaler macht anf der Mitte des letaten Abschnittes eine bogenförmige liegung und rerliuft sodann palaullel zml dritten, indem sie genau in die Spitze des Fliigels einmindet; sie nälert sich der dritten nicht anffïllig. weniger als hei Paraclius und iibnelt schon mehr der Fliigeladerung bei Lianralus.

1 laevigatum n. sp. o $^{\circ}$. . . . . . . . . . America merid.

5. - Thoraxriieken von metallisch blangriner Grundfarbe, aber durch griunliebbrame Bestiubung ganz matt. Ricken mit der oben angegebenen Beborstung; die Notoplenraldepression und cin Fleek iiber der Fliigelwurzel sind dentlich weifgrau bestiabt; in der Nïhe der Schulterbenle steben Zahluciche Humeralbïrstehen. Brustseiten blangrau bestiabt, die gelben Schiippehen schwarz bewimpert. Kopf anßerordentlich flach, etwas breiter als hoeh; das Untergesicht wird nach unten hin etwas breiter und nimmt etwa den vierten his fïnften Teil der Kopflneite ein; es ist anf der Mitte hronzefurhig bestäubt, unten mehr gelb; oben unter den Fiihlern kommt dic metalliseh blaue Farbe in einem Flecken zum Vorschem. Hinterkolf grau, an den Augenrindern weib bereift mit hellgelben Randborsten, ron denen nur ganz oben eimzclue schwarz sind. Die Fiiller sind hellrotgelb, auf der oberen Hiilfte schwarz mit langer schwarzer Borste; die schrarze Endlamelle von ovaler Form ist etwa su grob wie das dritte Fiihlerglied. Fibler und Borste zusammen biben die $1 \frac{1}{1 / 2}$ fache Hohe des Kopfes zur Lïnge. - Hinterleil, elzgriin mit dunklen Einsehnitten, Hypopyg groß, schwarz, mit großen rundlichen schwarzen, wenig beharten außeren Lamellen; die obere Penisscheide bat anf der Ilitte ihrer Unterseite einen kleinen dreieckigen Vorsprung mul ist an der Spitze etwas hakenfömig nach nnten gebogen; cin sticlfürmiges Organ ragt noch zwischen Hypopyg and Penisscheide herror; von den inneren Organen ist ohne Priparation niehts Bestimntes zu sehen. - Beine: Hiiften schwarzgrau, Spitze der Vorderbiiften nelst Schenkel und Sehienen gelb; Vorderschenkel gi'au bestiubt, :uf der Unterseite mit weitliufig reilıenförmig gestellten lellgelben Haren. Jittelsebenkel auf Aer Ober- und Unterseite sehr zart behart. Ilintersehenkel etwas verdickt, auf der Oberseite mit sehwarzen, anf der Unterseite mit blaligellien Haaren kriftig bekleidet (s. Figur). Die Vorderschienen sind an der Spitzenhialfte rerbreitert, au Ende sehriig albgeschnitten und mit zwei Borsten an der Seite, sonst ganz kilıl; diese breitere Endhälfte der .Schienen ist muldenförmig ansgehrihlt, gelb mit zwei brannen Riugen, die Mulde selbst mehr weif. Mittelschienen aulier einigen Einzelborsten an ler Wurzel mit zwei liorstenjartren anf der Mitte und zwci Einzelborsten auf del Unterseite. Hintersehienen mit zwei lieilien ron je vier Borsten an der llinteroder Oberseite und mit einer licihe rom rich feinen borsten anl der 


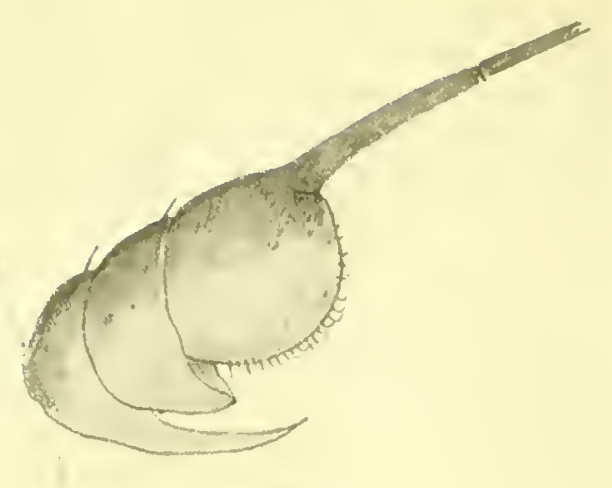

Fig. 32. Fühler. Psilischinm laevigatum Beck. 916:1.

Wurzelhäfte der Unterseite. Tarsen sehwar\%. Vordertarsen sehr kurz, das erste Glied auf der Mitte breit gello. - Fligel graubrïunlich mit der oben angegebenen Adermg (s. Higur 36). $4.5 \mathrm{~mm}$ lang.

Q. - Gesicht kiamu etwas breiter, gellggran liestiubt. Fiihlerborste etwas kiirzer, wenn anch an und für sich liinger als gewïhnlieh, ohue Endlamelle; anf der Stirne

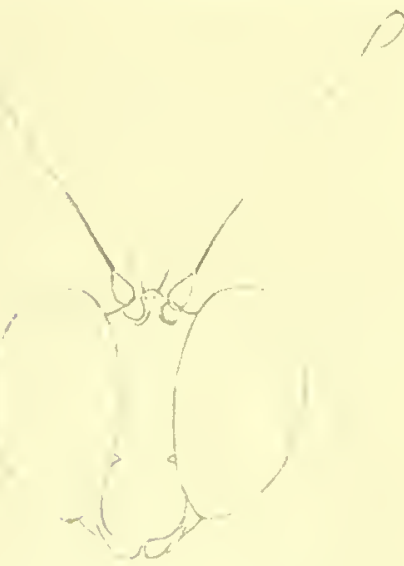

Fig. 33. Koplf vol vorne.

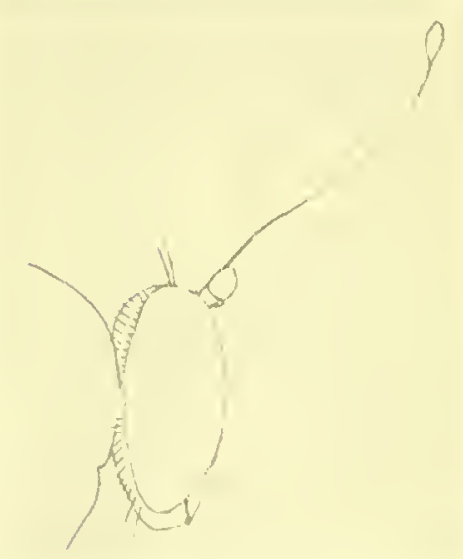

l'ig. 34. Kojt von der heite?

Psilischimm laevigutum Bock. 18:I.

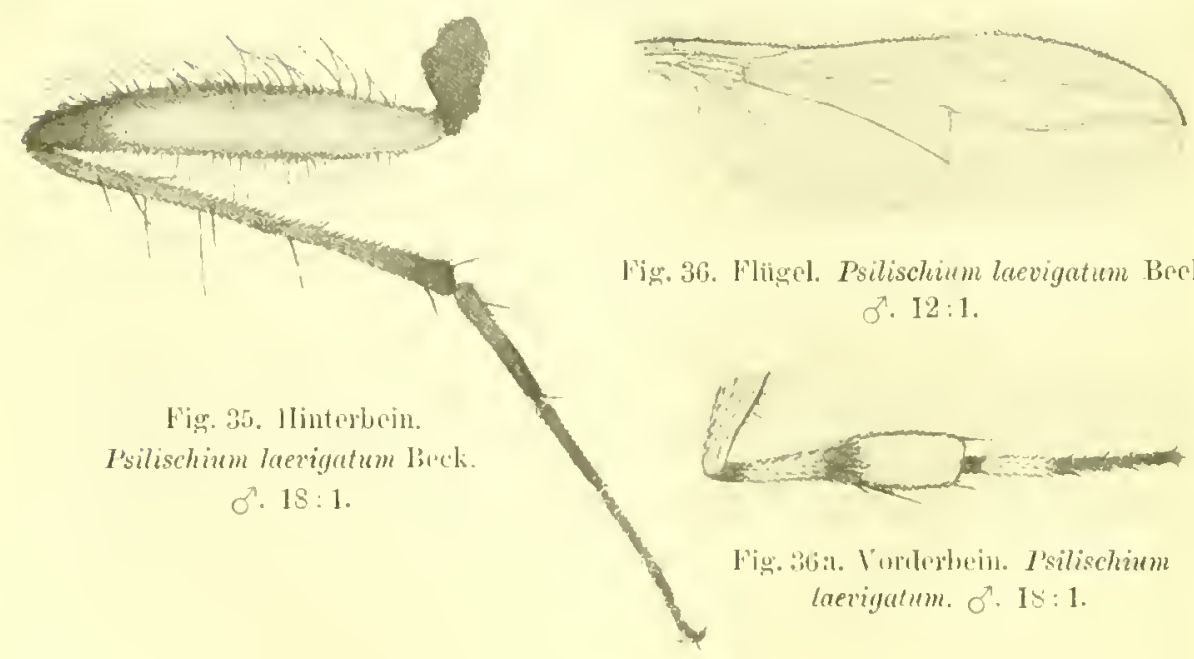


liommen zwei Scheitelborsten zum Vorsehein. Beine rotgelb, Vorder. und Hintersehenkel zum Teil bräunlieh, Schienen desgleichen, Tarsen schwarzbraun.

41 07. 16 의 aus Peru, Laristhal, $800-2000 \mathrm{~m}$ hoch. VIII. 1903 [Schnuse]. Samml. des Dresdner zoologiselien Museums.

\section{S!jbistroma.}

Meig. S. Beschr. IY 71. CXXIX (1824).

americana Schin. $\sigma^{7}$, Novara-Reise Dipt. 220. 28 (1968) . Brasilia

Thoraxricken metalliselı seluwarzhlan, vorue an den Seiten etwas grau bestäubt; die Notopleuraldepression intensir weiß. Schwinger und Schiippehen blaliggelb, letztere sehwaูrz bewimpert. - Kopf: Gesieht weißgrau, fast doppelt so breit wie das dritte Fiiblerglied, iilser dem Mundrande ockergelb gefiilbt. Fiihler rotgelb; drittes Glied selı kurz, abgerundet mit einteiliger langer Riickenborste, die auf der Mlitte eine sehmale lïngliche, an der Spitze eine lïnglichovale palettenartige Erweiterung hat; letztere ganz schwarz, ohne weiße Spitze. Hinterkopfzilien weiß. - Hinterleils erzgriin mit deutlich kreideweilen Seitenfleeken. Hypopyg linglichoval, ziemlich grob mit anschnliehen, fast kreisrunden roten Anallamellen, die einen breiten sebwarzbraunen Saum haben, der nur sehwaeh behaart, nicht geschlitzt und nieht beborstet ist. - Beine nit Vorderhiiften rotgelb, ziemlich nackt; Hintersehenkel oben an der Spitze mit kleinen, aber deutliehen sehwarzen Fleeken; auel an den Vittelselienkeln sieht man einen ebensolelien, aber sehwiieheren Fleeken; die Behorstung der Sehienen ist mäßig. Hintermetatarsus etwas kürzer als das zweite Glied. - Fliigel zalrt bräunlich, am Vorderrande stärker; die dritte Längsader ist selır wenig gebogen, der vierten von der Queraler al selılank S-förmig sich näherud; der zwischen beiden hiingsadern liegende Randaderabschnitt hat böebstens eine Länge, die dem vierten Teil der hinteren Querader entspricht; letztere steht senkrecht zur vierten. 5́ mı lang.

Ein Pireben in Schiner's Sammlung in Wiener Hofmuseum.

\section{Leptocor!/phea}

Akdr., Trans. Entum. Siuc, Lundon 315 (1896).

\section{liattungsbegrill:}

Diese Gattung hat Allrieh anf eine westindisehe Art gegriindet, die mit ihrem behaarten ersten Fiillergliede der Gruppe der Dolichopodina angelı̈̈rt; außerdem ist das erste Glied an der Spitze der inneren Seite etwas hornartig verlängert. Das dritte Glied ist groß und verlingert, trägt eine dorsale Borste und zeigt auf seiner Unterseite eine kurz belaante 
Fitze. Das Untergesicht ist nicht verlangert. Der Thorax hat die iibliche deutliche Beborstung der Dolichopodinen mit zwei Schildborsten; des weiteren zeigen sich in der Niihe der Sohulterbenlen Humeralbirstehen, die jederseits in einem dreieckigen lilerken zusanmengedriingt stehen. Ilinterleib kur\% mit starken Raudborsten; das Hypopyg ist gestielt mit kleinen Analanbängen. An den Beinen haben die Hinterhiften zwei Borsten. Die vierte Längsader zeigt in ihrem letzten Abschnitte eine krimmung und Aufbiegıng, welche die Nitte läilt zwischen der der Gattung P'elastoneurus und Paraclius.

An Besonderheiten zeigt diese Gsttung die doppelte Borste auf den llinterhiften und die besondere Form des dritten liilılergliedes. Es ist nur eine Art hekannt.

pavo Aldr. ơ, Trans. Entom. Soc. London 316 (1Sab) ans St. Tincent, Westindien

America centr.

\section{Gomionerrirm.}

Novam gaemus Thalichenpodinumem.

Yoll youros winklig und veüpor Ader.

\section{liatthugesehalialiter.}

Diese interessante Cattung rereingt in sich Eigensehaften der Cattungen I'lagioneme Lw. und Polymerlon O.S. Mit ersterer teilt sic die Fingelbildung, die eine etwas älnliche Adermong aufweist: die dritte Lingsader biegt stark nach when in len Fligelrand ab, weit stairker als bei I'lagioneums; der letzte Abschmitt der viepten Längsader uacht gleich hinter der hinteren Qnerader einen Knick und hiegt in stumpfem Winkel annälsemd parallel zur dritten liangsarter ebenfalls weit vor der Fitigelspitze in den Vorderand; die lintere Quevale ist banchig, fast parallel zum Hinterande. - Der Kopf hat ganz die Form ron P'olymedon, mit sehmalem, weit ijber den unteren Augenrand hinans verlingertem Gesicht. 'T'aster' schmal, mach beiden Seiten hin deutlich nach vorne hin abstehend. Die Fiihler stehen hoch oben an Kopre; das erste Glied ist behatart, das zweite querliegend, das dritte oval mit stumpfer. Spitze und nackter dorsaler Borste; die zwei Borsten aluf dem Punktaugenbicker sind stark, die Scheitelborsten sehr sehwall. Hinterkopf dicht an den dugenrändern ausgehïhlt. - Thorax mit sechs Dorsozentralhorsten und deutlichen Akrostikalbörstchen; am Schildrande stehen zwei starke Borsten; eine starke Prothorakalborste. - llinterleib mit seehs Ringen, von denen der letzte mur als Tergit alusgebildet ist. Dis Hylopygium ist fast olne Stiel, grof, unter den bauch geschagen mit zwei groben, dreieckig ovalen außeren Anhiingen, deren Rïnder stark behalart sind - Beine lang mit der gewoilnlichen Beborstung; Vorderbeine heim on etwas rerziert; an der Hinterhible eine lorste. Ilintcrmetatarks kiirm als das \%weite Glied. 
1 varum n. sp. o'. Zwei Figuren.

America merid.

ऽ. Thoraxricken dunkelblan mit griinen lieflexen, glinzend. Brustseiten und Notoplenralfurche nebst den Außenseiten der IIiften weiß, fast silberglinzend. Selıwinger helbgelb. Schiippehen sehmntzigbraun mit breitem schwazen Rande nud schwarzen Wimpern; anf der oberen Hälfte der Schiippehen stehen drei bis acht lange, anf dem hibrigen Teil kurze Wimpern; diese lïngeren Borsten stehen

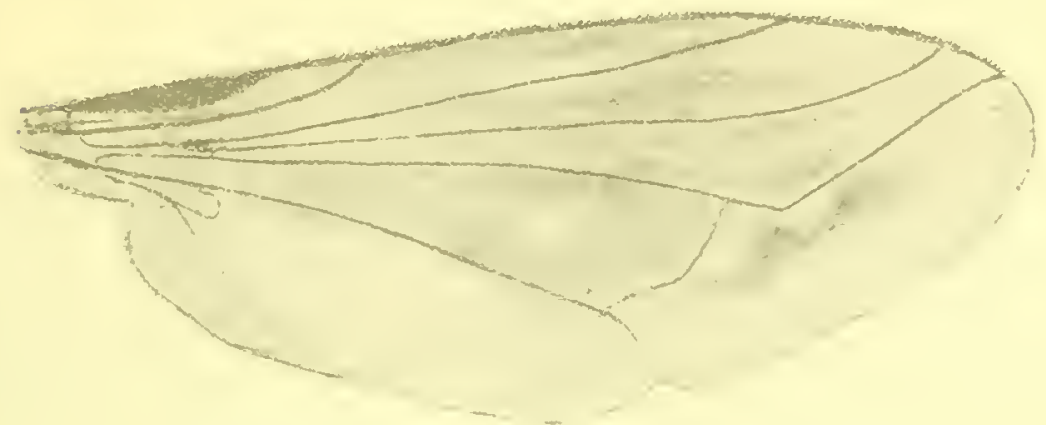

Fig. 37. Hligal. Gonionexmm zurm beck. $0^{7}$ 16:1.

dieht znsammengedringt, eine entfernte Reminiszenz an die Gattung. Polymedou. - Kopt: Augen sehr hoeh gestellt; Stirne dieht weiß bestäubt; Gesicht nur wenig breiter als das dritte Fiihlerglied, bis um die halbe AugenLöhe noch iiber den unteren Angenrand hinalggeführt, fast gleich breit bis zur spitze, silberweiß glinzend. Taster brann, fist nackt, ohne Borsten. Fiihler bruu, unterseits meln oder weniger rot. Hinterkopfrandborsten nuten weiß. Riissel nur von mäBiger Grölie. IIinterleib metillisehı schwarzgriin; llypopyg schwal'z mit schwar'zen :iıfieren Anliängen; son den inneren Oramen sind 7.ll selien zwei

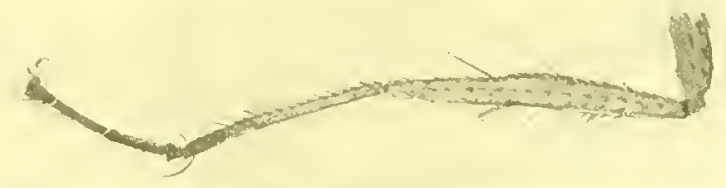
stiel- oder finger-

aihnliche mit lingerel Endborste und rou gelber Farbe. - Beine nebst Vorderhiiften blafigelb, Tarsen an der Spitze verdunkelt. Vorderschienen schwaeh spindelfurmig verdickt, auf der Oberseite mit einer lieihe feiner llatre, anf der Außenseite drei lingere kinzellorsten, auf der Unterseite deren zwei. Metatarsus stark verlängert, liinger als die vier folgenden Glieder, nnterseits kurz borstlieh lowimpert und an der Spitze mit einer besunderen Borste; das zweite Tarsengrlied verkiîrzt, kaum lïnger als lreit, das letrte ein wenig verlyreitert mit 
zwei großen weißen Haftliappehen, größer als an den iibrigen Beinen (s. Figur). Nittel- und Hinterbeine mit der gewöhnlichen Beborstung; Sehenkel ohne längere Behaarung anf der Unterseite. - Fligel bräunlieh gefärbt mit teilweise verdicktem Randaderabschnitt nnd mit einigen unregelmaßigen Flecken, wie angeriuchert (s. Figur). $6 \mathrm{~mm}$ lang.

$2 \delta^{7}$ aus Columbia, Sierra S. Lorenzo [Ujhelye]. Samml. des Ungarischen Nationalmuseums.

\section{Orthochile.}

Latr. Fen. Crust. et Ins. IV 289) D( LXXI [Orthochite] (I809).

Diese Gattung ist bisher weder in Nord-noeh in Siid-Amerika aufgefunden worden, obsehon Walker in List Dipt. Brit. Mus. III 667 (1849) eine Orthochile derempita aus Nord-Amerika besehrieben hat. Schon seine Erwaihnung der apikalen Fiihlerborste und seine Niehterwihnung eines verlingerten Riissels waren fiil Loew und sind anch ftir uns aussehlaggebend fiir die Annahme, daß Walker's Art keine Orthochile sein kann. Osten-Saken, der später die Type im Britischen Museum gesehen bat, hält sie für einen Chrysolus.

Da obige Art sowobl im Katalog Aldrich 1905, als anch im Katalog. Kertész 1909 noeb unter Orthochile genannt ist, so habe ich es nieht fiil iiberflissig gehalten, hier an dieser Stelle kurz das Tatsächliche nochmals zusammenzufassen. 


\section{Gruppe II.}

\section{Plagioneurinae.}

\section{Plugioneculus.}

Loew, Entomol. Monatssehr. I 43 (1857).

Wheol., l'roceed. Californ. Acal. Sce serie 3. Zool. I1 71. 71. tab. 11 tig. 105 (I899).

Diese merkwirdige Gattung, von Loew mur auf ein Weibchen erriehtet, ist uns dweh Wheeler I. e., der auch Hinnehen untersuchen konnte, etwas nähergeriekt worden. Wheeler gibt auch eine Profilzeiehnung rom Hypopyg, das im sechsten Ringe gauz eingebettet liegt. Ohne besondere Präparation läßt sieh so auch nieht viel erkennen; anffallend sind nur einige kammartig gestellte Randborsten und ein kleiner Sehopf von drei bis rier kurzen breitgedrijekten Borsten. Form nud Anlage der Hypopygialorgane sind jedenfalls außergewöhnlich und finden kein Analogon in dieser Familie. Aus der Sehnusesehen Sammlung liegt mir $10^{\circ}$ nebsi 2 o vor. Ieh kann nach Vergleichung nur. Wheeler Reeht geben, wenn er noeh einige andere Unterschiede zwisehen den Mannchen und Weibehen angibt; er findet sie in der etwas versehiedenen Grölie des dritten lihlergliedes, in der Gesiehtsbreite und in der Behaarung der Huften und Sehenkel; aber alle diese Jerkmale sind so geringfigig, dal es sehwer hiilt, sie iiherhanpt zn finden. leh kenue keine andere Gattung, in der der Gesehlechtsuntersehied so aufiallend gering zum Ausdruek gelangt wie hier, denn auch der Hinterleib des of hat eine stumpfe Endignng äbnlieh wie beim Weibehen. Um das Bild, welches Loew nud Wheeler gegeben, zn vervollständigen, will ieh hier noeh einmal ihre liemerkungen einheitlielı zusimmenfassen und hinzufïgen, was mir als bemerkenswert anfgefallen ist.

\section{(iattulugscharakiter.}

lletalliseh gefirbte größere Art. Fiinf paar Dorsozentralborsten, zwei Schildborsten; Akrostikalbörstehen fehlen in beiden Gesehleehtern; die iibrigen Thoraxborsten sind alle so vorhanden, wie wir sie bei den Gattungen der Dolichopolinae zu sehen gewohnt sind; Schippehen weil) bewimpert. Kopt etwas breiter als hoch; Gesicht breit, etwa den vierten Teil der Kopfbreite eimnehmend. Anf der Jitte des Gesiehts sehe ieh eine etwas erhabene, nael unten hin verbreiterte Leiste mit einer etwas vertieften Mittellinie; das ganze Gesicht ist dem Angenrande bolgend im Profil etwas nach außen 
hin gewölbt bis zum unteren Angenrande, eine Querteilung ist nicht ausgesprochen, sondern nur dureh zwei kleine seitliche Einschnitte angedentet. Das erste Fiblerglich ist nackt, umgekehrt kegelförmig mit ciner lappigen Verlingerung anf der inneren Seite; das zweite Glied ist quergestellt; dats dritte spitz dreieckig bis birnförmig mit nackter dorsaler borste; Taster mäßig groß, Riissel etwas sackartig vortretend; Kopfborsten normal. -

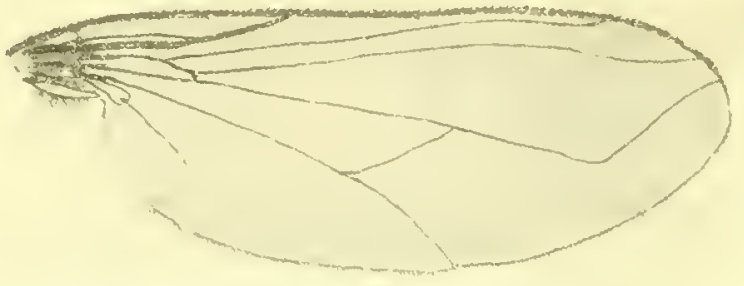

Fig. 39. Ftiiga. Plagioneums manitutus Lw. 14:1. Hinterleib mit sechs likgen; las Hypopy.y. ror dem stumpif ab. geschnittenen Eude kanm heranstretend wie oben geschildert. llinterleibsbeborstung schwacb. - Beine ziemliclı lang $11 \mathrm{ml}$ schlank; Hinterh iilten mit einer lBorste, l'rii-

apikalborste an den IJinterschenkeh rortunden, aber sehwach. Tordernnd Vitteltarsen länger als dic Schiencn. Ilintermetatarsus erheblich kiurzer als das zweitc Glied. Schienenbeborstung wenig cutwickelt und spinilich; am Ende der Mittelschienen zähle ich anstatt der fünf Borsten nur drei. - Flitgel von gewöhnlicher Form; hinsichtlich der Äderung siche heiliegende Fium. unicitlatus Lw. S Entomol. Nachr. I 43. (1857) et Nonogr. N.-Aucr. Dipt.

II 196. 1. tal).V'1, fig. $36(1864)$ et Wheeler e. c.

Hinsichtich der Forlong und Artmerkmale verweise ich auf obige Beschreibungen. Die Art ist itber Nold-und Siidamerika verheitet. W'heeler glanbt, daf diese in keine Gruppe passende Art ein Relikt ans friiheren Entwicklungsepuchen sei, was nicht unwahrscheinlich ist. Im Katalog Kertész VI ist mit dieser Gattung cine nene Gruppe gobildet; ich teile diese Ansicht. 


\section{Gruppe III.}

\section{Hydrophorinae.}

Wir kounten in der paläarktischen Region in dieser Cruppe 13 Gattungen unterscheiden und feststellen. Die hisherigen Forschungen in Amerika, die selbstredend noch lange nicht abgeschlossen sind, haben noch nicht eine gleiehgroße Maunigfaltigkeit f'eststellen kömnen, vielleicht ist sie auch gar nicht in dem greiehen Mafe vorhanden. Ton unseren paliarktischen Gattungen können wir die hauptsichlichsten vier nennen, die Amerika mit uns teilt: Iyylrophorus, Scellus, Thinophilus und Liancalus. Anerika hat außerlem drei Gattungen, die bei uns nicht vorkommen: Diostracus Lw., Iypocherassus Mik und, syntomoneum n. genus. Außerdem werden noch aufgefübrt: Phylarchus Aldr., cine von Adrich zu den Thinophitinae gestellte Gattung, und l'eudes Lw., die von Bigot genannt wirl; siehe hieriber meine Benerkungen an Schlusse der Gattungs-Bestimmungstabelle; ferner steht P'eloropeodes Wheel. im Kitalog Kertész bei den Mydrophorinae, in Aldricbs Katalog bei seimen Hedeterince; ich kann diese letztere Gattung nur bei meinen Rhuphimac nuterbringen. Wir haben es daher hier un mit sieben sicher beglaubigten Gattungen zu tun.

\section{Bestimmm!ngstabelle fïr die (iathmaen der Hydrophorinae.}

1 Thoraxricken ohne Akrostikalbirstehen . . . . . . . . . 2 Thoraxricken mit einreihigen Akrostikalbörstehen . . . . 4

- Thorixricken mit zweireihigen Bïstchen . . . . . . . . 7

3 Sechs Parl Dorsozentralborsten, zwei Schildborsten. Drittes Fiilılerglied kurz und abgermudet, mit dorsaler Borste; fiinf bis sechs IIinterleibsringe . . . . . . . . . . . . . 3 3

3 Erstes Fiahlerglied nackt. Gesicht mïßig breit, der untere Gesichtsand flach bogenformig endigend. Hinterhiifte mit einer, Prothorax mit drei Borsten. Dritte Lïngsader fast gerade verlanfend.

Thinophilus Walilb.

Erstes l'iblerglied behart. Gesicht breit, der untere Gesichtsrand in der Mitte dreieckig vorgezogen. Hinterhiifte ohne Borste, I'rothorax nur mit einem schwachen Haar. Dritte Längsader stark bogen. förmig . . . . . . . . . . . . . Diostrucus Lw.

4 Vorderschenkel anf der Wurelhälfte dentlich verolickt und unterseits stark beborstet. 
Vorderschenkel nieht verdickt und niehit so belourstet . . . 6

5 Sehildehen mit vier, ausnahmsweise mit zwei Borsten. Prothorax nu belaiart; Dor'sozentralbor'sten haarförmig in einer Zalıl bis zu 12-15. Drittes Fiihlerglied unterseits mit einer Einkerbung und dorsales Borste . . . . . . . . . . . . Hydrophorus Fall.

- Schildehen nur mit zwei Borsten; Prothorax mit drei Borsten. Dorsozentralborsten ans einer Reilie bis zu acht Haaren bestehend. Drittes Fiihlerglied kur, miten nicht eingekerbt. Hypopyg mit langen lappenförunigen weilen Anlïingen . . . . . . Scellus Lw.

(i) Sehildeben nit sechs borsten; sechs Dorsozentralborsten, Prothorakalborsten fehlend. Dritte und vierte Läingsadern banchig gekriimmt, an der Spitze konvergierend und parallel; hintere Querader sehr schräge gestellt. Fliigel des ơ an der Spitze fleckenartig verdunkelt.

Lienculus l,w.

7 Dorsozentralborsten nielit ausgebildet, nur unregelmaißig harförmig, vier Sehildborsten; drittes Fiillerglied rerlïngert, unterseits hakenförmig ausgeselınitten; Fiulırborste zweigliedrig, dick, endstïndig. Gesicht breit und kurz, olne Querfurche. Hinterleib mit sechs Ringen. Dritte und vierte Läingsadern bauchig gebogen, an der Spitze komvergierend . . . . . . . . . Mypocharassus llik.

- Sechs Dorsozentral, zwei Schildborsten. Drittes Fithlerglied oval, rorme spitz mit dorsaler Borste. Gesicht mißig breit, bis unter die Augen rerliingert. Hinterleib nit fünf Ringen. Vierte Längsader zweimal rechtwinklig gebogen und dann mit der dritten parallel verlaufend: zweite Längsader sehr kurz; hintere Querader nahe der Fligelwuzel, in nmgrekehrter Richtung sehrig liegend . . . Syntomoneurum n. sp.

Anurerkung. Die ('attumgen Feodes Lw. und Phylarchus Aldr. labe ich in vorstehende Tabelle nicht aufgenomuen; das Vorkonmen vou Peodes ist clurch dic bigotsche Art dichromatus aus 'bile nueh nicht ohne weiteres gewithrleistrt. vielmelur lü̈:hst problematisch und olme Typenvergleichnng nicht festzustellen. Bei Ihylarchus Aldr. erseheint mir anderseits die stellung dieser Gattumg in del Gruple der Hydrophorinac schn zwrifelhalt; siche das weitere bei den Gattungen selbst.

\section{H!/l10phorus Fall. (18:3).}

Aphozeta Perr., Méul. Aead. sie. Lyoun II 49 I (1850).

I'arhydrophorns Wheel., Entom. Ni*ws I'hiladelphia V'11 185 (1896).

Nearktische und neotropische Region.

Im Latalog Alclich 1905 sind nach Abzug einiger mkenntlich besehriebener Walkerseher Arten 15 nordanerikanische genannt. Loew hatte seinerzeit in seiner bekannten Monographic 1861 erst drei nambaft machen künnen. Später im Jahre 1899 lat Wheeler in den Proceed. of Californian Academy in einem Aufsatz iiber Mygdrophonus funf nene Arten binzugefiget. bie letzte amerikanisehe Arbeit iiber diese Gattung hat dann Aldrieh ge- 
liefert in P'syche $\mathrm{XV}$ VII Nr.2 (1911), in der er noeh acht nene Arten hinzufügte. Mit Ausnahme einer in Mexiko gefundenen Art war bis dahin keine neotropisehe Art bekannt. Erst in Sehnuses Sammlung und in der des Wiener Hofmuseums fand iel auch sechs Arten aus Sidamerika, wol:aus hervorgeht, dab, obgleich diese Gattung einen speziell nortischen Charakter angenommen lat, sie doeh aueh Vertreter in tropisehen Gegenden besitzt.

Aldrich hat in seiner eingehenden, interessanten kleinen Ablandlung eine kurz eharakterisierte bestinmungstabelle entworfen, der ieh meine nen entdeckten Arten einfiigen will, ohne eine besondere Unarbeitung der Aldriehsehen Tabelle vorzunelnmen. Aldrich hat bei der Einteilung seiner Arten den Schwerpunkt auf die Firbung der Schwinger gelegi, indem er sagt, dali ibm dies Merkmal anBerordentlieh konstant rorgekommen sei. Ieh kamn bei den nordamerikanisehen Arten iiber diesen Punkt kein eigenes Urteil fiillen, da ielı zu wenig Arten dureh Inaugenselreinuahme kenne, muf mich vielmehr auf Aldrich's Urteil verlassen; ieh will mu erwähnen, daß sich unter den suidamerikaniselıen Arten eine befindet, die in der Sehwingerfarbe eine auBerordentliche Mannigfaltigkeit darbietet; es kommen in gleicher Weise ror ganz gelhe, solche mit dunkelbrauner AuBenseite und ganz braune, so daf iel genötigt war, diese Art in der Bestimmungstabelle an zwei rerschiedenen Stellen einzustellen.

Bei Charakterisierung der Arten macht Aldrieh ferner anfuerksam anf die Stellung der beiden Postvertikalborsten: in der Regel stehen diese allein binter den Postorbitalborsten; bei einigen Arten ist aber an dieser Stelle eine ganze Borstenreihe vorlumden, an deren Endpunkten beide Postvertikale stehen. Die Anzahl der Sehildborsten weehselt ziemlieh häufiø. anch die Zahl der Notopleuralborsten soll nieht koustant sein.

Von rorhandenen Bestimmungstabellen sind zu nenuen:

Whecler, Proeeed. Califorminn Aead. Se. ser. 3. Zool. II 63 (1499).

Allrich, Psyehe XVIII Nr. 2, 49 (1911).

\section{Bestimmungstabelle}

\section{tiin die Anten der tiattum Hydrophorus lall.}

1 Sichwingerknopl gelb

Sebwingerknopf braun, wenigstens an! seiner AuBenseite . . . 17

2 Postvertikalborsten in einer lieihe von scchs oder melu Borsten . 3 Postrertikale wie gewöhnlich nur zu zwei . . . . . . . . 5

¿ Nur ein Paar Schildborsten

- Mebr als zwei S'childborsten gratiosus Alche. $\vec{\circ}$

4 Mehrere Prothorakalborsten

- Keine oder nur eiue schwarze l'rothorakalborste plumbeus Aldr.

5 Fliigel ohue lilecken auf der hinteren Querader und anf dem letzten Alsehnitt der vierten Liingsader . 
- Fliggel mit zwei solcher Flecken, anBerilem noch verschientenartig gefleckt .

6 Fligehrudader wellig geschwungen, ebenso alle Adern mit Ansuahme der dritten Liungsaler. Ilinterrand in gleicher Weise wellig gebogen und mit awei deuthehen Ansschnitten. Gesicht breit, stark goldgringlinzend. Vordersehenkel, Sehiene nud Metatasus unterseits verriert. $35 \mathrm{~mm}$ lang . . . . . . . . Titicaca n. sp. ठ

- Fligelrandader wenig oder nicht wellig geschwngen, Hinterrand nur mit einen Einschnitt am Ende der fïnften Längsader; letzter Absehnitt der vierten Läugsaler S-förmig aufgebngen; lintere Querader nach amßen gebogen. Gesicht breit, metalliseh bliulich bis grtinlich glïnzend, nur unten etwas gran bereift. Vorderbeine eintich. $3 \cdot 5-4 \mathrm{~mm}$ lang. . . . . . . . . . . Titicaca n. sp.

7 \%weite Längatuler sehr kur, der hinteren Querader gegeniber endigend. Gesicht mattweiß bestainht $\left(\sigma^{-7}\right)$, bein o gelblich. Drittes Fiiblerglied verlängert, 21/2-3 mal so lang wie breit $\left(\sigma^{3}\right)$, beim etwas ktirzes. $35-4 \mathrm{~mm}$ lang . . . . . cerutias Lw. oro $^{7}$ \%weite Liangsader nieht sehr kurz, viehmehr von der gewihnliehen Liinge .

8 Eine Prothorakalborste.

Keine Prothorakaliborste

9 Jorsozentralbursten mit Ausnilnme der letzten und die Akrostikal. bïstchen weiß. Hintershenkul auf der Unterseite nalle der Spitze bein o mit Aussehnitt. Vorderschiene entsprechend gekrïmmt. $45-5 \mathrm{~mm}$ lang . . . . . . . . canescens Wheel. ơ Dorsozentralborsten und Akrostikabörstehen schwarz. Endglied der Mitteltarsen beim of breit und schwar". $5 \mathrm{~mm}$ lang. ayglmu Wheel. of

10 Vier reutliche Selildborsten . . . . . . 12

Nur zwei Schildborsten. . . . . . . . . . . . . 11

11 Drittes Fithlerylied verlingert, beim on dreimal, beim q zweimal su lang wie breit. Gesicht silluerweib. $3 \mathrm{~mm}$ lang. . cleeatus n. sp. $3^{7} \mathrm{f}$ Drittes Fihlerglied nieht verlingert, nm klein nnd selnual. Gesicht mattweilj. $4 \mathrm{~mm}$ lang . . . . . . diminuutus n. sp.

12 Gesicht matt bestäubt, nicht metalliseh glinzend, weiß . . . 13

- Gesicht von metallischem Glanze, wenigstens auf des oberen IIillte 14

13 Thoraxilicken richt weiligelblich bestäuht mit zwei purpurtirbenen Liingstinien am llalse. Backen ling zipfelförmig herabiaingent. Fliigel glashell etwas weißlich nit gellen Adern an ler Wurzel. $3.2 \mathrm{~mm} \operatorname{lang}$. . . . . . . . . . . . . prerero Lehn. $0_{+}$

Thoraxricken glinzend schwarzgrü, katm etwas brangrau bereift. backen sehr schmal, kaum linienfirmig sichtbar. Fliigel schwach gelbbrïunlich wit dunklen Adern. $4.5 \mathrm{~mm}$ lang. regularis n. sp. on,

1t Das Ende der Vorderschienen in beiden Geselnlechten mit einem sharfen, gegen den Sohenkel gerichteten Winkel; eine bis drei 
Borsten an der oberen Subenecke der Vorderhinten. Gesicht im allgemeinen stark glinzend blaugrion bis zur Quernalit.

$4.8 \mathrm{~mm}$ lang . . . . . . . . . . . philombrius Wheel. ơ

Das Ende der Vorderschienen nicht oder nur in geringen Mabe winklig gegen den sehenkul gerichtet; keine Borsten an Wurzelteil der Vorderbiften. Gesicht nicht soweit nach unten glinzend . 15

15 Vordersehiene des 5 at $\% / 3$ ihrer Lange auf der Unterseite eingekerbt, die beiden letzten Glieder der Nitieltarsen verbreitert. $4.0 \mathrm{~mm}$ lang. brevisetı Thoms.

Torderschiene des of nicht eingekerbt

16 Art von 3 mm liange. lirustseiten dieht weif bestäubt

sodulis Wheel. ot?

- Art vou $4.5 \mathrm{~mm}$ Liange. Brustseiten zart gelb bestiinbt. magulalenae Wheei. ơ

17 Fliigel je mit einen loramen Flecken aut der Hitte des letzten $\mathbf{H}$. schnittes der vierten Liangsader und der hinteren Querader. Is

Fligel fleckenlos . . . . . . . . . . . . . . . . . . . . . .

18 Gesicht natt bestiulut, nicht metallisch gliumend . . . . . . 19

- Gesicht mit metallischem Glanze . . . . . . . . . . . 23

19 Gesicht braungelb, mit einem granen Elecken anf jeder Seite. bum lang. sigmiferus Corpuill.

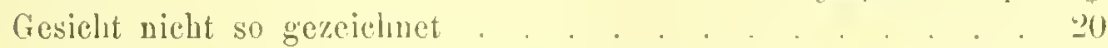

20 Vorderhiften aufer deu schwamen Borsten an der Spritze noch unit solelien an der Vorderseite . . . . . . . . . . 2. 2.

Vorderhiiften mur mit l'orsten an der Spitze. 4 mm lang. algens Wheel. Vorderhüften nur hell behart ohme jede Borste.

21 Irittes Fiblerglied sehr breit mul groh, beim $1^{1} / 4$ mal lïnger als breit. $4.5-5.5 \mathrm{~mm}$ lang . . . . . . laticomis $11.8 \mathrm{~s} . \mathrm{\sigma}^{\mathrm{T}}+$

Drittes Fiihlerglied ron gewöhnlicher Gröbe. Gesicht matt dunkelbraum. handader dick mul sehwarz. 45 mm lang' . . nervosus 11 . sp. o

22) Die beiden Flïgelflecken sehr dentlich mit bloßem Ange wahnehmbar. $3 \mathrm{~mm}$ lang . . . . . . . . elerysolygus Whecl.

Die beiden Fliigelffecken $n$ m schwah ansgebildet. $355-4$ mut lans.. pirata $\mathrm{l} / \mathrm{W} \cdot \mathrm{O}_{+}$

23 Die Brustseiten mit einer schwarzen Prothorakalen. 4 mm lang. alyens Wheel. o

Die Brustseiten mit einer blaligelben Prothorakalborste oder Halar. $3 \cdot 1 \mathrm{~mm}$ lang. . . . . . . . . . . . . phoce Alkr. o

Die Brustseiten mit einen Bischel gelber llatare olne lionsten an Prothorax. Fliigelfiache anBer den beiden Flecken anf den Adern noch mit versehiedenen liecken in den Kellen. Randader und Hinter land beim stark wellig geschwungen. Vierte Liungsader im letzten Abschnitt S-formig gelogen, hintere Querader stark konvex. $35-4 \mathrm{~mm}$ lang Titicaea n. sp. of 
24 Gesicht ganuz matt bestiubt

- Gesicht mit cinigen Metallglanze

25 Vorderhijften mit einer lieihe scliwarzer Dornen anf der Vorderseite, bis zur Spitze lanfend, der längste Dorn oben. $2.5 \mathrm{~mm}$ lang. parmes Liv. ơ

- Vorderhiiften mit einer lieihe schwarzer Dornen, der längste an der Spitze. $4 \mathrm{~mm}$ lang. . . . . . . . . . . pirata Lw. 9

- Vorderlififte nur an der Spitze mit Dormen. $3.8 \mathrm{~mm}$ lang. extrarins Aldr.

26) Vorderhiiften mit besonders langen Dornen anf der W" arzelhälfte der Vorderseite. 3.7-4.1 mm lang. . . . . . imotatus Lw. of Vorderhiiften obue Dornen auf der W'urzel- nud Vorderhälfte . 27

37 Die Backen reichen in Gestalt eines schmalen Latprens bis unter die Augen hinab. $4.7 \mathrm{~mm}$ lang . . . . . . altivagus $\mathrm{Aldr}$. o Die backen sind sehr schmal und reichen nicht bis unter die Augen hinab

2. Torderschenkel des on an der Unterseite mit einer Erhöhung dicht vor der Spitze, die nit einem Schopf kleiner Borsten besetzt ist. 4-4.-2mm lang . . . . . . . . . amplecters Aldr. ơ

- Vorderschenkel des on ohne solehe Bildung. . . . . . . . 29

39) Oberer Teil des Gesiclits glinzend blangriin. 5 mm lang. pensus Aldr. ơ o Oberer Teil des Gesichts matt, nnr wenigh glänzend griun. 3.8 mm lang. extrovius Aldr. G

\section{Register der Arten und Beschueibungen.}

arstum Lw. = maecor Lehm.

1 agulma Wheel. б+, Proceed. Caliform. Acad. Se. ser. 3. Zoolog. II 66. 67 tab. IV tig. 120, 121 (1899)

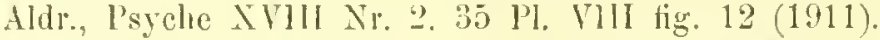

alloflorens Walk. Q, List. Dipt. Brit. Mus. 111656 [Medeterus] (1849)

Nur als Weibchen nnd unkenthich beschrieben.

America sept.

2 alyens Wheel. $0^{-9}$, Proceed. Californ. Acad. Sc. ser. 3. Zoolog. Il 63. li3 tab. IV fig. $123(1899)$. . . . . . . . . Ameriea sept.

Aldr., Psyche XVHIJ Nr. "2. 61 (1911).

3 altivagus Aldr. O; : Psyche XV]ll Nr. 2.67 (1911) America sept.

4 amplectens Aldr. Ofo, Psyche XVIII Ni. 2. 67 (1911) Imerica sept.

5 brevisete Thoms. Of, Eugenies Resa, Dipt. 510. 113 [Medeterus] $(1569)$. . . . . . . . . . . . Ameriea sept.

A3dr., Psyche XVIll Nr. 2. 58. Pl. VIll fig. 10, 11 (1911).

6 cunescens Whecl. of, Eutomol. News Philadelphial V'il 187 tign. [Perhyldropleoms] (1896) . . . . . . . America sept.

Aldr., Psyche XVlll Nr. 2. 53 Pl. V]II fig. 9, 5. (1911).

7 centias Lw. O'

Aldr. Psyche XVIll Nr. 2. 52 Pl. Vlll fig. 1, 5 (1911). 
chrysolygus Walk. $\sigma_{f}$, List. Dipt. Brit. Mus. III 635 [Merleterus] (1849) .

Ameriea sept.

Aldr., Psyele XVIII Nir.2. 622 (1911).

q. - Thoraxribeken dunkel olivenbraun, glänzend ohne nennenswerte Bereifung; anstatt der Dorsozentralborsten sehr feine dieht gestellte Hatre, etwa 16 hintereinander; nur dicht am Schildehen steht als letzte eine kraiftige Borste; Akrostikale einreibig; nn zwei Sehildborsten. Brustseiten asehgrau, eine sehwarze Prothorakalborste. Sehwinger gelb; Sehiippehen weiß, weiß bewimpert. Kopf: Hinterkopf gran; Scheitel und Stirne matt dunkelbrann mit zwei alleinstehenden Postvertikalborsten. Gesieht weiß bestäubt. Fiihler sehwalz, verhältnismiliig klein; Taster brann mit zartel weißer Beharung. Backen sehr selımal, mur linienförmig nuter dem Augenrande siehtbar. - Hinterleilı erzgriin, glänzend, der letzte Ring und die Seiten aller Ringe weif bereift. Behaarung obenauf selıwarz, an den Seiten weiB. - Beine: Iliiften sehwarzgran; Vorderhiiften weißgelb behart ohne jede Borste. Selrenkel erzgriin, etwas grau bereift; Vordersehenkel nur sehwach rerdickt, auf der Unterseite mit einer rollständigen inveren Borstenreihe, während die außere auf die Wurzelläilfte beschrinkt bleibt. Vordersehiene nnterseits mit knrzen Dornen, die an der Spitze in einen etwas hervortretenden Stacheldorn auslanfen. Hintermetatarsus fast dopuelt so lang wie das zweite Glied. Flitgel fast wasserklar; die Ratudader ist bis znr ersten Liingsader gelb, lernach ziemlieh stark nud sehwarz; dritte und vierte Längsadern dentlich bugenförmig konvergierend, der zwisehen ihnen liegende Randabsehnitt ist halb so lang wie die hintere Queraler, die nach anßen hin etwas gebogen ist. 4 mul lang.

6 Exemplare ans Buenos Aires aus den ITiener Hofunseum.

Anmerkung: Sach Aldrichs 'Tabelle stibt man aut aestuum Lw. = praeco." Lehm., die aber dureh dichte wribe Bestiubung und tiel herabhaingende Packen rerschieden geartet ist.

elevatus n. $\mathrm{sp}$. Оึ. 2 Figuren

Peru, Chile

$\sigma^{7}$ - Thoraxidicken olivenbatun bestaubt, wenig glainzend; ron Dorsozentrabborsten ist nu' das letzte Paar vorhanden, die iibrigen sind nu haurörmig entwickelt, etwa I2-14 an der Zalli; Akrostikale einreihig; am Sehildchen nur zwei Randborsten. Blustseiten aselgran; Sehippehen und Sehwinger blaßgelb, erstere weißlieh bewimpert. Kopf: Stirne matt dunkelbraun; Hinterkopf ebenso, jedoch an den Seitenrïndern weißgran; obere Randborsten sehwar", unten stehen wie wohl bei allen Arten keine Borsten, wohl aber eine Menge weißer Haare als Kinnbart; zwei einzeln stehende Postvertikalborsten. Gesieht silberweiB, oben ron der Breite eines halben Anges, nach unten hin etwas verbreitert; 'Taster selwarz, grau bestaubt, gelb hehaart. Fiilıler 
sehwarz, das dritte Glied erheblich verlingert, auf der Interseite mit ciner scharten Eeke mul uit einer dicken schwaycn zweigliedrigen borste, die etwa halb so lang ist wie das dritte flied und dic fast endstandig erseheint. - Hinterleib matt graubraun, auf der Oberseite kurz schwar\% -, an den Seitenrindern sehr zart weiß behaut. Beine: Haften schwarz, dicht aschgrau bestiubt wie die Brustseiten, Vorderhiiften weiß behaurt ohne Borsten. Schenkel und Schienen bronzebrau, Tarsen mebr sehwarz mit sehr zarter schwarzer Behaarmas mon Beborstung. Die Vordersehenkel sind an der Wurel nur mäißig verdickt, sic flihren auf der Unterseite zwei Borstenreilien, die beide ein-

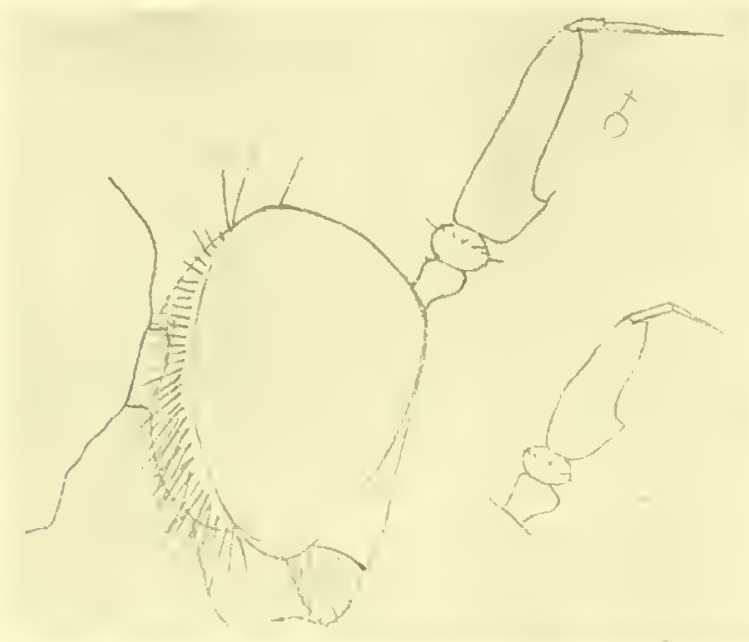

Fig. 40/41. Hydrophomes elevatus of $7.36: 1$. zeilig bis zur Spitze reichen; nur :n der Basis stelien mehrere gedrängt zusammen; die Vorderschienen endigen ander Spitze etwas dreieckig verbreitert, anf ilmer Unterseite stelıt eine selur yilrte Bursten reihe, die Endborste ist kaum etwas grioBer als die iibrigren. - Fligel graubräunlich mit braumen Adern, nur die Randader bis \%ur ersten Liangsader ist ge!l); die dritte und vierte Lïngsadern konvergieren deutlichs hintere Querader etwas bauchig. "3 $\mathrm{mm}$ lang.

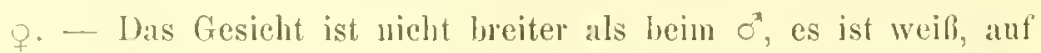
der oberen llailfte aber größtenteils gelubriunlich; die Fiihler sind etwas kiil'zer als das dritte Glied des o", und zwar um $1 / 3$ kiurzer; die Fiilılerhorste erseheint hier aber dentlieher subajikal oder schon dorsal, in iibrigen sind Unterseliede nielıt roshanden, aneh nicht in der Beborstung der Vorderbeine. -

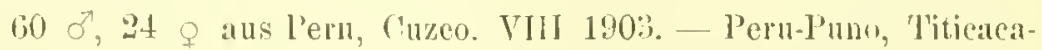
See Xl 1902 und V 1903. - Chile, Coruimbo I 1902 - Chile, Ariea XI 1902. - Peru, Juliaca VI 1903 [Sehnuse].

ntoradensis Whicel. = aestum $\mathrm{Lw}$. = praccox Lehm.

11 extrarius Aldr. ; Psyche XVII Nr. 2. 65 (1911) . America sept. gluber Walk, List. Dipt. Brit. Mus. 111655 [Medeterus] (1849) Amer. sept.

Ohne (ieschlechtsangabe unkenntlich beschrieben. 
12 gratiosus Aldr. כ, Psyche XVIhl Nr. 2. 49 (1911) Ameriea sept. infuscutus Big. +, Ann. Suc. Ent. Fr. sér. 6. I 294 (1890) Chile

Ganz ungeniigend und unkenntlich beschrieben.

13 imotatus Lw. So Monogr. Dipt. N. Amer. II 212. I tab. VII tig. 33

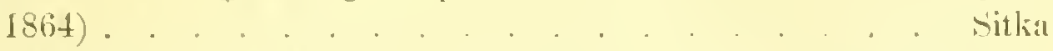

Aldr, Psyche XYlI] Nr. 2. 60 (1911).

- Anerica sejt.

14 intentus Aldr. ơ , Psyche XVIII Nr.2. 51 Pl. VIII fig. 4 (1911)

America sept.

15 laticornis n. s]?. oे . 2 liguren

America merid.

ơ. - Thoraxrïcken metallisch sehwarzgrün, dentlich etwas glänzend mit zahtreichen Hiarchen in der Reihe der Dorsozentralborsten, die nicht stiirker sind als die eimreihigen Akrostikalen. Schildehen mit vier borsten. Brustseiten dunkel aschgrau. Schïppchen blaßbraun mit weißen Zilien; Schwinger mit schwarzbraunem Knopf; anstatt der Prothorakalborste nur weiße Hairchen. Kopf: Stirue matt dunkelhraun oline Scheitelborsten. Hinterkopf dunkelgran bestiiubt;Gesicht unterden Fiiblern ungefilur ron ${ }^{1 /}$ : ller Kopfbreite, dunkelockergelb vder bräunlich; Tister dunkel-

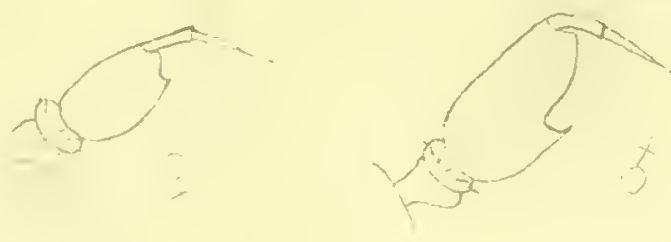

Fig. 42/43. Hydrophons laticomis ot $7.36: 1$.

grau, weiß behaart. Fiihler schwarz, das dritte Glied breiter und linger als gewöhnlich, anf der Unterseite mit dentlicher Eeke und Ausschnit (s. Figur). Borste sehwarz, kurz, zweigliedrig, an der Spitze weili. Hinterleib briunlich aschgrau, matt, auf der Oberseite mit kurzen schwarzen, an den Seiten mit helleren Haaren: am grau bestäubten Hypopyg ist ron Anlängen nielıts zu sehen. - Beine: Hiiften dnnkel aschgrau, Vorderhiiften lang weiß behant ohne eine Borste. Schenkel und Schienen bronzelraun, Schenkel zart weif behart, Schienenborsten sehr kurz. Die Vordersehenkel sind stirker als gewölntich verdickt: auf ihrer Unterseite sieht man zwei vollstandige Reiben kurzer schwarzer Borsten, dawischen stehen aber noch verschiedcue kleinere. Die Vordersehienen haben eine abgerundete Spitze und die Borstenreibe auf del Unterseite beginnt fast unseheinbar, ist auch an der Spitze nur sehwach entwickelt, ohne dentliche Endborste; die Voldertarsen sind nicht viel lïnger als die Schiene. - Die Flïgel sincl etwas bräunlich mit gam\% schwarzluamen Adern und je einem sehwirzlichen Flecken auf der hinteren Querader und der Fliggel beule; die Randader ist auf ihrer \%weiten llable deutlieh rerdiekt. $4 \overline{0}-\overline{0} \mathrm{~mm}$ lang. 
C. - Das Gesicht ist nicht breiter als beim $\sigma^{\top}$, sammetbraun; das dritte Fiihlerglied ist $n$ m die Jülfte kiirzer; in der Beborstung der Vorderbeine ist kein Unterselied zu sehen.

39 ơ, 14 o aus Chile, Magellanstraße X 1902. - Chile, Punta Arenas II 1908. - Argentinien, S. Julian I 1.08.

16 Magdalenae Wheel. ơ 9 , Proceed. Californ. Acad. Se. ser. 3. Zool. II 67. 68 tah. IV fig. 124 (1899) . . . . . . . . . N. Mexiko

Aldr. Psyehe XVIII Nr. 2. 66 (1911).

17 nervosus $\mathrm{n}$. $\mathrm{sp}$. $q$

Chile

- - Thoraxriicken dunkel olivenbramn nit etwas graulrauner Bereifung, jedoch noch glänzend; anstatt der Dor'sozentralborsten sieht man feine längere Hare, sehr diclıt gereiht, ich zahle mehr als 16; Akrostikale dentlich, aber auch fein und einreihig. Vier Schildborsten. Schwingerknopf braun, Stiel etwas heller; Schuippehen hellbrann mit weißen Wimpern. Brustseiten ganz aschgrau; am Prothorax steht keine Borste, wohl aber fahlgelbe Haare. - Kopf: llinterkopf oben meln bramn, unten melir grau. Scheitel und Stirne matt dunkelbraun; das breite Gesicht hat dieselbe Färbung, die nur um ein geringes beller ist. 'Taster' bram, grau bereift nnd weißlich behaart. Fïhler' schwarz, von gewöhnlicher Form uud Gröbe. Backen sehr schmal; die Postrertikalhorsten stehen allein ohne andere Reihenborsten. - Hinterlcib dicht dunkel aschgrau bestiubt, obenauf mit schwarzer, an den Seiten mit weißer Behaarung. - Beine: Hiiften dunkelgran; Vorderhiiften fahlgelb belatart ohne jegliche Borste. Schenkel und Schienen bronzefarbig, 'T'arsen schwarz. Die Tordersehenkel sind stark rerdickt mol zeigen auf ihrer Unterseite eine starke vollständige Borstenreilue :un der Innenseite, wihlueud die Reihe anf der Außenseite nur unvoll kommen und schwicher ausgebildet ist; aluch auf der Unterseite der Vorderschiene ist die innere Reilie der kurzen Dörnehen vollständig, an der Anlenseite ist sie etwas stiuker, aber weitlaiuliger gereiht, die Findborste ist nicht besouders stalk. - Die Fliagel sind von briilulicher Firbung und zeigen zwei dunklere Flecken an den bekannten Stellen; die Längsadern sind anch etwas brännlich gesiumt, die Randader ist hellbraun bis zur ersten Längsalder, damn aber erhält sie cine ausebnliche Stiarke und schwarte Firbung. $4.5-5 \mathrm{~mm}$ lang.

Zwei Weibchen ans Chile, Magellanstraße 2. IX. 1902 [Schnuse] Dresdner zoologisches Museum.

18 parvus Lw. O3erl. Ent. Zeitsehr. V1 214.67 (1S62) America sept.

Aldr., Psyche XVIII Nr. 2. 64 Pl. VIIT fig. 3 (1911).

19) pensus Aldr. o' 0 , Psyche XVIIl Nr. 2. 68 Pl. VIII fig. 7 (1911)

America sept.

20 phitombrims Wheel. of $\mathrm{q}$, Psyche V 378 (IS90). . America sept. Aldr., Psyche XiIII Nr. 2. 57 Pl. VIII fig. 14 (1911).

21 mora Aldr. o' l'syche XVIII Nr.2.68 P'l. VIII fig.2(1911) America sept. 
Aldr, Psyche XVIII Nr. 2. 64 (1911).

23 plumbeus Aldr. I'syche XVIIJ Nr. 2. 50 (1911). America sept.

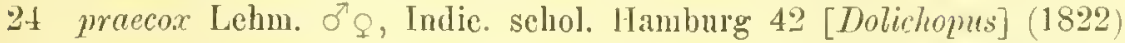

Enropa, Africa

aestum Lw., Berlin. Entom. Zeitschr. XVIII 36. 60 (1869)

America sept.

cincreus Perris, Mém. Acad. Se. Lyon II 492 [Aphrozeta] (1850)

America sept. et merid.

elcloradensis Wheel., Proceen. Californ. Acad. Sc. ser. 3. Zool. I]

65. 66 tab. IV fig. 125 (1899).

innequalipes Ilacr., S. it Buff. I 453. 5 [Medeterus] (1834).

litoreus Fall., Dipt. Snee. Dolichopus 3. 3 p. p. (1823).

oceanus Macq., Ann. Soe. Entom. Fr. VII 423 tab. XI tig. 1 [Medcterus] (183S).

Schönherri Bohem. in litt. apud Zetterst.

Loew beschrieb seine Art aestum im Jahre 1869, fiinf Jahre späiter als seine bekannte Monographie amerikanischer Dipteren ersehien, und zwar nur mittels einer knrzen lateinischen Diagnose. Wie alle diese in der Berliner Entom. Zeitsehrift von ibm veröffentlichten nenen Arten aus Nordamerika macht anch die Beschreibung voम aestum nicht gerade den Eindruek, als ob sie das Resultat eingehender Untersuchungen uud Vergleichungen mit anderen Arten ihrer Gattung sei; immerlin hat Loew aber doch am Sehlusse in einer "Nota" ausgesprochen, dah aestum der Art inaequalipes Macq. = maccox Lehn. selu ahnlich sei und sich von derselben nur durch lingere Backen unterscheide. Nun aber hat inceruchipes grade sehr lang herabhängende Backen. Loew muß hier einer Verweehslung oder einem Irrtnm anheimgefallen sein; gerade die langen Backen von aestum gaben mir bei Vergleich ung der Arten den Aulaß und haben mich dahin gefiihrt, diesen In'tum anfandecken. Die Art praecor scheint cine Allerweltsfliege, ein ,globetrotter" zu sein, denn ich kenne sie bereits ans allen Regionen nit Ausnahme der "orientalischen" und wahrscheinlich wird sie mir bei weiterem Studium der orientaliseheu Fauna anch dort noch begegnen; allenthalben wo sie auftritt, ist sie gemein. Ich habe alle diese Exemplare der versehiedensten Gegenden sorgfältig miteinander ver. glichen mit Bezug auf Fäıbung, Beborstung und Größe; ich fand keinerlei Unterschiede. Die Loew'sche Beschreibung von increqualipes und dic sorgfältige Beschreibung von acstum durch Aldrich stimmen vollkommen iiberein. Da weiter die Art eldoralensis Wheeler nach Aldrichs Untersuchungen auch gleich uestum ist, so tritt auch die Wheclersche Art noch als synonym binzn.

31 Exemplare ans Chile, Ariea, X und XI 1902 [Schnuse] Dresdner zoologisches Museum. 


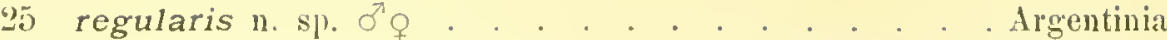

ठ․ - Thoraxriieken dicht braungrau bestiubt, matt, mit einem deutlichen hinteren Dorsozentralborstenpara; in der Reihe vorhel stehen mm zarte schwarze Härehen, nicht läuger als die eimreihigen Akrostikalbölstehen. Schildehen mit vier Randborsten. Brustseiten aschgran; schwinger hellgelb, Sehijppehen weiblich mit luramem Saum nnd weilien Wimpern; eine Prothorakalborste. Kopf: Stime mattbrann, Hinterkopf gelbgran nit zwei dentlichen l'ostvertikalen ohne Nebenborsten. 'I'aster gran bestäubt, weißlich behart. Fiibler schwarz vou gewöhnlicher Form nnd Größe, Fiilulerborste wie gewöhnlich kur\%. Backen fast uicht sichtbar. Hinterleil, matt braungran bis grau, auf der Oberseite kurz schwarz, an den Seiten etwas linger weiß behaart; das gran bestänle Hypopygium mit zwei sehmalen sehwarzen lamellenartigen Anhängen, deren Spiitze mit einigen lïngeren weißen Haaren besetzt ist. - Beine bronzebrann, Hïften grau, Vorderbuiften ohne Borsten, nur weißgelblich behart. Die Vorderschenkel tragen auf ibrer Unterseite eine vollständige innere Borstenreihe und eine äubere nur anf der Wnrzelhälfte; die Vorderschienen sind an der Spitze etwas dreieckig verbreitert und tragen an der Spitze eine starkere Borste. - Flitgel etwas gelbbräınlicb mit dunkelbramnen, an der Wurzel nehr gelblichen Adern ohne Flecken. - $45 \mathrm{~mm}$ lang.

ค. - olne wesentlielse Abweiclungen von $\sigma^{7}$.

$4 \sigma^{7}, 5$ \& aus Algentinien, San Julian 31. I. 1908 [Schnuse] Dresdner zoologisches Mnsenm.

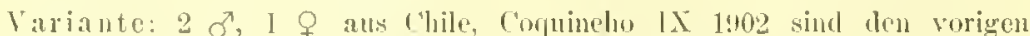

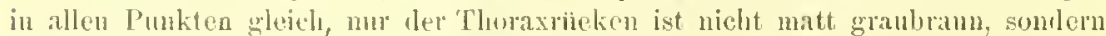
durchans griazend wivenloram, eino bemorkenswerte Variante.

Anuerkungr: (irube Älmliclskeit mit unserer Art hat intentus Aldr.. jerloclı

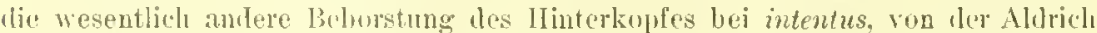

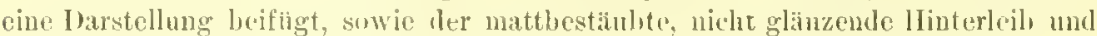
die dentich sichtharen Ilypopygialanhänge bei reguleris sprechen lagogen.

26 signifcrus Coquill. q, Fur Seals and Fur Seal Islands IV 344. 12 (1899)

Aldr., Psyche XYIII Nr. 2.61 (1911).

America sept.

27 solatis Wheel. 70 , Proced. Californ. Acad. Se. ser. 3 Zool. Ir 68. 69 tab. IV fig. 122 (1899)

America sept.

Aldr., Psyche XVIII Nr. 2. 59 (1911).

28 Titicaca ๖. sp. ठํ. 3 Figuren America sept.

\%. - Thoraxriteken metallisch glänzend, griingold mit blanen Reflexen; die Akrostikal. nnd die ebenfalls haarörmigen Dorsozentralborsten stehen aul mattbramen klemen kreisrnuden Flecken; zwei leine mattbrane Linien fassen die Akrostikalbörsteben ein; diese Linien sowie die perlsehnurihnliehen kreisrunden Fleckenreihen vereinigen sich auf den hinteren Teil des 'Thoraxrickens zu einer großen 
mattbraunen Fliche vor den Schildehen; auch das breite und sehr kurze Schildehen ist mattbraun und triigt $6-8$ längere feine Borstenhaare am Rande. Brustseiten branngrau; keine Prothorakale, nur gelbe Haare. Schwinger ganz gelb, gelb mit schwarzbrauner Oberseite oder atuch ganz braun; Sehiippchen dunkelbraun, dicht goldgelb behaart oder bewimpert. - Kopf: Stirne und Hinterkopf matt dunkelbraun, nur der äußerste Seheitel ist glänzend; zwei deutliche Postvertikale. Das Gesicht hat oben $3 / 4$, unten die volle Angenbreite und ist glinzend gringold, mitunter auch violett sehimmernd. Taster schwarz, schwarz behart. Fiihler schwar', von gewöhnlicher l'orm und Größe. Kinubart unten gelb. - Hinterleib metallisch griiu, gläuzend, obenauf fist nackt; die kurzen Häichen schwarz, an den Seiten etwas länger und gelb. Hypopyg schwarz ohne hervortretende

Organe. Beine schwarzbraun; Schenkel Fig. 44. Hydrophorus titicaca. Vorund Schienen ziemlich lang gell,brïnn-

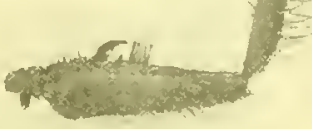
derbein. $18: 1$.

lich behart, Borsten zart. Vorderhïften mit zwei Höckern, auf der Mitte und an Ende. Vorderschenkel unten mit einem schwarzen kleinen Horn und einem dahinter stehenden Haarbiischel. Vorderschienen an der Spitze nit blattartig vortretenden Seiten, so daß sich zwischen ihnen eine Rinne

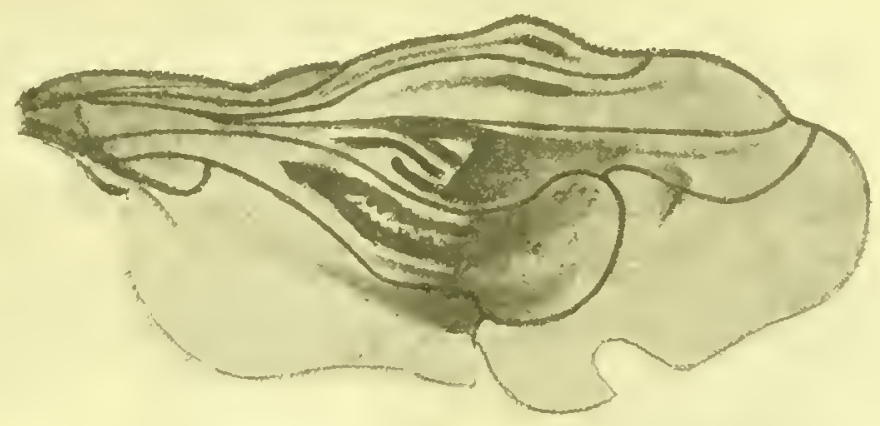

Fig. 45. Hydrophorus titicaca $\sigma^{7}$. Flïgel. 18:1.

bildet, unten mit einigen wenigeu Borsten, auf der Oberseite zwoiseitig lang behaart; der Vordermetatarsus ist an der Spitze hakenförmig verbreitert. - Flügel bräunlich, in Zeichnnng und Formen sowolıl des Umrisses wie der Aderung höchst eigentiimlich: von den Aderı ist nur die dritte fast ganz grade, alle anderen sind wellenformig gekriimmt, der Umriß ebenfalls und der Hinterand mit Einschnitten versehen; dazn kommt, daß dic Fliigelfliche keine Ebene bildet; der 
mittlere dunkler gefurbte Teil des Flïgels bildet eine große muldenförmige Vertiefung, die auf der innereu Seite benlenförmig hervortritt. O. - Das Gesieht ist ebenso breit wie das des $0^{7}$, metallisch blänlich bis griin, nnten etwas grall bereift. Die Beine sind einfach. Vorderschenkel anf der Unterseite ohne Borsten. Vorderschienen mit einer Reihe weitlänfig stehender Borsten, die Spitze abgerundet ohne stïrkere Endborste. Flïgel von gewöhnlieher Form; die Kriimmung des letzten Teiles der vierten Liingsader und der hinteren Qnerader erinnern noch etwas an die Aderung des männliehen Fliigels. $3 \cdot 5 \mathrm{~mm}$ lang.

12 \% , 12 \% aus Bolivia-Quaqui. 4000-5000 m hoeh. Titieaca-See VI (1903) [Sehmuse] Dresdner zoologisehes Musenm.

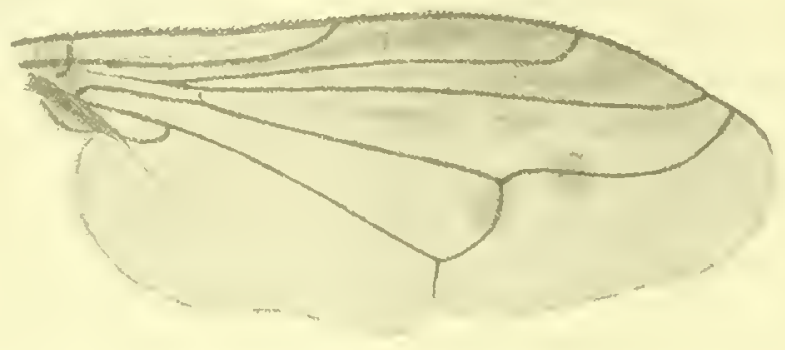

Fig. 46. Titicace f. Flïgel. $12: 1$.

viviliflos Walk. o, Inseeta Samder's. Dipt. I 212 [1Kedeterus] (1852) Nur als Weibehen, unkenntlich beschrieben.

\section{Scellus Lw. (1857).}

Aldrich hat in den Entomolog. News Philadelplia XV11I 133 (1907) eine kleine Studie iblor nordamerikanische Scellus-Arten veröffentlicht und gibt mit der Beschreibung einer nenen Art eine Tabelle zur Bestimmung der Männehen, die ich einfaeh in der Úbersetzung wiederhole, da ieh weder diese Arten selbst gesehen, noch anch andere Arten in dem mir vorliegenden Material gefunden babe. Aus Siidamerika haben wir noch keinen Berieht iiber das Vorkommen von Arten dieser Gattung erhalten. Daß die von Philippi hesehriebene Art poliogaster sehwerlieh ein Sicellus sein wird, habe ieh bereits hei Bespreebung der Gattung in der paliarktisehen Region erörtert.

Anmerkung. Aldrich gibt 1. c. einige Notizen ïber lundorte: lic Art vigil fimd er an steinen aul Hügeln und auch an stämmen vor Narlelhölzern, filifer desgl. an 
Baumstimmen. Demgegenüber bemerke ich, daß ich die Arten spinimanus Zett. und gallicamus Beck, anf sumptigen lluchgebirgswiesen, notata Fbr. anf Tiehweidcon der Rhene erbeutete: auf steinen und an Baumstimmen fand ieh kein Tier.

\section{Artverzeichuis.}

1 avidus Lw. O', Monogr. Dipt. N. Amer. 11207 tab. VII f. 37 (IS64) America sept.

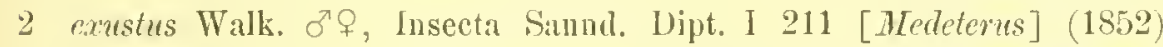
America sept.

3 filifer Lw. б̆, Monogr. Dipt. N. Amer. 11 209. 4 (1864) America sept. filiferus Aldr., Enton. News Philadelubia XVIIl 135 (1907) filiferes Aldr. = filifer Lw.

4 monstrosus O. S. б, Bull. Unit. Stat. Geol. Surv. IIl 319.2 (1877)

America sept.

? poliogaster Phil. क, Verh. d. z.-b. Ges. Wien XV 780 tab. XXV11I f. 52 [Iydatostega] (1865) . . . . . . . . . Chile

5 spinimanus Zett. O' 9 , Dipt. Scand. II 445. 5 [IIydrophoms] (1843]

6 vigil O.S. O’, Bnll. Unit. Stat. Geol. Surv. III 318. 1, (1877) America sept. 7 virago Aldr. ơ $q$, Ent. News Philadelphia XVIII 133 (1907) America sept.

\section{Restimnuminstalbelle.}

1 Drittes Fiihlerglied verlingert, nit epikaler Borste. . virago Aldr. ${ }^{\lambda}$

- Drittes Fihlerglied nicht rerlingert, nit dorsaler Borste . . . "

2 IIinterschenkel stark verdickt und gebogen. Fliigel ganz geschwärzt exustus Walk. ठ

- Mittelschenkel gebogen nud gegen dic Mitte verdickt. Fliigel nicht ganz geschwälıt . . . . . . . . . . . . . . . 3 Mittel- und Hinterschenkel nicht gebogen . . . avidus Lw. ठ

3 Spitzenbälfte der Flïgel schwarz. Thoraxriicken mit schnecwcißer Bestaiubung. . . . . . . . . . spinimumus Zett. ठ

— Anders gebildete Arten . . . . . . . . . . . . . . 4

4 Analanbänge orange gefäibt, löfelförmig, an der Spitze vergroßert monstrosus $\mathrm{O}$. S. O

- Analanhïinge an der Spitze nicht vergrößert . . . . . . . 5

5 Hinterschenkel längs der Mitte mit viclen langen weißen Haaren vigil O.S. $\sigma^{7}$

- Hinterschenkel ohne weiße Haare . . . . . . . filifer Lw. $\sigma^{7}$

\section{Lirrucalus.}

Loew, N. Beitr. Y 22 (1857).

Die vier nachstehend verzeichneten Arten, die uns aus Amcrikil bekannt sind, stammen alle aus Norlamcrika; daß diese Gattnng abcr auch in der neotropischen Region verbreitet ist, ersicht man ans den Ergchnis, daß ich in der Schnnseschen Sammlung ein Weibchen ans Pern fand, das 
sieh in seiner besonderen Kürperfïbnng als eine nene Art kennzeichnet. Waihrend die vier bekannten Arten alle eine metallisch gläuzende Färhung des 'Thoraxrickens zeigen, auf welchem verschiedene farbige Linien zu sehen sind, ist der 'Thoraxiticken bei nuserer Art ganz mattschwarz, fast sammetartig und fast ganz nackt, ohne sichtbare Reihen von Dorsozentralund Akrostikalbörstehen, anch das Schildehen hat abweichend nur zwei Randborsten, während alle iibrigen Arten deren sechs zeigen; aber der Charakter der Fltigelzcichunng stimmt mit dem auch unserer paliarktischen Arten iiberein; zum Berveis gebe ich die Fligelzcichnung der neuen Art. Oh letztere wegen ihrer Nacktheit, ihrer besonderen Thoraxfärbming und Schildbeborstung einem besonderen Subgenus wirl zuzuteilen sein, odler ob man hesser tmu wird, den bisherigen Gattungscharakter etwas zu erweitern, diese Frage wird spaiter besser als hente $\mathrm{zn}$ beantworten sein, wem aneh das Männehen dieser nenen Art zu moserer Kenntnis gelangt sein wird.

vidua n. sp. \&. 1 Figur. . . . . . . . . . . . . . Peru

. - Thoraxricken schwarz, ganz matt, Schìldchen mattbraun mit schwarzer Basis; anf der llitte des Riickens macht sich bei sehriiger belenchtung cin lunklerer, fast sammetschwarzer breiter Streifen hemerkbar, dem vorne vor der Quernaht je cin kreisrnuder sammetsehwarzel Fleck zur Seite steht. Die Rỉckenfliehe ist aulierdem noch durch weiße Bestiulonng gezeichnet: die breite llittelstrieme ist anf der Vorderhailfte des Thoraxriekens durch je eine weiße Längslinie cingefaßt, die vorne vor der Schulterbeule hakenförmig abbiegt und anf der Mitte des Rückens in einen größeren tropfenfürmigen Flecken endigt; anßerdem ist die ganze Notopleuralgrube nnd die Schulterbenle weiß bestäubt; dieselbe Farbe haben auch dic Brustseiten und Vorderhifften. Schwinger gelb, Schtippehen weiß mit breitem schwarzen Sam und ansgiebiger schwarzer Bewimpermg. - Kopf: Hinterkopf oben brann, unten gran; Stime sammetschwarz, an den Sciten grau; Gesieht von 1/4 der Kopfbreite, auf der oberen Hïlfte matt dunlielbrann, auf der unteren gran bestiubt; 'Taster schwarzgran; das Gesicht reicht nicht his zum unteren Angenrand hinab, ist erheblich kiirzer und hat unten eine ganz gerade Begrenzung. Von Borsten sieht man nu zivei mäßiggroße Ozcllarborsten. Scheitel- mod Postvertikalborsten fehlen; yon Postorbitalborsten stehen oben nur wenige schwarze, unten fehlen sie; der Kinnbart ist gelblich nud spairlich. - Hinterleib sehwarz, kaum etwas glänzend, fast nackt, die Härchen schwarz. Beine ganz sehwar, nackt. Hinterselıenkel diinu, etwas gehogen. Flïgel lang, schwach gebräunt mit der Adernng, wie in der Gattungsdiagnose angegeben (s. die Fignr). Lainge des Kinpluers 6 , des Fltigels $6.5 \mathrm{~mm}$.

Ein Exemplar ans Pern, Pichis Weg 5. I. 04 [Sehnuse] Dresdner zoolog. Museum. 


\section{Artregister.}

1 gemualis Lw. ơ $q$, N. Beitr. VIII 70.1 (1861) . . Ameriea sept.

2 hydroplitus Aldr. ơ 9 , Psyehe VI 569 (1893 . . America sept.

3 querulus O.Sack ơ \&, Bull. Un.Stat.Geol.Surv. III 318 (1877) Amer. sept.

4 similis Aldr. O’ 9 , Psyche VI 571 (1893) . . . . . Ameriea sept.

5 vidua n. sp. ㅇ. . . . . . . . . . . Ameriea merid.

\section{Restimmumgstabelle}

fiiir die Arten der latttung

\section{Liancalus.}

Aldrieh hat in der Psprelie V1 569 eine kurze Bestimmungstabelle reriffentlieht; ich werde die nene Art derselben hinznfïgen.

1 Arten mit metalliseh gliinzendem blangriinen Thoraxriieken, der rersehiedene metalliseh ge. fairbte Längslinien anfweist. Sehildehen mit sechs Borsten . . . . . 2

Thor:uxrieken mattsehwarz mit sanmetfarbigen dunkleren Nittelstreifen und Seitenfleeken sowie mit weiBbestiubten Linien und Fleeken; fist ganz nackte Ar't mit zwej Seliildborsten. vidua n.sp. ?

2 Erstes Tarsenghied der Vorderbeine beim of rerkiinzt 3

- Zweites Tarsenglied der Vorderbeine beim $\sigma^{7}$ verkiirzt . 4

¿ Die let»ten drei Glieder der" Vordertarsen beim or annihernd von gleicher Laiug'e

$$
\text { similis Aldr. } \sigma^{x}
$$

- Die letzten drej Glieder der Vordertarsen so lang wie das vierte und fünfte zusammen querulus $\mathrm{O} . \mathrm{S} . \mathrm{O}^{\mathrm{x}}$

4 Kuice gell

- Kniee nicht gelb

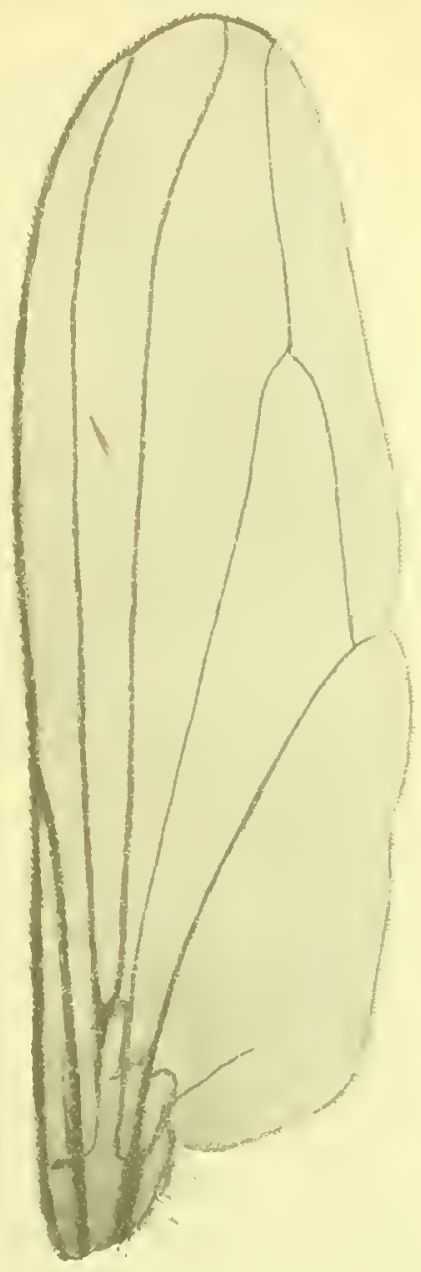

Fig. 47. Liancalus vidua. Fligel. 18:1. genualis Lw. ơ hydrophilus Aldr. o' 


\section{Thinopleilus.}

Walıll,. Öfrers. Kongl. Vet. Akad. Fürlanıll. 37 (1844).

Von dieser Gattung baben wil bislang ans Amerika nicht viel rernommen. Während wir aus der paläarktisehen Region 13 Arten kennenlernen konnten, sind uns aus Nordamerika nur zwei Arten gemeldet, von denen die eine nur als Weibelien bekannt ist. Ich kenne diese beiden Arten nicht aus Auschaunng und kann sie daher nur der Volistaindigkeit halber anfiihren.

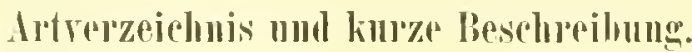

1 neglectus Wheel. P, Proceed. Californ. Acad. Sc. ser. 3. Zoolog. II 70.70 (1899) .

America sept.

१. - Thoraxriicken und Sehildehen matt gelbbraun. Akrostikale felılen; sechs Dorsozentralborsten, nul zwei Schildborsten. Schwinger und Schiippehen hellgelb, letztere kurz weiß bewimpert. - Kopf: Tastel groß gelb, silberweiß bestainbt. Gesicht von dunkler Grundfarbe, weiß bestaiubt. Fiuhler rotgelb; drittes Glied an der Spitze bräunlich; Borste dorsal. Stime matt branngelb. - Beine: Hiiften wie die Brustseiten und die Schenkelwurzeln von dunkler Grundfarbe mit silberweißem lieif. Beine gelb, Spitzen der Tarsenglieder schwarz, vierte und fiinfte Tarsenglieder ganz selwarz; feine silberne Haare sieht man an Selienen und Tarsen. Fligel etwas undurchsichtig weißlich, an (le $]^{\circ}$ Costa gelb mit gellien Adern; am letzten Abschnitt der vierten Liingsider und auf der hiuteren Querader je ein dunklerer Fleck. $2 \cdot 75-3.5 \mathrm{~mm}$ ling.

2 pectinifer Wheel. $\sigma$. Entomol. News 155 (1896) . . America sept.

ơ. - Thoraxulicken kupferfarbig mit zwei grauen Läugslinien. Schildehen mit vier Borsten. Schwinger gelb, Schippehen und Wim. pern weil. Hinterleib grỉn, schwarz behaart. Пypopygium schwarz, wenig sichtbar. - Gesicht kurz und breit, kupfergriin, rotbramn bestiubt. Fiihler rotgell, drittes Glied an der Spitze briunlich. Beine und Vorderhiiften gelb, letztere mit einigen sehwarzen Haaren. Tarsenglieder an den Spitzen gebriunt. Lirstes Glied der Vordertarsen mit einem flachen Ausschnitt dicht vol der Spitze und hier mit einem Schopf kurzer schwarzer Borsten, die an Lïnge allmilhlich zunehmen und rechtwinklig zur Lïngsrichtung der Tarsen stehen. Fliigel am Vorderrande gelblich, sonst graulich; Aderu vorne gelb, linten und an del Spitze brann; an den bekannten Stellen zwei dnukle Flecke.

?. Die Vordertarsen sind weniger tief ansgeselınitten und kïrzer behorstet, sonst dem on gleicl. 


\section{Diostracels.}

Loew, N. Beitr. VIII 43 (1861).

Diese Gattung ist ron Lw. I. c. nnd cbenfalls spaiter in seiner bekannten Monographie der nordamerikanischen Dipteren in gleicher Form nochmals beschrieben worden. Zur richtigen Bewertung der Gattung fehlte es aber in diesen Beschreibungen an dem Hinweis auf die Beborstung des Körpers. Dies bat Aldrich bej Beschreibung einer nenen Art olga in der Psyche 1911 nachgeholt, so laf wir hente besser als friilıe iiber diese Gattung urteilen können.

\section{Giallungscharakter.}

Gesicht breit wnd kurz, mit deutlicher Querteilung und einer spit\%en Endigung anf der Nitte, mit sebr großen, flachen, dem Riissel aufliegenden Tastern. Fühler von gewöhnlicher Form, klein, das dritte Glied alıgerundet mit einer dorsalen oder basalen fast nackten Borste. Auf dem Thoraxriicken stehen sechs Paar Dorsozentralborsten, aber keine Akrostikalbörstchen. Sehildehen mit zwei starken Borsten und einigen Haaren am Rande. 1 Humeral-, 2 Notopleural-, 1 Posthumeral-, 2 Supraalar-, 1 bis 2 Posthumeralborsten. Hiuterleib mit sechs deutlichen Ringen außer dem Hypopyg; der vierte Ring (Tergit) ist nach unten beiderseits dreieckig verlängert. Beine ohne besondere Beborstnug an Schenkeln und Schienen. IIintermetatarsus länger als das zweite Glied; Hinterhiffte obne Borste. Flïgel lang; dritte und vicrte Laingsaderu fast parallel; hintere Querader wahe dcm Hinterrande.

1 olga Aldr. ơ ․, Psyche XVIII Nr. 2. 71 Pl. VIII Fig. 15-18 (1911)

America sept.

2 masinus Lw. of $f$, N. Beitr. VIII 44. 1 (1861) . . America sept. olga Aldr. ist eine schwarzbeinje Art mit schwarzen Fibhlern, während masims Lw. gelbe licine und bräiunlichgelbe Fïhler hat.

Von letzterer sah ich ein typisches Pärchen in Loew's Sammlung.

\section{II!Ipochucuassus.}

Mik, Verh. zool, bot. (res. Wien XXvill 627 (1878).

Depranomia Wheel., Zowl. Bull. I 217 (1898).

Eine gute Gattung in dieser Gruppe, die Ilydrophorus Fall. hinsichtlich Kopf- und Fühlerbildung am näichsten kommt. Das Gesicht ist breit mit wenig ausgeprïgter Qucrteilnng, Augen pubeszent. Das dritte Fiilulerglied hat den charakteristischen Ausschnitt, dem wir bei Mydrophorms begegnen, unr ist das dritte Glied verlängcrt; ähnliche IIydrophomus-Arten mit verlaingerten Fublem gibt es aber mehrere: Loew beschrieb die Art rerulias aus Nordanterika, während ich mehrere Arten in Sehnuse's Samm- 
lung ans Sidamerika fund. Vergleicht man meine Figurenzeichnungen dieser Arten mit denen ron Mik und Wheeler I. e., so wird man jedoeh finden, daß die Fiihler bei Iypocharassus anders geartet sind. Das elste Glied ist hier oberseits deutlich behart, das zweite hat mehr napflibmige, nicht kugelige Gestalt wie bei Hydrophorus und die zweigliedlige Endlorste ist nieht zugespitzt, sondern fast bis zum Ende gleiehmäBig verdickt. Mik hat in seiner Beschreibung nnd Zeichung derselben hervorgehoben, daß das letzte Borstenglied anßerdem noeh dicht vor der Spitze benlen-

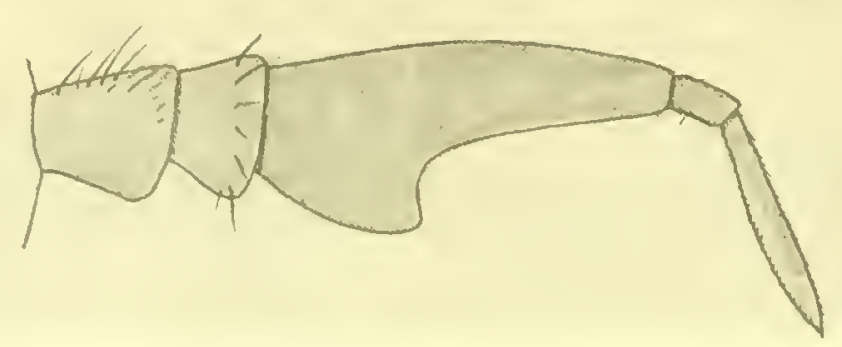

F'ig. 48. Hyprocharassus gladiator Mik. J'. Fühler. 48:1.

fürmig verdiekt sei, aber diese Auffassung kann nur auf einer Täinsehung beruhen: die Borste ist nn nu ein geringes anschwellend, bis mahe zur Spitze gleichmißig verdickt, ancl Wheeler hat sie so gesehen und gezcielunct. Der Thorax hat keine borsten, ist abel fast anf seiner ganzen filiche mit Reihen feiner Börstehen orler knrzer Haare besetzt, so daß da, wo sonst Dorsozentralborsten zn sehen sind, eine nnregelmäiige Reihe von zweizeiligen Hïrchen steht; die Akrostikilbörstchen sind ebenso dentlicl zweireihig vorhanden. Wie Mik daznkommt zn sagen, daß diese fellten, ohwohl sie bei beiden typischen Exemplaren, die ich in Hainden hatte, unter den iibrigen llairehen dentlich erkannt werden kimnen, ist einigermaßen anfïllig; im iibrigen ist die Borstenlosigkeit des typischen Tieres ylatiator Mik sehr groli, so daß die IInterhiften weder Borste noel Ilaar aufweisen. Die Fliigel mit ilurer bauehigen ersten IIinterrandzelle ähneln am meisten der Gattung Hydrophorus.

Es sind bis jetzt zwei Arten bekannt.

1 gludiator Mik ơ, Verhandl. zool.-bot. Ges. Wien XXVIII 629, taf. X, fig. 1-6 (1878) . . . . . . . . . . Ameriea sept. Florida . Tohnsoni Wheel., Zool. Bull. I 219 fig. 1, d, e, $/$ [Drepanomyia] (1898)

Vier Exemplare auch in der Samminng des Berliner Museums ans dem Staate Georgia.

reh gebe obenstehend eine Zeiehnung der Fiihler.

Johnsoni Wheel. = glatiator Mik. 
2 mminosus Wheel.. Zool. Bull. I 219 fig. 1, $a, b, c$ [Drepanomica] (1898). Florilli

Der Unterschied zwiscben beiden Arten liegt darin, daß prumosus Whecl. ein drittes Fïhlerglied hat, dessen Einschnitt erheblich tiefer geht, so daß fast das Bild einer Krebsschere entstelit. Iel besitze ein typisches Exemplar von Wheeler und gebe eine Zeichnung der Fiihler.

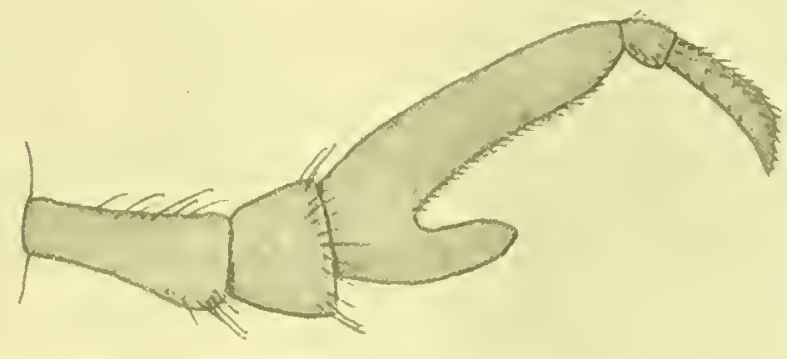

I'ig. 49. Hypocharussus pruinosus Whecl. o’. Fiille1 48: 1 .

\section{S!jutomonewrmm.}

Novum genus Hylrophorinarum.

Ganz rom Ilabitus eines Liancalus und nit einer Flügeladerung, die an Orthoceratim erinnert; von letzterer abweichend dureb andere 'Thoraxund Sehildbeborstung, durch das breitere bis unter die Augen berabgehende Gesicht, durch eine anffallend kurze zweite Längsader und andere Stellung der hinteren Querader; auch ist das erste Fthlerglied zart behaart. Der Kopf ist ganz wie der eines Liancalus; das Gesicht mïßig breit, reichlich von halber Angenbreite, es hat eine deutliche Querfurehung und reicht, unten kreisförmig endigend, ein gutes Stiick noch unter die Angen hiual. Taster ziemlich breit, zum Teil unter der Gesichtsfliche verborgen, dem dicken Riissel aufliegend; die Scheitelhorsten sind selu zart. Das erste Fiilılerglied ist mikroskopiseh sebr zart bebart, dis zweite Glied selır klein, das dritte oval mit vorderer Spitze und einer naekten zweigliedrigen dorsalen Borste. - Am Thorax sieht man sechs zarte Dorsozentralborsten nnd zweireihige Akrostikalbirstehen, am Schildrande nur zwei weit anseinanderstehende Borsten; eine Protborakale ist vorhanden, aber selur zart. Hinterleib mit funf ganzen Ringen; das Hypopyginm kurz nnd dick mit zwei griißeren ovalen Lamellen und verschiedenen inueren Organen. Die Beine sind lang und schlank, namentlich die Tarsen. Hinterhiiften 
mit einer Borste, Hintersehenkel mit einer Prïapikalen im dritten Viertel del Sehenkelliinge. Fliigel lang und verhiilnismäßig schmal, mit anffallend kurzer zweiter Längsader, die sehon vor der Flïgelmitte in die Randader liuft; beim $q$ ist sie etwas lïnger, aber auch noch kurz, denn sie

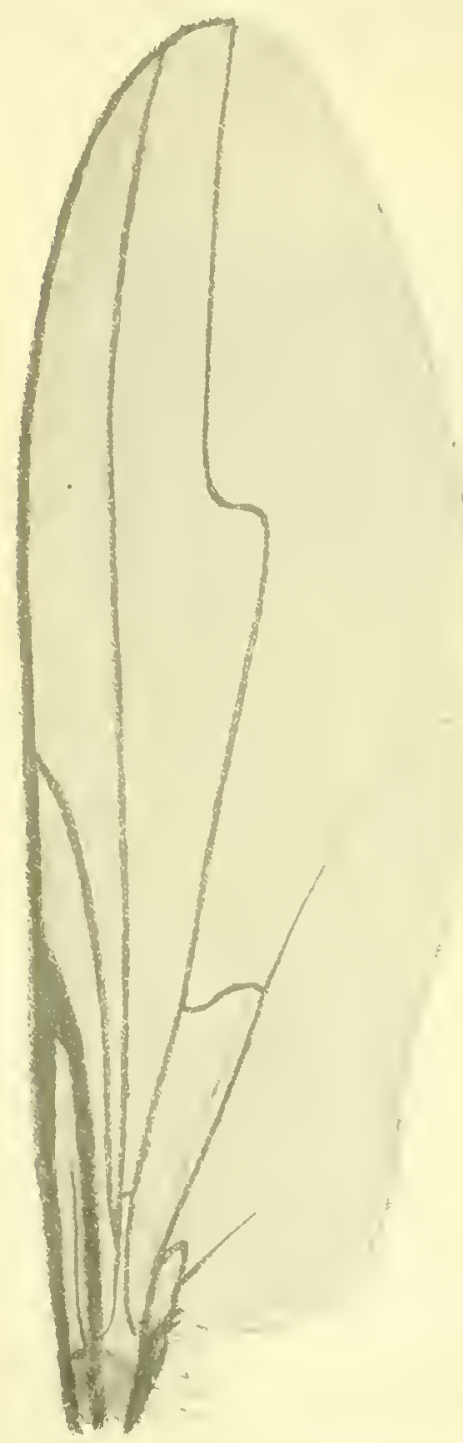

Fig. 50. Syntomoneurum alatum O'. Flïgel.18:1. miindet in die Randader gegeniiber der S-förmigen Krinmmng der vierten Luingsader, welche an der Fliigelspitze ansmiundet; die hintere Querader ist viel weiter" als gewöhnlich vom Fliigelhinterrande entfernt $\left(\sigma^{T}\right)$ und ist auch in umgekehrter Richtung seliriig S-förmig gestellt $\left(\sigma^{7}\right)$; beim Weibchen steht sie erheblieh weniger sehriig und auch näilıer den Fliigelrande.

1 alatum n. sp. on 1 Figur l'eru

ठ․ - Thoraxrieken metallisch sehwarz mit griinliehgranem Reif, so daßrom Glanz kaum efwas zu sehen ist. Die Notopleuralgrube ist dentlich weiß bestiinbt, eljenso sieht man hinter der Schulterbenle und über der Flügelwurzel je einen weißbereiften Flecken. Brustseiten sebwar'gran ; Schwinger braun; Sehiipuchen blaßgelb otme dunklen Saum mit sehwarzen Wimpern. Kopf: Angen hochgestellt, pubeszent; Gesicht reichlich von halber Augenbreite, nach unten iiber den Angenrand hinaus verlängert, mattlıraun mit dentlieher Querfurehe. Stirne matt grangriin. Hinterkopf oben graugriin, an den Seitemäindern weiß bestäubt; untere Hinterkopfrandborsten lang und weiß. 'Taster breit, unter dem verlingerten Gesicht dem dicken Riissel aufliegend. Fiihler mit etwas rerlangertem ersten zart behartem Gliede; das "weite ist ansuehment klein, das dritte oral, etwa $1 \frac{1}{2}$ mal so lang: 
wie breit, vorne zugespitzt mit dorsaler, jedoch nicht weit von der Spitze einsetzender Borste; die Fiihler sind sehwarz, jedoch ist die Unterseite aller Glieder rotgelb. - Hinterleib sehwarz mit knrzen schwarzen Haaren, Hypopyg wie oben besehrieben, sebwarz mit grauer liestäubung; die breiten ovalen Lamellen sind gelb und haben einen deutlichen braunen Saum, sind aber nur sehr kurz und spärlieh behaart. - Beine lang mit sehr langen und dïnnen Tarsen, sie sind mit den Vorderhiiften rotgelb, die beiden hinteren Hiiften sind scluwarzgrau. Sehenkel sehlank mit brauner Längsstrieme anf den oberen Seiten, Hintersehienen und Hintertarsen brännlieh. Die Mittelhüiften tragen auf der Mitte ihrer Vorderseite einen Borstensehopf aus drei dieht zusammengestellten Borsteu; die Vorderhiiften sind ganz naekt, nur an illrer Spitze sieht man zwei, anf der Unterseite an der Basis der Vorderschenkel ebenfalls zwei gespreizte Borsten. Die Sebienen haben seln' zarte Beborstumg, die Hinterschienen anf ihrer Unterseite eine feine dentliche Bewimperung auf ihrer ganzen Lünge. Die Tarsen sind alle diinn und naekt, mit sehr sehwach ansgebildeten Pulvillen; Hintermetatarsus etwas kiirzer als das zweite Glied, er ist anch etwas dicker als die ïbrigen sehlanken Glieder und trägt anf der Unterseite an seiner Basis eine Einzelborste. - Flitgel sehr lang und schmal, wie in der Gattungsdiagnose angegeben. S. Figur 30. 6-7 mm lang.

9. Das Gesicht hat die gleiehe Breite und Farbe wie bein $\sigma^{7}$, nnr die Länge ist ein wenig geringer, wenngleieh es aneh noch iiber die untere Augeneeke hinabreieht; an den Fiullern ist das dritte Glied ein wenig kiirzer und ganz sehwarz. Die Vorderschenkel entbehren der beidlen gespreizten Borsten an der Basis. Die Fliigel haben eine etwas andere Aderung: die zweite Liingsader ist nieht ganz so kurz, sie miindet der Biegung der vierten Lïngsader gegenüber in den Fligelvorderrand; die Randader und erste Längsader sind kaum etwats dieker als die iibrigen Aderu, die hintere Querader weniger sehräige und bis zur Fliigelmitte weitergeriickt.

Zwei o", drei $q$ aus Peru, Pichis Veg 1. 1904. - Peru-Urubambafi, Umahuankilia IX 1903. [Selonuse.]

Anmerkung. Unter diesen Exmplaren befindet sich ein etwas kleineres Weibchen mit etwas anderer Flïgeladerung und anders gefïrbtem Gesiclit; walıscheinlich stellt es eine andere Art dar, die mir aber bei dem einzigen Weibelien nieht hinreichend charakterisiert zu sein scheint.

\section{Pleylareleus.}

Aldr., Biolug. Centr. Amer. Ijipt. 13.12 (1901).

Aldrieh, der in seinem Katalog 1905 eine besondere Gruppe Thinophilinae anfgestellt und diese ron den Iydrophorinae getrennt behandelt, hat Phylarchus in die erstere gebracht. Ieh babe diese Trennung nicht fiir 
erforderlich erachtet, weiß auch nicht, wie Aldrich sie hegriinden will, und lasse Phylurehus zuniachst bei den IIydrophorince. Als typische Art ist nur das Weibehen einer Art tripartitus vorlanden. Das Gesicht ist breit, oben konkav, unten gewölbt, etwas vortretend wie bei der Gattung Pelastoncurus, anch das dritte Fuilılerglied ist mit einer kurzgefiederten dorsalen Borste versehen; das alles sieht ganz nach Pelastoneurus aus. Das erste Fiillerglied ist beharat; 'Tister klein. Thorax ohne Akrostikalbörstehen und ohne Abplattung vor dem Schildehen, letzteres mit zwei starken Randborsten. leine nicht stark beborstet; Hinterhiiften mit einer Borste und Nebenhaar. An den Fliigeln verläuft der letzte Abschnitt des vierten Liingsader grade und die dritte ist ein wenig gebogen. Diese Alerung stimmt allerdings nicht mit Pelastoneurus iberein, es ist aber anch das Einzige, das als abweichend gedeutet werden kann. Nïheren AufschluB iiber die Stellung dieser Art wird man wohl erst elhalten, wenn man anch bei dem Miinnchen dessen Fliggeladernng kenmengelernt haben wird. Alles deutet aber eher anf eine Gattung der Doliehopodinae hin; die gamze lionflbildung ist nicht die einer Hydrophorine. Ich lasse die Stellung dieser Gattung his anf weiteres als zweifelhaft bestehen.

1 tripurtitus Aldr. क, Biolog. Centr. Aner. Dipt. I 342, tab. VI, fig. 16 (1901)

Mexien

\section{Peodes.}

Loew N. Beitr. V 29 (1857).

Ob diese Gattung in Amerika vorkommt, bleibt zweifelhalt. In Katalog Kertész VI 318 ist eine Art ans Chile von Bigot genannt. Sieht man sich die Bigotsche Beschreibung niher an, so findet man keinerlei llinweis darauf, daß die von ilum beschriebene $\Lambda$ rt aus den und den Griinden zur Gattung Peodes gerechnet werden milisse; es ist alleh sehr fraglich, ob ligot die Gattung I'eodes überhanpt gekannt hat; in seiner ganzen beschreibung ist keine einzige Angabe, welche sich anf' die Form des 'Tieres, sei es des ganzen oder eines seiner Teile oder anch anf Beborstung bezieht, nur Färbnngsaugaben der einzelnen Körperteile, nichts weiter. Bigot geniebt nicht die Antoriät, daß man seiner Bestimmung ohne weitere Priifung Glauben schenken könnte; Gattungen zu bestimmen war stets seine schwache Seite. So besitzen wir denn anch in seimer Beschreibung. allein keine Gewähr dafiur, daß wir hier einen Peodes vor uns haben. Gattung wie Art bleiben gleich zweifelhaft.

- dichromatus Big. ơ 9 , Am. Soe. Ent. Fr. sér. 6 X 295 (1890) . Chile 


\section{Gruppe IV.}

\section{A phrosylina e.}

\section{Perectipos!jlus.}

Nov. sulogenus.

Aphrosylus Wheel. (nec. Mralk.), Pruceed. Californ. Acad. Sc. sir. 3. Zool. I $145-152(1897)$.

Wheeler hat l. c. drei Arten dieser Gattmug beschrieben und sie unter Hinweis auf Loew's Gattungsdiagnose von Aphrosylus Walk. in seines Monographie der Amer. Dolichop. 148 (1864) als damit ïbereinstimmend zu dieser Gattung gestellt. Loew kaunte vier paläarktisebe Arten; die bis heute bekannt gewordenen acht Arten gaben mir Veranlassung, im 1. Teil meiner Dipterologischen Studien über die Dilochopodiden (1917) den Gattuogscharakter noch etwas eingehender festzulegen, namentlich hinsichtlich der Beborstung, anf welche Loew nicht näher eingegangen war. Die paläiarktischen Arten baben einen ganz nackten Thoraxrỉcken, auf dem von Dorsozentralborsten nur vier Palue stehen, außerden zwei Schildborsten; Akrostikalbörstchen fehlen granz; die Vorderhiiften haben eine sehr kurze dornartige Beborstung, auch dic Schenkelglieder tragen zwei starke divergierende Borsten. Vergleicht man dies mit den Wheeler'schen Beschreibungen und Fignren, so fundet man doch eine ganze Reibe von Abreichungen: zunächst sind hier dentliche (prominent) Akrostikalborsten vorhanden und anßer den beiden starken Schildborsten noch zwei andere schwaichere; wie groß die Zahl der Dorsozentralborsten ist, wird leider nicht gesagt; die Vorderhiuften werden nur als behart beschrieben und dargestellt, die Schenkelglieder sind ohne Borsten. In Wheeler's Figml ron Aph pracdator wird der Riissel olne den charakteristischen lJaken dargestellt, was wohl nur cin Uberselsen bedentet, da loew dies Merkmal besonders hervorhebt und Wheeler die Ubereinstimmung ausspricht. Dann ist aber auch die Form des Gesichtes eine ganz andere; zwar ist die horizontale 'Teilnng anch vorhinden, aber diese wird hier durch eine Einschniirnug auf der llitte des Gesichtes verursacht, die bei keiner der paliarktischen Arten vorhanden ist; der besseren Vergleichung balber gebe ich die Fignr vom Kopte unserer Art Aphr. raptor Halid und daneben eine Kopie der Wheeler'schen Zeiclsnung rom Kopfe seiner Art praedator; im Profil gesehen springt bei letzterer Art der untere Teil des Gesichtes vor, wailurend bei unseren 
paliarktischen Arten das Gesicht gerade abfällt; schließlich sind die 'Taster der amcrikanischen Arten erhcblich kleiner nud bei deu Männchen anch kleiner als bei den Weibchen, ungekehrt wie bei den paliarktischen Arten.

Alles zusammengenommen ist das einc ganze Reihe von Unterschieden. Ieh bin der Ansicht, daß wir berechtigt und verpflichtet sind, die amerikanischen Arten wenigstens in ein Subgenus von Aphrosylus zu stellen, das ich Paraphrosylus nenne.

Bestimnum

1 Fiihlerborste nackt; hintere Qnerader rechtwinklig zur vierten Läingsader

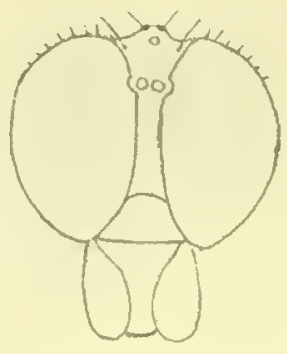

lig. 51. Aphr. raptor llalid ơ. línf von vorne.

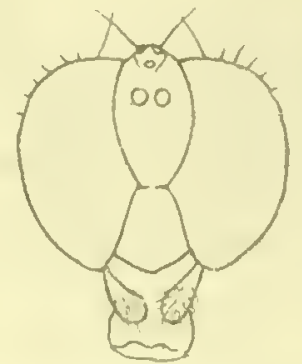

Fig. 52. Paraphros, pracklator Wheel. Konf ron vorne.

- Fiblerburste pubeszent; hintere Querader stumpfowinklig zur vicrten Längsader . . . . . . . . . grassator Wheel. ơ ?

2 Fliigel iiber der hinteren Querader mit einem schwarzen Flecken. Vorderund Hinterschenkel oberseits bewinpert . . direptor Wheel. $0^{\pi}$ 오

- Fliigel ohne solchen Flecken. Vorder- und Hinterschenkel oberseits nicht bewimpert . . . . . . maedator Wheel. of?

\section{Artverzeichinis.}

1 direptor Wheel ơ, Proceed. Californ. Acad. Sc. ser. 3. Kool. I 148 Pl. IV fig. 7-10 (1897) . . . . . . . . Amcrica sept. 2 grassator Wheel. $0^{7}$, Procect. Californ. Acad. Sc. ser. 3. Zool. I 149 PI. IV fig. $11-13$ (1§97) . . . . . . . . . America sept. 3 pracdator Wheel. ơ , Proceed. Californ. Acad. Se. ser. 3. Zool. I 146 Pl. IV fig. $1-6$ (1897) . . . . . . . . . Americal sept. 


\section{Gruppe V.}

\section{Me d e terina e.}

Der Gruppeneharakter erleidet bei den Arten der nearktischen und neotropisehen Region keine Abweichungen von demjenigen, den wir in der palïarktisehen Region anfgestellt haben. Won den hier vorkommenden funf Gattungen Medetera Fiseh, Oligochaetus Mik, Thrypticus Gerst., Submedetenus Beek. und Dolichopherus Liehtw. finden wir in Amerika nur Medetera und Thrypticus wieder; andere Gattungen sind bis jetat mit Sieherlieit nicht festgestellt worden. Aldrieh hat zwar in seinem Katalog nordamerikanischer Dipteren 1905 in diese Gruppe noeh die Gattungen Peloropeodes Wheel. und Coeloglutus Aldr. eingestelit, aber Peloropeodes wird, wie ieh an anderer Stelle sehon ansgefïhrt habe, zu den lihaphimen zn rechnen sein, während Coeloglutus naeh meinel Auffassung, die atueh im Katalog Kertész VI 1909 Ausdruek gefunden, eine Diaphorine ist; jedenfalls ist für diese beiden Gattungen kein Merkmal gegeben, das uns berechtigte, sie mit den Mcteterinen zu vereinigen. Wir haben also zu Zeit nu die beiden Gattnngen Medetera und Thrygticus, mit denen wil uns in beiden amerikanisehen Regionen zu besehiftigen haben.

\section{Merleter' Fisch (1819).}

Aus Siidamerika waren bisher keine Medetera-Arten bekannt, erst die Sehnusesehe Sammlung und einiges Material der Museen ron Berlin, Wien und Budapest haben uns einige Aufklärungen gebraeht, sodab man sagen kann, daß Medetera ziemlich gleiehmäßig in beiden amerikanischen Zowen verbreitet ist. Mit vier Schildborsten, dentlieh zweireihigen Akrostikalbörstehen und einer meist apikilen Fühlerborste sehließen diese Arten sieh unseren palaiarktisehen eng an; um vereinzelte Ausnahmeu mit zwei Sehildborsten kommen vor; die siidamerikanisehen Arten zeiehnen sich vielfaeh noch dadureh aus, daß die Mïmnehen verzierte Vordertarsen haben. Ieh kınn in ganzen 27 Arten vorfuiluren, wiihrend Wheeler in den Proeeedings of Californ. Aead. of Se. 189913 Arten und Aldrieh in seinem Katalog 1905 14 Arten bekanntgibt.

\section{Artregister mil Beschreilmugen.}

1 aberrans Wheel. o, Proceed. Californ. Aear. Se. ser. 3. Zool. II 22. 22 tab. 11 fig. 40 (1899)

America sept. 
Fine dureh etwas abweichende Ftihlerbildung nud starken Metallglanz, bemerkenswerte Art; das erste Fïhlerglied ist dicker als gewöulich und das kurze dritte Fiihlerglied ruht wie cine Eichel in dem zweiten Gliede; die Borste ist zentral, lang und pubeszent. Das Gesieht ganz glänzend, griin bis blau. Hüften braun, im ibrigen sind lie Beine ganz gelb. $2 \cdot 75 \mathrm{~mm}$ lang.

2 Aldrictii Wheel. ơ, Proceed. Californ. Acad. Sc. ser. 3. Zool. II 24. 25 (1899) . America sept.

๙. - Fubler schwarz, jedoch das erste Glied gelb, das dritte mit einer nackten subapikalen Borste. Thoraxrieken mit vier granen Lïingsstreifen. Beine ganz schwarz. $35 \mathrm{~mm}$ lang. Siehe die ausfulurliehe Beselureibung bei Wheeler l. e.

3 anus n. sp. $\sigma^{7}$.

Paraguay

ठ․ - Thoraxriicken schwarzgrin, hriunlich bereilt mit deutlichen Akrostikilborrstehen; von Dorsozentralborsten ist nur das hinterste Paar deutlich; das Schililchen hat zwar vier Borsten, abel zwei vou diesen sind zu feinen Härehen zusammengeschrumpft. Schwinger gelh; Schiippchen weiB, hell bewimpert. - Kopf: Stirn und Gesicht matt braunselwarz, der untere Teil glänzend braun. Fiblhler klein, sehwarz, Fiihlerborste zentral; Hinterkopfzilien unten weiß. - Hinterleib mattschwarz; Hypopygium schwarz, sehr lang und dick, reichlich so lang wie rer Hinterleib. Analanhänge wenig entwickelt, kanm einige bramne Spitzen sichtbar. - Beine nebst allen Hiiften sehwal'z; Knice und Tarsen mit Ausnahme der letzten Glieder rostgelb; zweites 'Iarsenglied der Hinterbeine dreimal so lang wie das erste. - Fliggel glashell; hintere Querader wn das 1\%/2 fache iller eigenen Länge vom Fliigelhinterrande entfernt. $-2 \mathrm{~mm}$ lang.

$2 \sigma^{7}$ aus Paraguay [Fiebrig] Ungar. Nat.-Mnseum.

4 appenticulata Wheel. ơ, Proced. Californ. Acal. Sc. ser. 3. Zool. Il

29. 32 tab. II tig. $41-43$ (I899) . . . . . . Ameriea sept.

07. - Mit sehwarzen Fühleru, ungestreiftem mattgranen Thoraxricken, gelben Beinen, hei denen $\%$ der Schenkel von der Basis an pechbrann sind, und mit einem Aderanliang an der hinteren Querader. $2.5 \mathrm{~mm}$ lang.

5 aminittata Wheel. ơo, Proceed. Californ. Aead. Sc. ser. 3. Zool. II 29. 31. tab. II fig. 47 (1899) . . . . . . . Ameriea sept.

б. - Fiihler sehwarz. Gesicht unten stablblau. Thorax mit drei goldbriunliehen Lïngsstreifen. Siehe die ansfiihrliche Beschreilıng lıei Wheel. 1. c. $2.5-2.8 \mathrm{~mm}$ lang.

6 californicnsis Wheel. ơ 27. 25 tab. II fig. 44, 45, (1899) . . . . . . America sept.

Siehe die kurze Charakteristik in meiner Bestinmungstabelle mul die ausfiahliche Beschrcibung bei Wheeler 1. c. $3-3 \cdot 5$ mm lang. 
Borsten und mit zwei Einzelborsten auf der Unterseite, ungereehnet die Endborsten; Hintersehienen ebenda mit ein bis zwei Borsten, außerdem noch mit einer Borste dieht vor der Spitze und mit gelben Wimperhaaren an der unteren Seite. Vordertarsen rotgelb, die letzten beiden Glieder geschwärzt; das zweite Glied kurz und breit, trapezförmig, das dritte an del Wurzel lappig erweitert und hier halbkugelig blasig aufgetrieben (s.Fignr). Mitteltarsen an den Endgliedern gesehwiirat, Hintertarsen desgleiehen, del Metatarsus halb so lang wie das zweite Glied. - Flïgel wasserklar; dritte und vierte Längsadern stark konvergiereud; hiutere Querader $1 \mathrm{~m}$ das $1^{1} / 2$ faehe iller eigenen Lainge vom Fliigelhinterande entfernt. $4 \mathrm{~mm}$ lang.

․ - Das Gesieht ist etwa um die Hälfte breiter, die 'Tarsen einfach, sonst dem or gleieh. $3-4 \mathrm{~mm}$ lang.

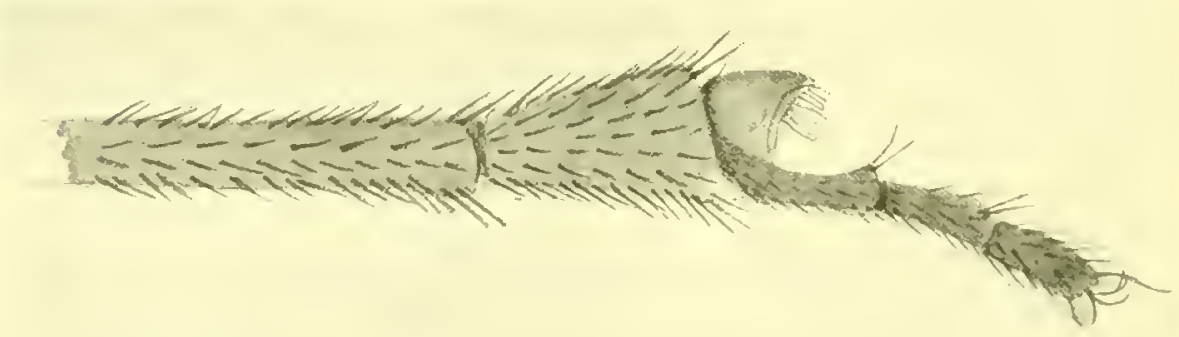

Fig. 55. Medetera excavata Beck. $\sigma^{7}$. Vordertarsen. $48: 1$.

3 ơ, 6 q ans Pelı-Pinipini [O. Garlepp] - Bolivia-Mapini, 4. III.03. Sarampioni, $700 \mathrm{~m}$ hoch. - Pern-Meshagua 26. IX. 03. Urubambafi [Sehnse] Dresdner zoologisches Museum.

! excavata n. sp. $0^{7} \uparrow .1$. Figur . . . . . . . Peru, Bolivia.

Eine der dilatata sebr nahe rerwandte Art, aber dureh etwas andere Verzierung der Vorderbeine und Beborstung der Mittellseine ron ihr geschieden.

万. - Thoraxriieken metalliseh bläulieh bis griin glïuzend und im Gegensatz zn dilatata mit deutlieh weibgraner Bereifung. Borsten und Behaarung wie bei dilatata; Brustseiten griingran, matt gliinzend. Sehwinger und Sehiippehen blaßgelb, letztere lang blaßgelb bewimpert; viel Schildborsten, eine braune I'rothorakalborste. - Kopf: Stirne und Gesicht glänzend veilehenblan, unter der Qnernalıt zart grall bereift; Taster und Rüssel braunselıwarz. Fiihler schwarz, klein, Borste deutlieh etwas beharat; Hinterkopfailien unten weißgelb. - Hinterleib glänzend erzgriin mit iiberwiegend gelblieher Behaarung; das glainzend sehwarze, nur an der Spitze gelbe Hypopyg hat ungefïhr dieselbe Größe und die Form wie bei der Art dilutula. - Beine nebst Vorderhiften hell 
rotgell, die letzten Tarsenglieder kaum etwas dunkler. Die Beborstung' der Sehenkel und Sehienen ist die gleielie wie bej dilatata, jedoch fehlen an den Mittelsehienen die beiden krïftigen Einzelborsten auf der Unterseite, ferner ist die Verzieruug der Vordertarsen cine andere: das zweite Tarsenglied luat zwar die gleiche trapezfömnige Form, ist aber verhäilnismäßig linger; das dritte Glied ist tief ausgesehnitten, an dem lappigen Wurzelteil anch blasig ansgrehöhlt und am Rande mit einer Reihe platter, an der Spitze gebogener Borsten besetzt; an den Hinterbeinen lat das zweite Tarsenglied nicht ganz die doppelte Länge des ersten Gliedes.

q .- Das Gesicht ist ctwas breiter, die Tarsen einfach, sonst dem $\sigma^{x}$ gleich. $3-4 \mathrm{~mm}$ lang.

2 o', 6 f aus Bolivia-Mapiri, 4. 111. 03, Sarampioni $700 \mathrm{~m}$ loeh. Peru-Neshagua, 3. X. 03, Urubambafi. - Peru-Ucayalifi, 20. X. 03, Unini [Selınuse] Dresduer zoologisehes Musenm.

Ђ. - Thoraxrîcken metalliseh griin, granbraun bestäubt; in der Reihe der Dorsozentralborsten stelien linten nur oine bis zwei dentliclse Borsten, am Sehildehen aber nu zwei; dabei sind die Akrostikal. börstchen dentlich zweireihig. Sehwinger und Sehiippehen gelb, letztere weif bewimpert; Protlorakalborsten weiß. - Kopf: Stirne mattbrann; Gesicht selır selımal weiß, anch unter der Qnernalit. Riissel und Taster ganz gelb. Fiihler ebenfalls gelb, las dritte Glied sehwarzbraun, etwas läinger als breit mit subapikaler, fast dorsaler nackter kurzer Borste; Hinterkopfzilien unten weiß. - Hinterleib metalliseh glïnzend griiu, schwarz behatut, die beiden ersten Ringe gelb; Hypopygium ganz gelb, kurz, breit mit gelben Anbiingen. - Beine mit allen Hiiften hellgelh, ohne Borsten und sehr lang. Vordertarsen ungefihr $1 \frac{1}{2}$ mal so lang wie die Sehiene. - Fligel wasserklar, dritte und vierte Längsadern dentlich konvergierend. Läinge des Randaderabsclnittes zwischen ibren Endpunkten gleich der halben hinteren Querader, diese mindestens um die dreifache eigene Länge vom Hinterrande entfernt. $2 \mathrm{~mm}$ lang.

ㅇ․ - Thoraxrieken etwas kriftiger grau bestäubt. Der llinterleib ist bei einem Weibehen ans Paraguay an der Basis nicht gelb, während bei einem anderen Weibchen aus Carolina die gelbe Farbe deutlieh auftritt; sonst kein Untersehied vom Männchen. Die weiblichen Genitalien sind hier auders gestaltet als gewöhnlieh; sie zeigen nieht dic gewölnnlichen teleskopartig angeordneten, kleiner werdenden Ringe, sondern der Hinterleib endigt in Gestalt zweier flacher gelbbrinnliclicr Sehalen, die mit ilırer hohlen Seite einander zugekehrt sind.

Anmerkung. Diese Art weicht erheblich vom allgemeinen Typus ab: die Furm des dritten Finhlergliedes mit der fast dorsalen Burste, das nur zweiluorstige Schildchen sowie die abweichende Form der männlichen unl weiblichen Geschleehts- 


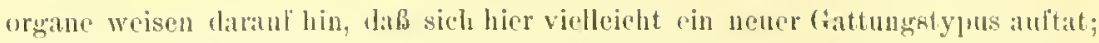
dazu bediufte es allerlings genamerer mikroskopiseher Intersuchungen, die ich an

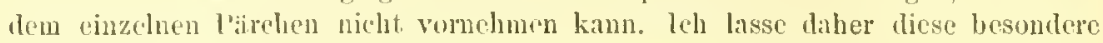
Art vorlantig liei dieser (Nattung.

107,1 a ans Paraguay, S. Bernardino [Fiebrig] Wiener llofmusetum.

1 q ans Carolina unerid. ['Zimmermann] Berliner zoolugiseles Museum Nr. 5214.

11 exigua Aldr. óq, Kansas Unio Se. Bullet. I 94 (1902) America centr.

Siehe die Charakterisierung in meiner Bestimmungstabelle und Aldrieh's Bescbreibung I. c.

12 fiabellifera n. sp. ơ 1 Higu . . . . . . . . . . Peru

$\sigma^{\top} Q$. - Thoraxinicken von metalliseh blatugriner Grundfarbe, glinzend, nur mit sehr schwachem gramen Reif ibergossen. Schwinger und Schiippelien blaligelb, letzterer mit bla@gelben, in gewisser Richtung

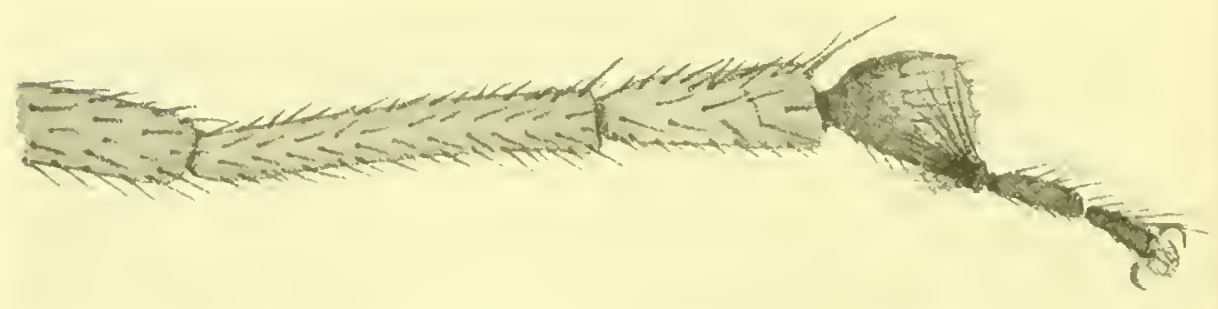

Fig. 56. Medetern flabellifera Beck. O’. Tordertisen. 48:1.

bräunlich sehimmeruden langen Wimpern. - Kopf: Stirn und Gesielıt stahblau ohne Bereifung. Fiihler schwar, klein, mit sehr diuner hebarter zentraler Borste. Taster und Riissel schwarz; IIinterkopfzilien unten gelb. - Hinterleib bronzefarhig mit größtenteils weißgelblicher Behaarung. Hypopyg schmal und lang nit kleinen gelben Anbiingen an der Spitze, Beharnng weiß. - Beine blaßyelb, weiß behaart; Hiiften und Sehenkel, letztere bis nahe znr Spitze schwarzbram; Hiiftgelenk rostgelb; Hintersehenkel dick; Vordertarsen rerziert: das dritte Glied in älnlicher hohlkugeliger Form wie bei der Art excavata, aber an der Spitze des Gliedes erhebt sich ein schwarzer fäeherfömiger, nach riickwiirts gerichteter Haarschopf; das vicrte und fiinfte Glied ist wie bei den ähulichen Arten ebenfalls sehr diinn mol verdunkelt; an den Hinterbeinen ist das zweite Tarsenglied nicht ganz doppelt so lang wie das erste. Die Beborstung der Beine ist die ibliche, aber nur sehr schwach entwickelt. - Fligel zart blaßbriunlieh mit gelbbräunlichen Adern; dritte und vierte Längsadern stark konvergierend, der von ihnen an der Fliigelspitze eingeschlossene Teil der Randader ist gleich $1 / 4$ der hinteren Queraderlänge. 3-4 1 m lang. 
10 , 1 a aus Peru-Meshagua, 9. X. 03. Urubanbali [Schnuse] Dresilner zoologiselies Museum.

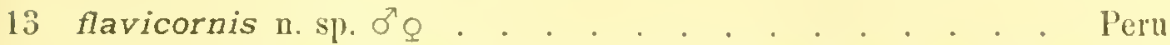

6. - Thoraxricken von metalliseh sehwarzgriiner Grundfarbe aber mit dichter mehlweißer Bestäibung bedeckt, so daf der Glanz nicht inmer deutlich hervortritt. Beborstung und Behaarung wie gewölınlich. Sehwinger und Sehiippehen blaßgelb, letztere lang dunkel bewimpert. - Kopf: Stirne und Gesicht schwarzblau, letztere von geringem Glanz, erstere fast ganz matt. Taster und Rissel schwarz. Fiihler brann, letztes Glied hellgelb mit langer feiner, kurzbeharater Endborste. Hinterkopfzilien unten selıwarz. - Hinterleib bronzefarbig, schwarz behatart. Hypopyg groß, lang, gliinzend schwarz, Endlamellen gelbbraun. - Beine mit Hiilten schwarz, das Spitzenviertel del vorderen Schenkel, vordere Schienen und Tarsen sowie die Knice der Hinterbeine rotgelb. Vorderschienen ohne Borsten; Mittelschienen mit einem divergierenden Borstenpar im ersten Viertel der Oberseite; Iinterschienen ebenda mit zwei Einzelborsten und kurzen Wimpern der Unterseite und an der Spitze der Oberseite. Vordermetatarsus so lang wie die beiden lolgenden Glieder zusammen. Hintermetatarsus laall so lang wie das zweite Glied. - l'ligel schwaeh gelbbriunlieh gefïrbt mit gelbbraunen Adern; dritte und vierte Lüngsadern dentlich kouvergierend; das von ihnen eingeseblossene Stiick des Flïgelrandes etwa so lang wie der dritte Teil der hinteren Querader; letztere nu ihre eigene Länge vom Fligelrande entfernt. liandader dicker als gewöbnlich. $3 \cdot 5-4 \mathrm{~mm}$ lang.

Q. Mit breiterem Gesicht, sonst dem ơ grleich.

2 ठౌ, 1 क aus Peru-Uealyalifi 19. X. 03. Unini [Schnuse] Dresiner zoologisches Musemm.

14 mura Wheel. $\sigma^{7}$, Proceed. Californ. Acad. Se. ser. 3. Zool. II 23.23 tab. II fig. $46(1899)$. . . . . . . . . . America sept. metallina n. sp. $\sigma^{\top}$. . . . . . . . . . . . . Pern

ơ. - Thoraxricken schwarzgriin bis kupferfarbig, vor dem Sehildehen mitunter messingfarbig glänzend und mit etwas graubrauner Bereifung, die aber nur sichtbar wird, wenn man die Flichen in sehriiger Riehtung betrachtet. Beborstung und Behaarung wie bei allen iibrigen Arten. Schwinger und Schippchen brann, letztere lang schwarz bewimpert. - Kopf: Stine und Gesicht gliinzend schwarzblan, letzteres mitunter auf der Mitte etwas matt nadelrissig. Taster, Riissel und Fiibler schwarz; drittes Glied klein mit langer feiner behaarter Borste; Postokularzilien unten scbwarz. - Hinterleib schwarggrin bis bronzefarbig, schwarz behaart. Hypopyg ziemlich dick und sehr lang, Endlamellen gelbbraun. - Beine: Hiiften und Schenkel schwarz, Wurzel der Sehienen braun, die iibrigen Teile der Beine rotgelb, nur die letzten Tarsenglieder dunkel. Tarsen einfach; der Vordermetatarsus 
ist so lang wie die ibligen vier Glieder zusammen; Hintermetatarsus ein wenig kiirzer als das zweite Glied; letzteres ungefilln $1 \frac{1}{4}$ mal so lang. Vordersehienen borstenlos; Mittelsehienen mit einem divergierenden Borstenpar im ersten Viertel der Oberseite, Hintersehienen mit zwei Einzelborsten. - Fligel sehwach gelbbräunlich; dritte und vierte Lïngsadem mïßig konvergierend; der vou ilnen an der Fliigelspitze eingesehlossene Randaderabschnitt ist etwa so groß wie die lathe hintere Querader. $3-35 \mathrm{~mm}$ lang.

7 ó, 7 q aus Peru-Meshagua, 9. X. 03. Unubambafi. - Peru, $150 \mathrm{~m}$ hoelt, Pachitea-Niindung, 3. XI.03. - Peru, 12. 1. 04, Chandramayo. - Pern-Ueayalifii, 20. X, 03. Unini [Selmuse] Dresdner zoologisehes Museum.

16 minor n. sp. ठ์. 1 Figur

America merid.

б. - Thoraxricken glinzendgriin bis veilehenblan mit drei bis vier starken Dorsozentralborsten; die ganze vordere Hälfte des Riiekens

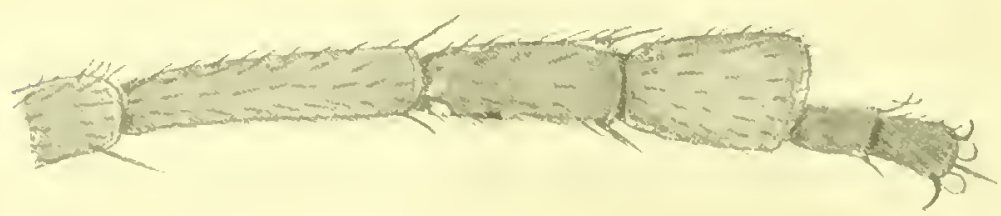

Fig. 57. Medetera minor Beck. $\sigma^{7}$. Vordertarsen. 48: 1 .

ist dicht mit Bïrstehen besetzt, zwischen beiden Reihen der Dorsozentralborsten stehen vier Reihen kurzer Bürstehen, von denen wir die beiden mittleren Reihen als Akrostikalbörstehen hezeichnen. Schwinger und Seliippehen weiß, Wimpern (?). Prothorakalborsten sehwarz. Schildehen mit vier gleich starken Borsten. - Hinterleib bronzegriin bis messingfaphig, selhwarz bebart; Hypopyg klein, sehmal mit kleinen gelblichen Anhaingen. - Beine rostgelb, Hiiften und Sclienkel, letztere bis nahe zur Spitze sehwarz; Tarsen alle rostgelb, nicht verdnnkelt. Vordertarsen etwas verziert; das erste Glied so lang wie das aweite und dritte, die ersten drei allmählieh etwas verbreitert, älnhlich wie bei meiner Art pedestris, aber nur halb so stark und nieht sehwarz, sondern rostgelh; das dritte Glied ist auf der Mitte hell durehscheinend; las vierte und fiinfte Glied zusammen sind so lang wie das dritte und kanm balb so diek. Hintermetatarsns ungefïh! halb so lang wie das zweite Glied; Vordersehienen ohne Borsten; Mittelsehienen mit einem Borstenpaar anf dem ersten Viertel der Oberseite; Hintersehienen oberseits weiß beborstet. - Flügel zart gelbbriunlieh gefirbt; dritte nnd vierte Läingsadern stark konvergierend, 
das von ilmen eingeschlossene Randaderstick hat nur 1/5 der Linge der linteren Querader; diese ist 1 m ihre eigene Länge vom Hinterrande entfernt. $3.8 \mathrm{~mm}$ lang.

Ein Exemplar ans Paraguay, S. Bermadino. [Fiebrig] Berliner zoologisches Museum.

17 nigripes Lw. Q, N. Beitr. VllI 73. 1 (1S61) . . . . Americal sept. 18 occidentalis Schin. o", Novara-Reise Dipt. 222.33 (1868) . Veneznela

$\sigma^{7}$. - Thoraxriicken metalliseh grünhlau, dic vordere Hiilfte etrvas glinzend mit vielen Humeralbörstehen dicht besetzt; hintere Hälfte und das Schildehen gran bestäubt, letztere mit vier starken Borsten. Drei starke Dorsozcntralborsten, Akrostikale deutlich, Prothorakale sehwarz. Schwinger gelb, Schippehen weiß, schwarz bewimpert. - Kopf: Stirne mattblau, Gesicht oben glainzendblau, nnten mattgran bestiult. Fiihler schwarz mit langer zentraler pubeszenter Borste; Taster schwar"; Hinterkopfzilieu unten weiß; die Scheitel. und Ozellenborsten sind auffallend stark. - Hinterleib glänzend griinschwarz, schwarz und am letzten Ringe auch weiß bchart. Hypopygium lang, sehr schlank (Analorgane nicht erkeuubar). - Beine: Hiiften alle schwargrau; die Vorderhiiften anf der Vorderseite weiß behart. Hinterheine bis anf die letzten Tarsenglicder ganz hellgelb. Mittel. und Vorderbeine anch gelb, aber die Schenkel sind von der Wulzel an bis etwas iiber ihre Nitte hinans pechbrann. Vordertarsen verziert, was Sehiner nicht erwähnt; sie sind im ganzen etwas länger als ilure Schicne; der Metatarsus ist nugefähr so lang wie die folgeuden vier Glieder znsammen; das zweite und dritte Glied sind gleich lang und jedes so lang wie das vierte nnd fünte Glicd zusammeu; beide Gliedel sind etwas verbreitert und mindestens doppelt so breit wie die etwas verdunkelten Endglieder. An den Anßenseiten der Hintersehenkel (nicht Unterseiten, wie Schiner schreibt) stehen zwei schwarze Einzelborsten, dic wohl als Priapikalborsten aufznfassen sind, obgleich rlie eine auf der Nitte des Sehenkels, die andere im letzten Drittel steht. Die Mittelschienen fithren auf ihrer Oberseite eine Borste an der Wurzel der Schiene; Hinterschienen ebenso mit je einer Borste an der Wurzel und vor der Spitze, außerdem mit feinen Wimpern in der Endhälfte. - Flügel zart gelbbräiulieh; dritte nud vierte Längsadern dentlich konvergierend; der zwisehen ihnen liegende Randaderabschnitt hat $1 / 3$ der Länge von der hinteren Querader; letztere ist nu ilure eigene Lüinge vom Hinterrande entfernt. $355 \mathrm{~mm}$ lang.

Ein Exemplar (Type) aus Venezuela [Lindig 1864] Wiener Hofmuseum.

19 pedestris n. sp. of. 1 Figur . . . . . . . . . . . . Pern

ơ. - Thoraxriicken schwarzblan, schwarzgriin bis veilelienblau, metallischglianzend mit starken Borsten; ganz von der Seite besehen sieht man namentlich anf der hinteren Thoraxlälfte feine grane 
liestaiubung; je drei Dorsozentralborsten; neben den Akrostikalbörstehen ist der ganze rordere Thoraxriieken mit feinen sehwarzen Humeralbörstehen hesetzt. Sebwinger gelb, Schtippehen hellbraun mit dunklen Wimperu. - Kopf: Stirne und Gesieht, aueh der untere Teil desselben metallischgrin bis veilehenblau. Riissel und Taster sehwarz. Finhler sehwa\%, nicht besonders groß, mit sehr zarter, aber langer und belaturter zentraler Borste. Hinterkopfzilien oben und unten sehwarz. Hinterleib bronze- bis kupferfarbig gliinzend, sehwarz bebart. Hypopyg glainzendselwwarz, nieht sehr diek, aber lang, Endlanellen gelblich. - Beine ganz sehwar", höehstens die äuliersten Kniee an den Vorderbeinen rostgelb bis bratun. Hintersehenkel stark verdickt oder verbreitert; Vordertarsen verziert: die ersten drei Glieder erweitern sielı allmiiblielı,

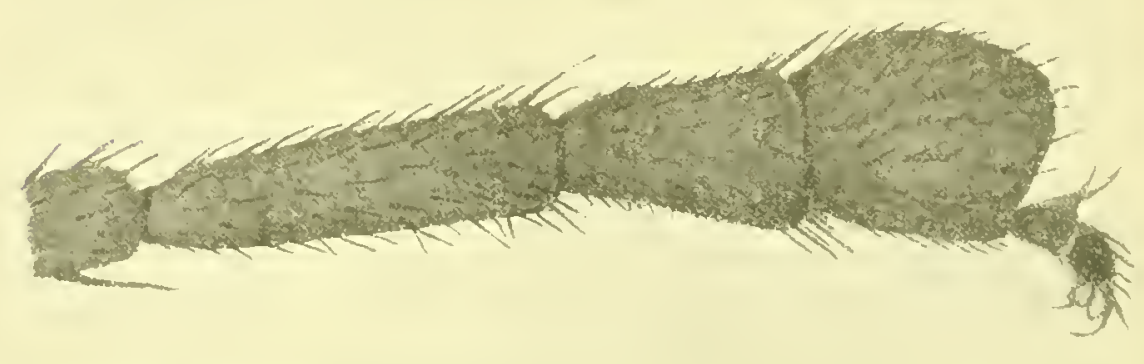

Fig. 58. Medetera pelestris Beck. 87. Vordertarsen. 48:1.

die beiden letzten sind anßerordentlieh diunn und kurz; das erste Glied ist fast so lang wie die beiden folgenden zusammen und linuun verbreitert, das zweite erweitert sich nach der Spitze hin, das dritte ist fast kreisförnig erweitert, dabei aber sehalen-, hohlkugelförmig gebildet und etwas braun durehsehimmernd; man sieht unter den Mikroskop verschiedene Läingsuähte oder Streifen, die mit kurzen Borsten besetzt sind. Der Hintermetatarsus ist kaum latb so lang wie das zweite Glied, unten an der Spitze mit einem Börstehen. Vordersehienen ohne Borsten; Mittelsehienen mit einer Einzelborste in ersten Viertel der Oberseite und mit kurzen kammartigen börstehen anf der Unterseite. Hintersehienen unregelmäßig kurz beborstet, nit zwei bis d.ei Einzelborsten anf der Oberseite und auf der Unterseite sehr kurz bewimpert. Fliigel fast farblos; dritte und vierte Längsaderu stalk konvergierend; hintere Querader um ihre eigene Läinge vou Hinterrande des Fliigels entfernt. $3-4 \mathrm{~mm}$ lang.

30 ơ, 15 q ans Peru-Ueayalifi. 21. X.03 Unini. - Pern, PachiteaMitudung, $150 \mathrm{~m}$ loch. 9. XI. 03. [Sehnuse] Dresdner zoologisehes Museum. 
Variante: Beine nicht ganz sehwath: außcr den Knicen ist die Silpitzenlailfte der beiden hinteren Beinpaare nebst ihren Tarsen rostgelb; andere Unterschiede vermag ich nicht zul finden.

$1 \sigma^{7}$ aus Peru, Paehitea-Miindung, 150 un hoeh. 24. XI. 03. [Sehnnse] Dresdner zoologisches Museum.

507 aus Para [Sehulz] und Snrinam, Palamaribo [Miehaelis] Berliner zoologisehes Museum.

20 petulca Wheel. o', Proceed. Californ. Acad. Se. ser. 3 Zonlog. II 21. 21 . $(1899)$. . . . . . . . . . . . . Ameriea sejt.

21 princeps Wheel. of $q$, Proceenl. Caliform. Acad. Se. ser. 3. Zoolog. 1125.

26 til). Il fig. $29-32(1899)$. . . . . . . . Americal sept.

22 unicolor n. sp. $\sigma^{7}$. . . . . . . . . . . . . Peru

'Thoraxricken metalliselı griugold bis blau, kaum etwas briinnlielı bereift, stark gliinzend. Sehwinger and Sehiippelien lramn, letztere unit dunklen Wimpern. - Kopf: Stirne und Gesicht matt schwarzbau; Fiihler sehwarz mit langer feiner pubeszenter Borste. Taster nud liaissel schwarz. Hinterkopfzilien aneh unten selıwarz. - Hinterleil, von gleieher Firbung wie del Thorax, mit kurzen sehwarzen IIaaren. Hypopyg groß, lang, an der Spitze mit gelben Organen. - Beine: Höften, Schenkel und die Spitze der Vordersehienen sehwarz, lliftgelenke, Schienen und Tarsen gelb. Tarsen eiufaeh (Hintertarsen fehlen). - Fligel ron der iibliehen zarten gelbbriiunliehen Firbung; dritte und vierte Läingsadern dentlieh konvergierend; die von ihmen eingeschlossene liandader ungefäh gleieh $1 / 3$ der hinteren Querader, letatere um ihre eigene Länge rom Hinterrande entfernt. 2.5 mm lang.

$1 \sigma^{7}$ ans Pern-Meshagua. 2. X.03. Urubambafi. [Schnuse] Dresdner zoologisehes Museum.

29 veles Lw. O’, N. Beitr. VIII 73. 2(1861) . . . . Americal sept.

24 vidur Whecl. ơ, Proceed. Calliforn. Aear. Se. ser. 3. Zool. Il 24. 24

tab. 11 fig. 39 (1899) .

25 viridicolor $11 . \mathrm{s} p .0$

$0^{7}$. - Thoraxricken nnd Sehildehen selıwarzgriin, glinzend mit selıwacher graner Bereifung, dentlich zweizeiligen Akrostikalbörstelıen und Dorsozentralborsten, weleh letztere von vorne bis nael hinten etwas stäker werden, ohne jedoeh in einer besondereu Länge hervorzutreten; das Sehildehen hat zwei starke und zwei schwiehere liand. borsten. Schwinger gelh, Schiipyehen weißlich mit weißen Wimpern; drei weiße Prothorakalborsten. - Kopf: Stime matt schwarkgriin; Gesieht in seinem lïngeren oberen Teil hellgrau bestiubt, der mutere ist sehr kurz und sehwïrlieh. Fiihler sehwarz, klein, das dritte Glied lat eine kurze Spitze und die Borste steht dentlieh subapikal. 'Zilien des Hinterkopfes aneh nnten weiß. - Hinterleib schwarkgriin mit dunkler Belıarung; das Hypopyg ist sebwarz, kur\% und dick, vorne abgestutzt; Anhänge sind nicht sichtbar. - Beine: Huiften und Sehenkel 
schwar, Kniee rostgelh, Schienen und Tarsen sehwarzhratur, - Filiget ghashell mit dunklen Arlem; die hintere Querader ist nu mehr als das Foppelte ilner eigenen Länge vom Fliigelhinterrande entfernt. $2.5 \mathrm{~mm}$ lang.

Q. - Beim Weibehen ist das erste Fiihlerglied rot.

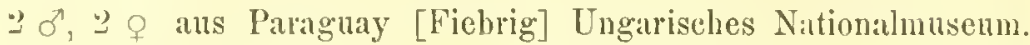

26 xanthotricha n. sp. \&

․ - Thoraxribeken nud Sehildehen gliinzend goldgriü olne Bereifung; alle Borsten weilgelb; in der lieibe der Dorsozentralen stehen vorne sehrache, hinten drei längere Borstenhare. Schildchen mit vier Borsten. Blustseiten ebenfalls glïnzend griun. Schwinger, Schiippeben und deren Wimpern weiß. - Kopf: Stime und Gesiebt glinzend blauselswarz ohne Bestainbung. Fiibler rotgell, drittes Glied klein mit langer weiflich sehimmernder Borste. Hinterkopl'zilien unten weil. Hinterleib goldgrin mit weifgelber Beharung. Beine mit allen Hiiften blaßgelb. Fliigel glashell mit farblosen bis gelhlielıen Adern. $1.5 \mathrm{~mm}$ lang:

1 a alus Trinidad, Port of Spain [Ujhelyi] Ungarisehes Nationalnutsenm.

27 reromile Whecl. o" $q$, Proceed. Califurn. Acad. Sc. ser. 3. Zoolog. II 28. 30 tab. 11 fig. 33 - 35 (18.99) Americat sept.

\section{liestimmmngstabelle fïr die Arten der Gattung Medetera Fisch.}

1 Sehenkel alle gelb bis gellbrïinnlich.

-- Schenkel gelb und pechbrann gezeichnet, an der Wurzel in gröfierer dusdehmmng brann

- Alle Sehenkel gan\% schwarz his pechbrann, höchstens die Sipitze gell,

y Filhler ganz schwar\% . . . . . . . . . . . . . . . 5

- Fiilıler ganz oder zun T'eil rotgelb . . . . . . . . . . 3

3 Fiibler ganz rotgelb, Borste weißlich. Stirne und Gesicht gliinzend blanschwar\% olme liestiubung: Hinterleih goldgrinn mit weiber Behaarnng. Beine mit allen Hiiften weißgelh. $1.5 \mathrm{~mm}$ lang

xanthotriche n. sp). 옹

- Erstes und zweites Fihlerglied gelb, drittes Glied schwarz mit subaprikaler sehwarzer Borste . . . . . . . . . . . . 4

4 Stim nnd Gesicht griun bis schwarz mit grauer Bereifung. Hinterleib metalliseh blau, sehwalz behaart; Hypopygium lang mo ziemlich diek, sehwarz mit gelben Anlüingen. Huiften und Beine brïuulich gelb, Tarsen seliwarz; zweites Glied der Hintertarsen $1 \% / 3$ mal läinger als das erste Glied. 2-2.3 mm lang . cyanogaster Wheel. of

- Gesieht sehr sehmal und weiß. Hinterleib metalliseh grtin, erster und zweiter Ring gelb. Hypopyg kurz breit und ganz gell,; beim 
Weibchen endigt der Hinterleib in zwei gelbbranne sclalenförmige runde Lamellen. Riissel und Taster ganz gelb, Sehildchen wit nur zwej Borsten, Beine selur lang, mit allen Hiften ganz hellgelb obne Borsten; zweites Glied der Hintertarsen kaum lïnger als das erste. $2.5 \mathrm{~mm}$ lang excipiens $11 . \mathrm{s}]$. $\mathrm{o}^{7}$ ㅇ

5 Vordertarsen verziert

- Vordertarsen einfach, nicht verziert. Drittes Fühlerglied klein, rundlich mit langer pubeszenter apikaler Borste. Gesicht metallisch gliinzend, unten blau, oben goldgriu olne Bestäubung. Stirne goldgriin. Thoraxriicken und Schildehen desgleichen. Hinterleib hellgelb bebart. Hïften braun mit gelben Borsten. Beine ganz gelb, nur die Spitzen der letzten Tarsenglieder brann; Hintermetatarsus reichlich halb so lang wie das zweite Gljed mit einer vorstehenden schwarzen Borste an der Spitze der Unterseite. $275 \mathrm{~mm}$ lang. . . . . . aberrans Wheel. $ᄋ$

(i) Stirne und Gesicht vom blauer Grundfarbe, Gesicht an der Quernaht grall. Beine ganz gelb; Mittelschienen auf der Unterseite mit zwei Einzelborsten. Das erste Glied der Vordertarsen $\left(\sigma^{7}\right)$ etwas kiirzer als die vier folgenden zusammen; das zweite trapezfürmig verbreitert, am Ende sehief abgeschnitten; das dritte ebenso lang, seitwia'ts lappig mit tellerförmigen Insbanchung. $4 \mathrm{~mm}$ lang dilatata n. sp. ơ $\mathrm{Q}$ Stirne, Gesicht und Beinfärbung wie bei der vorigen Art. Mittelschiene ohne die Einzellorsten auf der Unterseite. Das erste Glied der Vordertarsen ( $\sigma^{7}$ ) etwas länger als die vier folgenden Glieder zusammen; das zweite trapezförmig, etwas lïnger als bei dilatata; das dritte kiirzer, hohlkugelig, an der Basis hakenförmig ausgesclnitten. 3-4 mm lang. . . . . . . . . excavata n. sp. o?

7 Beine gelb; Hiiften und alle Sehenkel bis zur Mitte und dariber hinaus pechbraun bis schwarz. Fiihler schwarz. . . . . . S

Beine gelb; nur die Mittel- und Vorderscbenkel bis etwas iiber die Mitte nebst allen Hiiften pechbraun; Schenkelringe gelb. Zweites und drittes Vordertarsenglied verbreitert und gleich lang, viertes und fïnftes Glied sehr diinn und braun. Thoraxrieken scluwarzgriin. Gesieht oben metalliseh griun bis sehwarzblau, unten gran. Hypopygium lang und schlank. Fliigel glashell, an Vorderrande etwas braun mit verdicktel Randader. $3 \mathrm{~mm}$ lang:

occidentalis Schin. o

8 Hiiftgelenke, Spitze der Schienen und die Tarsen von der Spitze des ersten Tarsengliedes an pechbraun. Vordermetatarsus einfach. Thoraxrieken, Stirne und Gesicht mattgrau. Hypopygium sehwar\%, groß, geschwollen, Anhinge gelbbraun. Hintere Fliggelyneraler aul ihrer Hitte nit einem Aderanhang. $2.5 \mathrm{~mm}$ lang

appendiculatud Aldr. OPQ

Tboraxricken blangriin, hinten brïunlich bereift. Stirne und Fesieht letzteres nben glïnzend blan, nuten schwarz. Alle T'arsen gelb; Vorder- 
tilrsen verziert: die ersten drei Glieder allmählılich verbreitert, viertes und fiinftes Glied diinn. Ilypopyg klein, schmal, Anhïnge weiblich. $3 . \mathrm{mm}_{\mathrm{ang}}$. . . . . . . . . . . minor n. sp. o

- Thoraxricken braun bestiubt. Gesicht oben mattgran, unten mattgriin.

Hintermetatarsus an der Wurzel der inneren Seite mit einen kurzen Zahn-Hintere Qnerader obne Aderanhang. $25 \mathrm{~mm}$ lang veles Lw. ơ

9 Vordertarsen des of verziert. Fiihler seliwarz . . . . . . . 10

- Vordertarsen einfaleh. . . . . . . . . . . . . . 11

10 Vordertarsen ganz sehwarz; die ersten drei Glieder alluählich an Breite zunehmend $\left(\sigma^{\top}\right)$, die letzten beiden sehr dimn und kmr. Gesicht und Stirn metallisch griin. Beine schwar", kniee der vorderen Beine rotgelb; Hinterschenkel etwas verliekt. 3-4 mm lang pedestris $\mathrm{n} . \mathrm{sp}$. O $\mathrm{O}^{7}$

- Vorlertarsen gelb, nur die drei letaten Glieder etwas braun; das dritte Glied trapezformig, hohllsugelig (ơ) mit einem fächerförmigen llauschopf an einer Spitze. Gesicht und Stirne stahlblau. Hiften und Schenkel sehw:ırz, Schienen und Tarsen gelb; Hintersehenkel diek. 3-4 mm lang. . . . . . . . . flabellifera n. sp. o우

11 Fiihler ganz sehwarz . . . . . . . . . . . . 14

- Fiihler nicht ganz schwarz . . . . . . . . . . . . . 12

12 Drittes Glied sehwarz, die beiden ersten Glieder ganz oder teilweise gelb . . . . . . . . . . . . . . . . . 13

- Drittes Glied gelh, die ersten beiden braun. Gesieht und Sirime matt schwarzblau. Beine schwarz; Spitzenviertel der vorderen Schenkel, die vorderen Sehienen nud Tarsen gelb. 35-4 mm lang

flavicornis n. sp. o?

13 Erstes und zweites Fihlerglied gelb, das dritte schwarz. Gesicht metallisch blau, ïber der Quemaht ein graner Strich. Thoraxrỉeken und Stirue blauschwarz. Hiiften und Beine schwarz; Kniee, Mittelsehienen und die Wurzel der Mitteltarsen gelb; Hintermetatarsus lally so lang wie das zweite Glied. Flitgel wasserklar, an der Wurzel weißlich. 3.2-35 mm lang . . . . . . maura Wheel. of

- Erstes und zweites Fühlerglied gelb, Spitze des zweiten Gliedes und das dritte sehwarz. Gesieht sehwarz, etwas matt. Thoraxrieken vorne briunlich bestäubt mit zwei grauen Liingsstreifen. Hiiften und Beine schwarz, Kniee etwas gelb. Hinterschienen an der Spitze mit lingeren gelben Haaren, Hintermetarsus etwas länger als das halbe zweite Glied. 4 mm lang. . . . . . . . . . vidua Wheel. o

- Erstes Fïllerglied gelb, das zweite und dritte schwarz. Stirne matt graubrann; Gesieht unten metalliseb blau, iiber der Quernaht gran bestäubt. 'Thoraxricken brannschwarz mit vier granen Läugslinien. Beine ganz schwarz, zweites Glied der Hintertarsen $1 \frac{2}{3}$ mal so lang wie das erste Glied. $3 \cdot 5 \mathrm{~mm}$ lang . . . Aldrichi Wheel. $\sigma^{7}$

14 Schippehen hell hetionpert . . . . . . . . . . . . . 15

- Sehiiplechen sehwar\% his brann bewimpert . . . . . . . . 21 
15 Schildehen nur mit zwei Borsten. Ozellenhöeker boeh emporgehoben. $2 \mathrm{~mm}$ lang. . . . . . . . . . petulcus Wheel. or Schildchen mit vier Borsten . . . . . . . . . . . . . 16

16 Thoraxricken mit Lïngsstreifen. . . . . . . . . . . . 17 Thoraxricken ungestreift . . . . . . . . . . . . 20

17 Schienen und die Wurzel der Tarsenglieder gelb bis gelbbratm 18 Sehienen mit Sebenkeln und Hüften sehwarz . . . . . . . 19

18 Beine mit Ausnahme der Sehienen und Wurzel der Tarsenglieder sehwar\%. Hintermetatarsus mit einem kleinen Zahn an der Wurzel der Innenseite; zweites l'arsenglied der Hinterbeine $2^{1 / 2}$ mal so lang wie das erste Glied. Thoraxricken matt hellgran mit drei gelbbraunen Langslinien. Gesicht mattgriin, olsen etwas gelblieh. $3-5 \mathrm{~mm}$ lang californiensis Wheel. 079

Beine schwarz; Sebenkelglieder, Kniee, Schienen mud die ersten 'Tarsenglieder gellbraun. Hintermetatursus mit einem scharfen Zahn an der Wurzel der Innenseite; zweites Tarsenglied fust dremal so lang wie der Metatursus. Thoraxriicken griin, grau bestäubt mit fïnf brannen Liingslinien. Gesicht oben gelblich bestäul, unten glïinzend griin. 4-5 mm lang . . . . princeps Wheel. of $\mathrm{f}$

19 Peine sebwarz, Kniee und $3 / 3$ des Mittelnetatarsus gelb; zweites Tarsenglied der Hinterbeine $1 \frac{1}{2}$ mal so lang wie das erste Glied. Thoraxritcken hellgrau bestäubt mit drei hellbraunen bis goldgelben Lïingsstreifen. Gesicht unten stahlblan, oben mattgrau bestiubt; Stirne auch mattgrau. Hinterleib weiß behart. $25-2.8 \mathrm{~mm}$ lang

aurivitlats Wheel. ơ

Beine ganz seluwarz, die äubersten Kniespitzen kaum etwas heller; zweites Glied der Hintertarsen dreinal so lang wie das erste Glied. Thoraxrieken vorne braun mit zwei weißgelben Läingsstreifen. Gesieht oben sehwarz, unten mattbann. $3-3.5 \mathrm{~mm}$ lang nigripcs $\mathrm{Lw}$.

20 Beine ganz schwarz, Kniee rostgelb. Thorax etwas grau bestainht. Hintermetarsus etwas lïnger als das halbe zweite Glied. Fiihler schwarz $\left(\sigma^{7}\right)$ beim $q$ das erste Glied rot. Gesieht oben liellgran, unten schwïzlich. $25 \mathrm{~mm}$ lang. . . . viridicolor $\mathrm{n}$. $\mathrm{sp}$. $q$

Beine sehwarz, Kniee und Tarsen mit Ausnahme des letzten Gliedes rostgelb; zweites Glied der Hintertarsen dreimal länger als das erste Glied. Fühler in heiden Gesehleehtern ganz sehwarz. Gesieht oben matt seluwarzbrann, unten glänzend braun. Hypopyg sehr lang. $2 \mathrm{~mm}$ lang . . . . . . . . . . . anus 11. sp. 6

21 Sehwinger gelb

Sehwiuger bramn $\left(\sigma^{7}\right)$, beim o gelb. Stine und Gesieht matt sehwarzblau. Beine sehwarz, Sehienen und Tarsen gelb. $2 \cdot 5-3 \mathrm{~mm}$ lang anicolor 4. sp. $0^{\pi}$ ?

22 Stirne und Gesicht glänzend selswarzblan. Beine sehwarz; Hintersehienen rostgelb, an der Wurzel brann, weif boborstet, Vorder- 
schienen ganz braun. Tarsen sehwarzbraun $\left(\sigma^{\top}\right)$ und rotgelb (P). Zweites Glied der Hintertarsen zweimal solang wie das erste Glied. $3-35 \mathrm{~mm}$ lang . . . . . . . . metallina n. sp. o

- Stirne und Gesicht schwarz bis blau. Sclienkel schwarz, Spitze derselben, Schienen und Tarsen mit Ansnahme der letzten Glieder gelb. Zweites Glied der Hintertarsen mehr als zweimal so ling wie das erste Glied. Hintere Qnerader um mehr als die eigene Liinge rom Hinterrande entfernt. $1.5 \mathrm{~mm} \operatorname{lang} . .+. \quad$ exigua Aldr. ơ - Stime schwarz, mattgrau bestäubt; Gesicht mattgriin. Huiften schwarz, Beine peehbraun, Kiniee und die Wurzel der beiden vorderen Metatarsen gelb. Zweites Glied der Hintertarsen $1 \frac{1}{2}$ mal länger als das erste Glied. Fligel brïunlichgran; hintere Querader zweimal so lang wie Jas Endstiek der fünften Längsader. Schiippehen brann mit braunen Zilien. $1.5 \mathrm{~mm}$ lang . . . xerophila Mhdr. o'q

\section{Thu!lpticus.}

('ierst. stettin. Fnt. Zeitg. XXYII 48 (1800).

Aphantotimus Wheel., Psyclie 375 (1890).

Tanthotriche Altr., Trans. Ent. Soe. London 339 (1896).

Aneh diese Gattung ist wie Medetera Fisch. in Nord- und Siidamerika leimiseh. Aldrieh gibt in seinem Katalog 1905 seehs Arten all, von denen vier in Mexiko und Westindien vorkommen; ans Siidamerika kann ieh noch zwei nene Arten angeben, so daß die Zahl der uns ans Amerika bekannten Arten damit anf acht gestiegen ist.

Der Charakter der Gattung ist unveräindert geblieben; die Unterschiede von Merlctera bestehen in dem anderen Verlanfe der dritten mu vierten Liingsadern sowic in anderer Gestaltung der Geschlechtsorgane.

\section{Artregister und Beschreibungen.}

1 amoenus n. sp. o. 1 Figur. . . . . . . . Anerica merid.

ơ. - Thoraxriicken glïuzend goldgriin, alle Borsten liellgelb.

Brustseiten mattgriin. Schiiplpehen und Schwinger l,albgelb, erstere weiß bewimpert. - Kopf: Stirne

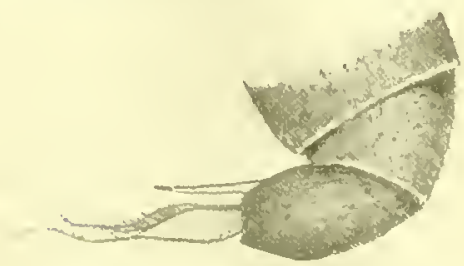

Fig. 59.

Thrypticus amoemus Becti. ơ. 11ypulyg. $24: 1$. und Gesicht gliinzend blau ohne Bereifung; die Augenränder konvergieren ziemlieh stark waeh dem Inndrande zu. Fithler braunrot bis sehwarz mit pubeszenter Borste; Taster gelblieh. - Ilinterleib gliinzend goldgriin, Hypopygimm schwarz mit lang dreieekigen in eine Endborste ansgezogenen gelben behaarten inßeren Anbiingen 
und einer graden gelben Penisscheide. -- Beine blaßgelb, Hiiften braun bis schwärzlich, die Spitzen gelb, weiß behaart. Flïgel glashell; dritte nod rierte Längsadern fast parallel, sebr sehwach konvergierend, die vierte an der Fliigelspitze endigend. $1.5 \mathrm{~mm}$ lang.

1 б' ans Bolivia, 20. XII. 1902. Sorata, $2300 \mathrm{~m}$ hoch [Sehnuse]. Dresdner zoologisches Musenm.

$\sigma^{7}$. - Thoraxriicken metallisch blangrion, anf der hinteren Hälfte zart grau bereift. Borsten alle gelb. Sehwinger und Schiippehen blaßgelb, ebenso bewimpert. - Kopf: Stirne und Gesicht glänzend reilchenblau ohne Bereifung, Angenäander nach dem Mundrande hin allmäblich konvergierend. 'Taster und Fỉbler ganz rotgelb mit subapikaler fast nackter Borste. - Kopfborsten gelb. - Hinterleib griunschwarz, glinzend, weißgelb behaart; der erste und zweite Ring blaßgelb. Hypopyg schwarz, von der gewöbnlichen Form; die Analanhänge bilden die in eine stumpfe gelbe Spitze anslanfende Verlängerung desselben ohne besondere Behaarnng und ohne eine besondere Form darstellend (soweit man nach dem trockenen Exemplar mreilen kann). - Beine nebst Hiiften ganz blaßgelb; Metatarsus der Hinterbeine halb so groß wie das zweite Glied. Flïgel farblos mit zarten gelben Adern, dritte nnd vierte liangsadern parallel, die vierte an der Fligelspitze endigend; hintere Querader $\mathrm{mm}$ die doppelte eigene Länge vom Fligellinterrande entfernt. $1 \mathrm{~mm}$ lang.

$1 \delta, 2$ aus Pirraguay, Chaco [Fiebrig]. Wiener zoologisches Hotmusenm.

3 cupulifer Aldr. ơ , Trans. Entom. Soe. London 339. 1 tab. XI fig. 106. 106 a [Xanthotrich 1 ] (1896).

రㅇ. - Thoraxricken glänzend grïn mit blaßgelben Borsten. Fithler ganz gelbrot, Gesicht glänzend blau. Hinterleib blangriin, gelb behatrt, der sechste Ring gelb; vom Hypopyg ist der erste Teil gelb. der zweite blann, Anhänge zart gelb. Beine mit allen Hiften blaßgelb. Fliigel farblos. $1 \cdot 2-1.5 \mathrm{~mm}$ lang.

Von Aldrich ans Westindien, St. Vincent bekannt gemacht.

4 fraterculus Wheel. ơ, Psyche 376 (1890). . . . America sept.

Mit schwarzen Fiillern, dunklen Tastern. Gesicht metallich griun, mit gelbem Reif ibergossen. Thoraxrticken metalliseh griin mit gelben Borsten. Hypopyginm mit gelben Auhängen. - Hüften und Beine schwar', Kniee und IIiftgelenke gell). Flitgel schwach briunlich getriibt; dritte und vierte Läingsadern parallel. $1-1.5 \mathrm{~mm}$ lang.

Anmerkung: Bislang die einzigste Art mit schwarzen Beinen.

5 minor Aldr. ठౌ๐, Trans. Entom. Soc. London 340. 2 (1896) Westindien

Aldrich vergleicht seine Art mit cupulifer Aldr. und gibt die Unterschiede an: Der Hinterleil) bat keinen gelben sechsten ling: Albandl. d. zool.-bot. Ges. Bd. XILI, Hett 1. 
die Analanhänge sind weit kiirzer und dic vierte Liingsader macht an der hinteren Querader einen Knick. $1.2 \mathrm{~mm}$ lang.

Aus Westindien, St. Vincent beschrieben.

6 musillus Aldr. +, Biolog. Centr. Amer. Dipt. I 349. 3 (1901) Mexien

Mit schwarzen Ftijlern. Gesieht glinzend violett. Thoraxriteken purpurfarbig mit gelblichen Borsten. Hinterleib mit bramen Haaren; Hypopygium mit großen zngespitzten blaßgelben Lamellen; nnter den juneren Organen die Form einer Lanze. Flitgel breit, farblos. 1 mm lang.

7 singularis Aldr. ơ, Trans. Entom. Soc. London 340. 3 (1896)

Westindien

Diese von Aldrich beschriebene Art soll sich (ठ) durch ein $\mathrm{Hy}$ popyg anszeichnen, das dic Gestalt ciner weiblichen Legeröhre besitzt; letatere endigt in unserer Gattung nicht wie gewöhulich mit zwei kleinen Lamellen, sie ist vielmelu hornig nit tubusartig ineinander gesehobenen stielfürmigen Ábschnitten nnd in grader Richtung nach hinten heranstretend. Wenn Aldrich uns nicht als gewiegter Dipterologe bekannt wäre, so möchte man vielleicht ein Fragezeiehen zu semer Sehilderung setzen, denn nach unseren bisherigen Erfahrungen zeichnet sich grade die Gattung Thripticus, ebenso wie Medetera, durch ein einheitlich gebildetes Hyponyg ans. Die Siche mit dem weiblieh gehildeteu Jypopyg ist also erust zu nehmen und wir missen eine Erklärung dafiil suchen; diese seheint mir anch nicht zu schwierig zu sein: offenbal haben wir hier cine Zwitterbildung vor nus, eine immerhin seltene Erscheinung. Ob singularis eine besondere Art darstellt oder vielleicht nur identiseh ist mit der kurz vorler beschriebenen Art minor, lißit sich bei der Unbekanntschaft mit dem Männchen und sciner normalen Genitalien natiorliels nicht feststellten. Ich habe in der Uber'zengung von der Richtigkeit meiner Ansicht diese Art in der Bestimmungstabelle nicht beriicksiehtigt.

8 Hillistoni Wheel. of. Psyche V 376 [Aphantotimus] (1890)

America merid. et sept.

ơf. - Thoraxrijcken metillisch blangriun mud zicnlich stark gelbbräunlich bestänbt, mit gelben Borsten. 5-6 Dorsozentralborsten; zwei grolic und zwei seh" kleine Schildborsten. Sehwinger und Schiippehen weiß, weiß bewimpert. - Kopf: Stirn und Gesieht glänzend veilchenblan ohne Bereifung; die Angemränder konvergieren alluählieh mach dem Mundrande hin, das Gesicht ist unten nicht breiter als das dritte Fuhlerglied. Fiiller schwarz mit fast nackter zentraler schwarzer Borste; Taster gelb; Seheitelborsten brann, Ozellenborsten gelb. - Hinterleib gliuzend schwarzgriin mit gelber Beharung. Hypopyg gliuzend schwarz mit langem gralen gelben Penis; an der Spitze des Hypopygs sieht man die außeren Anbinge in Gestalt dreieckig abgerundeter hängender gelber Lamellen, deren Ränder etwas behart sind; an der Spitze des Hypopygs stehen einige Borsten in fächer- 
förmiger Anordnung. Beine und alle Hiilten bis zum letzten 'l'arsengliede hellgelb. Fliigel wasserklar mit blaßgelben zarten Adern; dritte und vierte Laingsadern fast ganz grade, selr wenig gebogen und sehr wenig konvergierend, fast parallel; die vierte Längsader endigt an der Fligelspitze; die senkleeht stehende hintere Queradel ist $11 \mathrm{~m}$ das $2 \frac{1}{2}$ fache ihrer eigenen Liinge vom Fliigelrande entfernt. $1.2-1.5 \mathrm{~mm}$ lang.

Vier of, ein $q$ ans Paraguay, S. Bernardino [Fiebrig] Wiener zoologisehes Hofmuseum.

Anmerkung: Diese Art ist mit amocuus nalie verwandt, aber durch andere Billung des Hypopygs unterschieden; auch noeh dadureh, daß dic dritte und vierte laingsader näher aneinander stelen als bei amoenus: bei Willistoni ist nämliclı die Breite der ersten Hinterrandzelle gegeniiber der linteren Querader nur rom $3 / 4$ der Queraderlänge, wälıreud diese längen hei amoenus einander gleieh sind.

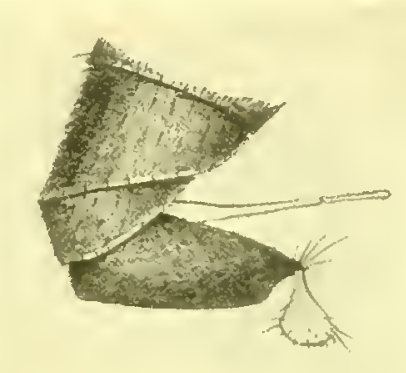

Fig. 60.

Thrypticus Wrillistoni Wheeler ơ.

\section{Bestimmmungstabelle}

\section{fiir die Arten der Gittnng Thrypticus.}

1 Fiilıler schwarz bis rotbraun.

2 Hiiften und Schenkel, beim $\&$ wenigstens die Schenkel sehwillz. $1-1.5 \mathrm{~mm}$ lang.

- Beine nebst Hiiften blaßgelb . . . . . . . . . . . . . 3

3 Stirne und Gesicht violett, glänzend, mit und obne Bereifung . 4

4 Thoraxrilcken purpurfarbig, Hinterleib desgleichen. Hypopyg dunkelbraun mit zwei lanzenihhnlichen iumeren Organen; die aiußeren Lamellen gelb, spitz, groß. $1 \mathrm{~mm}$ lang . . . . pusillus Aldr. o Thoraxrieken gliinzend, goldgriin. Hypopyg sehwarz mit zwei langen, dreieckig ansgezogenen behaarten gelben iußeren Lamellen. $1.5 \mathrm{~mm}$ lang . . . . . . . . . . . . amoenus n. sp. ठ

- Thoraxriicken griin, glänzend mit gelber Bestäubung. Hypopyg glänzend schwarz mit zwei rundlich dreieckigen gelben behaarten iußeren Lamellen. 1-1.5 $\mathrm{mm}$ lang . . . . TVillistoni Wheel. ơ

5 Die vierte Längsader macht bei der hinteren Querader einen Knick minor Aldr. or?

- Die vierte Lingsader ohne solchen knick . . . . . . . . is

6 Der sechste Hinterleibsring gelb . . . . . . cumlifer Aldr. of - Der erste und zweite Hinterleibsring gelb . . . . analis n. sp. 


\section{Gruppe VI.}

\section{Rhaphiinae.}

Diese Gruppe ist bei uns in der paliarktischen Zone dureh zehn verschiedene Gattungen vertreten; ein weit einfucheres Formenbild gewälnrt uns zur Zeit die amerikanische Fauna, denn außer unseren drei Hauptgattungen: Rihaphium, Porphyrops und Syntormon sind nur noch Xiphandrim und Achalcus, vielleicht anch noch Peloropeodes zn nemen. Ob dies cinfachere Resultat der Wirklichkeit entspricht oder nieht vichmehr der Unznlïnglichkeit der bisherigen Forsehungen zuzusclneiben ist, werden spätere Studien ergiinzend festzustellen haben.

\section{Rhorphirum.}

Meigen, in Illig. Magaz. f. Ins. II 272. 68 (I803).

Hydrochus l'all., Inipt. suec. Dolichop. 5 (1823).

Ebenso wic wir in der paläarlitischen Region nur eine Art longicome Fall. kennen lernten, ist anch die nearktische und neotropisele Region nur mit einer Art lugubre Lw, vertreten. Die im Katalog Kertess VI. 1909 noch unter Tihuphium anfgefiihrte Art Paulsoni Phil. aus Chile bleibt wohl als Weibchen nach wie vor cine unbekimnte Gröbe. Ob das von Philippi sehr kurz beschriebene Tier iiberhanpt unserer Gattung angehört, ist schon fraglich, um wie viel weniger wird man die Art feststellen können, da die Weibchen diescr ganzen Gruple der Arterkenunng, wie bekannt, bedeutende Sehwicrigkeiten entgegenstellen. Wir untissen daher diese Beschreibung ganz unberiicksichtigt lassen.

lugubre Lw. ․ N. Beitr. VIII 49. 1 (1861) . . America sept. ? Pantsoni Phil. \&. Verh. zool. bot. Ges. Wien XV 774 (1865) . Chile

\section{Porphymplos.}

Meig., S. Beschr. IV. 45. CXXVII (I824).

Anglearia Carl, Ann. Soc. Ent. Ir. IV 659 (1835).

Perethinus Halid., The Zool. Joum. I' 353 (1832).

Im Katalog Kertész VI 1909 sind nenn Arten angegeben, aber alle nnr aus Nordamerika; Aus Sidamerika ist bis jetzt nielts gemeldet; selbst Schnuse, der doch sechs bis sieben Jahre in Siid:merika gesammelt, brachte 
kein einziges Exemplar mit. Wir diilfen daher wohl mit einiger Sicherheit annehmen, daß diese Gattung anf die nearktische liegion besclurinkt ist, ebenso wie Rhaphium.

\section{Artrepzerichinis.}

1 consobrina Zett. $\sigma^{\nearrow}$ \&, Dipt. Ścand. II 471.11 [Ihaphim] (1843) Alaska

2 effilata Whecl. ơ $q$, Proceed. Caliform. Acad. Soc. ser. 3, Zoolog. II 34. 37 tab. II fig. 54, 55 (I899) . . . . . . America sept.

3 fumipennis Lw. \&, N. Beitr. VIII 51.3(1861). . . Americal sept.

+ longipes Lw. ð゙, Berlin. Ent. Zeitschr. VIII 95. 92(1864) Anerica sejt.

5 melampus Lw. ơㅇ, N. Beitr. VIII 50. 1 (1861) . . . America sept.

6 nigricoxa Lw. \&, N. Beitr. VIIl 51.2 (1861) . . . America sept.

7 rotundiceps Lw. ơ, N. Beitr. VIII $514(1861)$. . . America sept.

8 signifer O. Sack. ठ", Catal. Dipt. N. Amer. Edit. II 113 et 242.189 (1878) . . . . . . . . . . . . America sept.

9 xipheres Wheel. of, Proceed. Califor'n. Acad. Soc. ser. 3, Zoolog. II. 34. 36 tab. II fig. 53 (1899) . . . . . . . . . America sept.

\section{Bestimmungstabelle fiim die A'ten del Viattumg Porphyrops,}

Eine Bestimmungstabelle iiber acht nordamerikanische Arten besitzen wir ron Wheeler, Proceed. Californ. Acad. Sc. ser. 3, Zoolog. II 33 (1899). Ich habe weiter unten eine nene Tabelle aufgestellt und ihr die Art consobrina Zett, die sich als auch in Nordamerika heimisch herausgesteltt hat, hinzugefïgt. Die hautsiichlichsten Arteigenschaften habe ich in del Tabelle mit aufgenommen, so daß sich eine weitere Charakterisierung der Arten eribrigt, eventuell sind die Originalbeschreibungen heranzuziehen. Die beiden ron Wheeler in seiner kurzen Tabelle mit eingefibrten, ron Loew $n n$ als Weibchen beschriebenen Arten nigricoxa und fumipennis Lw. habe ich in weiner Tabelle nicht heriicksichtigt. Ich halte die Beschreibungen nicht fiir ausreichend, um die Arten, falls es selbständige Arten sein sollten, zu charakterisieren; es ist ziemlich anssichtslos, wit Sicherheit die zugehörigen Mïnnchen zu finden, es sei denn, daß man sie in copula finden sollte. Die Gesetze, nach denen die Weibchen sich ron den Miunchen nnterscheiden, sind hier noch nicht festgestellt und werden auch wahrscheinlich nur auf empirischem Wege gefunden werden; bis dahin ist es ein unfruchtbares Bemiihen, einzelne Weibchen verwerten zu wollen.

1 Beine schwar" oder iiberwiegend schwarz . . . . . . . . 2

- Beine gelb oder iiberwiegend gelb . . . . . . . . . . 3

2 Kniee und Spitzen der Vorder- und Mittelschienen bräunlichgelb. Drittes Fühlerglied ziemlich lang $\left(\sigma^{7}\right)$, Füblerborste $1 \frac{1}{2}$ mal so lang wie das dritte Glied. Anallamellen klcin, schwar'z, behaart. $4-4.5 \mathrm{~mm}$ lang' . . . . . . . . melampus Luw. o’ . 
Vordersehienen und dic Wurzelhälfte der Hinterschienen rostgelb. Hinterschienen nebst Tarsen verdickt. Vorderschenkel unterseits mit einer Reihe starker schwarzer Borsten. Analanhänge länglieloral, klein, braun. Drittes Fihlerglied zweimal so lang wic an der Wurzel brait. Fiihlerborste $1 \frac{1}{2}$ mal so lang wie das dritte Glied. $4.5 \mathrm{~mm}$ lang. . . . . . . . . . . . discolor Zett. O’ 9

3 Fiihlerborste in eine sehwarze Lamelle auslanfend . . . . . 4

- Fiihlerborste einfach . . . . . . . . . . . . . . . . 5

4 Drittes Fiblerglied lang zugespitzt, Borste ron gleicher Länge. Beine gelb; Wurzel aller Hinften, Hinterschenkel auf der Oberseite, Hintersehienen und deren Talsen schwarz. $5 \mathrm{~mm}$ lang . signifer O.S. 万o

5 Äußere Analanhïnge gegabelt . . . . . . . . . . . . 6

- Äußere Analanhäinge nicht gegabelt . . . . . . . . . . 7

6 Änßere Analanluänge fadenförmig, rostgelb, gegabelt, weiß belıart. Htiften schwarz. Vorderbeine und Mittelbeine gelb, die beiden letzten 'Tarsenglieder' sehwarz. Hinterbeine mit Ausnahme der Schenkelnud Sehienenwurzeln sehwarz. Hinterschienen nicht verdickt. $6 \mathrm{~mm}$ lang . . . . . . . . . . . longipes Lw. $\sigma^{7}$

- ÄuBere Analanhïnge lang, nogleich gegabelt, sclimntzig graugelb. Hïften schwarz, jedoeh dic Vorderhiiften an der Spitzenhälfte gelb. Hintersehenkel an der Spitzenhiifte und Hinterschienen im letzten Drittel sehwarz. $4 \mathrm{~mm}$ lang . . . . . . rotundiceps Lw. ठ

7 Äıßere Analanhänge schwarz, lang dreieckig, behaart, an der Wurzel mit weißem Fleck. Drittes Fiilhlerglied fiunfmal so lang wie breit, Ftihlerborste gleich $1 / 4$ des dritten Gliedes. Hiiften, Hinterschenkel an der Spitze, Hintersehienen und deren Tarsen sehwarz. $3.5 \mathrm{~mm}$ lang . . . . . . . . . . . . xipheres Wheel. $\sigma^{7}$

- ÄnBere Analanliainge gelb, lang fadenförmig;, so lang wie $1 / 3$ des Hinterleibes. Das dritte Fiillerglied zweimal so lang wie breit, Fihlerborste etwas liinger als das dritte Glied. (Beim $q$ ist das dritte Glied $1 \frac{1}{2}$ mal so lang wie breit.) Hiiften schwarz. Vorder- nnd Mittelbeine gelb, Hinterbeine schwarz. $3.5 \mathrm{~m}$ lang effilatifs Wheel. ơ

\section{ripleandrium.}

Loew, N. Beitr. V 36 (1857).

Aldrich gibt keine Art dieser Gattung an; ich fand aber doch eine Art in der Sammlung des Wiener Hofmuseums, so da $B$ auch diese Gattung nicht ganz ohme Vertreter in Nordamerika geblicben ist.

discolor Big. q, Aun. Soc. Ent. Fr. sér. 6. X 292 (1890) . . . Chile

Diese Art ist nur als Weibehen, außerdem nnkenntlieh beschrieben; da Bigot die Größe mit $4 \mathrm{~mm}$ angibt, so ist es walırseheinlich, daf gar kein Xiphantrim-Weibehen, sondern ein Porphyrops-Weilohen darmuter verborgen ist. 
o. - Thoraxricken glänzend schwarzgriin, an der Hinterseite der Quernalit matt purpurfarbig, jedoch ohne scharf abgegrenzte Fleckung. Sehwinger gelb, Schiippchen und deren Wimpern weil. - Kopf: Stirne stablblan ohne weiß bestiinbte Flecken. Gesicht schmal, weib, etwa lalb so breit wie das dritte Fiihlerglied. Fiihler schwarz, drittes Glied vier- his fiinfmal so lang wie an der Wurzel breit, die Borste nicht ganz halb so lang oder reichlich $1 / 3$ so lang wie das dritte Fiihlerglied. Backenbart weiß, 'Taster schwarz. - Hinterleib bronzefarbig, schwarz behaart; Hypopyg mit länglich zugespitzten, etwas beharten schwarzen Lamellen, die an der Basis gelb sind und gleielzeitig dort etwas ausgeklinkt erscheinen; die inneren Organe sind ohne Präparation nicht erkennbar. - Beine schwarz, aber die Schenkelglieder, Kniee, Schicnen nnd Mletatarsen der vorderen Beine sind gelb; Hinterbeine mit A usnahme der Schenkelwurzeln sehwarz. Hinterschienen und deren Tarsen etwas verdickt. Fliigel selhwach biäunlichgran mit feinen dnnklen Adern in gewölnnlichem Verlaufe. $250 \mathrm{~mm}$ lang:

Q. - Das Weibchen bat ein breites graues Gesicht; das dritte Fiblerglied ist etwa $1 \frac{1}{2}$ mal so lang wie breit: an den Hinterbeinen ist die gelbe Farbe an den Schenkelwurzeln ansgebreiteter, auch dio Hintersehienen sind branugelb.

Zwei ơ', ein $q$ aus Colorado [Morrison] im Wiener zoologischen 11ofmusem.

\section{Syllotomon.}

Loew, X. Beitr. I 35 (1857).

Plectroms Halid., The Zool. Journ. I 353 (1832) pracoccup. 1826.

Synarthrus Lw.. N. Beitr. V 35 (1857).

I'arasyntormon Wheel., Proceed. Californ. Acal. Sc. ser. 3, Zoul. II 41 (1899).

Eutarsus Lw., $\mathrm{X}$. Beitr. Y 43 (1857).

Im Katalog Aldrich 1905 und im Katalog Kertész VI 1909 stehen finf Arten ans Nordamerika und Mexiko verzeichnet. Wheeler bat in den Proceed. Californ. Acad. Se. ser. 3, Zool. II 36-40 (1899) eine kleine, die ihm bekannten Arten zusammenfassende Studie mit einer Bestimmungstabelle veröffentlicht; es sind vier Arten, die er unter dem Gattungsnamen Synarthrus Lw., nicht Syntormon, zusammenfaßt. Obgleich er in seinel Einleitung selbst anerkennt, daß der einzige ron Loew zwischen beiden Gattungen hervorgehobene Unterschied, das Behaartsein oder die Nackt. heit des ersten Fiihlergliedes, sich nicht als bestandig und anwendba erwiesen habe, hat er doch den Namen Synarthrus vorgezogen. Als einzige Art, welehe in Gegensatze zil den ïlurigen Arten ein nacktes erstes Fiihlerglied zeigt, latte Loew die Art pallipes Fbr. genannt; eine zweite Ausnalıme hatte später Mik. lıervorgehoben, ich habe dann weiter in meiner Abhandlung uiber die paliagrktischen Dolicbopodiden bei dieser Gattnng ans- 
gefiilurt, daf nicht nur eine oder zwei, sondern eine ganze Reihe von Arten ein nacktes erstes Fiilulerglied habe und daß somit der von Loew konstruierte Untersehied zwisehen beiden Gattungen ganz geschwunden sei, was Loew nur ans Mangel an Artkenntnis entgangen. Die amerikanisehen Arten scheinen alle ein nacktes erstes Fiihlerglied zn laben. Wir miissen somit aus Prioritaitsgriinden den Namen Syntormon behalten. Die Fiihlerborste ist bei unseren paliiuktisehen Arten iiberwiegend apikal, nu. bei ein odel zwei Arten nimmt sie eine subapikale oder dorsale Stellung ein; bei den amerikanisehen Arten ist diese Abweichung ebenfalls, aber noeh deutlicher vorhanden; eine weitere Abweichung tritt dann noch hinzu iusofern, als das dritte Filhlerglied nicht immer seine spitze Form mit apikaler Borste beibehält, sondern sich trapezförmig bis viereckig abstumpft, und zwal dann mit dorsaler Borste; Übergainge sind vorhanden, es lassen sich daher diese gelegentlichen Formabweichungen nieht dazu benntzen, um sie als Gattungen oder Untergattungen auszuseheiden, da sonst alles, Habitns, Färbung und Beborstung ïbereinstimmt.

Wheeler hat im weiteren Verfolge seiner Dolichopodiden-Studie I. e. dann noch eine nene Gattung Parasyntormon anfgestell, die meiner Auffassung nach der Bereehtigung entbehrt, da sie mit Syntormon zusammenfailt; el hat sechs Arten beschrieben: asellus Wheel., occidentalis Aldr., lagotis Wheel., himulus Wheel, emarginatus Wheel. und montivagus Wheel. Unter diesen sind asellus und lagotis ganz normale Syntormon-Arten mit dreieckig spitz verlaufendem dritten Fühlergliede und apikaler Borste; etwas subapikal wird die Borste bei himmlus, dorsal bei emarginatus. occirlentalis und montivagus. Das unterseheidende Gattungsmerlsmal seheint fiir Wheeler del Umstand gewesen zn sein, daß diese Arten alle ziemlicl gleichmäßig verzierte Vordertarsen haben, bei denen das zweite Glied etwas liurz und rerdickt ist, aber dieser Unstand allein kann nicht eine besondere Gattung reehtfertigen; da wil bei Syntomon verzierte 'Tirsen an Hinterbeinen, Mittelbeinen und Torderbeinen beobachten können, so miibten wir darnach die Gattung in drei versehiedene 'Teile teilen. Eine ilnnliche 'Tarsenbildung findet bei unseren palaiaktischen Arten statt; wir kennen vier Arten: Miki Strobl, triungulipes Beck, mmilus Meig. und metathesis Lw., bei denen die Hintertarsen einfaeh gestaltet sind, unter diesen haben die drei letzten anch Vordertarsen, die dureh Verkiirzung mehrerer Glieder eine nngewöhnliche Form zeigen; diese als besondere Gattung abzutrennen, liegt kein Anlaß ror. Ich verweise des weiteren auf ihnliche Tarsenbildungen bei anderen Gattungen wie Dolichopus, Tuchytrechus u. a.; ich glanbe sicher, daß es keine Billigung finden wiirde, diese Gattungen nach ilırer 'Tarsenbildumg in drei Teile zu zerlegen. Die Wheeler'sche Gattung Parasyntormon muß daher mit Syntormon vereinigt werden; ieh habe ihre sechs Arten mit den iibrigen sechs Arten von Symtormon zusammengefaßt und fiil sie gemeinsehaftlich eine Bestimmungstabelle entworfen. 
Was die ron mil nel eingefiihrte Synonymie der Gattung Éntarsus anlangt, so babe jel letztere mit jluren drei amerikanischen Arten einer besonderen Bespreclung unterzogen und wolle man bier die Begrindung meiner Ansicht verfolgen; dic ron mir als Eutarsus angesehene Art Loewi Aldr. habe ich meiner T'abelle von Syntormon hinzugefiigt.

Der Gattungsbegriff von Syntormon ist fiu die amerikanischen Arten nu ein geringes zn erweitern mit Bezug auf Fthlerbildung: Das IIauptmerkmal der Gattung, das anch bei allen sonstigen Abweichnngen gewahrt bleibt, ist die Form des zwciten Fiihlergliedes, das scheinbar anf das dritte iibergreift, wiilurend eigentlich das dritte an der Basis nur entsprechend der Form des zweiten ausgeschnitten ist; das dritte Glied ist füir gewöhnlich dreickig verlaingert mit apikaler Borste ( $\left.\sigma^{7}\right)$; es treten danu aber hinzu Formen mit subapikaler und dentlich dorsaler Borstenstellung; bei letzterer erleidet dann die Spitze eine Abstumpfung; im iobrigen sind Unterschiede ron den uns bekannten paläariktisehen Formen nicht rorhanden.

\section{Irtrepteiclinis.}

1 uffinis Wheel. 5 , Proceed. Californ. Acad. Sc. ser. 3. Zoolog. 1138. 39 tab. III fig. 56-59 [Symarthus] (1899). America sept.

2 asellus Wheel. O' 9 , Proceed. Californ. Acad. Sc. ser. 3. Koolog. 1142. 41 tab. III fig. 6t-67 [I'arasyntormon] (1899) . . America sept.

3 cineveiventris Lw. +, N. Beitr. VIII 48.1 [Synarthrus] (1861) Amer. sept. 4 emarginatus Wheel. $\sigma^{7}$, Proceed. Californ. Acad. Sc. ser. 3. Zoolog. II 45. 45 tab. III fig. 75 [Parasyntormon] (1899) . . . America sept.

5 himnulus Wheel. ơ $q$, Proceed. Californ. Acad. Sc. ser. 3. Zoolog. II. 44. 44 tab. III fig. 72-73 [Parasyntommon] (1899) . . America sept.

6 lagotis Wheel. $\delta^{7}$, Proceed. Californ. Acad. Sc. ser. 3. Zoolog. II 43. 43 tab. III fig. 70. 71. [Parasyntormon] (1899) . . . America sept.

7 Loewi Aldr. O’, Biolog. Centr. Anner. Dipt. I 349.1 [Eutarsus] (1901) Mexico

8 montivays Wheel. of $\sigma^{7}$, Proceed. Californ. Acad. Sc. ser. 3. Zoolog II 46. 46 tab. III fig. 74 [Parasyntomon] (1899) . . . America sept.

9 occidentalis Aldr. O', Kans. Univ. Quart. II 153 [Sympycurs] (1893) Am. sept. 10 palmaris Lw. o क , Monogr. Dipt. N.-Amer. II 135. 1 tab. IV fig. 17, e, d [Synarthrus] (1864) . . . . . . . . . . America sept. 11 quarlratus Aldr. $\sigma^{7}+$, Biolog. Central Amer. Dipt. 1 342. 1. tab. VI fig. 18, 18a (1901) . . . . . . . . . . . . Mexico

12 strataegus Wheel. ơ $q$, Proceed. Californ. Acad. Sc. ser. 3. Zoolog. Il 39.

40 tab. IlI fig. 60 -61 [Synarthrus] (1899) . . . . Americas sept.

13 Wheeleri Aldr. of 7 , Biolog. Centr. Amer. Dipt. I 343.1 tab. VI fig. 19 [Parusyntomon] (1901) . . . . . . . . Mexico 


\section{Bestimm!nugstibelle \\ fiil die Lrten der fiatmug Syntormon Lw.}

1 Tarsen der Hinterbeine verziert . . . . . . . . . . 2

- Tarsen der llittelheine verziert . . . . . . . . . . . 4 4

- Tarsen der Vorderbeine verziert. . . . . . . . . . . 5

— Tarsen aller Beine einfach . . . . . . . . . . . . 11

2 Drittes Fiihlerglied lang dreieckig mit apikaler Borste . , , 3

3 Hintermetatarsus ( $\sigma^{\prime}$ ) mit einer selıäg abstehenden krummen Borste auf seiner Unterseite. Hiiften schwarz. Beine gelb. Drittes Filhlerglied (ठ) etwa zweimal so lang wie breit, Borste apilkal; beim $q$ ist das dritte Ftihlerglied kanm länger als breit mit dorsaler Borste $3.5-4 \mathrm{~mm}$ lang . . . . . . . . affinis Wheel. $\sigma^{7} \mathrm{c}$

- Hintermetatarsus ( $\left.\sigma^{7}\right)$ etwas verdickt, anf der Unterseite ansgehobht und nahe der Basis mit zwei gekriimmten Borsten. Hiffen metallisch grtin, Beine gelb. Selsenkel an der Wurzel mehr oder weniger erzgriin verdunkelt. Drittes Fiihlerglied (ठ) fast zweimal so lang wie breit und mit apikaler Borste; beim \& so lang wie breit nit stumpfer Spitze und anch mit apikaler Borste. $4-5 \mathrm{~mm}$ lang strataegus Wheel. or?

4 Erstes Tarsenglied der Mittelbeine $\left(\sigma^{7}\right)$ so lang wie die vier folgenden Glieder zusammen; das zweite selu breit weillich mit sehwarzem Spitzenrand; drittes und viertes Glied auch verbreitert und mit den fiinften nicht verbreiterten Gliede tiefselıwarz. Drittes Fiihlerglied lang dreieckig zugespitat mit fast apikaler Borste; beim $q$ ist das dritte Ftillerglied oval mit stumpfer Spitze. Hiiften und Beine gell. $3 \mathrm{~mm}$ lang . . . . . . . . . pulmaris Lw. of

5 Erstes Tarsenglied der Vorderbeine $\left(\sigma^{\star 7}\right)$ verlängert, auf der Wurzelh:̈lfte der Unterseite mit 3-4 Borsten; das zweite Glied kurz und etwas verdickt; das dritte Glied unten an der Wurzel mit einer gekrimmten Borste .

6 Zweiter und dritter Hinterleibsring geelb oder wenigstens an den Seiten gelbgefleckt

- Hinterbeib ganz bronzegriin. Fiibler ganz seliwarz; drittes Glied dreimal so ling wie an der Wurzel breit, Borste von $1 / 5$ der Lainge des dritten Gliedes. $25-3 \mathrm{~mm}$ lang. . . . . asellus Wheel. $\sigma^{7}$

7 Drittes Fiblerglied $\left(\sigma^{\top}\right)$ viercekig, vorne abgestumpft mit dorsalel langer Borste . . . . . . . occidentalis Aldr. $\sigma^{7}$

Drittes Fiilılerglied $\left(\sigma^{7}\right)$ spitz endigend . . . . . . . . . 8

8 Fiillerborste des $\sigma^{7}$ dentlieh dorsal . . . . . . . . . . 10

- Fiblerborste des $\sigma^{7}$ subapikil oder apikal . . . . . . . . 9

9) Erstes Fiillerglicd fast ganz gelb; dieses dreimal so lang wie breit, Borste halb so lang wie das dritte Ftihlerglied. $2 \cdot 5$-3 mm lang layotis Wheel. ơ? 
- Fihlerglieder alle schwarz; das dritte Glied etwa zweimal so lang wie breit, Borste subapikal, etwas länger als das halbe dritte Glied. $2 \mathrm{~mm}$ lang. . . . . . . . . himmulus Wheel. 'o

- Fuhlerglieder alle sehwarz; das dritte Glied ungefähr viermal so lang wie breit. Borste a pikal, etwa von $1 / 5$ der Länge des dritten Gliedes. Hiiften gelb, zu $\frac{2}{3}$ seliwarz, z11 $1 / 3$ an der Spitze nelsst den Beinen gelb. Hintersehenkel oben anf der Spitzenhälfte schwarz. Hinterleih am zweiten und dritten Ringe mit kleinen gelben Seitenfleeken. Baneh gelb. $2.2 \mathrm{~mm}$ lang. . . . . . Wheeleri Aldr. $o^{x}$

10 Fihlerborste nahe der Spitze des dritten Giliedes, dieses zweimal so lang wie breit. $2 \cdot 2-2.5 \mathrm{~mm}$ lang . . . . cmarginatus Wheel. o Fiilulerborste anf der Nitte des Oberrandes des dritten Gliedes, letzteres zweimal so lang wie breit. $2 \cdot 3-3 \cdot 3 \mathrm{~mm}$ lang montivagus Wheel. $\sigma^{7}$

11 Filuler ganz sehwar\%. Hinterleib olne gelhe Flecken . . . . 12

- Filhler gelb, Spitze des dritten Gliedes etwas geloräunt; letzteres kurz mit subapikaler Borste. Hinterleib mit gelben Binden anf den ersten drei Ringen; Banch, Hiiften nnd Beine gelb. Fliigel zart gelbbrimnlich. $3 \cdot 3 \mathrm{~mm}$ lang . . . . . . . . . . . Loevi Aldr. o

12 Drittes Fihlerglied viereckig; vorue stumpf mit dorsaler Borste. Beine schwarzbraun mit gelben Knieen. $3 \mathrm{~mm}$ lang quadratus Aldr. of

Drittes Fiihlerglied von gewölsnlicher Form und Borstenstellung. Beine gelb. $3 \mathrm{~mm}$ lang . . . . . . . . . cinereiventris Lw.

\section{Eutarsus.}

Lw., N. Beitl. I 45 (1857).

Drymonoeca Beck., Zeitsehr. IIym. Iipt. VII 108 (1907).

Bei Bearbeitung der palïarktischen Dolicbopodiden habe ich frïher schon ausfiihrlicher iiber die etwas zweifellafte Berechtigung der Gattung Eutarsus verhaudelt; damals kannte iel nur die paläarktiseben Formen und nahm noch Abstand davon, die Gattung ganz zu verwerfen, hehandelte sie vielmelr noeh als Untergattung zu Syntormon. Hente muß ich mich nach Kenntuisnabme der amerikanischen Formen dahin aussprechen, daß ich Eutarsus Lw. nur noel als Synonym von Syntormon ansehen kanu.

Im Katalog Kertész VI 1909 sind bei dieser Gattung Lintarsus drei amerikanisclse Arten genannt, die wir zunäelst anf ihre Z11gehörigkeit priffen wollen.

1 cques Lw. O", Monogr. Dipt. N. Amer. II 154. 1 (1864) . . Veneznela

Größere Art mit langen Beinen und Hinterleib; Hintertarsen roul besonderel Bildung; das erste Glied ist besondel's kul'z, das zweite ist $4 \frac{1}{2} \mathrm{mal}$, das dritte $2 \frac{1}{2} \mathrm{mal}$ so lang wie das erste Glied und das vierte ist auf seiner Oberseite in einen starken Dorn ausgezogen. Beine gelh. Das dritte Fihlerglied ist kurz, oval mit dorsaler nackter 
Borste; das erste Fiihlerglied naekt. Die Fliigel sind besonders lang und schmal. $5-6 \mathrm{~mm}$ lang.

Loew hat diese Art als einen Eutarsus gedentet, allerdings nicht mit Uberzeugung; in seiner am Schlusse der Beschreibnng folgenden Bemerkung sagt er zunichst, daß sich seine Alt von Eutarsus aulicus Meig. nach verschiedenen Richtungen hin unterschiede, er lasse seine Art aber doch wegen Ubereinstimmung verschiedener Eigen. schaften bei dieser Gattung, da er sie in keine andere stellen könne; er erachte es noch als rerfriiht, anf sie eine besondere Gattung zu errichten.

Man muß einräumen, daß zwisehen eques Lw. und aulieus Meig.

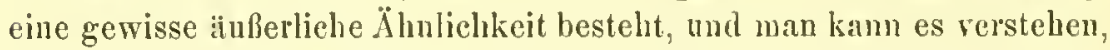
dal Loew trotz mancher von ihm eingeriumten Verschiedenheiten, sieh nieht dazu entsehließen konute, auf dies eine Exemplar hin eine besondere Gattung zu griinden. Nachdem es mir aber gegliekt ist, anßer eques Lw. woch drei andere gleich organisierte Arten aufznfinden, ist die Aufstellung ciner Gattung, die icl Stolidosoma nenne, gerechtfertigt; weshalb ich diese Gattung sogar als Träger einer nenen Gruppe Stolidosominae bezeichnete, labe ich in der Einleitung zu dieser Gruppe auseinandergesetzt. Die Hauptunterschiede dieser Gattung von Syntormon oder Eutarsus bestehen in der Kopf- und Fühlerform sowie in der Gestalt und Aderung der Fliigel.

2 Loewi Aldr. Biolog. Centr. Amer. Dipt. I 349. I (1901) . . . Mexico

Ich halte diese Art fiur einen echten Eutarsus oder Syntormon. Vou den iibrigen Arten der Gattung durch ganz gelbe Fiihler ausgezeichnet; die Fiihlerborste wird als subapikal geschildert.

3 simatus Aldr. ơ, Trans. Ent. Soc. London 334. I tab. XI fig. 104, tab. XII fig. 110, 115 (1896) . . . . . . . America centr.

Leider hat Aldrich nur die Fligel, nicht anch die Fiihler ah. gebildet, sich anch ïber die Form derseben nicht geïubert, wahrscheinlich weil er glaubte, iiber dieselben nichts Besonderes sagen zn können. Hätte das zweite Fỉhlerglied diese längere daumenförmige Form gehabt wie bei Syntormon oder Eutarsus, so hätte er dies wahrscheinlich gemeldet; daß simuatus keinem Syntomon entspricht, geht aber weiter noch daras herror, daß Aldrich das Weibchen mit einem eingedrickten Gesicht schildert, das sonst als ein vorspringendes liatte bezeichwet werden miissen. Ich komme auf Grund der Fligelzeichnung trotz der verlïngerten und vergrößerten Pulvillen der Vorderbeine zu dem Schlusse, daß hier eine Art del Gattung Lyroncurus vorliegt, anf welche Aldrich sich anch in seiner Besehreibung bezieht, und die er in der Art simplex vorftihrt. Wir stellten als besondere Fliigeladerung die Gattung Lyronemus f'est, daß die dritte Läingsader beim ơ bauchig' nach oben gebogen ist; diese Eigensehaft finden wir bei der Flïgelzeichnung von simuatus ebenfalls ror, weun auch die zweite Laingsader etwats 
anders als gewöhnlich verlaiuft. Da ich die Art simatus nur aus der Beschreibung kenne, habe ieh sie nieht in mein Verzeichnis und meine Tabelle bei Lyroneurus ohneweiters aufgenommen. Ich mache hier aber darauf aufmerksam, daß kein Eutorsus oder Syntormon unter dieser Art verborgen sein kann.

\section{Achalcus.}

loew, N. leitr. V 30 (1857).

Es sind uns von Aldrich zwei Arten dieser Gattung zur Kenntnis gebracht worden und in seinem Katalog verzeiehnet. Ich kenne sie nicht von Ansehen und kann sie nur nach der Beschreibung rolftibren, auf welche ich verweisen muB; beide Arten sind sehwarz, nicht gell gefuirbt, haben anch keine gelben Borsten; die eine Art $\left(\sigma^{7}\right)$ ist durch einen Fliigelflecken ansgezeichnet.

1 caudatus Aldr. ơf, Kansas Unir. Se. Bull. I 93 (1202) . America centr. aus Grenada, West-Indien.

2 sordidus Aldr. o' , Trans. Entom. Soe. London 339.1 tab. Xl fig. 107, 107 a (1896) aus St. Vincent, West-Indien.

\section{Peloropendes.}

Wheeler, Psyehe V 373 (1890).

Im Katalog Kertész VI (1909) ist diese Gattung zu den Hydrophorinen gestellt. Aldrich hatte sie in seinem Katalog del nordamerikanischen Dipteren 296 (1905) zu den Medeterinae gebracht, wahrseheinlich einer Anregung von T. Mik folgend. Mik hatte sich nämlich in der Wiener entom. Zeitg. X 3. 85 ( I891) iber die Stellung dieser Gattung ausgesprochen; zuerst sagte el, Peloropeodes stehe der Gattung Systenus Lw. so nahe, daß man sogar an eine Teleinigung mit dieser denken kömne, wenn die Art salax nieht ein sitzendes Hypopygium besäife; dann meint er, die Gattung ließe sich anch wohl in die Gruppe der Medeterinae einleihen. Ich fasse Milk's Äußerung als eine unverbindliche persönliche Ansicht auf, die, ohne eine Begriindung zu bringen, anch weiter keinen größeren Wert besitzt und besitzen kann. Ich glaube auch nicht, dalf eine Begriindung bei Bewertung dieser Galttung möglieh ist, sofern wir nicht weitere Aufschliisse tiber dieselbe bekommen oder die Type vergleichen kinnnen. Wheeler hat von vorneherein darauf verzichtet, iiber die Verwandtschaft dieser Gattung und ibre Stellung irgendeine Ansicht zu äußern; die Sache mag auch vielleicht bei dieser Fliege nicht so ganz einfach und klar liegen. Soweit man der Beschreihung nach sich ein Urteil erlauben darf, würde ich diese Gattung der Gruppe der Rhaphiince zugesellen, wohin auch Systenus Lw. gehört und wozn das sehr lange kegelförmige dritte Fiuhlerglied mit der apikalen Fîhlerborste einladet; an eiue Medeterine ist grade der Fiblerbildung wegen und weil auch die Flïgeladerung hierfiir keinerlei 
Anhalt gibt, nicht zu denken, ebenso wenig wie an eine Hydrophorine. Wie hieraus erhellt, ist ein abschließendes Urteil über die Stellıng diesel Gattung zurzeit nicht möglich.

1 salax Wheel. $\sigma^{\top}$, I. c. $374(1890)$. . . . . . . Ameriea sejt.

Einige Pärchen atus Milwakkee.

\section{Systenus.}

Loew, N. Beitr. V 34 (I857).

Von dieser Gattung ist bisher keine amerikanische Art bekannt geworden. Ich fand jedoch einen Vertreter delselben in der Sammlung des Ungarisehen Nationalmuseums.

raptor n. sp. or. 2 Figuren America merid.

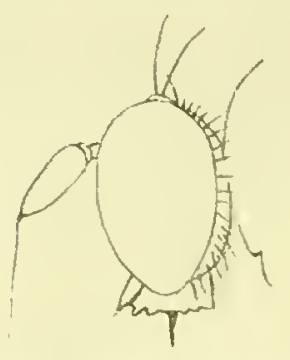

Fig.61. Systenus raptor Beek. $0^{7}$

Kopf ron der Seite. $24:$ I.

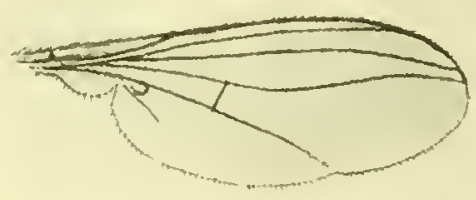

Fig.62. Systenus raptor Beck. ơ. Flügel. 16:1.

$\sigma^{7}$. - Thoraxriicken dunkelmetallisch, etwas grau bereift. Schwinger und Schiippchen gelb, Wimpern der letzteren (?). Stirne und Gesicht dunkel. Fibler schwarz, drittes Fihlerglied $21 / 2$ mal so lang wie lreit, zngespitzt mit Endborste, die so lang ist wie die Fiihler. Ruissel nnd Taster gelb. -- Hinterleib glänzend schwarz, zweiter Ring gelb. Hypopyginm dentlieh gestielt, groß, blaßgell, ähnlich in der Form wie Hercostomus chacrophylli Meig., vivax und misticosa Lw., die Form del gelben Anhäinge ist nicht dentlieh erkennbar. Beine mit allen Hiiften ganz blaßgelb, seln lang. Die Längenverhältnisse sind bei 24 facher Vergrößerung gemessen wie folgt:

Vorderschiene 31, Metatarsus 20, die übrigen Glieder zusammen $27 \mathrm{~mm}$.

Verhältnis der Schiene zu den Tarsen wie $31: 47=1: 1 \bullet 44$.

Mittelschiene 40, Metatarsus 40, die iibrigen Glieder zusammen 40.

Verhailtnis der Schiene zu den Tarsen wie $40: 80=1: 2$.

Hinterschiene 58, Metatarsus 22, die ỉbrigen Glieder znsammen 46.

Verbältnis der Sehiene \%u den T'arsen wie $58: 68=1: 1 \cdot 2$.

Fliigel wasserklar, Adern ganz im Charakter unserer paliarktisehen Systenus-Arten. $2 \cdot 2 \mathrm{~mm}$ lang.

Ein Exemplar aus Paraguay [Fiebrig]. Ungarisches Nationalmuseum. 


\section{Gruppe VII.}

\section{Neurogoninae.}

\section{Nenrogone.}

Rond., Dipt. Ital. Prodr. 1. 142.7 [Neurigona] (1856).

Dactylomyia Aldr., Kansas I'niv. 11. 151 (1893).

Saucropus Lw., N. Beitr. I 41 (1857).

Vou amerikanischen Arten sind bislang folgende 10 Arten bekannt geworden, denen ich nur eine nene hinzufiigen kann.

1 brasiliensis Schin. \&, Novara-Reise, Dipt. 218.22 (1868) . . Brasilia

2 rarbonifera Lw. o’, Berlin. Ent. Zeitschr. XIII 177. 84 [Sancropus] (1869)

America sept.

floridula Wheel., Proc. Calif. Acad. Se. ser. 3. Zool. II 72 (1899).

3 cinereicollis v. d. Wulp, o Tijdschr. v. Ent. XXXI 370.10 [Saucromus] (1888) . . . . . . . . . . . . . . . Argentinia

4 decora Aldr. 9, Kansas Univ. Se. Bull. I 83. (1902) . . Ameriea centr.

5 dimiliata Lw. ठ, N. Beitr. VIII 75. 1 [Saucropus] (1861) America seppt. floridula Wheel. = carbonifera Lw.

gracilipes Aldr. = lateralis Say.

6 lateralis Say. of $q$, Journ. Acad. Nat. Sc. Philadelphia VI 1 [Medeterus] (1829) . . . . . . . . . . America sept. graeilipes Aldr., Kansas Univ. Quart. II 151. [Dactilomyia] (1893). superbiens Lw., N. Beitr. VIII 76. 3 [Sucropus] (1861).

7 lienosa Wheel. 9 , Proc. Calif. Acad. Sc. ser. 3. Zool. II 73. 74 (1899).

America sept.

8 orbicularis n. sp. of . . . . . . . . . America merid.

9 rubella Lw. †, N. Beitr. VIII 76. 2 [Saucropms] (1861) America sept.

10 signifera Aldr. ơ, Trans. Ent. Soc. London 337. 1 (1896).

superbiens $\mathrm{Lw}$. = lateralis Say.

America centr.

11 temis Lw. б", Monogr. Dipt. N. Amer. II 228. 4 [Sancropus] (1864).

\section{Bestimmungtabelle.}

Männcben.

1 Hypopyginm gelb . . . . . . . . . . . . . . . 2

- Hypopygim schwarz . . . . . . . . . . . . . 4 
2 Vordertarsen einfaeh; Thoraxriicken von metalliseh griuner oder blaner Grundfarbe . . . . . . . . . . . . . . . . . 3

- Vordertarsen rerziert: viertes Glied weil, fuinftes verbreitert und sehwarz. Thoraxriicken gelb, vor dem Schildchen verdunkelt, Metanotum ganz. selıwarz. Hinterleib gelb, auf dem zweiten und dritten Ringe mit je ciner schwarzen, auf der Mitte verschmilerten Vorderrandbinde. Beine und Hïften gelb. $4 \cdot 5-5 \mathrm{~mm}$ lang . . carbonifera Lw. o

3 Augen oben unter den Fiihlem zusammenstoßend. Stirne metallisch matt; Fithler gelb, drittes Glied an der Spitze bram. Hinterleib: die ersten beiden Ringe gelb, die anderen griin. Beine nebst Hiiften griin, Mittelliiften an der Basis verdunkelt; das zweite Glied der Vordertarsen an der Spitze der Außenseite mit einem einzelnen Haar. Vierte Längsader etwas konvergierend und vor der Fliggelspitze endigend. $3 \mathrm{~mm} \mathrm{lang} \mathrm{.} \mathrm{.} \mathrm{.} \mathrm{.} \mathrm{.} \mathrm{.} \mathrm{.} \mathrm{decora} \mathrm{Aldr.} \mathrm{o}$

- Augen linienförmig getrennt; Stirne weiß bestiubt. Fühler wie bei decora. llinterleib gelb, an den ersten dlei Ringen mit sehwarzen Seitenflächen oder schwach verbundenen Binden; die iibrigen Ringe sind oberseits metalliseb gliinzend. Beine lang, mit den Hiiften gelb, Tarsen ganz einfach. 3-4 mu lang . . . . lateralis Say $\sigma^{7}$

4 'Thoraxriaken gelb, vor dem Schildehen nietalliseh gefirbt; Tarsen einfach

- Thoraxrieken ron metallischer Grundfarbe, durch Bestiubung graugriin. Vordertarsen verziert: viertes Glied teilweise, das fiunfte ganz schwarz, beide etwas verbreitert und sehwarz gewimpert. Stirne weif bestäubt. Hinterleib gelb, zweiter und dritter liing mit schwarzen dreieckigen Ritckenflecken, vierter und finfter Ring scluwarz.

$35-4.5 \mathrm{~mm}$ lang . . . . . . . . . . . tenuis Lw. O

- Thoraxriicken von metalliseher Grundfarbe, grau bestiubt. Mitteltarsen lang und diinn, viertes und fiinftes Glied verbreitert und schwarz. Beine und Hiiften gelb, Hintertarsen sehwarzbram. Hinterleib auf der Vorderhälfte gelb, hinten braun. Vierte Lïngsader an der Spitze der dritten parallel. $35 \mathrm{~mm}$ lang . . . cinereicollis Wulp. o'

5 Hinterleib gelb, am zweiten und dritten Ringe je ein kreisrunder schwarzer Seitenfleck; Metanotum mattgelb. Gesicht hellgrau. Vierte Längsader der dritten parallel, etwas hinter der Fltigelspitze ausmiindend. 2.8-3 mu lang . . . . orbicularis n. sp. o

- Hinterleib gelb, zweiter, dritter und vierter Ring mit gleich breiten schwarzen Vorderrandsbinden; Metanotum sehwarz. Vierte Längsader stark mit der dritten konvergierend und ror der Fligelspitze mindend. $5 \mathrm{~mm}$ lang . . . . . . . . dimilliata Lw. o

- Hinterleib gelb, rom zweiten Ringe an mit schwarzen Vorderrandsbinden in zunehmender Breite, so daf der ftinfte ganz schwarz ist, Vierte Läingsader der dritten parallel. $35 \mathrm{~mm}$ lang 


\section{Weibchen.}

1 Arten mit gelbem Thoraxriicken, gelbem Schildchen und dunklen metallisch gliinzenden Flecken vor dem Sichildchen . . . . 2

Arten mit metallisch glänzenden Thoraxrïcken und Sehildehen, Rand des Schildchens gelb.

2 Stirne weißgran bestiubt . . . . . . . . . . . . 3

- Stirne metallisch, matt bereift . . . . . . . . . . . . 4

3 Metanotum ganz schwarz, grau bereift. Thoraxrieken auBer dem Flecken vor dem Schildehen noch mit einer dunklen Mittellinic und einem solchen Wurzelflecken anf dem Schildchen. Hinterleib gelb, rom zweiten Ringe an mit immer breiter wcrdenden schwarzer Vorderrandsbinden, der fiinfte Ring ganz schwarz. Vierte Liingsadcr parallel zur dritten. $4.5 \mathrm{~mm}$ lang . . . Wrasiliensis Schin. \&

- Metanotum gelb mit dunklem oberen Rande und Mittelstrich. Bisst. seiten gelb mit schwarzen Flecken. 'Thoraxriicken ohne dunklere Nittellinie. Hinterleib gelb, vom zweiten Ringe an auf allen Ringen mit gleichbreiten schwarzen Vorderrandbinden, die letzteren nndentlicher. Beine gelb, T'arsen von der Spitzc des ersten Gliedes an braun. Vierte Längsader mit der dritten stark konvergierend. $6 \mathrm{~mm}$ lang . . . . . . . . . . . rubella Lw. ?

4 Hinterleib gelb, vom zweiten Ringe an mit schmalen schwarzen vorderen Seitenflecken auf allen Ringen. Metanotum ganz mattgelb. Bcinc ganz gell, Vierte Liingsader an der Fliigelbeule dentlich aufgebogen, an der Spitze parallel zur dritten. $35-4 \mathrm{~mm}$ lang. orbicularis 11. sp. 9

- Hinterleib gelb, rom zweiten Ringe an mit immer breiter werdenden schwarzen Vorderrandbinden aur allen Ringen. Beine gelb, Tarsen von der Spitze des ersten Glicdes an braun. Vierte Längsader der dritten parallel. $3.5 \mathrm{~mm}$ lang . . . . . . signifera Lw. +

5 Stimc weiß bestäulst . . . . . . . . . . . . . . . 6

Stirne metallisch matt bereift. Hinterleib gelb, dritter, vierter und fiinfter Ring metallisch griin. Beine ganz gelb. Vierte Liingsader mit der dritten konvergierend und vor der Fliigelspitze susmiindend. 2.8-3 mm lang. . . . . . . . . . . decora Aldr. 9

6 Filhlerborste deutlich pubeszent. Hinterleib fast ganz schwarz mit weißer Bereifung, nur die Hinterceken des zweiten, dritten und vicrten Pinges und der Banch gelb. Beine gelb, Tarsen von der Spitzc des ersten Gliedes an braun; bintere Querader 110 das $21 / 2$ fache ihrer eigenen Länge rom Hintcrande entfernt. 4.5-5 mm lang lienos $\ell$ Wheel. ?

- Fiiblerborste wie gewöhnlich fast nackt. Hinterleib gelb, erster und zweiter Ring an den Seiten mit schwarzen Flecken, die iibrigen Ringe oberscits metallisch gliinzend. Beine gauz gelh. $3-4 \mathrm{~mm}$ $\operatorname{lang}$ 
orbicularis n. sp. o' $T$

Ancricar merid.

$\sigma^{7}$. - Thoraxrieken und Sehildchen mattgelb, der flache Eindruek rol dem Sehildehen sehimmert metalliseh grin; die Dorsozentralborsten nehmen an Stairke nach dem Sehildehen hin zu, die letate derselben vor dem Sebildchen sowie die beiden Schildborsten selbst sind sehr stark, waihrend die vordersten von den fiunf Parren nur sehr schwach siud; Akrostikalbörstehen deutlich zweireihig. Brustseiten ganz nattgelb ohne sehwarze Flecken. Sehwinger, Schiippehen und deren Wimpern gelb. Metanotum mattgelb. Hinterkopf oben graulsehwarz. Stime matt metallfarbig, das sehmale Gesicht weißgrau; Taster und Fiihler rot. - Hinterleib mattgelb mit je einem kreisrunden sehwarzen Seitenflecken an Vorderrande des zweiten und dritten Ringes. Hypopygium scheimbar ungestielt, plump, pechsehwarz, zum Teil glänzend mit kurzen fadenförmigen dunklen Anhängen. - Beine nebst Hifteu und Tarsen gelb; die letzten Tarsenglieder sind kaum etwas gebriunt. Vordertarsen etwa zweinal so lang wie die Schienen; Mitteltarsen etwa $1 \frac{1}{2}$ mal so lang, Hintertarsen ebenso lang wie die Schienen; die Beborstung ist selur schwaeh; das erste Tarsenglied der Hinterbeine ist etwas kiirzer als das zweite. Fliigel zart gelblich getrtibt; die vierte Längsader weicht an der Flügelbeule kaum etwas von ihrer Richtung ab und verliuft parallel zur dritten bis zur Flïgelspritze; die hintere Querader ist $11 \mathrm{~m}$ ihre eigene doppelte Länge vom Fltigelhinterlande entfernt. $3.5 \mathrm{~mm}$ lang.

१. - Am Hinterleibe sind der zweite, dritte und vierte Ring gefleckt; die Flecke liegen seitlich am Vorderrande der Ringe und haben eine längliche Form. Die beiden Endlamellen am Hinterleibe sind stabformig, gelb mit schwarzer Endbälfte. Die Beine sind im ganzen etwas kiirzer, sonst keine Unterschiede vom Männchen.

2 o’, 3 a aus Paraguay, S. Bernardino [Fiebrig]. Wiener Hofmusenm.

2 б, 6 б ans Paraguay. Berliner zoologisehes Museum. 


\section{Gruppe VIII.}

\section{Diaphorinae}

der nearktischen und neotropischen Region.

In dieser Gruppe kommen Diaphorus Meig., Chrysotus Meig. und Asyndetus Lw., wie in der paläarktischen Region, auch in Nord- und Stidamerika vor. Lyroneurus Lw. ist eine Gattung, die anf Siidamerika beschränkt ist, während Argyra Macq. und Leucostolus Lw. bisher nur in Nordamerika gefunden wurden. Coeloglutus Aldr. ist aus Zentralamerik: bekannt. Zwei neue Gattungen Arhradocera und Symbolia konnte ich ans Siidamerika feststellen.

\section{Tabelle der tiattungen.}

1 Randader nur bis zur dritten Lüingsader lanfend, die vierte Laingsidel nur schwach ausgebildet, mit der dritten stark divergierend, im letzten Absehnitt nur sehwach zusammenlängend oder dentlich getrennt, der letzte Abschnitt parallel . . . . Asyndetus Lw.

Randader bis zur vierten Längsader lanfend . . . . . . . 2

2 Silberschimmernde Arten . . . . . . . . . . . . . 3

- Metallisch gefärbte Arten ohne Silberschimmer . . . . . . 4 Gelb-, nieht metallıseh gefärbte Arten . . . . Tanthina Aldr.

3 Erstes Fiihlerglied nackt, Schildehen mit zwei Borsten . Lencostola Lw.

- Erstes Fiihlerglied behart, Sehildehen mit vier Borsten Argyra Macq.

4 Drittes Fỉhlerglied birnförmig, mit lang ausgezogener Spitze und apikaler Borste. . . . . . . . . Acleradocera n.

Drittes Fiihlerglied knr, dreieekig, mit deutlich dorsaler Borste. Fliigel an der Basis am breitesten und mit parallelen Längsadern wie bei Diaphorus . . . . . . . . . . . . Symbolia n. ..

- Drittes Fiihlerglied abgerundet, nierenförmig, mit zentraler, apikaler oder subapikaler Borste . . . . . . . . . . . . . . 5

5 Fliigel an ihrer Spitze breit abgernndet . . . . . . . . . 6

- Fliigel an ihrem Ende zugespitzt . . . . . Coeloglutus Aldr.

6 Augen auf der Stime und dem Gesicht etwa nm $1 / 4$ der ganzen Kopfbreite getrennt mit parallelen Augenräindern; die erste Hintelrandzelle breiter als gewölnnlich, dureh die Biegung der dritten und 
vierten Lïngsader in Form einer Leier. Vorderbeine ohne verliiugerte Pulvillen . . . . . . . . . . . Lyroneuns Lw.

- Augen auf der Stirne sich beriilıend; wenn schmal getrenut, dann die Augenrïinder in Bogenform sich nïluernd und reren Entfernung schmäler als das Gesicht; dritte und vierte Längsader'n parallel lanfend, beide grade oder lcicht gebogen; erste Hinterrandzelle in der gewöhnlichen Form. Vorderbeine in der Regel mit verlängerten Pulvillen; langgestreckte mittelgroße Arten . . . . . . Dinphoms Meig.

- Augen am Gesicht zusammenstoßend; wenn getrennt, dann deren Entfermung schmäler als die breite Stim; dritte und vierte Längsadern parallel, meist grade, selten etwas abweichend in Verlaufe. Pulvillen der Vorderbeine in der Regel unselieinbar; kleincre kurz gebante Arten Chrysotus Meig.

\section{Dictpheorus.}

Meig., Syst Brachr. IN 32. (1824).

Wir brauchen die Gattung als solehe hier nieht mehr in ihren Eigenschaften festzulegen, nachdem wir dies bereits bei Behandhung der palïiarktischen Arten getan und nachdem wir die Untersehiede von Lyroneurus Lw. alleh bei Besprechuug dieser Gattung angegeben haben. Vielleicht eriibrigt es sich noch, die Uuterschiede von den amerikanischen (HrysotusArten zu bespreehen. Es ist dies aber meiner Ansieht nach auch schon ansgiebig geschelien durch Aldrich, der bei Besprechung der DianhorusArten ron Grenada in Kinsas Univ. Se. Bull. I Nr. 3. 85 (1902) folgendes ausführt: Zu Chrysotus gehiren alle Arten, hei denen die Augen des o untel den Fiihlern genähert sind, und zu Diaphorus, bei denen sie a uf der Stirn genähert sind. In zweifeluaften Fillen entselueidet das Vorhandensein ron stiukeren Borsten am Hypopyg für Tiaphorus. leh glaube, wil können uns im allgemeinen mit dieser Trennung einverstanden erkliaren.

\section{Artrepzeichnis, Bemerkungen mud Beschreilmngen.}

1 amoemus Aldr. ơ 9 , Kans. Univ. Se. Bull. I 86 (1902) . . . Antillae óq. - Thoraxricken griin. etwas bestäubt. Schiippehen mit weilgelben Wimpern. Angen auf Stim und Gesicht zicmlich breit getrennt; erstere glinzend griin, letztere mit gelber Bereifung. Fiibler sehwarz, Taster gelbweiß, anffillig groß, um $1 / 3$ der Kopfeslänge lierabläingend, in einer Breite von $2 / 3$ der Länge. Beine nebst Vorderhiiften gelb, Hinterschenkel an der Spitze brinn. Vorder- und Vitteltursen liinger als ibre Schiene. Vorderpulrillen groß. Fliigel fleckenlos, granlich mit pilallellanfenden Längsadelı. $205 \mathrm{~mm}$ lang.

Von Aldrieh aus Grenada, Westindien beschrieben.

aproximatus Aldr. = spertabilis Lw. 
ठ․ - Thoraxricken griingold mit gelbgraner Bestiubung. Schiippchen weingelb mit weißen Wimperu. Stime und Gesicht gleich breit, crstere matt braungrau, letzteres grau. Taster gelb, Fiihler sclwarz. Hinterleib bronzegriin, der zweite nud dritte Ring ganz oder teilweise gelb, Hypopygium dentlich beborstet. - Beine und Vorderhiften ganz liellgelbrot, nur die Endglierler der Tarsen bran und die Wnrzelhilfte der Mittel- und Hinterhiuften grau. Fligel in gelblichem Ton und nit gelbbraunen Adern; dritte und vierte Längsadern etwas gebogen, aber parallel; hintere Querader um ilue eigene doppelte Lainge vom Fliigelhinterrande entfernt. $3 \mathrm{~mm}$ lang.

Ein Exemplar aus Bolivia, Provinz Sare, 600-700 m hoch und zwei Exemplare ans Nordargentinien. Sammlung des Berliner zoologischen Museums.

Anmerkung. Clmbich dem parvulus Adre, aher durch matte, schmilere stirn. hellere Beine, Ilinterleih und (tröbe abweichend

ठ7. - Thoraxriicken metallisch griin, glänzend, durch Bestäubung' kaum etwas matt; Wimpern der weißen Sehiippehen weib. Augen anf der Stirne schmal getrenut, Zwischenraum kamm so breit wie der Punktaugenhöcker, grau bestiulut wie das etwas breitere Gesicht. Fiihler schwarz, drittes Glied klein nit zentraler Borste und weißer Pubeszenz. Taster braun, Hiuterkopfzilien unten weiß. Hinterleib hronzef:ırbig; Hypopyg mit deutlicher Beborstung (etwa sechs Borsten). - Hiften schwar\%grau, Vorderhiften mehr braungelb; Beine gelb, Endglieder der Tarsen kaum etwas gebräunt; Hintersehenkel obenauf an der Spitze braun. Hinterschienen auf der Ober- und Unterseite der ganzen Länge nach deutlich gewimpert. Vordertarsen nur wenig linger als die zugehörige Schiene. Flügel zart gelbloran getribt von der gewöhnlichen etwas breiten Form und der normalen Aderung: dritte nnd rierte Längsadern parallel, kaum etwas gehogen. $2.5 \mathrm{~mm}$ lang.

$1 \delta^{7}$ aus Peru-Meshagua, 9. X. 03. Urubambafi [Schnuse], Sammlung des Dresdner zoologischen Museums.

Anmerkung. Nach Aldrich s Bestimmungstabelle in Kansas Lniv. Nic. Bull. 185 (1902) knmmt man auf paruhes Aldr.; diese Art hat jedrcl cine glänzende stim, breiter als das (irsieht, ein großes drittes Fühlerglied mit sul)apikaler Borste, keine Borsten am llyopyy und llintersehienen mit dunkler Wurzel usw.

contigutus Aldr. $\sigma^{7}$, T'Tans. Entom. Soe. London 323. 5 (1896) Antillae

5. - Thoraxrioken sehwarzhraun mit dichter gelber Bestäubung; Wimpern der Sehiippehen schwarz. Augen anf der Stirn in längerer Linie zusammenstoßend. Gesicht mattschwar\%, Fïhler und Taster desgleichen, Borsten am Angenhinterande muten schwiirzlicl. Hinterleib mattschwarz mit sehwaren Haren und langen Endborsten. Hiiften 
und Sehenkel schwarz, spitze der letzteren, Schienen und die beiden ersten Endglieder der Tarsen gelb. Vordertarsen etwa $1 \frac{1}{2}$ mal so lang als die Schiene, Mitteltarsen kanm länger. Fliigel breit, in der Nähe der Basis mit starker Entwieklung des Anallappens, wasserklar mit parallellaufenden Aderu. $2 \mathrm{~mm}$ ling.

ᄋ. Gesicht breiter und kurz, graubraun, Taster breit; Stirne mattbraun. $2 \mathrm{~mm}$ lang.

Von Aldrieh bei St. Vineent gefangen,

$1 \delta^{7}$ ans Paraguay, S. Bernardino [Babarizy] Sammluug des Ungarisehen Nationalmuseums. - Drei Exemplare ans Bolivia, Provinz Sara, [Steinbaeh] Sammlung des Perliner zoologisehen Museuns.

Variante mit dunkleren gelbloranen bis braunen Sehienen. Lin Exemplar ans Bolivia, $600-700 \mathrm{~m}$ hoch. Berliner Sanmmlung.

deceptivus Aldr. = subsejunctus Lw.

5 dimidiatus Aldr. O’, Trans. Entom. Soe. London 322. 4 (1896).

Antillae, Mexiko

3. - Thoraxrieken hell blaugrin mit weißgrauer Bereifung. Schiippehen gelb mit schwal\%en Wimpern. Angen anf der Stirn breit getrennt, Gesieht etwas sehmiler. Fiihler schwarz mit dorsaler Borste. Hinterleib am zweiten und dritten Ringe gelb durehscheinend, die iibrigen Ringe griin. - Beine nebst Vorderhüften gell,, Endglieder der Tarsen braun. Vordertarsen länger als ihre Sehiene, Pulvillen lang. Mitteltarsen etwas kürzer mit ungefähr gleich großen Pulvillen. Fligel fast farblos im Diaphorus-Charakter. $2 \mathrm{~mm}$ lang.

Aldrich besehrieb diese Art aus St. Vineent und Mexiko.

6 dubius Aldr. ठ7., Trans. Ent. Soc. London 324. 7 (1896).

Ameriea centr. et merid.

5. - Tholaxricken bronzegriin, etwas matt; Wimpern der Deekschitippehen sehwarz. Stirn und Gesieht gleich breit, gelblieh, beziiglich weilich bestänbt. Fiihler und Taster sehwarz. Hinterleib bronzegriin mit vier Borsten am Ilypopygium. Hiiften und Schenkel sehwarz; Vorderhiiften schwarz behaart; Schenkelglieder und Spitze der Sehenkel rot. Uber die Sehienenfärbung speziell sagt Aldrieh nichts; da er aber ron den Tarsen sagt, daß das erste Glied fast ganz gelb sei, so ist anzunehmen, daf anch die Sehienen gelb sind. Flitgel fast farblos mit der gewöhnlichen Diaphorus-Aderung. 25-3 $\mathrm{mm}$ lang.

․ - Das Gesicht etwas breiter, sonst dem of gleich.

Von Aldrieh ans St.Vincent besehrieben; siehe dort die ausfiihrliehe Besehreibung.

Ein ठ ans Bolivia-Mapiri. 8. I 03. S. Carlos $800 \mathrm{~m}$ hoelı [Sehnuse] Sammlung des Dresdner zoologisehen Museums.

exunguis Thoms. = spectabilis Lw.

femoratus Walk. o', lus. Saunders. Dipt. I $206^{\circ}$ (1852) . . . Brasilia 
Die Beschreibung bringt nicht die zur Erkennung und Unterscheidnng der Diaphorus-Arten notwendigen Merkmale; die Art bleibt zweifellaft.

7 flavines Aldr. ơㅇ, Trans. Entom. Soc. London 323. 6 (1896)

America eentr. et merid.

o. - Thoraxriieken griin, etwas matt bereift. Schiippchen gelbbraun mit gelben Wimpern. - Augen auf der Stirne sich kurz berührend; Gesicht sebmal, grau bestänbt; Futhler brann, Tastel gelb. Hinterleib mit gelbenı Bauch und Haren. Beine mit allen Hiiften gelb, nur die Mittelhiiften an der Wurzel schwïrzlicb; Tarsenspitzen etwas brann. Vordertarsen länger als ihre Sehiene; Vorderpnlvillen vergrößert. Flïgel gelblich, auf der Mitte am breitesten. $2-2.5 \mathrm{~mm}$ lang.

ㅇ. - Stime ebenso breit wie das Gesicht, oben noch etwas breiter, gelblich bestiubt. Pulvillen klein, sonst dem ơ gleich

Aldrich beschrieb diese Art aus St. Vincent, Antillen. - Ein $\sigma^{r}$ aus Porto Allegre [Dr. Hensel] Berliner zoologisches Museum.

Variante. In der Sammlung des Berliner Inseums steekt eine Reihe von Exemplaren ans Bolivia, Provinz Sara, welche lieser Art sehr nahe kommen; sie unterscheiden sich nur daIurch, laß der Hinterleib keinen getben Banch hat und nicht gelb, sondern schwarz behart ist; ich hinde sonst keinen [nterschied und bin nieht der Ansicht, daß diese Unterschiede ansreichen, eine neue Art darin zu erblicken; ich halte sie nur für eine etwas dunklere Farbensariante.

8 lamellatus Liv. ơ, Mowogr. Dipt. N. Amer. II 165.5 (1864)

America sept.

б. - Thoraxricken crzfarbig, etwas gelbbräunlich bestäubt; Wimpern der weißgelblichen Schüppchen schwarz. Gesieht weif bestaiubt, 'Taster klein, weiß. Stirn oben nur schmal, unten etwas breiter, sehmïler als das Gesieht. Fiuhler klein, schwarz. Hypopyg mit sechs starken Borsten und verlängerten sehmalen, an der Spitze abgeruudeten brannen behaarten Lamellen. - Beine nebst Hüften schwarz; Schenkelglieder an den Vorderbeinen, die äulierste Spitze der vier vorderen Schenkel und die Wurzelbälfte der vier vorderen Schienen gelb. Vorderpulvillen stark verliingert, die mittleren Pulvillen wenig, die linteren gar nicht. Fligel groß und breit, die größte Breite etwas vor der Mitte, Aderung normal. $3 \mathrm{~mm}$ liug.

Loew beschrieb diese Art aus den Mittelstaaten Nordamerikas. leucostomus Lw. Оౌo, N. Beitr. VIII 58.5 (1861) . . America sept.

$\sigma$. - Thoraxrieken erzarbig mit zarter weißlieher Bestiiubung. Sehïppehen weiß bewimpert. Gesicht breit, dicht weiß bestäubt. Taster groß, vorstehend, schneeweiß bestäubt. Fiihler groß, sehwarz. Stirue gleich breit, mindestens so breit wie das Gesiebt. Hiiften und Schenkel schwarz; Spitze der Schenkel, die Sehienen und 'Tarsen gelb, letztere an der Spitze braun. Vorderpulvillen groß und verlängert. Vordermetatarsus lïnger als die vier folgenden Glieder zusammen, Mittel- 
tarsen ebenso lang wie die vier Glieder, P’ulvillen nicht ganz ebenso groß. Fliigel glasartig. $2 \cdot 5-3 \mathrm{~mm}$ lang.

- C Gesicht wenig breiter, weißgran bestäubt, Taster weißlich. Ftihler kleiner; Stirne entsprechend breiter; Pulrillen einfach. mediotinctus u. sp. $\sigma^{7}$. Eine Figur . . . . . . . . . Peru

ठ․ - Thorax von metalliseb griiner Färbung, anf dem liiicken graubriunlich bestiiulst, jedoch noch ziemlich gliinzend; die Fulppunte der 'Thoraxborsten erscheinen als dunkle kleine Kreise. Brustseiten, Hiiften und namentlich die Notopleuraldepression weifgran bestaubt. Sehwinger gelb, die weißgelblichen Sehtippchen dentlich schwarz bewimpert. - Augen auf der Stirne deutlich getrennt, letztere gleich

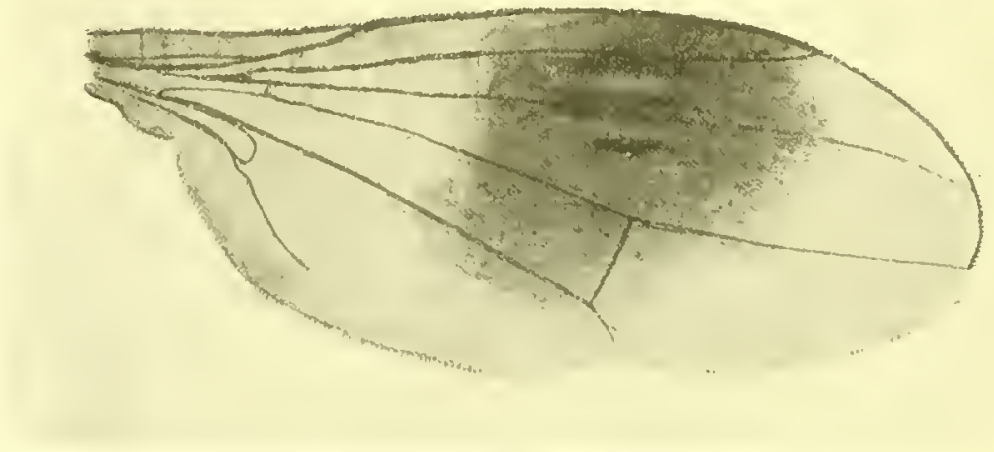

1ig. 63. Diaphorus mediotinetus Beck. o7. Fligel. 16:1.

breit von etwa $1 / 5-1 / 6$ der Kopfbreite, blangriin, gelbgran bereift. Fesicht etwas schmäler als die Stirn, weifgran; Taster gelb, nieht besonders groß, auf der Oberfläiche weiß bereift. Fiihler rotgell, das dritte Glied knl', nierenförmig, braum nit subapikaler nackter Borste; Hinterkopfzilien unten weiß. - Hiuterleils stahlblan, an den Einsehnitten dunkler, schwarz behaart und beborstet, an den Seiten dentlieh gran bestäubt; acht deutliehe Borsten am Hypopygium. - Beine nebst Vorderhiiften rotgell, iiberall kur' schwarz behart, Tarsen vom kndpunkte des Metatarsus an verdunkelt. Vorderhiiften schwarz behaart und beborstet; die Schenkel sind auf ihrer Unterseite nur sehr zart unt kurz bewimpert. Vorderschienen anf der Oberseite mit einer dentlichen Borste im ersten Viertel und mit einer sehwächeren anf der Mitte; die Scbienenunterseite ist der ganzen Länge nach sehr zart und kurz bewimpert, desgleichen der Metatarsus. Mittelsehicnen mit einer Borste anf der Unterseite und mit drei Borsten auf der ersten Hälfte der Oberseite. Hintersebienen woeh stälker beborstet; Hintermetatarsus etwas länger als das zweite Glied. Pulvillen der Vorderbeine nicht nder kaum gröber als the der iilırigen Beine. Fligel grol, schwaeh 
gelhbräiunlich gefärbt, namentlich auf der Wurzelläifte, und mit einem großen seliwarzbraunen Flecken oder einer solehen Querbinde etwas jenseits der Fligelmitte, den Hinterrand aber nicht ganz erreichend. Die dritte und vierte Iäingsader verlanfen annähernd parallel, die vierte ist im letaten Abschnitt gerade, die dritte beugt sich sanft konvergierend etwas zur vierten hinab; die Randader ist kaum etwas verdickt. $5 \mathrm{~mm}$ lang:

2 o aus Pern-Meshagua, Urubambafi. 26. 1X. 03 [Sehnuse] Situmlung des Dresiner zoologischen Museums.

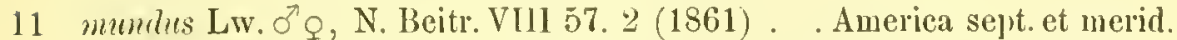

o. - Thoraxriicken metalliselı griin, ockergell, bestaiubt; Schiippchen gelblich mit schwarzbrannen Wimpern. Gesicht clunkelblau, weiß bestäubt; Taster gelbbråtunlich; Füh]er gelbbraun. Augen auf der Stirne im oberen Teile zusammenstofiend. Hiften und Beine gelb; Mitte]hiiften an der Wurzelbälfte geschwärzt, Tarsenspitzen kaum dunkler. Pulvillen der Vorder - und Mittelbeine groß und verlängert. Fliagel graulich, vorne meistens etwas gelb. $3-3.5 \mathrm{~mm}$ lang.

Loew beschrieb die Art aus Pensylvania. 10 Exemplare aus Ostbolivia, Provinz Sura [Steinbach] und aus Surinam [Heller] Sammlnng des Berliner zoologischen Museums.

12 nigresccns Aldr. రౌo, Biolog. Centr. Amer. Dipt. 1346.4 (1901) Mexico

○. - Thoraxriicken schwarzgriin, wenig glänzend. Wimperu der Schiippchen schwarz, Scliwinger gelb. Gesicht, Stirn, Fiihler und Taster schwarz. Stirne schmal mit parallelen Augenräudern. Hinterkopfzilien unten weiß. Beine fast ganz schwarı, nur die Kniee gelblich. Pulvillen weiß, ziemlich groß. Fltigel gleichmäßig gebräunt mit normaler Diaphorus-Aderung, die breiteste Stelle an der Wurzel. $3 \mathrm{~mm}$ lang.

․ - Etwas größer, Fltigel breiter, Stirne auch etwas breiter. Beine noch etwas sehwiilzer. $4 \mathrm{~mm}$ lang.

nigricans Meig. O Syst. Bescht. T] 33. 2 (1824) Emopa centr. et sept. America merid.

opacus Lw. o, N. Beitr. VIll 56. 1 (1861) . . America sejt.

Loew besehrieb seine Art nach einem Exemplar von New-York; ich fand zwei Exemplare ans Argentinien in der Berliner Sammlnng, die ich als nigricans Meig. bestimmte. Wenn Loew damals schon selber der Ansiclit war, daß seine Art init niyricans lleig. zusammenfallen werde, so wirl seine V'emutung durch meine Funde in der Berliner Sammlung sicher noch mu ein gutes stiick wahrscheinlicher gemacht. Ich finde ebenso wenig wie Loew irgendein unterscheidendes Merkmal zwischen beiden Arten und stelle opacus als synonym. Loew beschrieb seine Art kum wie folgt:

$\sigma^{7}$ Thorax sehwar", liijeken etwas braun bestäubt. Sehwinger nnd Deckschiippchen schwal\% und schwarz bewimpert. - Gesicht. Taster und Fïhler schwarz, drittes Glied klein; alle Hinterkopfzilien schwarz. 
Augen auf der Stime zusaumenstoßend. Hiiften und Beine schwarz. Schienen gelbbraun bis schwarzbraun. Vordermetatarsus so lang wie die drei folgenden Glieder zusammen. Pulvillen mäßig groß. Fliigel rauchschwirirlich, gegen den Vorderrand dunkler, an rer Basis am breitesten. $2 \cdot 5-3 \mathrm{~mm}$ lang.

20 ans Nordargentinien, Provinz Salta, 2500 m hoch [Steinbach], 1 q aus Brasilien, S. Catarina [Miehaelis] Sammlung des Berliner Iluse ums.

Anmerkung. Die etwis gethiraunen bis schwarzbaunen Schienen, ron donen Loew spricht, kimmen von piner Uneifheit des ihn bekannten Exemplares herriilıren.

opacus Lw. = nigricuns Meig.

pralpiger Wheel. $\sigma^{\pi}$, Psyehe V. 360 (1890).

Amerien sept.

б. - Thorax goldgriin, anf dem Riieken dicht gell, bestiubt; Wimpern der Schiippehen gelb. Stirne und Gesieht breit mit parallelen Augenrändern, gelb bestiunbt. 'Taster weiß, an der Wurzel gelblich, nm die Gesiehtslänge vortretend. Fiuhler schwarz, das dritte Glied nierenförmig, zweimal so breit wie lang. Anallamellen gelb. Hiiften nnd Beine ganz schwarz, nur die Knniee gelb. Pulvillen an allen Beinen groh und verlingert. Fligel ein wenig grau; dritte und vierte Liingsader ein wenig an der Spitze konvergierend, in iibrigen parallel. $2.8 \mathrm{~mm}$ lang

parvulus Aldr. ơ Trans. Ent. Soe. London. 321. $3(1896)=$ Chrysotus geurs

L. St. Viucent.

Beim Lesen der Beselureihung tritt nuwillkiirlieb der Gedanke sofort herror, daß diese Alt vielleicht ein (7wysotus sein könue. Wenn man sich vergegenwärtigt, was Aldrieh später iiber die Unterschiede zwischen Chrysotus und Diaphorus im Jahre 1902 in seiner Abhandlung iiher die Dipteren von Grenada gesagt hat, wie ieh das auch sehon in meiner Einleitung zur Gattung Diaphors anseinander gesetzt habe, so muls man sagen, daß hier naels Aldrieh's eigener Ansicht ein Chrysotus vorliegeu mul: 1. wird die Stirn als erheblich breiter gesehildert als das Gesieht, was bei einem Diathorus niemals vorkommt, mögen die Augen anf der Stirn anch noch so sehr getrennt stehen, 2. fehlen die fiir Diaphorus charakteristisehen stiirkeren Borsten des Hypopygs, 3. ist die geringe Größe rou nur $1.2 \mathrm{~mm}$ wohl bei Chrysotus, nicht aber bei Diaphorus iblieh und beobachtet worden. Die vergrößerten Pnlvillen der Vorderbeine von frarvulus kömnen ancl kein Beweisstick für Diaphorus sein, denn wemn aneh im allgemeinen die Chrysotus-Arten sich durch kleine Pulvillen auszeichnen, so ist das Fehlen der vergrößerten Pulvillen doch durehans kein Gattungsmerkmal; hat doch Aldrich in derselben Ablandlung iiber die Dipteren von Grenada zwei Chrysotus-Arten besehrieben: albipalpus und inemis, bei denen die Pulvillen der Vorder- 
beine dentlich verläingert sind. Es sprieht somit nichts gegen Chrysotus und fast alles gegen Diaphorus. lel werde diese Art als einen Chrysotus beliandeln.

Der von mir beschriebenen Art mediotinctus durch ähnliehe Fliigelzeichnung verwandt, abweiehend jedoeh durch die sehmälere Fliigelquerlinde, ganz rotgelbe Fiihler, schmäleres Gesielıt und selımïlere Stirne.

б’. - Die stahlblaue, brann bestäubte Stirne hat $1 / 6$ der ganzen Kopfbreite zur Breite; das Gesieht ist sehwar, Taster weißlieh, Fiihler ganz rotgelb. Der Hinterleih ist glänzend blaugriin, an den Seiten aller Ringe weißgran gefleekt; zweiter und dritter Ring an den Seiten gelb durchseheinend. Beine und Hiiften hell rotgelb, Mittel- und Hinterhiiften an der Wurzel grau. Fliigel gleiehmäßig etwas gelblieh gefärbt mit schwarzbranuer, allmählich nach hinten verwasehener schmaler Qnerbinde; diese leginnt am Flïgelvorderrande au der Nündung der zweiten Längsader und verläuft ijber der hinteren Querader; die Fiorbung au Vorderande ist dunkler, Heckenatig, der Flecken hat ijbrigens nur die lablbe Breite wie bei $D$. mediotinctus; die dritte Längsader liegt parallel zur vierten und ist nur an der äufersten Spitze um ein geringes kouvergierend.

1 б aus Peru-Neshagua 13. X. 1903, Urubambafi [Schunse] Sammlung des Dresdner zoologisehen Mnseums.

q. - Das Weibchen gleicht dem Männchen in Kölperfïibung und Größe so genau, daß ein Zweifel an der Zugehörigkeit unberechtigt erseheinen wiirde, wenn nieht ein besonderer Punkt der Erwiihnung wert wiire: die Fliigel sind neulich bei gleieher Aderung und gleieher gelbbriinulieber Grundfäbung fleekenlos. Es seheint, daß die Fleekung der Fligel nur ein männliehes Privilegium ist, ähnlieh wie wir dies bei der Gattung Lyroneurus gesehen haben.

3 q von derselben Herkunft wie das $0^{\prime}$.

16 Rautenbergi Wheel. ơ, Psyche V 360 (1890) . . . 2. St. Vincent

Ђ̆. - Thoraxricken metalliseh griin mit gelber Bestiubung. Wimpern der Schiiplpehen gelb, in gewissem Licht braiunlich sehimmernd. Gesieht and Stim ziemlich breit, gelb bestäulst. Taster gelbbraun, obenauf weißlich. Fỉhler sehwar', drittes Glied groß, Hiiften und Sehenkel sehwarz, Sehienen und Tarsen gelb. Pulvillen an allen beinen verlängert. Fliigel etwas gran gefürbt. $3 \mathrm{~mm}$ lang.

17 satrapa Wheel. ơ, Psyehe V $35 !(1890)$. . . . . . Nebraska

$\sigma^{7}$. - Thoraxrieken dunkel bronzefarbig. Wimpern der Sehippelıen weiß. Gesieht sehmal, silherweiß bestainbt. Stirn dunkel bronzefarbig; weil bereift. Fübler gelbbrann, drittes Glied mit Spitze. Hinterleib bronzegrin, der zweite nnd dritte Ring gelb; Hypolyg bram, gelb behaart. Htiften und Beine gelb, Vorderliuften gelb beharart, Endglieder 
der T'arsen hrau, Spitzenhälfte aller Schenkel oberseits braun gefleckt, Schienen bran und die Tarsen mit Ausnahme der Wurzel des ersten Tarsengliedes der Vorderbeine schwarzbraun. Fligel branngrau; dritte und vierte Liingsadern parallel, aber ziemlich stark gebogen. '2 mm lang:

Anmerkung: lch vermute, dab diese Art ein ("hrysotus ist; das schr schunale desiclat dentet daranf hin; die stime wird breiter. nicht sebmäler sein. obwohl Wheeler hieriiber niehts sigt; das Ilypopygm lat keine borsten. sondern nur leine grelbe Haare. Pulvillen scheinen nicht verlängert zu sein; die geringe (irißße, :llt:s surieht für Chrysotus; auch die Pirloung der Sehenkel und Schienen ist cine für Diuphorts ganz ungewöluliche Zusammenstellung.

8. - Thoraxriicken gringold, lichtgran bestiiult; sechs Paal Dorsozentrale, Akrostikathörstchen dentlich zweireihig: Schwinger hellgelb, Sehiippehen desgleichen mit schwarzen Wimpern. - Stime schmal, die Augen nähern sich in bogenförmigen Linien, der kleinste Zwisehenraum ist etwas schmäler als der Punktangenhöcker. Gesicht Ireiter, mit dem kleinen Stirndreieck hell aschgran. Riissel, Taster, Ftihler scliwarz, das dritte Glied nierentörmig nit einer kleinen vortretenden Spitze, die Borste steht etwas oberhalb dieser Spitze subapikal. Hinterkopfrandborsten auch unten schwarz. - Hinterleib glinzend schwarzgrin, Hypopygium mit einigen dentlichen Endborsten und kleinen dreieckigen schwarzen behaarten Analanhängen. - Beine mit allen Hüften schwar, katum dab mau eine etwas liellere rostbraune Färbung an den Knicen und den Vorderschienen wahrnchmen kann. Die Schenkel sind auf ihrer Unterseite alle dentlich zum Teil kräftig reihenförmig behart and alle Schienen dentlich bewimpert. Die P'ulvillen sind an allen Beinen besonders lang und gleich kräftig entwickelt und von grauer Farbe. Flitgel wasserklar mit normaler brauner Aderung. $3.5 \mathrm{~mm}$ lang.

$1 \delta^{7}$ aus Peru, Callanga, Sammlung des Ungarischen Nationalmuseums.

I $\sigma^{7}$ ans Brasilien, Sammlung des Berliner zoologischen Museums. sodalis Lw. O̊. N. Beitr. VIII 5S. 4 (1961) America sept. et centr.

ऽ. - Thoraxrỉcken metallisch griin. Wimpern der Schiippchen sehwarz. Gesicht gleich lreit, griinblau, dicht weib bestiubt. Stime ebenfalls mindestens so breit mit parallelen Angevrindern. Fühler sehrarz, Taster weißlich. Hinterleib erzgriin mit sehwarzbraunen kleinen Lamellen. Hiiften und Schenkel schwarz: Spitzen der vorderen Schenkel und die Schienen bräunliehgelb, Spitze der Hinterschienen and Hintertarsen schwarzluranu; Vorder- und Mittelmetatarsen an der Wurzel gelblich. Pulvillen nur mit greringer Vergrößerung. Flïgel grall getriibt, grof, breit, am lreitesten vor der Witte; Aderung normal. 3 um lang.

Von loew a New-York beschrieben.

4 Exemplare vom Äyuator: Loja, El Angel, Nirador $3800 \mathrm{~m}$ loch [Rivet] Pariser entomologisches Musenu. 
20 spectabilis Lw. ơ, N. Beitr. VIII 57. 3 (1861) 1 Figur

America sept et merid.

approximatus Aldr., Trans. Enton. Soe. London 321. 2(1896).

exunguis Thoms. Eugenies Resa Dipt. 506. 10 sิ (1869).

б. - Von kupferfarbigem Metallglanz mit schwarz bewimperten Schiippchen. Augen auf der Stirne zusammenstoßend, Gesicht weiß bestiubt. Taster, Riissel und Fiihler schwarz, letztere klein. Hiiften und Schenkel, letztere bis nahe zur Spitze schwarz, Schienen nebst Metatursen gelb; Pulvillen der Vorderbeine etwas verlingert. Vordertarsen fist $1 \frac{1}{9}$ mal so lang als die Schiene. Fliigel zart gelbgraulich, an der Vrurzelbälfte am breitesten; die vierte Längsader, der dritten parallel, etwas jenseits der Fliigelspitze miindend. $3 \mathrm{~mm}$ lang.

Sielse die aus. fiihrliche Beschreiloung bei Loew.

$10^{7}, 2$ o aus Peru, Pachita-Miindung $150 \mathrm{~m}$ boch. 20. XI. 1903 [Sehnuse] Sammlung des Dresdner zoologischen IInseums.

13 Exemplare aus Ost-Bolivia, Provinz Sarah [Steinbach] und ans Paraguay, S. Bermardino [Fiebrig]. Sammlung des Berliner Museums.

Was die Synonymie von approximatus Aldr. anlangt, so bat Aldrich selbst diese festgestellt. S. Kansas Univ. Soc. Bull. 85 (1002).

Mit Bezug auf exunguis Thomson kann ieh folgendes sagen: Wenn man absieht Fun der ein wenig abweichenden Größe des Tieres, die von Loew mit 3 min, von Thomson auf fast $4 \mathrm{~mm}$ Länge angegeben wird, fiihren alle Angaben, die man der längeren Beschreibung entnehmen kann. soweit sie für die Charakteristik brauchbar sind, auf spectabilis Lw.; sicher ist die 'T'onson'sche Art keine andere.

21 sulsejunctus Lw. O’, Berlin Ent. Zeitschr. IX 179. 83 (1865) Líuba deceptivus Aldr., Biolog. Centr. Amer. Dipt. I 346 (1901) Mexico

o. - Thoraxricken glinzend grtin, etras grau bestiubt. Schiippchen braun mit hellen, in gewisser Richtung dunkel schimmerndeu Wimpern. Augen auf der Stirne sehr sehmal getrennt, schwarz mit grauer Bestäubung. Gesicht grau und verhältnismäßig auch schmal. Fiihler klein, schwarz. Hinterleil, dunkelgrtin. Beine nebst Vorderlıtiften gelb, 'Tasten nur sehwaeh gebriunt. Pulvillen der Vorderbeine groß. Flígel blaßgelblich. $3 \mathrm{~mm}$ lang. 
Anue an $11 \mathrm{~g}$. Aldrich matht sehr richtig quatul aufuerksan, daB seine Art del luew'schen subsejuctus selu nahe kommo; das ist in ler 'T'at der Fall: Größe. nud Firbumg stimuch durehans ïberein. Ubor die Untersoliede sagt Aldrich damn weiter: "hut differs in having the front of the male olnterated by the contignity of the eyes. the cilia of the tegulae darker. and the posterion tarsi more infuseated". Was dip stime anlangt, so sagt Loew: "venli maris fronte angustissima lineari

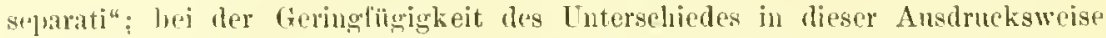
kann letztere mit dor ron Aldrich nieht im Widerspruch stehen; die Färmmg der Wimpern an den sulhippchen ist läufig schwankend mu der Eindruek ihrer Firbung kann bei vrsehieden einfallendem Licht leicht individuellen Tänschungen unterliegen, wem man seino Benbachtmgen nieht eimeitlich unter dem gleichen (iesiehtswinkel vornimnt; es ist haher auf die Ansdricke: gell, mit bramnem Schimmor ader umgekehrt kein entschcidendes fiewicht zu logen; anch die rin wenig geringere ofler starkere Branmmng der Tarsen kam liir sieh allein keinu

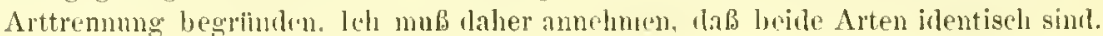

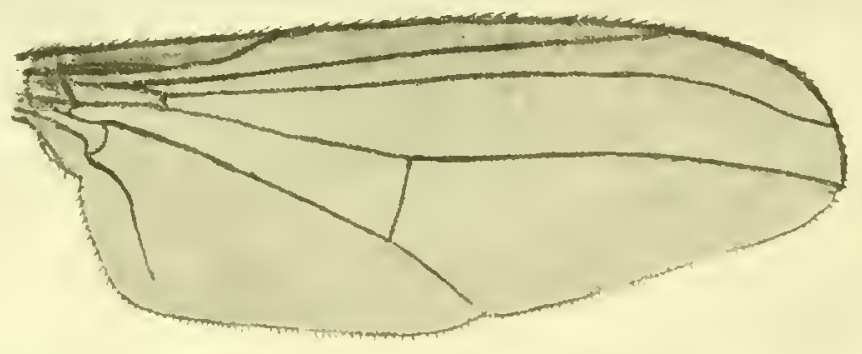

Fig. 65. Thuthon vicinus Beck. o'. Flïgel. 16:1.

ऽ. - Von metallisch griiner Grundfarbe, anf dem Riicken durch grane Bestäubung etwas matt olivengrion. Wimpern der weißen Schüppchen weiß bis hellbriunlich. - Kopf: die Angen berühren sich auf der Stirne nicht, die bogenfïrmigen Angenrinder nähern sich auf der Hitte erlieblich, bleiben aber $\mathrm{mm}$ die Lalbe Breite des Punktaugenlöckers getrennt. Stime und Untergesicht weiligran, letzteres doppelt so breit wie der Punktangenliöcker (s. Figur). Taster weißlich; Fỉller klein schwar'z mit nackter zentraler Borste; Hinterkopfizilien unten weiß. Hinterleib glänzend bronzefarbig, schwarz behaart. Hypopyg mit 6-7 dentlichen kandhorsten, die ebenso lang sind wie das Hypopyg. - Beine: Hiiften schwargran; Vordertuiften an der Snitze mit den Schenkelgliedern rostgelb, weiß bereift, schwarz behaart und beborstet. Schenkel bis nalıe zur Spitze schwarz mit schwacher graner Bereifung; Schienen und Metatarsen der beiden vorderen Beinpastre rostgelb; dic iibrigen Tarsenglieder, Spitze der Hinterschiencu nebst ibren Tarsen scluwarzbraun. Vordertursen 1.25 nal so lang wie die Schiene, letztere 
oberseits schu zart bewimpert; dic vorderen Haftläppchen größer als die an den Hinterbeinen. - Flïgel groß, wässerig brïunlich getribt; dritte und vierte Liingsadern etwas gebogen, im ganzen parallel, aber die dritte an der Spitze merklich zur vierten hin geneigt. Die Randader ist kriffig; aber doch nicht auffaillig verdickt. $4.5 \mathrm{~mm}$ lang.

Anmerkung: Vergleicht man diese Art mit spectabilis Lw.. so wird man im Jlabitus sowie in dor allgemeinen Kinperfirloung swiel daleiches und Älmliches finclen, dab man versucht sein kimnte, unsere Art als eine größere Variante anlzulassen; alweichend simul die lee spectabitis zusammenstobenden Augen. die Gribe, dir seliwar hewiuperten Sehiiprehen. die etwas helleren llinterheine, die lingeren Vordertarsen und die durchaus normale Flïgelarlerung. L'm die Unterschiede in der Adrung und der stimbreite zu veranschaulichen. hahe ieh Flügel und liopl' ron ricinus gezeichnet. Bei Vergleichung beider l'ligelzeichnumgen sieht man sehr bald, dab die summe aller dieser Terschiedenheiten, namentlich wem man die abweiehend. F'ligellorm noch nit ins Ange laBt, nieht ledighieh anl eine Variante hinweisen kann.

2 ơ aus Peru, Rosalina, 31. VIII. 1903, Urabambafi [Sclunuse]. Sammlung des Dresdner zoologischen Musenms.

107 ans Bolivia, Prorinz Sara, $300-700 \mathrm{~m}$ hoch [Steinbach]. Sammlnng des Berliner zoologischen Nuseums.

\section{Bestimmnngstabelle fiil die Diaphorus-}

\section{Arten.}

1 Sebenkel ganz oder iiberwjegend gelb 2 Schenkel metallisch griu bis schwalz. 11

2 Augen auf der Stirne zusammenstoliend 3 Augen auf der Stirne sclumal getrennt 4

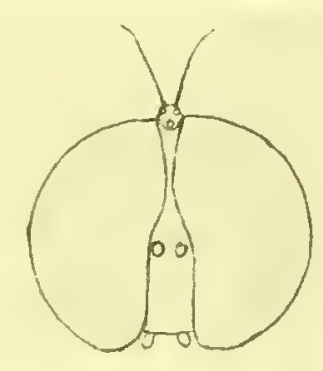

Fig. 66. Diaphones ricinns Beek. б. Kopl von vorne. $24: 1$. Augen breiter getrennt

3 Schủppchen weiß bewimpert. Bauch meist gelb. Fiihler bräiunlich,

Gesicht grau. Pulvillen der Vorderbeine größer als an den iibrigen Beinen. 2-2.5 $\mathrm{mm}$ lang . . . . . . . flavipes Aldr. of Schiippeben schwarz bewimpert. Bauch nicht gelb. Fiuller schwarz. Gesicht weiß. Pulvillen der Vorder- und Mittelbeine vergrößert. $25-3 \mathrm{~mm}$ lang . . . . . . . . . . mundus Lw. ठ

4 Vorderhiiften braun; Hinterschenkel an der Spitze brann; Hinterschienen auf Ober- und Unterseite der granzen Länge nacb dentlich bewimpert. Schïppchen weiß bewimpert. $2 \cdot 5 \mathrm{~mm}$ lang. . ciliatus n. sp. o Vorderbiiften und Beine ganz gelb; Hinterschienen nicht so bewimpert. Schiippehen bräunlich hewimpert. $355 \mathrm{~mm}$ lang sulbejunctus Lw. O’

5 Flügel gefleckt. Schiippchen schwar\% bewimpert . . . . . . 6

- Fliigel nngefleckt . . . . . . . . . . . . . . . 7

6 Fligel mit einer breiten brannen Querbinde etwas jenseits der Fligel- 
mitte. Fijhler rotgelb, drittes Glied briunlich. Hinterleil, ohne gelbe Seitenflecke. Vordere Pulvillen klein. $5 \mathrm{~mm}$ lang

mediotinctus n. sp. 0

- Fligel mit einer schmalen bramen Qucrbinde. Fiihler ganz rotgelb.

Hinterleib an den Seiten des zweiten und dritten Ringes geth durchscheinend. Vordere Pulvillen etwas größer als die iibrigen. $4 \mathrm{~mm}$ lang. . . . . . . . . . mopinums 11. sp. ठౌ

7 Schiippchen weiß bewimpert . . . . . . . . . . . . . 8

- Sehiippchen schwarz bewimpert. Beine und Vorderhiften gelb, letztere nit schwarzen lorsten; Pulvillen an Vorder- und Mittelbeinen groß. Hinterleib am zweitch und dritten Ringe gelb durelsscheinend. $2 \mathrm{~mm}$ lang . . . . . . . . . . . dimidiatus Aldr. O

8 'Taster groß, weißgelb, um $1 / 3$ der Kopfloöhe herabhỉingend. Hinterschenkel an der Spitze etwas lram. Vordere Pulvillen grob. $25 \mathrm{~mm}$ lang . . . . . . . . . . . amoenus Aldr. O

- Taster von gewöhnlicher Größe . . . . . . . . . . . . 9

9 Gesicht breit, Fibler selıwarz . . . . . . . . . . 10

- Gesicht sclimal, Fiihler hellbraun. Beine mit Vorderhiiften und den vorderen Schienen gelb; alle Schenkel auf der Spitzenbilfte oberseits braun. Hinterleib bronzegriiu, zweiter und drittes Ring gelb. $2 \mathrm{~mm}$ lang . . . . . . . . . . . satrapa Wheel. o'

10 Beine mit Vorderhiiften ganz gelb; zweiter und dritter Hinterleibsring gelb. 3-35 mm lang. . . . . . . chanaeleon $\mathrm{n} . \mathrm{sp} . \mathrm{O}^{7}$

11 Augen anf der Stirne zusammenstoßend . . . . . . . . . 12

- Augen auf der Stirne sehmal getrennt . . . . . . . . . 14

- Augen breiter getrennt . . . . . . . . . . . . . 16

12. Beine ganz schwarz. Gesicht matt sehwarzbrann, Thoraxricken cbenso, Schwinger, Schiippchen und Wimpern desgleichen. $25-3 \mathrm{~mm}$ lang' nigricans Meig. $0^{7}$

- Beine nicht ganz sehwarz, Schienen ganz oder teilweise gelb . 13

13 Gesieht matt schwarzbran; Thoraxricken mattbran. Sputze der Sehenkel, Sehienen mit den beiden ersten Tarsengliedern gelb. Hinterleil, mattschwar\%. liligel farblos. Hinterkopfzilien noten schwiil"zlich. $2 \mathrm{~mm}$ lang . . . . . . contiguus Aldr. $\sigma^{\prime}$

- Gesicht weiß; Thoraxrifcken erz- bis kupferfurbig. Vordere Sehenkelglicder, Schienen und die vorderen Metatarsen gelbbraun. Hinterkopfzilien unten weib. Fliigel etwas grangelblich. $3 \mathrm{~mm}$ lang

spectabilis Lw. $\sigma^{7}$

14 Beine ganz schwarz; Hinterkopfzilien anch unten schwarz. Taster und Fiihler schwar\%. Gesicht nud Stirnteil iiber den Fiiblem aschgrau. Pulvillen an allen Beinen groß. $35 \mathrm{~mm}$ lang secundus n. sp. 万ั

- Beine nicht ganz schwarz. Hinterkopfzilien unten weiß

15 Vorderbiiften und Schenkel schwarz; erstere mit den Schenkelgliederu, die Schicnen und Hetatarsen der beiden vorderen Beinpaare rostgell; 
Spitze der Hinterschienen nebst Tarsen schwarzbraun. $3.5-4.5 \mathrm{~mm}$ lang . . . . . . . . . . . vicinus n. sp. ơ

Beine nebst Huiften schwarz; vordere Schenkelglieder, die iußerste Spitze der vier rorderen Schenkel und die Wurzelhäfte der vier vorderen Schienen rostgelb. Hypopyg mit längeren braunen behaarten Lamellen. $3 \mathrm{~mm}$ lang . . . . . . . . lamellatus Lw. O

16 T'aster nugeröhnlich groß, weit volstehend. . . . . . . . 17

Taster von gewöhnlicher Größe . . . . . . . . . . . . 18

17 Gesicht und Taster schneeweiß. Fiubler schwarz, drittes Glied groß mit dentliclier Spitze. Schüppchen weiß bewimpert. Hüften schwarz, an der Spitze weißlich. Schenkel metallisch grůn; Kniee, Schienen und Tarsen gelb. Pulvillen der Vorderbeine groß. Fliigel farblos. $2 \mathrm{~mm}$ $\operatorname{lang}$. . . . . . . . . . . lencostomus Lw. ठ

Gesicht gelb bestäubt. Taster weil, an der Basis gelb. Fiibler schwarz, das dritte Glied pechbraun, nierenförmig, breiter als lang ohne Spitze. Schiippchen gelb bewimpert. lliiften schwarzgrau; Schenkel grün bis schwarz, Kniee gelb, Schienen und Tarsen schwarz. Pulvillen an allen Beinen groß. Fliigel etwas graulich. $2.8 \mathrm{~mm}$ lang

palpiger Wheel. $\sigma^{9}$

1s Schïppchen schwarz bewimpert

Schiippchen weiß bewimpert. Gesicht und Stirue gelblich. Fiihler schwarz, drittes Glied groB, Borste apikal. Schenkel metallisch griin, Schienen und Tarsen gelb, Endglieder der letzteren braun. Pulvillen an allen Fußen groß. $3 \mathrm{~mm}$ lang

Liantenbergi Wheel. o'

19 Gesicht schneeweiß . . . . . . . . . . 20

Gesicht anders gefärbt . . . . . . . . . . . . . 21

20 Beine schwarz; Spitze der vorderen Schenkel, alle Schienen sowie die Wurzel der vorderen Tarsen gelb. Pulvillen kaum etwas rergrößert. $30 \mathrm{~mm}$ lang . . . . . . . . . . . sodalis Lw. of

21 Gesicht und Stirue matt schwarz. Beine schwarz, nur die Kniee gelb. Pulvillen der Vorderbeine ziemlich groß. $3 \mathrm{~mm}$ lang nigrescens Aldr. o Gesicht weißlich griin, Stirne griin. Beine schwarz, Fuiee, Schienen und Metatarsen der vorderen Beine gelb. Pulvillen der Vorderbcine erweitert. $2 \cdot 4-2 \cdot 7 \mathrm{~mm}$ lang . . . . . . dubius Aldr. Of

\section{Lymonewrus.}

Loew, Wiener Entonol. Monatssehr. I 38 (1857).

Loew lıat 1. c. auf einige ihm damals aus Amerika bekannt gewordene Diaphorus-Arten auf Grund verschiedener Abweichungen von unseren paliiarktischen Gattungsreltretern die Gattung Lyronewrus aufgebaut. Den Charakter dieser Gattung, auf den wir weiterbin näher eingehen müssen, laat Loew später in den Monogr. Dipt. N. Amer. II 169 (1864) teils etwas abgeändert, teils erweitert, dabei aber anch ausgesprochen, daß die Ähn- 
lichkeit mit der Gattung Dinthoms doch größer sci, als el sich dies 1857 vorgestellt habe. - Aldrich in den Kansas Univ. Sc. Bnll. 85 (1902) hat dann bei Besprechnng der nordamerikanischen Diaphorus-Arten einesteils auf die große Ähnlichkeit mit Chrysotus, anderseits auf dic vielfache Übereinstimmung mit Lyroneurus Lw. hingewiesen und kommt auf Grund seiner Kenntnisse der nord- und mittelamerikanischen Arten zu dem Resultat, das die Loew'sche Gattung Lyronemrs nicht ausreichend charakterisiert sei; er weist dabei auf die grolie Úbereinstimmung der beiderseitigen Weilychen von Lyroneurus mud Diaphorus hin und meint, wenn man diese Weibchen schwer oder gar nicht unterscheiden köune, damn sei es auch nicht angängig; diese in zwei verschiedene Gattungen zu stellen. Icb muß gestehen, daß ich dieser Ansicht Aldrich's nicht beitreten kann; wollten wir dies als Grundsatz fiir die Gattungsbegrenzungen aussprechen, so mißten wir verschiedene als durchaus giiltig anerkannte Gattungen einziehen, die fast allein auf männliche Eigenschaften anfgelıant sind.

Da der Kreis unserer Kemntnisse dureh eine Reihe siddamerikanischer Arten cine nicht unerhebliche Erweiterung erfabren hat, erscheint es mir angezeigt, diese Frage der Synonymic zwischen Diaphorus und Lynoneurus nochmals anzuschneiden und zu prifen, ob es nöglich und ratsam ist, die Loew'sche Gattung anfrecht zu lalten oder sie fallen zu lassen, wie dies im Katalog Kertész VI wahrscheinlich anf Aldrich's Anregung hin bereits geschehen ist. Zu dem Zwecke wollen wir die ron Loew angegebenen Gattungsunterschiede bei den amerikanischen Arten der Reihe nach prifen, um zn schen, ob sie angesichts unserer hente erweitcrten Artlienntuis standhalten oder ob wir etwa noch andere Gattungsmerkmale hinzufïgen können.

Loew gibt den Gattungseharakter von Lyroneurus 1864 an wie folgt: "Kööper verlångert. Augen auf Stirn und Gesicht in beiden Geschlechtern hreit getrennt. Fihlel kurz; das erste Glied nicht behart, das zweite querliegend, das dritte kurz, gerumlet, dentlich pubeszent; Borste apikal. Fliigel sehr groß, an der Spitze breit und sehr stumpf; die hintere Querader ist dem Fliigelrande nicht genähert; die dritte Längsader liegt der zweiten schr nalue und wendet sich an der Spitze weit nach riokwärts; der Ranm zrvischen der dritten und vierten Längsadel ist rou erheblicher Breite; der letzte Abschuitt der vierten Längsader mit dentlicher Biegung. Beine lang, aber nicht schr schlank; das erste Glied der Hintertarsen ohne Borsten. Polvillen der Vorlertarsen beim o nicht verlingert. Hypopygium klein, eingesenkt, am hinteren Ende mit vier starken Borsten, die Anhïnge schr klein und rerborgen."

Ich kenne zurzeit von Lyroneurus-Arten folgende zehn: ammlatus Macq., adustus Wied., coerulescens Lw., suavis Lw., simplex Aldr., apicalis n. sp., laetus n. sp., frotellus n. sp., marginalis n. sp. und accultus n. sp. Die vorstehenden Arten stanmen alle ans Sindamerika, keine einzige ist aus Nordamerika bekannt, der nördlichste Fundort ist anf den Antillen 
und in Mexiko. Was diesen Arten gemeinsam ist und was sie gleichzeitig von Diaphorus unterscheidet, ist dreierlei:

1. Ist die Stirne bei den o breit, etwa von $1 / 4$ der ganzen Kopfbreite, mit parallel laufenden Angenaindern (bei Diaphorus berïhren sich die Augen auf der Stirue oder sie sind nur schmal getrennt und die Augenränder dann bogenförmig einander melı oder weniger genähert).

2. Hauptsäclilich die dritte, dann aber meist anch die vierte Längsader sind S.fürmig geschwungen und stehen etwas entfernt voneinander (bei Diaphorus liegen sie parallel zueinander, entweder gerade im Verlauf oder etwas gebogen in gewöhnlicher Entfernung).

3. Die Vorderbeine zeigen keinerlei verlängerte Pulvillen (hei Diaphorus haben die Vorderbeine in der Regel verlingerte Pnlvillen).

lch gebe zu, daf diese drei Besonderbeiten uur relativer Art sind, aber das gleiclizeitige Vorbandensein derselben in Verbindung mit dem riaumlich scharf getrennten Vorkommen der Arten geben letzteren einen besonderen Charakter und Wert, der es nicht gestattet, sie einfach als eine Gruppe der Gattung Diaphorus zu nennen. Ans diesen Grtinden habe ich Lyroneurus als besondere Gattung behandelt. Es gibt ja hin und wieder eine Diaphorus.Art, die sich, sei es in ller Stimentwicklung, sei es in der Fliigeladerung oder Eutwicklung der Pulvillen, dem LyroneurusFormenkreise nähert; damit ist aber nichts erreicht. Wir miissen betonen. daß nur das gleichzeitige Vorbandensein aller drei Merkmale den Gattungscharakter ansmacht.

\section{Bestimmungstabelle.}

1 Schenkel ganz oder iberwiegend gelb .

Schenkel metallisch griin bis schwarz. . . . . . . . . . 5

2 Fliigel ungefleckt . . . . . . . . . . . . . . 3

Fliigel gefleckt .

3 Schenkel auf der Mitte mit breiter dunkler 13inde. Hinterleib an den Seiten nicht gelb. $35 \mathrm{~mm}$ lang . . . . amulatus Macq. O’ 9 Schenkel und Vorderhiiften ganz gelb. Schiippchen mit hellen Wimpern. Fiuhler schwarz, das erste Glied mehr oder weniger rotgelb. Hinterleib an den Seiten des zweiten und dritten Ringes gelb gefleckt. $35 \mathrm{~mm}$ lang . . . . . . . . . survis Lw. o

4 Fiihler schwarz. Hinterschenkel an der spitze mit schwarzem Ringe. Fliigel an der Spitzc zwischen zweiter und dritter Längsader schwar'braun gefleckt. $35 \mathrm{~mm}$ lang . . . . . . apicalis n. sp. O Fiibler rotgelb, drittes Glied etwas dunkler. Hinterschenkel an der Spitze nur mit braunem Flecken auf der Oberseite. Fligel am Vorderrande bis zur Spitze mit braunem Läingsstreifen. $4 \mathrm{~mm}$ lang laetus n. sp. . o

5 Flïgel gefleckt. 6

- Flïgel ungefleckt, fast farblos 10 
6 Flligel mit Spitzenrandfleck zwisehen der zweiten und dritten Långsader . . . . . . . . . . . . . . 7

- Fliigel liings des Vorderrandes sehwach bis dunkelbrann gefirbt 8

7 Gesicht grau. Fühler und Taster sehwar, letztere an der Spitze weiß. Thoraxrieken metalliseh griin. Hiiften und Schenkel schwarz, Kniee breit gelb; Sehienen und Tarsen gelb, Hintersehienen an der Spitze braun. Hintermetatarsus unterseits an der Basis mit einer längeren Borste. $5 \mathrm{~mm}$ lang. . . . . . . . . adustus Wied. $0^{7}$

8 Flïgelvorderrand deutlich gehräunt; dritte Längsader starli geschwungen. Gesicht stablblau, graugelb bestaiubt. Fiihler und Taster sehwarz, letztere mit weißlicher Spitze. Thoraxrỉeken und Hinterleib stahlblau. Beine nebst Htiften sehwar, Kiniee und Schienen gelb bis blaun. $5 \mathrm{~mm}$ lang. . . . . . . . . . marginalis n. spl.

-_ Flitgelvorderrand schwach gebriunt; dritte Laingsader dentlieh, aber etwas weniger geschwungen. Schenkel sehwar, Kniee und Sehienen gelb bis braun . . . . . . . . . . . . . . . 9

9 Hintermetatarsus anf der Unterseite und an der Basis mit einer kleinen abstehenden Einzelborste. Hinterschienen unterseits auf der Endhïlfte dentlich etwas borstlich. $5 \mathrm{~mm}$ lang. . occultus $1 . \mathrm{sp}$. ठ

- Hintermetatarsus und Hinterschienen ohne Einzelborste und ohne borstliche Behaarung. $5 \mathrm{~mm}$ lang. . . . fratellus n. sp. o

10 Hintermetatarsus gelb mit einer lïngeren abstehenden Borste an der Basis seiner Unterseite. $35-4 \mathrm{~mm}$ lang. . . . simplex Aldr. $\sigma^{7}$

- Ilintermetatarsus sehwarzbraum mit zwei längeren Borsten unterseits simplex Aldr. var. bispinosus $0^{7}$

- Hintermetatarsus sehwarzloram ohne abstehende Borste. $4.5 \mathrm{~mm}$ lang. coernlescens Lw. O

Weibchen:

In den mir znr Verfiignng gestellten Sammlungen waren Weibehen sehr spärlich vertreten; ich bin daher sehon ans Mangel an Material nicht in der Lage, lier viel Aufklärung zu bringen; so viel ist aber sicher, daß die Unterscheidung große Sehwierigkeiten bietet, da Flïgelfärbung und anormaler Aderverlauf bei den Weibchen nicht rorhanden sind nnd daher anch die Unterselseidung mit Hilfe dieser Merkmale in Wegfall kommt; man wird auf Reinfärbung, Größe, Taster-, Gesiehts- und Fiihlerfarbe beschrinkt sein.

\section{Artrerzcichnis, Bemerkungen mnd Beschreibungen.}

1 adustus Wied. o', Anherenrop. zweifl. Ins. II 231 [Dolichome] (1830). Ameriea merid. chalybaeus v. Röd., Societas Entom. VII 81 (1892).

Typisehe Exemplare stecken in der Sammlung des Berliner zoo. logisehen Museıms. Die Art, welehe im Katalog Kertész VI unter Dolirhoms anfgefiihrt ist, gehört zur Gattung Lyroneurus, wie Loew dies 
auch schon in seiner Monogr. Dipter. Nord-Amer. II 170 (1864) elwähnt hat.

o Thoraxiicken metalliseh griin bis blau, durch gelbgraue Bestäubung etwas matt, Schildchen stahlblau. Schwinger blaBgelb; Schipppehen weiß mit dunklen Wimpern. Stirn etwa von $1 / 4$ der Kopfbreite, goldgriu mit graubrauner Bereifung. Gesicht gleich breit, grau. Taster schwarz, obenauf weißgrau. Fiiller ganz schwarz. Hinterleib metallisch grijnblan, an den Seiten weiß bereift. Hypopyg sehr schwach beborstet. Beine: Hiften schwarz, nur die Vorderhiiften an der änßersten Spitze mit den Schenkelgliedern rostgelb. Schenkel schwarz; Spitze derselben und die Schienen nebst Metatarsen der rolderen Beine rotgelb; Spitze der Hinterschienen, alle Hintertarsen sowie die ijbrigen Tarsenglieder schwarzbraun. Der Hintermetatarsus fiihrt an der Besis seiner Unterseite eine abstehende Borste. Flügel schwach gelbbriunlich mit braunen Adern und braunem verwaschenen Spitzenfleck zwischen der zweiten und dritten Längsader. Die Randader ist anf der ganzen Länge stark verdickt; die Fliigel sind sebr breit, namentlich auf der Spitzenhälfte. $5 \mathrm{~mm}$ lang.

Die Art chalybaeus v. Röd. ist dieselbe, wie aus der Beschreibung hervorgeht, von der ich die lateinische Diagnose hier beifiuge:

"Viridis, thoracis abdominisque dorso chalybaeo micante; femorum apice tibiis tarsisque totis testaceis; alis cinereo-byalinis, sed inter marginem anteriorem et venam tertiam longitudinalem saturate fuscis. Long. $5 \mathrm{~mm}$. б. Hab. America meridionalis (Cordilleren von Eenador)."

Hiernach kann bei der Vergleichung nur adustus Wied. in Frage kommen, deren Beschreibung genau stimmt; bei marginalis, die zur Vergleichung aluch noch herangezogen werden könnte, ist der ganze Fliigelvorderrand rom Ende der ersten Längsader an gebräunt, was v. Röder erwähut haben wiirde, wenn es der Fall gewesen, bei adustus reicht der Spitzenfleck anch läufig bis zur vierten Lingsader; dann sagt $v$. Röder iber die Beine: "tibiis tarsisque totis flaris"; das stimmt wohl mit adustus, aber nicht mit marginalis, bei der die Tarsen ganz schwarz sind. Die Borste auf der Unterseite des Hintermetatarsus erwähnt . Röder nicht, die kann aber auch abgebrochen gewesen sein.

3 ठ ans Paragnay. Hohenan 22. X. 1907. $250 \mathrm{~m}$ hoch [Schnuse] Sammlung des Dresdner zoologischen Museums. - $3 \sigma^{\prime}$ aus La Plata im Berliner zoologischen Museum. - 8 Exempl. ans Brasilien, Sammlung des Ungarischen Nationalmuseums. - 11 Exempl. aus Brasilien in Coll. Winthem., die Loew seinerzeit als n. sp. latipennis (i. litt.) bestimmte. Die Art scheint in Siidamerika sehr gemein zu sein. - $5 \sigma^{\pi}, 2$ aus Brasilien und Porto Allegro in Loew's Sammlung. Berliner zoologisches Museum.

2 anmulatus Hacq. O7 Dipt. exot. II 2. 111 tab. XXII fig. 6 [Chrysotus] (1842) 
? simplex Aldr., Trans. Entom. Soc. London 333 tab. XII fig. 117 (1896)

Antillac, Mexiko.

$\sigma^{7}$ Von goldgriiner Farbe. Gesieht und Stirn breit weiBgrau bestiubt. Ftihler schwarz. Beine gelb mit breiten schwarzen Schenkelringen. Fliigel farb- und fleckenlos, Aderung im Lyroneurus-Charakter.

Ich habe diese Art in meimer Tabelle in die Abteilung mit gelben Beinen gestellt; wiirde man sie in die Gruppe mit schwarzen Schenkeln einreihen, so käme man unweigerlich anf simplex Aldr., bei der die Schenkelspitzen und anch die Schenkelgliedel mehr oder weniger gelb sind; zwischen beiden Arten ist in der Scheukelfaibung kein größerer Untersehied vorhanden; damit wiirde denn alles andere auch iibereinstimmen mit Ausnalnme der Einzelborste auf der Unterseite des Hintermetatarsus bei simplex Aldr. Daß Macquart dariber nichts gesagt hat, kann angesichts seiner iblichen Methode der Charakterisierung nicht wundernelmen. leh habe die nicht unbegriondete Vermntnng, daß beide Arten identisch sind. Da dic beiden Typen mir nicht vorliegen, kann ich meine Vermutung allerdings nicht handgreiflich bewcisen und ich will deshalb simplex Aldr. anch noch besonders autfiuhen, muß jedoch dabei hervorheben, daf große Waln" scheinlichkeit ftir die Richtigkeit meiner Bchauptung rorhanden ist. apicalis 12. sp. $\sigma^{\pi}$. . . . . . . . . . . America merid.

ठౌ. -- Thoraxricken von blangriner Netallfarbe, mit gelbgrauem Reif dicht bedeckt und fast ganz matt. Schwinger und Schiippehen weilgelb, letztere schwarz bewimpert. Lopl: Stirn und Gesicht ungefảhr gleieh breit von etwa $1 / 4-1 / 5$ der Kopfbreite, braun und grau bestiiubt, Tastel' gelb; Fibler schwarz mit zentraler naekter Borste. Hinterleib grinblau, die Seiteu des zweiten, dritten, mitunter auch des vierten Ringes durehseheinend gelb, schwarz behaart. Hypopyg mit nur schwachen Endborsten. Beine nebst Vorderhiuften rotgelb; Hinterschenkel vor der Spitze mit sehwarzbrauner ringförmiger Binde; Tarsen vom Ende des ersten Gliedes an lraun. Flïgel zart gelbbrïunlich getribt; dritte und vierte Lïngsaderu deutlich etwas im Lyroneurus-Charaktel gebogen, mit einem großen schwarzbaunen Spitzenflecken namentlich zwischen der zweiten und dritten Läingsader, aber anch noch ctwas iiber letztere hinausrigend; hintere Qucrader um ihre eigene doppelte Länge vom Hinterrande des Fliigels entfernt. $3 \cdot 2-4 \mathrm{~mm}$ lang.

$2 \sigma^{7}$ aus Argentinien, 27. X1I. 1907. Formosa i Chaco [Schnuse] Sammlung des Dresdner zoologischen Museums - 3.07 aus Paraguay, S. Bernardino [Fiebrig] Sammlung des zoologisehen Hofmuseums in Wien. approximatus Aldr. = spectabilis $\mathrm{Lw}$.

chalybaeus v. Röd. = adustus Wied.

4 cocrulescens Lw. ơ , Entom. Monatsschr. I 39 Taf. I fig. 9, 10 (1857) America centr. et merid. 
$\sigma^{7}$. - Blaugrün, gelbgrau bestäubt, ziemlich matt, Deckschiippchen schwärzlich bis braun gewimpert. Stirne und Gesicht gleich breit, letzteres weiß bestäubt. Taster schwarz mit weißlicher Spitze. Fiihler schwarz. Hiiften und Schenkel schwarz; rordere Schenkelglieder, Kniee und Schienen bräunlichgelb; Spitze der Hinterschienen dunkelbrann: Fỉße fast ganz schwarzbraun. Vordertarsen etwas länger als ihre Schiene, Mitteltarsen gleich lang. Fligel graulich im LyronewnsCharakter. $5.5 \mathrm{~mm}$ lang.

Q. - Stirne und Gesicht breiter, erstere mattgriun, letzteres mattgrau. Flígel mit parallellaufenden Adern.

Neun Exemplare aus Nordargentinien und aus Surinam. Sammlung des Berliner zoologischen Mnseums. - 3 Exemplare vom Äquator: Loja, $2200 \mathrm{~m}$ boch [Riret] Pariser Entomologisches Musenm.

Anmerkung. Es kommen Exemplare vor, welche an der Flügelspitze eineu schwachen Schattenflecken zeigen und die beim Aufsuchen in der Tabelle wegen dieser Fürbung anf die Art adustus Wied. hinführen könnten; sie sind damn abee doch leicht auseinanderzuhalten. da der Art coerulescens die abstehende Burste fehlt. die wir bei adustus Wied. anl der Lnterseite des Hintermetatarsus fanden.

0 . Diese Art ist der nachstehend beschriebenen Art occultus so nahestehend, daB ma sie bei nicht aufmerksamer Betrachtung leicht mit dieser verwechseln könnte. Ich will hier nicht die Beschreibung von occultus wiederholen, ersuche vielmehr, sie dort nachzulesen; ich will hier nur anf die Unterschiede anfmerksam machen; diese liegen in der Beborstung der Peine und in den Flïgeln: Die Hinterschienen sind hier nicht struppig und borstlich bebaart wie bei occultus, sondern mit Ausnahme von drei Börstchen der Oberseite und namentlich unterseits ganz nackt; ebenso entbehrt der Metatarsus der charakteristischen Borste an der Basis. An den Fliigeln ist die Randader merklich verdickt und die Biegung der dritten Längsader ist um ein geringes größer; das Hypopygium scheint auch etwas anders konstruirt zi sein, denn ich sehe hier die Penisscheide deutlich herunterbängen, während sie bei occultus unsichtbar bleibt; damit siud aber auch die Unterschiede erschöpft. 4.5 $\mathrm{mm}$ lang.

Zwei Exemplare ans Columbia, Sierra di S. Lorenzo [Ujuelyi] und Argentinien, Lules X 1905 [V'ezényi] Sammlung des Ungarischen Nationalmuseums.

5. - Thorax von blauer Grundfarbe, auf dem Rỉcken durch gelbgraue Bestiubung griinlich erscheinend. Brustseiten aschgrau. Schwinger und Schiippchen blafgelb, letztere schwarz bewimpert. Stirne und Gesicht gleich breit, reichlich von 1/4 der Kopfbreite, erstere durch Bestänbung hellgran, letzteres weißgrau; Taster weißlich. Fiihler hell rotgelb, das dritte Glied klein, nierenförmig, etwas dunkler 
gefirbt mit apikaler Borste; Hinterkopfzilion unten weiß. - Hinterleib schön stahlblau, der zweite und dritte Ring an den Seiten und am Banche gelb, letzter Ring mit dentlichen Randborsten, Hypopyg. kaum sichtbar. Hinterlicken mattgrau. - Beine mit Vorderhiiften und Hinterhiften und allen Hiiftgelenken blaßgelb; Hintersehenkel oberseits an del Spitze braun gefleckt; 'Tarsenendglieder kaum etwas verdunkelt. Dic Beborstung der Beine ist außerordentlich schwach entwickelt; die Vorderschienen laben oberscits im ersten Vicrtel nur ein winziges l3̈rstchen; an den Mittelschienen steht auf der Oberseite dicht an der Wurzel eine liingere Einzelborste, anßerdem sieht man zwei bis drei Endborsten. Hinterschienen oberseits mit einigen zerstreut stehenden Börstchen. - Fligel breit, glashell mit einem braunen Vorderrandstreifen, der, an der Wurzel gelb, allmälulich bis in's Schwarzhraune ibhergeht; der Streifen reicht his etwa iber die dritte Lingsader hinaus; eineu brannen Saum sieht man bei ansgereiften Exemplaren auch noch an der vierten Längsader, so dab in der ersten Vorderrandzelle dann cin weißer Kernstreifen iibrig bleibt; die dritte und vierte Lingsader haben in ihrer Biegung ganz den Charakter von Lyroneurus. 4 nm lang.

$2 \sigma^{7}$ aus Paragnay [Fiebrig] Sammlung des Ungariseben Nationalmuseums.

Eine größere etwas dunkler gefärhte Art mit schwarzbraun angeriiuchertem Fltigelvorderiande.

万. - Thorax von stahlblauem Glanz, auf dem Riicken, namentlich vorn und ror dem Schildchen gelbgrau bestiubt und teilweise matt. Brustseiten, Hiiften und die Notoplenraldepression weißgrau. Sehwinger und Schiippchen lyaggelb, letztere dentlich schwarz bewinpert. Kopf: Augen breit getrennt, Stirne gleich breit, von 1/4 der Kopfbreite, stablblan, an den Räudern gelograu bereift. Gesicht kanm etwas schmïler als die Stirn, gelbgran, an den Augenrïindern weißlich bereift; Taster schwarz, oberseits grau; Fihler schwarz; Hinterkopfzilien unten weiß. - Iinterleib stahlblan nit purpurfarbenem Sehimmer, schwarz behart und beborstet und mit weif bereiften Ringseiten. Hypopyg sehr klein obne sichthare Anhänge mit etwa sechs kurzen Borsten. Beine: Hiften und Schenkel, diese bis nahe zur Spitze sehwarzgrau, Schienen gelbbriunlieh, Tarsen braun bis schwarz. - Fltigel etwas lauchgrau getriibt, groß, längs des Vorderiandes schwarzbraun verdunkelt, mit stakk ausgeprägter Lyroneurus-Aderung und dicker schwarzer Randader. $5 \mathrm{~mm}$ lang.

‥ - Von der gleichen stah]- bis veilchenblauen Färlung. Stirne und Gesicht ein wenig breiter, Gesicht grau bestiubt. Beine etwas dunkler, Hinterschienen rostbrann. Fliigel gleichmäßig etwas rauch- 
grau getribt mit einfacher schwarzer Adernng; dritte und vierte Längsadern sehr wenig gebogen und vollkommen parallel. $5 \mathrm{~mm}$ lang:

Ein Pärchen aus Bolivia 12. X. 1906. 1200-2500 m loch; ferner aus Peru 19. I. 1904 Tarma [Sclunuse] Sammlung des Dresdner zoologischen Minsenms.

8 occultus n. sp. $0^{7}$.

- America merid.

ot. - Thoraxriicken griingold, etwas grau bereift. Schiippehen unıl Schwinger blaßgelb, erstere mit schwarzen Wimpern. Stirne und Gesicht gleich breit von blauer Grundfarbe, erstere mattbraun, letzteres graugelblich bestiaubt; Taster hellbrann mit weißer Spitze. Fiibler scliwarz mit fast apikaler Bolste. - Hinterleib blaugriin, Нуроpyg unsichtbar. Beine nebst allen Hiiften schwarz; Kniee, Scbienen nebst Metatarsus der vorderen Beine rostgelb bis rost-

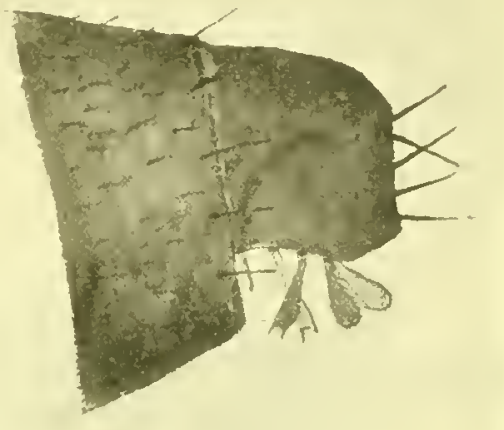

Fig. 67. Diaphorus simplex Aldr. ठ7. Hypopyg. $24: 1$.

braun, Spitze der Hinterschienen auch braun. Schenkelglieder der Vorderbeine gelb. Vorderschienen ncbst Metatarsus sind auf der Unterseite zart, aber dentlich bewimpert, die ersteren tragen eine Einzelborste oberseits an derWurzel; Mittelschienen oberseits ebenfalls an der Wurzel mit einer Borste und auf der Mitte mit einer zweiten. Hintel" schieneu oberseits mit mehreren Einzelborsten und unterseits anf ıler Endhälfte mit mehreren dicht zu-

sammengestellten Borsten; der Metatar-

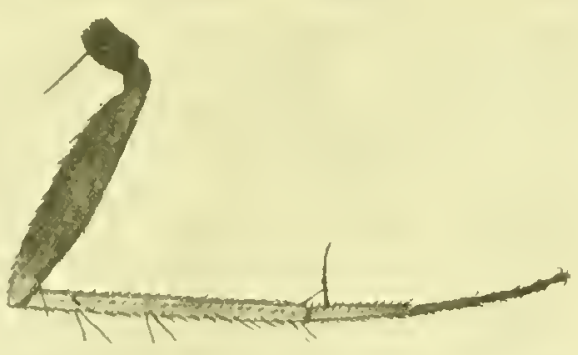

Fig. 68. Lyroneurus simplex Aldr. $\delta^{7}$. Hinterbein. 24:1. sus unterseits an der Basis mit einer kurzen, aber dentlich senkrecht abstehenden Borste. - Fligel glashell mit einer schwachen Biäunung. am Vorderrande, die bis zur dritten Lïingsader reicht; die erste Hinterrandzelle ist sehr breit, die Biegung der dritten Längsader nicht auffällig. $4 \cdot 5-5 \mathrm{~mm}$ lang.

$2 \sigma^{7}$ aus Columbia, Sierra S. Lorenzo [Ujhelyi] Sammlung des Ungarischen Natioualmuseums. 
9 simplex Aldr. O'q. Trans. Entom. Soe. London 333 tab. XII fig. 117 (1896)

America merid.

- - aus Mexiko, von den Antillen und aus Siidamerika.

Diese von Aldrich aus Mexiko und ron den Antillen bekanntgegebene Fliege findet sich auch in Siidamerika und scheint dort durchaus nicht selten zu sein; daß sie durchaus der Art ammlatus Macq. gleicht und ron mir damit als identisch angesehen wird, habe ich bereits bei anmlatus erklärt. Aldrich erwihnt I. c. eine Variante, die erheblich kleiner ist und dabei eine weit weniger ausgeprägte Lyronzurus-Fliggeladerung zeigt, so daß man zunächst eine andere Art darin vermuten könnte. Da mir diese Variante ebenfalls vorliegt, so kounte ich durch rergleichende Untersuchung del Hypopygien fest-

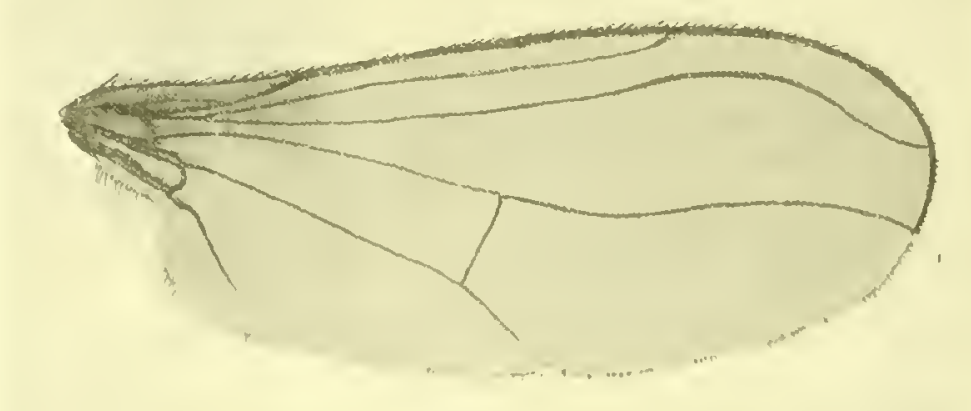

Mig. 69. Lyroneurus simplex Aldr. ऊ’. Flïgel. 16: I.

stellen, dalj Abweichungen in der Konstruktion und Form der Analanbïge nicht vorhanden sind. Tch gebe noch die Zeichnung dieses einfachen Gebildes. Es wird damit also bestiitigt, was Aldrich behauptete, daß bei dieser Art die Fligeladerung einer nicht mnerheblichen Schwankung ausgesetzt ist.

$0^{7}$. Die Augen sind bei der Stirn und dem Gesicht gleich weit getrennt. Ftibler mittelgroß, schwarz, Taster gelb, Wimpern der Deckschtippchen hellbrann. Schwarze Beine, Kniee, Schienen und Metatarsen rostgelh, Metartarsus der Hinterbeine unterseits mit einer charakteristischen, senkrecht abstehenden Borste. Fliigel mit verdickter Randader im Iyroneurus-Charakter. $5 \mathrm{~mm}$ lang.

q. Die Weibchen haben cinfache Fliigel und sind ohue Sporn an dem Hintermetatarsus.

Variante Aldrich $\sigma^{7} Q$. Die Krümmung der Längsadern ist nur noch sehwach vorhanden. $3 \mathrm{~mm}$ lang.

Tariante bispinosus $\sigma^{7}$. Abweichend ist die Farbe der Hintersehienen und Tarsen; die Hintersehínen sind braungelb und der Metatarsus sehwarzbram; letaterer laat ant der Cnterseite zwei starkere Borsten. 
16 б, 3 q ans Peru. Meshagua, Urubambafi VllI et $X 1903$. [Schnuse] Sammlung des Dresdner zoologischen Museums.

Valiante Aldrich. $4 \sigma^{7} 2$ o derselben Herkunft nud Sammlung.

Variante bispinosus. $1 \sigma^{7}$ ans Brasilien. Collectio Winthen (ron Loew als modestus $\mathrm{n}$. sp. bestimmt).

10 suavis Lw. $0^{7} \rho$, Wien. Entom. Monatsschr. I 40 taf. I fig. $11-12$ (1857).

Anerica merid.

ơ. Stirne matt braungran wie del Thoraxriacken, Gesicht ğleich breit, weiß bestäubt. Fiihlel schwarz, jedoch das erste Glied ganz oder teilweise gelb, was Loew nicht erwähnt und iuberseben haben mag; Taster gelb. Wimpern der weißen Schtippchen dunkel. Hinterleib bronzefarbig mit gelben Seitenflecken an den ersten drei Ringen. Borsten am Hypopyg deutlich. Beine ganz gelb. Fligel fast farhlos mit Lyroneums-Geider wie simplex. $35 \mathrm{~mm}$ lang.

2 ơ, 1 q aus Bolivia-Mapiri. 18. 111. 1903. Sarampioni $700 \mathrm{~m}$ hoch [Schnuse] Sammlung des Dresdner zoologisehen Museums.

Die Loew'sche Type, ơ, konnte ich in der Sammlung des Berliner zoologiselıen Museums vergleichen.

\section{Chrysotus Heig. (1824).}

In der paläarktischen Region funden wir nicht so vicle Schwierigkeiten, die Gattungen Chrysotus und Diaphorus auseinanderzuhalten, anders gestaltet sich dies Studium in der nearktischen und neotropischen Region. Hier begegnen wir einer Reihe von Arten mit anuähernd gleich weit getrenuten Augen sowohl auf der Stirme wie im Gesicht, so daß mau im Zweifel bleibt, zu welcher der beiden Gattungen die Alt zu stellen ist. Aldrich machte zuerst darauf anfmerksam in seinen Dolichopodiden of St. Vincent, Trans. Entom. Soc. London (1896) und giht an, daß er bei Arten, bei deneu Gesicht und Stirne annihernd gleich breit seien, die Unterscheidung so vornehme, daß el alle Männchen, bei denen er erweiterte Pulvillen der Vorderbeine und deutliche Endborsten am Hypopyg sehe, zu Diaphorus rechne. Später iu den Kansas Univ. Soc. Bull. 1 Nr. 3 p. 85 (1902) spricht er ebenfalls von der Schwierigkeit eimer Trennung beider Gattungen und wiederbolt seine frtiher angegebenen Merkmale, jedoch mit Weglassung des Merkmals der Pulvillen; hiernach bliebe also nur die Beborstung des Hypopygs als einziges T'rennungsmerkmal iibrig.

Ich habe bei Bearbeitung der siidamerikanischen Fauna die Schwierigkeiten bestätigt gefundeu, die Aldrich bei den ilum bekannten nord- und siidamerikanischen Arten erwihnt und ist es daher notwendig, zunäichst die Frage zur Klitrung zn bringen, ob und mit welchen Merkmalen eine Trennung zu begriinden ist. Aldrich bat eigentlich nur die stärkere Beborstung des Hypopygs angegeben; es mag sein, da $B$ er damit bei den meisten Arten die Trennumg hat richtig einleiten könuen, aber ausreichcud ist dies 
Merkmal anch nicht, denn es kommen Ubergänge vor je nach selıwächerer oder stärkerer Entwick]ung der Borsten an den iibrigen Körperteilen. Daß Aldrich das Merkmal der Pulvillenentwicklung anf'gegeben, später wenigstens nicht wieder erwïhnt hat, kann ich nach meinev Beobachtnngen nur fiil richtig erkliiren; es ist das höehstens ein Merkmal fiil eine Art, kommt in beiden Gattungen vor und ist auch an und fiir sich so sehwankend, daß selbst Exemplare einer und derselben Art mitunter nur an den Vorderbeinen, dann aber anel gleichzeitig an den iibrigen Beinen vergrößerte Pulvillen zeigen. Wir miissen dies ron Loew eingeftihrte Merkmal als nicht stichbaltig hier fallen lassen, wenngleich es richtig ist, daß es bei allen denjenigen Diaphorus-Arten seine Bedeutung belialt, die wir zur Gattung Lyroneurus Lw. gestellt haben.

In allgemeinen unterseheiden sich die Diaphorms.Arten von Chrysotus dureh deı größeren Körper, dureh verläingerten 'Thorax; hier macht sieh die Verlängerung dadureh bemerkbar, daß man in der Regel sechs Paar Dorsozentralborsten zählt, während bei Chrysotus meistens nur fiunf Paare vorhanden sind; es kommen jedoeh hei beiden Gattungen Ausnahmen vor.

Das erste und beste Unterseheidnngsmerkmal bleibt immer noeh die Stellung der Aligen.

Arten, bei denen die Angen sielı auf der Stirne beriihren, gehören stets zu Diaphorus, Arten, bei denen sich die Augen unter den Fiihlern beriihren, stets zu Chrysotus.

Nun kommen die abweichenden Formen:

Arten bei denen die Augen auf der Stirue sehmal getrennt sind, das Gesieht aber breit und breiter als die Stirn ist, gehören zn Diaphorus.

Arten, bei denen das Gesicht schmal, die Stirne ungefähr doppelt so breit ist, gehören zı Chrysotus.

Sind Stirn und Gesieht gleich oder annïhernd gleich breit, sind seehs Paar Dorsozentralborsten vorhanden und die Pulvillen der Vorderbeine groß, wird man die Art zu Diaphorus rechnen; sind nur fünf Dorsozentrale und kleine I'ulvillen und ist die Körpergröße entspreehend kleiner, so wird es ein Chrysotus seiu. Nach diesen Regeln ist hier verfalıren.

Von Bestimmungstabellen fiir die Gattung Chrysotus sind folgende zu nennen:

Loew, Monogr. N. Amer. Dipt. II 173 (1864). Tabelle iiber zwölf nordamerikanische Arten.

Aldrich, Kansas Univ. Soc. Bull. I Nr. 3. 88, 89 (1902) Tabelle liber 25 Arten; es miibten eigentlich 27 sein, denn Aldrich bat die beiden Arten flavus Aldr. und apicalis Aldr. vergessen, in diese Tabelle zu stellen. Von diesen 27 Arten sind 14 aus Westindien genannt, gehören also sehon zur neotropisehen Region, die iibrigen 13 zur nearktisehen. Mit den 10 von mir neu beschriebenen Arten aus Siidamerika kennen wir bis jetzt also 24 neotropische und 13 nearktische Arten. 


\section{Artrerzeichnis, Bemerkungen nnd lieschreibungen.}

1 acuticornis u. sp. $0^{7}$. . . . . . . . . . . . . Brasilia

Durch das spitz dreieekig verlängerte dritte Fiihlerglied ansgezeicbnet, ein Seitensttick zu der Art ucutus Aldr.

o. - Thoraxriicken stark glainzend griin bis bronzefarbig olne jede Bestäubung. Schwinger gelb, Schiippehen weißlich, Wimpern kann ich nicht erkennen. Stirne breit, glänzend griin, Gesicht sehr schmal, Augen nicht ganz zusammenstofend. Taster und Fiihler schwarz, letztere mit der zentralen Borste mikroskopisch deutlich pubeszent; die Gesichtsfarbe ist ein mattes Schwarz. Hinterleib obenauf glänzend schwarz mit kurzen schwarzen Haaren; Hypopyg eingesenkt, unsichtbar. - Beine mit allen Hiiften hellgelb, die letzten Tarsenglieder etwas braun, Vordertarsen etwas länger als die Sehiene, Pulvillen klein, etwas graubraun. Fliggel wasserklar, hintere Querader um reichlich ihre eigene doppelte Lüinge rom Flügelrande entfernt. $1 \mathrm{~mm}$ lang.

\& Gesicht eheufalls mattschwarz, ctwa $1 \frac{1}{2}$ mal so breit wie das dritte Fühlerglied.

$1 \sigma^{7}, 2$ q aus Brasilien, Blumenau [Lothar Hetschko]. Wiener zoologisches Mnsenm.

2 acutus Aldr. ơ, Trans. Entom. Soc. London 329.9 (1896) I. St. Vincent

Diese Art hat die gleichen spitz verliingerten Fiiller wie acuticomis mit subapikaler Borste. Fïrbung metallisch griin. Wimpern der Schiippchen schwarz. Die Beine sind aber an Hiiften und Schenkeln schwarzbraun. 1.1 mm lang. Siche die ansfiulntiche Beschreibung bei Aldrich.

3 affinis Lw. $\sigma^{7}$, N. Beitr. VIII $64,4(1861)$. . America sept. et merid.

${ }^{7}$. Augen am Gesicht zusammenstobend. Fühler schwarz. Hiiften und Schenkel schwarz, Vordersehienen gelbbraun, Mittelschienen bramschwarz, Hinterschienen schwarz. $25-3 \mathrm{~mm}$ lang. Siebe die Beselireibung bei Loew.

4 Exemplare ans Paraguay, S. Bermardino. Wiener zoologisches Museum.

4 Exemplare vom Äquator, Cisitagua, Yausai [Rivet] Pariser Entomologisches Huseum.

4 albipalpus Aldr. ơ

ơ. Augen sich kurz beriihrend. Fübler klein, schwarz, Taster groß, schneeweiß. Schüppchen schwarz bewimpert. Hüften und Schenkel schwarz, Schienen gelb bis brann. $1.5 \mathrm{~mm}$ lang. Sielie die ausfilhrliche Beschreibung bei Aldrich.

americanus Wheel. = barbatus $\mathrm{Lw}$.

apicalis Aldr. = barbatus Lw. 
5 auratus Lw. э, N. Beitr. VIll 65. 7 (1861) N.-York et Anerica centr.

Nur als Weibchen beschrieben mit schwarzschenkeligen Beinen. Siche bei Loew.

2 vom Äquator: El-Angel, Casitagua, 3000-3500 m bocl [Rivet] Pariser Entomologisches Musenm.

6 barbatus Lw. O N. Beitr. VIII 48. 2 [Synarthrus] (1861)

America sept. et centr.

americanus Wheel., Eutom. News Philadelphia VIII 154 [Xiphandrium] (1896).

apicalis Aldr., Trans. Entom. Soc. London 330. 11 (1896).

validus Lw. ․ N. Beitr. VIII 63. 2 (1861).

Obige Synonymie ist von Aldrich festgestellt worden; siehe die Beschreibungen 1. c.

11 Exemplare rom Äquator: Loja, Mirador, Troya. $3500 \mathrm{~m} \mathrm{hoch.}$ [Rivet]. Pariser Entomologisches Museum.

basalis Philippi, Verh. zool.-bot. Ges. Wien XV 775.1 (1865) Chile

Obne Angabe des Geschlechts unkenntlich beschrieben.

7 choricus Wheel. Јै, Psyche V 357 (1890) . . . America sept.

Eine schwarzbeinige Art mit gelben Vorderschienen; siehe das Nähere bei Wheeler.

concinnarius Say, Journ.Ac. Nat.Sc. Philadelphia VI 168 (1829) Mexiko

Loew vermntet, daß die Art ein Diaphorus sei; ohne Angabe des Gesehlechts unkemntlich beschrieben.

8 cormutus Lw. О7, Berlin. Ent. Zeitschr. VI 21465 (1862) America sept.

Eine Art mit schwarzen Schenkeln, rotgelben Schienen, die sich durch ein verlingertes drittes Fïhlerglied auszeichnet. Siehe dic ausführliche Beschreibung auch in Lw., Monogr. N. Amer. Dipt. II 174. 1. tab. VI fig. 31 (1864).

9 costalis Lw. ơg. N. Beitr. VIII 64.5 (1864). . America sept.

Fliigel des of mit einer Verdickung am Vorderrande. Wimperm der Schipplenen hell. Siche die Beschreibung bei Loew I. c.

10 discolor Lw. ơ, N. Beitr. VIII 65. 6 (1861). . . . America sept.

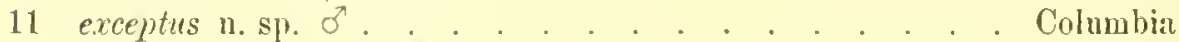

万. - Thorax schwarzblau, anf dem Riicken ziemlich dicht gelbgrau bestäubt, mit fïnf Paar Dorsozentralborsten. Brustseiten mattschwarz. Schwinger und Schïppchen schwarzbraun, letztere schwarz bewimpert. Koplf: Stime und Gesicht mattschwarz; erstere ziemlich breit, dolpelt so breit wie das Gesicht, das die Breite des dritten Füblergliedes lat, nud $1 / 4$ der ganzen Kopfbreite. Fiihler und Taster sowie die llinterkopfzilien ganz schwarz. Hinterleib glänzend schwarzblau. Hypopyg versteckt, Endborsten schr zart. - Beine nebst Hiiften ganz schwarz. l'ulvillen an allen Beinen lang entwickelt, schmutzigweiß. Fliigel nngleichnälitg schwarzbraun, an Vorderraude stärker gefirlbt, nach dem Hinterrande hin allmählich verblassend. Lüngsaderu parallel. $3.5 \mathrm{~mm}$ lang. 
Anmerkung. Eine l'bergangsform zwischen Chrysotus und Diaphorus. Die mattschwarze Färbung, die Entwieklnng der Pulvillen und die Größe splechen für Diaphoms; im llabitus und in del Firbung ist große Ïhnhichkeit mit Diaphorus nigricans Meig. mul anch mit $D$. nigrescens Aldr. rorhauden, aber der Charakter des Gesichts und der Stim spricht zu deutlich für Chrysotus.

$1 \sigma^{7}$ aus Columbia, Sierra S. Lorenzo [Ujhelyi] Sammlung des Ungarischen Nationalmuseums.

12 excisus Aldr. ơ o, 'Trans. Entom. Soc. London 325.1 (1896) I. St. Vincent

Eine Art mit schwarzen Beinen, siehe das Nähere bei Aldrich.

femoratus Big. \& (nec Zett.), Anu. Soc. Ent. Fr. sér. 6. X 205. 1 (1890) .

Chile

Ein Weibchen mit gelben Beinen, unkenntlich beschrieben. Da Zetterstedt bereits einen Chr. fomoratus beschrieben hat, könnte die Bigot'sche Art ihren Namen nicht behalten; da diese Art aber nnkenntlich ist, ist der neue Name iibertlissig.

13 flavus Aldr. $\sigma^{7}$, , Trans. Entom. Soc. London 326.3(1896) I St. Vincent

Eine kleine, fast ganz gelbe Art. Siehe bei Aldrich.

14 Tirsutus Aldr. O’o, 'Trans. Entom. Soc. London 328.6 (1896) I. St. Vincent

15 imitator n. sp. $\sigma^{\top}$ ㅇ. 2 Figuren . . . . . . . . . . . . Peru

Eine Schwesterart ron longimames Lw., durch größere Taster, etwas schmäleres Gesicht und rotgelbe Fưhler unterschieden, auch wegen der Taster verwandt mit longipalpas Aldr.

o". - Thorax ron metallisch griiner Grnndfarbe, anf dem Riicken durch dicbte Bestäubung mattbraun mit unbestimmter Streifung und Fleckung, mit finf Paar Dorsozentralborsten. Schwinger gelb, Schiippchen weißlich mit blaßgelben Wimpern. -- Kopf: Stirne etwas breiter als das Gesicht, nach dem Mundrande bin allmählich etwas rerschmälert; die Gesichtsbreite unter den Fiilılern beträgt 1/5 der ganzen Kopfbreite; Stime und Gesicht sind ron graubrauner Färbung Die auf der Mitte des Kopfes sitzenden Fiiller sind nur klein und von rotgelber Farbe, das dritte Glied an der Spitzenhälfte etwas braun mit zentraler Borste; die Taster sind ausnehmend grob, fast um Kopfeslänge vortretend, länglichoval, von weißgelber Farbe, auf der Oberfläche perlmutterartig glïnzend, ungefähr zweimal so lang wie breit. Riissel schwarz, Hinterkopfzilien unten weif. - Hinterleib erzfarbig, schwarz behaart; Hypopyg mit einigen scliwachen Borsten. Beine: Hiiften schwarzbraun, Hiiftgelenke zum Teil rostgelb; Schenkel bis auf die Spitzen metallisch griin glänzend; Schienen und alle Metatarsen gelb, die iibrigen Tarsenglieder braun. Fligel etwas graulich Längsadern parallel, die vierte an der Fliigelspitze miindend; hintere Querader anf der Fligelmitte $11 m$ die doppelte eigene Länge rom Fligellinterrande entfernt. $2.5 \mathrm{~mm}$ lang. 
○. - Sti'n und Gesicht sind fast vou gleicher Breite, erreichen aber nicht ganz den dritten Teil der ganzen Kopfbreite. Taster erheblich kleiner, gelb, vorgestreckt. $3 \mathrm{~mm}$ lang.

$4 \sigma^{7}, 3$ aus Peru. 20. Juni 1903, Sicuani [Schnuse]

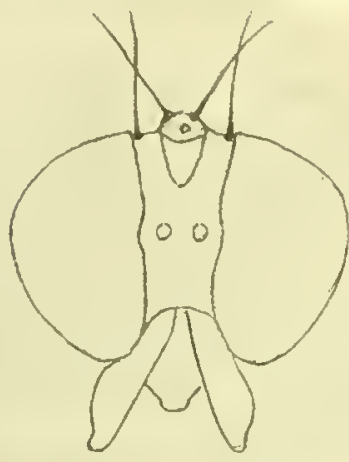

Fig. 70. Chrysotus imitator Beek. ठ liopf von vorne. $24: 1$. Sammlung des Dresdner zoologischen Musenms. incertus Walk., List Dipt. Brit.

IIns. III 651 (1849)

America sept. Unkenntlich beschrieben, ohne Geschlechtsangabe.

16 inermis Aldr. ơ, Trans. Entom. Soc. London 330. 10 (1896) . . I. St. Vincent

17 laciniatus $\mathrm{n}$. sp. $0^{\pi}$

America centr. ठౌ. - Thoraxriicken glïnzend erzfarbig, mit kupferfarbjgem Reif dentlich bedeckt. Scbwinger und Schiippchen gelb, letztere mit schwarzen Wimpern. - Die Augen beriihren sich auf dem Gesichte in einer längeren Linie; letzteres ist von dunkelgraner Farbe, die Stirne

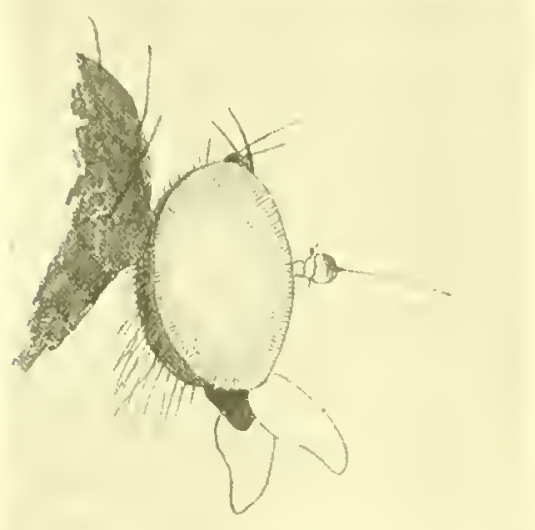

Fig. 71. Chrysotus imitator Beek. ठ․ Kopf ron rler seite. $24: 1$. ron metallischem Glanze. Taster' klein, gelb. Fiihler schwilz, das dritte Glied ist rolne schriig abgestutzt, dentlich behart mit apikaler Borste. Hinterleib ron gleicher Fürbnng wie der Thoraxriicken. -... Beine mit Hiiften schwarz; Schenkel von metallischem Glanze. Schienen und die ersten 'Tarsenglieder der vorderen Beinpare gell). Hinterschienen in eine lange lappenförmige Spitze auslaufend. Hintertarsen mit Aus. nalme der Basis des ersten Gliedes bratur. - Fliigel graulich mit gewöhnlicher Adermug. $2 \mathrm{~mm}$ lang.

Acht Exemplare vom Äquator, Cnenca [Rivet 1905] Sammlnug des Pariser zoologischen Museums.

Anmerkung. Wegen der Herkunft dieser Art siehe meine Bemerkungen bei der Art unicolor. 
18 laminatus n. sp. o'. 1 Figur

Pern

8. - Von metalliseh griiner Grundfarbe, am Riteken und Schildchen mit leichter weißlieher Bereifung. Sehwinger gelb, Schiippehen weiß mit weißen Wimpern. Kopf: Stirne vou der Färbung des Thoraxriickens; die Augen beriihren sich nnter den Fihhlern kaum; das schmale Gesicht weißlich. Taster gelb. Fïhler gelb, das zweite und dritte Glied anf der Oberseite schwarzbrann, das dritte Glied ungefäln doppelt so lang wie an der Wurzel breit; die Borste sitzt an der Spitze in einer Kerbe, das zweite Borstenglied ist mackt, sehr lang, an der Spitze zu einer ovalen schwarzen Lamelle breitgedriickt (diese Lamelle bildet kein besonderes Glied). Hinterkopfzilien weiß. Hinterleib dnnkel erzfarbig, sehwarz behaart, an den Sciten und am Hypopyg auch mit weißen Haaren. - Beine: Htiften dunkel aschgrau, Schenkelglieder zum Teil rostgelb. Schenkel bram, metallisch glïnzend mit gelben Knieen. Schienen rotgelb, Hinterschieneu nebst allen Tarsen schwarzbraun, Behaarung der Hintersehienen zum Teil weißlich. Fliigel glashell bis graulich mit feinen schwarzen Adern, dritte und vierte längsadern parallel; hintere Querader reich-

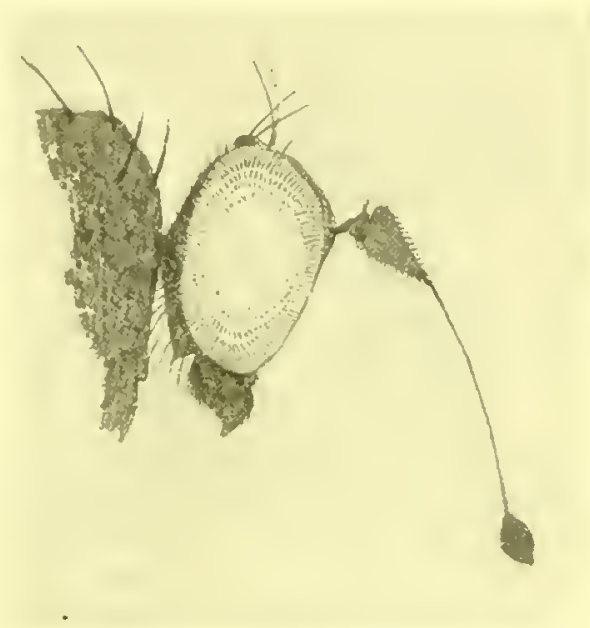

Fig. 72. Chrysotus laminatus Beck. O'. Kint von der Seite. $24: 1$.

lich um die dreifache eigene Länge rom Flügelhinterande entfernt. $2 \mathrm{~mm}$ lang.

$2 \sigma^{7}$ aus Peru rom Titicacasec 23. XI. 1902 [Sehnuse] Sammlnng des Dresdner zoologischen Mnseums.

19 longimanus Lw. o, N. Beitr. VIII 62. 1 (1861) America sept. et centr.

Eine durch lange weiße 'Taster ausgezeiclınete Alt. Zwei Exemplare vom Äquator, Cuenca [Rivet] Pariser Entomologisches Museum.

20 longipalpus Aldr. ợ, Trans. Entom. Soc. London 329. 7 (1896)

1. St. Vincent

Ebenfalls wegen der langen weißgelben Taster mit longimanus Lw. und mit imitator $\mathrm{m}$. verwandt; mit letzterer lat sie die rotgelben Fiihler gemein, ist aber mit nur $1 \mathrm{~mm}$ Länge erleblich kleiner; ferner bertibren sich dic Augen auf dem Gesicht. Siehe das Weitere bei Aldrich l. c. 
21 metatarsatus 11. sp. ठ . . . . . . . . . . Argentinia ठ․ - Thoraxricken metalliseh blaugriin, briunlich bereift. Sclıwinger und Schiippchen ganz weiß und weiß bewimpert. - Kopf: Stirne matt brïunlich, Gesicht grau. Augen am Gesicht mu die Breite des dritten Fuihlergliedes getrennt, Taster grangelb. Fiihler schwarz; drittes Glied ziemlich groß, nierenförmig mit zentraler Borste. Hinterleib schwarzblau, schwach gliinzend, schwarz behaart. Hypopyg mit kleinen dunklen beharten Anhingen. - Hiiften und Schenkel schwarz, Schenkelglieder der Vorderbeine, liniee nud alle Schienen rostgelb, Hintersehienen von del Endhïlfte an allmählich gebräunt; Hintertarsen und die ïbrigen Tarsen vom zweiten Gliede an branuschwarz. Hintermetatarsıs länger als das zweite Glied, anf der Unterseite beborstet: eine liingere Borste steht im ersten Drittel, eine sehwiichere auf der Mitte. Fliigel glashell; die vierte Liingsader endet an der Fliigelspitze und die hintere Queraler ist un ibre eigene doppelte Länge vom Fliigelhinterrand entfernt. $2.5 \mathrm{~mm}$ lang.

$1 \delta$ aus Nordargentinien, Proviuz Salta, $1100 \mathrm{~m}$ hoels [Steinbaclı] Berliner zoologiselues Musemm.

22 niger Aldr. ơ ${ }^{2}$, 'Trans. Entom. Soc. London 327.5 (1896) I. St. Vineent mubilus Say, Journ. Acad. Nat. Soc. Philadelphia VI 168. I (1829)

Ameriea sept.

Unkenntlich beschrieben. Loew vermutete eine Medetera darunter. 23 obliques Lw. ơ , N. Beitr. VIII 63. 33 (1861) Amerien sept. et merid.

Vier Exemplare ans Paraguay, S. Beruardino. Wiener zoologisches Insenm. $43 \sigma^{2} \rho$ vom Äquator: El-Angel, Alausi, Cnenca, Loja [Rivet] I'ariser entomologiselies Mnsenm.

24 pallipes Iw. $0^{7}$, N. Beitr. VIII 66. 8 (1861). . . . America sept. Zwei Exemplare ans Georgia, Nordamerika. Wiener zoologisehes Museum.

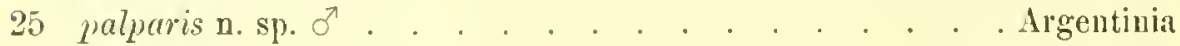

ơ. - Thoraxriicken glinzend griinblau bis kupferfarbig, kamm etwas bereift. Schwinger und Schippchen weiß, weiß bewimpert. Kopf: Stime matt braungrau, das Gesicht allmählich nach unten verengt, die Angen aber mindestens nu Fiblerbreite getrennt. Taster gelb mit siberweilier Spitze und perlmutterartigem Glanze, langgestreckt, dreimal so lang wie breit, im Profil nm die ganze liopflïnge horizontal vorgestreckt. Fibller schwarz, erstes Glied jedoch deutlich gelb; drittes Glied nicht nierenförmig, sondern mit kurzer stumpfer Spitze und apikaler Borste. Hinterleib glänzeud schwarzgriu, schwar\% behaart; Anallamellen klein, schwarz. - Beine: Hiiften, Schenkel und Tarsen schwarz; Schenkelglieder, Spitze der Schenkel und Schienen sowie die Metatarsen der Vorderbeine rostgelb. Vordertarsen kamm linger als ibre Schiene. Fliigel wasserklar mit normaler dunkler Aderung. $2 \mathrm{~mm}$ lang. 
Ein Exemplar ans Argentinien, Provinz Salta, $2000 \mathrm{~m}$ loch [Steinbach] Berliner zoologisches Museum.

Anmerkung. Meiner Art imitatus nahe stelend; ilre Untersehiede sind in der Bestimmungstabelle zusammengestellt.

26 paradoxus Aldr. o', Kansas Univ. Se. Bull. I 90 (1902).

Grenada et Bolivia

Sechs Exemplare aus 0.-Bolivia, Proviuz Sara. 700-1900 m hoch [Steinbach] Wiener zoologisches Museum.

Diese stidamerikanischen Exemplare sind mit $1 \mathrm{~mm}$ Lïnge etwas kleiner, als Aldrich sie mit $1.4 \mathrm{~mm}$ beschreibt; der Bauch ist nicht gelb, anch vermag ich gelbe Analanbinge nicht zu entdecken, ebenso sind die Pulvillen kanm groß zı nennen; immerhin reichen diese Unter. schiede nicht aus, $n \mathrm{~m}$ eine audere Art darin zu erblicken, es wird sich hier uur um eine lokale Abïnderung von den nordamerikanischen Exemplaren bandeln.

27 parvulus Aldr. O'o, Trans. Ent. Soc. London. 321. [Diaphorus] (1896).

Americal centr.

Thoraxriicken glänzend griin. Gesicht schmal, grau bestänbt; Stirn glänzend griiu, breiter, Fibler schwarz, drittes Glied ziemlich grob, mit subapikaler Borste. Hinterkopfzilien unten weiß. Hinterleib bronzefarbig mit gelbem Banch; Hypolyg ohue schwarze Borsten mit zwei kleinen, an der Spitze gelben Anbäingen. Beine nebst Hiiften gell, Mittelhiuften an der Wurzel verdunkelt. Vordertarsen $1 \frac{1}{2}$ mal so lang wie die Schiene mit vergrößerten Pulvillen. Fliigel zart gelblich mit del gewöhnlichen Aderung. 1.2 mm lang.

Von Aldrich aus St. Vincent, Westiudien bekannt gemacht.

Anmerkung. Ieh habe schon bei Vorliulnung der Gattung Diaphorus die Griinde angegeben, die mich reranlaßten. die Aldrieh'sche Art Diaphorus parculus zu Chrysotus zu stellen.

28 phittrum Meland. Entom. News Philadelphia XIV 72 Fig. (1903)

America sept.

29 picticomis Lw. \%", Bcrlin. Entom. Zeitsehr. VI 214.66 (1862)

America sept, centr. et merid.

Eine in Nord- und Siidamerika rorkommende Art.

$1 \sigma^{7}, 2$ aus Brasilien, Blumenau [Lothas Hetschko] Wiener zoologisches Museum. - 3 $\sigma^{7} 4 q$ aus Chile. 9. X. 02; Arica [Schmse] Dresdner zoologischen Insenm.

pictipes n. sp. $\sigma^{\pi} f$

Peru, Boliria

б. - Thorax gliinzend blaugriin, braun bereift. Schwinger nud Schippchen gelb, letztere weiß bewimpert. Kopf: Augen auf dem Gesicht sich rollkommen beriihrend; Stirme glänzend griun, 'T'ster weißgelb. Fiihler schwarz, drittes Glied nicht gerade verliingert, aber doch mit einer etwas rortretenden stumpfen Spitze und einer subapikalen Borste. Hinterleib glïnzend schwarz mit kleinen sehwarzen, 
wenig vortretenden Anlingen. Beine nebst Vorderbiften gelb, aber alle Schenkel, vornehmlich die Hintersehenkel auf der Spitzenhïfte schwal"z, auch dic Hinterschienen sind ron glcicher Zeichnung; alle Tarsen rom Ende des ersten Gliedes an sebwarz. Fliigel glashell; hintere

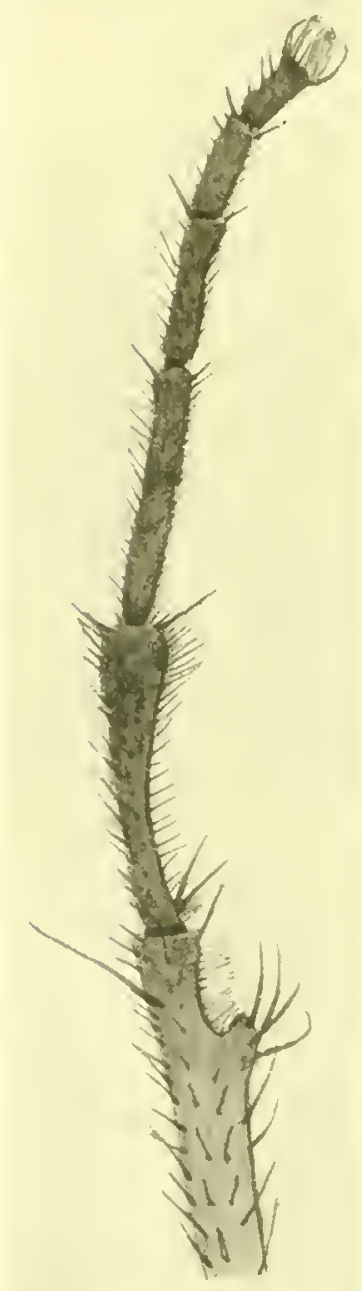

Fig. 73. Chrysotus soleatus Beck. ơ. Hinterbein. 48:1. Querader $1 \mathrm{~m}$ das $3-4$ fache ihrer eigenen Länge vom Fliigelhinterrande entfernt. Pulvillen kaum bemerkbar.

Ein Exemplar aus O.-Bolivia, Provinz Sara [Steinbach] Wiener zoolo. gisehes Musenm.

Variante. Einige Exemplare aus Peru zeigen nur an den Hinterschenkeln das letzte Drittel schwarz.

Q. - Gesicht breiter, ungefähr von $1 \%$ der Kopf breite, sonst dem o’ gleich.

7 б, 2 aus Perm - Mollendo. 10. XI. 1902 [Sehnuse] Simmlung des Drestner zoologisehen Musenms.

31 matincola Wheel. ơ, Psyche V 357 (1890)

Nehraska

32 proximus Aldr. \%", Trius. Entom. Soc.

London 326. 2 (1S96). 1. St. Vincent

33 soleatus n. sp. ơo. 1 Fignr . Peru

5. - Thoraxriicken von goldgriiner' Grundfarbe, ein wenig grau bereift, Schildehen melı bläulieh. Sehwinger blaßgelb, Schiippehen weiß mit weißen Wimpern. Kopf: Breite der Stirne und des Gesiehtes etwa 1/5-1/6 der Kopfbreite, weifgrau bestiubt: Taster deutlich etwas vortretend, gell, oben weiß. Fiiller schwarz, das dritte Glied nieht liinger als breit, mit stumpfer Spitze, iiber welcher die nackte Borste subapikal sitıt. Hypopygium mit schwacher Beborstung. Beine: Hiuften mit Sehenkel schwarz; nu॰ die Hüftgelenke der Vorderbeine, die Spitze der Scbenkel — diese vorne mebl als hinten -, die Schienen und die Metatarsen der beiden vorderen Beinpare rostgelb, die amderen Tarsenglieder schwarzbriunlich. Vorclertarsen erheblich lïnger als die zngehörige Schiene, Hintertarsen etwas kürzer. Hinterschienen an der spitze der Uuterseite mit eimem Höcker und Ausschnitt; anf ersterem 
stehen zwei gerade nud zwei gebogene Borsten, der Aussehnitt ist biirstenförmig bewimpert; der Metatarsus, etwas längel als das zweite Glied, ist in ganzen anf der Unterseite etwas verdunnt oder alısgeschnitten, bewimpert und an der verdickten Spite stiirker behart; die Haftläppchen aller Beine sind gleich groß. Flïgel schwach gelblich. $2 \cdot 5-3 \mathrm{~mm}$ lang.

૨. - Stirn und Gesicht von 1/4 der Kopfbreite. Beine einfacb, etwas ktirzer. Haftläppehen klein.

$1 \sigma^{\top}, 2$ ㅇ aus Peru-Ulubambafi, Umahuankilia 13. IX. 1903. Peru-Rosalina, Urubambafi. 2\%. VIll. 1903 [Sclınuse] Dresdner zoologisches Husenm.

Anmerkung. Diese Art ist im ILabitus ein vollkommener Chrysotus trotz deutlicher Haftläploclen und iler Borsten am Hypopyg - wiederum eine Ansnahme unserer Regel.

subapicalis n. sp. $\sigma^{7} \mathrm{q} \cdot 2 \mathrm{Fi}$. guren . . . . Bolivia

$\sigma^{7}$. - Ausgezeichnet durch lappenförmige Verlingerung der Hintersehienen und dentlich subapicale Futhlerborste des birnförmig verlängerten dritten Fühlergliedes. - Thoraxriicken gliinzend grtingold ohne Bestiiubung; Schildchen bläulich schimmernd. Schwinger gelbbraun, Schippehen weißlich, weiß bewimpert. Kopf: Stime metallisch griin, schwach glänzend; Gesicht weiß, Augen unter den Füblern sich beriihrend, Taster dunkel. Fiihler schwarz, drittes Glied etwas birnförmig verläingert, deutlich pubeszent mit eiuer subapikalen nackten

Fig. 74. Chrysotus subapicalis $\sigma^{7}$. Hinterbein. $24: 1$. oder mikroskopisch pubeszenten Fiiblerborste, die etwas länger als die Fiihler ist (s. Figur 75). - Hinterleib glänzend gringold, schwar\% beharit. Beine: Hiiften alle schwar\%; Hiiftgelenke rostgelb. Schenkel bis auf die Spitzen schwarz, Schienen gelb, Hintersehienen bis nahe zul Spitze braun; Tarsen gelb, Lndglieder braun. Die Hinterschenkel tragen wie gewöhnlich an der Spitze der Außenseite einige lïngere Borsten, dazu auf ihrer Unterseite etwas vor der Mitte einen kleinen Schopf kurzer Hä chen; die braunen Hinterschienen sind verbältnismäßig knuz und endigen in einem gelben Lappen, der in eine gebogene Spitze ausläuft und einige Börstehen träigt. Der Metatarsus ist ganz gell, lang, kurz aber dentlich behart und trägt etwas vor seiner Mitte eine lïugere Borste. Die Fligel sind ganz farblos mit braunen, parallel laufenden Adern, die vierte endigt an der Fliigelspitze. $1.8 \mathrm{~mm}$ lang:

$1 \sigma^{7}$ aus Bolivia-Mapiri 25. IV.03 Lorenzopata [Schnuse] Dresdner zoologisehes Museum. 
Q. - Dem o gleich in 'Thorax- und Beinfärbung sowie Fliigeladerung, nur sind die lhinterbeine ganz einfach. Gesieht grau, doppelt so breit wie das dritte Fiihlerglied, das anch eine entsprechende Größe hat, aber nieht verlingert ist.

Ich betrachte die mir vorliegenden Exemplare als die zugchörigen Weibchen, da sie unter drei verschiedenen Arten die einzigen sind, welche zu den Mïnuehen gut passen, allerdings sind die Sebtippehen dunkel bewimpert. Ieh teile aber nieht Aldrieh's Ansieht, der in seiner Bestimmungstabelle die IIampteinteilnng nach der Farbe der Wimpern rorgenommen hat, dab dies hier ein hinreiehend zurerlïßliehes Einteilungsmerkmal ist; ieh funde, daß die Farbe sehr schwankend und triigeriseh ist; vicle Arten zeigen keine entschiedene Färbung;

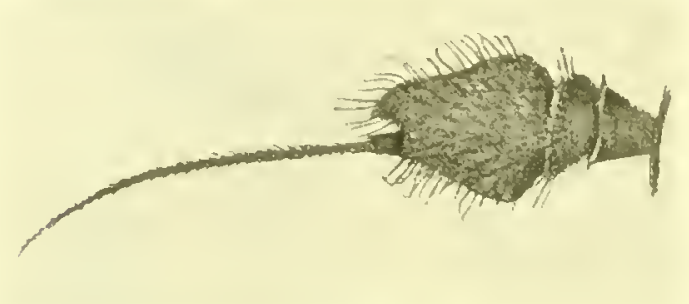

F'ig. 75. Chrysotus subupicalis Beek. б. Fühler. 96:1. die Wimpern erscheinen bell anf einem dunkle. ren Hintergrunde und dunkel anf einem hellen Grunde.

$$
1 \delta^{7}, 3 \text { alus Boli- }
$$
via-Mapiri IV. 1903 Lorenzopata [Sehnuse] Dresdner zoologisches Museum.

Anmerknng. Das dritte Fihlerglied des of thnelt durchas dem der Art acutus Alltr; bei dieser Art sind aber die flinterschienen einfach.

35 subcostatus Lw. О’, Monogr. Dipt. N.-Amer. II 181.8 (1864).

America sept.

36 teapamus Aldr. o'o, Biolog. Centr. Amer. Dipt. 1 347. 1 (1901) Mexiko thoracicus Philippi, Yerh. zool.-bot. Ges. Wien XV 775. 2 (1865) Chile

Unkenntlich und ohne Geschlechtsangabe.

37 tumidipes n. sp. $\sigma^{T}$. 2 Figulen . . . . . . . . . Peru

Eine charakteristische Art mit verdiekten und lang beharten Hintersehienen und geschwungenen Längsadern.

ऽ. - Thoraxribeken ron erzgriner Grundfarbe, aber dureh diehte graubraune Bestiubnng ganz matt. Sehüppehen weißlich, dunkel bewimpert. Kopf: Gesicht sehr sehmal, weiß, Die Angen berithren sich beinahe anf dem Gesieht; Taster auf der Oberfliche fast silberweif bestïubt; Stirne mattbriun wie der Thoraxrieken. Fihhler sehwarz, das dritte Glied groß mit sehr feiner Borste. Hinterleib erzgriin, schwarz behaart. - Beine mit Hiiften schwarz; Hinterschenkel und Schiene starkt verdiekt, ersterer am Ende der Außenscite mit längeren Haaren, Schienen halb auf der Ober-, halb auf der Außenseite lang sehwarz behaart; auch der Metatarsus ist noch lang behaart. Fliigel hraungrau getribt; dritte und vicrte Längsadern etwas aufiällig in der Rielitung des Flügelrandes geschwungen und konvergierend; hintere 
Querader weiter als gewöhnlich nach der Basis zuriickgedrängt. 2 bis $2.5 \mathrm{~mm}$ lang.

Q. - Dem ơ gleich mit normalen Beinen und etwas weniger stark geschwungenen Lüingsadern.

6 ઠึ, 3 † ans Peru, Tarma, 20. 1. 1904 [Schnuse] Dresdner zoologisches Museum.

unicolor n.sp. $\sigma^{\top}$ Am. centr.

o. - - Thoraxricken metallisch schwarzgriin, sebr zart briunlich bereift. Schwinger und Schippchen gelb, letztere mit schwarzen Wimpern. Dic Augen beriihren sich anf dem Gesichte in eincm Punkte. Gesicht matt schwar", Stirne glänzend Fig. 76. Chrysotus tumidipes Beck. O'. Hinterschwarz. Fihhler und 'Tastel'

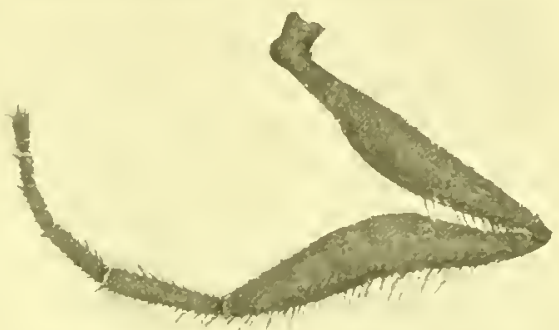

schwarz, drittes Glied nur von mittlerer Grölie. Hinterleib dnnkel kupferfarbig. Die Beine sind ganz einfach und ganz schwarz. Fligel fast farblos mit parallelen Längsadern; die hintere Querader ist fast

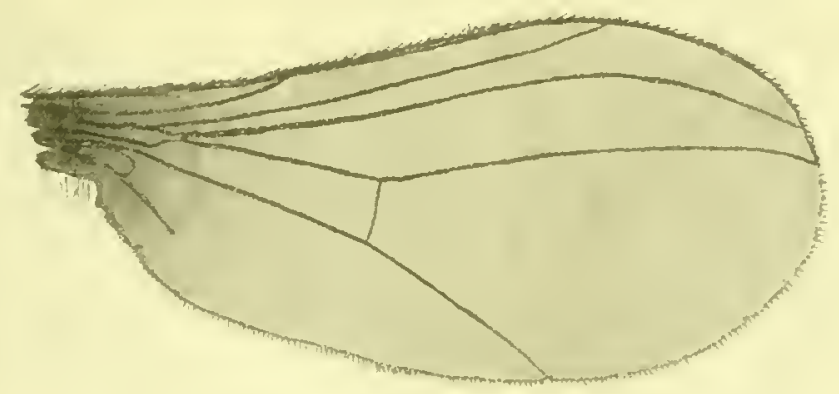

Fig. 77. Chrysotus tumidipes Beek. ठ7. Flügel. 24:1.

um ihre dreifache eigene Länge vom Fligelhinterrande entfernt. $1.8 \mathrm{~mm}$ lang.

Anmerkung. Diese Art hat mit meiner ganz schwarzbeinigen viritis ans Peru große $\mathrm{A}$ lınliclikeit; letztere ist aber durch andere fiesiclıtsfarbe und Behaarung fer Ifinterbeine abweichent. Anch die nordamerikanische Art niger Aldr, muB verglichen werden; bei dieser sind aber die Schwinger schwarz und die Schienen braun, beim Weibchen sogar gelb.

2 ó vom Äqualor bei Borma, $3126 \mathrm{~m}$ hoch nnd bei Casitagua $3568 \mathrm{~m}$ hoch [Rivet]. 
Diese Art unicolor, eine zweite laciniatus nnd andere stammen von ciner Expedition der Herren G. und P. Rivet, die in den Jahren 1902-1905 in den hohen Äquatorialgegenden von Sidamerika auf Kosten der französischen Regierung mit Gradmessungen besehäftigt waren. Dieser Aufenthalt wurde nun anch naturwissenschaftlich ausgenutzt und das Resultat dieser wissensehaftlichen Expedition sollte in einem besonderen Werke hekannt gemacht werdeu. Es war im Jalure 1907, als man seitens des Pariser zoologischen Museums an mich herantrat mit der Bitte, cinen Teil der dipterologischen Ausbeute zu bestimmen und zn beschreiben; ich willigte ein und habe meine Arbeit 1909 abgeliefert. Ob eine vorläufige Drucklegung derselben, wenn anch nur der lateinischen Diagnosen der neuen Arten erfolgt ist, entzieht sich meiner Kenntnis. Nachdem die unterbrochene Pnblikation nach dem Kriege wieder anfgenommen worden und mir mein Arbeitsanteil zur Korrektur vorgelegen hat, so daB die Publikation mahe bevorsteht, halte ich mich für berechtigt, die Resultate meiner damaligen Mitarbeit, soweit sie hier in Frage kommt, dieser meiner Arloeit einverleiben zu dirfen.

calidus Lw. = barbatus Lw.

riridifemora Macq., Dipt. exot. suppl. 4. 124. 2 tab. XII fig. 3 (1849).

Unkenntlich beschrieben.

ð. Thoraxriicken glänzend kupferfarbig, Brustseiten dunkel aschgran. Sehwinger gelb bis hraun, Schijppchen weißlich mit schwarzen Wimpern. - Kopf: Angen unter den Fliblern fist zusammenstoßend; Stirne braun, ziemlich matt, Gesieht hellgrau. Taster und Fïhler schwarz, drittes Glied ziemlich groß, Hinterkopfzilien nnten weiß. - Hinterleil glïnzend knpferfarbig, schwarz behaart. - Beine nebst Hiiften ganz schwarz, Schenkel etwas metallisch glänzend; Hinterschenkel an der Außenseite nud nalse der Spitze mit einer Reihe von 4-5 lingeren schwarzen Borsten; Hinterschienen auf der Außenseite (nicht Hinteroder Oberseite) der ganzen Liinge nach deutlich bewimpert. Flingel etwas granlich getriibt, dritte und vierte Längsadern parallel, die vierte dentlich vor der Fliggelspitze mindend; hintere Querader um das $2 \frac{1}{2}$ fache ihrer eigenen Länge rom Fliggelhinterrande entfernt.

․ - Stirne mattbranu, Gesicht aschgrau; Taster schwarz, obelseits aschgran. $1.6 \mathrm{~mm}$ lang.

5 бో, 25 q aus Peru, Tarma 20. I. 190t, 3000-4000 m hoch. - Pern-Pnno am Titicaca-See 19. X1. 1902. - Bolivia, Sorata $2300 \mathrm{~m}$ hoch. 29. XIl. 1902. - Peru, Urubamba $3000 \mathrm{~m}$ hoch. 16. II. 1906 [Schuse] Dresdner zoologisches Museum. 
Anmerknng. Dieser Art steht excisus Aldrich von st. Vineent jedenfalls sehr nahe; abweichend ist die Färlong des riesichtes und der Stirn surrie die deutliche Bewimperung del Hinterschiene des $\sigma^{7}$, die dem excisus fehlt.

40 vividus Lw. ơ, Monogr. Dipt. N. Amer. Il 178. 6 tab. VI fig. 29 e, d, $g(1864)$. . . . . . . . . . . America sept. et centr.

41 wisconsinensis Wheel. ơ $q$, Psyche V 356 (1890) America sept.

Von den 42 bis jetzt aus Nord- und Siidamerika bekannten Chrysotus-Arten gehören 16 der nearktischen, 32 der neotropischen Region an, während 6 unter diesen in beiden Regionen rorkommen. Ich wiederhole hier nochmals, daß ich alle in Zentralamerika und in Mexico gefundenen Tiere zur neotropischen Fauna rechne.

Yon den neotropischen Arten kenne ich 15 ans eigener Anschannng und gebe iiber diese nachstehend eine besondere 'Tabelle; sie mag als Ergainzung der Loew'schen und Aldrich'schen Bestimmungstahelle dienen; letztere umfaßt 24 Arten der nord- und zentralamerikanischen Fauna; der Vollständigkeit halber füge ich letztere in Ubersetzung hinzu.

\section{Bestimmungstabelle}

uilher die mir bekannten neotropiselten Chrysotus-drten.

II ïn $\mathrm{n}$ he $\mathrm{n}$.

1 Schenkel gell

- Schenkel gelb und schwarz gezeichnet . . . . . . . . . 5

- Schenkel schwarz . . . . . . . . . . . . . 6

2 Drittes Fiiblerglied verlingert, Borste apikal. Gesicht sehr schmal, mattschwarz. Beine mit allen Hiften hellgelb. $1 \mathrm{~mm}$ lang

acuticornis n. sp.

- Drittes Flihlerglied ron gewöhnlicher Form, nicht verlängert . 3

3 Fïhler ganz schwar\%. Angen am Gesicht etwas getrennt . . 4

- Fiihler schwarz erstes Glied rotgelb. Augen am Gesicht zusammenstoßend. Gesicht unten und oben weiBlich, Schiippchen hell bewimpert. Beine nebst Vorderhiiften rotgelb. $1.6 \mathrm{~mm}$ lang . . picticormis Lw.

4 Hinterleib anf der Oberseite mit vielen schwarzen Haaren. $2.5 \mathrm{~mm}$ lang

Hinterleib mit spïrlicher Behaarung . . . . . . . . . 4a

4 a Drittes Fiihlerglied groß. Hypopygium mit kleinen schwarzen, an der Spitze gelben Anbăngen. $1.2 \mathrm{~mm}$ lang . . . parvulus Aldr.

- Drittes Fïhlerglied klein. Hypopygyinm mit kleinen ganz gelben Anhängen. $1.4 \mathrm{~mm} \operatorname{lang}$. . . . . . . . paradowes Aldr.

5 Schenkel gelb, auf der Spitzenhialfte, namentlich dentlich an den Hinterbeinen schwarz, auch die Hinterschienen auf der Spitzenhilfte 
schwarz; alle Tarsen rom Ende des ersten Gliedes an schwarz. $1-1.5 \mathrm{~mm}$ lang . . . . . . . . p pietipes n. sp.

6 Taster ungewöhnlich groß, um Kopfesläinge vortretend . . . . 7

- Taster nur von gewöhnlicher unbedeutender Größe . . . . . 8

7 Taster weilgelb, perhnutterfarbig, blattförmig, doppelt so lang wie breit. Fiihler rotgelb. Thoraxrieken gruingold, dieht matt bramn bestäubt. Schcnkel glänzend grüingold; Schenkelglieder, Spitze der Schenkel, Schienen und alle Jetatarsen gelb. Hinterschienen stark beborstet. $2.5 \mathrm{~mm}$ laug. . . . . . . . . . imitator n. sp.

- Taster gelb mit silberweißer Spitze, dreimal so lang wie breit. Fiulıler sehwarzbraun, erstes Glied gelb. Tboraxriicken glänzend griinblau, unbestäubt. Schenkel gliinzend schwarz; rordere Sehenkelglieder, Spitze der Schenkel, Schienen und Metatarsen der vorderen Beine gelb. Hintersehienen schwach beborstet. $2 \mathrm{~mm} \operatorname{lang}$ palparis n. sp.

8 Fiihler ganz sehwarz . . . . . . . . . . . . . 9

- Fiihler gelb, das zweite und dritte Glied obenauf schwarz, Fiihlerborste an der Spitze in eine schwarze kleine Palette endigend. Schwinger und Taster gelb, Schippchen weilo, weiß bewimpert. Angen am weißlichen Gesicht nicht ganz sich beriihrend. Hiiften uud Schenkel schwarz; Schenkelglieder, Spitze der Schenkel und die vorderen Schienen rostgelb. $2 \mathrm{~mm}$ lang . . . . . . laminatus n. sp.

9 Beine ganz schwarz, Wimpern del Schiippehen schwarz . . . 10

— Beine nieht ganz sehwarz . . . . . . . . . . . 12

10 Schwinger, Schijppehen und resicht schwarz, Fligel sebwarzbraun, namentlich am Vorderrande. $3.5 \mathrm{~mm}$ lang . . .exceptus n. sp.

- Schwinger, Gesicht und Schïppehen nicht schwarz, Fliigel nur scbwach braungrau getribbt. . . . . . . . . . . . . . . . 11

11 Hinterschenkel und Sehienen verdickt und mit dem Metatarsus ziemlich lang schwarz behaart. Taster oherseits weif, Gesicht weiß. Fligel br:iunlich; dritte und rierte Läingsadern etwas geschwungen nnd kouvergierend. $2-25 \mathrm{~mm}$ lang . . . . . tumidipes n. sp.

- Hinterschenkel und Sehiene nicht verdickt und nicht so behant. Taster' schwarz . . . . . . . . . . . . . . . . . 11 a

11 a Stime braun, matt; Gesieht bellgran. Drittes Fthlerglied ziemlich groß. Hintersehienen all den Außenseiten der ganzen Länge nach deutlich bervimpert. $1.6 \mathrm{~mm}$ lang . . . . . . . viridis n. sp. ot

- Stirne metallischschwar\%, Gesicht mattschwarz. Drittes Fiihlerglied ziemlich klein. Hinterschienen nicht so bewimpert. $1.8 \mathrm{~mm}$ lang

$$
\text { unicolor n. sp. ठ }
$$

12 Wimpern der Schnipplenen schwarz; Gesicht braungran. Augen auf dem Gesicht sich beriihrend. Hiiften und Schenkel schwarz; Spitze der Schenkel, die Schienen und der größte Teil der Metatarsen gelb. $25-3 \mathrm{~mm}$ lang. . . . . . . . . . . . oblique $\mathrm{Lw}$.

- Wimpern der Sehiippehen schwarz; Gesicht sehwarzgran. Angen fast 
anf der ganzen Länge des Gesichtes zusammenstoßend. Hiiften und Sehenkel metalliseh sehwarz; Sehenkelglieder, Sehienen und die ersten Glieder der vorderen Beinpare gelb. Hinterschienen mit einer längeren spitzen lappenförmigen Endigung. $2 \mathrm{~mm}$ lang

laciniatus n. sp. ठ

- Wimpern del Sehiippehen weiß

13 Angen auf dem weißen Gesicht sich bertilurend. Hiiften und Selıenkel sehwarz; Kniee, Sehienen und Tarsen zum größten Teil gelb, Hinterschienen an der Wurzel bram, an der Spitze in einem gelben Lappen endigend. Metatarns gelb, unterseits mit einer liingeren zarten Borste. $1.8 \mathrm{~mm}$ lang. . . . . . . . subapicalis n. sp. Augen anf dem granen Gesieht getrennt. Beine schwarz; Schenkelglieder, Kniee und alle Sehienen gelb. Hintermetatarsus unterseits mit zwei Borsten. $2.5 \mathrm{~mm}$ lang. . . . metatarsatus n. sp. Augen auf dem gramen Gesieht getrenut. Beine sehwarz; Sehenkelglieder der Vorderbeine, Kniee, Schienen und Metatarsen gelb. Hintersehiene am Ende mit beborstetem Anhang, der Metatarsus an der Wurzel verdinnt und beborstet. $1.8 \mathrm{~mm}$ lang soleatus $\mathrm{n}$. $\mathrm{sp}$.

Bestimmungstabelle von Aldrich iiber Chrysotus-Arten ans Nordamerika, Mexiko unl Westindien.

1 Sehenkel überwiegend schwarz orler brann . . . . . . . . 2

- Schenkel gelb, Spitzen der IIinterschenkel mitunter braun . . 16

- Hintersehenkel schwarz, Mittelschenkel gelb, Vordersehenkel gewöhnlielı oberseits mit einem dunklen Streifen . . . . . barbatus Lw.

2 Wimperu der Sehiippehen sehwarz oder braun . . . . . . 3

- Wimpern der Sehiippehen hell . . . . . . . . . . . . 10

3 Drittes Fiiblerglied beim $\delta^{7}$ groß, in eine schlanke Spitze ausgezogen acutus Aldr.

- Drittes Finhlerglied beim o groß, mit einer stumpfen Spitze; die obere Kante des dritten Gliedes springt erheblich iber das zweite Glied hinaus, die untere Kante ist gerade. Augen des $\sigma^{7}$ znsammenstoßend . . . . . . . . . . . . . obliquus Lw.

- Drittes Fiiblerglied beim $\sigma^{\pi}$ verlängert, abgestumpft, symmetriseh

cormutus Lw.

- Drittes Fỉhlerglied nicht besonders verlängert

4 Augen des o anf dem Gesicht nicht genihert vivilus Lw.

- Augen des $\sigma^{7}$ genähert oder zusammenstoßend

5 'Taster des $\sigma^{7}$ groß, vorgestreekt, selmeeweiß . . albipalmus Aldr.

— Taster des ơ ron gewöhnlicher Bildung. . . . . . . . . 6

6 Sehenkel metallisch sehwarzgriin . . . . . . . . . . 7

- Sehenkel schwarzbraun . . . . . . . . . . . . . . . 8 
7 Mittclschienen ganz gelb . . . . . . . . . obliquus Lw.

- Mittelschienen erheblich gebrïunt . . . . . . affinis Lw.

8 Drittes Fiuhlerglicd beim $\sigma^{7}$ klein, nackt. . . . . . niger Aldr.

- Drittes Fühlerglied beim ơ mondförmig, die Fuillerborste steht in der Spitze in einer Kerbe . . . . . . . . . . . . . 9

9 Schienen schwarz oder brann . . . . . . . . . cxcisus Aldr.

- Sehienen ganz gelb . . . . . . . . . . . proximus Aldr.

10 Angen des o genähert. . . . . . . . . . . choricus Wheel.

- Angen des o nicht genähert. . . . . . . . . . . . . 11

11 Taster weiß . . . . . . . . . . longimanus Lw.

- Taster sehwarz . . . . . . . . . . . . . . . . . 12

12 Fliigel beim on mit verdickter Randader . . . . . . . . 13

- Fliigel beim o ohne verdickte Randader . . . . . . . . 15

13 Randader mit einer starken Verdickung . . . . . costalis Lw.

- Randader nur mit schwacher Verdickung . . . . . . . . 14

14 Hinterleib mit hellen Hataren. . . . . . . . pratincola Wheel.

- Hinterleib mit schwarzen Haaren . . . . . . subcostatus Lw.

15 Schenkel dunkelgriin, glïnzend . . . . . . discolor Lw.

- Schenkel schwarz. . . . . . . . . . . . . auratus Lw.

16 Wimpern der Schiippehen bell . . . . . . . . . . . 17

- Wimpern der Schiippehen schwarz . . . . . . . . . . . 21

17 Fiihler schwarz, erstes Glied gelb . . . . . pictiromis Lw.

— Fiihler schwarz . . . . . . . . . . . . . . . . . 18

18 Angen des o genäliert, nicht zusammenstoßend . . . . . . 19

- Angen des or sich berlihhend . . . . . . . . . . 20

19 Hinterleib anf der Oberseite mit vielen schwarzen Haren pallipes Lw.

- Hinterleib mit sehr wenigen Haaren . . . . . paradoxus Aldr.

20 Ninnchen anf der Außenseite der Hintersehienen und ihrer Tarsen dicht braun behaart . . . . . . . . . . .hirsutus Aldr.

- Nïnnchen olme solche Hare . . . . . wisconsinensis Wheel.

21 Fiihler gelb, Taster anßerordentlich groß, gelb . . . . . . 22

- Fiibler schwarz . . . . . . . . . . . . . . . . . 23

22 Die drei letzten Glieder der Mitteltarsen beim of verbreitert und schwarz. $1.75 \mathrm{~mm}$ lang . . . . . . philtrum Meland. $\sigma^{7}$

- Das \%weite, dritte und vierte Glied der Vordertarsen etwas verbreitert und braun. $1 \mathrm{~mm}$ lang. . . . . . . . longipalpus Aldr. $\sigma^{7}$

23 Angen des of nicht gentihert . . . . . . . . . inermis Aldr.

- Augen des $\delta$ sich beriibrend . . . . . . . . . . . . 24

24 Drittes Finhlerglied des $\sigma$ in eine seharfe Spitze auslaufend acutus Aldr.

- Drittes Fïhlergłied nicht so ausgezogen. . . . .hirsutus Aldr.

As!maletus Lw. (1869).

Die bislang bekannten fünf amcrikanischen Arten stammen aus Nordamerika und rou den Antillen; aus Sidamerika selbst war noch keine Art 
zu nus gelangt, ich kann jedoch eine neue Art aus Paraguay hinzufiigen, ferner fand ich in der Schnuse'schen Sammlnng anch eine der bekannten Arten aus Chile ror. Der Charakter der Gattung ist genan derselbe wie bei unserer paläarktischen Fanna.

Von Bestimmungstabellen der amerikaniselien Dipterologen besitzen wir zwei :

Wheeler, Proceed. Californ. Acad. Se. ser, 3. Zool. I1 32. (1S99).

Aldrich, Kansas Univ. Sc. Bnll. I Nr. 3. 87 (1902).

\section{Bestimmungstabelle}

\section{der nearktischen und neotropischen drten.}

1 Der letzte Abselınitt der vierten Lïngsader ist an der Flifgelbeule nnterbrochen mnd der letzte Teil der Ader endet selbstiindig in paralleler Richtung am Fliigelrande nahe der Spitze. Hiiften und Schenkel schwarz . . . . . . . . . . . . . . . . 2

Der letzte Abschnitt der vierten Längsader ist an der Fliggelbenle zwar etwas sehwächer, aber nicht nnterbrochen nnd miindet, sich nach unten abbiegend, unterhalb der Fligelspitze. Fihler schwarz; das zweite Glied mit etwas iiberläingendem Lappen auf der inneren Seite, das dritte Glied $2 \frac{1}{2}$ mal so lang wie breit. $2.8-3 \mathrm{~mm}$ lang. syntomoides Wheel. ơ

2 Vordertarsen normal, obne Verzierungen . . . . . . . . . 3

- Vordertarsen verziert. Sehienen braun bis schwarzhraun . . . 5

3 Thoraxricken mit breitem braunen Mittelstreifen, der von zwei blanen Linien eingefaßt wird. $25 \mathrm{~mm}$ lang. . . . . fratellus Aldr. $\sigma^{7}$ f Thoraxricken ohne brannen Mittelstreifen . . . . . . . 4

4 Schienen schwarzbran; hintere Querader vorhanden. 4.5-5 num lang intermptus Lw. ơ

- Beine sehwarzbraun, beide vordere Sehienenpaare rostgelb; hintere Querader fehlend. $1.5 \mathrm{~mm}$ lang. . . . . . . geminus n. sp. ơ

5) Erstes und zweites Glied der Vordertarsen gelb; erstes Glied verdickt, das zweite kurz mit einer starken Borste. $3 \mathrm{~mm}$ lang.

ammoplitits Lw. ठ"

- Erstes Glied del Vordertarsen gelb, zweites Glied mit zwei gelben Anhängen. $25 \mathrm{~mm}$ lang . . . . . . . appendiculatus Lw. $0^{7}$

\section{Artverzeichnis mul bescheibung.}

1 ammophiles Lw. O', Berl. Ent. Zeitsehr. XIII 34. 58 (1869) Amer. sept. 2 appendiculatus Lw. ơ, Berl. Ent. Zeitschr. XIII 36.59 (1869) Amer. sept.

3 fratellus Aldr. oto, Trans. Ent. Soe. London 332.1 tab. XII fig. 114. (1896) .

I. St. Vincent et Grenadal 
4 geminus n. sp. $\sigma^{\top} \mathrm{O}$. . . . . . . . . . America merid.

ð. - Thoraxriicken glänzend griingold, durelı weife Bereifung: ziemlich matt. Schwinger und Schiippehen weiß, letztere weil bewimpert. Stime metalliselr griin, matt. Gesicht breit, weißlich, Taster schwarz, Fiihler desgleichen, mit dentlich dorsaler Borste. Hinterleib griin bis bronzcfarbig, sehwarz behatrt. - Beine: Hiiften und Schenkel sowie dic ganzen Hinterbeine sehwarz, Vorderschienen und Mittelschienen gelb. Tarsen einfach; Vordertarsen bräunlich, Mitteltarsen schwarz. Fligel etwas grau; die vierte Laingsader ist dentlich in zwei Teile geteilt wie bei interruptus Lw., hintere Querader gänzlich fehlend. $1.5 \mathrm{~mm}$ lang.

๑. - An den Hinterschienen ist die Wurzel rostgelb, sonst dem वै gleich.

Ein Pärehen aus Paraguay, S. Bernardino [Ficbrig] Wiener Hofmus.

Anmerkung. Von intermptus getrennt durch hellere Beinfärbung und geringere Körpergröße, auch durch die lehlende Querader; von aure-cupreus Strobl auch durch die fehlende Querader.

3 intermutus Lw. o', Wien. Lnt. Monatsehr.V.37.9 [Di(uphorus](1862) Kuba 6 syntormoides Wheel. ơ $\&$, Proceed. Californ. Acad. Se. ser. 3. Zool. II 32.35

tab. II fig. 50-52 (1899) . . . . Ameriea sept., centr. et merid.

$1 ठ, 19$ aus Chile, Arica. 9. X. 02 [Sclunuse] Dresdner zoologisches Mnseum; diese Excmplare haben etwas dunklere Schienen, als Wheeler angibt: nur die Vordersclieuen sind rostgelb, die hintere schwarzbraun ohne sonstige Abweichungen.

$1 \sigma^{\top}, 2$ aus Paragruay, Asuncion 1904 [Vezenyi] Ungarisches Nationalmuseum.

1 aus Georgia [Morrison] Berliner zoologisches Museum Nr. 7963.

\section{A'g!IJa Macq. (1834).}

Nearktische Region.

Da mir in den versehiedenen Sammlnngen keine Argyra-Arten begegnet sind, so vermag ich hiezu anch keinen weiteren Beitrag zu lieferu und gebe daher nur das Verzeichnis der bis jetzt bekannten Arten.

1 albicans Lw., N. Beitr. VIII 45. 1(1861). . . . . America sept. 2 albiventris Lw., Monogr. Dipt. N.Amer. II. 128.3 (1864) . . Sitka

3 Aldrichi Jolıs., Psyche XI 18 (1904) et XHI 60 (1906) America sept.

4 calceata Liv., N. Beitr. VIJI 47.4 (186I) . . . . Ameriea sept.

5 calcitrans Lw., N. Beitr. VIII 46.3 (1861) . . . . America seppt.

6 cylindrica Lw., Monogr. Dipt. N.-Amer. II 132.7 (1864) . . . Sitkal

7 minuta Lw., N. Beitr. VIll 46. 2 (1861) . . . . . America sept.

8 nigripes Lw., Monogr. Dipt. N.-Amer. II 127.2. (1864) . . . Sitka

Eine Bestimmungstabelle iiber seine sieben Arten gab Lnew in den Monogr. Dipt. N.-Amer. 11 124 (1864). 
Lencostola Lw. (1857).

1 cingulata Lw., N. Beitr. VIII 53. 1 (1861)

Anerica sept.

2 Slossonae Johns., Psyche XIII 59 (1906)

Americal sept.

\section{Achrocloceru.}

Novum genus Diaphorinarum.

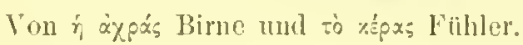

Mit Trigonoceve Beck. verwandt. Angen nuter den Fiblern genäihert, Stime breit. Gesicht nieht gleich breit, sondern naclı dem Mundrande hin verengt. Filhler: erstes Glied naekt, zweites knopfförmig (nicht daumenförmig auf das dritte iibergreifend wie bei Trigonocera); drittes an der Wurzel birnförmig verbreitert, dann scharf abfallend und in eine schlanke

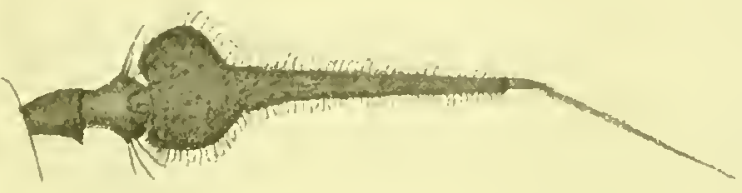

Fig. 78. Achradocera angustifucies Beck. \%'. Fiiller. 48:1.

Spitze endigend, stark pubeszent; Fiullerborste zweigliedrig, fast nackt. Thoraxrieken mit fïnf bis seehs Dorsozentralborsten, Akrostikalbörstehen deutlieh zweireihig. Hinterleib mit fïnf Ringen, ziemliels kurz und vorne von oben flachgedriekt, breit, nach hinten spitz zulaufend; Hypopyg kappenfürmg mit undeutlichen Endborsten (bei Trigonocera vier Endborsten), Beine und Fliigel ohne besondere Merkmale, dritte und vierte Längsadern parallel.

\section{Aitverzeichis.}

1 angustifacies n. sp. o, 1 Figur . . . . . . . . . . Chile

ð. - Von metalliseh griner Grundfarbe, anf dem liieken dieht braungrau bestiubt, kaum etwas glänzend: Schiippehen weißlich, sehwarz bewimpert; Sehwinger gelb. - Stirn mattbraun von der gewöhnlichen Chrysotus-Breite, die Angenränder nähern sich aber nnter den Fillern bis zum Mundrande, ohne sich zn berihren; Gesieht matt gelbgrau, Taster klein, gelbbräunlich. Fiihler schwarz von der oben angegebenen Form (s. Figu 7S). Hinterkopfzilien unten weiß. Hinterleib glänzend l)ronzefarbig, schwarz belaart. Hypopyg klein, kappenförmig, Endborsten kanm entwiekelt, olne dentlich sichtbare 
Anlüinge. Beine nebst Hiiften sehwarzgrau; Scherkel rostgelb, die vorderen oberseits mit sehwarzer sehmaler Längsstriemc; Hintersehenkel ganz schwar's; Sehienen der vorderen Beine rostgelb, Hintersehienen nebst allen Tarsen sehwarzbran; Hintermetatarsus etwas länger als das zweite Glied. Flitgel seluwach granlich mit gewöhnlieher Aderung. $2 \cdot 5 \mathrm{~mm}$ lang.

$4 \sigma^{7}$ aus Chile, Quillota 20. IX. 1902 [Schnuse] Dresdner zoologisehes Musemm.

ठ․ - Thoraxricken glinzend goldgrtin, nur vorne an Halse etwas weillich bereift mit fünf Paar Dorsozentralborsten und deutliel zweireibigen Akrostikalen, Schildehen blangrin. Brustseiten asehgran; Schwinger und Sehippehen hellgelb, Wimperu sclıwarz. - Kopf: Stirne mattbraun, Gesieht von goldgriiner Grondfarle, aber durelı bereifung fast ganz matt gelbgran, 'Taster gelb. Fiihler sehwarz, von der gleichen Konstruktion und gleichen Größenrerhältuissen wie bei der vorigen Art. Hinterkopfzilien mud der Backenbart weiß. - Hinterleib bronzegriin; Hypopyg mit kleiuen, blattförmig vortretenden dunklen Auhängen und olune Endborsten. - Beiue: Huiften selıwarzgrau, Sehenkelglieder gelb; Selienkel der vorderen Beine fast zur Hiilfte, Hinterschenkel ganz schwarz; Sehienen und Tarsen mit Ausnahme deren letzter Glieder rostgelb. Fliigel fast wasserklar. 2-3 mm lang.

$3 \delta^{x}$ alus Paraguay, S. Bermardino. II-III 1906 [Babarczy] -Trinidad, Port of Spain [Ujhelyi] - Columbia, Baranquilla III 1912 [Ujhelyi] Ungarisehes Nationalmuseum.

Anmerkung. Beide Arten sind nahe verwandt; die Unterschiede liegen in den Bestäubungsverhiltnissen des Thoraxuïckens und der verschiedenen Beinfärbung.

Man könnte vielleicht die lirage aufwerlen, weshalb man diese Gattung nebst Trigonoceru niclit bei den Rhaphiinen untergebracht hat, da doel die lang dreieckige Foru des dritten Fülularglieiles nelsst der apikalen borste auf diese Gruple hinweist. Man wird aul diese lrage antworten müssen: Beide Gattungsvertreter sind im llabitus durchaus Diaplorinen; sie haben den kurzen Leib eines Chrysotus, desgleichen die charakteristiselse kappenförunige Endigung des 11ypo. pygs mit mehr oder weniger dentlichen Borsten; ebenso sind die Fligel in ihrer Form und Adermng dnrehitus Chrysotus-Flïgel. Trïgt man diesen Verhilitnissen Rechnung, so kann die Fiihlerendigung allein trotz ihrer Besonderheit nicht ausschlaggebend sein.

3 merillionalis n. sp. $\sigma^{\star}, 1$ Figur . . . . . . . . Ameriea merid.

万’. - Thoraxrỉcken glänzend erzgriin. Schwinger und Schiippelien gelb, letztere schwarz bewimpert. — Stirne und Gesieht mattbramn, letzteres sehr schmal. Fillıler schwarz, von der gleichen Gestalt wie bei angustifacies und femoralis, nur das dritte Glied ist im Endteil etwas länger und die Endborste etwas kiirzer. - Hinterleib metalliseh grin; Hypopyg klein, kappenfürmig mit zwei kleinen sehwarzen 
Lamellen; Borsten sind an Hypopyg nieht sichtbar. - Beine: Hïften schwarz; Vorder- und Mittelsehenkel an der Wurzel etwas rerdickt und bis $\% 1 / 3$ oder $1 / 2$ der Läinge sehwarz, Hintersehenkel anf der Wurzelhälfte stark verdiekt und ganz schwarz. Spitze der Schenkel, Schienen und Tarsen gelb. Nittelbeine etwas verziert: Nittelsehienen auf der Nitte der Unterseite etwas geschwollen und hier kurz beborstet, Metatarsus an der Basis und am Ende etwas verdiekt und dadureh anf der Unterseite konkav ersebeineud. Flig'el zart gelbbriuunlich, dritte und vierte Lïngsadern gerade nud parallel. $2 \cdot 2 \mathrm{~mm}$ lang".

Eiu Exemplar aus Costa Rica [Belize] VII. Sammlnng des Ungarisehen Nationalmusenms.

\section{Irenthince.}

Ahr., Kansas Lniv. sice Bull. 192 (1902).

Aldrich hat in seinem Katalog 1905, 294 vier Gattungen mit gelber Kôperfarbe und zum Teil gelben Körperborsten zu einer Gruppe, den "Xamthorhlorinae" vereinigt. Ich vermag seiner Ansieht mich nicht anzuschließen, daß die gelbe Körperfarbe allein ausreicht, um eine Gattung, gesehweige denn eine besondere Gruppe zu bilden. In dieser Gruppe stehen Achalcus Lw., Chrysotimus, Xanthochlorus Lw. und Trunthina Alch. Die erste Gattung habe ieh ihres verlängerten dritten Fïhlergliedes wegen mit der fast apikalen Borste, die an Systenus Lw. erinnert, zu den Rhaphiinen gestellt. Die beiden folgen. den Gattungen mit ihren kurzen dritten Fiilılergliede, der dorsalen Fiblerborste, dem schmalen Gesichte und dem wenig entwiekelten Hypopyg stehen gut bei den Cumpicueminue. Die Gattung Xas. thina selbst erinnert in inem ganzen

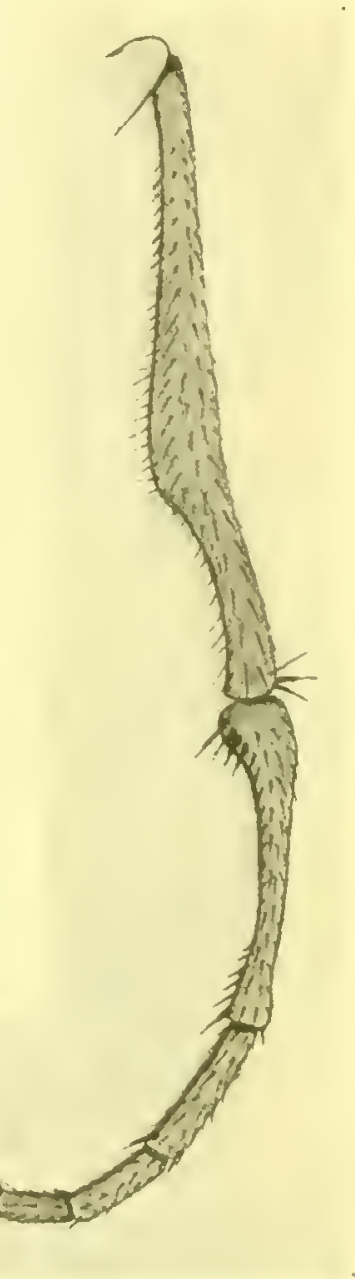

Fin. 79. Achradocera merilionalis Buck. d. Mittelbein. $48: 1$. Habitus an einer (Mrysotus oder Diaphorus; der kurze Hinterleib, das kapplenfünnige Hypopyg nud Fligeladeruug passen durebaus zu diesem Charakter; das Gesicbt, wie es anch besonders ausgesprochen wird, uur schmal; das dritte Fiihlerglied ist kurz, abgerundet mit einer zentralen Fiblerburste, wie dies bei den amerikanisehen Jiaphorms-Arten meistens der Fall ist; die großen vorspringenden Taster kommen ebenfalls bei chrysotus nud Dirmhorus 
vor; es stimnt dies alles mit den Diaphorinen iberein. leh komme daher zu der Ansieht, daß Tanthina Aldr. in dieser Gruppe gut untergebracht ist. Über Beborstung des Thoraxribekens und des Schildehens macht Aldrich keine weiteren Angaben.

leh gebe nachstehend Aldrich's Beschreibnng der Gattung und der Art:

Similar to Tanthochlorus, in the deseribed speeies without metallic colour; bristles of legs brown, of body dark brown, almost black; face very uarrow in both sexes, eyes almost contignous in the male; preseutellar depression very distinct. Antennae short, first joint minute, third rounded, hairy; arista with moderate pubescence, almost or completely apical; acrostichal bristles in two rows. Hypopygium eoncealed, with two hairy filaments nearly as long as the abdomen. Palpi and legs hairy, hind tibiae especially so. Venation as in Chrysotus.

1 Santhina plumicauda n. sp. (Plate IV fig. 1).

Male: Front and very narrow face, dorsum of abdomen except the base and a spot below the tegula black, elsewhere yellow; palpi decidedly large and haily; hind tibiae with two rows of pale bristles on opposite sides toward the tip; wings hyaline.

Female: Abdomen dark brown on the middle of the dorsum; hind tibiae with ordinary but coarse hairs.

Length: $1.4-2.6 \mathrm{~mm}$; wing about the same. 1 万ै, $3 \%$ from Grenada (West Indies).

Anmerkung. Allrich vergleicht seine Art der gelben liörperlarbe weyen mit Xanthochlorus, aber die skizze, die er l. c. Pl. IV f. I. negeben, dentet aul rine der Chrysotus nathestehende Gattung; Flïgel. Iypopyg und der ganz" Labitns

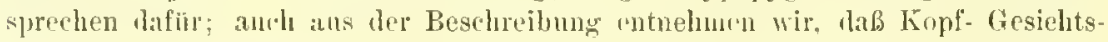
und Fühlerform durehaus dem trmplencharakter der Diaphlorinen entsprechen.

\section{Symbolia.}

Novun genus Diaphorinarum.

\section{fiattumgshegrifi.}

Schlanke gelbe Art mit kurzem Thorax und langem Hinterleib; fiint Paar Dorsozentralborsten und dentlich zweireilige Akrostikale; zwei Sebildborsten. Der Kopf besteht fast nur ans zwei Angen, die sieh von oben bis unten annäheml berihluen. Der Kopf hat von vorne gesehen Kreisform; die Fiihler stelıen höher am Kopf als bei irgendeiner anderen Gattung, dicht unter dem Pnnktangenhöeker, so daß Stirn wie Untergesieht fast ganz fehlen; das erste Fihlerglied ist lang und oberseits kurz bebart, das zweite becherförmig, das dritte kurz dreieckig mit dorsaler naektel Borste. Hinterleib mit sechs Ringen; das Hypopyg ist klein wie hei lraphorns, anch in gleicher Weise kappenformig gebildet mol mit sehwachen Endborsten, es zeigt kleine sebanfelformige behatate aubere und gabel- 
förmige innere Organe. - Beine sehr lang und schlink, an den Vorderbeinen sind die Pulvillen verlingert. Die Flïgel sind groß, Fliigelform und Aderung wie bei Diaphorus; die dritte und vierte Laingsader sind ohne bemerkenswerte Biegung, konvergieren aber der Spitze zn ein
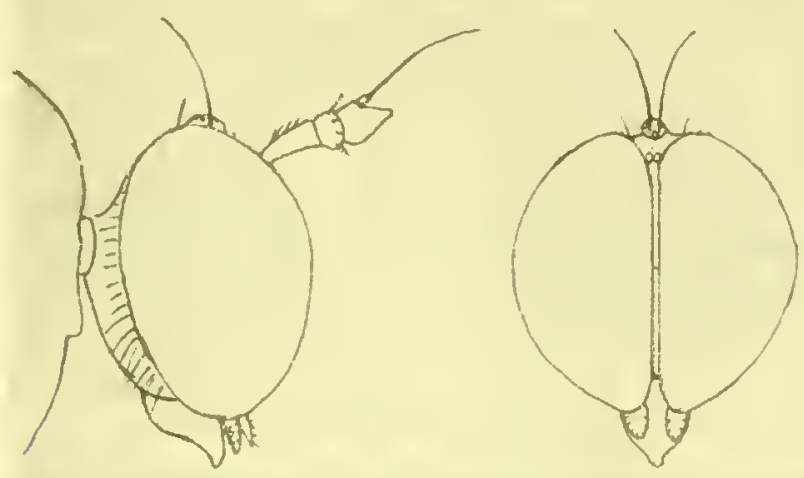

Fig. 80 แ. 81. Symbolia ochracea ơ. Kopll ron der seite und von vorne. $24: 1$.

wenig; die erste Laingsaler leicht fast bis zul Fliigelmitte, wie dies bei unseren paliarktischen Jiaphorus-Arten anch der Fall ist, wailurend bei den amerikanisehen die erste Laingsaler meist sehr kur ansfältt; die sechste Längsader geht dentlieh bis znm Fliigelrande.

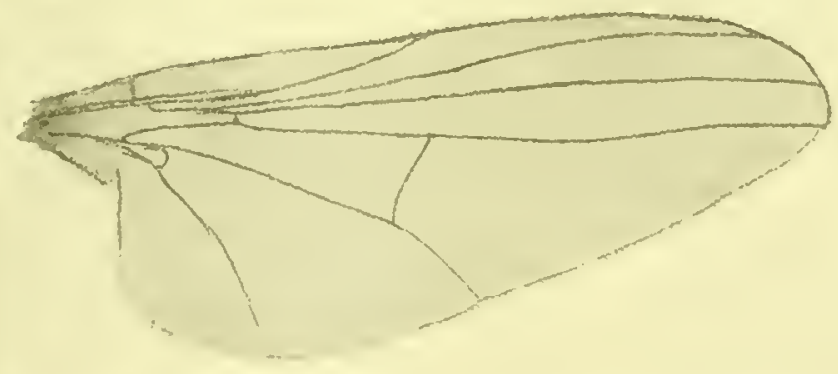

Fiu. 82. Symbolia ochrucen Beck. 万. Fliigel. 12:1.

1 ochracea n. sp. ơ. 3 Figuren

Boliviat

Ђ. 'Thorax oekergelb, glinzend, anf' dem Riieken briiunlieh, fast metalliseh verdunkelt. Brustseiten matt weiligelblieh. Sehwinger gelb, an der Spitze des Knopfes braun, Seliippehen blaligelb, letztere an der Spitze sehwarz mit dentlich schwarten Wimpern. Kopf wie oben angegeben; die schmale Gesichtslinie weil, Taster und liiissel rost- 
brann. Stirn rostgelb, Hinterkopf sehwirzlich mit spärlichen weißen Haaren. Fiihler rotgelb, drittes Glied braun, dorsale Borste nackt. Hinterleib rostgelb, in den Einschnitten brannschwarz gesäinnt; diese Säume werden an den letzten Ringen so breit, daß die gelbe Farbe fast verschwindet. Hypopyg rostbraun; Behaarung sehwarz, am Banche ling, aber spärlich. - Beine gelb; Hiiften sehr lang, vordere Schenkel und Schienen selur dinn. Hinterschenkel anf der Mitte und Hinterschienen nach der Spitze zn $\mathrm{um}$ ein geringes verbreitert. Hintermetatarsus sehr kurz. Behaarung sehwarz, an den vorderen Beinpaaren sebr zart und kurz, an den Hinterbeinen etwas liinger. Fliigel blaß gelbbräunlieh gefïbt; hintere Querader fast rechtwinklig zur vierten und nm das $1 \frac{1}{2}$ fache ihrer eigenen Länge vom Hinterrande entfernt.

$1 \sigma^{\text {t }}$ aus Bolivia-Mapiri, Sarampioni 11. II. 03. $700 \mathrm{~m}$ hoch [Schnuse] Dresdner zoologisches Museum.

\section{Coeloglutus.}

Alitr., Trans. Entom. sioc. London 338 (1896).

Aldrich hat hicr auf ein einzelnes Weibchen die neuc Gattung anfgestellt. Nach der Beschreihung nnd der zh der nenen Art concavus gegebenen Fliigelzeichnung ist der Fligel an Ende nicht abgerundet, sondern zugespitzt etwa so, wie wir dies an unserer paläarktischen Drosophilinen Gattung Camilla Halid. sehen; andere von Diaphorus Meig. abweichende Eigenschaften habe ich nicht auffinden können. Es ist möglich und wahrseheinlieh, dilß das noch unbekannte llännehen noch andere besondere Merkmale anfzeigen wird.

1 concavus Aldr. Trans. Entom. Soc. Loudon 338. Pl. XI fig. 105 (1896)

I. St. Vincent 


\title{
Gruppe IX.
}

\section{Stolidosominae.}

\author{
Nova Dolichopodidarum tribus.
}

Ich fithle mich veranlaßt, auf eine neue Gattung mit einigen Arten der neotropischen Region eine neue Gruppe einzufïhren, da es unmöglich ist, diese Gattung irgendeiner der bisher aufgestellten Gruppen einzuverleiben, ohne scharfen Widersprnch hervorzurufen. Man findet hier eine Mischung von Eigenschaften, welehe unsere Diaphorinen und Neurogoninen auszeichnen. Der allgemeine Habitus spricht ftir die letzteren; der lange Hinterleib, der anfgestiilpte faltige Hinterrandsaum des ersten Ringes, der bei der Gattung Nenrogona besonders ansgebildet ist, die Kopfform, die langen Beine machen auf den ersten Blick den Eindruck, als wiire hier eine besondere Gattung der Neurogoninae vorbanden. Diesen Ähnlichkeiten gegenüber ist aber festzustellen, daß der flache Eindruck auf dem Thorax. rícken vor dem Schildchen, ein Charakteristikum für die Neurogoninue, hier ganz fehlt und daß ferner das frei entwickelte Hypopyginn hier ebenfalls nicht vorhanden ist; es liegt im Gegenteil versteckt und erinnert durchaus an das der Diaphorinen-Gruppe. Es erscheint daher ratsam, fiir diese Arten und Gattung eine neue Gruppe aufzustellen; vorlänfig häitten wir es allerdings nur mit einer Gattung Stolidosoma zu tun.

Eine zweite Gattung, die der letzteren nahe steht, aber doch eine Reihe von Eigenschaften mit Diaphorus Meig. teilt, wie die besondere Fliigelform und die Entwicklnng der Pulvillen an den Vorderbeinen, die Gattung Symbolia habe ich dieserhalb bei den Diaphorinen belassen, obgleich sie mit ihrem stark verkiirzten Hintermetatarsus und ihrer Kopfform an Stolidosoma erinnert; sie ist als letztes Glied in der Gruppe der Diaphorinae und als Verbindungsglied zwischem diesen und unserer newen Gruppe gut untergebracht, als deren hauptsiichlichste Eigenschaften ich diejenigen bezeichnen möchte, die ich bei der bis jetzt einzigen Gattung. Stolidosoma als Gattungseharakter aufgeftilirt habe.

\section{Stoliclosoma.}

Novnm genus stolidosominarum.

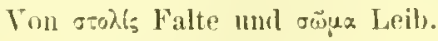

\section{Gattungscharakter.}

Größere metallisch gefiirbte Arten. Thorax mit fiinf Paar Dorsozentralborsten, ohne flachen Eindruck vor dem Schildchen; Akrostikale vorbanden, 
aber selı klein, bei einer Irt fehlen sie; zwei starke seitliche Schildborsten. liopf loeh gestellt, von vorne gesehen kreisrund oder loöher als breit. Augen sellr groß, schr schmal getrennt oder anf der Mitte genihert. Hinterkopf konkar, sich dem 'Thoraxriicken ansehmiegend. Fiihler sehr hoch gestellt; erstes Glied verliugert. nackt; wweites Glied becher- oder knopfförmig; drittes Glied meist limr, wenn verliingert, anf der Oberseite ausgeschnitten mit zarter naekter oder nur mikroskopiseh beharter dorsaler. der Basis sehr genailierter Borste. Stirn etwas ausgehöhlt mit stark vortretendem Punktangenhöcker; zwei Scheitel- und zwei starke Ozellenborsten. Rlissel unbedeutend, Taster klein, flach vorgestreckt, dem Riissel aufliegend. Das Gesieht reieht bis zum Unterrand der Augen, bei einer Art ist es dariber linans verlängert. Hinterleib lang nit seels vollstaindigen Ringen; das Hypopyginm nicht vortretend, vielmelır kappenförmig nach oben schlagend und die kleinen äußeren und inneren Organe verdeckend. Beine sehr lang, namentlich aueh Htiften und 'T'arsen; Sebienen mit deutlieliel Beborstung. Hinternetatarsus anffallend kurz. Pulvillen nicht entwickelt. Flizgel lang und schmal; die erste Längsader kurz; die erste Hinterrandszelle ist hinter der Querader etwas bauchig erweitert; die dritte und vierte Lïngsader konvergieren etwas nach der Spitze hin.

\section{Artrerzeichnis und Beschreibung.}

1 lucidum n. sp. $\sigma^{\text {T’ }}$. 2 Figuren .

Peru

Ђ. - 'Thoraxrlieken stahl- his veilehenblau, stark glinzend, olme Bestiubung mit fünf Dorsozentralborsten. Akrostikale fehlen. Brustseiten mattgelb, welehe Farbe aneh die Schulterbenle und die Notoplenraldepression erfaßi hat. Schildehen mit zwei starken seitlichen Randborsten. Schwinger gelb mit etwas brïunlieh verdunkeltem Knopf. Sehiippohen weißlich mit brannem Saum und ebensolehen Wimpern; Metanotum gelb. - Kopf: Stirne stahlblau, gliinzend; der schmale Gesiehtsteil unter den Fiihlern ist mattbramn, der nntere Teil silberglïnzend und um $1 / 4$ der Kopl'höhe nach unten verlingert. Riissel und die kleinen 'Taster brann. Fiihler wie in der Gattungsdiagnose, das dritte kurze abgerundete Glied deutlielı pubeszent mit nackter dorsaler Borste. Hinterkopf sehw:lr, Hinterkojffilien unten weiß. Hinterleib: erstes Glied gelbbramn, dis zweite braun, dic ibrigen vier Ringe weißgelb bis braun, anf der Oberseite mit mattem Silhersehimmer, der bei bestimmter Belenchtung lrervortritt. Hypopyg selıwarz, klein, lalbkugelig etwas vortretend; Bcharung des Hinterleibes kurz seliwar'. - Beine nebst Hiiften gelb, nul' die letzten 'Tarsenglieder etwas braun; Hintermetatarsus sehr kur, das zweite Glied dreimal so lang wie das erste. Pulvillen sehr klein. - Flïgel an der Basis keilförmig, schwach gelbbråunlich; vierte Liingsader etwas bauchig der dritten 
genihiert, hintere Querader um das $1 \frac{1}{2}$ fache ihrer eigenen Länge vom Hinterrande entiernt. $2.2 \mathrm{~mm}$ lang.

$1 \sigma^{7}$ ans Peru-Piehis, Punto Bermudes. X1I. 1903 [Sehnuse] Dresdner zool. II seum.

Q. - Die Angen stehen etwas breiter anseinander als beim $\sigma^{n}$, das Gesicht bleibt aber immer noch schmal; es ist von liellglaner Farbe und reicht nur bis zum Angenunterrande. Hinterleib unten gelb, oberseits und namentlich an den Rüindern bram. Beine wie beim $\sigma^{\gamma}$, nur etwas kiirzer. Hintermetatarsus ebenfalls kurz, das zweite Glied $2 \frac{1}{2}$ mal so lang wie das erste. 3 mm lang.

$1 \%$ ans Peru, Callanga.Uug. Nat.-MInseum.

cyaneum n. sp. ơ 3 Figuren . Bolivia

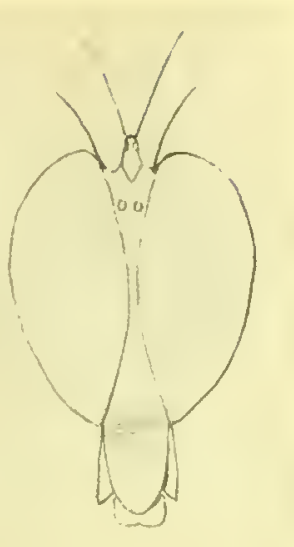

l'ig. 83. Stolidosoma lucidum б. liopf ron rorne.

0. - Thoraxriicken und Schildehen stahl- bis veilchenblau, glänzend, ohne Bereifung. Brustseiten nebst der Notopleuraldepression hell asehgrau. Sehwinger blaßgelb mit braunem Knopf, Sehiippehen hellgelb mit breitem braunen Saum und dunklen Wimpern. - Kopf: Hiuterkopf matt sehwarzbraun, konkar eingedritekt. Stirne matt dunkelbraun mit silberweißem kreisrunden Flecken zwischen Punktaugenhöcker und Fiihler; letztere sehwarz; das schmale Gesicht und die Taster silberweil schillernd, Rissel klein, brann. - Hinterleib metalliseh sehwarz, aber teilweise gelb; der erste Ring mit anfgestiilptem Hinterrand ähulich wie bei der Gattung Neurogona; die breite Bindehant zwisehen ibm und dem zweiten Ringe ganz gelb; letzterer hat gelbe Seitenflecken; die Behaarung ist schwarz. Das Hypopygium kappenfürmig. Beine mit Hîften ganz gelb und sehr lang; einzelne Glicder haben besondere Läingenverhältuisse; bei 16 facher Vergrößernug stelle ich folgende Lïingen fest:

Vordersehiene :33, Metatusus 32, die iibrigen Tarsenglieder $24 \mathrm{~mm}$

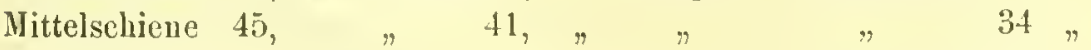
Hinterschiene 64, $\quad . \quad 7, \quad, \quad, \quad, \quad, \quad, \quad 31$ "

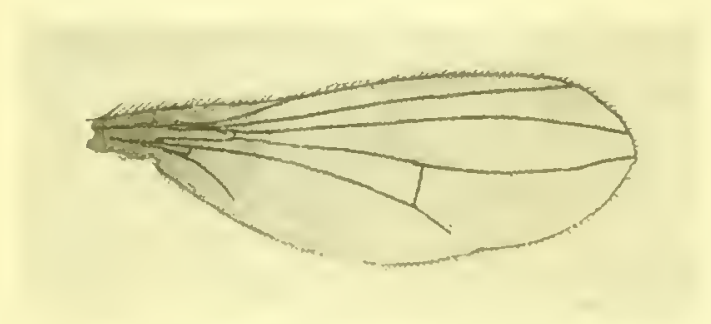

Fig. St. Stolidosoma Tucidum o'. Niigel. 12:1.

Das Lïngenverhiiltnis der Schienen zu ihren 'Tarsen ist der Reilie naeh wie $33: 56,45: 75,64: 38$.

Hieraus ergibt sich, dali die Vordertarsen $1 \frac{2}{3}$ mal lainger sind als ihre Schiene: die Mitteltarsen laben dasselbe 


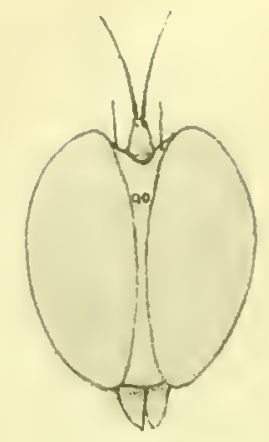

Mig. 85. Stolidosomu cyaneum 万. Kople rom vorlue. 24:1.
Verhäitnis, die Hintertarsen erreichen aber nieht viel melı als ilne halbe Liinge; ferner selıen wir, dab die Metatarsen der vorderen Beine ansnehmend langr, der Hintermetatarsus aber ansmehmend kurz ist. Die Fligel sind $3 \frac{1}{2}$ mal so lang wie ihre groißte lireite, granbriunlieh getribt, mit etwas weiß selim. mernder Spitze. 5 mu lang.

. - Bei den Weibchen kommt die gelbe Grundfarbe mehr zur Erseheinung; hier sind Prothorax nebst der Sehulterbenle gelb, anßerdem ist am Hinterleibe nieht $n m$ r der erste Ring gelb, sondern es haben der zweite, dritte und vierte Ring aluch gelbe Hinterrandsloinden. Das Gesielit ist mur wenig

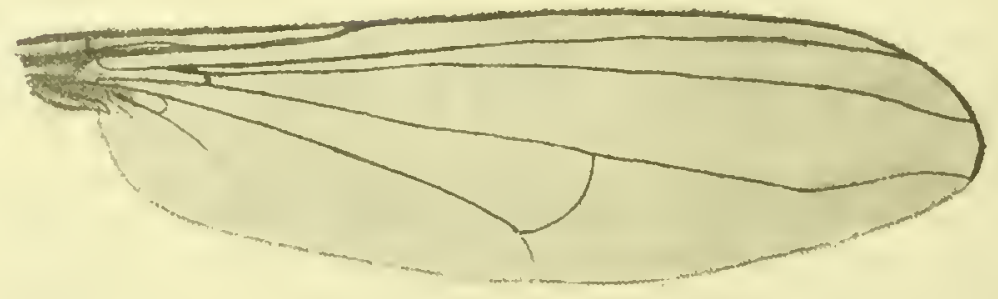

Fig. 87. Stolidosoma cyanexm ठ․ Fliigel. $16: 1$.

breiter als beim $\sigma^{\lambda}$, es ist mit Stirue und Ftihlern matt rotbraun. - Die gelben Beine sind mit Ansuahme der Vorderbeine etwas kiirzer, deren Tarsen bei gleicher Sehienenlïnge bei gleicher Vergrölerung nm 11 nm (16.1) länger sind. Der Hintermetatarsus niihert sielı sehon melı den iibliehen Größenverhảitnissen, bleibt aber immerhin dentlich ktirzer als das zweite (ilied. Die Hliigel haben die gleiche graubraune Fïbung, die Biegung der vierten Laingsader an der Spitze ist flacher md die hintere Querader bleibt gerade.

Ein Pärehen aus Bolivia-Mampiri, Sarampioni $700 \mathrm{~m}$ hoeh. 14. 111. 1!03 [Schmuse] Dresiner zool. Museum.

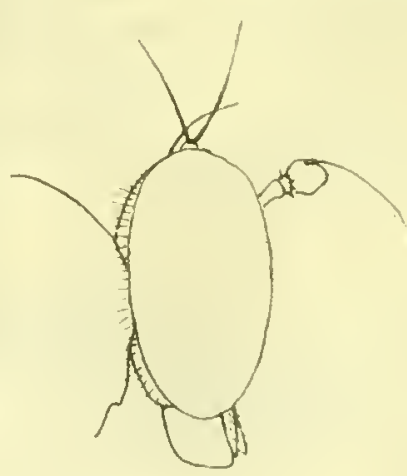

Fig. S6. Stolidosoma cyaneum. ऊ’. Kind ron der seite. $24: 1$. 
3 permutans n. sp. $\sigma^{7}$. 2 Figuren . . . . . . . . Columbia $\sigma^{3}$. - Thoraxriicken glianzend erzgriun, vorne ein wenig gran bestaiubt mit finf bis secls Paar Dorsozentralborsten und feinen, aber dentlichen zwcizeiligen Akrostikalen. Am Schildchen zwei starke Randborsten ohne Seitenhörstchen. Schwinger hellgelb; Schiippchen weißlich, am Ende selu hreit schwarz gesiumt mit zahlreichen schwarzen Wiupern. - Kopt: Augen auf der Nitte des Gesiehts stark genähert, pubeszent. Stilne glainzend stalılblan, weil gefleckt, das schmale Gesicht und die Taster obenauf silberschimmernd. Hihler seliwar, an der W' nel rotgelb. J)rittes Glied oben stark ausgeschnitten mit feinel mackter Borste dicht an der Basis. Hinterkopfzilien unten weiß. - Hinterleib gelb mit breiten dreieckigen schwarzen Vorderrandsbinden, die anf der Mitte oben fast die ganze Kingbreite einnehmen und nach beiden Seiten spitz dreieckig anslaufen. - Beine mit allen Hüften gelb, schwach beborstet, schlank; Hinterschienen bram, Hintertarsen sowie die Endtarsenglieder der rordereu Beine schwarzbrann. Vordertarsen $n \mathrm{~m} 1 \frac{3}{4}$ mal lïnger als die Sehiene; Vordermetatarsus von $3 /$. Schienenlïnge, das zweite Glied rerkiirzt, nicht länger als das letzte Tarsenglied. Nlitteltarsen $1 \frac{1}{4}$ mal liin-

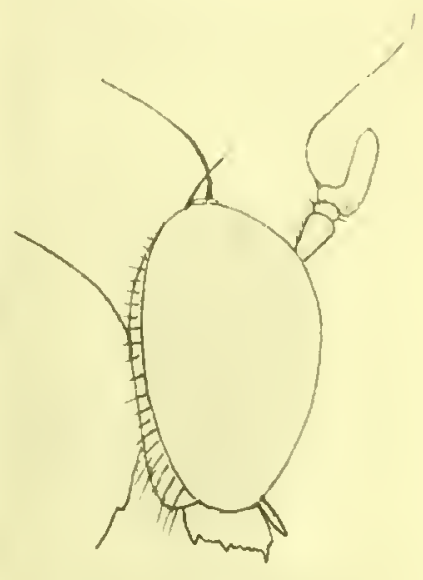

Fig. 88. Stolidosoma permutans o7. Kopt von der Seite. $24: 1$. ger als die Schiene; Hinterschienen $1 / 4$ mal lïnger als die Tarsen, der Metatarsus ein wenig verdickt und sehr kurz, kaum doppelt so lang wie dick, das zweite Glied viermal so lang. Vorlerschienen vorue auf der Mitte mit drei zarten Einzelborsten, Mittelschienen vorne oder oben mit drei bis vier solehen Borsten, Hinterschienen oben mit sechs bis sieben. Fliigel etwas bräunlich gefürbt. $6 \mathrm{~mm}$ lang.

q. Das dritte Fïhlerglied ist etwas kiirzer und weniger tief ausgeschuitten; Fiibler rotgelb, las dritte an Ker Spitzenhailfte braun. Gesicht kanm etwas breiter als beim ơ; das zweite Glied der Vordertarsen ist von gewöhnlicher Läuge, das erste Glied der Hintertarsen kaum etwas länger. $6 \mathrm{nmm}$ lang.

$3 \delta^{7}, 3$ ans Columbia, Sierra S. Lorenzo [Ujhelyi] Ungarisches Nationalnuseum.

4 eques Lw. ठ", Mon. Dipt. N. Amer. II 154. 1 [Eutarsus] (1864) Amer. merid.

07. - 'Thoraxricken stahlblau, wenig braun bereift. Angen groß, anf dem Gesicht in lingerer Linie zusammenstoßend. Stime stahlblau. 
Fiihler kurz abgerundet, schwarz, das erste Glied an der unteren Ecke gelbrot, Borste dol'sal nalle del Basis. Hinterleib bronzefarluig mit schmaler gelher Querbinde an der Basis des zweiten Ringes und mit allmälich abnehmenden gelben Seitenflecken am zweiten und den folgenden Ringen. Hypopy gim versteckt ohne sichtbare Anlüinge. Beine und Hitlen grelb, die vorderen Tarsen rom Ende des ersten Gliedes an braun. Hinterschenliel an der Spitzenhälfte und

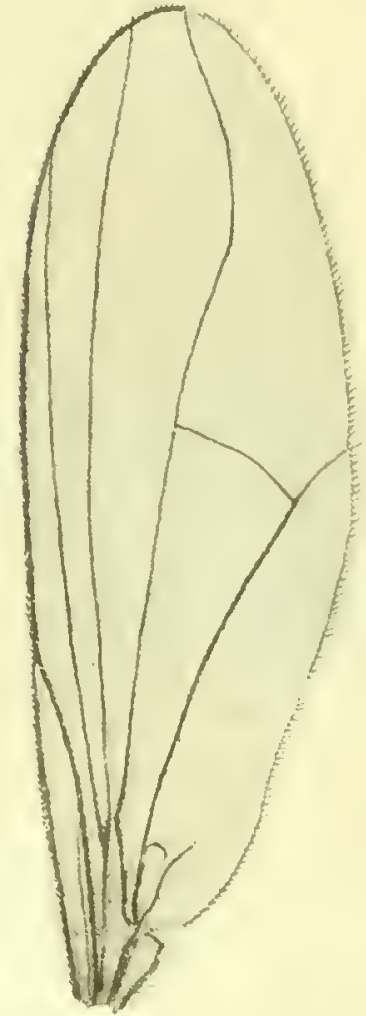

Fig. S9. Stolidosoma permutans Bick. ठð. Flïgrel. $16: 1$. oberseits seluwarzbraun. IIntersehienen und Tarsen braun und schwar\%. Metatarsus sehr kurz; zweites Glied $4^{1 / 2}$ mal, drittes Glied $2 \frac{1}{2}$ mal so lang wie dats erste Glied; das vierte so lang wie das erste, an der Spitze in einen starken Dorn anslan. fend. Flügel sehr lang und schmal, graulich glasartig. $5 \cdot 5-6 \mathrm{~mm}$ lang.

Loew beschrieb diese Art ans Venezuela.

Siehe meine Ausfiilurungen bei der Gattung Eutarsus Lw.

\section{Bestimmmostabelle}

fïir die Arten der Gattun Stolidosoma.

1 Stirne gläuzend stahlblan, mitunter weiß gefleckt . . 2

- Stirne mattbraun mit kreisrunden silberweifem Fleeken. Thoraxriteken veilchenblau olne Bereifung. Hinterleil netallisch sehwar\%; erster

Ring, ein Teil des zweiten und Seitenflecken des zweiten und dritten linges gelb. Beine und Hiften gelb, IInterschienen brïunlich, Hintertarsen selwar\%; das zweite frlied $41 / 2$ mal, das dritte $21 / 2$ mal so lang wie das erste. Fliigel blabbräunlich. 5 um lang

cyaneиm $11 . \mathrm{sp} \cdot \mathrm{o}^{-9} \mathrm{q}$

2 Gesieht silberweib, nicht unter die dugen herabgehend. . . . :

- resicht oben braun, unten silberweiß, nm 1/4 der Kopflible unten iiber den Angenrand hinabreichend. 'Thoraxriicken stahlblan, Brust- 
seiten und Schulterbenle gelb. Hinterleib gelb mit branner Zeichnung and Silbersehimmer auf der Oberseite. Beine und Hüften gelb; zweites Tarsenglied der Hinterbeine dreimal so lang wie das erste. Fliigel blaßbräunlich. $2.2 \mathrm{~mm}$ lang. . . . lucidum n. sp. ơ 3 Drittes Fiihlerglied etwas verlingert, oberseits ausgesehnitten, Borste dieht an der Basis; Fïhler sebwarz, an der Wurzel rostgelb. Augen genähert. Thoraxriieken erzgriin. Hinterleib gelb mit breiten dreieckigen schwarzen Vorderandsbinden. Hüfen und Beine gelb. Hinterschienen bram, Tarsen schwarz. Zweites Glied der Vordertarsen verkiirzt, nieht lainger als das letzte Glied. Hintermetatarsus sehr kurz; zweites Glied viermal, drittes Glied $1 \frac{1}{2}$ mal so lang wie das erste. Fliigel etwas briunlich. $6 \mathrm{~mm}$ lang . . permutans n. $\mathrm{sp} . \mathrm{O}^{\mathrm{T}}$ ? Drittes Fühlerglied nieht verliingert und nicht ausgeschnitten. Fiihler schwarz, erstes Gliel an der unteren Ecke gelbrot. Augen sich anf lïngerer Strecke beriihrend. Thoraxrỉeken stablblan, wenig braun bereift. Hinterleib bronzefarbig; zweiter Ring an der Basis gelb, quergestreift. Seiten der Ringe in abnelımender Stärke gelb gefleckt. Beine und Hiuften gelb. Hintersehenkel oben, Schienen braun, Tarsen schwarz. Zweites Hintertarsenglied $4 \frac{1}{2}$ mal, drittes $21 / 2$ mal so lang wie das erste; das vierte so lang wie das erste mit starker dornartiger Verlängerumg am Ende. 5-6 mm lang . eques Lw. O’ 


\section{Gruppe X.}

\section{Campsicneminae.}

Von den 13 Gattungen dieser Gruppe, die wir in der paliarktischeu liegion vorfïluren konnten, treffen wir in der nearktisehen und neotropisehen nur die folgenden 6 an: Campsimemus Walk., Sympycnus Lw., Chrysotimus Lw., Xanthochlorus Lw., Anepsiomyia Bezzi und Tenchophonus Lw.; drei nene Gattungen treten hinzn: Sulbympycnus Beck., IIyptiocheta Beck nnd Calyxochaetus Big. Dic herrsehende Gattung der Zahl nach ist entschieden Siympycuns.

\section{Crompsicnemus.}

Walk., Insecta Brit. Dipt. I 187. VI (1851).

Camptoscelus Halicl., The Zool. Journ. V 357 (1832). [Camptosceles] praeocc. Dej. Coleopt. [Camptoscelis] (1828).

Im Kataloge Kerteśz VI (1909) sind sieben Arten aufgefiihrt, eine von diesen ist von Walker; es ist aussichtslos, bei der bekannten fabrikmäßigen Herstellung der Walker'sehen Beschreibung, irgendein die Art charackterisierendes Merkmal ans derselben entnehmen zn können. Wir werden sie daher nicht weiter herticksiehtigen, wie Wheeler dies bereits getan hat. Letzterer hat 1899 Proeeed. Californ. Acad. Se. ser. 3 Zool. II 58 eine Bestimmungstabelle iber dic anderen sechs Arten gegeben, dic ich mangels eigener Konntnis der Arten der Vollstindigkeit halber lier nur wiederholen kann; zu den Beselıreibungen hat er erläuternde Fignrenzeichnnngen gegeben. Aus Siidimerika sind bislang Vertreter der Gattung nicht bekannt geworden.

\section{Artverzeidhnis.}

1 claudicans Lw. O" o, Monogr. Dipt. N.-Amer. II 194. 2 (1864) Amer. scpt.

2 degener Whecl. $\sigma^{7}$ o, Proceed. Callif. Aead. Sc. ser. 3 Zool. II 58. 57. tab. IV. fig. 110-112 (1899) . . . . . . . . America sept.

3 Thirtipes Lw. O’o, N. Beitr. VIII 68. 1 (1861) - . America sept.

4 Gedimus Wheel. $\%$, Proceed. Calif. Acad. Se. ser. 3 Zinol. II 60.60 tab. IV fig. $114(1899)$. . . . . . . . . . America sept.

5 Phitactetes Wheel. ${ }^{7}$, Proc. Calif. Acad. Se. ser. 3 \%ool. 59. 59 tab. IV fig. 115-117 (1899) . . . . . . . . America sept. 
sequex: Walk. ठ", List Dipt. Brit. Mus. III 666 [Dolichopus] (1849) America boreal.

6 Thersites Wheel. $\sigma^{7}$, Proceed. Calif. Acad. Sc. ser. 3 Zool. 61. 61 fab. IV fig. 118 (1899) . . . . . . . . . America sept.

\section{Bestimm!n!mstabelle.}

1 Mittelschienen mehr oder weniger verdickt . . . . . . . "2

- Mittelschienen nieht rerdickt. . . . . . . degener Wheel. ठ

2 Mittelschienen auf der Wurzelhïlfte etwas verdiekt hirtipes Lw. $\sigma^{7}$

— Mittelschienen durehweg verdickt . . . . . . . . . . . 3

3 Mittelschienen mit einem gestielten Knopf an der Spitze

Philoctetes Wheel ơ

Mittelschienen olne sulehen Knopf . . . . . . . . . . . 4

4 Mittelschienen ganz schwarz. . . . . . Oedigus Wheel. $\sigma^{7}$

- Mittelschienen zum großen T'eil gelb . . . . . . . . . 5

5 Mittelmetatarsen stark gebogen . . . . Thersitcs Wheel. $\sigma^{7}$

- Nittelmetatarsus nicht stark gebogen... . . claudicans Lw.

\section{S!/mp)!cums.}

Luew, N. lieitr. Y 42 (1857).

In allgemeinen ist der Clarakter der Gattung derselbe, wie wir iln bei unseren paläarktischen Arten kennen lernten; die Mehrzahl der amerikanischen Arten besitzt anch ein knrzes drittes Fiiblerglied in dreieckiger Form; es kommen aber anch Ansuahmen vor: so \%. B. endigrt das dritte Fiihlerglied mitmuter rundlielı ohne Spitze, in einem Falle zeigt es sich in st:urk vergrößerter und verliingerter Form, olne daß andere Untersehiede hinzutriten. Die Beine sind im allgemeinen lang, die Hinterbeine meist dentlich etwas verdickt. Was die T'arsen anlangt, so beschräkt sich deren Verzierung bei den paliarktisehen Arten fast ganz auf die Hinterheine; bei den amerikanischen Arten ber'seht eine größere Mannigfaltigkeit; die Verzicrungen greifen anch anf die Vorder- und Mittelbeine iiber; immerhin bleiben alle diese Abweichungen von der normalen Form und Borstenstellung innerbalb mnaffailliger Grenzen. -

In Aldrich's Katalog der nordamerikanischen Dipteren 1905 sind 14 Arten anfgenommen, von denen jedoeb 3 als zum Subgenus Nothosympycuus und Parasyntomon gerechnet werden, so daß noch 11 Arten iibrig bleiben. Ans der Schnuse'schen Sammlung und aus den Bestanden der Musenmssammlungen von Berlin, Wien nnd Budapest treten aber noch 22 Arten hinzu. Die Gattnng Sympyenus scheint sowohl in Nord- wie in Siidamerika gut vertreten und in kriftiger Entwicklung begrifien an sein, denn jeh konnte außer ler Untergattung Nothosymyonus Ildr. noch eine

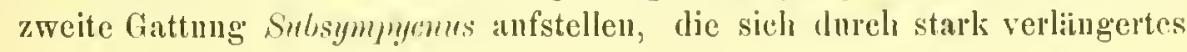


erstes nud drittes finhlerglied charackteristisch von den ibrigen abhebt. Aldrieh hat in seinen versehiedenen Mitteilungen iber diese Gattung mehrere Arten besebrieben, von denen er annimmt, daß sie vielleicht eine besondere Gattung bilden könnten; es sind dies die Arten coxalis, frater, similis und falco; alle haben am fiunften Tarsengliede $\mathrm{dcr}$ Vorderbeine lappenförmige Auswiichse oder eine Zusammenstellung von Borsten, die im Verein mit der inneren Klane der Vordertarsen ein Greif- und Haltorgan aufweisen sollen, das bei den iibrigen Arten nicht vorhanden ist. Da Aldriel leidel keine Zeiehnung dieses 'Tarsengliedes gibt, so liißt sich nach der Beschreibung allein sehwer feststellen, ob diese Eigensehaft zur Abtrenung als Gattung berechtigt oder nieht. Ich habc daber diese Arten in meiner Bestimmungstabelle beieinander gelassen, un so ilre Besonderheit anch inßerlich zum Ausdruck zu hringen, lasse sie aber vorläufig bei Sympycurs stehen.

\section{Artrerzeichnis mul lieschreibungen.}

1 aequalis $11 . \mathrm{sp}$. ठ

America merid.

Ђ. - Thoraxrieken erzgriin, dureh Bestiiulung matt graugriin. Schiipprehen und Sehwiuger hellgelb, erstere mit schwarzem Saum und Wimpern. Stirn von der Farbe des Rijekens; Gesieht und Taster weiß bestäubt. Ftibler ganz schwarz, drittes Fithlerglied kurz dreieekig. Hinterleib erzgrin olune hellgelbe Seitenfleeken. Hypopyg mit nieht siehtbaren Anhängen. Beine mit allen Hiiften gell); Tarsen rom Ende des ersten Gliedes au schwarbram, einfach, ohne besondere Formen oder Beborstung; Metatarsus der Hinterbeine nur wenig kürzer als das zweite Glicd. Die Tarsen der Vorder- und Mittelbeine sind nur wenig länger als ihre Sebienen. Fliggel schwach graubräunlich; dritte und vierte Liingsadern schwach gebogen und parallel; die bintere Queradel ist um mehr als ihre eigene doppelte Lünge rom Fligelhinterlande entferut. 2-2.5 num lang.

$3 \delta^{7}$ alls Nordargentinien, Provinz Salta, $2500 \mathrm{~m}$ boeh [I. Steinbael]. Berlinel zoologisehes Museun. aequatorialis $11 . \mathrm{s}]$. $\sigma^{7} \mathrm{f}$.

Amerieal eentr.

$\sigma^{7}$. - Thoraxrieken metallisebschwar, durch dichte Bestiubung matt; Schwinger Jran. Stirne metalliseh, matt. Gesicht und die sehwarzen 'I'aster oberseits silberweiß bestïnbt. Fiihler sehwarz, kurz dreieckig. Hinterleil von Kupferfarbe. Beine nebst Hiiften ganz sehwarz, Sehienen schwach beborstet; das dritte Glied der Hintertarsen an der Wurzel ter Unterseite mit rier Borsten mod an der Spitze mit zwei sehr kleinen Lamellen; an ien Vorderbeinen ist das dritte Glied rerkiurzt. "Fliigel etwas gelbgran in 'T'on; dritte und vierte Längsadern etwas gehogen und l'ast parallel. 2um lang: 
11 Lxemplare vou Äquator. Chillacocha 3590 m hoeh [l'. Rivet 1905] Sammlung des Pariser Entomologisehen Museums. Sielıe meine Bemerknngen bei Chrysotus unicolor.

3 angustipennis Aldr. ơ , Biolog. Centr. Amer. Dipt. 1341 tab. VI fig. 20 (1901) . . . . . . . . . . . Mexico

Eine Art mit einfachen Beinen, gelbbriiunliehen Fiblern und Hinterleib, an dem der erste Ring teilweise gelb gefürbt ist. Siehe Aldrich's Beschreibung und die liestimmungstabelle.

$t$ antennatus v. sp. $\sigma^{\top}$ o, 1 Figur . . . . . . America merid.

Eine dureh nngewöhnlich große Fiihler ausgezeiebnete Art.

ot. - Thorax.

riicken ist glänzend schwarzgriin bis bronzefarbig, fast olne Bereifung. Schiiplychen und Sehwinger blaBgell, erstere mit braunem Saum nnd schwarzen Wimpern. - Stirne metallisch griin, an rten Augenrändern denllich weil bereift, Gesicht ebenfalls weiß, Taster und Fiihler schwarz; das

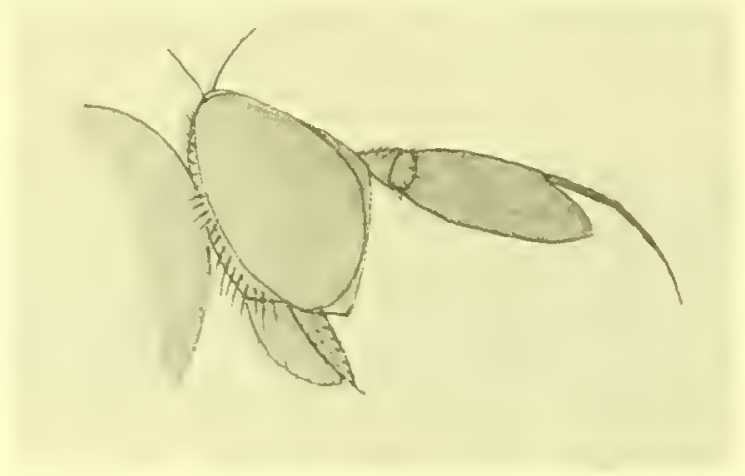

Fig. 90. Sympycuus untennatus Beek. OJ. Kopf son der Scite. $24: 1$.

erste Fuhlerglied zart beharrt, dis dritte Glied groß und breit, $2 \frac{1}{3}-3$ mal so lang wie breit; Hinterkopfzilien unten weiß. Hinterleib erzgriin, sehwarz behiart, ohne gelbe Flecken und ohne dunklere Binden. Analanhïnge rersteckt. - Beine mit Vorderhiffen gelb, letztere anf ihrer Vorderseite sehwar behart und beborstet. Hintersebenkel an der Spitze sebwarz, Hintersehienen braun, Tarsen einfach, schwarz; die vorderen Tarsen mit Ausuabme der Wurzel des Metatarsus sehwarzbraun; der Hintermetatarsus ist ungefiihr so lang wie das zweite Glied. Vorder- und Mitteltarsen ungefihh eben so lang wie ihre Sehiene. - Flügel selıwach gelbbrännlich; dritte und vierte Längsadern parallel, die vierte an der Fliggelspitze miindend; hintere Querader un die eigene dreifache Lainge vom Hinterande des Fliigels entfernt.

Q. - Gesielıt gelbgran seidensehillernd, zweimal so breit wie das dritte Fibhlerglied; dieses kaum etwas länger als breit. Stirne und Tboraxribken mehr stahlblau. Vorderhiiften elenso beborstet wie beim б. Hinterschenkel nit schwarzem Spitzenfleck; vordere Tarsen etwas heller, sonst liein Unterschiert. 3 mm lang: 
2 ơ, 1 a alls Nordargentinien, Provinz Salta, $2500 \mathrm{~m}$ hoeh [1. Steinbreh] Berliner zoologisehes Mnseum.

7. - Thoraxrïcken metallisehschwillz, matt. Schwinger gelb, Schïppchen gelb mit sehwarzen Wimpern. Stime matt erzgriin, Gesieht sehwarzgran, Taster oberseits silbersehimmernd; Fihhler sehwil', kurz dreieckig. Hinterleil, kupferfarbig. - Hiiften sehwarz, nur die Spitze der Vordertarsen gelb. Beine gelb; die Schenkel sind auf ihrer Oberseite sehwarz gestreift, Spitze der Hintersehienen nebst ihren 'Tarsen sehwarz, an den vorderen Beinen sind nu die Tarsenendglieder gesehwärzt. Die Hintertarsen ( $\left.\sigma^{7}\right)$ sind stark sehwar'z behaart; das let\%te Glied der Vordertarsen ist ein wenig verbreitert und anf seiner Unterseite mit 3-4 starken Borsten versehen. Flingel etwas grau, die vierte Längsader miindet an der Flingelspitze ans. 22.5-3 mm lang.

Q. - Die Tarsen sind einfach, die Sehenkel fast ganz gelb.

7 б’, 10 q vom Äquator, Casitagua $3560 \mathrm{~m}$ hoch. - El-Angel $3020 \mathrm{~m}$ hoch. - Mirador $3830 \mathrm{~m}$ hoeh. - Cuenea $3830 \mathrm{~m}$ hoch [G. Rivet 1903_I905] Sammlung des Pariser Entomologisehen Mnseums.

Anuerkung. leh habe diese Art den vier anderen Alurichischen Arten cocalis, frater, similis und falco zugeselt. Wa das letzte tilied der Turdertarsen

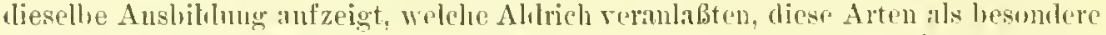

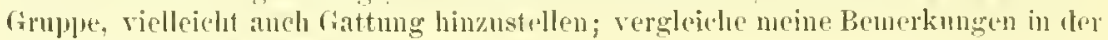
Einleitung s. Sympycnus.

6 armatus n. sp. ठ․ 2 Figuren . . . . . . America merid.

$\sigma^{7}$. - Toraxriieken glainzend sehwar'z, griingran bereift, matt mit sechs Paru' Dorsozentralborsten, einzeiligen Akrostikalen und zwei starken Sehildhorsten. Brustseiten asehgrau. Sehwinger und Sehiippehen

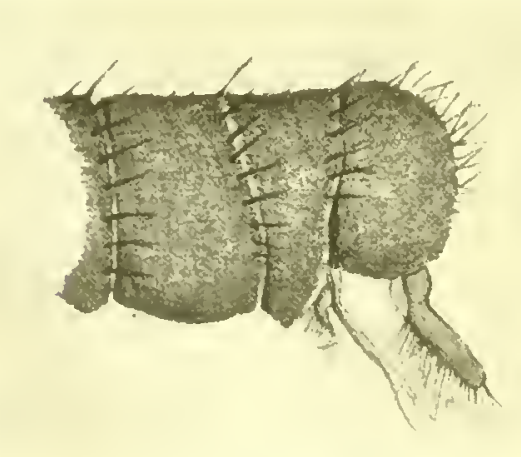

Fig. 91. Sympycuns armatus lieek. ơ'. 11 ypolyg. 24:1. hellgelb, letztere branu gesaitm mol selıwarz gewimpert. Kopf: Stime mattbraun, das sehmale Gesieht weißgelb,'Taster ebenso. Fühler sehwarz, das dritte Glied ku\% dleieckig mit last nackter Iiiickenborste. Hinterleib mit sechs deutlichen Ringen, metalliseh griin mit breiten purpurfarbigen Vorderrandsbinden rond hellgramen Seitenfleeken. Hypopyg klein und halbkugelig mit sehmalen bramnen beharten, länglieh ovalen äuBeren Anhingen und dentlieher sehlanker Penisscheide. Beine lang, mit den Vorderhniften rotgell; Hintersehenkel auf der Spitzenhälite Iraun, Hintersehienen mit Ausmahme der Wurzel sowie die Hintertarsen und die lind glieder der vorderen 'l'arsen sehwarbraun. 
Vordersebienen und Metutarsus unten fast kammartig beborstet; an ler Spitze der Torderschienen stehen dieht nebeneinander zwei längere Borsten. Hintermetatarsus mugefilur ebenso lang wie das zweite Glied. - Flügel etwas rauebgran getriibt; die vierte Lïngsader biegt in der Fliggelbenle etwas bogenförmig naeh oben und verliaft damn parallel zur dritten in die liigelspitze; hintere Querader fast um die doppelte eigene Liange rom Fligelhiuterande entfernt. $4.5 \mathrm{~mm}$ lang.

10 aus Peru, Callanga. Sammlung des Ungarischen Nationalmusenms.

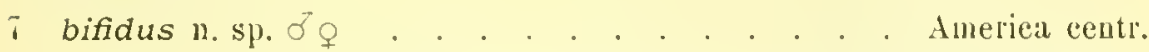

ơ. - Thoraxrieken metallischsehwarz, dureh braungraue be stiubung matt, Sehwinger Lraun, Schippchen mit sehwalzen Wimpern. Stime von del farbe des Thoraxriekens, Gesicht dunkelgran, 'T'aster' und Fiihler sehwarz, drittes Glied kurz dreieckig, jubeszent. - Hinter-

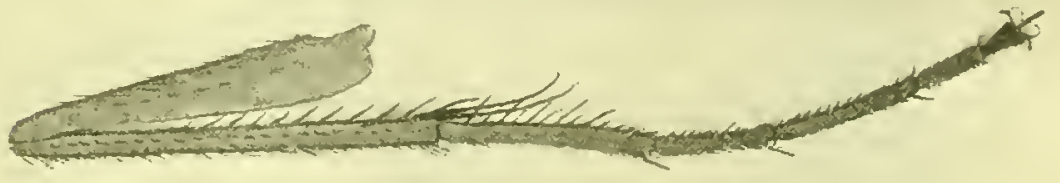

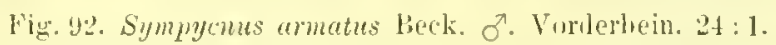

leib sebwarzblaun, zweiter, dritter und vierter Ring mit groben gelben Seitenfleeken; Hypourgium mit langen fadenförmigen gegabelten äußeren Anhängen, von denen del lingere Zweig auf der einen Seite lange gekriimmte Borsten trïgt. - Beine mit allen Hiiften gelb; die Hinterschenkel sind anf ihrer Oberseite brïunlich gefarbt, auf ihrer Unterseite stelit eine Einzelborste in der Mitte; die Mittelsehenkel tragen zwei solche Borsten und mehrere Wimpern auf der Spitzenhailfte; der Hintermetatarsus ist viel kiirzer als das zweite Glied. Die Fligel haben eine zarte gelbgrane Tribung; die dritte und vierte lüngsader konrergieren unmerklieh, die vierte endigt an der Fligelspitze. $2 \cdot \overline{5}-3 \mathrm{~mm}$ lang.

$4 \sigma^{7}, 10$ fom Äquator; Cuenea, Loja $2220 \mathrm{~m}$ hoeh. - Tinsai $3740 \mathrm{~m}$ hoch - Miradol $3830 \mathrm{~m}$ hoeh - Casitagua $3512 \mathrm{~m}$ hoch [Rivet 1903-1905] Pariser Entomologisehes Musenm.

brevitarsis n. sp. o. 1 Figu . . . . . . Anerea merid.

$\sigma^{7}$. - Thoraxiieken grangriin bereift. Schwinger und Sehippchen gelbbriunlieh, letztere weiBlich bewimpert. - Stirne mattbrianlieh, Gesicht selur sehmal, weißlieh. Fiihler an der Wurzel rot, drittes Glied braun mit fast naekter Dorsalborste, Taster brann. - Ilinterleil, Abhanal. del zool,-botan. Gies IBd xill, Heft 1 
metallisch er"zgriun; der zweite Ring und die Seiten des dritten und vierten Ringes sind gelb. Ilypopygium klein, kappenförmig, mit zwei schmalen lïnglich dreicekigen behaarten Anallamellen. - Beine nebst allen Hiften gelb, Hintertarsen sehwarzbraun; Hinterschienen nach der Spitze zu cin wenig verdickt; anch die finf kurzen, untereinander fast gleichlangen 'Tarsenglieder sind gleichfills schwach verdickt und mit den Sehienen etwas ranh behaart (sielıe Figur 93). Ilintersehenkel an der Spitze etwas dick und hier brännlich. - Fliigel leicht geJriiunt, dritte und vierte Längsadern parallel rerlaufend; hintere Quelader fast mu die doppelte eigene Liinge rom Fligelhiuterrade entfernt. $3 \mathrm{~mm}$ lang.

1 o aus Parnguay, S. Bernardius [Fiebrig 1908] Sammlung des Ungarisehen Nationalmaseums.

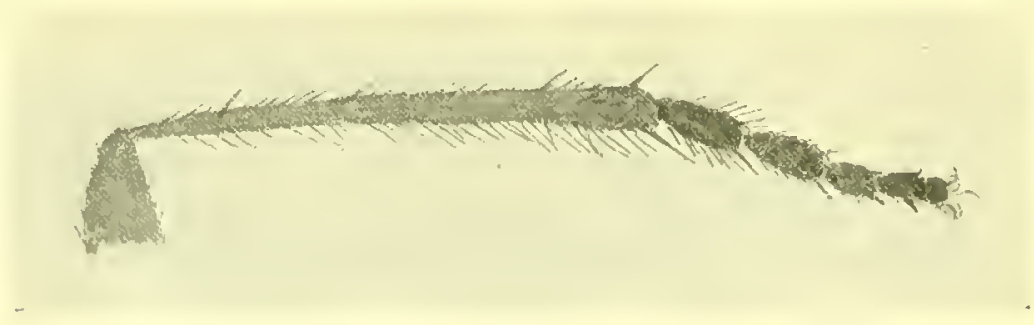

1ig. 98. Sympycnus brevitarsis lieck. o*. Hinterbein. 24:1.

ciliatus $\mathrm{n}, \mathrm{sp}) \cdot \sigma^{\mathrm{T}}$.

America merid.

o'. - Thoraxriicken ertgriin, von Bestỉubung matt grangriir. Sehwinger und Schïppelren blaligelb, letztere scheinen cine weifliche Bewimperung zu haben. Stirne ron der Farbe des Thoraxriekens; Gesicht und Taster ron dunkler Firbe, jedoch schimmern die Spitzen der Taster weiß. Fïhler sehwarz, an der Wurzel etwas rötlich, das Aritte Glied kurz dreieckig; llinterkopfzilien unten weiß. Hinterleib glinzend griin, an den seiten gran bestiubt, mit dunkleren braunen Vordemandbinden auf fast allen Ringen. Ilypopygialanhäinge kurz lamellenförmig, gelblich ohne auffallende Behaarung. Beine nebst Vorderbiften gelb, selır lang; Mittelbeine sebr diinn; Vorderhiiften zart weif behart, auch die Borsten der Mittel-und Hinterhiften sind weiß; an den Torderbeinen sind die Tarsen rom Ende des ersten Gliedes an hran und the drei bis vier letzten Glieder annihernd gleieh kurz. Die Mittelbeine sind sehr schlank und werden allmihlich an den Tarsen fast fadenfümig (die beiden letzten Glieder fehlen); die Mittelsehienen tragen anf ihrer Oberseite nahe fler Wurzel ein schwarzes Borstenpall und sind auf ihrer ganzen Unterseite mit weißen, kammartig gereihten Borsten besetzt, desgleichen der Metatarsus; die Endpunkte der Tarsen sind etras gebriunt. Hintersehenkel und 
Hinterschienen sind an ilner Spitze bram; die Hintertarsen, mit $A$ us. nalume der Wrurel des ersten Gliedes, sind seluwarz; Schienen und Tursen sind scluwacl verbreitert wic bei den meisten Arten; der Metatarsus ist ein wenig lïnger als das zweite Glied und mit den iibrigen Gliedern olune Behaarung odier Beborstumg. - Flïgel schwach bräinlich gefärbt; dritte Lings ader etwas gebogen, die vicrte an der Fligelbenle stumpfwinklim gekniekt und sodann mit der dritten etwas konvergierend, an der Flïgelspitze miindend; hintere Quer. ader um das $21 / 2$ fache ihrer eigenen länge vou Fligelhinterrande cntfernt. 3 'ōmm laug.

Ein Exemplar atus Nordargentinien, P'rovinz Salta, $2500 \mathrm{~m}$ hoch [J. Steinbacl] Berliner zoologisches Museum.

coxalis Aldr. o, Biolog. Centr. An. Dipt. 1 344. 3 tab. Vl tig. 221 (1901) . . Mexico

б. - 'Tboraxricken grangrüu, Sime desgleichen, Gesicht grau. Fialler gelb, drittes Glied braun (?). IIypopygium ungewönlich dick und unsymmetrisch. Beỉe mit Vorderhiiften gelb, Nittelschicnen an der Wurzel braun, das letzte Glied der Vordertarsen ist mit drei bis vier kurzen dicken Borsten besetzt und bildet mit der inneren Klauc ein Greiforgan, welebes jedoch weniger entwickelt ist als bei den Arten falco nud similis; an den littelhiiften stehen fuinf dicke stumpfe Borsten in einer lieibe an der Vorderscite; in iibrigen nichts Bemerkenswertes. Siehc dic Beschreibung ron Aldrich. 1.7 mm lang.

Aldrich beschrieb diesc Artaus Mexiko.

11 crinipes n.sp. o7.1 Figur . America merid.

o. - Thoraxiicken mattluaun be. staiubt. Scluwinger blaßgelb, mit brannem Sticl, Schiippehen weiblich, bram gesäumt und weiß bewimpert. - Kopf: Stirne mattbraun, das schmale Gesicht liellgrau, 'Taster
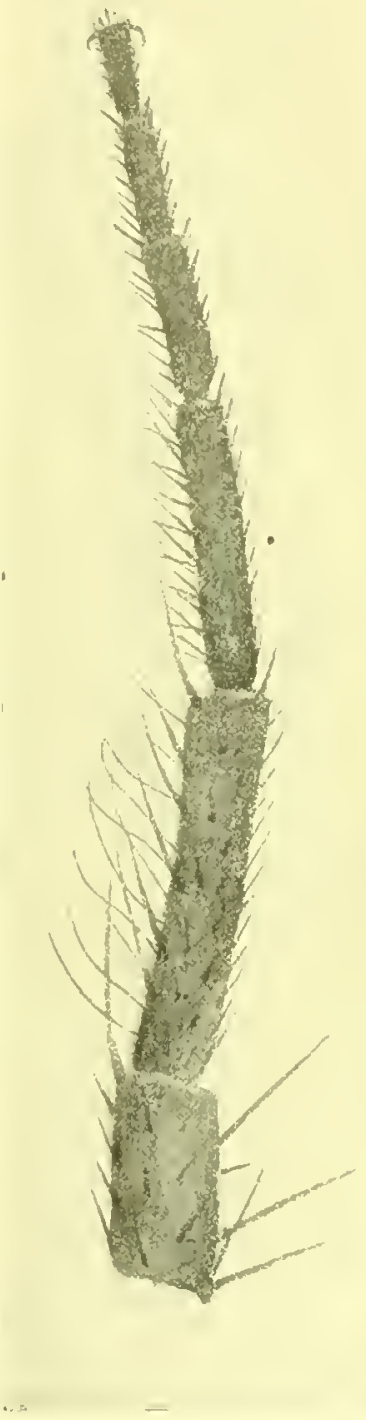

Fig. 94. Sympyemes crinipes Beck. OT. Hintertarsen. $48: 1$. braun. Fiihler schwarz, drittes Glied kurz. - Hinterleib gliinzend bronzefurbig, schwarz behart. - Beine briiunlichgelb; lluften schwargrau, die vorderen au der Spitze gelblich, zart weiß behalut. 
Vorderschenliel bis nahe zur Spitze schwarzhan: Mittelschenkel gelbbriunlich; Hinterschenkel schwarzbraun, nur anf der Unterseite heller gestriemt; vordere Schienen und Metatarsus der Vorderbeine rostgelb; Hinterschiene nebst Tarsen sowie alle iibrigen Tulsenglieder schwarzbrann. Metatarsus der Hinterbeine lïnger als das zweite Glied, unten mit einer Reihe von Borsten und lïngeren IIaren, das zweite Glied ist anf sciner Unterseite auch noch riemlich ranb beborstet, alle Tarsenglieder in abnehmender Liinge. - Flifgel schwach bräiunlich gefïbt, an Volderrande etwas gesättigter; dritte und vierte Läingsader schwach gebogeu, aber nach der Spitze hin dentlich etwas konvergierend, die vierte an der Fligelspitze endigend; hintere Querader nur um wenig mchr als $u m$ die eigcne Liinge vom Fligelhinterande entfernt. $3 \mathrm{~mm}$ lang.

20 ans Peru, Sicuani 21. VT. 1903. - Peru-Puno, 'Titicacasee 23. Xl, 1902 [Schnuse] Dresdner zoologisehes Museum.

12 cuminus Wheel. ơ $q$. Proceed. Californ. Acad. Se. ser. 3. Zoolog. II 50. 49. tab. 1V. fig. $99-100$ (1899) . . . . . . America sept.

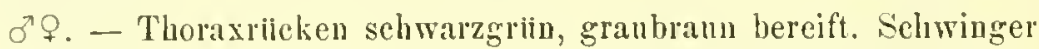
und Schippchen gelb, letztere schwarz gesaiumt und mit brannen Wimpern. Gesicht und 'Taster' silberweiß. Fiuhler' schwar'z, das dritte Glied etwa doppelt so lang wie breit. Hiiften schwarzgran, Vorderhitften silberweiß behaart, Mittel- und Hinterhüften mit weißen Borsten. Beine gelh; Vorderschenkel zu $\% / 3$, Hinterschenkel auf der Oberseite und spitzenhälfte schwarz, Vorder- und Mitteltarsen von der Spitze des ersten Gliedes an, Hintertarsen ganz schwarz. Das letzte Glied der Vordertarsen ist etwas verdickt, Pulvillen vergröbert; Hintertarsen einfach.

․ - Gesicht glau; das dritte Fiihlerglied nicht linger als breit. $2 \cdot 5 \mathrm{~mm}$ lang.

Wheeler erbentete diese Art in Kalifornien.

13 El-Angeli n. sp. 0 .

America centr.

б. - Thoraxriicken metallischschwarz, dicht bram bestiubt. Schwinger gell, Schippehen schwarz bewimpert. Stime in der Färbung des Thoraxifickens, Gesicht grau, Taster weib. Ftihler schwarz, drittes Glied knrz dreieckig, pubeszent. Hinterleib glinzend schwarz. Beine mit den Vorderhiften rotgelb; Hinterschenkel und Schiene an der Spitze schwarz, Hintertarsen ganz schwarz; das dritte Glied der Ihintertarsen ist ku1"\%, oval, kirrzer als das folgende Glicd und unten mit längeren schwarzen Halren und zwei kurzen dicken Borsten geziert. Fligel graulich: vierte Liingsader an der Flïgelbeule dentlich gebogen. $3 \mathrm{~mm}$ laug.

10 vom Äquator hei El-Angel $3020 \mathrm{~m}$ hoch [Rivet 1903] Pariser Eutomoligisclues Muscum. 
๘. - Thoraxriicken ron blaugriiner Grundfarbe, durch Bestaiubung matt grangriin. Schijppehen nnd Schwinger blaßgelb, erstere olne dunklen Saum mit weißen Wimpern. Stirn von der Farbe des Thoraxrijekens, Gesicht und Taster weiß. Filller schwar, drittes Glied kur" dreieckig, Zilien des Hinterkopfrandes unten weiß. Hinterleib bronzegriin mit sehwarzer, an den Seiten des ersten Ringes mit weiRer behaarung. Hypopyginm mit kleinen schmalen, schwarzen, sebwach behaarten Anbingen. Beine mit allen Iliften schwargrin, Vorderhliften dentlich weiß behart. Sehenkelglieder der Vorderbeine, Spitze der Sehenkel, die rorderen Schienen und Metatarsen (letztere nuit Ausnahme der Spitze) gelb; Mittelsehenkel gelb; an den Ilinterschienen ist die Wurzelhälfte gelbbraun. An den Vordertarsen sind die dree mittleren Glicder annähernd gleich lang oder linrz; auf der Unterscite der Vordersehienen steht in der Wurzelhälfte eine lingere Borste; der Hintermetatarsus ist nur wenig länger als das zweite Glied; im iibrigen sind die Tarsen ganz einfach in Form und Beborstung. Die Fliigel haben einen blaßbraunlichen Ton; die dritte und vierte Lüngsader sind deutlich gebogen, nach der Spitze hin etwas konvergierend und die vierte an der Fliigelspitze ausmitudend, hintere Querader reichlich um die doppelte eigene liinge vom Fligellinterrande entfernt. $2-2 \cdot 2 \mathrm{~mm}$ laug.

$20^{x}$ aus Nordargentinien, Provinz Salta, $2500 \mathrm{~m}$ loeh [J. Steinlach] Berliner zoologisches Museum.

Anmerkung. Bei der ziemlich gleichmißigen Verteilung der gellen und schwarzen Färbung an den Beinen labe ich diese Art in der Tabelle an den beiden entsprechenden Stellen angeführt.

15 falco Aldr. O’ ; Trans. Entomol. Soe. London, 336.1 (1896) Amer. centr.

o. - Thoraxriticken griin, von geringem Glanze. Selwwinger und Sehitppchen gelb, letztere iiberwiegend sebwarz bewimpert. Stime und Gesicht sehwäzlieh. Fiilhler sehwarz, drittes Glied kurz, dreieckig, mit subapikaler Borste. Hiiften gelb bis braun, die Torderhiften gelb be haart. Beine gelb; das letzte Glied der Vordertarsen rerlingert mit einem Anhang an der Basis der Unterseite; die innere Klaue, riickwärts gebogen, bildet hiemit ein fireiforgan; die Tarsen sind alle naeh der Spitze zu stufenförmig verdunkelt. $16-2 \mathrm{~mm}$ lang.

9. - Gesicht nicht sebr breit, schwarz, weif bestiubt. Aldrich hesehrieb diese Art aus Westindien, St. Vincent, wo sie bis zu 3000 Fuß iiber lem Meere rorkommt; siehe seine spezielle lesehreibung.

16 fruter Aldr. of 7 , Kansas. Univ. Se. Bull. I 83 (1902) . America centr.

ठ ₹. - Tholaxrỉcken dunkelgriin mit geringer Bestäubung. Sehwinger gelb. Stirne und Gesicht grau. Fibler gelb, das dritte Glied schwar, knrz dreieekig, Tister gelb. Iypopre dick, hallb so 
lang wie der Ilinterleib, Lamellen gelb. Beine nebst allen Hiiften gelb, nur die Mittelhiiften hahen eine dunklere Außenseite, die Tarsen sind lsamm elwas gebrïunt. Die letzten drei Tarsenglieder an den Vorderbeinen sind ron gleieher Liingre, das letzte ist sehwarz; die innere Tarsenklane ist gröBer als die außere, zuriokgebogen und vereinigt sich mit dem fiinften Tarsengliede zu einem Greiforgan. An del Unterseite der llintersehenkel steht eine Reihe schwar"zer Borsten, die nach del Spitze zu liinger werden. Fliggel grau, der letzte Abschnitt del vierten laingsader ist fist ganz gelade, die dritte konvergiert ein wenig. $2 \cdot 2-2.4 \mathrm{~mm}$ lang.

Aldrich beschreibt diese Art ans Frenada, Westindien.

17 globulitarsis n. sp. O․ 1 Figur . . . . . America merid.

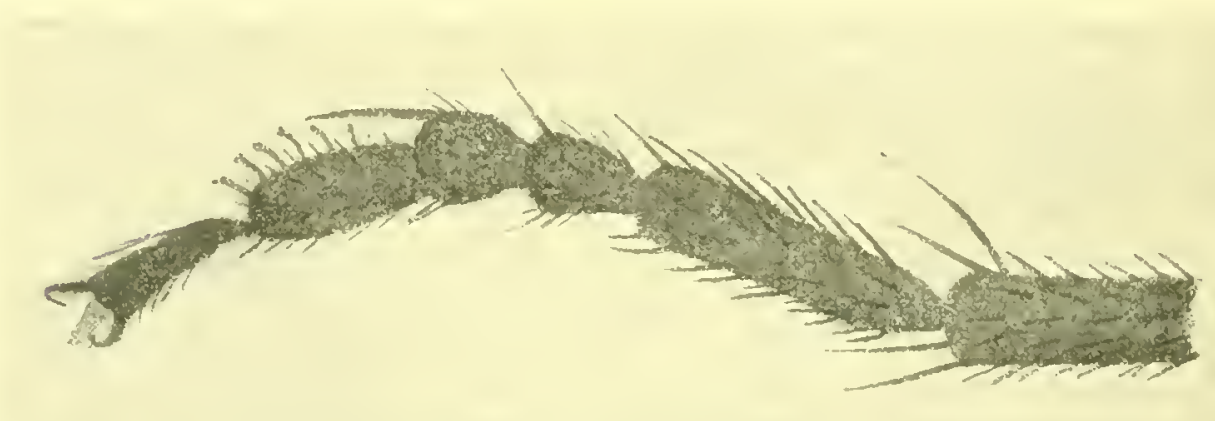

Fig. 95. Sympycnus globulitarsis lieck. o’. Hintertarsen. 48:1.

万. - Thoraxricken mit branngraner Bestioubugr, welche eine dunklere IIttellinie in die Erseheinung treten liißt. Sehwinger und Sehiippchen blaßgelb, letztere dunkel bewimpert. - Kopf: Stime matt dunkelbramn; Gesieht etwas breiter als gewöhnlich, hlafgelb wie die 'laster. Fiihler sehwarz, Hinterkopfwimpern unten weiß. - Jlinterleib bronzefarbig, schwarz behart. - Beine nebst Hiiften ganz schwarz, Forderhiften weif behart. Ilintertarsen von besonderer Form und Beborstung; der Metatarsus ist lang, so lang wie die drei folgenden Glieder zusammen; das zweite und dritte Glied sind liaum langer als breit, loeide tragen auf ihrer Interseite eine Bolste, die beim dritten Glied sehr stark ist; das vierte Glied ist hingliehoval, auf der Unterseite mit einer Reihe kurzer, breitgedrickter, stumpf endigender Borsten (s. Figur 95). Flïgel zart graubrïunlich getrïbt; die drei mittleren Längsadern sind nahe aneinander geriickt, so daß die vierte noeh erheblich vor der Fligelspitze in die Randader ansmindet; letztere macht an der liigelbenle eine kleine Biegnung zur dritten und rerläuft alsdann anuäherod parallel; liutere Querader anf der Fliggelmitte, um das Doppelte ihrer eigenen Lïnge rom Fliigelrande entfernt. $2 \cdot \bar{\partial}-30 \mathrm{~mm}$ lang. 
f. - Gesicht breit, oben untel den Fihlern mattbraun, unten schwargyran, auch die dunklen Taster sind auf der Oberseite grau bestiiubt. Beine einfach, Vorderhiften schwarz behart. Hinternetatarsus etwas kiirzer als das zweite Glied, sonst dem $\sigma^{-7}$ gleieh. $3 \mathrm{~mm}$ lang.

3 ơ, 1 ค a rus Peru.Puno 23. XI. 1902. Titicacasce. - Peru-Tama 21. I. $1904.3000-4000 \mathrm{~m}$ hoch [Schnuse] Dresdner zoologisches Museum.

hamatus n. sp. $0^{x} \mathrm{q} \cdot 2 \mathrm{Fi}$ -

guren. . Aner. merid.

o. - Thoraxricken matt bramgram bestiulst, zwischen den Akrostikalen und den Dorsozentrablorsten etwas heller gran, so dab die drei Hasureilien dunklel hervortreten; die Borsten stehen meist anf dunk-

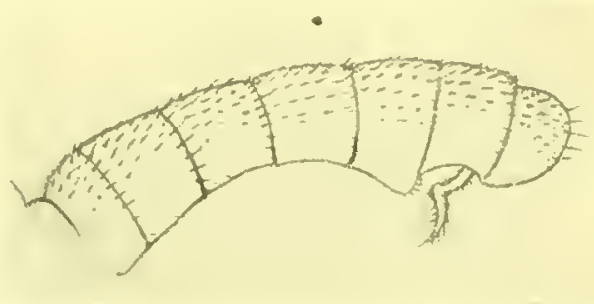

rig. 96. Sympycnus hamatus Beck. O'. Ininterleib. $16: 1$.

leren Punktflecken. Schwinger gell, Schiippchen weib mit dunklem Rande und Wimpern. - Kopf: Stirne wie der Tloraxricken gefärbst, das schmale Gesicht und die kleinen Taster weib. Fibhlel schwarz, drittes Glied

klein dreieckig. - Ilinterleib erzgliin mit mattschwar zen bis purpurfarbenen Vorderrand binden, die bei der weißlichen Berei-

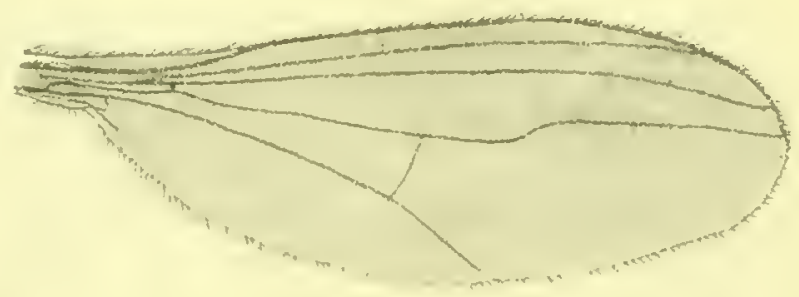

Fig. 97. Symmycnues hamatus linck. of. Fïgel. 16:1.

fung der Seiten stäker herrortreten. Hypopyg kappenfömig, halbkugelig, glïnzend seluwar\%, die äferen Organe sind winkelförmig gelogen, behart, ron ritticlier Farbe. - Beine nebst Vorderbiiften rotgelb, letztere weif hehart; die hinteren Iliften aschgran. Vorderschenkel auf der Oberseite schwach - Finterschenkel deutlich sehwarzbrann gestreift. Vorderschienen gelb, Vittelschienen an der Spitze, Hinterschienen ganz sehwarz. Vordel- und Jitteltarsen von der Spitze des ersten Gliedes an, Hintertarsen ganz schwarz. Beine lang und diinn; Klanen und Pulvillen sehr klein. Vordertarsen etwas länger als die Schiene, Metatarsus so lang wie die ibrigen rier Glieder zusammen; Mitteltarsen $1 \%$ mal so lang wie die Schiene, Metatarsus 
auch ebensu lang wie die folgenden vier Glieder; Hintertarsen fast so lang wie die Schienen, Metatarsus ungefähr so lang wie das zweite Glied. Behaarung der Beine sehr spärlich. $25 \mathrm{~mm}$ lang.

๑. - Die drei bramen Lïngsstreifen anf dem Thoraxrijeken sind dentlicher. Gesicht breit, weißgran; Taster gelh, an der Wurzel bramn. Beine dem Miunchen ziemlieh gleich, jedoch der Hintermetatarsus deutlieh kiurzer als das zwejte Glied. Fliigel an der Basis nicht so keilförmig; dritte und vierte Längsidern fast ganz parallel obne Biegung.

10 o 56 o aus Chile, Corral 8. IX. 1902 - Peru-Laristal 9. VHI. 1903 3000-4000 m hoch - Pern-Urubamba $2000 \mathrm{~m}$ hoch Chile, Valparaiso - Bolivia, La Paz 30. Xl. 1902 - Peru-Cuzoro IV. $19053200-4200 \mathrm{~m}$ hoeh [Schnuse] Dreshner zoologisches Ifnsenm.

1 ठै, 1 a aus Nordargentinien, Provinz Taenmani $1200 \mathrm{~m}$ hoch [J. Steinbach] Berliner zoologisches Ifuseum.

I9 integer $\mathbf{n}$. sp. $\sigma^{7}$ ? America merid.

б. - Thoraxriicken erzfitbig, graubraun bestaiubt. Schwinger und Sebtippehen gell, letztere mit sehwarzem Samn und Wimpern. Stirn und Gesieht mattbraun. Fihler rotgelb, drittes Glied etwas gebriinnt, kur dreieckig. Taster und Rissel bran. Hinterleib erzfarbig; der zweite Ring fast ganz gelb, am dritten Ringe gelbe Seitenflecke, Banch gelb. Hypopyginm mit deutlichen anßeren Anhingen, die Form derselben ist lang, schmal, lanzettförmig zugespitzt mit lingeren Borstenbaren, braun. an der Warzel gelb. Beine mit allen IIiften blaßgelb. Yorderbeine sehr lang and diun. Ilinterschenkel auf der Vitte etwas geschwollen mud brann gestreift; Hintersehiemen ein wenig rerdickt, Hintertarsen desgleichen und schwarz, letztere sind nicht besonders ansgezcichnet, sind aber alle etwas ranl hehaart; der Metatarsus ist etwas linger als das zweite Glied. Die Längenverhïlnnisse der einzelnen Teile der Beine sind, bei "24 facher Vergrößerung gemessen, wie nachstehend angegeben:

Yorderschiene 32, Metatarsus 20, die iibrigen vier Glieder zusammen $18 \mathrm{~mm}$ lang. Verhültnis der Sehiene zu den Tarsen wie $33: 39=$ $1: 1 \cdot 25$.

Mittelschiene 57, Metatalsus 30, die tibrigen vier Glieder zusammen $24 \mathrm{~mm}$ lang. Verhaltnis der Schiene zu den Tarsen wie 57:54 oder annihlernd wie $1: 1$.

Hintersehiene 55, lletatarsus 8 , die ibrigen vier Glieder zusammen $21 \mathrm{~mm}$ lang. Terhailtnis der Schiene zu den Tarsen wie 50 :29 oder annihernd wis $2: 1$.

Fltigel etwas graubraun; Jritte und vierte Längsadem fast parallel, kanm etwas gebogen; hintere Qneraler fast um die eigene doppelte Liinge rom Fligelhinterrande entfernt. 
․ - Der zweite IInterleibring ist an seinem Vorderrande nu. wenig gelb, der Bauelı lingegen gelb.

$5 \sigma^{T}, 1$ a a P Praguay, S. Bcruadino [Fiebrig] Wiener Hofmuseum.

Annerkung. Diese Art hat große Ähnlichkeit mit meiner Art simplicipes, dic ich auf den Kanarisclen Insehn fand; letztere unterscheilet sich aber sofort dureh die ganz schwarzen Fiihler.

intermedius n. sp. ơ 0.1 Figur.

Americal merid.

0’. - Thoraxtieken mattbraun, zuweilen mit drei dunkleren Laingslinien iiber den Haarreihen. Selıwinger blaßgelb, Schïppelıen weißlich, braun gestiumt und weiß bewimpert. Kopf: Stirne mattbram, das sehmale Gesielıt und die Taster weißgrau; Hinterkopfzilien unten weib. Fiihler an ersten und zweiten Gliede rotgelb; das dritte branu. llinterleib selı schlank, gliuzend erzfarbig, an den Ringeinsehnitten

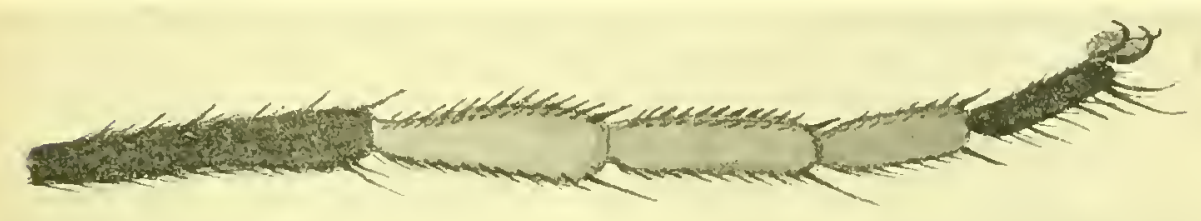

Fig. 98. Sympycnus intermedius. Beck. o7. Mitteltarsen. 48:1.

matt sehwiilzlieh. Hypolygium mit halbkngeliger Endigung; die sicbtbaren Teile der iuferen Anlänge sind seliwarz. - lieine nebst Vorderhüften rotgelb, letztere weiß behart. Vorderschenkel oberseits mit dunkler Laingsstrieme; Hinterschenkel etwas gekrtimmt, gegen die Spitze hin ebenfalls dunkel gestriemt; alle Sehienen gelb, die Hinterschienen jedoeh nur an der Wurzelhialfte, die Endhailfte nebst den Tarsen ist seluwarzbraun. Die Vordertarsen sind ungefälur so lang wie ilıe Seliene, der Metatarsus halb so lang, nur die letzten Tarsenglieder brann. Mitteltarsen etwas länger als die Schiene, der Metatarsus unverhältnismäßig lang, $1 \frac{1}{2}$ mal so lang wie die iibrigen vier Glieder zusammen; von diesen sind die ersten drei, also die drei mittleren Tarsenglieder breit gedriekt und uur an den Rindern kurz beborstet. liellgelbliel ron Farbe, wähend die Metatarsen und das letzte Glied braun sind. - Die Fligel sind etwas grauliel von Farbe, an del lasis keilförmig; dritte und vierte Längsadern etwas banehig gegeneinander gebogen und konvergierend; an der iußersten Spitze biegt die dritte etwas nacl oben, die vierte lïuft an der Flïgelspitze aus; die hintere Querader ist um las 1\%/2 fache iluer eigenen Länge rom Fligellinterrande entfernt. 5 nm lang.

२. - Die Fiilıler sind rot, das dritte Glied etwas braun, das breite Gesielst grau; die Seliujpehen laben neben weißen auch häutig 
branne Wimpern. Beine nebst allen Hiften gelb, nur die aiußersten Tarsenglieder braun. Die Fligel haben nicht die keilfomige Gestalt wie beim $\sigma^{7}$; die hintere Querader ist mitunter etwas braun mosinmt.

5 ơ, 11 q ans Peru-Cnzco IlI. $19053200-4200 \mathrm{~m}$ hoch Peru-Puno, Titicaea-See 23. XI. 1902 - Bolivia, Cordilleren 24. XII. 1902 $4000-5000 \mathrm{~m}$ hoeh [Schnnse] Dresdner zoologisches Musenm.

21 lineatus Lw. O’, N. Beitr. VIll 67. 2 (1861) . . Ameriea sept.

o Thoraxricken matthriunlieh. Schwinger und Sehiippehen blaßgelb, letztere mit lramnem Rande nnd hellgelben Wimpern. Gesieht weiß bestaibt, Taster sehwairzlieh. Finller gelb, das dritte Glied braun, länglich eifömnig. Hinterleib branngran, Banch gelblieh. Hypopygialanhänge von falenförmiger Gestalt und sehmutzig gelbbraner Firbung. - Beine nebst allen Hiiften gelb; alle Tarsen einfach, melı oder weniger gehräunt, siehe Loew's Beselıreibung und die Tabelle. $2.8-3 \mathrm{~mm}$ lang. 22 marcidus Wheel. ơ 9 , Proceed. Californ. Acad. Sc. ser. 3. Zoolog. II 48. 47 tab. $1 \mathrm{~V}$ fig. 92-39 (1899) . . . . . . . Ameriea sept.

7. - Thoraxriteken matt metalliseh griin mit einel etwas dunkleren Mittellinie. Sehwinger und Sehitppelien reißgelb mit ebensolehen Wimpern. Stime von der Farbe des Thoraxrỉekens, Gesicht weiß. Fibler schwar, drittes Glied kurz dreieckig. Hinterleib metallisel griin, an den Seiten gran, Batuch gelb; Analanhinge gelb, gerade rorgestreckt, schmal. IIiften alle gelb, jedoeh Hittel- und Hinterhïften anken etwas gran. Beine gelb, die Tarsen sind von der Spitze des ersten Gliedes an gebräunt; Ilintersehienen und Spitze der Hintersehenkeln mitunter braun. Das letzte Tarsenglied der Vorderbeine ist mit den Pulvillen dentlieh verbreitert. Hintertarsen sehwaeh verbreitert, drittes Glied mit melıreren lingeren Borsten, ron denen die letzte am stiolisteu und gebogen ist; auch das vierte Glied ist mit einigen abstehenden Borsten besetzt. $25-3 \mathrm{~mm}$ lang.

Q. - Gesicht breit, gran, Taster gelb. Tarsen einfach. Flügel an der Basis breiter.

Wheeler beschrieh diese Art ausfiihrlich, aus Western-Wyoming; bis zur Höhe ron $7200 \mathrm{FuB}$ wurde sie beobachtet

23 monticolus n. sp. ơ . . . . . . . . . . America centr.

J. - Thoraxrieken metalliseh matt graubraun. Schwinger und Sehippchen gelb, letztere mit weißen Wimpern. Stirne mattbram. Gesicht weiß, T'ister gell, Fithler seluwarzbraun, erstes Glied anf der Unterseite gelb, drittes Glied abgermudet mit langer Borste. Hinterleib netalliseh sebwarz, zweiter bis fiufter Ring an den Seiten mit gelben dreieekigen Flecken; Hypopy mit sehwarzen fadenförmigen beharten Anhängen. - Beine mit allen Hïften gelb. Hinterschenkel an der Spitze sehwal'z gefleekt, Hinterschienen und Metatarsus an der Spitze gebrïunt; desgleichen die letzten Glieder aller iibrigen 
Tarsen braun. - Fliigel schwach grangelb; dritte und vierte Liangsadero parallel, vierte Ader an der Fligelspitze endigend. $2 \cdot 5-5 \mathrm{~mm}$ lang.

4 ơ, 6 q rom Äquator, Quincaloma $4000 \mathrm{~m}$ hoeh, im April La Rinconado $3100 \mathrm{~m}$ hoch - Tanssi $3740 \mathrm{~m}$ hoch - El Angel, $3020 \mathrm{~m}$ boch - Riobomba $3754 \mathrm{~m}$ loch - Cuenca [Rivet 1901, 1903, 1905] Pariser Eutomologisehes Museum.

24 nigriciliatus $\mathrm{n} . \mathrm{sp} . \sigma^{\circ}$. . . . . . . . . . . Chile

๘. - Thoraxricken metallisch schwar, dicht brann bestiubt. Sehwinger gelbbraun mit dunklem Sticl, Sehtippehen blabbraun, dunkel gesäumt und gewimpert. - Kopf: Stirne und das schmale Gesicht nebst Tastern matt sehwarz. Fiihler sehwarz, drittes Glied kurz; Hinterliopfzilien auch unten schwar. - Hinterleib glinzend bronzefarlig. Hypopyg ohne Besonderheiten. - Beine nebsi Hiften schwarzgran, Kniee gelb, vordere IIiiften schwarz behart. Schienen mit kriftiger Beborstung. Hintermetatarsus ungefuhl so lang wie das zweite Glied. - Flifgel sehwach gelbbrïunlich; dritte und rierte Längsadern fast parallel, unmerklich nach der Spitze hin konvergierend; bintere Querader um das $2 \%$ fache der eigenen Länge vom Fligelhinterande entfernt. $2.5 \mathrm{~mm}$ lang.

․ - Gesieht breit schwarz; die Schienen zeigen anf ilurer Wurzelhialfte eive rotgelbe Firl)ung, sonst dem ơ gleich.

$4 \sigma^{\top}, 1$ f ans Chile-Quillota, 10. IX. 1902 [Schnuse] Dresdner zoolngisches Museum.

America merid.

o. - Thoraxricken glinzend schwarggrin. Schwinger blaßgelb, Schiippehen blabbraun mit dentlichem schwarzen Rande und sehwarzen Wimpern. Stime von der Falje des Riickens, Gesicht und Taster weib. Fiihler schwar, drittes Glied klein, dreieckig; Hinterkopfzilien unten weiß. Hinterleib glinzend ergriin; Hypopyg mit schwarzen lamellenförmigen äulieven Anhängen mit lïngerer Beharung. - Beine nebst allen IIiften scluwar\%, Vorderliuften weil behaart. Knice der Vorderund llittelbeine gelb. Vorderschienen oberseits vor der Nitle mit einer Einzelborste, auf ler Aubenseite mit deren zwei; Vordertarsen nur wenig lianger als die Schiene. Mittelschienen oberseits nahe der Basis mit 1-2 Borsten, mitunter etwas rothrum, kanm etwas kibrer als die Tarsen. Minterschienen auf der Oberseite slibler als ge. wöbulich behorstet: es stehen gewoilmlich acht Borsten in zwei Reihen. llintermetatarsus etwas länger als das zweite Glied: im iibrigen sind die Tarsen gan\% einfach. - liligel sehwach graubräunlich; dritte und vierte Laingsadern olme nemnenswerte Biegung, fast parallel; die vierte an der lihgelspitze mindend; hintere Querader um das Doppelte ihrer eigenen Länge rom Fligelhinterrande entfernt. $2 \cdot 5-3 \mathrm{~mm}$ lang. 
Q. - Gesicht grau, voa doppelter Fiihlerbreite, 'Taster gelbbrann. 5 o7, 1 q aus Nordargentinien, l'rovinz Salta $2500 \mathrm{~m}$ loelı [I. Steinbaeb] Berliner zoologisehes Musemm.

๑. - Thoraxrijeken dureh Bestiubung natt dunkel braungrau. Schwinger gelb mit schwarzem Sticl, Sehitppehen hellgelb mit braunem Rand und weiben Wimpern. - Stirn von der Farbe des Thoraxriekens, das schmale Gesicht und die Taster sehwarz. Fiihler schwarz, drittes Glied knr\% dreieckig; IIinterkopfzilien unten weiß. Hinterleib glänzend bronzefarbig, seliwarz behart, IIypopyg mit schmalen dreieckigen sehwarzen Anlüngen. - Beine mit Hiiften ganz schwarz, Vorderhiiften schwarz hehart. Vordertarsen so lang wie ihre Sebiene; Metatarsus fast so lang wie

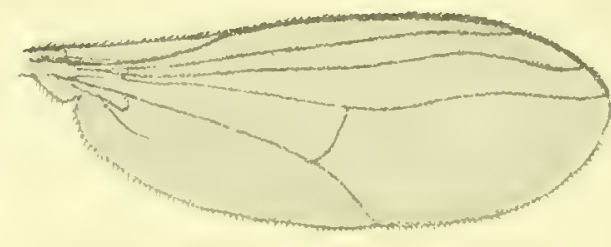

[ig. 99. Sympucnus patellitarsis Beck. ot Flïgel. 16: 1. die halbe Schiene, die iihrigen Tarsenglieder sind fast alle gleieh lang, Mitteltarsen etwas länger als ihre Sehiene; das letzte Tarsenglied ist kurz und breit gedriekt. Hintertarsen ungefïhlu so lang wie die Selriene, Metatarsus nur wenig kiirzer als das zweite

Glied. Flitgel rauehgrau; dritte und vierte Laingsadern gesehwungen und an der Fltigelspitze einander etwas genäliert; die dritte an der iußersten Spitze etwas nach oben anfgebogen, die vierte vor der Flïgelspitze endigend; hintere Querader naeh anßen hin gebogen und etwas schräg liegend. $3 \mathrm{~mm}$ lang.

q. - Gesieht breit mattsehwarz, 'Taster an der Spitze heller. Beine ganz einfach, sonst dem ol gleich.

is ơ, 14 a a Peru-Puno, Titicaca-See, 20. XI. 1902. - PerllCnzco, 27. VI. 1903 [Schnuse] Dresdner zoologisehes Museum.

૨. - Thoraxricken braun bestaiubt. Schwinger und Schippelien gelblich, letztere an der Spitze hram mit dunklen Wimpern. - Kopt: Stirne matbraun, das sebmale Gesieht nebst Tastern weiß. Fiililer seliwarz (das dritte Glied aligebrochen); Hinterkopfoilien unten weib. Hinterleib bronzefarlig, gliazend; Hypopyg mit zwei kleinen selıwarzen, ovalen, sehwach behararten äuBeren Anhängen. - Beine nebst Hiiften sehwarz, Vorderhiften weiß behart; Kniee gelb, an den Vorderbeinen sind noeh die iußerste Wurzel der Sehienen, ihre Spitze und die erste Hälfte des Metatarsus gelh, au den Mittelbeinen noch die Hälfte 
der Metatarsen. Hinterbeine ganz selwwar, deren Metatarsus länger als das zweite Glied; anf der Wurzelhälfte seiner Unterseite stehen etwa flinf lange Hatare (s. Figur 100). - Fliigel etwas rauchgrau getribt; die Form des Hinterrandes ist etwas abweiehend, da der unter der fïnften Lïngsader liegende Teil des Flijgels an seiner Unterseite dentiiclr ausgehaucht vortritt (s. Figur 101); dic dritte und vierte Liingsader sind

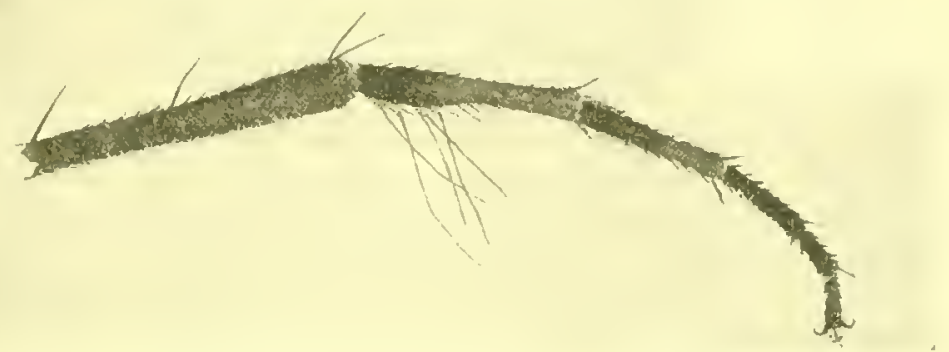

Fig. 100. Sympycnus pilizarsis lieck. ơ. Hinterbein. $24: 1$.

geschwungen, an der Spitze parallel laufend, die vierte an der Fligelspitze miindend. $35 \mathrm{~mm}$ lang.

$10^{7}$ ans Peru Sicuani, 21. VI. 1903 [Schnuse] Dresiner zoologisches Nuseum.

28 platypus n. sp. OP, 1 Figm . . . . . . . . . . . Chile

o. - Thoraxricken schwarz, graubraun bestäubt, kaum etwas glïnzend; Brustseiten dunkel aschgrau. Schwinger gelb mit schwarzem Stiel, Sehiippehen hellgelb mit brat nem Silum und langen deutlichen dunklen Wimpern. Stirne von der Farbe des Riilckens; das sehr schmale Ge-

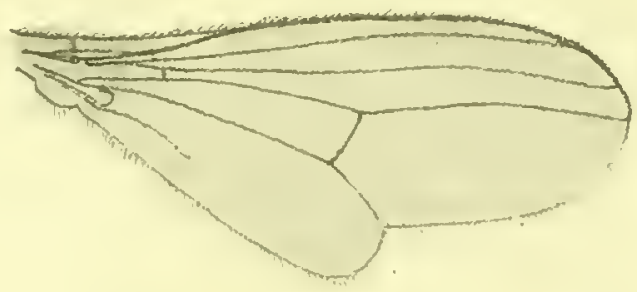

sicht und die Taster weiß. Fiiller sehwarz, das dritte Glied nicht länger als breit. Ilinterleib glänzend bronzclarbig, schwarz belaart, erster Ring lang beborstet. Iypopyg mit liurcen dreieckigen schwarzen Anhingen. - Beine mit lliften sehwar\%, Vorderhiiften weib be haart. Vordersehienen und ihr Mfetatarsus bis nahe zur Spitze, Mittel. sehienen bis nahe zur Spitze rotgelb; Hinterschienen ganz schwarz, an der Spitze ein wenig rerdickt. Erstes und zweites Tarsenglied ein wenig verbreitert und zart beborstet, erstes Glied fast doppelt so 
lang wie das zweite (s. Figur 102). Fligel selıwach graubrann getribt; die dritte nul rierte Liingsader sind efwas geschwungen und nïhern sich an der Spitze ein wenig, die vierte mitudet an der

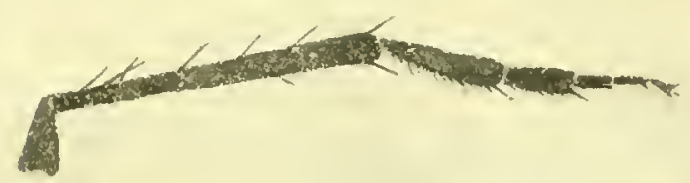

Fig. 102. Sympycuus platypus beck. $\sigma$. Hinterbein. 16:1. liligelspitze aus; hintere Queraler um das $1 \frac{1}{2}$-faehe ihrer eigenenLäinge rom Fliigelbinterraude entfernt. $4 \mathrm{~mm}$ lang.

१. - Gesicht breit, grau bestiubt, ebenso die Taster. Beine einfach, aber heller gefübbt, briiunlichgelb. Schenkel, namentlich die Vorderschenkel von der Wurzel an bis nahe zur. Spitze schwar, Hintersehenkel mit sebwarzer Liingsstrieme auf der Oberseite, Hinterschienen an der Wurzel rostbraun. Fliggel etwas dunkler gefirbt, dritte und vierte Liingsadern aber etwas weniger gebogen. $35 \mathrm{~mm}$ lang.

19 o, 2 ans Chile-Palca, 6. X. 1902 [Schnuse] Dresdner zoologisehes Nuseum.

29 pugit Wheel. q, Proceed. Californ. Acad. Se. ser, 3. Zonlog. If 51. 50 tah. IV ñg. 101-102 (1899) . . . . . . . . . America sept.

ob. - Thoraxriedien mattgriin. Schwinger und Schiippchen gelb, letztere gelb gewinupert. Stirne mattgrin, Gesicht gran. Fỉhler schwar, drittes Glied kurz. Bcine und Vorderliiften gelb; Hinterschenkel auf der Oberseite gebräint; Vorder- und Hintertarsen ron der Spitze des ersten Gliedes an, Mitteltarsen am vierten und fiinften Gliede schwarz. Die drei mittleren Glieler der Vordertarsen gleiel kur, nicht lainger als breit, das fünfte Glied mit den Pulvillen verbreitert; die beilen letzten Glieder der Mitteltarsen sizd schrarz nud rerbleitert, anch etwas linger beborstet. An den Hintertarsen sind die ersten drei Glieder deutlich dicker als die beilen letzten, das erste ist so lang wie das zweite, dieses an lier Spitze der Oberseite mit einigen lïngeren Borsten. - Fligel grau, etwas keilförmig; vierte Laingsader an der Fhigelspitze endigend; hintere Querader um nieht riel mehr als die eigene Lïnge rom Flitgelhinterande entfernt. $25 \mathrm{~mm}$ lang.

Wheeler besehrieb diese trt rou Washington.

30 similis Alir. q, 'Transaet. Ent. Soe. London 336.2 (1896) America centr.

Aldrich selbst gibt keine besondere Beschreibung, sondern nur den Untersehied ron sejner Art falco an, der darin bestehen soll, daB an der Ober-oder Vorderseite der Vorderschienen eine Reihe von vier steifen stumpfen Borsten von mäßiger Lïnge steht, welche der Art fulco fehlt. $1.7 \mathrm{~mm}$ lang

Ebenfalls wie fulco aus St. Yineent, Westindien. 
31 tenuipes $\mathrm{n}$. sp. o 7

Ameriea eentr.

67 . - Thoraxrieken von metalliseber Grundfarbe mit grangelber Bestiiubung, Brustseiten bläulich grau. Schwinger und Sehiippehen gelb, letztere weiß bewimpert. Stirne mattbraum, Gesieht gelbgran, Taster weiß. Fiilıler sehwarz, drittes Glied kurz. Hinterleib metallisehgriin mit purpurfarbenen Vorderrandsbinden der Ringe unit weißgran bestaiubten Seiten. Lamellen des Iypopygs klein, selıwarz. Beine lang und zart, mit den Vorderbiiften gelb. Hintersehenkel auf ier Oberseite braungestreift; Tarsen mit Ausnahme der Wurzel der Metatarsen schwarz; in tibrigen sind die Beine und Tarsen einfach. - Flïgel ohne Besonderheiten. $3 \mathrm{~mm}$ lang.

11 or, 7 rom Äquator: Cuenca, Tulean $3000 \mathrm{~m}$ hoeh. El-Angel $3020 \mathrm{~m}$ hoeh. - La Rineonado $3100 \mathrm{~m}$ hoeh. - Alansi $2390 \mathrm{~m}$ hoeh. - Yansai $3740 \mathrm{~m}$ hoeh [Rivet 1903-1904] Pariser Entomologisches Museum.

32 tertianus Lw. O’9, Monogr. Dipt. N.-Amer. II 187. 1 tal). VI fig. $34 \mathrm{c}$ (1864).

America sept.

$\checkmark$ T. - Thoraxriieken mattgriin. Gesieht grat, Taster gelb. Fülıler gelb, drittes Glied sehwïzlieh, etwas gerundet. Analanhïnge schwarz, klein, lamellenförmig: - Beine mit allen IIïften gelb, alle Tarsen rom Ende des Metatarsus an braun bis schwarz. Metatarsus der Hinter. beine kiirzer als das zweite Glied; das dritte Glied ist etwas klirzer als das vierte und mit längeren schwarzen Haaren besetzt. Siehe Loew's Besehreibung. 2-2.5 mm lang.

Die Art st:mment ron sitka.

33 varipes Aldr. ơ, Biolog. Centr. Amer. Dipt. I 344. 21901 Mexieo

o. - Thoraxriteken von Besti̊ubung mattgrau. Sehwinger und Sehiippchen gelb, letztere mit braunen Wimperm. Stirn und Gesicht mattbraun. Fiibler schwarz, drittes Glied kurz dreieekig, pubeszent. Hinterleib bronzegriin mit purpurfarbigen Vorderrandsbinden der Ringe; Hypopygium von der gewöhnlichen Form ohne sichtbare Anhäinge. Beine mit den Vorderluiffen grelb; das letzte Vordertarsenglied sehwarz und mit den Pulrillen rergrißert. Mitteltarsen gebriunt, das letzte Glied sehwarz. Hinterschenliel oberseits wahe der Spitze gebriunt; iulferste Spitze der Hintersehienen nebst allen Tarsen sehwarz. Metatarsus ebenso lang wie das zweite Glied. Flïgel ron gewöhnlieher Färbung und Aderung. $2 \cdot 6 \mathrm{~mm}$ laug.

Aldrieh besehrieb diese Art aus Mexieo.

\section{Bestimmnngstabelle fïr die Arten der liattung Sympycnus Lw.}

I Beine ganz rotgelb oder iiberwiegend rotgell . . . . . . . 2

- Beine ganz oder iiberwiegend schwarz. Fihler ganz sehwarz . 23

2 Das letzte Glied der Yordertarsen mit einem Anhang oder mit Borsten auf der Unterseite, die sich mit der inneren Klane zu einem Greif- 
organ vereinigen. Körper verhıiltnismäßig kurz. Hypolygium kurz, dick, unsymmetrisch . . . . . . . . . . . . . 3

- Das letzte Glied der Vordertarsen nicht so gebildet, Körper nicht besonders kurz. Hy popygium nieht von gewöhnlieben Typus abweichend 7

3 Das letzte Glied der Vordertarsen unten mit drei bis fün starken Borsten 4

- Das letzte Glied der Vordertarsen unten mit einem Anhang. . 5

4 Ftiller gelb, drittes Glied (?) schwarz. Vorderhiffen gelb mit drei bis vier sehr langen schwarzen Borsten. Mittelhiften nit eimer Reihe von fïuf dicken stumpfen Borsten. Hittel- und Hintertarsen schwach gebriunt. $1.7 \mathrm{~mm}$ lang . . . . . . coxalis Aldr. o

- Fibhler schwarz. Hiiften alle sehwarz. Schenkel gelb, oberseits schwarz gestreift; Hintersehiene an der Spitze nebst den Tarsen schwarz. Hintertarsen des $\sigma^{7}$ stark behaart. $25-3 \mathrm{~mm}$ lang. anticus n.sp. $\sigma^{7}$ q

5 Ftihler ganz schwarz . . . . . . . . . . . . . . . 6

- Ftihler gelb, drittes Glied schwarz. 222-250 mm lang. frater Aldr. ơ $q$

6 Vordersehienen an der Vorderseite mit vier starken stumpfen Borsten. $1.6 \mathrm{~mm}$ lang . . . . . . . . . . . similis Aldr. o

- Vordersehienen ohne solehe Borsten. 1.6-2 $\mathrm{mm}$ lang. falco Aldr. $\mathrm{o}^{7} \mathrm{f}$

7 Arten mit einfachen Tarsengliedem . . . . . . . . . 8

- Arten, bei denen sich Vordertarsen oder Sehienen dlureh besondere

Form oder Beborstung auszeichnen . . . . . . . . . 17

- Arten mit verzierten Hintertarsen. Hibften in der Regel alle gelb . 20

- Arten mit verzierten Mitteltarsen und Sehienen . . . . . . 21

- Arten mit verzierten Tarsen an allen beinen. . . . . . . 22

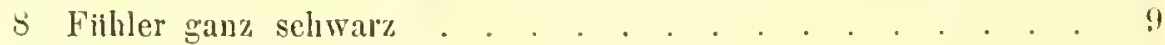

- Fibler nicht ganz sehwarz . . . . . . . . . . . . . 15

9 Fibler $\left(\sigma^{7}\right)$ grob, so lang wie der kopf hoch, $2 \frac{1}{2}-3$ mal so lang wie breit. Thorax und Hinterleil, glinzend selwarzgrin. Vorderhiften rotgelb. Hinterselienkel an der Spitze braun; Hinterschienen und Tarsen brann bis selwarz. $3 \mathrm{~mm}$ lang . . antennatus n. sp. ơ

- Fiihler klein, weder breit noch lang . . . . . . . . . . 10

10 Alle IFtiften gelb . . . . . . . . . . . . . . . . 11

- Alle Htiften sehwarz . . . . . . . . . . . . . . . 12

Nur die Vorderhliften gelb . . . . . . . . . . . 13

11 Zweiter, dritter und vierter Hinterleibsring an den Seiten gelb gefairbt. Analanhäinge fadenförmig usd gegabelt. Hinterschenkel oberseits braun gestreift, unten mit einer Einzelborste; Mittelschenkel unten mit zwei Borsten $\left(\sigma^{\prime}\right)$. Hintertarsen mit Ausnalame des ersten Gliedes schwarz. $25-3 \mathrm{~mm}$ lang . . . . . . bifidus n. sp. $\sigma^{7}$ q

- Ihinterleib olue gelbe Seitenflecken. Analanhänge nicht so gebildet. Hinterselrenkel ganz gelb olne untere Borste. 'Tarsen von der Spitze des ersten Gliedes an sehwarz. $2.5 \mathrm{~mm}$ lang . . acqualis n. sp. $0^{7}$

12 Vorderseluenkel z" $3 / 4$ seiner Lüuge, Hinterschenkel bis auf die Kniee, Hinterschienen bis auf die Wurzel sehwarz. Vorder- und Mitteltarsen 
von der Spitze des ersten Gliedes an, Hintertarsen ganz sehwarz. $2 \mathrm{~mm}$ lang. . . . . . . . . erraneus 1. sp. ठ

13 Sehenkel nicht ganz gelb . . . . . . . . . . . . . . 14

14 Hinterschenkel obenuuf sehwarz. 'Tarsen mit Ausnabme der Wurzel der Metatarsen sebwarz. Hinterleib erzfarbig mit purpurfarbenen Vorderrandsbinden und weil) bereiften Seiten. $3 \mathrm{~mm}$ lang.

temupes n. sp. ơ

Hintersehenkel oberseits schwarzbraun gestreift, Vordersehenkel desgleiehen; Mittelsehienen an der Spitze, Hintersehienen ganz sehwarz. Sehijppehen sehwarz bewimpert. $35 \mathrm{~mm}$ lang. hamatus n. sp. OT

15 Hinterleib an den Seiten gelb gefleekt; alle Hiiften gelb . . . 16 Hinterleib braungrau, nicht gelb gefleckt. Aualanhänge fadenförmig, schmutzig gelbbrann. Fiihler braun, erstes Glied gelb. Vordertursen am vierten und finften Gliede, Mitteltarsen von der Spitze des ersten Gliedes an sehwarz. Schiippehen gelb bewimpert. 2.8-3 mu lang. lineatus Lw. $\sigma^{7}$ ?

16 Hinterleib bronzefarbig, der erste $\operatorname{Ring}$ an den Seiten gelb. Finhler gelbbräunlich. 'Tarsen kaum gebriunt. $2 \cdot 1 \mathrm{~mm}$ lang.

angustipenis Aldr. Or

Hinterleib sebwarz, zweiter bis fünter Ring an den Seiten gelb. Fïhler schwarzbrann, erstes Glied unten gelb. Spitze der Hinterschenkel, Sebiene und Tarsen sehwarz. $2 \cdot 5-3 \mathrm{~mm}$ lang. monticolus n. sp. ot? Hinterleib grïn, zweiter Ring;, Seiten des dritten und der Baneb gelb. Fiibler gelb, drittes Glied brïunlieh. Hintersebenkel etwas kenlenförmig verdickt und braun gestreift. Hintersehienen und Tarsen ein wenig verdiekt, letztere sehwarz, etwas raub behaart.

$2 \mathrm{~mm} \operatorname{lan} \mathrm{g}^{\circ}$. . . . . . . . . . . integer n. sp. o 9

17 Fubler ganz sehwarz. Hinterleib obne gelbe Seitenflecken . . 18

18 Nur die Vorderhiiften gelb . . . . . . . . . . . . . 19

Alle Hüften gelb. Sehiuppehen weiß bewimpert. Spitze der Hinterschenkel und Hintersehienen mitunter brann; Tarsen von der Spitze des ersten Gliedes an sehwarz; letztes Glied der Vordertarsen nebst den Pulvillen verbreitert, außerdem noch die Hintertarsen an dritten und vierten Gliede beborstet. $2 \cdot 75-3 \mathrm{~mm}$ lang. marcidus Wbeel. ơ Alle Hiften schwarz. Sehiippehen braun bewimpert. Vordersehenkel bis zur Hälfte, Hintersehenkel oberseits an der Spitze schwarz. Vorder- und Mitteltarsen ron der Spitze des ersten Gliedes an, Hintertarsen ganz sebwillz; letztes Glied der Vordertarsen mit den Pulvillen verbreitert. Drittes Fiihlerghied zweimal so lang wie breit. $25 \mathrm{~mm}$ lang . . . . . . . . . cuprinus Wheel. ơ

19 Sehiippeken braun bewimpert. Hintersehenkel an der Spitze sehwarz; letztes Glied der Vordertarsen schwarz und mit den Pulvillen verbreitert, letates Glied der Mitteltarsen selıwarz. $26 \mathrm{~mm}$ lang.

varipes Aldr. O' 
Sehiippehen sehwarz bewimpert. Hintersehenkel und Hintersehienen an der Spitzenhälfte braun, Endglieder der vordereu Tarsen und die Hintertarsen braun: Vorderschienen nebst Metatarsus interseits mit kammartigen Borsten; Vorderschienen an der Spitze mit zwei langen Borsten. $4.5 \mathrm{~mm}$ lang . . . armatus n. sp. of

20 Fiihler schwarzbraun, erstes Glied rot. Schïppehen weiß bewimpert. Hinterleib erzgriin, zweiter Ring und die Seiten des dritten und vierten Ringes gelb. Hintersehenkel an der Spitze etwas verdickt und braun, Hinterschienen an der Spitze schwach verdiekt; Hintertarsen sehwarzbraun, alle Glieder last gleich lang, etwas verdickt und beborstet. $5 \mathrm{~mm}$ lang. . . . . brevitursis n. sp $\sigma^{n}$

- Erstes und zweites Filhlerglied gelb, dasdritte schwar". Metatarsus der Hinterbeine libuer als das zweite Glied; das dritte kirzer als das vierte und mit längeren schwarzen Haaren besetzt. Vierte Längsader ror der Fliigelspitze endigend. 2-2.5 mm lang. tertianus Lw. C우

- Hiibler ganz scliwarz . . . . . . . . . . . . . . 21

21 Sehlippehen schwarz bewimpert. Hinterschenkel nieht verdiekt und ganz gelb. Hinterschenkel und Hinterschienen an der Spitze braun. Hintertarsen schwarzbraun; drittes Glied der Ilintertarsen kurz, oval, unten kurz beborstet; $1211^{\circ}$ die Vorderluiften gelb. Vierte Längs ader an rler Fligelbenle kur\% gekniekt. $3 \mathrm{~mm}$ lang.

$$
\text { E'l-Angeli n. sp. O’ }
$$

Schiippchen weiß bewimpert. Hiiften alle gelb. Drittes und viertes Tarsenglied der Ilinterbeine beborstet, anBerden nocl das finfte Glied der Vordertarsen nit den Pulvillen rerbreitert. Spitze der Hinterschenkel und Hintersehienen mitunter braun, Tarsen von der sipitze des ersten Gliedes an selıwarz. $2.75-3 \mathrm{~mm}$ lang. marcidus Wheel. ơ

22 Wrstes und zweites Fiihlerglied rotgelb, drittes braun. Vorderhiften šelb. Vorder- und Hintersehenkel oberseits etwas braun gestriemit; Hinterschienen an der Spitzenhälfte braun, Hintertarsen schwarz; Mitteltarsen brann, die drei mittleren Glieder verbreitert und hellgelb. $5 \mathrm{~mm}$ lang. . . . . . . . . intermedius m. sp. ठ

- Flibler gauz schwarz. Vorderhiitten gelb; Spitze der Hintersehenkel und Sehienen sowie die Hintertarsen braun. Mittelschiene nebst Netatarsus kammartig behaart, die ibrigen 'T'ursenglieder sehr' lang und dïnn; an den Vordertarsen sind die letzten vier Glieder gleich kurz und braur. $35 \mathrm{~mm}$ lang . . . . . ciliatus n. sp. 3

- liibler ganz sehwarz. Hinterschenkel aul der Oberseite gebriunt; das finfte Glied der Vordertarsen mit den Pulvillen verbreitert; das vierte und fünfte Glied der Mitteltarsen seliwarz, verbreitert nnd behart, ferner sind die drei ersten Glieder der Hintertarsen breiter als die beiden letzten und las zweite Glied ist an der Spitze lang beborstet. $25 \mathrm{~mm}$ lang. . . . . . . . migil Wheel. o 
23 Beine ganz schwarz. . . . . . . . . . . . . . . 24

- Beine uieht ganz schwar\%, wenigstens die knilee rostgelb. . . 26

24 Hintertarsen verziert. . . . . . . . . . . . . . . . 25

Mitteltarsen verziert, das fihnfte Glied kurz und breit gedriiekt. Sehiipp)chen weif bewimpert. Gesieht und Taster sehwarz. Vorderhiuften schwal'z behaart. Dritte und vierte Längsadern etwas gesehwungen, die vierte Lingsader etwas $\mathrm{v} \cap \mathrm{r}$ der Fliigelspitze endigend. $3 \mathrm{~mm}$ lang. patellitarsis $11 . \mathrm{sp} . \mathrm{O}^{x} \mathrm{y}$

25 Das zweite und dritte Glied der Hintertarsen sehr kurz, fast kugelartig, das dritte nit einer starken, das zweite mit einer selrwäieheren Borste, das vierte längliehoval mit cingen kurzen breitgedriiekten Borsten. Sehiippehen selwarz berwinpert. Vorderhiiften weiß bebart. Gesieht und Taster blaBgelb. $3 \mathrm{~mm}$ lang. globulitars is n. $\mathrm{sp}$. O'

Das dritte Glied der Hintertarsen unten an der Basis mit vier Borsten und anf der Mitte mit zwei sebmalen Lamellen. Gesieht und Taster silberfarbig. $2 \mathrm{~mm}$ lang. . . . . aequatorialis $\mathrm{n} . \mathrm{sp} . \mathrm{O}^{\circ} \mathrm{C}$

26 Sehlippehen sehwarz bewimpert . . . . . . . . . . . 27

Schiippehen weiß bewimpert. Gesicht hellgrau, Taster braun. Mittelschenkel, Vordersehienen, Nittelsehienen nebst ihren Metatarsen gelblich. Metatarsus der Hinterbeine lainger als das zweite Glied, unten mit Borsten und längeren Harren. $3 \mathrm{~mm}$ lang. crinipes n. \$p. O

Sehïppehen weiß bewimpert. Gesicht und Taster weiß. Mittelsehenkel, Sehiene und Metatarsus bis zur Spitze, Vordersehiene und Metatarsus bis zur Spitze, Kiniee der Hinterbeine gelb. Metatarsus der Hinterbeine etwas lïger als das zweite Glied, aber ganz ohne Haare. $2 \mathrm{~mm}$ lang. . . . . . . . . . erraneus n. sp.

27 Vorderliuften weiß behaart. Taster und Gesiebt weil . . . . 28

Vorderhifften selrwarz behart, Kniee gelb. Hintersehienen stäker als gerölnnlieh beborstet. Hintermetatarsus so lang wie das zweite Glied. $25 \mathrm{~mm}$ lang . . . . . nigriciliatus n. $8 p . \sigma_{7}$

28 Vordersehiene und Metatarsus bis nahe zur Spitze rotgelb; das erste und zweite Glied der llintertarsen verbreitert und zart beborstet. Fliggelhinterand wie gewiohnlieh geformt; dritte und vierte Längsadern etwas gesehwungen. $35 \mathrm{~mm}$ lang. . platypus n. sp. o7

- Knice gelb; die anßerste Wurzel und Spitze der vorderen Sehienen und die Wurzelhälfte ihrer Netatarsen gelb. Hinterbeine ganz sehwarz; Hetatarsus längel als das zweite Glied, an der Wurzelbälfte mit funf langen Borstenharen besetzt. Hinterrand des Fliigels von der Basis bis zur Niindung der fiuften Längsader banehig vortretend.

$3.5 \mathrm{~mm}$ lang . . . . . . . . . pilitarsis n. sp. J"c

- Nur die Kniee der Vorder- und Mittelbeine gelb. Hintermetatarsus etwas linger als das zweite ftlied. ohne Haare. $25-3 \mathrm{~mm}$ lang. 


\section{Subsympycuus.}

Subgenis novum Sympycni generis.

Ieh bin genötigt, anf eine vorliegende Form ein neues Subgenus zu Sympycmus aufzustellen. Die Unterschiede liegen darin, daß sowohl das erste wie das dritte Fühlerglied und anch das erste Füllerborstenglied anf'ällig verlängert sind; die Ftuhlerborste stelt ganz basal und ist nackt. Die Vorderbeine sind stark verziert; sonstige Unterschiede finde ich nieht. Ieh verweise liierbei anf einen ähnlichen Vorgang ron Wheeler, der auf bestimmte Merkmale hin anch eine Untergattung Nothosympycmus aufgestellt lat.

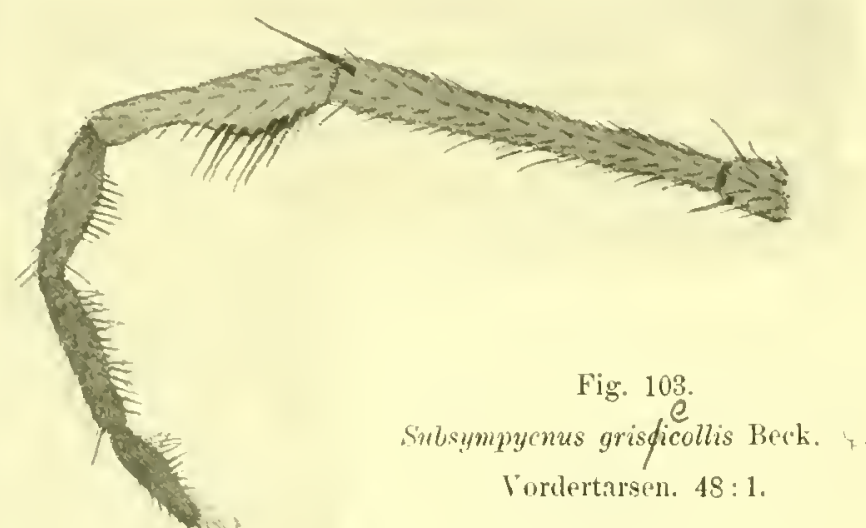

1 griseccolles n. sp. ð. 22 Figmren . . . . . . . Ameriea merid.

o. - Thoraxriicken und Schildehen gauz aschgrau bestiubt mit 6 Paar Dorsozentralborsteu. Akrostikalbörstchen fehlen. Schwiuger und Schtippehen blaßgelb, letztere weiß bewimpert. Brustseiten hell aschgran, welche Färbung naeh unten bin allmälich in die gelbe Farbe der Hiiften iibergeht. - Kopf: Stirne mattbraun, Untergesieht sehmal, weiß, Taster und Rtissel gelb. Fiihler gelb, drittes Glied gebrïunt; das erste ist sehr lang und ganz nackt, ungefïlur so lang wie der zweite und dritte zusammen; das zweite kurz napfïormig, das dritte reiehlich doppelt so lang wie breit, oral mit etwas stumpfer Spitze; die Fiihlerborste steht auffallend basal, das erste Glied derselben fast so lang wie das dritte Ftihlerglied und ist ebenso wie das zweite Borstenglied ganz nackt, selbst bei 48 facher Vergrößermng. - Hinterleib sehr seblank, zylindriseh, erzfurbig gläuzend, die ersten drei Ringe sind aber gelb, sehwarz behaart. Das Hypopygium hat die gleiche Form wie bei Sympycnus. - Beine mit Hiiften gelb, sehr seblank und lang; Hintersehienen von der Wurzellïlfte an nebst Tarsen allmiihlich 
schwarzbraun gefärht; Vitteltarsen rom zweiten Gliede an, Vordertarsen rom dritten Gliede an cbenso gefïrbt; an den Vorderbeinen ist das erste Glied einfach, so lang wie das zweite und dritte zusammen; das zweite ist auf der Wurzelhilfte der Innenseite, das dritte ebenda auf der Nitte ansgebancht und hier kräftig beborstet; das vierte ist etwas liinger als das dritte und nit dem fünfteu unterseits etwas beborstet (s. Figur 103). Nittel- und Hinterschenkel zeigen deutlich feine Prilipikalborsten. - Fliigel schwach graubräunlich, an der Basis ein wenig keilförmig; dritte nud vierte Längsadern etwas gebogen und parallel laufend; hintere Querader um das Doppelte ilrer eigenen Läinge vom Flügelhinterrande entfernt. $3: 5 \mathrm{~mm}$ lang.

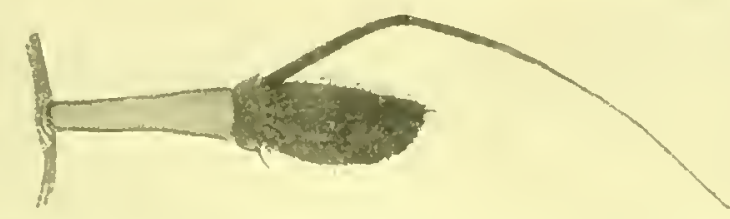

Fig. 104. Subsympycmus grisficollis Beck. Fühler. 48:1

$1 \sigma^{\circ}$ ans Peru-Arequipa, 18. XI. 1902 [Schnuse] Dresdner zoologisches Musenm.

\section{Hyptiocheta.}

Novum genus Campsicneminarum.

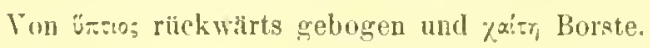

\section{Gattungscharakter.}

Eine durch Fïhlerbildung und Fliigeladerung yleich ansgezeichnete Art $\left(\sigma^{7}\right)$, soust durchaus im Habitus eines Sympycnus. Thorax mit sechs Uorsozentralen, ohne Akrostikale und mit zwei Schildborsten. Kopf: Stirne breit, Augen unter deu Fühlern stark genihlert, auch beim $q$ nicht sehr breit. Rissel und Taster unbedeutend. An den Fiihlern ist das erste Glied kurz, nackt, das zweite querliegend, das dritte im ganzen länglich dreieckig, auf der Oberseite stark konvex mit einer hart an ler Basis einsetzenden, stark nach vorne gebogenen nackten Borste, deren Wurzelteil sehr lang ist und deren Endteil unter dem Mikroskop etwas behaart erscheint. Fühler des $q$ normal. Hinterleib mit sechs Ringen; llypopyg klein, deutlich hervortretend, aus zwei Teilen bestehend mit deutlichen einfachen Anbiingen. - Beine lang, ganz einfach mit langen Metatarsen all allen Beinen und geringer, nur zartel Bcborstung. Priapikale del lliuterschenkel zart, aber 
vorbanden. Pulvillen und Krallen klein. Fliigel groß, von der gewöhnlichen Form, die Aderung hat aber einc besondere Abweichung dadureh erhalten, dali die dritte Liingsader nicht in den Fligelrand ausläuft, sondelı sich vorher mit der zweiten verbindet, so daß hierdureh eine geschlosseneund gesticlte Zelle entsteht; die vierte

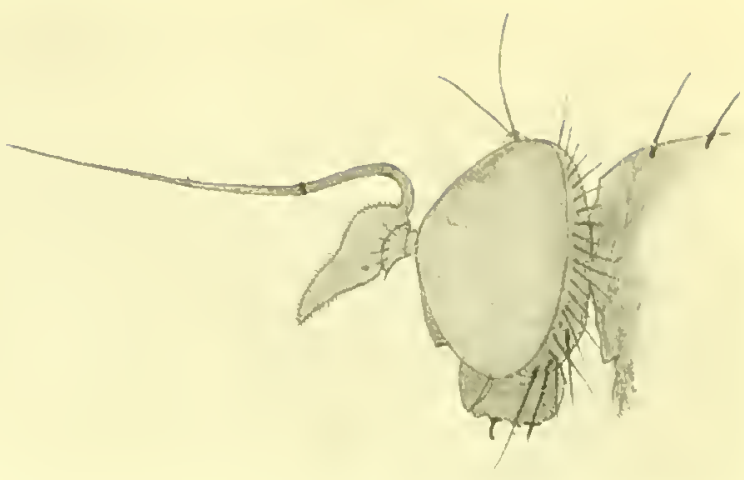

Fig. 105. Hyptiocheta convexa Beek. ठౌ.16:1.

Längsader ist dadurch weiter als gewöhnlieh von der dritten abgeriickt und mindet etwas hinter der Fligelspitze (s. Figur 106).

1 convexa n. sp. $d^{\pi}$. 2 Figuren. . . . . . America merid. 0. - Thorax ron metallisch grinlichblauer Grundfarbe, anf dem Rïcken graubräinulich bereift, schwach glänzend. Sehwinger nnd Sehtippchen hellgelb, lctatere braun gesäumt, mit Wimpern von verschiedener Farbe, lald weiß, lald braun schimmernd. Kopf: Stirue von metallischblaner Grundfarbe, durch Bestäubung aber matt brïunlich; das sebmale Gesicht ist weiß, die Taster gelb. Riissel schwarz, kurz und ziemlich dick mit kleiner, etwas gebogener Stcchborste. Hinterkopfailien unten weib. Fiihler schwarzbraun, die beiden ersten Glieder rotgelb, die nackte, dicke Borste schwarz; Hinterkopf auch schwarz. - Hinterleils glinzend schwarzgrïn bis bronzefarbig mit ziemlich langer weißer, häufig braun schimmernder Belaarung. Hypopyg im ersten Teil metalliscl glänzend, zweiter Teil gelb mit schwärzliehen, lamellenförmigen behårten äußeren Anhängen. - Beine ganz gelb, die anßersten Tarsenglieder kaum etwas gebräunt; Vorderhiiften weiß bchaart, die Borsten der

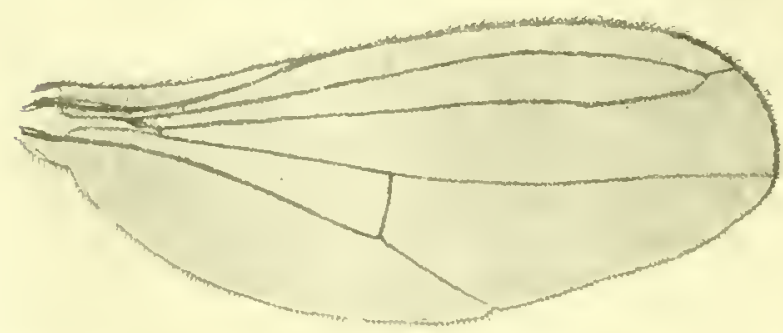

Fig. 106. Hyptiocheta convexa beck. o. litugel, 16:1. linteren Hïften ebenfalls weiß. Fliigel fast wasserklar mit gell)brüunlichen Adern, diese im Verlauf wie oben angegeben. $3 \mathrm{~mm} \lg$. 
Q. - Das nicht sehr breite Gesicht ist aschgrau bestiiubt; dic Fiihler sind normal; das dritte Glied nicht langer als breit, mit dorsaler Borste. Flügel ebenfalls normal, dritte und vierte Läingsadern parallel, im iibrigen dem ơ gleich.

\& ơ, 1 a ans Peru-Urubamba, 18. II. 1906. $3000 \mathrm{~m}$ hoch [Schnuse] Dresdner zoologisches Museum.

\section{Cal!rxochuetus.}

Big., Ann. Sur, Entow. Fr. ser. 6. VIII 13ullet. XXIV (1888).

Big., Ann. Soe. Entom. Fr. ser. 6. X 282 (1890).

Notosympycnus Wheel. Iroceed. Californ. Acad. Se. ser. 3 Zoulug. II 47 (1899).

Wheeler hat sechs Arten in diese seine Gattung gestellt; er zwcigt sie von Sympycnus ab mit folgendem Unterschiede: Das dritte Fiihlerglied ist groß, länglicboral; die Fiblerborste sitzt ganz an der Wurzel des dritten Gliedes und ist beim $\sigma$ namentlich an der Spitze deutlich rerdickt; an den Beinen sind die Vordermetatarsen stark verkỉrt.

Da ich diese Gattung durch Inangenscheiunahme nicht kennen gelernt habc, muß ich mich darauf beschrïnken, die Bestimungstabelle in der Ubbersetzung wiederzugeben mit dem Hinweis aluf Wheeler's Beschreibungen.

\section{Bestimmungstabelle.}

1 Stirne metallisch violett, glïnzend . . . . . . . . .

— Stime niclit metallisch violett . . . . . . . . . . 5

2 Vorderschienen verdickt . . . . . . . . . . 3

- Vorderschienen nicht verdickt . . . . . . . 4 4

3 Zweites Tarsenglied der Vorderbeine an der Spitze nit einer langen Borste . . . . . . . . . . fortunatus Wheel. 0

- Zweites Tarsenglied der Vorderbeine ohne solehe Borste vegetus Wheel. $\sigma^{7} q$

4 Alle Hiiften gelb.

Nur die Spitze der Vorderhuiften gelb

$5 \quad$ Fühlerborste spitz auslaufend

- Fïhlerborste an der Spitze rerbreitert frontalis Lw. Ot? solrinus Wheel. of Oreas Wheel. $\sigma^{7}$ nodatus Lw. ơ?

\section{Artrerzeichnis.}

1 fortunatus Wheel. of, Proceed. Calitorn. Acad. Sc. ser. 3 Zool. II 52. 51 tab. III fig. \$3-85 [Nohlosympycmus] (1899) . America sept. 2 frontalis Lw. O̊ 9 , N. Beitr. VIII 67. 1 [Sympicnus] (1861 America sept. 3 nodatus Lw. ơ, Berlin. Entom. Zeitschr. V1 ⒖ 6i [Sympycnus] (1862) . . . . . . . . . America sept.

4 Oreas Wheel. 07, I'roceed. Caliform. Acal. Se. ser. 3 Zoolog. II 55. 54. tab. III fig. 86-87 [Nothosympycuus] (1899) Imerica sept. 
5 sobrimus Wheel. of, Proeeed. Californ. Acad. Sc. ser. 3 Zoolog. II 54. 53 tab. III fig. 88-91 [Nothosympycnus] (1899) Amerie:ı sept.

6 vegetus Wheel. $0^{7}+$, Proceed. Californ. Aead. Se. ser. 3 Zoolog. Il 53. 52 tab. III fig. 76-79 [Nothosympycnus] (1899) America sept.

L.oew, N. Beitr. V 48 (1857).

\section{Chrysotimus.}

Der Charakter der Gattung ist der gleiche wie bei unseren palaiaktisehen Arten. Es sind nur drei Arten bis jetzt bekannt, eine aus Zentralamerika ınd zwei aus Nordamerika, letztere jedoch nur in weiblichen Geschlecht.

\section{Bestimmungostabelle.}

1 Thorax und Hinterleib metalliseh gefïrbt. Fïhler schwarz . . :

- Thorax und Hinterleib gelb, dicht grau bestiubt. Ftihler gelb. Hintermetatarsus kiirzer als das halbe zweite Tarsenglied mit einer feinen dichten

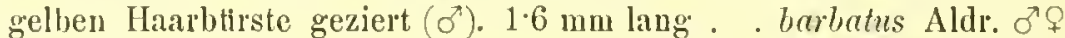

2 Hinterleib gelb, der letzte Ring metallisehgrin. $2 \mathrm{~mm}$ lang pusio Lw.

- Hinterleib gelb, der erste nnd die beiden letzten Ringe metallischgrün. $2 \mathrm{~mm}$ lang delicatus Lw.

\section{Artverzeiclinis.}

1 burbatus Aldr. O’ , Kansas Univers. Sc. Bull. I 91 (1902) America centr.

2 delicatus Lw. Q, N. Beitr. VIII 74.2 (1861) . . . America sept.

3 musio Lw. O, N. Beitr. VIII 74. 1 (1861) . . . . Ameriea sept.

Laew, N. Beitr. V 42 (1857).

\section{Nomthochlorus.}

Chrysochlorus Lw., N. Beitr. Y 48 (1857) lapsus.

Leptopus Halid., Thle 'Loolog. Journ. V 358 (1832) prafeoceup. Latr. Hemipt. 1809. Raf. P'ise. 1815. - Lam. Crust. 1819. - Fall. Dipt. 18:3.

1 helvinus Lw. o, N. Beitr. VIII 75. 1 (1861) . . . . Chicago

\section{Anepsiom? yir.}

Bezzi, Zeitschr. syst. Hymen. Dipt. 11 192. 5 (1902).

Anepsius Lw., N. Beitr. Y 45 (1857) pracocenp. Le (unt. Culeopli. (1851).

1 linearis Aldr. $\sigma^{7}$, Trans. Ent. Soc.London 317. 1(1896) America centr.

Ich kenne die Art nur aus der Beschreibung und verweise anf dieselbe.

Loew, X. Beitr. I 14 (1857).

\section{Teuchophorms.}

1 clavigerellus Wheel. ơ, Proceed. Caliform. Acad. Se. ser. 3 Koolog. Il 57. 66 tab. IV fig. $103-104$ (1899) . . . . . . America sept.

Ich kenne diese Art nicht weiter als durch die Beschreibung; diese zeigt uns aber, daß eine Ubereinstimmung mit einer unserer europäischen Arten nicht vorhanden ist. 


\section{Gruppe XI.}

\section{Chrysosomatinae.}

Nach dem Stande unserer lentigen Kenntnis kännen wir ill der nearktischen und neotropischen Region bei vorstehender Gruppe vier, vielleicht fünf verschiedene Gattungen unterscheiden. Die herrschende, schr zahlreich vertretene Gattung ist die, welche Bigot 1859 C'ondylostylus nannte; sie hat eine dorsale Fiblerborste und schwarz bewimperte Schiippchen; bei dem größten Teil der Arten zeigen die Flijgel zwei braune, am Vorderrande verbundene Querbinden; sic ist hauptsächlich in Südımerika vertreten, ihre Verbreitung nimmt dann mach Norden lin allmäblich $a b$, aber selbst in der eigentlichen nearktischen Region finden wir noch verschiedene Arten. - Bei der großen Zahl der Arten habe ich beide Regionen getrennt behandelt.

Als zweite Gattung zeigt sich uns dann unsere paliarktische Sciopus Zell. mit dorsaler Füblerborste und weißen Wimpern der Schtippehen; sie ist in beiden amerikanischen Regionen zu finden, wenn auch im Norden etwas bäufiger: Die Artenzahl ist aber beschränkt.

Als dritte können wir vielleicht die von Aldrich 1893 anf gestellte Gattung Leptorhethum ansehen; sie ist mit Sciopus nahe verwandt und weicht nur ab durch ein schmilleres Gesicht und durch eine weniger vertiefte Stirn; sie wurde nur auf ein einziges Exemplar gegriindet, dessen Kopf nach Aldrich's Angaben zusammengeschrumpft war. Ob die geringere Gesichtsbreite und Vertiefung der Stirn angesichts der Einschrumpfung des Kopfes eine besondere Gattung begriinden können, läßt sichcrlich einige Zweifel berechtigt erscheinen, namentlich da Aldrich in seiner ansfïhrlichen Beschreibung "Diptera of St. Vincent" (1896) selbst zugibt, daB die geringere Vertiefung der Stim wohl zum Teil durch Einsehrumpfung hervorgerufen sein könnte; irgendwelche andere Unterschiede kann man der Beschreibnng nach auch nicht herausfinden. Ich komme zu der Ansicht, daß man dieser Gattung höchstens den Wert einer Untergattung von Sciopus beimessen kann, wenn man sic nicht ganz einziehen will, was wobl das beste sein wird.

Schiner machte uns 1868 bekannt mit einer vierten Gattung WLesorhaya, dic sich bei dorsaler Ftihlerborste hauptsächlich durch abweichenden Verlauf der vierten Längsader unterscheidet.

Als wcitere Gattung können wir dann Megistostylus Big. nennen mit lang kegelförmig ansgezogenem dritten liihlerghiede ohne sichtbare Trennung von der langen ap̧ikalen Ftiblerborste. Dieser anch in Stidamerika auf- 
tretenden Gattung werden wir in der orientalisehen und athiopischen Region wieder begegnen, die wohl ibre eigentliebe Heimat ist; sie hat in Stidanerika nur eine geringe Verbreitung nnd ist hier wohl kaum als eine indigene aufzufassen, sondern als ein Überbleibsel einer längst vergangenen geologisehen Epoche, in der Siidamerika noch mit Afrika verbunden war.

\section{Bestimmmingtabelle fïr die Gattungen der Chrysosomatinae.}

Ieh will aus den oben angefïhrten Grinden die Aldrielı'sehe Gattung Leptorhetum hier in der nachfolgenden Tabelle nieht mit auffihren; anstatt deren bringe ich aber noeh die Gattung Chrysosoma Guér, obgleieh sie aus der orientalisehen Region staumt und auch mit aus dem Grunde, weil sie dort die Hauptstelle einnimmt. Hit ihr sind dann in dieser Tabelle alle bisher bekannten Gattungen dieser Gruppe zusammengefaßt und cinander gegeniibergestellt.

1 Arten mit gegabelter vierter Läingsader; sieben Hinterleibsringe . 2

- Arten ohne Gabelung der vierten Längsader, die aber an der Fligelbeule eine duppelte, fast rechtwinklige Biegnng macht. Selitdchen mit uu zwei Hauptborsten, denen nu zwei nubedeutende Härchen noeh zugesellt sind. lieine und Hinterleib fast borstenlos. Wimpern der Schiippchen weif nud schwarz, in der Regel weiß; nur seehs Hinterleibsringe . . . . . . . . . Mesorhaga Schin.

¿ Arten mit dorsaler litihlerborste . . . . . . . . . . . . 3

- Arten mit apikaler Fühlerborste . . . . . . . . . . 4

3Wimpern der Fligelsehiippehen weiß. Akrostikallörstchen meist nur haarförmig. Schildehen um mit zwei Randborsten. Sciopus Zell. Wimpern der Fligelschïppehen schwarz. Akrostikalbörstehen so stark wie die Dorsozentralborsten Schildehen mit rier gleichwertigen Randborsten

romdiylostylus Big.

4 Erstes Fiblerglied kugelig rerdickt, nach unten hin etwas banchig vortretend ohne Beborstung; zweites Glied sehr verkiirzt, unten mit einer lingeren Borste; drittes Glied kegelförmig in eine lauge nackte Borste ibbergehend, olme sichtbaren Borstenansatz, die ohere Seite dieses Gliedes glatt und glainzend; in der Regel uur drei Dorsozentralborsten und drei Akrostikalborstenjaare. Schildchen mit zwei Haluptborsten nnd zwei Nebenbörstehen. Gabelader reehtwinklig abzweigend, hintere Querader S-förmig grebogen. Sehijpchen weiß bewimpert . . . . . . . . Megistostylus Big.

Erstes und zweites Fiilılerglied ron der gewöhnliehen Form; drittes Glied kegelförmig nit deutlich angesetzter gegliederter Endborste. Thorax in der Regel uur mit zwei Paar Dorsozentral- und drei Paar Akrostikalborsten. Schillehen mit nu zwei Paar Randborsten. Sehiippehen weiß, selten schwarz hewimpert . . Chrysosoma Guér. 


\section{Neotropische Region.}

\section{Conerlylostylus.}

Bigut, Aun. suc. Euton. F'r. B sėr. VII 215 (1859)

Type: Psilopus bituberculatus Macp.. Dipt. exot. 11.2. 120. 14 tab. XX lig. 2 (1812) brasilia.

Aedipsilopus Big., Aun. Sone. Ent. Hr. 21: (1859) Blikilial.

Condilotylus Big.. Am. soc. Ent. kr. sir. 3 V11 223 (1859).

Dasypsilopus Big.. Ann. Soc. Ent. l'r. 215 et 224 (1859).

Type: Psilopus pilipes Maci., Dipt. exot. 11. 2. 117 tah. XXI tig. 6 (1S42) Brasilia. Gymnoceromyia big.. Ann. Sue. lint. Fr. 27 ci et 293 (1890).

Tspe: Gymnoceromyia andicola Big. I. c. 293 (1890) Chile.

Oedipsilopnes Big., Ann. Soc. Ent. Fr. 224 (1559).

Type: Psilopus posticutus Wied.. Außerenrop. zweit. Ins, 11 217. 7 (1830) Mrasilis. Psilopodinus Aldr. (nee Big.). Trans. Amer. Ent. Sive. XXX 279 (1904),

Psilopus Aldr. (nec Meig.), Kansas Iniv. (quat. Tol. II Nr. 1. 48 (1893).

Psilopus Enderl. (nee. Heig.), Zool. Jahrb. Apengel, suppl. XT 1. 367-408 (1912). Tylochaetus Big., Ann, ,oe. Ent. Fr. Bullet.'XXIV (1888).

Ton den neun Gattungsmamen, die hicr fiil siodamerikanische Arten zur Verfiigung stehen, bleiben nach Ausschluß der bereits anderweitig verbrauchten oder irrtimlich benutzten Namen Psilopus Meig. und Psilopodinus Big. sicben Bigotsche Namen tibrig, von denen Condylostylus 185:! zuerst gen:lnut wird, und zwar als Gattung mit dorsaler Ftihlerborste. Wir können meiner Ansicht nach diesen Namen ruhig annehmen, da die typische Art " Psilopus bituberculatus Naco. unserem Gattungsbegriff entspricht. Bigot hat $z$ wal diese typische Art anch noch fiir zwei andere Gattungen, spathiopsilopus und Tylochaetus, verwaudt, aber man wird diese gedankenlosen Wiederholungen oder Verbesserungen als ungiiltig ansehen können, da sie spïter vorgenommen wurien und rernachlässigt werien können, ohne dic Gesetze der Priorität zu verletzen. Die Fihlerborste ist bei dieser Art etwas verlängert und trägt anf iluer Mitte cine lamellenförmige Verbreiterung. Solehe l'ormen, auch mit kleinen Lamellen an der Spitze der Fiblerborste kommen in dieser Gattung melnfach vor, olme daß sonst irgendeine del eharakteristischen Eigenschaften feblte oder cine Abäinderung erfiihre; es eriibrigt sich also, diese lediglich männlichen Artmerkmale zu rattungsmerkmalen emporzuschrauben, wie Bigot dics getan hat. Was die beiden rorlin genannten Gattungen sputhingsilopus und Tylochaetus anlangt, so ist letztere einfach synonym mit gleicher 'I'ype; crstere ist zunächst synony'm ron Maryaritostylus ligg., deren Type I'silomus globifer Wied. ist, eine indische Gattung mit apikaler Fiihlerborste (Chrysosoma Guér.); ihrem Synonym Suathiopsilopus hat Bigot dam noch überfliissigerweise den ganz anders gearteten I'silopus bituberculatus Macq. angehängt; siehe hieriber das Näberc in meincr Einleitung zur paläarktischen Gattung sciopus Zell. 
Aldrieh hat in den Transact. Amer. Entom. Soc. XXX 279 (1904) fiir unsere Gattung Condylostylus den Namen Psiloporlinus Big. gewählt; Bigot nannte als Type unsere palaiarktische Art platypterus Fbr. mit weißen Wimpern der Schiippehen. Es seheint, daß Aldrieh unsere durehaus einheitlieb organisierten Sciopus-Arten rerkannt hat, da el sie mit seinen amerikanischen schwarz bewimperten und anders beborsteten Arten gleichgestellt bat.

\section{liattungscharakter.}

Ganz in Habitns unserer Sciopus-Arten. Alle Arten, die ich gesehen habe, sind ron herrlieh blauer bis goldgriiner Farbe; Arten mit bestäubten 'Thoraxriieken, wic dies bei den paliarktischen Arten die Regel ist, kommen ror, sind aber seln selten. Der Thoraxriieken hat je fïnf Dorsozentralhorsten (selten nn vier); die Akrostikalbörstchen sind in Gegensatz zu Sciopus zu gleichwertigen Borsten geworden; nu je vier Paare, selten drei, die an der Abplattung vor dem Sehildehen baltuachen; von Sehildborsten sieht man vier, aunihernd gleich starke Borsten, anstatt deren zwei, ferner noch eine Humeral, eine Posthumeral, eine Sutural-, zwei Supraalarund eine Postalarborste. Die Wimpern der tegulae sind fast stets sehwarz. Kopf flach, etwas breiter als der Thorax. Stirn und Gesicht breit; die erstere ist am Scheitel tief eingesattelt mit hervoragendem Punktangenhöcker, letzteres auf der Mitte durch einc seichte Furehe geteilt, der untere Teil meist bestaubt; am Seheitel und inneren Angemrande sieht man schwielenartige Erhöhungen, die mehr oder weniger stark behart sind; solche Schwielen fehlen bei unseren paliarktischen Arten. Fiihler klein, das erste Glied ist naekt, das zweite mit starken Randborsten, das dritte rund, Fiihlerborste nackt, dorsal, selten subapikal, lang, mitunter so lang wie der ganze Körper, auch mit lamellenförmiger Verbreiternng auf der Mitte und an der Spitze. IInterleib mit seehs ganzen und einem siebenten nicht immer vollwertigen Ringe, deren Hinterränder längere Borsten tragen, während die eigentliehe Behaarung nur spärlich und kurz ist. Das Hypopyg ist klein, etwas kelchförmig umgebogen, mit siehtbaren iußeren Anbaingen, die meist unbedentend, entweder zangenförmig oder blattförmig siud, mitunter sieh aber anch zu ungewöhnlieher Linge entwickeln. - Beine lang und sehlank mit fust stets eharakteristiseher Beborstung ( $\sigma^{7}$ ). Fliigel lang, die Gabelader in verschiedener Biegung mit und ohne Anhang; die hintere Querader ist gerade oder nur wenig gehogen, sie steht meist steil; bei der iiberwiegenden Anzahl der Arten sind die Fligel durch zwei Querbinden gezeichnet, ron denen die eine iiber der hinteren Querader, die andere iber der Gabelader liegt; beile sind aun Vorderrande verbunden und schließen gewöhnlich einen hellen Streifen ein, der mitunter bei gröBerer Ausdehnung der Briunung zu einem Fensterfleeken zusammensehrumft; in einzelnen Fällen lösen sich diese zwei brannen 
Binden in zwei isolierte Flecken anf oder auch nur zu einem Scbattenflecken am Vorderrande.

Im Kataloge Kertész VI stehen 120 Arten alls Nord- und Siidamerikit anfgefiibrt. Sieht man die älteren Beschreibungen dureh, so erkennt man bald, daß diese fast alle gar keinen Wert haben. Schon Loew 1861 und Aldrich 1901 geben dieser 'Tatsache hinreichend Austruck. Es handelt sich hier hauptsächlich $11 \mathrm{~m}$ die Beschreibungen von Fabricius, Macquart, Wiedemann, Walker und Bigot, die alle nur die gewölnnlichen, stets wiederkelırenden Fiirbungsverhïltnisse angeben und wiederbolen, olune bemerkt zu haben, daß die Miinnchen, selbst sebr nahestehender Arten, bei fast gleichbleibendem Habitus und Firbung sich in erster Linie dureh charakteristische Gestaltung und Beborstung der Beine unterscheiden; bei den Arten mit gefärbten Fligeln tritt noch hinzu Form, Ausdehnung und Stärlie der Bindenzeichnung, schließlich auch die Form der Analanlïinge; von allen diesen zu' Unterseheidung notwendigen und braltehbaren Merkmalen findet man bei allen diesen Schriftstellern kaum eine Andeutung, man muß daher ibre Beschreibungen als unbrauchbar beiseite legen. Auch Wierlemann, der sonst so viele gute Beschreibungen geliefert hat, ist bier auffallend oberfiichlich; offenbar hat $\mathrm{cl}^{\mathrm{s}}$ sich durch die herrlichen Firmen blenden lassen und ist dabei an den eigentlichen Artmerkmalen wie ein Blinder roribergegangen; seine Arten wiirden uns auch weiter nicht interessieren können, wenn wir nicht das Gliick bätten, von ihm noch eine Reihe typischer Exemplare zu besitzen, so daß wir an der Hand dieser Dokumente doch noch viele seiner Arten haben auffinden, feststellen und rerwerten können.

Bei Bestimmung des mir vorliegenden Materials und der Einreilung desselben in die Tabellen habe ich mich beschrainkt auf diejenigen Arten, die mir durch 'lypen ron Wiedeman 11. a. bekannt geworden sind, sowie anf solche, die von Loew, Aldrich, Coquillet und Wheeler als mit seluwaren Wimpern der tegulae versehen beschrieben sind; es sind dies im ganzen 52 Arten; dazn treten natiulich die vielen nenentdeckten. Von vorhandenen Bestimmungstabellen kommen in Frage:

Loew, N. Beitr. VIII 81 (1S61).

Loew, Monogr. Dipt. of N. Amer. Il 244 (1862).

Aldrich, Biolog. Centr. Amer. Dipt. I 351 (1901).

Aldrich, 'Transact. Amer. Entom. Soc. XXX 279 (1904).

Meine folgende Bestimmungstabelle habe ich möglichst nach gleichen Gesichtspunkten aufgestellt, wie man sie in den Loew'schen und Aldrich'schen Tabellen vorfindet, sie geht jedoch selbstiindig und parallel in erweitertem Umfange nebenher; sie fubt hauptsichlich ant der charakteristischen Be. borstung und Behaarung der Schienen und Tarscu. Ich habe mich daranf 
beschrankt, un Arten zu lueschueiben, bei denen aueh das o bekannt war. Weibchen allein als besondere Art zu beschreiben, wie Wiedemann, Walker und auch noch Schimer in seinen Noraradipteren getan laben, halte ich fiur ein unfruclithares Bemiihen, das man nicht erst beginnen sollte. Weibehen zu unterseheiden mud zu bestimmen ist eine sehr schwierige Anfgabe, die selbst bein Bekanntsein der Männehen nieht immer restlos gelist werden kamn.

\section{Bestimmungstahelle fül die Männchè der Gattung Condylostylus Big.}

1 Schenkel alle rotgell

- Die hinteren Sehenkelpare schwar', Vorderschenkel gelb . . 26

- Schenkel alle sehwarzbian bis sehwarz . . . . . . . . . 33

2 Fliigel mit zwei am Vorderrande verbundenen braunen Querbinden 3

- Niigel mit einer vom Vorderrande bis zum hinteren Eude der Querader reichenden Querbinde. Fiihler schwarz. Fliigelyorderrand bewimpert, namentlich am Ende der zweiten Längsader. $3-4 \mathrm{~mm}$ lang infumatus Aldr.

Fligel glashell, olne Zeiebnumg.

; Fiihler schwar\%

- Fililer gelb

4 Brnstseiten silberschimmernd. Hinterleib gringold, zwciter und dritter Ring mit gelben Querbinden. Anallamellen länglieh dreieckig, schwarz. Beine nebst allen Hiiften lellgelb, Hintertarsen sehwarz. 6-65 lang. busilaris Wied. 0

- Brustseiten gelb. Hinterleib gelb, die Hinterränder der ersten ftinf Ringe und die iibrigen metallisch blau. Anallamellen lïnglieh dreicekig, gelb. Beine nebst allen Hiiften gelb, Hintersehienen und Hintertarsen schwarz. Die bramne Fliggelzeiehnung nit den am Vorderande bis zur dritten Liingsader verbundenen Querbinden krïftiger als bei basilaris. $7-8 \mathrm{~mm}$ lang'. caesar n. sp.

Brustseiten aschgrau. Hinterleib sehwarzgriin wit grauen Hinterrandsbinden. Anallamellen ziemlich gleich breit, lïnglich, schwïrlieh behaart. Beine nebst allen Hiiften hellgelb, Hintertarsen schwar\%. Fliigel schwach gelblieh getribt mit zwei sehwach ansgebildeten bramnen Querbinden, die am Vorderrande nu bis zur zweiten Lïngsader verbuuden sind. $5 \mathrm{~mm}$ lang . . . . vigilans $\mathrm{n}$. sp.

5 Die Fligelquerbinden sind am Vorderrande nur bis zur zweiten Liugsader verbunden.

- Die Fligelquerbinden sind am Vorderrande bis zแ dritten Längsader verbunden. . . . . . . . . . . . . , 14

6 Die Fiihlerborste ist in einem Punkte, auf $3 / 4$ ibrer Länge palettenartig verbreitert. $6 \mathrm{~mm}$ laug . . . . . bitulierenlatus Hacq. o 
Dic lühlerborste einfach, olne Verbreiterung . . . . . . 7

7 Alle Hiiften sehwarzgrall . . . . . . . . . . . . 8

- Alle Hiiften gelb. . . . . . . . . . . . . . . 9

Nnr die Vorderhiuften gelb . . . . . . . . . 10

s Hypopyg mit runden sehwarzen Lamellen und kleinen fadentörmigen

Anhingen. Vordermetatarsus $1 \frac{1}{2}$ mal so lang wie die Scbiene, an der Spitze weiß, die folgenden Glieder schwarz, das vierte schwarz bewimpert, das fiinfte weiß bewimpert. $7 \mathrm{~mm}$ lang interceptus Aldr.

Hypopyg grob mit langen federartigen Anbingen vou branner Farbe.

Hintersehenkel an der Spitze gebriunt. Vordermetatarsus etwas länger als die Schiene, an der Spitze nicht weiß. Außer der braunen Querbindenzeichnung haben die Fligel noch einen solchen Streifen am Vorderrande bis zum Ende der ersten Laingsader. $5.2 \mathrm{~mm}$ lang pennifer Aldr.

9 Fliigelquerbinden nur schwach ausgebildet. Vordertarsen zweimal so lang wie ilure Schiene, an dritten Glied mit mehreren blattförmig verbleiterten Borsten. Hypopyg mit langen wimpelförmigen Anläingen, $5-6 \mathrm{~mm}$ lang . . . . . . patellitarsis 11. sp. б

Flïgelbindenzeichnung deutlich, jedoch in ihrer Begrenzung verwaschen. Vordertarsen fast $21 / 2$ mal so lang wie ilhre Sehiene und nackt. Hypopyg mit kleinen fidenfürmigen, sehwaeh behaarten schwarzen Anhängen. $5 \mathrm{~mm}$ lang . . . . . . . . mulipes n. sp. ơ

10 Spitze der Mittelsehienen (Unterseite) mit einer starken abstehenden dornartigen Borste. . . . . . . . . . . 11

Spitze der Mittelsehiene ohne solche Borste . . . . . . . 13

11 Analinhäinge lang geißelfönig, anf der Wurzcliälfte etwas verbreitert, auf der Spitzenhälfte fadenformig und behaurt, ungefill $2-4 \mathrm{mal}$ so lang wie das Hrpopygium selbst . . . . . . . . . 12

Analanhänge nicht lianger als das llypopygium, stiel- oder fadenförmig anfgeriehtet, an der Spitze selbst hakenförmig mmgebogen und behaart. Mittelsehienen anßen fein behart, die abstehende Borste gebogen. Tordertarsen $1 \%$ mal so laug wie ihre Sehiene. 6 min lang

- subcordatus n. sp. ca

12 Wurzelteil der geifelförmigen Analauliange anf der Unterseite lang behaart und schopfförmig mit breitgedriekten stumpfen Borsten bewehrt, die fadenförmigen Spitzenteile am Ende verbreitert. Yordertarsen $13 / 4$ mal so lang wie die Sehiene. $7-7 \mathrm{~mm}$ lang. . . . flugellipodex n. sp. o

- Wurzelteil der geißelförmigen Analanbänge auf der Unterseite nur sehr spärlieh behaart, die Spitzen der fadenförmigen Endteile ohne Verbreiterung. Anhỉinge reiehlich viermal so lang wie dis Hypopygium. Vordertarsen zweimal so lang wie die Sehiene. 7 mm lang:

flagellatus n. sp. o

Wurzelteil der geeißelförmigen Anhänge kaum etwas rerbreitert, obne besondere liehaalung. Analaubänge fadenförmig, zweimal so lang 
wie das Hypopygium. Vordertarsen $1 \frac{1}{2}$ mal so lang wie die Sehiene. $7 \mathrm{~mm}$ lang . . . . . . . . serenus n. sp. O’

13 Sehwinger schwarzbraun. Hypopygium selwwarz mit zwei gelben, zangenförmig gebogeneu, am Ende löffelförmig elweiterteu und auf einer Scite sturk beborsteten Organen. $6-7 \mathrm{~mm}$ lang cochlearis u. sp. ठ Scliwingel gelb. Hypopyg schwarz mit zwei gelben, schmal dreieckigen Lamellen. $5.2 \mathrm{~mm}$ lang flavicoxa Aldr. ơ

14 Alle Htiften schwarzgran . . . . . . . . . . . . . 15 Vorderhiuften gelb . . . . . . . . . . . . 18

15 Mittelsebienen außen olue, oder nur mit weitlaufiger bewimperung 17

17 Sehwinger hellgelb. Hypopyg mit mäßig großen braunen, dreieckig zugespitzten Lamellen. Vorderhtiften an der Spitze etwas gelb. Vordertarsen ron besonderer Bildung: erstes Glied sebr lang, an der Spitze etwas erweitert, unten beborstet. Zweites und drittes Glied gleiel kurz, mnterseits mit einigen stumpfen Dornen. Fliigelzeiehnung gewöhnlich. 7-8 $\mathrm{mm}$ lang . . . . . . . . pedestris n. sp. $0^{7}$

- Sehwinger selıwarzbrann. Hypopyg mit langen fadenfömigen behaarten Anhängen. Vorderhuiften ganz sebwarz, Vordertarsen ohne besondere Bildung. Fliigel mit Querbindenzeiehnung, die sieh fast iiber die ganze Fläche ausbreitet, so daß diese rauehgrau erscheint. $7 \mathrm{~mm}$ lang completus n. sp. o

18 Mittelsehienen auf der Außenseite der ganzen Läinge nach bewimpert 19

- Mittelschienen olne solehe Bewimperung. . . . . . . . . 20

19 Hypopyg mit kurzen sehwarzen Anhängen. Vordersehienen außen mit vier bis sechs Einzelborsten. Vordertarsen $1 \frac{1}{2} \mathrm{mal}$ so lang wie die Sebiene. Fliigelquerbinden von gewöhnlieher Ausdehnung. $6 \mathrm{~mm}$ lang sipho Say o"

20 Ifypopyg mit zwei kurzen ovalen sehwarzen behaarten Lamellen und zwei sehr langen fadenförmigen behaarten Auhïngen. Fliigel uit zwei selı breiten bramen Querbiuden. 6-7 mm lang.

filiformis n. sp. $\sigma^{\text {"9 }}$

- Hypopyg olne lange fadenförmige Anhänge

21 Vordersebienen anf ihrer Außenseite mit einer Reihe lïgerer Borsten oder Haare, Mittelschienen desgleichen . . . . . . . . 2.2

- Vordersebienen fast naekt oder nur anf der Vorderseite mit zwei bis drei kurzen Einzelbörstehen . . . . . . . . . . . 23

22 Hypopyg mit Jreiten sehwarzen behatrten Lamellen. Vordermetatarsus so lang wie die Sehiene mit einer unregelmäißgen Borstenreihe anf der Aubenseite; zweites und drittes Glied kurz, viertes Glied unten kurz beborstet; Mittelsehieue nur wit einigen liurzen Börstehen. Fligelbiuden gewöhnlich. $7 \mathrm{~mm}$ lang . . . . clavipes Aldr. O

- Hypopyg mit kleinen kurzen stabförmigen gebogenen Organen. Vordermetatarsus im letzten Viertel der Unterseite mit einer charakteri. 
stischen Einzelborste. Vordertarsen 1.8 mal so lang wie ihre Schiene. Fligelquerhinden schwach und sehr sehmal. $4 \mathrm{~mm}$ lang

elegantulus n. sp.

23 Vorderschienen auf ihrer Ol,erseite mit zwei bis dreikurzen Börstchen 24

Vorderschienen nackt oder fast nackit. . . . . . . . . 25

24 Hypopyg mit zwei schwairzlichbramnen spitz dreieckigen behaarten Anluangen. Tordertarsen zweimal so lang wie die Schiene, Metatarsen unterseits mit kurzen Einzelbörstehen; ron den Fliłgelbinden ist die erste schmal, die zweite breit. $7-8 \mathrm{~mm}$ lang imperator Aldr. $0^{7}$

95 Alle Teile der Beine fast nackt. Vordertarsen fast doppelt so lang wie die Schiene. Von den Fligelquerbinden ist die rordere nur schmal. $3.50-4 \mathrm{~mm}$ lang . . . . . . brevis n. sp. o

Vordertarsen 1.8 mal so lang wie die Sebiene: Metatarsus unterseits kurz wimperartig belıart und mit fünf bis sechs etwas lïngeren Einzelbürstchen, das zweite Tarsenglied unterseits kriftiger beborstet. Fliigelquerbinden sehwach entwickelt. $6-7 \mathrm{~mm}$ lang.

felix n. sp. o

26 Hiiften schwarz, Torderhỉften an der Spitzenhälfte mit den Vorderbeinen, allen Schienen und Metatarsen rotgelb. Vorderschienen unten weitläufig be wimpert, oberseits mit zwei Einzelborsten; Mittelschienen mit einigen zarten Einzelbirstchen. Vordertarsen $1 \frac{1}{2}$ mal so lang wie ihre Schicne. Fliggelquerbinden nur sehwach entwickelt.

$4 \mathrm{~mm}$ lang . . . . . . . . . . . simplex n. sp. $\sigma^{\circ}$

27 Fiihlerborste rerliangert, an der Spitze palettenartig verbreitert.

imperialis Fbr. $0^{7}$

Fiihlerborste nicht besonders rerlingert, an ibrer Spitze nicht rerbreitert . . . . . . . . . . . . . 28

29 Analanhïge stark verlingert, in der Wurzel etwas verdickt, im letzten Drittel bandförmig verkingert, gegahelt und behaart. Vorderschienen etwas geschwollen und unterseits fein bewimpert. $4 \mathrm{~mm}$ lang.

$$
\text { singularis n. sp. } 0^{7}
$$

Analanhïnge stark verlängert, im Wurzeldrittel etwas rerbreitert, im Endteil fadenförmig, behaart und nieht gegabelt. Vorderschienen nackt, nicht geschwollen. $4 \mathrm{~mm}$ lang . . filipeniculatus Enderl. Analanbiinge nicht stark rerlängert . . . . . . . . . . 29

29 Hinterleib am zweiten Ringe mit gelh durchscheinenden Seitenflecken; die beiden letzten Glieder der Mitteltarsen schwach rerbreitert und schwarz gefiedert. $7 \mathrm{~mm}$ lang . . . . . andicola Big. o

Hinterleib ohne durchscheinende Flecken . . . . . . . . 30

30 Vordertarsen einfach . . . . . . . . . . . . . 3 32

32 Mittelmetatarsus an der Spitze der Oberseite mit dichten etwas gebogenen Wimpern. Hinterschienen selu dentlich behart. Analanhänge schmutziggrau, zangenförmig. $4.5 \mathrm{~mm}$ lang . . . insularis Aldr. O

- Mittelmetatarsus eiufach. Analorgine schwarz. 4 mm lang. tonsus Aldr. $\sigma^{7}$ 
33 Fliagel mit zwei, an Vorderrande in der Regel bis zul dritten Längsader verbundenen brannen Qnerbinden iiber der hinteren Querader nnd der Gabelader; Hiiften fast immer schwarz . . . . . 34

- Fligel nur mit einem Sehattenflecken an der Miindung der zweiten Längsader oder anders gefärbt . . . . . . . . . . 77

- Flitgel ganz wasserklar, ohue Triibung oder l'leekung . . . 88

34 Mittelschienen in der Regel der ganzen Liinge nach bewimpert. Außenseite der Vordersehienen mit einer Reihe längerer Borstenhaare . 35

- Mittelsehienen olme Wimpermeihe . . . . . . . . . . . 50

35 Mittelsehienen auf ilrer Außeuseite grob borstlich bewimpert . 36

- Mittelsehienen und die drei ersten Glieder ihrer Tarsen sehr fein, dieht und schwarz bewimpert; drittes und viertes 'Tarsenglied der Hinterbeine etwas rerbreitert. $6 \mathrm{~mm}$ lang . cititursis r. d. Wulp.

- Mittelschienen auf ihrer Oberseite bewimpert . . . . . . . 48

36 Sehwinger hellgelb . . . . . . . . . . . . . . . . 37

- Sehwinger schwarzbraun . . . . . . . . . . . . . . 43

37 Mittelmetatarsus nicht bewimpert, sondern nur auf seiner Unterseite mit fiunf bis neun kurzen, weitläufig gestellten Eimzelbörstchen . 3s

— Mittelmetatarsus hewimpert . . . . . . . . . . . . . 39

38 Fliggelvorderrand fein, dicht und ziemlich lang bewimpert, ähnlieh wie bei mudus Wied. Vorderschienen alußen mit fiinf bis seehs Borsten. Vorder- und Mittelmetatarsus nackt oder nur mit winzigen Einzelbürstehen auf der Unterseite. Vordertarsen fast doppelt so lang wie die Sehiene; letzte Hintertarsenglieder nieht verbreitert. $4-5 \mathrm{~mm}$ lang. . . . . . . . . . . . . alatus n. sp. $\mathrm{C}^{7}$

- Fliggelvorderrand sehr knl'z bewimpert. Beine verhältnismaßig kräftig behaart. Vordersehienen außen mit einer Reihe von sechs bis sieben Borsten. Vordermetatarsus anf seiner Unterseite und Endhälfte mit zwei Einzelbörstehen; Mittelmetatarsus unterseits mit fünf bis seehs Einzelbörstchen; letzte Hintertarsenglieder verbreitert. $6-7 \mathrm{~mm}$ lang atrox $\mathrm{u.sp.} \mathrm{\sigma}$

39 Hintersehienen sehwarz, an der Spitze etwas verdiekt. Mittelmetatarsus auf seiner Aubenseite l'ein und dieht bewimpert; die letzten Hintertarsenglieder nicht verdiekt. 4.5-5 nm lang. Tumiformis n. sp. ठ

- Hintersehienen gelb oder höelıstens an der Spitze braun nnd nielit verdiekt . . . . . . . . . . . . . . . 40

40 Vordertarsen besonders gestaltet . . . . . . . . . . 41

- Vordertarsen einfach . . . . . . . . . . . . . . . 42

41 Erstes Glied der Vordertarsen an der spitze etwas verhickt, zweites Glied unten etwas verdickt und dort mit dem dritten und vierten Gliede zart beborstet. Mittelmetatarsus anf der Außenseite mit feinen, nicht allzu dicht gestellten Wimperbörstehen besetzt. Hintersehienen an der Spitzenhïlfte braun, Vorder- und Mittelsehienen braungelb. Costa bis zum linde der zweiten Lingsader deutlich fein und dicht bewimpert. $75 \mathrm{~mm}$ lang . . . . . Grerimames Enderl. $\sigma^{7}$ 
42. Mittelmetatursus auf der Oberseite fein und dieht bewimpert, auf der Anßenseite mit fünf his sechs stiirkeren geraden stumpfen Einzelborsten in einer anderen Reihe. Sehienen gelb, Hintersehienen an der Wurzel und der Spitze brann. 5-6 $\mathrm{mm}$ lang. posticatus Wied. Mittelmetatarsus auf der Außenseite mit etwa zwanzig stumpfen Borsten grob bewimpert; alle Scbienen gelb. $6-7 \mathrm{~mm}$ lang.

equestris I Ibl. o"

43 Vittelmetatarsus bewimpert oder mit reiheuförmigen Einzelborsten 44

- Mittelmetatarsus einfach, ohne Wimpern oder reihenförmige Beborstung . . . . . . . . . . . . . . . 46

44 Iittelmetatarsus oberseits bewimpert. Beine schwarz, nur die Vorderselienen und der lletatarsus del Mittelbeine gelbbriunlich; letzte Glieder der Hintertarsen etwas verbreitert. Hypopygialanlünge sehwarz, klein und unbedentend. 6--7 mm lang . pilosus Lw. o

- Mittelmetatarsus anf der Außenseite nur mit einer weit]infigen lieilue von etwa zwölf Einzelborsten. Vordermetatarsus unten mit vier bis fïnf kurzen Börstehen. Beine schwarz, nur Schienen und Metatarsen rotbraun, letzte Glieder der Hintertarsen etwas verbreitert. Fliigelbinden mit Fensterflecken. 6-7 mm lang. . uniseriatus n. sp. $\sigma$

- Vittelmetatarsus auf der Außenseite fein und dieht bewimpert . . 45

45 Mittelmetatarsus außerdem noch mit einer zweiten Reilue ron zelu bis zwölf stumpfen Börstehen; die Wimpern des Metatarsus blattförmig verbreitert. Mypopygialanhinge sehwarz, sehmal, stab- bis zangenförmig rorgestreekt. Die Flügelflïehe längs des ganzen Vorderrandes braun. 5-6 mm lang. . . . . . squamifer n. sp. ठ Mittelmetatarsus außerdem noch mit einer zweiten Reile von zehn bis zwölf stumpfen Bïrstehen; die Wimpel'n des Metatarsus nicht blattförmig verbreitert. Analanhinge sehwarz, schmal, stab- bis zangenförmig vorgestreckt. Der braume Vorderrandsaum des Fliigels vor dem Ende der ersten Längsader unterbroeben. 5-6 inm lang. ctenoms Enderl. $\sigma^{7}$

- Mittelmetatarsus olne eine zweite Borstenreihe; die Wimpern des Metatarsus nicht blattfönnig rerbreitert. Analanhänge gelb in Form von zwei ziemlielı großen ovilen Lamellen. Die Zeiehnung der Fliigelquerbinden am Vorderrande ohne Verlïngerung nach der Wurzel des Flïgels hin. 5-6 mm lang . . . flavilamellatus n. sp. $0^{7}$

46 Beine ganz schwarzbram bis sehwarz . . . . . . . . . 47

- Beine seluwarz, Vorder- und IIttelschienen rostgell, Vordermetatarsus außer zartel dichter Bewimperung noeh mit drei bis vier kleinen Einzelbörstehen; letzte Glieder der Hintertarsen etwas verbreitert. Flïgelbindenzeichnung verwaschen. 4-5 mu lang.

$$
\text { diversipes n. sp. ठ }
$$

47 Fligelquerbinden ineinander geflossen, in der ersten Hiuterrandzelle ein runder Fensterfleck. $5-6$ mm lang. . . . guttula Wied. o' 
— Flïgelquerbinden sehwaeh entwickelt, die Adern braun umsäunt. 4 mu lang . . . . . . . . . . guttula Wied. var. ő

48 Sehwinger hellgelb . . . . . . . . . . . . . . . . 49

- Sehwinger sehwarzbraun. Beine ganz selıwarz. Vorderschienen auf der Außenseite mit drei bis vier längeren Borstenharen. Mittelsehienen auf der ganzen Länge der Oberseite feinlaarig bewimpert. $6 \mathrm{~mm}$ lang . . . . . . . . . barbatulus n. sp. o

- Sehrvinger britunlich. Beine nebst Hiiften sehwarz. Vorder- und Mittelschieneu nebst einem Teil des Vordermetatarsus gelb, Hintersehienen bram. Mittelsehiene vorne mit einer Reihe ron neun Borsten; Metatarsus vorne diebt und lang bewimpert, anßerdem oben und unten woeb mit einer Reihe von Börstchen. 4.5-5 mm lang . . triscriatus Aldr. ठ

49 Beine entweder ganz schwarz oder anch Vorder- und Mlittelsebienen rostgelb. Mittelsehienen miteinander nur an der Spitze der Oberseite mit dem ganzen Metatarsus fein bewimpert. Vordersehienen anfihrer Anßenseite mit seehs bis sieben Borsten. 6-7 mm lang. superfluts Sehin. on

- Beine sehwarz, alle Sehienen gelb. Mittelsehieneu anf der Oberseite grob borstlich bewimpert; das erste und zweite Vordertarsenglied an der Außenseite kurz beborstet. $5.5 \mathrm{~mm}$ lang. genualis Aldr. $\sigma^{7}$

50 Vordertarsen verziert oder besonders beborstet . . . . . 51

- Vordertarsen einfach, ohne besondere Beborstung oder Verzierung . 56

51 Beine ganz schwarz; Schwinger sehwarz. Vordersehienen mit einigen Einzelbörsteben oder längeren Borsten . . . . . . . 52

- Beine nieht ganz sehwarz . . . . . . . . . . . . . . 54

52 Gesieht weiß behaar. Vordermetatarsus an der Spitze mit einer Reihe yon sehwarzen Borsten. Mittelmetatarsus oberseits zart pubeszent.

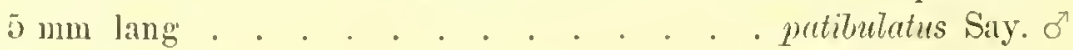
Gesieht naekt . . . . . . . . . . . . . . . . 53

53 Vordermetatarsus der ganzen Lïnge nach, lanptsäiehlieh an der Spitze mit sieben bis zehn Borsten. Vordersehienen anf der Außenseite mit vier bis fiuf borsten. Hypopyg mit kleinen sehwarzen Lamellen. Fligelvorderrand deutlieh, wenn aneh knu bewimpert. $5-6 \mathrm{~mm}$ lang melampus Lw. ot

_- Vordermetatarsen an den beiden letzten Gliedern einseitig kammartig behaart. Analanhänge braun, bandförmig, am Ende breiter, in Gabelform, sehwarz behart. Fliggelquerbinden selır breit. $7-8 \mathrm{~mm}$ lang: Oedipus n. sp. O’

$5 t$ Alle Schienen rostgelb. . . . . . . . . . . . . 55

- Nur die Vordersehienen rostgelb. Hintertarsen sebwarz, uamentlieh die drei Mittelglieder deutlieb verbreitert. Vordermetatarsus olıne besondere Beloorstung. $4 \mathrm{~mm}$ lang. . . confluens n. sp. o

- Nur die vorderen Sehienen rostgelb bis rostbraun. Hintertalrsen selnwarz, nicht rerbreitert. Vordermetatarsus unten anf der Mitte mit zwei Finzelborsten. $4 \% \mathrm{~mm}$ ling . . . . . . triseta n. sp. $\sigma$ 
- Vorderschienen schwarzbran, Mittelschienen gelb. Hintersehienen an der Spitze gelb; viertes und finftes Glied der Vordertarsen schwarz gewimpert; erstes Glied der Mitteltarsen an der Spitze weil - zrveites und drittes Glied sclwwarz gewimpert. Vorderrand der Fliigel fast ganz braun. $7-8 \mathrm{~mm}$ lang . . . . . bifmbriatus Aldr. o

$5 う$ Erstes Glied der Vordertar'sen unterseits mit kurzen Einzelbörstchen. Zweites Glied unten dentlich beborstet. Fliigelquerbinden sehr schwach entwickelt. $5 \mathrm{~mm}$ lang. . . . . . . unguipes n. sp. ठ7

- Erstes Glied der Vordertarsen unterseits im letzten Viertel mit einer dentlichen Einzelborste. 5-5.5 mm lang. . uniseta n. sp. o

- Erstes Glied der Vordertarsen unterseits zart berrimpert nud an der Spitze verdickt; das zweite Glied auch etwas verdickt und nuten mit einem Polster. $7 \cdot 2 \mathrm{~mm}$ lang. . . . . . . coxulis Aldr. of

56 Die beiden Flïgelquerbinden sind an Vorderrande nur bis zur zweiten Längsader rerbunden. Vorder- nnd Mittelsehienen gelb. Vorderschienen auf ihrer Außenseite nit zwei längeren Borsten. Analanhäinge gelbrann, lappig, zangenförmig rorgestreekt und gebogen. $5 \mathrm{lnm}$ lang . . . . . . . . . . . . superbus Wied. O

- Die beiden Fligelquerbinden sind am Vorderrande bis zur dritten Läugsader miteinander verłunden

57 Hypopyg und der siebente IIinterleibsring am Ende anferordentlich lang behart. Anallamellen gelb mit starkem Dorn. Vorderschienen oberseits mit 3-4 langen Borsten, Metatarsus fist nackt. Hintertarsen allmählich dïnner werdend. Fliigelquerbinden nur als zwei zarte Flecken schwach angedeutet. 4.5 -5 mm lang Schuusein. sp. ठ7

Hypopyg und der siebente Hinterleibsring nur mit Haaren von gewöhnlicher Länge . . . . . . . . . . . . . . . 58

58 Vorderschienen vorne oder oberseits mit einigen längeren reibenförmig gestellten Einzelborsten . . . . . . . . . . . 59

- Vorderschienen auf der Anßenseite nud Wurzelliilfte mit einigen reilınförmig gestellten Einzelborsten . . . . . . . . . 692

- Vorderschienen nackt oder nur mit einzelnen knrzen börstchen ohne besonderen Charaktel . . . . . . . . . . . . 72

59 Beine sanz schwarz. Vorderschienen oberseits mit 2-3 Einzelborsten, Mittelschienen desgleichen. Analanhäinge ziemlich groß, weißgelb, lappig aufgerichtet, an der Spitze mit einer Ausbuchtung. Fliigelquerbinden sehr schwach ausgebildet, mitunter die Fliigel nur mit Schattenfleck an der Spitze. Thoraxribeken ganz silberweiß bestiubt. $35 \mathrm{~mm}$ lang argentatus Aldr. o

- Vorder- und Mittelschicnen gelb, Ilintersehienen schwarz . . . 60

- Nur dic Vorderschienen grelb. . . . . . . . . . . 61

60 Vorder- und Mittelschiencn oberseits mit 1-2 Einzelborsten, Vorderund Mittelmetatarsus horstenlos. Fligelquerbinden nur schwach aus- 
gebildet. Analanhïinge rostgelb, kurz, zangenförmig. $85 \mathrm{~mm}$ lang ignobilis n. sp. כૅ

61 Vorderschienen oberseits mit sechs Borsten, Mittelsehienen desgleichen mit : 4 lïngeren Borsten, beide letzten Mitteltarsenglieder sehneeweiß behaart. Analanhäinge gelbbraun, lappenförmig. Fligelquelbiuden rou gewöhnlicher Ansdehnung. $6 \mathrm{~mm}$ lang diffusus Wried. ठج

62 Alle Sehienen gelb . . . . . . . . . . . . . 63

- Vordel- nnd Mittelselienen gelb, Hinterschienen braun bis seliwarz 65

- Nur die Vordersehienen gell. . . . . . . . . . . . . 71

63 Mittelsehienen unterseits mit 4-5 Einzelborsten. Mittelmetatarsus unten mit $7-8$ Borsten, außerdem auf der A u Benseite fein und dicht bewimpert. Analanhinge gelbluraun, behaart, an der inneren Seite gegabelt. Fligelquerbinden versehwommen; Flügelvorderrand braun gesäumt. $5-5.5 \mathrm{~mm}$ lang . . . . tenuipes n. sp. o

- Mittelschienen anf der AuBenseite mit längeren Borsten. Vorderund Vittelmetatarsus nackt. Analanhänge mit vier fingerähnliehen Organen, die an der Spitze geschwärzt sind. Fligelquerbinden sehr breit $m$ it vicreckigem Fensterfleek $.6 \mathrm{~mm}$ lang gracilis Aldr. o

- Mittelsehienen auf der A ufe ns e it e und Wurzelliailfte mit 4-5 kurzen Borsten; Metatarsus einfach. Vorderselienen und deren Metatarsus auf der Außenseite kurz und fein bewimpert; letzterer in der Niilse der Spitze mit einer Einzelborste. $5 \cdot 5-6 \mathrm{~mm}$ lang mulchripes n. sp. ठ

- Mittelsehienen oberseits mit cinigen lïngeren Einzelborsten. Metatarsen nackt; zwei kleine schwarze Anallamellen. Fligeloguerbinden schmal. $6 \mathrm{~mm}$ lang . . . . . . . . purpuratus Aldr. o

- Mittelschicnen nackt, fast borstenlos . . . . . . . . fit

61 Analanhänge gelb, schlank, gebogen. Fliigelquerbinden von gewölunlieher Form und Ausdehnung. 6-7 mm lang . . . atricauda Aldr. O Analanläinge braun, fingerilunlich. $45-5.5 \mathrm{~mm}$ lang simitis Aldr. o

65) Mittelschienen oberseits mit einigen längeren Borsten . . 66

- Mittelsehienen auf der A u Benseite mit einigen Einzelborsten 67

- Mittelschienen nackt oder nur mit rereinzelten 13örstchen... 68

60 Mittelschienen oberseits mit drei Borsten; Mittelmetatarsus auf der Außenseite mit einer Reilıe etwas breitgedriickter sehmal blattförmiger Borsten, unten mit einigen längeren Einzelborsten. Fliigelquerbinden gewöhnlich. Anallamellen gelbbraun, gebogen, stabfirnig, behart. (6) $\mathrm{mm} \operatorname{lang}$

ignotus n. sp. ठౌ

- Mittelschienen mit melueren Einzelhorsten oberseits und auch an rerschiedenen Seiten. Hittelnetatarsus nackt: Analanhäinge schwarz, kiein. Fligelquerlsinden nur schwach entwickelt. $4.5 \mathrm{~mm}$ lang similis Aldr. O

Anmerkung. Wegen der etwas schwankenden Farbung der Beine hier nochmals angeführt.

67 Mittelschienen auf der Außenseite nit drei liingeren Borsten; Mittelmetatarsus unterseits mit $S-9$ kurzen Börstehen. Vordermetatarsus 
unterseits mit etwa 4-5 Börstehen, von denen die letzte die längste ist. Fligelqueradern schwach briiunlich. $5.5-63 \mathrm{~mm}$ lang lactus $\mathrm{n} . \mathrm{sp}$. $\sigma^{\circ}$

(is Nittelmetatarsus oberseits nackt . . . . . . . . . . . . 69

69 Schwinger gelb . . . . . . . . . . similis Aldr. o

- Sclıwinger selıwarzbraun. Fliigelquerbinden breit, aneh lïngs der vierten Längsader miteinander verbunden, nit einem Fensterflecken. $6 \mathrm{~mm}$ lang

ignoratus n. sp.

71 Vittelmetatursus nelsst den beiden folgenden Gliedern auf der Unter. seite sehr weitläıfig und grob bewimpert. Analanhänge lappig, brann, aufgeriehtet. Fliggelquerbinden ziemlich breit aber sehwach entwickelt. $4 \mathrm{~mm}$ lang . . . . . . . . . perspicus n. sp. or

72 Alle Schienen schwarz. . . . . . . . . . . . . 73

- Sehienen sehwarz, Vordersehienen rothrann. . . . . . . . 74

- Sebienen sehwarz, Torderschienen gell, . . . . . . . . . 75

- Alle Selienen gell), Hinterschienen hïıfig an der Spitze braun 76

73 Seluwinger schwarzlmann, Mittelmetatarsus anf der AuBenseite fein nnd kurz hewimpert. Analanhïnge schwarz, länglich dreieckig, behart. $6 \mathrm{~mm}$ lang . . . . . . . . . . . . impretiens n. sp. o

- Schwinger gelb. Mittelmetatarsus nieht so bewimpert. Analanhiinge schwarz, breit bandförmig. 6-6.5 $\mathrm{mm}$ lang. . praestans Aldr. o

$7 t$ Selıwinger gelb. Mittelmetatarsus muterseits weitliufig beborstet. Hypopyg diek, kugelig mit lïnglich dreieckigen gegabelten aufrecht stehenden sehwarzen Anbingen. $4 \mathrm{~mm}$ lang perspicuus n. sp. o

Anmerking. Wegen der etwas unsicher zu beurteilenden Beburstming der Vorderschienen hier nochmals aufgefiuhrt.

75 Schwinger schwarzbraun. Mittelmetitarsus kahl. Hintertarsen auf der llitte etwas dicker. llypopyg klein, schwarz mit zwei kurzen zylindrisehen schwarzen stark behaarten Anhängen. 4-5 mm lang imornatus Aldr. o

76 Vordere Hiiftgelenke schwarz. Analanhänge breit, flach, sehwarz mit Einsehnitt und krummen Borsten an der Spitze. Erste Fliigelquerbinde breit, bis an's Ende der ersten Längsader heranreichend. 4-5 mm lang. . . . . . . . c atrolumellatus Aldr. o Yordere Hiiftgelenke schwarz. Analanhinge oval, flach, sehwarz, etwas kleiner als bei atrolamellatus, olune Einsehnitt und Borsten. Erste Fliigelquerbinde schmal, erst hinter dem Ende der ersten Liingsader beginnend. $45 \mathrm{~mm}$ laug . . . . diminuans n. sp. ot

- Vordere Huiftgelenke gelb. Analanhäinge braun, fingerähnlich. $4 \cdot 5$ bis $5.5 \mathrm{~mm}$ lang . . . . . . . . . . depressus Aldr. ơ

77 Fliigelfiache mit Schattenfleck an der Spitze des Vorderrandes 78

— Flügelfiache in anderer Weise gefärbt . . . . . . . . . 86

78 Fiblerborste so lang wie der Körper und an Ende mit kreisfömiger Verbreiterung 
- Fiblerborste kurz orler wenn liinger, so doch olne Verbreiterung 80

79 Alle Schienen gells. Vordersehienen auf der Aufenseite mit sieben Borsten; Vordertarsen weißlich, nackt, das fiinfte Glied mit silbersehimmernden Haaren; an den Nitteltarsen sind die beiden letzten Glieder weißlich und silberweiß behaart. IJypopyg an den Seiteneeken mit zwei wellig gekrïuselten Borstenbiiseheln, die nach unten hin geneigt sind. Analaubänge blaßgelb, groß. 45-5 mm lang nobitissimus Aldr. o

80 Alle Sehienen und die Schwinger gelb. Vordersehienen anf ihrer Oberseite mit einer Reilhe von $3-5$ Borsten in zunebmender Länge 81

- Schienen gelb, Hinterschienen anf der Endhïfte braun. Vorderschienen olne Borsten. Fliigelrandader bewimpert . . ciliipennis Aldr. o

- Vorder- und Mittelschienen gelb. Hinterschienen schwarz . . . $\$ 3$

81 Vordermetatarsus borstenlos . . . . . . . . . . . . . 82

- Vordermetatarsns oberseits mit zehn lïngeren Borsten, auch alle iibrigen Tarsenglieder an der Spitze mit einer Borste. Mitteltarsen in ähnlicher Weise, wenn auch etwas kirzer beborstet. Analanliinge rostgelb, spitz dreieckig mit borstenförmiger Verlängerung. $4 \mathrm{~mm}$ lang. comatus Lw. o

82 Hypopyg und Bancluringe seln lang behaart. Aulünge hellgelb, lappig. $6 \mathrm{~mm}$ lang . . . . . . . . . . . . . Schumsei n. sp.

Anmerkung. Wegen der schwankenden Fliggelzeiehnung auch an dieser Stelle anfgefiihrt.

- Hypopyg und Banchringe in gewöhnlieher Weise behaart. Anlänge weifgrau; das vierte Glied der Witteltarsen weiß und weiß behart. $4 \mathrm{nim} \operatorname{ling}$. . . . . . . . . . . . . bellulus Aldr. ठ

83 Vordersehienen a ibrer Oberseite mit einer Reibe ron Borsten in zunehmender Lainge . . . . . . . . . . . . . . . $\$ 4$

84 Vordermetatarsus nackt. . . . . . . . . . . . . . 85

- Vordermetatarsus oberseits lang behart, an der Spitze am längsten; Mittelmetatarsus desgleichen. Analanbïnge sehwarz, lappig. $4 \mathrm{~mm}$ lang . . . . . . . . . nubeculus n. sp. on

85 Hypopyg und Banchringe selu lang behaart. Analanbinge gelb, lappiz. Mittelmetatarsus nackt. $5.5 \mathrm{~mm}$ lang . . . . vagans n. sp. $\sigma^{2}$

- Hinterleibsspitze nit zwei langen wellig gekrimmten Borsten. Mittelmetatarsus nackt, das fünfte Glied oberseits weiß behaat. $5 \mathrm{~mm}$ lang

86 Alle Beine fast nackt oder ohne irgend eine charakteristisehe Behorstung, sebr schlank . . . . . . . . . . . . 87

S7 Schienen alle gelb. Hintertarsen naeh der Spitze zu rerjiungt. Fliigelfläche mit einem am Vorderrande liegenden schwarzbraunen Fleeken, der ungefähn $1 / 3$ der ganzen Fläche deckt und die Mitte des Flügels eiunímmit. $4.5 \mathrm{~mm}$ lang . . . . . . . medianus n. sp. ठ 
- Sehienen gelb, Hinterschienen brann; Hintertarsen nach der Spitze hin verjüngt. Fliigelfliche mit einem am Vorderrande liegenden sehwarzen Fleeken, der von der Basis an mit Ansnahme des Hinterrandes $2 / 3$ der ganzen Fliche bedeekt und bogenförmig und parallel zur hinteren Querader dicht linter derselben endigt. $5 \mathrm{~mm}$ lang dimidiatus Lw. of

88 Thoraxrücken ganz silberweiß hestäubt; Sehwinger gelb. Analanliänge klein, braun, gekrimmot. Beine ganz schwarz. Vorderschienen und Mittelsehienen an der Oberseite mit drei bis vier längeren Borsten, die iibrigen Beinteile ohne besondere Beborstung. Gabelader spitzwinkelig nach riekwiirts abzweigend. $3.3 \mathrm{~mm}$ lang argentatus Aldr. o

Anmerkung. Diese Art schwankt in der Flïgelzeichnung zwischen schwachen Flïgelbinden, Flïgeh nur mit Schattenfleek und ganz glashellen Flïgehn und ist Heshall, auch an dieser Stelle genannt.

- Thoraxriicken wie gewölnlich in seiner metallisehen blangritinen Färbung

89 Erste Längsader bis iiber die Fliigelmitte hinaus verlängert, die erste Vorderrandzelle banchig erweitert und der Fliigelvorderrand lang bewimpert. Beine ganz seliwarz. Vordersehienen und Tarsen auf der Anßenseite ziemlich lang behaart, das zweite Tarsenglied nieht linger als breit. Gabelitler rechtwinkelig abzweigend, hintere Querader schräge. $5 \mathrm{~mm}$ lang . . . . . . . mundus Wied. o7

- Erste Lüngsader nicht so lang oder wenigstens der Fligelvorderrand niclit bewinpert . . . . . . . . . . . . . . . . 90

90 Gesieht lang behaart. Spitze der Mittelschienen mit einer langen ab. stehenden Borste, Mittelmetatarsus mit gekrimmten Borsten . 91

- Gesicht naekt. Mittelsehienen und Metatarsus nicht so beborstet 94

91 Der siebente Ilinterleibsring lang beborstet . . . . . . . . 92

- Der siebente Ring mit der gewrilhnlichen kurzen Beborstung. . 93

92 Gesiehtsliaare weißlich; alle Sehienen gelb; rordere Il iiftgelenke gell. $3 \mathrm{~mm}$ lang . . . . . . . . . . caudatus Wied. o

- Gesiehtshaare schwarz. Vorder- und Mittelschienen gelb; Hintersehienen sehwarz, die vorderen Hiuftgelenke desgleichen. $4.5 \mathrm{~mm}$ lang

barbatus Aldr. $\sigma^{7}$

93 Gesicht weißlich bebart. Hypopyg mit sehr kleinen Analanhängen scobinator Lw. $0^{7}$

94 Mittelschienen auf der Aunenseite kammartig beborstet . . . 95

Mittelsehienen anders beborstet . . . . . . . . . . . . 97

95 Vorderschienen anf der Außenseite mit einer lieihe von funf bis sieben Borsten. Gabelader sjitzwinkelign nach riickwiirtsabzweigend 96

- Vordersehienenbeborstung ohne besonderen Charakter. Gabelader fast rechtwinkelig abzweigend. Beine schwarz, nur die Vorderschienen gelb. Vittelmetatarsen deutlich bewimpert. $5 \mathrm{~mm}$ lang 
96 Mittelmetatusus unterseits nackt oder lö̈hstens mit drei bis rier Bïrstelen. Sehienen rostbraun bis schwarz. Hintertarsen gleich hreit, an Ende nieht breiter. $4 \mathrm{~mm}$ lang. . . . . semiater n. sp. $\overrightarrow{0}$

- Mittelmetatarsus mit dem zweiten Gliede fein bewimpert und auBerdem mit eiver Reihe weitlïufig gestellter Borsten. Sehienen nnd 'Tarsen gelb. Fndglieder her IIntertarsen etwas breiter. $6 \mathrm{~mm}$ lang pectinatus n. sp. o

97 Selienen ganz selıwarz bis rosthraun

- Alle Sehienen oder wenigstens die beiden vorderen ganz rostgelb 99

98 Alle Sehienen ranh behaart, die llintersehienen mit einel Reile abstehender Borsten auf der Außenseite. Vordersehienen und Metatarsen an der Hinterseite mit einer Reihe langer Borsten. Vorderrandader des Fliggels bis zum Ende del zweiten Iängsader bewinpert. Hypopyg kleiu mit kleinen sehwarzen Anhïngen. $3.5 \mathrm{~mm}$ lang

hirlipes Aldr. o

- Vordersehienen oberseits mit vier Einzelborsten, Mittelschienen ahnlich beborstet. Hypopyg krebsschwanzihnlich umgebogen, dicht behatut, nit loreiten sehwarzbraunen Anhingen. Vorderandader nieht bewimpert. $4.5-5 \mathrm{~mm}$ lang. . . . . . . decorizes n. sp. ठ

99 Alle Sehienen gelb. Hypopyg mit lïngeren bis langen Borsten 100

- Vordere Sehienenpaare rostgelb. Hinterschienen ganz oder teilweise schwarz . . . . . . . . . . . . . 101

100 Vordermetatarsus auf der Unterseite fein nnd kur\% bewimpert, im iibrigen fast nackt. Analanliange gelb, anf einer Seite lang beborstet. $4 \mathrm{um}$ lang . . . . . . . . veliformis n. sp. or

- Vordermetatarsus auf seiner AuBensejte mit neun kurzen Borsten. Analanhinge loraun, gebogen, mit starker Borste. $4.5 \mathrm{~mm}$ lang tibialis Wied. o"

- Vordermetatarsus auf der Oberseite mit nen bis elf lingeren Borsten, das zweite Glied ebenfalls an der Spitze mit einer Borste. Hypopyg nnd letzter Ring sehr lang belıart; Analanluinge gelb, dick, spitz endigend. Gabelader spitzwinkelig nach riickwiirts abzweigend. $5 \mathrm{~mm}$ lang . . . . . . . . . . . . hirsulus n. sp. of

101 Vordermetatarsus einfich, ohne besondere lieborstung. . . 102

102 Siebenter Ilinterleibsring mit zwei biisehelförmigen Ilaarsträhnen. Anbinge schwarz, stielförmig, vorgestreekt, an der Spitze umgebogen, verbreitert und zugespitzt. Gabelader reehtwinkelig abzweigend. $3-3.511 m$ lang. . . . . . . terminalis n. sp. o

- Siebenter Hinterlejbsring ohne solcbe Haırsträhne. Anhänge des Hypopygs hellgelh. $4-45 \mathrm{~mm}$ lang . . . . purpureus Alds. O7

- Siebenter Hinterleibsring nur mit kurzen Borsten. Anhinge schwarz, stabförmig, an Ende spitz- lakken orler pfeilfürmig umgebogen. 35 mm lang . . . . . . . . . . . erectus n. sp. б 


\section{Bestimmmugstabelle fül die Weibchen der lattmug}

\section{Condylostylus Bing.}

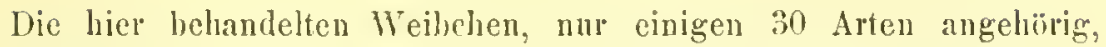
sind solehe, ron denen ich mit Bestimmtheit bebaupten kann, daß sie zu den heschriebenen Mainnehen gelı̈ren. Viele einzelne Weibchen in den verschiedenen Sammlungen, von denen eine größere Anzahl auch noch neuen bisher unbekannten Arten angehören wird, mußten unbericksichtigt bleiben und haben weder in dieser Bestimmungstabelle noch bei der lieschreibung einen Platz gefunden. Es ist besser sicl zu bescheiden, als auf einzehe Wreibchen hin Arten aufzustellen, die späiter doch vielleicht wieder fallen miissen oder deren Mämmehen anfzufinden und festzustellen uniiberwindliche Sehwierigkeiten bereiten wiirde. Wir stehen erst am Anfang nnserer Kenntnis dieser stark berölkelten Gattnng.

1 Fligel anf der Endhïfte mit zmei braunen rorue verbundenen Querbinden, die mitunter zusammenfliefen, dann aler noch einen hellen Fensterfleek in der ersten Hinterrandzelle zeigen . . . . . 2

- Flïgel mit einem brannen am Vorderrande liegenden, bogenförmig nach unten begrenzten ungeteilten Fleeke . . . . . . . 24

- Fligel mit cinem am Vorderrande am Ende der ersten Längsader liegenden Seliattenflecken. IIiften und Schenkel schwarz. Schwinger gelb 25

- Fliigel ganz fleckenlos . . . . . . . . . . . . . . . 28

2 Fiihler und IIiften gelb . . . . . . . . . . . . . 3

- Fübler gavz sehwarz . . . . . . . . . . . . . . . 4

3 Brustseiten nud Hinterleib gelb, letzterer nut stahlblanen Hinterrandsbinden. 6-7 mm lang . . . . . . . . . caesar n. sp. q

- Brustseiten silbergrau bestiubt. Hinterleib stalıblau, zweiter Ring am Vorderrande gelb. $7-8 \mathrm{~mm}$ lang . . . . basilaris Wied

4 Beine ganz schwarz . . . . . . . . . . . . . . . . 5

- Beine nieht ganz scliwarz oder welb. . . . . . . . . . R

5 Schwinger gelb. Vorder- und Mittelsehienen anf der Aulienseite reilienweise beborstet. Größere Arten von ungefiihr $6 \mathrm{~mm}$ Läinge . 6

- Sehwinger schwarzhrann. Vorder- und Mittelsehienen oberseits beborstet. Kleine Art von $4 \mathrm{~mm}$ Länge . .. . . . . . argentatus Aldr.

6 Gesicht lang behaart . . . . . . . patibulatus Say.

- Gesicht nackt . . . . . . . . . . . . . 7

8 Alle Hiiften und Schenkel schwal\%, Schienen alle oder zum Teil rotgelb. Fligelquerbinden am Vorderrande bis zur dritten Längsader miteinander verbunden 
- Nicht alle Hijften und Schenkel schwar\%. . . . . . . . . 16

9) Schwingerlónopf selıwarzbraun . . . . . . . . . . . . 10

- Seluwingerknopf gelb. . . . . . . . . . . . . . . . . . 11

10 Nur die Vorderschienen gelb. Vorder- und Mittelsehienen oberseits mit drei bis vier Borten. 6 mm lang . . . diffusus Wied. o

- Alle Schienen rostgelb. Vorder- und Ilittelsehienen anf der Außenseite mit einigen Borsten. Flügel mit Fensterflecken. $6-7 \mathrm{~mm}$ lang miseriutus n. sp.

11 Vorder. und Mittelschienen auf den Außenseiten mit einigen Borsten 12

- Vorder- und Mittelsehienen oberseits mit einigen langen Borsten. Schienen alle gelb. $5-6 \mathrm{~mm}$ lang . . . . Schursei u. sp. q

12 Alle Sehicnen gelb . . . . . . . . . . . . . . 13

13 Flïgel mit Fensterflecken . . . . . . . . . . . . . . 14

- Fliigel olne Fensterflecken mit den gewölnnlichen Querbinden. $6 \mathrm{~mm}$ lang

14 Arten von 4 mm Länge. posticatus Wied. ?

- Art von $5-6 \mathrm{~mm}$ Liinge

- Art ron $4 \mathrm{~mm}$ Liinge

- Art von $5 \mathrm{~mm}$ Länge

- Art von $6-7 \mathrm{~mm}$ Linge

16 Vorderluiften und Schenkel gelb . . . . . . . . . . . 17

- Vorderliuften gelb, Schenkel sehwarz, Sehienen gelb. . . . . 92

— Alle Hiiften und Selienkel grelb, Schienen gelb . . . . . . 23

17 Fligelquerbinden am Vorderrande his zur dritten Liingsader mitcinauder verhunden . . . . . . . . . . . . . . . . . 18

- Fligelquerbinden nur bis zur zweiten Lingsader verbunden. Arten von $6-7 \mathrm{~mm}$ Lïinge . . . . . . . . . . . . . . . . 20

18 Flïgel mit Fensterflecken in der ersten Hinterandzelle. $5 \mathrm{~mm}$ lang. pulchripes n. sp. ?

- Fliggel ohne deutliehen Fensterflecken. Vorder- und Mittelsehienen anf der Ober- nnd Außenseite mit einigen wenigen, mehr oder weniger ausgebildeten Borsten . . . . . . . . . 19

19 Kleine Art von $3-4$ mm Lïnge . . . . . . brevis 1. sp.

- Größere Arten von 6-8 mm Länge $\left\{\begin{array}{l}\text { sipho Wied. } \\ \text { equestris Wied. } \\ \text { imperator Aldr. } \\ \text { felid n. sp. o } \\ \text { completus n. sp. } \\ \text { filiformis n. sp. } \\ \text { perlestris n. sp. }\end{array}\right.$

20 Schrvingerknopf sehwarzbrann . . . . . . serenus n. sp.

— Schwingerknopf gelb bis gelbbraun . . . . . . . . . 11 
21 Schwinger gelbbraun. Vordel- und Mittelschienen nackt.

cochlearis n. sp. 우

- Schwinger hellgelb. Vorder - und Mittelschienen mit einigen Einzelborsten . . . . . . . . . flagellatus n. sp. f

22 Vorder - und Mittelschienen anf ihrer Oberseite mit einigen Borsten. $4 \mathrm{~mm}$ lang . . . . . . . . . . ignobilis 1. sp. ?

23 Vorder- und Mittelschienen oberscits mit einigen kleinen Borsten. Fligelquerbinden an dem Vorderrande nur bis zur zweiten Liingsarler verbunden. $5 \mathrm{~mm}$ lang . . . patcllitarsis n. sp. 오

24 Beine mit Vorderhiiften ganz geli; Schwinger gelb. Vorder- und Mittelschienen einfach, ohne bemerkenswerte Beborstnog. $6 \mathrm{~mm}$ lang. macula Wied.

25 Hinterschienen gelb. . . . . . . . . . . . . . . . 26

- Hinterschienen schwarz. Vorder- nnd Mittelschienen oberseits lang beborstet. $5 \mathrm{~mm}$ lang. . . . . . . nubeculus n. sp. 웅

26 Vorder- und Nittelschienen oberseits lang beborstet . . . . . 27

- Vorder- und Mittelschienen einfach, fast nackt. 4 mu lang.

bellulus Aldr. 우

27 Art von 5-6 mm Länge

- Art von $4 \mathrm{~mm}$ Liinge. . Schnusei n. sp. q

28 Schenkel und alle Hiiften schwarz . . . . . . . . . . . 29

- Schenkel und die Vorderhifiten gelb, Schienen desgleichen; Schwinger gelb . . . . . . . . . . . . . . . . . 34

29 Gesicht nackt . . . . . . . . . . . . . . . . . 30

- Gesicht lang schwarz behart. Schienen und Schwinger gelb. Vorderund Mittclschiencn fast nackt. Gabelader rechtwinklig abzweigend. $4-5 \mathrm{~mm}$ lang . . . . . . . . . . . barbatus Aldr.

30 Scliwingerknopf schwarkbraun . . . . . . . . . . 31

- Scliwingerknopf gelb . . . . . . . . . . . . . 33

31 Schienen schwarz. Vorder- und Mittelschicnen oberseits lang beborstet. Gabelader spitzwinklig abzweigend. $4 \mathrm{~mm}$ lang. decoripes n. sp.

- Schienen gelb, bran bis schwarz. Vorder- und Mittelschienen nackt oder fast nackt . . . . . . . . . . . . . 32

32 Vorderschienen gelb. Gabelader fast rechtwinklig abzweigend. $4-5 \mathrm{~mm}$ lang . . . . . . . . . . chrysoprasius Walk.

- Schicnen rostgelb bis braus. Gabelader spitzwinklig abzweigend. $4 \mathrm{~mm}$ lang. . . . . . . . . . . . semiater n. sp. +

- Alle Schienen gelb. Vordersehienen auf der AuBenseite mit längeren Borsten. Gabelader spitzwinklig. $6 \mathrm{~mm}$ lang. pectinutus n. sp. ?

33 Schienen gelb. Vorder- und Mittclschienen oberseits nit drei bis vicr lïgeren Borsten. Gabclader spitzwinklig abzweigend. $4-5 \mathrm{~mm}$ lang. . . . . . . $\left\{\begin{array}{l}\text { veliformis } 11 . \mathrm{sp} . \\ \text { comatus Lw. }\end{array}\right.$

34 Gesicht ling, weiß behaart . . . . . . . . . . . 35 
— Gesieht nackt . . . . . . . . . . . . . . . $36^{\hat{0}}$

35 Vorder - und Mittelsehienen mit wenigen kurzen I3̈irstehen. Gabelader rechtwinklig oder fast rechtwinklig abzweigend. $35-4 \mathrm{~mm}$ lang

I camdatus 1 ied. $q$ scobinator Lw.

36 Gabeladel rechtwinklig abzweigend. $3 \mathrm{~mm}$ lang. | insuluris Aldr. l erectus n. sp.

Artverzeichnis, kritische Untersuchungen, Synonymie, Beschreibninger.

1 alatus n. sp. $0^{x}$. . . . . . . . . . . . . . . Pern

Fine schwarzschenlige Art mit schwarzen Iibihlern, gefleckten Fliigeln und fein bewimpertem Fliigelvorderrande.

3. - Kürper blangiin, Sehwinger blafgelb. Kopf und Hinterleib wie gewöhnlieh, letzterer jedoch selur sehlank und mit ansehnlicher Randbeborstnng. Hypopyg von gewöhnlieher Form mit kurzen sehwar\%brannen zangenfürmig gebogenen Anhängen. Beine mit allen Hiiften sehwarz, alle Sehienen und die Hetatarsen der beiden vorderen Beine rostgelb; llintersehienen an der Spitze braun. Vorderschiene auf der Aufenseite mit funl bis sieben lingeren Einzelborsten; Hetatarsen nackt, auf der Unterseite mit einigen kaum sichtbaren Einzelbörstehen. Vordertarsen etwa $13 / 4$ mal so lang wie ihre Sehiene. Mittelsehienen der ganzen Lünge naeh auf der Anßenseite grob hewimpert; Metatarsus : Iuf der Unterseite mit acht bis neun sehr kurzen Linzelbörstehen in ziemlich gleiehen Abständen voneinander; Nitteltarsen 1 1/2 mal länger als ilıre Sehiene. Hintertarsen am Ende nicht verbreitert. Flïgel mit zwei loraunen, am Vorderrande bis zur dritten Längsader verloundenen Querbinden; Fliigelvorderrand dentlich fein und dielit bewimpert, ähnlich wie bei mundus Wied. 4-4.5 mm lang.

Ein Exemplar ans Peru, Vileanota, desgl. $1 \sigma^{7}$ ans Paragnay [Vezínyi] Sammlnng des Ungarischeni Nationalmuseums.

Anmerkung. Diese Art lat große Ähnlichkeit mit genualis Aldr. in Gröbe,

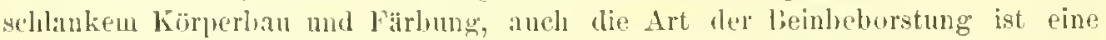

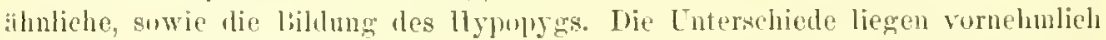

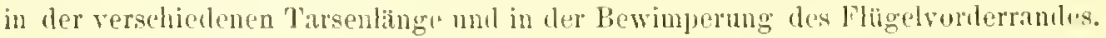
amoris Walk, List Dipt. Brit. Mus. 111647 [Psilopus] (1849). Brasilia

Olnne Angabe des Geschlechts, mur mit den gewihnliehen Merkmalen der Firbung des Körpers, mit rotgelben beinen, schwarzen Fiilılern und branu gebinderten Flïgeln. Diese Beschreibung hat keinen Wert, die Art kann hiernach nicht erkannt werden.

unceps Wied. $9,=$ caudatus Wied. s. dort.

2 andicola Big. O, Ann. Soe. Ent. Fr. ser. 6. X 293. [Gymnoceromyia] (1890). 
Gehört der Besehreibung nael zu unserer Gattung. Sehwarze Fïhler; Sehwinger gelbbraun. Hinterleib am zweiten Ringe mit gelb durehseheinenden Fleken. Beine rotgelb, die beiden letaten Glieder der Mitteltarsen verbreitert und sehwarz. Fligel glashell. $7 \mathrm{~mm}$ lang.

Die Verbreiterung der beiden letıten Glieder der Mitteltarsen und die besondere Hinterleibsfärbung sind Merkmale, die uns in den Stand setzen, diese Art aueh ohne spezielle Kenntnis der Type mit in unsere Tabelle aufzunelimen.

3 argentatus Aldr. \%, Biolog. Centr. Amer. Dipt. I 361. 20 [Psilopus] (1901) . . . . . . . . . . . Mexieo, Bolivia

o. - Von blangrüner Grundfarbe, aber dieht weiß bestäul,t, so daß die Oberfläehe des 'Thoraxriiekens matt graugriin erseheint. Schwinger schwarzbraun. Kopf wie gewöhnlich mit schwarzen Ftilslern, jedoelı Gesieht und Stirne dieht weiggra u bereift. Hinterleil) ebenfalls mit dielıter weifgraner Bestäubung bedeekt, mit zarten Randborsten. Hypopyg klein, sehwarz mit gelben aufreeht stehenden lappigen, gekrimmten außeren Anhängen. Beine ganz sehwarz; Vordersehenkel unterseits mit einigen langen sehwarzen Borstenharen. Vorderschienen anf der Oberseite mit drei längeren Einzelborsten, Tarsen einfaeh ohne Borsten. Mittelsehienen auf drei Seiten mit kurzen Einzelbörstehen und einfachen Tarsen, sonst ohne eharakteristisehe Beborstung. Vordertarsen 11/2-, Mitteltarsen $1 \%$ mal so lang wie ihre Sehienen; Hintertarsen von $3 / 4$ der Schienenliinge. Fliigel glashell olne Fleekung, mitunter mit einem Sehattenfleeken am Ende der zweiten Längsader und mit zarter Briiunung der Gabelader und der hinteren Querader. Gabelader spitzwinklig abzweigend und hernaeh reehtwinklig bogenfömig zmr Spitze abbiegend; hintere Querader senkreeht zur vierten Liingsader. $3 \mathrm{~mm}$ lang.

Q. - Die Weibehen, welehe ich als zngehörig craehte, haben ihre metallisebe Firbung bewahrt und zeigen nur sehwiehe Bereifung, dahingegen sind die Fligel deutlieher, wenn aueh nur sebr schwach, am Vorterraude und an den Queradern gebriunt.

2 ơ, 10 q aus O.-Bolivia, Provinz Sara, $600 \mathrm{~m}$ hoeh [Steinbaelı] Sammlung des Berliner Museuns.

Anuerkung. Aldrich beschrieb seine Art mit gelben Selwingem und unit schwarzbrunen gekrümmten Anhingen, wibrend die von mir hier vorgefiihrten Exemplare sehwarzbratue Seluwingev und gelbliche Analanhänge zeigen. Das sind aber ancl die cinzigen Untersehiede, die ich anfzufinden vermag. lob kenne zwar die Allrich'sche 'Type nicht ans Anschaung, glaube aber nicht, dab die vorhin angegehenen geringen Färbungsunterschiete eine Grundlage fiu eine neue Art abgeben kïnnen, namentlieh da die silberhelle bestiubung des liorpers, die ielı sonst bei keiner anderen Art bemerkt habe, lier iibereinstimnt. Aldrich's Exemplar stammt ans Mexico und die meinigen ans bolivia; in dieser Verselnedenheit des Ursprunglandes finden die Fitrbungsuntersehiete wahracheinheh ilue begrindung.

armines Big. o", Ann. Sne. Ent. Serie 6. X 284. 3 [Psilome] (1890). 
Fiihler selwwarz; Sehwinger brann. Beine rotgelb mit schwarzen Schenkeln. Vorder- und Mittelschienen an den Anlenseiten mit langen Einzelborsten. Iypopyg braun. Fliigel glashell. $5 \mathrm{~mm}$ lang.

Die Besehreibnng, so wie sie gegehen jst, kollidiert zwar nicht mit einer bekannten Art. Ob Bigot's Bezeichnung: "A uBenseite der Schienen" siel nit unserer Anffassung deckt, bleilot immerhin fraglich. Sollte Bigot damit vielleicht die "Oberseite" gemeint haben, so wiare es denkbar, daß meine als veliformis heschriebene Art trotz etwas geringerer Grijle damit zusammenfiele. Angesichts dieser Zweifel und nicht ansreichenden Beschreibung muf ich bis zur weiteren Aufklärung durch Typenvergleichung meine Art aufrecht erhalten.

- astequinus Big. o", Ann. Soc. Ent. Fr. Serie 6. VIII Bull. XXX [Psilopodinus] (1888). . . . . . . . . . . Hexico

Fibler und Taster schwarz, Fühlerborste ling, Schwinger gelb. Beine schwarz, Schienen rotgelb. Fliggel glashell mit einem braunen Flecken, der tief eingeschnitten ist (zwei vorne verbundene Querbinden). $6 \mathrm{~mm}$ lang.

Es fehlt die Angabe der die Art charakterisierenden Merkmale, daher bleibt die Art fiin nns nnverstiindlich.

5 atricaula Aldr. Biolog. Cent. Amer. Dipt. I 3579 [Psilopus] (1901) Mexico

Fiihler sehwarz, iußerste Wurzel gelb. Schwinger braun. Hinterleib mit breiten Querbinden. Hypopyg klein, sehwarz; Anhiinge schlank, gekrimmt, gelb. Hiiften und Sehenkel schwar\%, Sehienen gelb, an der ¿ußersten Wurzel schwarz, Hintersehienen auch an der Spitze. Vorderschienen anf der Außenseite reilhenfiomig beloorstet, Mittelschienen fast borstenlos. Vorder- md Mitteltarsen lang und schlank, an der Wurzelhiblfte gelb, drittes und viertes Glied der Ilintertarsen etwas geschwollen. Fliigel mit dentlichen Querbinden. 6-6.5 mm lang.

Anmerkung. Die grute Besehreibung Alurieh's gestattet uns, seine Art auch ohne speziellere Kenntnis der Type der Bestimmungstabelle mit einzufiigen.

6 atrolamellatus Aldr., Biolog. Centr. Amer. Dipt. I 359913 [Psilopus] (1901).

ठ․ - Thorax und Kopf wie gewöhnlich, Scheitel anßerordentlich tief eingesenkt. Schwinger gelb. Hypopyg glïnzend schwarz mit schwarzen großen flachen Lamellen, die an der Spitze einen Anssehnitt haben und ant der inneren Seite mit gekuiuselten Hauren besetzt sind. Beine mit Hiiften schwarz, Schienen und rordere Metatarsen rotgelb, Hintertarsen und die Endglieder der iibrigen Tarsen schwarzbraun. Die Schieven und Tarsen entbehren fast ganz einer eharakteristischen oder reihenweisen Beborstung, es sind nur vereinzelte scheinhar unregelmäßig gestellte wenige Börstehen zu seben; auf der Unterseite der Vordermetatarsen stehen zwei Borsten nicht weit auseinander, die man vielleicht als Charakteristikum ansehen kann. Die Hintertarsen 
sind verhältnismäßig dtiun, wenn anch um ein geringes dicker als die vorderen, so doch etwas diinner als die Hiuterschiene selbst. Vordertarsen um 1.5 länger als die Schiene, diese 1.2 mal linger als der Metatarsus und letzterer 1.3 mal länger als die folgenden vier Gliedel zusammen. Mitteltarsen nur wenig linger als die Schiene, diese reichlich doppelt so lang wie der Metatarsus und letzterer $11 \mathrm{~m}$ 1.4 kiirzer als die vier folgenden Glieder. Hintertarsen um 1.9 kiirzer als die Schiene. - Fligel mit zwei breiten braunen, am Vorderrande bis zur dritten Lïingsader verbundenen Querbinden; bintere Queradel zicmlich steil. $4.5 \mathrm{~mm}$ lang:

$1 \delta^{7}$ aus Bolivia-Mapiri II. 1903, Sarampioni $700 \mathrm{~m}$ hoch [Schnuse] Königliches Museum Dresden.

Anmerkung. Dieses Excmplar stimmt durchaus mit Aldrich's Beschreibung iiberein, so daß ich keinen Zwcifel habe, die Aldrich'sche Art vor mir zu haben. atrox n. sp. $\mathrm{O}^{\pi}$. . . .

Perı

$\overrightarrow{0}$. - Metallisch blaugriin; Schwinger hollgelb. Kopf wie gewöbnlich mit schwarzen Fühlern. Hinterleib mit matt purpurfarbenen Querbinden und scliwacher Beborstung. Hypopyg klein, schwarz, mit diinnen, gleich gefärbten, fast nackten rorgestreckten Anbängen. Beine und Hüften schwarz, Vorder- und Mittelscbieucn bellgelb, Hinterschienen und Vordertarsen gelbbrïunlieh. Torderschienen mit sieben abstehenden Aufeuborsten, Metatarsen nit einer kleinen Einzelborste anf der Mitte der Unterseite und einer zweiten etwas längeren dicht vor der Spitze. Vordertarsen zweimal so lang wie die Schiene. Mittelschienen auf der AuBenseite grob und veitläufig bewimpert (ich zähle auf der ganzen Länge nur acht bis zehn gleich lange Borsten) su daß hier der Charakter der Bewimperung eigentlich schon fast g:inz verschwunden ist, immerhin kinn man aber noch von Bewimpermug. sprechen; der schlanke nackte Metatarsus zeigt auf seiner Unterseite fünf knrze Einzelbörstchen; dic Mitteltarsen haben die $1 \frac{1}{2}$ facbe Linge der Schiene. Die schwarzen Hintertarsen sind reuig kürzer als ihre Schiene und baben etwas verbreiterte Endglieder. Fligel mit zwei schmalen und breit voneinander getrennten braunen Querbinden ron schwacher Fäbung, die rorne bis zur dritten Lïugsader zusammenlängen. Gabelader spitzwinkelig abzweigend und hernacl rechtwinkelig und kurz bogenförmig abliegend; die hintere Querader steht ctwas schräge und weiter von der Gabelader entfernt als gewölnnlich. $6-7 \mathrm{~mm}$ lang:

$10^{\pi}$ aus Peru, Callanga. Sammlung des Ungarischen Nationalmuseums.

8 barbatulus n. sp. o 0 . . . . . . . . . . Mexico

5. - Blaugruin, Schwinger schwarzloram. Kopf mit schwarzen Ftihlern wie gewöhnlich, das zweite Glied mit langen Randborsten. Hinterleib mit ziemlich langen Randborsten. Hypopygium klein, schwarz, Abbandl. d. zool.-bot. Ges Bu Xlll, lleft 1. 
Anallamellen ron gleieher Farbe, klein, spitz dreieckig endigend, mit kurzen Borsten. Beine mit allen Iliften ganz sehwarz. Vorderschienen nnit etwa drei lois vier längeren Einzelborsten anf der Außenseite und Wurzelhälfte; Metatarsus kahl, jedoeh anf der Außenseite mit sechs bis sieben ziemlieb gleiehmäßig verteilten Einzelborsten, die iibrigen Tarsenglieder kahl. Mittelsehienen oben und unten mit zwei bis funf kurzen Börstchen, anßerdem auf der Oberseite deutlieh und ziemlieh fein bewimpert, Tarsen kahl. Hintersehienen nebst Tarsen wie gewöhnlich nur etwas rauh behaart, letztere bis zum Endgliede hin gleich stark, ohne Terbreiterung einzelner Glieder. Die Vordertarsen sind reiehlieh $1 \frac{1}{2}$ mal, die Nitteltarsen $1 \frac{1}{4}$ mal so lang wie ihre Sehiene, Hintershienen lïnger als ihre Tarsen. Fligel mit zwei braunen, schwach gefirbten, an Vorderrande bis zur dritten Laingsader mit einauder verbundenen Qnerbinden; die Gabelader zweigt spitzwinkelig naeh rickwïrts ab und macht anf der Vitte eine rechtwinkelige kurze Biegung; die hintere Querader steht fast senkreeht auf der vierten Längsader. $6-5.5 \mathrm{~mm}$ lang.

5. - Die Weibehen haben ebenfalls ganz sehwarze l3eine, die nur noch etwas kahler nud kiirzer sind.

$2 \delta, \&$ atus Mexico. Sammlung des Tiener Hofmnseuns.

1 o in der Winthem'sehen Sammlung, das als diffusus Wied. gedentet wal, sieh aber von diffusus dureh stärkere Kopfbeborstuug und andere Beinbeborsiung unterseheidet.

() batuatus Aldr. O 9 , Biolog. Centr. Amer. Dipt. I 35916 [Psilopus] (1901) . . . . . . . . . . . Mexico, Brasilien

万. - Fibler schwarz; Kopf wie gewöhnlieh, aber das Gesieht auf der unteren Hälfte lang schwarz behaart. Schwinger gelb. Hintelleib mit breiten, mattschwarzen Querbinden und Jangen Haaren aneh am Ilypopygium wie bei caulatus Wried., mit weleher Art barbutus anch hinsichtlieh der Beinbeborstung große Ähnliehkeit hesitat. Hypopyg klein schwarz; Anhảnge sehwarz, vorstehend und gekriinmt, an den Spitzen mit einem Schopf sehwarzer Haare. Hiiten und Sehenkel sehwarz, Vorder- und Mittelsebienen gelh, Hintersehienen nebst Tarsen schwarz. Mittelselienen mit einer langen abstehenden Borste an der Spitze der Innenseite und der Mittelnetatarsus anf der Unterseite mit gekrïmmten Borsten. Fliigel glashell. $4 \cdot 5 \mathrm{~mm}$ lang.

q. - Die Weiluchen haben einfaehe Mittelsehienen nud Tarsen, sind aber an der sehwarzen Gesichtsbeharung von caudatus zu unterscheiden, bei der die Gesichtshare bell sind; auch bleiben die Sehenkel bei den barbatus - Weilschen sehwarz, während sie bei caudatus gelb werden.

Aus Mexieo und Brasilien (naeh Aldrich).

10 hasilaris Wied. o AuBereurop. zweill. Ins. II 215 (1830) . Brasilien. 
In Winthem's Sammlung steekt ein schlecht erbaltenes Weibchen, jedoch kann man die Zugehörigkeit noch erkennen. Aldrich in der Biol. Centr. Amer. I 362 spricht von vier Weibehen dieser Art mit hellen Wimpern der tegulae, mit gelben Brustseiten und mit gelben Hinterleibsbinden. Wiedemann sigt vou den Brustseiten, dali sie silbersehimmernd seien; anch die liellen Wimpern wollen nicht ohne weiteres zn basilaris passen, so wie ich diese Art kennen gelernt habe; ebenfalls sind am Hinterleib, (wenigstens bei dem $\sigma^{7}$ ) nur die Wurzel des zweiten, eventuell noch des dritten Ringes, nicht die Wurzel aller Ringe gelb gefïrbt. Ich vermute daher, daß Aldrich eine andere, nahe verwandte Art vor sich gehabt hat, die ich in Schnuse's Sammlung fand und spiter auch in anderen Sammlungen wiedergefunden und caesar genannt habe, auf welche alle von Aldrich bervorgehobenen Merkmale passen; siehe das Niihere bei dieser Art.

$\sigma^{\top}$. - Thorax und Seliildchen azurblau, Riicken vorne am Ilalse weiß bereift. Schwinger gelb. Schtippchen wie bei allen nir bisher bekinnten Arten dieser Gattung schwarz bewinpert, jedoch sind die Wimpern läufig anch nur braun, auch schimuern sic dann, in bestimmter Richtung betrachtet, hellgelb. Kopf mit rotgelben Fiillern und Riissel, Taster dunkel. Gesicht bis etwas iiber die Fibler linaus weiß bestiubt. Hinterleib griiugold, erster und die letzten Ringe blau, die Wurzelhïlfte des zweiten Ringes gelb, am dritten Ringe ist diese Binde gelbbraun, wenn sie iberhaupt vorhanden ist. Hypopyg sehr klein, schwarz, Anallamellen sebr klein, schwarz, länglich dreicekig, etwas behaart. Beine und alle Htiften gelb, Hintertarsen und die Endylieder der ibbrigen Tarsen schwarzbraun. Vorderhiiften und alle Schenkel unterseits sehr kurz weiß behart. Vorderschienen nebst Tarsen aufer der kurzen anliegenden Behaarung noch mit wenigen kurzen Einzelborsten; an den Mittelbeinen fehlt ebenfills eine besondere charakteristische Beharung; die beiden letzten scliwarzen Tarsenglieder sind gleich liurz und kaum merklich verbreitert. Hinterbeine ebenfalls einfach. Fliigel glashell mit den gewïhnlichen braunen Querbinden, die am Vorderrande bis zur dritten Längsader verbunden sind; die innere Querbinde ist nur schmal; die erste Längsader reicht nicht ganz bis zur Fligelmitte; Gabelader rickwärts spitzwinkelig abzweigend, an der mittleren sclaafen Biegung sieht man mitunter einen riicklaufenden Aderast. $6 \mathrm{~mm}$ lang.

$\varnothing$ dem ö ähnlich; am Hinterleibe sieht man außer der ersten gelben Binde mitunter auch noch dreieckige Seitenflecke an den beiden folgenden Ringen. 6-6.5 mm lang.

Vorkommen in Peru, Callanga. Sammlung des Dentschen Entomologischen Museums Berlin und des Ungarischen Nationalmuseums. 11 bellulus Aldr, ơ , Transact. Ent. Soc. London 343. 3 [Psilopus] (1896) Antillae, Mexico, Brasilia. 
8ౌ. - Eine Art mit schwarzen Flihlern und Schenkeln, Schienen gelb. Schwinger gelb. Hypopyg schwarz, mit hellgranen Lamellen. Vorderschienen auf der Oberseite mit einer Reihe von vier allmählich läinger werdenden Einzelborsten, die librigen Schienen ohne besondere Beborstung. Das vierte Glied der Mitteltarsen weiß und weiß behaart, nieht verbreitert. Fliigel mit sehr sehwach ansgebildeteu Querbinden, die zu einem Schattenflecken an Vorderrande zusammengeschrumpft sind. $4 \mathrm{~mm}$ lang.

१. - Vorder- und Mittelschienen auf der Oberseite mit einer Borstenreihe, dem $\sigma^{7}$ ähnlich. Viertes Glied der Mitteltarsen schwarz.

(Nach Aldrich.)

12 bifimbriatus Aldr. ơ, Biolog. Centr. Amer. Dipt. I 353. 1 [Psilopus] (1901) . . . . . . . . . . . . . . . . Mexico

$0^{7}$. - Fihler sehwarz, drittes Glied sehr klein; Selıwinger gelb. Hypopyg groß, schwarz, mit kleinen bräunlichen Lamellen. Beine nit Hiiften sehwarz, Vorderschienen schwarzbraun, Mittelschienen gelb; Hinterschienen an der Endhälfte gelb; Vordertarsen schwarz, deren viertes nnd fiuftes Glied beiderseits dicht sehwarz gefranzt. Mittelmetatarsus an der Spitze weiß, zweites und drittes Glied gleielı lang, schwarz, oben und nnten gefranzt, aber kuirzer als an den Vordertarsen. Fliigel mit den zwei gewöhnlichen braunen Querbinden; der Fliigel vorderrand ist der ganzen Länge nach gebräunt, mitunter siud die Querbinden anch an der vierten Längsader etwas verbunden. 7.-8 mm lang.

Aus Mexico (nach Aldrich). Siehe seine ausfiihrliche Beschreibung.

13 bituberculatus Macq., Dipt. exot. II 2. 120.14 tab. XX fig. 2 [1'silopus] (1842).

Brasilia.

7. - Flihler seluwarz mit langer Borste, die auf $2 / 3$ ilırer Länge palettenartig verbreitert ist. Beine gelb, Hintertarsen sehwarz. Flïgel wit zwei braunen Querbinden, die am Vorderrande bis zur zweiten Längsader verbuuden sind; Fligelvorderrand auch vorne gebriiunt. $6 \mathrm{~mm}$ lang.

Anmerkung. Ich kenne diese Art nieht rom Ansehen. In der Sammlung des Wiener Infmuseums befindet sielı ein Weibchen, das von Schiner's Novarareise herstamut und als bituberculutus Mact. bestimmt ist. Schiner hat sich hei dieser Bestimmung durch die I'ligelzeichnumg leiten lassen, sieher mit einem gewissen Reehte, da bei dieser Art naeh Maeyuart's Zeiehnung der Zwisehenraum zwisehen den heiden Querbinden bis zur zweiten Längsader reieht, jedoch ist dies Kennzeichen allein zur Bestimumug nicht ausreichend, denn es konkurrieren hier verschiedene andere Arten. Weun nun auch die Weibchen so ohne weiteres nicht zu erkennen sind. so sint die Männchen dureh die Form ihrer Fïhlerborste leieht kenntlich, so daB wir liese Art whe Bedenken unserer Tabelle einverleiben können.

14 Zrevimanus Enderl. ơ, Zool. Jabrb. Suppl. XV 1, Baud. [Psilopus] 398 (1912) . Ameriea merid. 
Diese Art schließt sich mit der Konstruktion ihrer Vordertarsen eng an zwei andere Arten an und zwar an coxalis Aldr. und pedestris m.; letztere weicht aber durch ganz rotgelbe Beine ab, wiihrend coxalis Aldr. und brevimanus Enderl. schwarze Schenkel haben $\left(\sigma^{\top}\right)$. Nun ist coxulis Aldr. aber obne Mittelbeine beschrieben, die der Type fehrten, während bei brevimanus Ender. diese gerade eine charakteristische Beborstung zeigen. Es tritt nun zunächst die Frage auf, ob coxalis Aldr. und brevimanus Enderl. nicht doch eine und dieselbe Art darstellen könnten. Aldrich schildert die Beinfïirbung so, daß Schenkelspitzen und auch die Schienen hellgelb sind, was mit brevimanus nicht tibereinstimmt, auch erwähnt Aldrich nicht die feine nnd dichte Bewimperung der Vorderrandader, was er bei ähnlich organisierten Arten sonst nicht ïbersehen hat. So ist die größere Wabrscheinlichkeit vorhanden, daß brevimamus eine besondere Art ist, und daß die Mittelbeine ron coxalis Aldr. sich als auders gebildete erweisen werden. Zur Unterscheidung von coxalis ist es aber erforderlicl, die in Enderlein's Beschreibnng nicht erwiihnte Bewehrung der Mittelbeine sowie der Fligelrandader anzuftihren, deshalb gestatte ich mir, dic vervollständigte Beschreibung hier unter Weglassung alles unwesentlichen in aller Kiarze zu gebeu.

$\sigma^{7}$. - Thoraxricken blangrin; Schwinger hellyelb. Kopf nit kleinen schwarzen Fïhlern, zweites Glied sehr kurz beborstet. Hinterleib meist griingold, an den Einschnitten nur schmal schwarz. Hypopygium mit kurzen schwarzen zugespitzten, oberseits gespaltenen mul beborstetcu Anbängen. Beine mit Hüften schwarz, Vorder- und Mittelschienen braungelb, Hinterschienen an der Spitzenhïlfte braun, Tarscn ganz schwarz. Vorderschienen anf der Anßenseite mit nnr wenigen nicht auffallenden Einzelborsten; die Tarsen sind etwa $1 \frac{1}{2} \mathrm{mal}$ so lang wie die Schiene; der Metatarsus ist anf der gleichen Seite etwas dichter beborstet und zeigt an seiner Spitze eine stiirkere Borste; dic Vordertarsen sind fast ebenso gebildet wie bei den beiden genannten verwandten Arten coxalis und pedestris, auf deren Zeichnung ich verweise, sowohl hinsichtlich der Längenverhältnisse als anch in del Beborstung, nur das zweite Glied scheint mir etwas dicker zu sein. Die Mittelschienen sind auf der Außenseite weitliufig borstlich bewimpert (ich zähle 10-11 Borsteu); die Tarsen sind 11/2 mal läinger als die Schiene; der Metatarsus ist etwas kuil'zel als diese und auf der Außenseite der ganzen Länge nach mit kurzen, feinen, nicht allzu dicht stehenden Börstchen wimperartig besetzt, jedoch auf der Wurzellälfte deuthicher als an der Spitze, die tibrigen Tarsenglieder sind in abnehmender Liinge nackt. Die Hinterschienen sind etwas zottig behart, ihre Tarsen nehmen ohne Verbreiterung nach der Spitze zu allmaililich an Dicke etwas ab. - Die beiden braunen Querbinden des Fliigcls, die am Vorderrande bis zur dritten Laingsader miteinander verbunden 
sind, stehen weiter auseinander als gewoolnnlich; eine weitere Verbindung derselben durch Bräunung längs der vierten Längsader bricht auf Aer Mitte ab, so laß der länglieh viereckige helle Fleck in der ersten Hinterraudzclle nicht ganz eingesellossen ist; die hintere Querader steht fast senkrecht zur vierten Längsader. Die Vorderrandader ist bis zur Mijudnng der zweiten Liangsader ziemlich lang und fein bewimpert, in ähnlicher Weise, wenn auch nieht ganz so lang wie bei mundus Wied. (s. dort die Figur). $7 \cdot \overline{0} \mathrm{~mm}$ lang.

$1 \sigma^{7}$ aus Costa Rica in der Sammlung des Stettiner zoologischen Musenms.

Anmerkung. Enderlein rergleicht diese Art mit superfluus Schin. und pilosus Lw. die aber beide ganz einfache Vordertirsen laben.

Obgleich die Weibchen so olne weiteres nicht zu erkennen sind, so sind die Mäunchen durch die Form ihrer Fiihlerborste doch leicht kenntlich, so daß wir diese Art ohne Bedenken nnserer Tabelle einverleiben können.

15) brevis n. sp. $\sigma^{\circ}$. . . . . . . . . . America merid.

$\sigma^{7}$. - Kopf und 'Thorax von der gewöhnlichen Bildnng' und Färbung. Sehwinger gelb. Hinterleib mit schwarzen Binden. Hypopyg. mit zwei kleinen schwarzen ovalen beharten Lamellen. - Beine mit Vorderhiiften rotgelb, Hintertarsen ganz, die ibrigen Tarsen zum Teil schwarz. Schenkel unterseits nackt. Vorderschienen nackt, Vordermetatarsus anf der Unterseite mit ftinf wiuzigen Einzelbörstehen, an den iibrigen 'Teilen der Bcine keine bemerkenswerte Beborstung. Vordertarsen fast doppelt so lang wie die Schicne, diese etwas ktirzer als der Metatarsus und letzterer $11 \mathrm{~m} 1 \frac{1}{3}$ länger als die folgenden vier Glieder zusammen. Mitteltarsen $1^{1 / 3}$ mal länger als dic Schiene, diese um $1 \frac{1}{8}$ linger als der Metatarsus und letztere fast doppelt so lang wie die rice folgenden Glieder zusammen. Hintertarsen reichlich so lang vie die Schiene; liese un 1.8 mal lïnger als der Metatarsus und letzterer etwas linger als die nachfolgenden vier Glieder. Fliigel glashell wit zwei brauneu Binden, dic an Vorderrande bis zur dritten Lingsader verbunden sind; vordere Querbinde nur sehmal. 355-4 mm lang.

๑. - Die Beine sind im Verhältuis etwas kỉrzer, sonst dem $\sigma^{7}$ gleich.

$1 \delta$, 19 aus Custa Rica, Surubres. Sammlung des Ungarischen Nationalinuseums.

16 breviseta Coquill. O, Jolln. New-York Ent. Soc. X 140 [Sciopus] $(1902)$

Gchört der Beschreibung nach hierber. Fiuhler seluwarz, zweites Glied sehr knrz beborstet. Hiiften und Schenkel sehwarz, Sehienen gelb, Tarsen braun. Vorder- und Mittelschienen mit verscbiedenen Borsten in rerschiedenen Reiluenstellungen. Leider ist uns durch dic hesondere 
Ansdrueksweise hinsichtlieh dieser Stellungen der Charakter der Beinbeborstung unverstaindlieh geblieben, so daß ieh die Aufuahme dieser Art in meine Tabelle labe beanstanden miissen.

Coquillet spricht bei den Vordersehienen von einer Borstenreihe auf der inneren Hinterseite, ferner bei den Mittelsehienen ron Borsten anf der änßeren Vorderseite und der inneren Vorderseite. Welehe Borsten damit gemeint sind, ist olne eine Erklirung dessen, was der Autor unter "vorne, hinten, außen, innen“versteht, nieht mit Sieherheit zu sagen; ieh wage nicht eine siehere Erklärung dariber abzugeben.

Ameriea merid. basilaris Aldr. (nee Wied), Biolog. Centr. Amer. Dipt. I 362. 24 (1901).

Eine große präehtig gefärbte Art, die mit basilaris Wied. sehr nahe rerwandt ist, und anf welehe Wiedemann's Besehreibung in allgemeinen anch Anwendung finden könnte, alser Wiedemann besehreibt seine Art mit silbersehimmernden Brustseiten; bei unserer Art ist ron Silbersehimmer keine Rede, die Brustseiten sind einfirch matt hellgelb. Es liegt hier eine andere. wenn aueh nabe verwandte Art vor, die sich ferner noeh dureh stärkere Flügelzeichnung, durch größere Ausbreitung der gelben Hinterleibsbinden, sowie dureh grelbe dreieekige, nicht schwarze Anallamellen unterseheidet.

б. +. - Thorax ganz hellgelb, nur auf dem Riteken liegt eine vielleieht dureh zusammengeflossene Streifen entstandene azurblaue Decke, die den Vorderrand und die Seitenränder freilißßt. Sehildehen obenauf blau. Von Borsten zählt man je vier Dorsozentral- und drei Akrostikalborsten. Sehwinger gelblich. Sehuippehen desgleichen mit dunklem .Sanm, im allgemeinen mit sehwarzen, hin und wieder mit gelbliehen Wimpern, ähnlich wie bei basiluris. Gesicht bis etwas iiber die Fiihler hinaus weiß bestuiubt. Riissel, Taster und Fiihler gelb, letztere mit klåftiger Randbeborstung am zweiten Gliede. Hinterleib gelb, die Hinterründer der ersten fuinf Ringe sowie der ganze seehste Ring blau. Hypopygium glinzend blauschwarz, klein, mit lang zugespitzten dreieekigen gelben äußeren Anhängen; die Randborsten der Ringe sind so lang, wie die Ringe dick, in iibrigen ist der Hinterleib ziemlieh kahl. Beine mit allen Hüften blabgelb, Hintersehienen und Hintertarsen ganz schwarz, die iibrigen Tarsen der rorleren Beine braun bis sehwarz. Unterseite der Sehenkel naekt. Vordersehienen und Tarsen ohne besondere Beborstung; Mittelsehienen auben mit drei bis vier, unterseits mit drei kuren weitliufig gestellten Einzellorsten; Hinterschienen und Tarsen kurz aber etwas rauh belaart. Tordeltarsen zweimal so lang wie die Sehiene, diese $1 \%$ mal kirzer als der Metatarsus, letzterel $1 \cdot 6$ mal linger als die vier folgenden Glieder zusammen. Mitteltarsen $14 / 5$ mal linger als ihre Sehiene, diese etwas kiirzer als der Metatarsus, letzterer $13 / 4$ mal länger als die vier folgenden 
Glieder zusammen. Hintertarsen kỉrzer als die Sehiene, diese doppelt so lang wie der Metatarsus und letzterer $1 \frac{2}{s}$ mal länger als die vier folgenden Glieder. - Fliigel anf der Wurzelhälfte gelblich, sonst farblos mit zwei dentlichen braunen Querbinden, ähnlich wie bei meiner Art "hamatiformis" (s. Fig.), $11 \mathrm{nr}$ die erste Binde ist etwas sebmäler; die kleine Querader ist etwas braun umsäumt, die Spitze der Vorderrandzelle ist braun, ferner liegt ein graubramuer Zellkernfleck zwischen ler fiinften und seehsten Liingsades. $7-8 \mathrm{~mm}$ lang.

$18 \sigma^{7}, 27 q$ ans Bolivia-Mapiri, Il 03, Sarampioni $700 \mathrm{~m}$ hoch. Pern 12. 104 , Chanelamayo. - Peru-Ucaydifi 20. X 03, Unini. Peru-Mleshagua, '21. X 03, Urubambafi [Sehunse]. Samml. des Dresdner Huseums.

Sieben Exemplare ans Peru, Chanehamayo. Sammlung des Dentschen Entomologisehen Museums, Berlin-Dahlem. custus Lw., Berl. Ent. Zeitsehr. IX 180 (1865).

Aldr., Trans. Amer. Ent. Soc. Philadelphia XXX 285 [Agonosoma](1904).

lst wit weißen Zilien der tegulae ein Sciopus Zell. caudutulus Lw. = candatus Lw.

18 crmmatus Wied. of A Anßereurop. zweif. Ins. II 224 [Psilopus] (1830). Ameriea merid.

Lw., N. Beitr. VIII 79 (1861) et Monogr. II 239 (1864). unceps Wied. f, Auliereurop. zweifl. Ins. II 228 [Psilopus] (1830). cundatulus Lw. o N. Beitr. VIII 93 (1861) et Monogr. N. Amer.

Dipt. II 271 [Psiloms] (1864). smaragdulus Wied. F, Außereurop. zweifl. Ins. II 225 (1830). ? virgo Wied. f, Auliereurop. ziveifl. Ins. II 224. 24 [Psiloms] (1830).

万. - Die Art ist sehr eharakteristiseh dureh das beharte Gesieht, Juch die langen sehwarzen Hinterleibsborsten, die in einem Sehopf von mindestens acht Jis zehn schirmartig am Rande des siebenten linges stehen und dureh die Beborstung der Mittelbeine. Die äußeren dumklen Analanluänge sind band-oder zangenförmig gebogen und tragen an ilıer Spitze drei längere starke stumpte Borsten, (s. Fig.) Beine nebst Itiften sehwarz; die vorderen IIiftgelenke, die Spitzen aller Sehenkel, die Sehienen und die Wnrzeln der vorderen Metatarsen sind gelb. Die Vorlerbeine laben keine besondere Beborstung, immerhin tragen die Vordersehienen anf ihrer Oberseite zwei bis drei kleine Einzelbörstehen. Mittelschienen an der Spitze mit einer senkreeht abstebenden, spornartigen Borste, Mittelmetatarsus unterseits mit gekriimmten Borsten (s. Hig.). Hintersehienen und T'arsen wie gewöhnlieh etwas rauh belaart. - Fligel glashell; die erste Liingsader reicht nieht ganz bis zur Mitte des Fligels; die Gabelader biegt in einem großen Bogen reehtwinklig ab; die hintere Querader ist gerade und rechtwinklig zull liunften Lïngagader, sie ist von der Gabelader reiehlieh nm ilne eigene Lïnge entfernt. :" num lang. 
Ich fand ein typisches Exemplar in Winthem's Sammlung, das der Wiedemannschen und Loewschen Auffassung entspricht; es stammt aus S. Amerika; die langeren Borsten am Hinterleibsende waren zum großen Teil abgebrochen; dies mag auch wohl der Grund gewesen sein, daß Loew dieses Exemplar nicht gefunden hat und in seiner Monographie p. 240 sagt, er habe in Wiedemann-Winthem's Sammlung iber caulatus Wied. keinerlei Aufklïrung erhalten können.

1 व aus Paraguay, Gonzales 31. XII 07 [Schunse] Dresdner Museum. - $1 \delta^{7}$ o aus N. Amerika, Tifton [von Aldrich als crudatulus Lw. bestimmt] in Lielitwart's Samming Berlin. - 3 o o aus Paragnay, S. Bermardino [Fiebrig] Wiener zoologisches Hofmuseum.

Der bereits festgestellten Synonymie von caulatulus Lw. stimme ich bei. Liest man Loew's Beschreibung N. Beitr. VIII 93 (1861), so kommtman zunächst zu der An. sicht, dab diese Art von candatus Wied. verschieden sein muli; wie Loew sie ancli darstellt, denn er sagt von den Mittelbeinen seiner Art: "calcare tibiarnm intermediarum brevissimo, priuno tarsolnm intelmediorum articulo

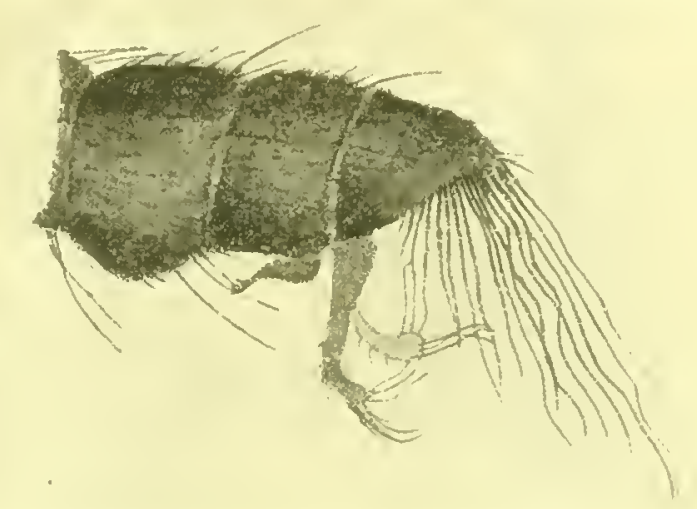

Fig. 107. Condylostylus caudatus Wied. O'11ypupyg. 24. 1 simplici." Dies stimmt duchans nicht mit caudatus Wied. iiberein, bei dem der Nittelmetatarsus unten mit krummen Borsten besetzt ist. Loew scheint hier wahrscheinlich ein falsches Exemplar zur Beschreibung beniitzt zu haben, vielleicht dic greich daranf von ilın beschriebene Art inermis. In seiner Monographie II. 271 trennt er zwar auch noch caudatulus von caudatus, beschreibt aber hier, ab. weichend ron seiner fritheren Darstellung, dic Mittelbeine genau so wie bei caudatus, olne irgend eine erklairende Bemerkung daran zu knïpfen. Es erscheint daher richtig, wie anch Aldrich angenommen, curulatulus als synonym von caudatus anzusehen.

. - Wiedemann hat das Weibehen noch zweimal beschrieben, als unceps und smaragululus. Die Type ron anceps befindet sich im Frankfurter Senkeubergischen Museum; ich konute sie einsehen: ein Weibchen, klein von Figur, mit schwarzen gewöhnlichen Fiihlern, rotgelben Beinen, dunklen Tarsen und glashellen ungefleckten Fliigeln bei $3-3 \cdot 5 \mathrm{~mm}$ Länge. Die Type von smaragrlulus Wied., ebenfalls 
nnr ein Weibehen ans Brasilien im Berliuer Museum, konnte ich mit anceps Wiel. vergleichen und fand volle Ubereinstimmung: Fliigeladerung, Größe, Beinfiirbnng und beborstung sind gleich; im besonderen sielıt man am Ende der Mittelsehienen cine stiilkere Endborste auf der Unterseite, sowie anfierdem noch mehrere gleichwertige und gleichgestellte Einzelbörstchen an den Schienen.

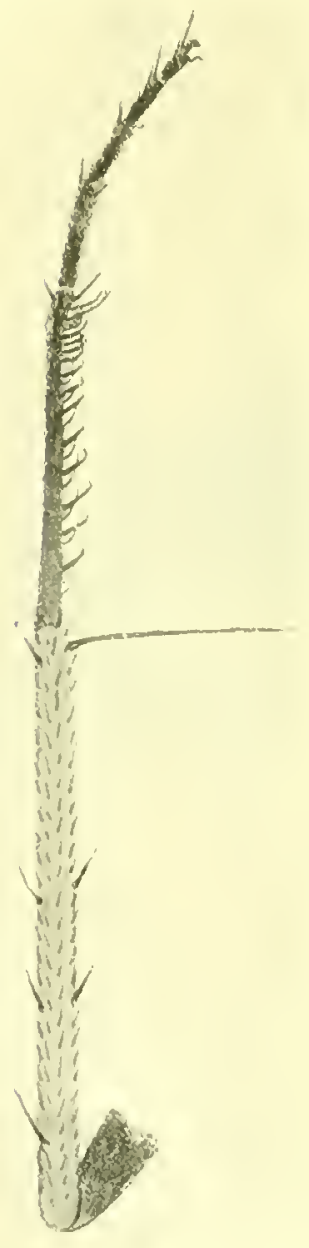

l'ig. 108. Contylustylus cur datus Wierl. O? Mittalbein. $24: 1$. Die Schenkel sind bei den Männchen schwarz, bei den Weibchen gelb, wie Wiedemann dies auch schon bei caudatus angiebt. Ich bin daher zu der Ansicht gekommen, daß anceps und smaragululus Wied. dieselbe Art darstellen. Das zngehörige llännchen muß an den Mittelschienen eine längere Borste fiihren, wie wil dies bei caudains Wied. sehen, die Beborstung del weiblichen Mittelschiene weist daranf hin. -

In diese Gruppe gehören auBer caudatus Wied., caudatulus Lw., smaragdulus Wied., anceps Wied. noch barbatus Aldr., ringo Wied. und scobinator Lw., alle diese Arten haben, sorveit sie als Minnchen beschrieben worden, einen mit gekriimmten Borsten verzierten Hetatarsus der Mittelbeiue; dieseu schließen sich noeh zwei Arteu: calcaratus und inermis Lw. : im iibrigen aher alle anderen Eigensehaften mit denen der ersten Grmpe teilen, ferner erectus n. sp. mit unbehaartem Gesicht.

Vou den erstgenaunten sieben Arten sind camdatulus, smaraydulus und anceps Synonyme von caudatus, virgo als $q$ nicht sicher zu clenten, aber doch wohl ais cumlatus Wied. anznnehmen, die zwei iibrig bleibenden sind jedoch im männlichen Gesehlecht bekannte und sieher begriindete Arten. barbatus Aldr. kenne ich zwar nicht von Ausseben, sie unterscheidet sich aber der Beschreibung nuch von den beiden anderen zunäiclist durch selıwarze Gesichtshare, dann durch dunklere Hinterschienen und etwas andere Hypopygialanhainge; scobinator Lw. entbehrt im Gegensatz zu den beiden anderen Arten caudatus und barbutus der langen selimartigen Behararug des letzten Hinterleibsringes, auch die Analanbinge sind weit kleiner als bei caudatus. Von diesen Arten sind caudutus, bubatus und scobinator als Bewohner 
von Slidamerika bekannt, während die beiden anderen Arten calcaratus und inermis Lw. bisher nur als in Nordameriká vorkommend gelten.

Die Weibchen, welehe ich bisher sehen konnte, gleichen sich alle derartig, daß man nur eine Art glaubt herausfinden zu können, daher geben die Wiedemann'schen Besebreibungen von virgo $f$, smaragdulus $f$ und anceps o auch keinerlei Anhaltspunkte dafiir, daß unter den anderen Namen auch andere Arten als caudatus Wied. verborgen sein könnten; caudatus Wied. ist in ganz Stidamerika zu Hause und sebeint anch allenthalben häufig vorzukommen, während ieb von scobinator $\mathrm{LW}$. nur ein einziges Exemplar $\left(\sigma^{-1}\right)$ aus Brasilien in der Wiener Sammlung gesehen babe. Man kann daher aueh mit größter Wabrseheinliehkeit annehmen, daß neben smaragdulus und anceps auch virgo Wied. ? nichts anderes sein wird, als caudatus Wied. Was ich von als "virgo Wied." bestimmten Exemplaren (q) in der Wiener Sammlung vorgefunden, bestätigt diese Ansielit.

Im Wiener Museum fand ich als smaragdulus Wied. bestimmt anch ein Mainnchen, das aber nieht in diesen Formenkreis gehört, vielmehr eine besondere Art darstelit, die ich als n. sp. singularis beschrieben habe.

chaetophorus Sebin $q=$ diffusus Wied.

Anmerkung. Wine Vergleichung der beiden von schiner aus Brasilien brschriebenen Weibehen mit demen dre Art diffusus Wied., von der typisehe Exemplare vorhanden sind, ergibt vollkommene ltbereinstimmung. Schiner's Beschreibung linsiehtlieh der Beborstung der Vorder- und IIintersehienen ergibt alterdings keine richtige Vorstellumg. Nach Sehiener ist die $A$ ubensoite der Schimen mit mehrerm langen Borsten versehen; es muß heißen: dir Vorderseite oder Ohersuite.

chrysoprasius Walk., List. Dipt. Brit. Mus. III 646 [chrysoprasi] (1849) . . . . . . . . . . . Antillen, Brasilien ciliipes Aldr., Biolog. Centr. Amer. Dipt. I $35 \overline{5}$ (6. tab. VI. fig. 2: (1901).

grisoprasius r. d. Wulp, Tijdschr. d. Entomol. XXV 1201 (1882) lapsus.

longicornis Wied., (nee. Fabr.) Anßeremop. zweill. Ins. II 22014 (1830).

Eine dunkelblane Art mit schwarzen Beincu, nur die Vordersehienen nebst Metatarsus sind rostgelb; Mittelsehiene und Metatarsus bewimpert.

ণొ. - Thoraxrizeken azurblau mit grilnliehen Reflexen und langen Borsten. Selwwinger brann. Sehiippehen ebenfalls branu mit seluwarzen Wimpern. Riissel, Taster und Fiilhler selıwarz; das zweite Fiillerglied auffallend stark beborstet. Hinterleib grtin bis blan mit matt purpurfarbenen Vorderrandsbinden, Behaarung unten und oben krätig. Hypopygium ron der gewöhnliehen Form, mit den mäig großen spitz endigenden Lamellen schwarz. Beine nud alle Hitten sehwarz, 
nur die Vorderschicnen nebst Netatarsus rostgelb. Vorder- und Hinterbeine olne jede charakteristiselue Beborstung. Mittelschienen anf der A ußenseite mit 15-16 Borsten dentlich kammartig besetzt; Metatarsus und das niichstfolgende Glied anf ilırel Oberseite fein kummartig bewimpert, aber etwas weitlüufiger als bei meiner Art pectinatus (s. Fig. bei Aldrieh und hei pectinatus m.): anf der Unterseite stehen ungefälı acht ziemlich regelmäßig verteilte kurze Bürstchen Vordertarsen $1 \frac{1}{2}$ mal so lang wie die Sehiene, diese etwas lainger als der Metatarsus, letzterer $1 \frac{1}{4}$ mal so lang wie die vier folgenden Glieder zusammen. Mitteltarsen $1 \frac{1}{3}$ mal so lang wie die Sehiene, diese etwas lïnger als der Metatarsus und letzterer $1^{3 / 4}$ mal liinger als die folgenden vier Glieder. Hintertarseu kirzer als die Schiene, diese $1.2 \mathrm{mal}$ länger als die Tarseu und reiehlich doppelt so lang wie del Metatarsus, letzterer $1.2 \mathrm{mal}$ so lang wie die vier folgenden Glieder zusammen. Fligel rasserklar, eine kleine grane Wolke soll mach Aldrich vor der dritten Läingsader liegen, von der ielı nicht recht etwas wahrnehmen kitun. Die Gabelader biegt fast rechtwinkelig ron der vierten Lïngader ab und velliuft auf der Mitte in einem großen stumpfen Bogen zur Spitze. 5 mm lang.

\&. - Die Veibehen mit einfacher Beborstung des zweiten Fiillergliedes und der Beine. Tarsen etwas kiirzer, sonst dem Nänneben gleich. $4-5 \mathrm{~mm}$ lang.

3 \%, 3 Q aus Bolivia-Mapiri 31. XII. 1902. S. Carlos 800 in hoel. - Peru $150 \mathrm{~m}$ loelı. 19. XI. 1903, Paehitea-Ninndung - ParaguayGonzales 31. Xll. 1907 [Schnuse] Dresdner Mnseum. Ans Florida, Sammlung des Deutschen Entomologischen IIuseums.

Neun Exemplare im Wiener Hofmuseum ans Brasilien.

Anmerkung. line sthr sehwache Briunung der Flügelfäche zeigt sich nituntel an der Ausmindung der ersten Liangsader: dies ist wohl die I'raehe gewesen, dab Aldrich seine Art ciliipes von chrysoprasius getrennt vufgeliuht hat.

20 cilionennis Aldr., Biolog. Centr. Amer. Dipt. I 366. 4 tab. VI fig. 24 [Gnamptopsilonus] (1901) . . . . . . . . . . . Mexico

o . - Mit schwarzen Fiilılern, Selienkeln und Hiften, schwarz bewimperten Schiippelien und vier Schildborsten, von denen das zweite Paar allerdings erheblich schwiicher ist als das Hauptpaur. Selienen olıne Borsten. Fliigel wasserklar, aber mit einem Selattenflecke an der Spitze des Vorderrandes und mit bewimperter Randader; reichlieh $4 \mathrm{~mm}$ lang:

Ielı bin geneight, diese Art zu Condylostylus Big. zu stellen, obgleieh Aldrieh sie zu ściopus Zell. rechnet. Wegen der schwarz bewimperten Schïpuchen gehört sie zunäichst nieht zu Gnamptopsilopus Aldr. = Sciopus Zell., und da auch vier Schildborsten, wenu anch nicht gleichwertige, vorlanden sind, so ist eigentlich nieht einzuselıen, warum Aldrich seine Art nicht zu seiner Abteilung Psilopus = 
Condylostylus Big. bat stellen wollen; es kommt noch hinzu, daß am Vorderrande des Fliggels ein Schattenfleck rorbanden ist, eine Figenschaft, die wir gerade in der Gattung Condylostylus häufiger vorfinden. Aus allen diesen Griinden scheint mir die Art ciliipennis bei letzterer Gattung besser untergebracht zul sein.

ciliipes Aldr. = chrysoprasius Walk.

21 cilitarsis v. d. Wulp, Tijdschr. v. Entom. XXXI 3699 (1888) Argentinia

o. - Blaugriin. Schwinger blafogelb. Kopf mit schwarzen Fiihlem, drittes Glied mit einer subapikalen etwas verlïngerten Borste, die etwa dreimal so lang wie der Kopf ist. Beine sehwarz, Sehienen alle gelb. Vorderschienen an der Außenseite mit einer Reihe von vier Borsten. Mittelsehienen und deren ersten drei T'arsenglieder anf der Außenseite sehr fein, dicht und schwarz bewimpert. Die beiden vorletzten Tarsenglieder der Hinterbeine etwas rerbreitert. Fliggel mit zwei brannen, vorne verbundenen Querbinden. $5 \mathrm{~mm}$ lang.

1 ơ ans Cordova, Argentinien. Sammlung des Brtisseler Museums - (nach v. d. Wulp).

clathratus Mraeq. o Dipt. exot, II 212115 tab. XXI fig. 2 [Psilopus] (1842) . Brasilia

९. - Fühler sehwarz. Beine gelb, Hintersehenkel an der Spitze sehwarz. Fliigel mit zwei braunen Binden, die an Vorderrande, sowie längs der vierten Längsader miteinander verbunden sind. $5-6 \mathrm{~mm}$ lang.

Der Besehreibung nach ist diese Art unkenntlich.

22 clavipres Aldr. 0", Biolog. Centr. Amer. Dipt. I 363 28. [Psilopus] (1901) .

3. - Fiahler sehwarz, Schwinger gelb. Hypopygium schwarz mit größeren behaarten schwarzen Anliängen. - Beine nebst Vorderlhtilten gelb. Vordersehienen mit einer Reihe von Borsten anf der Anßenscite. Vordermetatarsus so lang wie die Schiene, an der Spitze schwarz, mit einer unregelmißßigen Reihe von Borsten an der AuBenseite und an der Spitze; das vierte Tarsenglied unterseits kurz beborstet. Fliigel mit zwei braunen Binden; Gabelader auf der Nlitte mit spitzwinlicliger Biegung. $7 \mathrm{~mm}$ lang.

- clunalis Coquill. O', Journ. N. York Entom. Soc. X 141 [Sciopus] (1902) . . Hexico

o". - Corquillet gibt clie Untersehicde diescr Art ron breviseta an. Bei letzterer Art waren wir aber hinsichtlich ibrer Beborstung im Unklaren geblieben, kömen daher anch clunalis nicht riehtig deuten, müssen sie vielmehr ebenfalls vernachlïssigen: s. meine Bemerkungen bei treviseta.

ơ. - - Griinblau mit nur vier Paar Dorsozentral- und drei Paar Akrostikalborsten. Schwinger schwarzbraun. Fuihler selhwarz, Riissel rostgelb. Hypopyg klein, schwarz, mit zwei gelben, zangenförmig. 
gebogenen, an Ende löffelförmig erweiterten äuberen Organen, die anf ihrer Unterseite und an der Spitze lang gelblich beborstet sind. Beine nebst Vorderhiften rotgelb, Hintertarsen und die Endglieder der vorderen Tarsen brann. Beine olme besondere Beborstung. Vordertarsen $1 \frac{2}{3}$ mal linger als die Sehiene, diese ebenso lang wie der Hetatarsns und letzterer 1.4 mal länger als die vier folgenden Glieder zusammen. Hitteltarsen $1 \frac{1}{4}$ mal liinger als die Sehiene, diese nm $1 \frac{1}{4}$ lainger als der Metatarsus und letzterer fast doppelt so lang wie die vier folgenden Glieder. Hintertarsen kiirzer als die Schiene, diese um $1 \frac{1}{4}$ mal lïnger als die Tarsen und reiehlieh doppelt so lang wie der Metatar'sus, letzterer $1 \frac{1}{4}$ mal lïnger als die vier näiehsten Glieder zusammen. - Fligel mit zwei braunen selmalen binden, die am

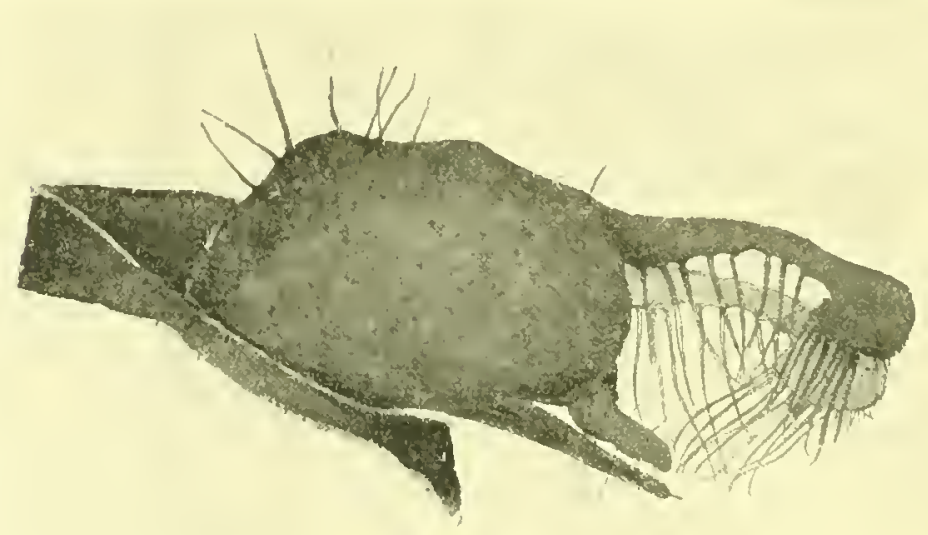

Fig. 109. Condylusiylus cochleuris Beck. 万. Hypopyg. 24:1.

Vorderande nur bis zur zweiten laingsader verbunden sind; am Vorderrande setzt sich die Bräunung fort bis zur Mlindung der ersten Liingsader; die Gabelader hiegt an der Basis spitzwinkelig, anf der Mitte rechtwinkelig ab. $6-7$ mm lang.

- - Die Beine sind etwas kitrzer, sonst dem $\sigma^{7}$ gleieb.

$4 \sigma^{2}$, to a as Brasilien, Theresopolis, St. Paulo, Paraguay. Sammlung des Ungarischen Nationalmusenms.

24 comatus Lw. Ot, N. B. VIII 89 (1861) Monogr. II 262 (186i4)

S. Amerika, N. Amerika

o. - Kopf, Thorax und Hinterleib azurblau mit sehr langen Borsten. Schwinger blaligelb, Schiippehen sehwarz mit langen sehwarzen Wimpern. Aueh die Fủhlerborste ist lang, so lang wie Kopf nnd Thorax zusammen; Finhler und Taster schwarz, Rtissel gelbbraun. Anf dem blauen Hinterleibe sieht man kleine oder nur schmale mattsehwarze Querbinden. Hypoyyg schwarz mit kräftigen rostgelben, 
spitz dreieckig rerlanfenden Anhäingen, die eine starke borstenförnige Verlängerung zeigen; auch an siebenten Hinterleibsringe sieht man melrere lange schwarze Borstenhare. - Beine nebst Hiiften schwarz, Schienen und Tarsen gelb, Hintertarsen braun. Vordersehienen anf der Oberseite bis reichlich zur Mlitte mit etwa vier bis fünf Einzelborsten, von denen die letzte die lïngste ist; Vordertarsen sehr diinn, Metatarsus reichlich so lang wie die Sehiene, auf der Oberseite mit einer Reihe vou etwa zehn längeren, gleichmäbig verteilten Borsten, ron denen die letzte an der Spitze die lïngste ist, die folgenden Tarsenglieder zeigen ebenfalls alle an der Spitze eine längere Borste, nieht nur das dritte Tarsenglied wie Loew sagt. Mittelschienen auf der Mitte der Oberseite mit zwei lïngeren Borsten; der Mittelmetatarsus ist ähnlielı beborstet wie der Vorlermetatarsus, nur etwas kiirzer. Hinterschienen nebst Tarsen anßer ihrer kurzen Behaarung ohme besondere Borsten. Die Vordertarsen sind fast $z$ weimal so lang wie ihre Sehiene, die Mitteltarsen etwas liinger, die Hintertarsen etwas kiirzer als ibre Sehiene. Alle Sehenkel, namentlich aber die Vordersehenkel zeichnem sich dureh längere weiße und aluch schwarze Beharung atus. Fliigel glashell, an der Syitze des Vorderrandes mit einem brannen Schattenfleck, den Loew nicht erwïhnt nud der auch vielleicht nur bei voll ausgereiften Exemplaren vorkommt. Die erste Läingsader erreieht nicht ganz die Flügelmitte; die Gabelader zweigt spitzwinkelig nach ritekwiirts ab und biegt anf der Mitte knrz bogeuförmig, reehtwinkelig, zur Spitze anf; die kleine Querader liegt sehr sehriige. $4 \mathrm{~mm}$ ling.

๑. - Dem ơ iibnlich, anch die Beborstung der Vorder- und لlittelsehienen ist anniherud dieselbe, der Vordermetatarsus ist oberseits aber etwas kiirzer beborstet und am Mittelmetatarsus fehlen die oberen Börstchen fast ganz.

Ich sah zrei Exemplare (ठ) im Wiener IInseum aus Venezuela, ferner einige Exemplare aus Nordamerika in der Sammlnng des Ungarisehen Nationalmuseums. completus n. sp. ơ

Man wird in Aldrich's Tabelle auf viridicoxa Aldr. gefubrt, die aber durch Beborstung der Mittelbeine und sehwiehere Fltigelzeichuung sowie einfachere Analanluänge anders geartet ist. Das llypopyg muserer Art hat große Ähnlichkeit mit dem der Art filiformis (vgl. die Figur).

o. - Vit der gewöhnlichen blaugrüuen Färbung und Beborstung. Schwinger sehwarzhraun. Fibler schwarz, Borste subapikal. llinterleib sehwarzriin mit breiten sammetschwarzen Vorderrandbinden. Hypopyg mit langen fadenfürmigen behaarten Anhängen wie bei filiformis. Beine rotgelb bis rostbriunlich, alle Hüften schwarzgran, Hintertarsen sehwark, mitunter auch die Hiutersehienen und die Spitze der Hintersehenkel verdunkelt; Hintertarsen so breit wie die Sehiene. Vorderschenkel ober- 
seits mit einer dunklen Lïngsstrieme. Die Unterseite der Sehenkel ist nur spïllich behaart; Vorderschienen und Tarsen nackt; Nittelschienen nur mit drei winzigen Einzelborsten; Tarsen ebenfalls naekt, aueh die Hinterbeine haben nur eine äußerst kurze Beborstung. Vordertarsen $13 / 4$ mal so lang wie ihre Sehiene, diese um $1 / 8$ mal kiirzer als der Metatarsus und letzterer fast zweinal so lang wie die vier iibrigen Glieder zusammen. Mitteltursen reieblich so ling wie die Sebiene; diese $1 \% / 3$ mal länger als der Metatasus, letzterer 1.4 mal lïnger als die tibrigen vier Glieder. Hintertarsen kiirzer als die Sehiene; diese un $1 \%$ mal länger und dreimal so lang wie der Metatarsus, letzterer $1 \frac{1}{4}$ mal so lang wie die iibrigen Glieder. - Flïgel mit bramen Querbinden, die sieh fast iiber die ganze Fläehe verbreitet haben, letztere ist ganz rauehgrau und zeigt nu an denjenigen Stellen, die sonst glashell bleiben, eine etwas geringere 'Triibung. $7 \mathrm{~mm}$ lang.

q. Die Vorderliuften sind rotgell, sonst dem of gleieh. $2 \sigma^{7}, 6$ q itus Brasilien, Theresopolis. Sammlung des Ungarisehen Nationalmuseums.

25 a confluens n. sp. б".

б". - Tlıolaxibicken und Schildehen dunkel blangriun mit flinf Panr Dorsozentral- und drei Par Akrostikalborsten. Schwinger, Sehiippehen und deren Wimpern selwwarzbraun. - Kopf blau, Gesieht weiß bestäubt. Riissel und Taster sehwarz. Fiihler' sehwarz, zweites Glied unten lang beborstet, Fiiblerborste kurz, kiirzer als der' Thor:ax; am Seheitel steben außer der starken Borste am Augenrande versehiedene sehwarze Hare. - Hinterleib griingold, fünfter und seehster Ring stablblau, miifig lang sehwarz behaart und beborstet. Hypopyg selıwarz mit kưen dicken Anhïngen von trapezfölmiger Gestalt; der siebente Ring stark schwarz beborstet. - Beine mit allen Hiften sehwarz, Vordersebiene nebst Metatarsus rotgelblich, Mittelsehiene nnd iln Metatarsus rostbraun. Torderbiffen und die Unterseite der Sehenkel zart weiß behart. Vorder- und Mittelsehienen ohne besondere Be. borstung, nu nit wenigen kleinen Einzelbörstehen, Hinterselienen desgleichen. Hintertarsen ganz sehwarz, rom Ende des ersten Gliedes an bis zum fiinften Gliede dentlieh rerbreitert. - Fliigel etwas grall mit zwei sehwachen braunen, an Vorderrande bis zur dritten Längsader verbundenen Querbiuden ohne seharfe Begrenzung, anch an der vierten Längsadel streifig verbunden, so daß der helle Zwisehenranm fast wie ein Fensterfleck erscheint; Gabelader spitzwinklig nach riekwirts abzweigent, heruach knieförmig zur Flïgelspitze umbiegend; bintere Queladel gerade und fast reehtwinkelig zur vierten Längsader gestellt. 4 mm lang.

$10^{\pi}$ aus St. Catharina, Brasilien, Theresopolis [Miebaelis S.]. Berliner zoologisehes Museum. corculum Walk. O’, List. Dipt. British Mus. IIl 645 [Psilopus] (1849) Brasiliaı. 
ऽ. - Der nichtssagenden Beschreibung entnehmen wir, dalk abgeseben ron der gewihnlichen Kärperfarbe dic Flahler schwar sind; ferner Schenkel schwarz, Schienen rostgelb, Tarsen braun. Fliigel glashell mit zwei brannen Binden. $21 / 2$ l. lang.

Die Art bleibt wie bisher unbekannt.

26 coralis Aldr. C., Biolog. Centr.

Amer. Dipt. I 357. 10 [P'silofus] (1901) . . Mexico dur Schin.(necWied.) Nor.Reise,

Dipt. 210.3 (1868) . Mexico

o7. - Fibler scliwarz, schwach beborstet. Sehwinger gell. Sebenkel und lliften schwar, Vorderschienen gelb, Vordertarsen braun mit Ansnalme eines Teiles des ersten Gliedes: Spitze der Vorderhiiften, Schenkelgolieder, Spitze und Basis der Vorderschenkel gell). Vorderschienen auf der Anbenseite beborstet; erstes Glied der Vordertarsen lang; unterseits bewimpert, an der Spitze ein wenig verdickt, zweites Glied kurz nit einem Polster anf iler Unterseite und anch etwas verdickt, drittes Glical kur, ricrtes verlaingert. Fliggel mit zwei Querbinden. 1.2 $\mathrm{mm}$ lang.

Zwei Exemplare der Schiner'sehen Sammlung, Wrien, stimmen damit vollkommen iiberein (Typen von dur. Sebin.).

27 ctenopus Enderl. 7 , Zoolog. Jalurl.

Suppl. XV. Festschr. fiur J. W.

Spengel B. I 401 ['silopus]

(1912) Peru, Bolivia, Ecuador.

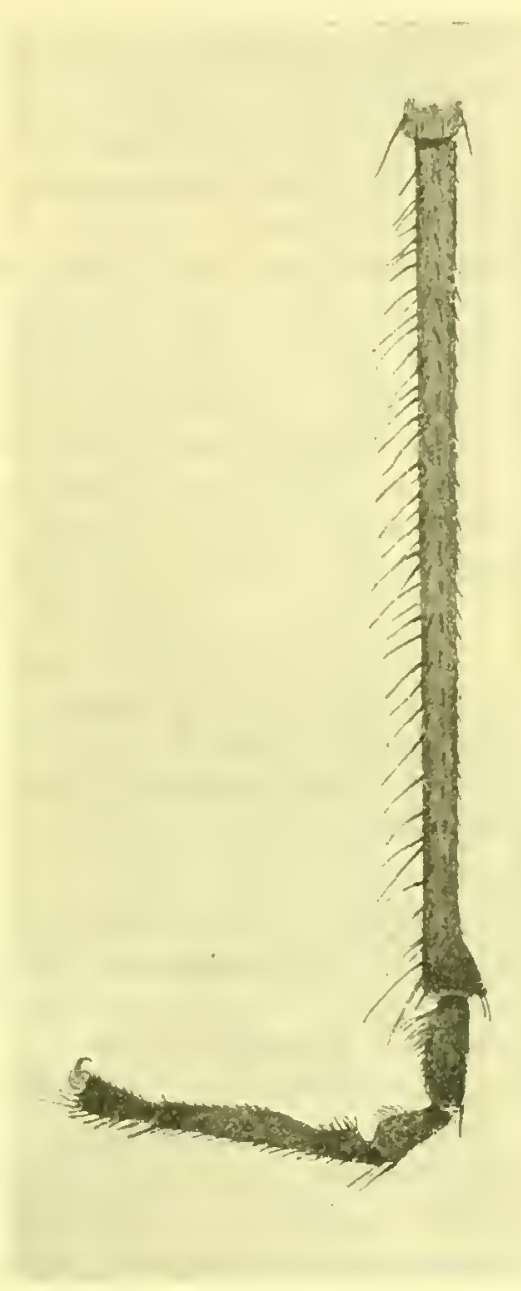

Fin.110. Conclis Aldr: $\mathrm{C}^{*}$. Vorderbein. 24:1.

o". - Fïhler schwarz; Schwinger schwarzbraun. Beine nebst Hiiften schwarz; rordere Schicuenpare nebst Tarsen rostgelb bis braunschwarz. Vorderschienen auf del Außenscite mit $4-5$ lingeren Borsten; Vordermetatarsus unten nahe der Spitze mit $1-2$ kurzen Einzelhorsten. Mittelschienen mit gleich langen, kammatig gereihten Borsten auf der Aubenseite; der Netatarsus und das zweite Glied ebenda mit sehr feinen, dicht gestellten Härchen; diese feinen Wimperu 
fehlen bei aler Art uniseriatus $m$; mit der diese Art sonst viel Ähnlichkeit besitzt; die Wimpern sind anch nielıt blattörmig verbreitert, wie dies bei der Art squamifer m., der Fall ist; dieht daneben in einer zweiten Reilse mehr nach der Unterseite hin stehen noch, ebenso wie bei pectinatus m., ungefïlur zwölf stirkere, aber nicht lïngere stumpfe Einzelborsten; an den Hintertarsen sind die letzten drei Glieder etwas verbreitert. Vordertarsen $1^{3 / 4}$ mal linger als die Sehiene: der Metatarsus kaum länger als diese, aber $1^{1 / 9}$ mal so lang wie die iibrigen vier Glieder zusammen. Mitteltarsen reichlich 1 1/2 mal so lang wie die Schiene; Metatarsus etwas lainger als diese und 24 mal länger als die tibrigen vier Glieder. Hintertarsen ktirzer als die Sehienc; der Metatarsus fast halb so lang wie diese, aber $11 / 3$ mal so lang wie die iibrigen Glieder. Am Hypopyg sind zwei sehware bis rotbranue Anhïinge sichtbar, die sieh zangenförmig zusammensehließen und spit\% dreieckig vellingert sind. - Die Bindenzeiehunng der Fligel ist etwas versehwommen, die Binden sind nieht breit; die Verlindung oben am Fligelınde reicht bis zur dritten Lïngsaler, anBerden sind die Binden anch längs der vierten Lïngsader etwas verbunden, so daß cin Fensterfleck entsteht; ferner ist die Spitze der Costalzelle gebriiunt. 5 min lang.

Tpye aus Kenador, Banos, im Stettiner roologischen Husem.

2 ơ ans Peru-Urambati 19. X1. 1903 und ans Bolivia 23. 1. 1903, Sarampioni $700 \mathrm{~m}$ loch [Sehnuse]. Samm]ung des Drestner Museums.

1 to aus Paragua, S. Bernarlino [Ficbrig]. Sammlnug des zoologisehen Wiener Hofunsenms.

decoripes 11. sp. o $q$

Ameriea merid.

o. - Azmrblau. Sehwinger sehwarzbraun. Kopf mit schwarzen Fiihlern wie gewöhnlich. Hinterleils nu mit schwaehen dumkleren Querbinden. Hypopyg krebssehwanzartig nnter den Banch gesehlagen, ziemlich grob mit breit entwickelten sehwarbraunen Organen, deren besondere Gestalt olne Präjaration nicht genaner angegeben werlen kann. Hinterleibsringe lang l,elorstet, auch das Hyopyg hat ziemlieh diehte, wenn auch nieht auffallend lange Behaarung. - Beine nebst Hiiten schwar\%, un die Vordersehienen und Metatarsen sind rostbraun. Vordersehienen allf der Oberseite mit vier nach unten hin länger werdenden Einzelbursten, Ifutatrsus borstenlus. jedueh auf seiner Unterseite mit einem weißen diehten biirstenahnliehen Filz belileidet. Toriertarsen doppelt so lang wie die Solniene. Mittelsehienen wie die Vorderschiene anf iluer Oberseite mit vier nach der Spitze hin länger werdenden Borsten besetzt, Metatarsus nackt, jedoeh anl seiner Unterseite mit mehreren kalum bemerkbaren Einzelbörstelen weitlänig hewehrt. Tarsen $1^{1} / 2$ mal linger als ihre Sehiene. Hintertarsen kiurzer als die Sehiene, Tarsenendglieder nicht verlureitert. - Fligel glashell olne fleckung, lirichstens mit dem Seluatten einel mbedeutenden 
Triibung am Ende der zweiten Lïngsader; Gabeladel spitzwinklig nach rickwirts nnd heruach reehtwinklig abbiegend; hintere Queraler ziemlich steil, $4 \cdot \bar{\jmath}-\overline{5} \mathrm{~mm}$ lang.

. - Dic Beborstung anf der Oberseite ler Vorler- und Mittelschienen ist die gleiche wic beim $\sigma^{*}$, die 'Tarsen sind etwas kiilzer, sonst dem $\sigma^{x}$ gleiels; an del Querater, der Gabelarler und der Spitze der zweiten Längsadel zeirgt sich mitunter einc schwaehe Bräunung. $2 \sigma^{7}, 3$ a a Per'l, Callanga. Sammlnng des Ungarisehen National. unuseums.

29 demessus Aldr. O", Biolog. Centr. Amer. Dipt. I 3อ̃.? 16 [I'silopus] (1901) . . . . . . . . . . . . Hexien

6. - Fiihlel sehwarz, die Randborsten des zweiten Gliedes lang. Schwinger gell, Beine mit Hiiften sehwarz, vordere Hiiftgelenke mul Sehienen gelb, letztere mit cinzelnen Borsten, die aber nicht reihenweise stehen. Fligel nit breiten Querbinden, anßer am Vorlerinde anch längs der vierten Längsader verbunden. Gabelader fast reeht winklig abzweigend. Hintertarsen an alen letzten Gliedem rerlureitert. $4.5 \mathrm{~mm}$ lang (nach Aldrich).

30 diffusus Wied. Oㅇ. AnBereurop. zweifl. Ins. II 221 (1830). Brasilien.

Lw., Monogr. N. Amer. Dipt. 11234 (1864).

chactophorus Schin. P, Novara-Reise 214. 15 (1869).

0. - Thorax und Schildehen dunkelblan, Schwinger schwarbrann, Schippchen schwarz mit eben solchen etwa zwilf selu langen Wimperu. Kopf wie gewöhnlieh; 'Taster, Riissel und Fỉhler schwar, \%weites Glied mit langen Endborsten, Fiillerborste ron mittlerer Lainge. Hinterleib grïnschwarz mit schwarzen Querbinden und ziemlich langen Randborsten. Hypopyg schwarz, außere Anhiinge gelbbraun, riemlich groß, lappenförmig, am Rande kurz beborstet. Beine nebst allen Iriften schwarz, Yordersehienen nelost deren Tarsen rostgelb. Die Unterseite aller Schenkel ist lang weiB, an den Yorderschenkeln sehwarz nud weiß licht behart. Die Vorderschienen sind anf der Oberseite bis $7 n 3 / 4$ ihrer Liinge mit fiinf bis seehs Einzelborsten besetzt, die an Länge allmählich zunehınen, die Tndertarseu siud gan\% nackt. Mittelsehienen ebenfalls auf ihrer Oberseite bis $z{ }^{3} \%$ der Liinge mit drei bis vier langen Einzelborsten besetzt, unten an der Spitze eine lingere Enlborste. Nitteltarsen ebenfalls maekt, nur del Metatarsus zeigt anf seiner Unterseite einige weitliufig gestellte knrze Einzelbiirstchen mul die beiden letzten Tarsenghlieder haben kure, aber sehneeweiße Behaarung. Die Hiuterschienen und Tarsen sind nur etwas raulrer behatrt. Vordertarsen reichlich zweinal so lang wie die Schicne, diese kiirer als der Metatarsus. Mitteltarsen etwa $1 \frac{1}{2}$ mal so lang wic die Sehiene, diese etwa ron gleicher Linge mit dem Metatarsus. Hintertarsen wie gewöhnlich erbeblich kiirzer als die Schiene. - Fliigel glashell mit den gewöhnlichen Querbinden, die bis zu der tritten Liingsader an 
Rande verbunden sind; die Britunung des Vorderandes reicht bis zur Nindung der elsten Laingsader: sie ist nicht seharf begrenzt, vielmehr allenthalhen verwsehen; eine schwache Verbindung beider Querbinden itber der vierten Lảngsader ist rorhanden, so daß der weiße Fleck als Fensterfleck erscheint; in der Näle der Adern ist die Fälbung am stärksten. Die crste Längsader reicht kaum bis zur Fliigelmitte, die lintere Querader steht sehräige zur vierten Iängsader und die Gabelader zweigt spitzwinklig nach rickwärts ab, um sich dann auf der Uitte hogenförmig, aber rechtwinkelig zur Spitze zu wenden, mituntel wird ein riicklanfender $\lambda$ derast sichtbar. $6 \mathrm{~mm}$ lang.

Anmerkung. Loow sagt bei diffitsus 1. e. p. 284. dab in Wiedemam's mnd Winthen's Simmhng in Wien zwei verschieden Mimelien moter den Ximen diffusus strekten. und zwat anBer diffusus noch die Art jucumbs. Ich find die

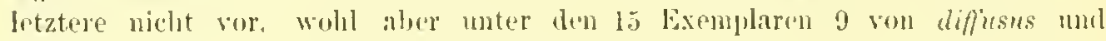
anBorden moch versehiedme ander" Aran.

Q. - Dem of gleich sowohl in der Firbung der Beine als anch in der Beborstung der Vorder- und Vittelschienen.

31 dimidiatus Lw. O’, Berl. Ent. Zeitsehr. VI 216 [Psilojus] (1K62).

Mexico, Brasilia

07. - Blangrian, Sehwinger gelb bis braun. Thoraxricken nur mit vier Paar Dorsozentral- und drei Akrostikalborsten, in Verbindung damit auch nur mit zwei Schildborsten. Seliappchen sehwarz bewimpert. linterleib nur mit sehr schmalen mattschwarzen Querbinden; Hypopyg klein, schwarz mit schwarzen, dreieckig zugespitzten, etwas behaarten Lamellen. Beine nebst allen Hiften schwarz; Schienen gelb bis rostbrïunlich, Hintersehienen rostgebl, bis schwarghraun. Die Schenkel sind anf ihrer Unterseite fast ganz nackt. Vordersehienen und Tarsen ohne Borsten; letrtere 1.8 mal linger als die Schiene. Nittclsehienen und 'Tarsen ebenfalls olne Borsten, jedoeh ist die feine kurze Behatung nicht immer anliegend, vielmehr etwas struppir abstehend: die Tarsen sind 10 1.7 mal läuger als ibre schiene. Hintersehienen und 'Tarsen ebenfalls kalhl und die Tarsenglieder nicht verbreitert. Fliigel glashelh mit einem großen schwarzbrannen Flecken, ler am Vorderrande von der basis an nicht ganz bis zum Ende der zweiten Laingsadel reicht und dessen untere Begrenzung vou hier aus in einem großen Bogen parallel del hinteren Quelader und dem Fligelhintermande bis zur Fligelbasis zurieklaiuft, so dab ungefilır \%/: der ganzen Fligelfliche schwarkbratun gefiilht ist; die dritte Liingsader ist stark geschwnngen, die Gabelader zweigrt fast rechtwinklig ab. Die Vorderrandader zeigt eine sehl kurze, aber dentliehe Bewimperung (s. Fig.). $5 \mathrm{~min}$ lang.

:3 ans Venezuela [Lindig] ron Schiner's Novara-Dipteren; Wiener zoologische Sammlnug des llofmusenms, als dimidiatus Lw. beschrieben, in der Sammlnng als smmater Sohin. bezettelt. - 1 in ans Ilexico 
9. $\mathrm{X}$ 08, Sammlung des Deutschen Entomologiselien Museums in BerlinDihlem.

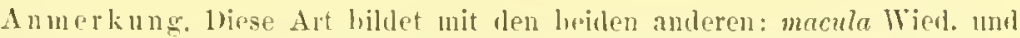
medirmus me einen klrinen Formenkreis. der sich dureh geringere Anzalil der Schildborsten rom allgemeinen Gattungwehatrakter absondert und an Sciopus Zell. erinnert. Aus diesem Grunde hat anch Aldrich die Art dimidiatus l,w. als einen Sciopus [Gnamptopsilopus] behanlelt. Wenn die sehüpreh'n lıell hewimpert wären. wïrdr ich diese Absmlerung anch für berechtigt und notwendig erachten. wegen der sehildborsten allein will ich jedoch tine solehe nicht vornehmen.

dimimuans $11 . \mathrm{sp}$. $\mathrm{O}^{7}$

America merid. triseriatus Euderl. (nee Aldr.), Zoolog. Jahrb. Supplem. XV Zeitsehr. fiur 1. W. Spengel 401 [Psilopus] (1912).

๖े. Thorix gringold, sehildehen blar. Selıwinger lıellgelb. Kopf wie gewöhnlich mit schwarzen Fiihlern, zweites Fiihlerglied mit eingen

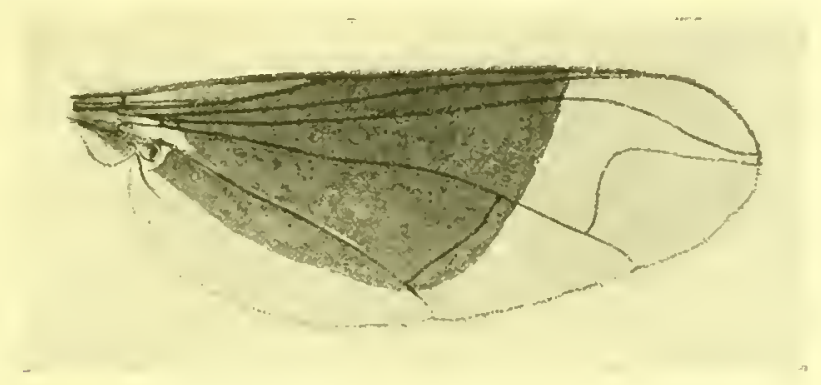

Fig. 111. Condylostylus dimidiatrs 1.W. O . Fhigel. 12:1.

langen Borsten (drittes Fïhlerglied fehlt). Hinterleih gringold mit sehmalen mattschwarzen Ringrändern. Hypopygium klein, sehwarz mit selwarzen ovalen, sehwach behaarten Anhängen. Beine nebst allen Hiiften schwarz; Kiniee, alle Schienen und die Metatarsen der vorderen Beinparare gelh. Tordersehienen borstenlos, die Tarsen desgleiehen, nu ant der l'nterseite des Metatarsus in der Nahe der Spitze steht eine kleine linzelborste. Läinge der Tarsen ungefähr $13 / 4$ der Sehienenlinge. Mittelschienen nur mit rereinzelten kurzen Börstehen hesetzt, die in versehiedenen Reihen stehen; Tarsen mack, etwa ron $11 / 4$ der Sehienenlïnge. Hinterschienen gleichmäig knrz behaart, etwas länger als die Tarsen; diese nieht verdickt, viehmehr nach dem Ende zu allmählich etwas schwächer werdend. - Fligel mit zwei am Vorderraude bis zur dritten Längsader rerbundenen brannen Querbinden. deren Grenzen nicht scharf, sondern verwasehen sind; Gabelader spitzwinklig abzweigend, hernach rechtwinklig gebogen; hintere Qnerader rechtwinklig zur vierten längsader, reichlieh um die eigene Länge ron der Gabelader entfernt. $4.5 \mathrm{~mm}$ lang.

$10^{\rightarrow}$ (Type) aus S. Catterina, Brasilien. Sammlung des Stettiner zoologischen Museums. 


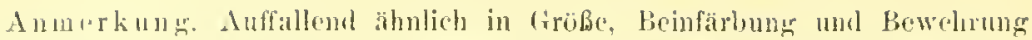
nit atrolamellatus Mlalr., alur bei diminuans sind die Analantainge kleiner und

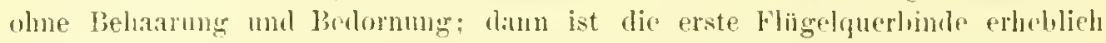
schnajler. wabrenul diese bei atrolamellatus bereits an Ende der rorsten lingsader breginnt; andere Enterschiede vamar joh allerdings nicht \%u finden.

Encierlein hat diese Art für triseriatus Aldr. angeselıen. aber bei dioser sind die Hinterschionen niclit ganz gell, sundern an del Wurzel bram; die Vordersehirnen tragen and der Anßenseite eine lieihe von borsten, lic Mittelschienen pine solehe aul der Vurdrseite, die Analanhänga sind bei triseriatus klein, gellhram, die llintertarsen sind an den letzten drei Ciliedern gleich lang und breitgerlsickt.

Eine der guthlu Wied. nahestehende Art, aher durch bosondere lieborstung des Tordermetatarsus abweichend.

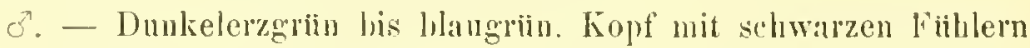
in der gewönlichen Formgehung. Selnwinger sehwarzbraun. Hypopyg klein, schwarz mit cinfachen länglichovalen schwarzen beharten Lamellen. Beine und alle Hiften schwaltz, Torder und Vittelsehienen rostgelb bis bramn. Vorderschienen anf der Außenseite nit rier bis füf Einzelborsten. Torlertarsen etwa doppelt so lang wie die Schiene, Metatarsus läuger als dic Schiene, auf seiner Unterseite zalt und dicht hewimpert, anferdem nit drei bis vier lingeren, gleichmilfig verteilten Börstehen besetat. Mittelsehienen auf der Aulienseite der ganzen Länge nach grob hewimpert, an der Spitze und Unterseite eine lingere Borste; die Tarsen 1\% mal so lang wie die Sehiene und einfach, Metatarsus so lang wie die Sehiene. Hintersehienen etwas länger als die Tarsen, diese so dick wie die Schiene und die letaten Glieder etwas verbreitert. - Fligel mit zwei brannen verwaschenen, am Vorderande bis zur dritten Laingsader rebumdenen Querbinden, nitunter ist anch eine schwache Verbindung längs der vierten Längsader vorbauden; in der Mediastinalzelle ist eine Bräunng in der Spitze. $45-5 \mathrm{~mm}$ lang.

40 aus Brasilien. Collect. Wintlem. Wiener Hofmuseum.

dorsalis Lw., Berl. Ent. Zeitsehr. IX 180. 85 [I'silopus] (1865). Cuba

Ist mit weißen Wimpern der tegulae ein Sciomus. dux Wied. = equestris Fbr.

aux Schin. (nec Wied.) = roxalis Aldr.

electus Walk. O . . . . . . . . . . . . Brasilien

Eine Art mit schwarzen Fiblern und Beinen, Sehienen rotgelb. Fligel mit brannen Quertinden. Eine Charakteristik der Art ist nicht angegeben. Wir missen die Art beiseite legen.

it elegantulus n. sp. 0 . .

Blasilien

Eine kleine schlanke Art.

$0^{7}$. - Thoraxrizeken blan bis griin. Sehwinger gelh. Kopf und Stine wie bei allen Arten nit schwaren Fiihlem. Hinterleib blan und goldgriin. Hypopyg klein schwarz mit zwei kurzen schwaren, 
stabförmigen, grebogenen, stumpt endigenden Organen, dic nur sehwach behart sind; die Penisseheide ist an der Spitze etwas becherförung gestutzt. - Beine mit Vorlerlitiften rotgelb, Hintertarsen und die Endglieder der vorderen Tarsen schwarz. Forder- und Hinterbeine fast ganz borstenlos. Mittelschicuen aul der AuBenseite whit aht bis neun weirläufigo gestellten liorsten; an den llinterbeinen sind die letzten drci Glieder kurz und glcichzeitig etwas verbreitert; an den Vorderbeinen steht am Metatarsus eine clanakteristische Borste im letzten Viertel der Unterscite. Vordertarsen 1.S mal so langr wie die Schiene, diese etwas langer als der Netatarsus und letzlerer ebenso lang wie die vier ibrigen Glieder zusammen. Mitteltarsen 1/4 nal länger als die Sebiene, diese $n \mathrm{~m} \quad 1 \frac{1}{3}$ länger als del Metatarsus und letzterer wieder um $1 \frac{1}{3}$ länger als die iibrigen Tarsenglieder. Ilintertarsen kiurzer als die Schiene, letzterc um l·If länger und iiber zweimal lïnger als der Metatarsus, letzterer reichlieh so lang wie die vier folgenden Glicder zusammen. - Fliagel mit zwei selumalen hraunen Binden, dic am Vorderrande bis znr dritten Längsader miteinander verbunden sind: die binden bilden eigentlich nu eine breite Sïumung der linteren Querader und der Gabelader, diese zweigt spitzwinklig nach rijckwilts ab und ist anf der Mitte rechtwinklig gebogen. 4 mim laug.

20 aus Costa Rica, Surrulres. Sammlung des Ungarisehen Nationalmuseums.

35 equestris Fbr, Syst. Entom. 75\%. 40 [Musca] (1775) . . Brasilia

Wied. Außerenrop. zweitt. lus. Il 214. :3 (1430).

dux Wied., Auberenrop. zweitl. Ins. Il 216. à ['silopus] (1830).

Wiedemann zitiert l. c. Fabricins Beschreibung, aus der hervorgeht, daß cquestris eine größere Art mit gebinderten Fligeln und sehwarzen Sehenkeln darstellt. Die Analanhiange des $0^{\top}$ werden als hakenfömigg geschildert. Wiedemann fügt hinzu, dab er in Fabricius' Sammlung nur noch ein liellbeinges Weibchen gefunden habe, dem man aber trot: verschiedener Schenkelfärhung die Zngehörigkeit nicht ohne weiteres absprechen kam, da wir vicle Arten besitzen, bei denen die Weibclien liellere lieine haben.

In der Wience Sammlung betindet sich eine mannliche Type, allerdings ohne kiopf, aber sonst noch eingermaken rerwendbar [kurze Nadel]. Ich gebe zunichst die besehreibung.

3. - Thorax, Kopf und IInterleib von der gewiolnolichen metalliscben Färbung. Beinc: alle Hiiften und die Selienkel bis anf dic Kniee schwar; alle Sehienen und die Metatarsen der vorderen Beine gelb, die ubrigen Tarsen sehwarz bis braun. Vordertarsen annailiernd doppelt so lang wie ihre Schiene, beide ohne besondere lieborstung. Jitteltarsen reiehlich $1^{1 / 2}$ mal so lang wie die Schienc, diese aul der Außenscite mit grober sehwarer liewimperung; Metatarsus 
etwas kiimer; aber anch borstlich bewimpert; an den Hintertarsen sind das dritte und vierte Glied deutlieh etwas verbreitert. - Fliigel glashell mit zwei braunen Binden, die am Vorderrande bis zm dritten Längsader mit einander verbunden sind. Gabelader nach riekwiirts spitzwinkelig abzweigend und hernach kurz bogenfirmign und fast reehtwinklig alshicgend.

Am Hinterleibe lilit sich rom Hypopyg nieht viel sagen; es ist schwarz und klein und die inferen Anallamellen sind nur kurz, sehwarz und endigen spit\%. $6-7 \mathrm{~mm}$ lang.

Anmerkung. Schiner, Mre in seinen Lovara-Dipteren diese Art ausfidıliclı beschreibt, hat eine ganz andere Art vor sich gehabt; hei dieser sind die Schenkel ganz gelb und die Vordertarsen haten in Form nud Beborstung eine hesondere Auszeichnung; mit dem Wietemanuschen Exemplar, das wir als Type loch woht anzuerkennen berechtigt sind; ist keine Ubereinstimmung wohanden. Schiner hat die Wiedemannsche Type jedenfalls nicht zu Rate gezogen. leh habe tiese neup Sichinersche Art perestris genannt, siche dort.

Zur Symonymic ron dux Wied. bemerke ieh folgendes: 1)ie Type von rlux im Frankfurter. Senckenbergisehen Husenm babe ieh gesehen, sie ist nur ein Weibehen mit gethen Beinen und ziemlich breiter bindenzeiehnung der Fliigel; sie ist nielıt melı in guter Verfassung; es fehlt ein Teil des Hinterleibes, der Beine und ein Fligel, inmerhin läßt sieh noch folgendes feststellen:

q. - Fiihler sehwarz, drittes Glied klein, das zweite Glied ohne lingere Borsten. Sehwinger hellgelb. Hinterleib nur mit schmalen sehwarzen Querbinlen. Beine nebst Vorderhiiften gelb, außerste Spitze der llinterselienen braun; alle 'Tarsen braunsehwarz. Vordersehienen an der Ober- und Außenseite nit je drei kleinen Einzelhörstehen. Mittelsehienen auf der Oberseite ebenfalls mit zwej soleher Börstehen, eine an der Basis, die andere ungefälu anf der Mitte, ferner mit 3-4 Börstchen auf der Anßenseite. Hintersehienen mit einer Borste nieht weit von der basis der Oberseite. Fliigel nit zwei breiten branen Binden nnd einem brannen Fleeken in der Kostalzelle, beide Binden sind am Rande bis zur dritten Längsader miteinander verbunden. $6-7 \mathrm{~mm}$ lang.

Wiedemann spricht von einem Exemplar mit abgeindeter Fligelzeiehnung im Museum von Berlin; ich habe zwei Weibehen dort grefunden, bei denen die Fligelbinden anch unten an del vierten Lings. ader zum groben Teil, wenn anch njelst gan\%, rerbunden sind, im iibrigen aber durlians dem Weibchen des Frankfurter Itusemus entsprechen. Ein drittes Weibehen des Berliner Musemms hat schwarze Sehenkel und Hinterschienen und stellt eine andere Art dar.

Hieraus und ans der Vergleichnng dieser Weibchen mit denen ron equestris Wied. geht hervor, daß sie einer und derselben Alt angeliören. 
ร. - Thoraxriicken glinzend griin bis blau, Brustseiten aschgran; Schwinger blaßgelb. Kopf wie gewölnnlich, das Gesielıt aluer nielıt behart. Hinterleib blau bis griingold nit breiten mattschwaren Vorderrandsbinden. Hypopy gium sehr klein mit stabformigen, an der Spitze hakenförmig nmgebogenen schwarzen Anlängen (s. Figur). Beine: Hiiften und Schenkel schwarz, Kniee, Schienen, Wurzelhälfte des Vordermetatarsus gelb, Spitzenhilfte der Hinterschienen braun, alle Tarsen schwalz. Vorderbeine ulme besondere Beborstung, fist nackt. Mittelsehienen auf der Oberseite mit 2-3 kleinen Einzelborsten, an derSpitze der Unterseite mit einer langen senkrecht abstehenden Borste, die an Länge $1_{13}$ der Sehienenlänge gleichkommt, der Metatasus unten mit zwei Reihen schriggestellter gebogener Borsten. Hintertarsen so dick wie die Schiene, die beiden Endglieder kaum etwas rerbreitelt. Voldertarsen etwas lïnger als die Sehiene, diese um 1.6 mal länger als de! Metatarsus und letzterer $11 \mathrm{~m}$ 1 1/3 mal längel als die viel folgenden Glieder zusammen. Mitteltarsen fast so lang wie die Schiene, diese doppelt so lang wie der Metatarsus und letzterer so lang wie die vier folgenden

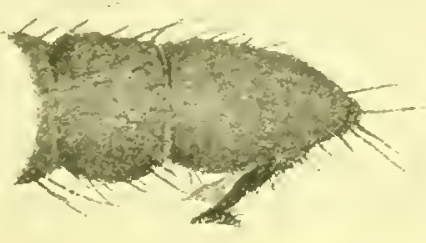

I"ị. I11a. Cundylostylus erectus Beck. of Hypupye. $24: 1$.

Glieder. Hinterschiene $m$ 1 1/2.

mal länger als die Tarsen und reichlich dreimal linger als der Metatarsus. Fliigel zart gelblieh; die Gabelader zweigt rechtwinklig und weiter stumpfirinklig bogrenförmig ab. $\$ 35 \mathrm{~mm}$ lang.

5 ơ aus Paragnay, Asuneion 1904 [Vezélyi]. - Auch aus Tordamerika, Adirondack, Long lake 1907 [Heros]. Sammlnug des Uugarischen Xationalmuseums. - Aus Argentiuien, Corrientes. fi. Nill. 1907 [Sehnuse]. Lresdner Nuseum.

A nmorkung. 1)iese Art ist mit caudutus Wied. mul scobinutor Lw. rerwandt ron levilen aber durch das nicht beharte (icsicht und indere Analanhänge al). weichumi.

expmtus Walk. O", Ius. Samuler. Dipt. I 20 [Psilopus] (1852) Brasilia

Eine Art mit sehwarzen Fihlem und Beinen. Vorderschienen gelb. Fligel mit braunen Binden; charaliteristische Eigenschaften sind nicht genanut, die Alt bleibt fraglich.

exruisitus Walk., Ins. Saunders. Dipt. I 210 [T'silopus] 1852) Brasilia

Eine Alt mit schwarzen Fiihlern, branen Beinen und hellen ungefirbten Fligelu. Ohne Angabe des Ceschlechtes und olne Armerkmale; auch diese Art ist uicht zu denten. 


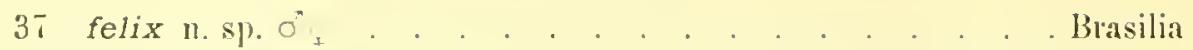
3. Körperfarbe und liopf wie gewöhnlich. Fiihler schwarz. drittes Glied mitunter lontbaun. Sehwinger gelb. Hinterleib nur mit schmalen matten Querbinden. Iypougg klein, sehwar\% mit dunklen dreieckig \%ugespitzten, unbedentend behaarten Limellen. Beine und Vorderhibten helgelb, Tarsen mit Ansmahme der vorderen Metatarsen sehwar\%. Vorderschieuen auf der Außenseite nur mit unbedentender kurzer Behaarung und Beborstung; Mefatarsus so lang wie die Seliene, unterseits knr\% wimperartig behart und mit 5-6 etwas lingeren Einzelbörstchen; das zweite 'Tarsenglied ist unterseits kriffiger beborstet, das fiunte Crlied zun Untersehied ron imperator m. ohne Borsten anf der Unterseite. Vordertarsen $1^{3}$ mal so lang wie die Sehiene. Hittelschieneu und Tarsen olme charakteristische Beborstung, letztere $1 \frac{1}{2}$ mal so lang wie die Sehiene. Minterschienen und Tarsen einfach, letatere von ${ }^{3} / 4$ der Sehienenlänge. - Fligel mit zwei schwachen hramnen Querbinden, die am Vorderande bis zur dritten Laingsader verbunden sind; die dritte Längsader verläuft fast granz gerade; die Gabelader zweigt spitzwinklig naelı riekwärts ab; der mittlere Bogen ist fast reehtwinklig und die hintere Quemder steht nur wenig schrige \%ul vierten Längsader. 6-7 mm lang.

๑. - Dem o gleich, aher mit ganz einfachen Beinen. Ëin Pärehen aus Brasilien, Savannah und Rio Grande do Sul. Sammlung des Wiener Itofmuseums. - 1 ó aus brasilien in der Loew'schen Sammlung des Berliner zoologischen Museums.

:8 filiformis n. sp. . . . . . . . . . . l'ern

o. Thoraxpicken dunkelviollett lis veilehenblau, gläuzend ohme Bereifung : fiun Dorsozentrallon'sten, viel Akrostikalborsten von gleieher Stairlie, die in ihrer stellung mit erstereu korresponlieren. Brustseiten weiBgran hereift. Sehwinger grelb. Kopl: Stirue glanzend stahlblan, in gewisser libehtung etwas weibgrau schillernd; Gesicht oben noch metallisel glainzend, unten weil bis sibberoänzend: nackt. Fibluler und Taster schwar\%, hiissel rostgelb; die liandbeborstung des zweiten Glieles der Fiihler verhälnismaißig knr. Ilinterleib glanzend stahlbau bis bronzelabig nit selwwaren handhorsten der hinge und von einer Linge, die der Dieke der limge entspricht. Hypopyginm sehwarh, nuffirmig, mit zwei kurzen ovalen behaarten Lamellen und zwei langen fadenförmigren und kur behuaten Anhängen (s. Fign 112). Beine nebst den Vorderhtiften rotgelb, Tarsen bram bis sehwall; Vorderhiblen kur\% weili behaart mit zwei bis drei schwarzen Borsten. Sehenkel anl der Unterseite nackt oder nur spälich weil behart. Vordersehienen fast nackt, Vorlermetatarsus oberseits nackt, moten auf del Wurzelbailfte mur mit selur kurzen birlstehen, die nach der Vitte hin allmählieh versehwinden; die Voldertarsen sind 1.5 mal so lang wie die Sehiene, der Jletatarsus un wenigg linger als die ijhrigen Glieder \%n- 
sammen. Mittelschienen oberseits mit zwei bis drei sehwaehen Einzelborsten, unten mit deren drei; Mittelmetatarsus uackt. unten nur mit kaum siehtbaren Börstehen; Mitteltarsen 1 m 1.2 mal lïnger als die Sehiene und der Metatarsus ein wenig lainger als die iibrigen vier Glieder zusammen. Hinterschienen oben nnd unten sehr zalt borstlich bewimpert: Hintermetatusus nuten sehwach horstlich: die llintertarsen

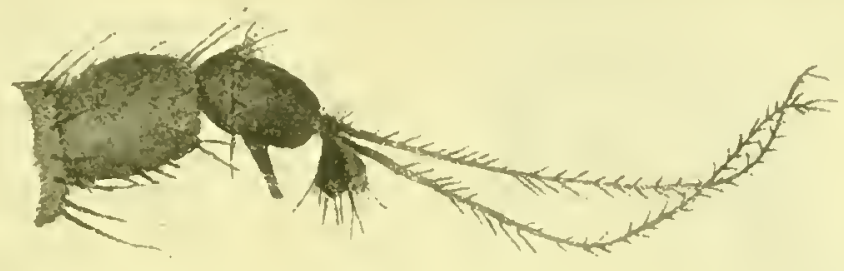

Fig. 112. Condylostylus filiformis Beck. O. Hymplyg. :-4. 1.

sind kiuzer als die Schiene, die um 1.3 mal langer ist, der lletatarsus ist ron glejcher Länge wie die iibrigen vier Talsenglieder znsammen. - Fliagel etwas granlich mit zwei breiten braunen, oben am Fligelrande verbundenen Querbinden, deren heller Zwisehentan bis zur dritten Laingsader reicht, alleh unten an der vierten Läingsadel sind die Binden hin und wieder ein wenig verbunden; die zweite Quer-

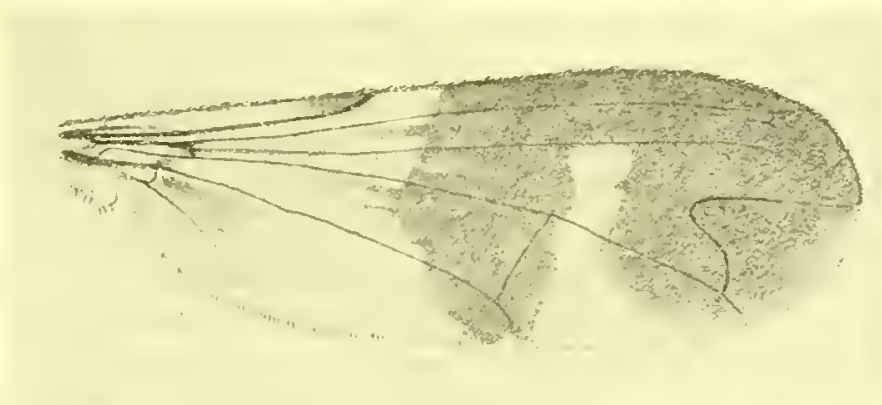

Fig. 113. Condylostylus filiformis lieck. O’. Flïgel. 16:1.

binde fiillt die ganze Fliigelspitze bis iiber die vierte Laingsader hinaus ans, jedoch nimut die Färbung am Hinterande an Starke alluablich ab; die Gabelader zweigt auch riiekwairts gebogen spitzwinklig ab und anch der Bogen anf ihrer Mlite hat nur spitzwinkligen Cbarakter (s. Figur). 6-7 mu lang.

f. - Die Weibehen gleiehen in der Farbung ganz dem Mlinnchen; die Hintersehenkel siud an der spitze dentlich gebräunt, die lbeborstung 
der Beine ist noch etwas kirzer und die Flaigelzeichnung noch etwas kriftiger.

5 ơ, 2 q aus Peru-Mesbaguay, Urubambafi. 26. IX. 1903: - aus Bolivia-Mapiri. 1. Yll. 1903, Sampioni $700 \mathrm{~m}$ hoch, - aus Peru, Pachitamiandung $150 \mathrm{~m}$ hoch. 4. Xl. 1903 [Sehnuse]. Sammlung des Dresdner Iluseums.

39 filipenicillatus Enderl. O\%, Kool. Jalub. Suppl. XV. Festsehr. fiir J.W. Spengel. 403 [Psilomus] (1912) . . . . . . America merid.

5. - Fithler schwarz, das wweite Glied nur sehr kurz beborstet. Schwinger gelbbraun. Hinterleib blaugritn ohne mattsehwarze Querbinden. Hypopyg selur klein, schwarz, mit zwei langen fadenfömigen Anbïngen, die im Wurzeldrittel etwas rerbreitert sind und ungefahr die halbe Luinge des Hinterleibes besitzen. Beine nelst Vorderhiften hell rotgelb, Hintertarsen und die vorderen 'Tarsen mit Ausnahme ihres ersten Gliedes schwarzhlaun. Schenkel unterseits nur sehr zart und spïrlich behart. Die beine sind iberhant fast ganz borstenlos; auf der Oberseite del Vittelschienen in ersten Drittel sieht man eine kleine Einzelborste. Vordertarsen 11/2 mai so lang wic die Schiene, Mitteltarsen 11/, mal so lang. Hintertarsen dentlieh kirzer und ebenso dick wie die Schiene; die drei letzten Clieder sind annïbernd gleich lang, kamm etwas verbreitelt. - Flitgel zart graubräunlich olne Bindenzeichnung; die erste Lüngsider reiclit fast bis zur. Jitte, die dritte verläuft deutlich bogenförmig. Gabelader rechtwinklig abzweigend, hernach stumpfwinklig bogenförmig rerlaufend; hintere Querader etwas schräge, um die eigene Lainge rom Fubpunkte der Gabelader entfernt. $4 \mathrm{~mm}$ lang.

$1 \delta^{7}$ (Type) aus S. Catherina, Brasilien in der Sammung des Stettiner zoologischen Ifuseums.

40 flagellatus n. sp. $\sigma^{7}$. Zwei Higuren . . . . . . . . . . Peru

ङ. - Thoraxriicken goldgriu, mattglïnzend, hintere Hälfte und das Sehildelen veilchenblau. Brustseiten aschgrau. Schwinger gelblich. Kopf: Stime nud die ubere Hälfte des Gesichts stahlblan, die untere Hălfte weißgrau bestinbt. Riissel rostgelh, Taster und Fiihler schwarz. - Hinterleib: erster ling blau. die anderen bronzefarbig mit breiten purpurschwarzen Yorderandsbinden; Behaarung schwarz, die Randborsten so lang wie der Ring dick. Das schwarze Hypopygium mit seinen dunklen Anhïgen lat Äbuliebleit mit dem del Art filiformis, jedoch sind die andieren langen beharten Anhïnge anf der Wu'zelhïlfte verbreitert, auf der Endhäilfte fein bebaart und fadenförmig; die wenig sichtbaren inneren Organe sind kurz dreickig, fast uackt; die Penisselıeide ist dentlich (s. Fig. 114). - Beine nebst Vorderhiilten rotgell, Tarsen brann bis sclwarz. Vordertarsen zweimal so lang wie die zugehirige Sehiene, der Mctatarsus $1 \frac{3}{4}$ mal so lang wie die iibrigen vier Glieder zusammen. Mitteltarsen 1.4 mal so lang wie die Sebiene, der Metatarsus $21 / 2$ mal so lang wie die ibhrigen Tarsenglieder; die 
Hintertarsen sind kỉrzer als die Schiene, und zwall ist letztere $11 /$ mal linger; der Metatarsus $1 \%$ mal so lang wie die folgenden vier Glieder zusammen. Alle Sehenkel haben aut" ihrer Unterseite eine ziemlieh lange, wenn anch spairliche weiße Behaarung, Vorderhiiften auRerdem mit einigen sehwarzen Borsten. Voldersehienen auf der Oberseite mit drei, auRen mit zwei Einzelborsten.

Mittelschienen oben mit rier; anßen mit zwei, aulierlem steht an der spitze der Schienenunterseite eine lange charakteristisehe Borste. Bei den langen Hinterschienen sieht man im ersten Viertel del Oberseite eine lingere Einzelborste, aufierdem nur noch kiirzere, unregelmaibig sestellte Bürstchen, willrend die ganze Unterseite, wenn atueh nur kur, so doeh deutlich borstlich bewiupert ist. Der Vordermetatarsus und das zweite Tarsenglied sind auf ihrer Unterseite kurz berwimpert, beim Metatarsus wird diese Bewimperung erst etwas deutliehel' g"egen das Ende. - Die Fliigel zeigen wiederum die beiden rlunkelbramen Qnerbinden, die am Vorderande nur bis zur zweiten Lïingsader miteinander verbumden sind; der Vorterrand des Fliigels ist ebenfills bis über die Miindung der ersten Längsader hinaus bram gefärbt, desgleichen hat die kleine Queradereine braune fleekenartige Siumung. $7 \mathrm{~mm}$ lang.

10 aus Peru - Meshagua 2!. September 1903, Urulsumbati [Sehnuse] Sammlung des Dresdner Museums.

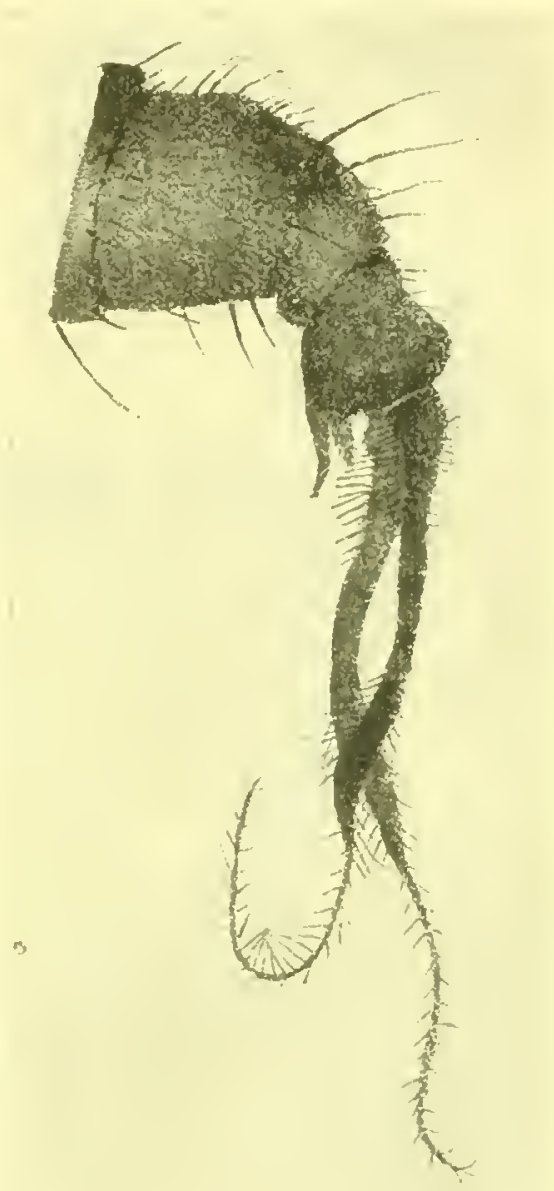

Fig. 114. Condylustylus thegellatus biecti. c. Hy]ongy. :2: : 1 .

41 flagellipodex n. sp. $\sigma^{*}$. Eine Figur 116. . . . . . Palluguay

Hat Ähnlichkeit nit der vorhergehenden Art flagellatus in Größe, Fligelzeichumg nnd Konstruktion des Hypopys, weicht jedoeh ab in der For'u der Analanhïinge und in den Lïngenverhälnissen der Beine. $0^{*}$. - Thoraxrieken grinlieh, Sehildehen blatu. Schwinger gelbbraun. Stirne und Gesicht stahlblau, letzteres bis etwas iiber die Fihler 
hinaus weiß bereift. Fiihler klein, sehwarz, mit un mäßig langen Randborsten am zweiten Gliede. Riissel gelbbrann, Taster sehwairzlich. Hinterleib an den ersten Ringen blau, hernaeh goldgriin bis messingfurbig. Hypopyg sehwarzbran mit langen brannen Anhingen; diese sind an der Wurzel etwas verdiekt und endigen fadenförmig mit blattförmig verhreiterter fein behaarter Spitze; der verdickte Wurzelteil ist auf seiner Unterseite dieht gelblieh behant und trigt in der Niihe der Basis einen Sehopf gelber verbreiterter Borsten (s. Figur 116). Beine nebst Vorderhiiften rotgelb, Spitze der Hintersehienen braun, Hintertarsen und Endgrlieder del vorderen Tarsen sehwar" bis brann. Unterseite der Schenkel zalt weiß behaart. Sehienen und Tarsen ohme besondere Beborstung, am Endpunkte der Mittelsehienen steht jedoch ebenso wie bei flayellutus eine stäkere Einzelborste. Längenverbältnisse: Tordertarsen un 1\$2/4nil

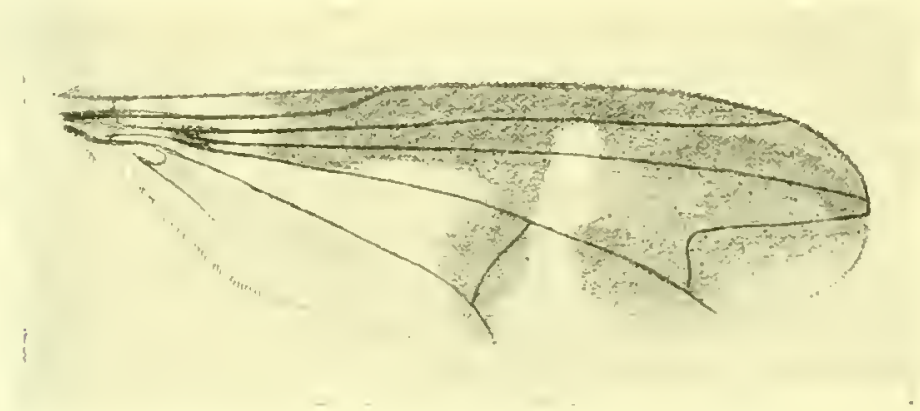

l"ig. 115. Condylostylus flagellatus Beck. of. Flïgel. 16 1.

linger als die Sebiene, diese ebenso lang wie der Metatarsus und letzterer $1 \frac{1}{3}$ mal liinger als die vier letzten Glieder zusammen. Mitteltarsen reiehlich um 1.t mal linger als die Schiene, diese ebenso lang wie der Metatarsus und letzterer reiehlieb doppelt so lang wie die vier folgenden Glieder. IIintertarsen kuirzer als die Sehiene, letztere $11 / 8$ mal liinger als die Tarsen und fast doppelt so lang wie der Metatarsus, letzterer um 1.4 mal liinger als die vier Gilieder zusammen. Flïgel mit breiter Bindenzeiehnung und Vorderrandbräunnng; der lielle Zwisehenranm der beiden Binden reieht bis zur zweiten Laingsader. $6 \cdot 5-7 \mathrm{~mm}$ lang.

$10^{7}$ aus Paraguay [Fiebrig]. Sammlung des Ungariselien NitionalNuseums.

42 flaricornis Aldr., Trans. Ent. Soe. London 342. 3 [Gnamptopsilopus] (1896) . . . . . . . . . . . . . Ameriea centr.

Gehört nit seinen weißen Wimperu der tegulue zur Gattung Sciopus Zell.

Wiedemann luat frliher hereits eine Art flavicomis ans sumatra besehrieben und Aldriehı's Art milite einen anderen Namen erhalten, 
wemn bejde Arten derselben Gattung angehorten. Das wird aber nicht der Fall sein, denn flavicumis IIied. (Type in Kopenhagen) hat eine apikale Fthllerborste, gehört also dem allgemeinen indischen Typus an; ler Name flaciromis Aldr. kam somit bestehen bleiben. 43 flaricoxa Aldr. on, Biolog. Centr.

Amer. Dipt. I $363.27[$ Psilomus] (1901). . . . Mexico o. - Fiibler schwarz: Schwinger gelbbrianlich. Hypopyg mit schmalen gelben Jamellen. Beine nelsst Vordejhiiften gelb, hintere Kniee etwas gebräunt. Beine ohne besondere charakteristische $\mathrm{Be}$ borstung. Fliigel mit zwei braunen, am Vorderrande nur bis zur zweiten Längsader verbundenen Querbinden; dıe Vorderrandbraiunung hegimut am Ende der ersten Liingsader. 5*2 mm lang. (Nach Aldrich.)

flaridus Aldr.. Trans. Ent. Soe. London 3+1.

1 [Gnamptopsilopus] (1896) Am. centr. Ist mit den weißen Wimpern seiner tegulae höchst wahrscheinlich ein Sciopus Zell. 44 flavilamellatus 11. sp. 5 . Am. merid. c. - Kopf mit schwaren Fiihlern. zweites Glied mit kuiftigen Randborsten. Fiillerborste mäirg lang. Schwinger bramnschwar. Hypopyg klein, schwar, mit ziemlich großen gelben Lamellen, die heiderseits. uamentlicl aber auf der Außenseite dentlich schwar behart sind. Beine mit allen Hiiften schwar' bis schwarzbrann; Vordersehjenen rostgelb, an den Außenseiten mit vier bis funf Rinzelborsten; 'Tarsen ganz einfach, borstenlos. Mittelschienen aulien grob und weitliuufig bewimpert, der Metatarsus ebenfalls an" der Aubenseite, abel selur fein und dicht bewimpert. Hinterselienen und Tarsen ohne besondere Be-

Fig. 116. Condylostylus plagellepodex Beck. Ilypmyg. 24: I borstung, nur das dritte, vierte und fiinfte Glied sind etwas verbreitert. Fliigel mit zrei braunen Querbiuden, welche rorne bis etwas iiber die dritte Liingsader hinaus und etwas laings der vierten läingsader mit- 
einander verbunden sind. Gabelader spitzwinklig abzweigend, hiutere Queraler gerale und steil. 5-6 $\mathrm{mm}$ lang.

Ein Exemplar ans Bahia. Sammlnng des Wiener Hofmuseums. (In Coll. Winthen als equestris Wied. bezeichnet.)

- flacimunus Macq. $0^{7}$, Dipt. exot. II 2. 122 [Psilopus] (1842). Brasilia J. - Fïhler und Beine selwarz. Schienen nud Vordertarsen gelb. Fligel glashell, ohue weitere Angabe charakteristischer Merkmale. $2 \cdot 1 \mathrm{~cm}$ lang. Dic Art bleibt mbekannt.

45 forcipatus Aldr. o', liolog. Amer. Dipt. I 362 [I'silopus] (1901). Mexico

o. - Fiblel schwal"z, Randborsten des zweiten Gliedes lang, Arista nicht besonders lang. Selıwinger brann. Hinterleibspitze mit zwei langen, wellig gekrimmten Borsten. Hypopyg sehwar\%, groß, unit zwei groben brannen zangenformigen Organen. Beine mit lltiften and Sehenkeln schwar\%; voldere und mittlere Schienen gelb, Metatarsus fast ganz gelh, Tarsen braunschwarz; Mittelmetatarsus naekt, das liinfte Glied der Mitteltarsen weiß behart. Vordersehienen mit einer Reihe längerer Bursten anf der Oberseite. Flitgel glashell mit einer schwachen Bräunnng anf der Lndhilfte. $5 \mathrm{~mm}$ lang. (Nach Aldrich.)

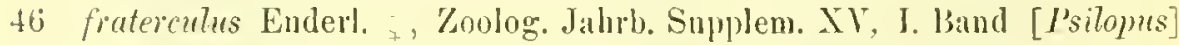
$405(1912)$. . . . . . . . . Brasilia merid.

‥- Thorax blau, metalliseh glänend. Sehwinger gelh, Sehiippchen blafgelb bewimpert. Schildehen dentlich nit viel fast gleichstarken borsten; Akrostikale auch borstenförmig (drei l'arr). Hinterleib blan, an der ainßersten Wrumel des zweiten Ringes und an Banche haßgelt ohme schwarze Querbinden. Beine mit allen Hiften baßgelb, letate 'Tarsengliedel maun; Beine nackt, nur an den Mittelsehienen sieht man im ersten Viertel ihrer Oberseite eine Einzelborste. l'litgel ghashell; dritte Iängsader wenig gebogen. Gabelader rechtwinklig abzweigend, auch anf der Mitte rechtwinklig gebogen; hintere Querader rechtwinklig zur vierten Liingsader, um das 1\%, fache ihrer eigenen Länge ron der Gabelader entfernt. $3 \cdot 7 \mathrm{~mm}$ lang:

Ein Exemplar ('Type) ans S. Catherina, Brasilien iu Stettiner zoologischen Wusemm.

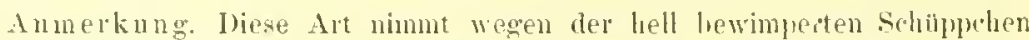

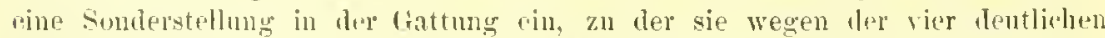

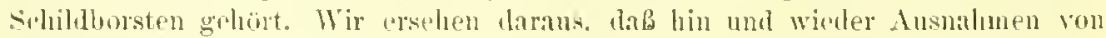

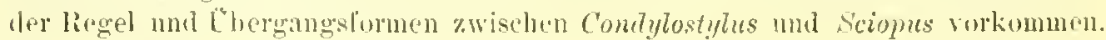
gemmifer Walk. = simho Say.

47 genulis Aldr. O', Biol. Centr. Am. Dipt. I Bew [Psitopus] (1901). Mexieo

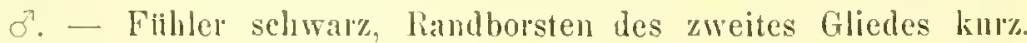
Schwinger gelb (Hinterleib abgebrochen , Hïften und Sehenkel schwarz, alle Schienen gelb. Vorlerschienen wit fiuf bis sechs schlanken Borsten ' anf der Ilinterseite (Anßenseite?). Mittelschienen mit einer dichten Reihe kleiner Borsten auf der Oherseite, zwei oler drei Einzelborsten 
an der Außenseite und einer unregelmäligen Reihe kleinerer Borsten anf der Hinterseite. Vordertarsen doppelt so lang wie die Schiene; Metatarsus mit einigen kleinen Borsten all der AuBenseite nahe der Spitze; atteh das zweite Glied trïgt eine Reihe etwas kiirzerer Biorstehen (Nitteltarsen abgeloroehen). Fliigel mit zwei braunen, am Vorderrande bis zur dritten Lïngsader verbundenen Querbinden. $5 \circ$ óm lang. (Nach Aldrieh.)

48 gitvipes Enderl. q, Zool. Jahrb. Supplem. XV, l. Band [I'silonus] p. $404(1912)$ - Brasilia

․ - Thorax blat. Schwinger rostgelb, Sehijppehen blißgelb bewimpert. Fíhler schwar, Gesicht nackt. Hinterleib mit seluachel Beborstung. Beine mit allen Hiiften blaßgell, nackt; Schenkel nnterseits ohne Belaarung. Fligel farblos; dritte Lingsader im Endteil nach uuten gebogen; Gabelader etwas spitzwinklig abzweigend, ant der Nitte reehtwinklig. $35-4 \mathrm{~mm}$ lang.

Ein Exemplar aus S. Cathurina, Brasilien. Type im Stettiner zoologiseben IInseum.

Anmerkung. Da die sehüplehen habgelb bewimpert sint, tritt hier die l'rage auf, ob diese Art deswegen zu Gattung Scioms zu rechnen sein wirt. Leider kann man wegen schlechter Besehaffenleit des Thmax und des Sehilichens nicht sehen, wie die Beborstung heschaffen ist, so daß man ïber die Zugehörigkeit dieser Art zu einer der beiden in Frage kummenden trattungen kein klares Bill gewinnen kann.

49 gracilis Aldr. [Psilopodinus] (1904) . . . . . . . . . . . . Brasilia

6t. - Thorax, Kopf und Hinterleily weichen aucl hier von der fast allgemein sieh zeigenden Form und blanen Färbung nieht ab. Das Hypopyg ist klein; die iußeren Organe bestehen ans vier kleinen gelbbrannen, an der Spitze schwarzen vorgestreekten Lamellen. Beine schwarz mit rostgelben Schienen und Tarsen; vordere und mittlere Hiiftgelenke gelb. Vorderschienen auf ilrer Anßenseite mit einjgen weitläufig gestellten Borstenharen, der Metatarsus nackt. Mittelschienen außen ebenfalls mit einigen Borsten, Metatarsus nackt. Hintersehienen gelb, Spitze und Basis brann; Tarsen mit der gewöhnlichen rauhen Behaarung; Hintertarsen etwas verdiekt, die letzten drei Glieder auel etwas verbreitert. Vordertarsen reichlieh doppelt so lang wie die Schiene, Mitteltarsen etwa $1 \frac{1}{2}$ mal so lang. An den Fligeln sind dic beiden brannen Querbinden ziemlich breit nud an der vierten Liingsader anelı etwas zusammengeflossen, so daß in del ersten Hinterrandzelle nur ein weißer Fleck iibrig bleibt, der die Längsadern nicht beriihrt. $6 \mathrm{~mm}$ lang. (Nach Aldrich.)

griseoprasius Wulp. = chrysomasius Walk.

guttipennis Rond. = stigma Fbr.

Abhandl. der zool -botan. Ges. Bd. XIIl, Heft 1. 
50 gutula Wied. $\sigma_{f}^{7}$, AuBereurop. zweifl. Ins. II. 222. IS [Psilopus] (1830) Brasilia

Mehrere Exemplare in Winthem's Sammlung, welehe der Beschreibung entsprechen und die man ohne Bedenken als typisehe Vertreter ansehen kann. Loew kinnte diese Art nicht.

87. - Kopf, Thorax und Hinterleib ron der gewöhnliehen Fïrbung olne besonders herrortretende Merkmale. Seluwinger brann. Hinterleib mit mattsehwarzen Querbinden. Hypopyg sehr klein sehwarz mit kleinen braunen spitzdreieckigen äuBeren Lamellen. Beine mit allen Hiiften selwwarz, mit sehwarzbrannen Sebienen nnd spïrlieher Beborstung. Vorderschienen außen mit vier bis funf lïngeren Einzelborsten; 'Tarsen einfach, ungefilu $1 \frac{1}{2}$ mal so lang wie die Sehiene. Mittelschienen nit rauler Bewimperung anf der Aufenseite; Tarsen einfach, kalum 11/4 mal so lang wic die Sebiene. Hintersehienen verhailtnismißig zart bebart olne Borsten; Tarsen kiirzer als die Sehiene, so diek wie die Schiene, aber ohne deutliehe Verbreiternng der letzten Glieder. Flïgel mit der gewölıulichen Bindenzeiehnung, die aber ganz znsammengeflossen ist, so daß sie kann noch lervortritt, die Bräinung am Vorderrande geht noel liber die dritte Liingsader himaus, aneh dic vierte Längsader ist breit braun nusïumt, so daß sich ein fast kreisrnnder heller Fleck in der ersten Hinterrandzelle iiber der hinteren Querader zeigt. - $5 \mathrm{~mm}$ lang.

o Die Weibchen laben rotgelbe Sehienen und fast borstenlose Beine.

$40^{7}, 7$ o ams Brasilien in Winthem's Sammlung Wiener Hofmusenm, zum Teil als "pulcher Wied." bestimmt.

Variante. Mit etwas schwicherer Flïgelzeichnung, bei der sich die Binden in breite Streifen zu beiden Seiten der Adern auflosen. - 2 o" aus Peru, Vileanota und Bolivia, Cillutincara in der Sammlung des Ingarischen Nationalmusenms.

- ymyanensis Macq. q, Dipt. exot. 1I 2. 1189 [Psilopus] (1842). Brasilia

Ein Weibchen mit selwarzen Fiihlern und Beinen, langen Randborsten des zweiten Fiihlergliedes; Vorder- und Mittelsehienen gelb. Fliigel glashell. 2.1 Linien lang. Die Art bleibt nnkenntlieh.

- haereticus Walk. o Trans. Ent Soe. London n. S. V 257. [Psilopus] (1S60) Mexieo

Ein ungeniigend eharakterisiertes Weibehen.

51 hamiformis n. sp. oै. 1 Figur . . . . . . . . . . Paraguay

ङ. - Kopf und Thorax wie bei den übrigen Arten gefïbt und beborstet. Schwinger gelb. Hinterleib mit mattsehwarzen Torderandsbinden. Hypopyg schwarz mit zwei etwas nael oben gebogenen und zangenförmig sieh nähernden stabförnigen Anhïngen, die an den Riindern beborstet sind. Beine nebst allen Hiiften schwarz; llinterbeine ganz schwarz, nur die vorderen Sehienen nnd der Mittelmetatarsus sind gelb. Die Außenseiten der Vorderschienen sind mit fünf lingeren Borsten besetzt, die der Mittelsebienen mit zehn Borsten; der Mittel- 
metatarsus ist fein und dicht bewimpert, mol zwar sind die feinen, senkrecht abstebenden Härelıen an der Spitze lakenförmig umgebogen (s. Figur 117). Hintersehienen und Tarsen haben keine besondere Borsten; die Hinterselienen sind an der Spitze etwas verdickt und die Tarsen rerlaufen in gleicher Dieke wie die Schienen bis zum Ende. Die Vordertarsen sind $1 \frac{1}{2}$ mal so lang wie die Sehiene, diese un $12 / 5$ länger als der Metatarsus und letzterer ist etwin lïnger als die iibrigen rier Glieder zusammen. Mitteltarsen um $1 \frac{2}{5}$ lïnger als die Schiene, diese reichlich so lang wie der Metatarsus, letzterer doppelt so lang wie die vier Glieder zusammen. Hintertarsen ktirzel als die Schiene, diese doppelt so lang wie der Metatarsus und letaterer um $1 \frac{1}{4}$ mal länger als die folgenden vier Glieder. - Fligel mit zwei miaßig breiten Querbinden, dereu obere Verbindung an Fligelrande bis zur dritten Längsadel reicht und die an der vierten Längsader anch eine schwache Verbindung zeigen; die Binden stellen sich dar als eine breite Umsäumung der linteren Queradel und der Gabelader. 4.5-5 mm lang.

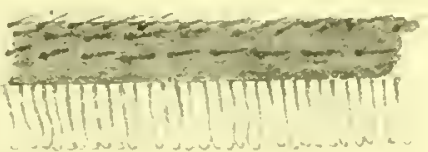

Fig. 117. hamiformis Beck. ot. Mittelferse. 48:1.

10 aus Paraguay [Fiebrig] Sammlung des Ungarischen Nationalnullsenms.

50 ans Paraguay, S. Bernardino [Fiebrig] Samm]ung des Wiener Hofmuseums.

52 hirsutus n. sp. $\sigma^{7}$. . . . . . . . . . . . Brasilia

б. - Azurblau mit hellgelben Schwingern. Kopf mit seliwarzen Fiihlern, deren zweites Glicd lange Raudborsten hat, das dritte Glied mit subapikaler Borste, die etwas linger als gewöhulich ungefïh so lang ist wie Kopf nnd Thorax zusammen. Stirne lang weil behaurt. Hinterleib bis zum dritten Ringe azublau, dann grijngold mit nur sehr schmalen mattschwarzen Querbinden; die Randborsten sind sehr lang, reichlich doppelt so lang wie der Ring dick; der siebente Ring oder das Hypopygialstiek trägt sebr lange Haare, die fast doppelt so lang sind wie die Randborsten der Ringe. Hypopygium klein, kelch. förmig, aus đen gelbe Anhänge senkreeht emporwachsen; diese sind zienlich dick, endigen spitz, nach vorne gebogen und zeigen an der einen Seite eine Abzweigung. Beine: Hiiften und Schenkel schwarz, Schienen und Tarsen gelb, Hintertarsen etwas gebräunt. Schenkel unterseits alle mit sehr langer weißer, fast wolliger Behaarung. Vorderschienen auf der Oberseite mit viel bis füinf langen Einzelborsten, von denen die letzte im zweiten Drittel der Schienenlïnge besonders lang ist; der Metatarsus ist sebl lang und diinn und tright auf seiner Oberseite ebenfalls eine Reihe ron nenn bis elf Borsten, ron denen die letrte die laingste ist; anch das zweite Tarsenglied endigt mit einer End- 
borste. Die Vordertursen sind mehr als doppelt so lang wie die Sehiene; del Charakter der Beborstung ist dem del Art mubculus gleieh (s. die Figur bei mueculus), nur sind die Borsten hier noeh kräftiger und liinger. Mittelschienen: anch diese tragen anf ihrer Vorder-oder Oberseite drei bis vier lange Borsten in ahnlicher Anorduung wie an den Vordersehienen; die Unterseite ist gleichfalls mit drei Einzelborsten bewehrt, von denen die an der Spitze die längste ist; der Metatarsus triigt auf seiner Oberseite eine wimperartige Beharung, die vier folgenden Glieder ebenfalls, jedoeh sind die Järehen kiirzer, feiner und dichtel gereiht. Die Mitteltarsen sind $1^{3 / 4}$ mal so lang wie die Sehiene. llinterschienen und Hintertarsen sind außer der feinen anliegenden Beharung borstenlos, letztere sind etwas klirzer als die Schiene. Nliigel farblos; die erste Fligelader reieht bis zur Fligelmitte; die Gabelader zweigt spitzwinklig naeh liickwärts ab, die zweite Biegung ist rechtwinklig; die hintere Querader steht sebr schräge, fast parallel zum Hinterrande des Fliigel. 5 mm lang.

$1 \sigma^{7}$ aus Brasilien. Sammlung des Wiener Hofmuseums.

¿3 hirtipes Aldr. ơ, Biolog. Centr. Amer. Dipt. 1361.21 [Psilopus] (1904).

Mexico

3. - Fỉhler schwarz, zweites Glied mit langen biisehelförmigen Randborsten. Thorax und Hinterleib stark beborstet. Hypopyg klein, sehwarz, mit kleinen schwarzen Anlü̈ngen. Beine sehwarz bis brannschwarz, Sehienen ranhbehairt. Vordersehienen und Metatarsen an der Ilinterseite mit einer Reilse langer Borsten, Hintertarsen an den drei mittlereu Gliederu etwas verbreitert. - Fliigel glashell, lang; Costa bis zum Ende der zweiten Längsader bewimpert. 3-4 1nm lang. (Nach Aldrich.)

- hirtulus Big. o', Ann. Soe. Ent. Fr. ser. VIII Bull. XXIX [Psilopodius] (1888) .

Haiti

Unkenutlich beschrieben.

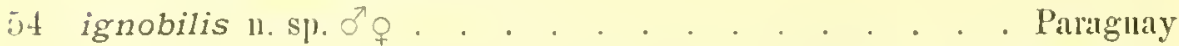

o Nur un ein geringes kleiner als modestus 11 . in Körperfarbe und Fliggelzeichnung gleieh, abweichend dureh das Fehlen jeglieher charakteristischer Beborstung an Schienen und Tarsen. Beine und alle Hiiften schwarz, rordere Sehienen und Wurzel der Metatarsen rostgell. Schwinger gelb. Iypopygialanhänge kurz, zangenförmig, rostgelb. Tordertirsen $1{ }^{1}$ a mal so lang wie die Schiene, diese $1 \frac{1}{4} \mathrm{mal}$ länger als der Metatarsus und letzterer $1 \frac{1}{5}$ mal länger als die viel folgenden Glieder zusammen. Mitteltarsen $1 \frac{1}{6}$ mal länger als die Schiene, diese fast $1 \frac{1}{2}$ mal so lang wie der Metatarsus und letzterel chenfalls $1 \%$ mal so lang wie die näehsten vier Glieder. Hintertarsen kiirzer als die Schiene, der Metatarsus so lang wie die iibrigen Glieder. Fligelzeiehnung nu schwach entwickelt. Gabelader spitzwinklig nael riiekwiirts abzweigend, hernaeh rechtwinklig bogenförmig. $350 \mathrm{~mm}$ lang. 
1 ठ, 12 f aus Paraguay, Assuncion 1904 [Vezényi] Sammlung des Ungarischen Nationalmuscums.

б. - Thorax wie gewöhnlieb goldgriin bis blau. Seluwinger schwarzbraun. Kopf wie gewöhnlicl. Gesicht etwas graugelb bestiubt. Fiihler schwarz, zweites Glied mit verhältnismäßig selı schwacher lie. borstung. Hypopyg schwarz mit gelbbraunen, zangenförmig gebogenen, stabförmigen, wenig behaarten Anbïngen. Beiue mit allen Hüftcn schwarz; Hinterschienen rotbraun, vordere Schienen rostgelb. Schenkel unterseits nur sehr spärlich weif belaart. Torderschienen an der Wurzel dèr Außenseite mit 4-5 starken Haaren, Tarsen nackt. Mittelsehienen nebst Tarsen olıne Beborstung, nur mit der gewölnlichen feinen anliegenden Belıanrung. Hintertarsen so dick wie die Schiene, die Endglieder aber ohne Verbreiterung. Vordertarsen $1 \frac{1}{2}$ mal so lang wie die Schiene, diese $11 \mathrm{~m} 1 \frac{1}{8}$ länger als der Metatarsus und letaterer nu $1 \frac{1}{3}$ mal länger als die vier folgenden Glieder zusammen. (Nitteltarsen abgebrochen.) Hintertarsen um $1 \frac{1}{3}$ kiirzer als die Schiene, diese fast $21 / 2$ mal so lang wic der Metatarsus und letzterer nur um ein geringes länger als die vier iibrigen Glieder. Fliigel mit zwei ziemlich breiten braunen Querbinden, die am Vorderrande bis zur dritten Laings ader, sodann anch an der vierten Lüngsader etwas verbunden sind, so da $B$ in der ersten Hinterrandzelle ein Fensterfleck entsteht. Die Gabelader zweigt in spitzen Winkel ab und bildet anf der Mitte bogenförmig einen rechten Winkel. $6 \mathrm{~mm}$ lang.

$1 \sigma^{7}$ aus America centr., Costa Rica. Sammlung des Ungariselien Nationalmuseums.

56 ignotus n. sp. ठ․ 1 Figur . . . . . . . . . . . Britsilia

ơ. - Thorax und Schildeben wie gewölnnlich. Sehwinger gelh braun. Kopf blau, Gesicht weiß, 'Taster und Fitbler schwarz, zweites Glied mit langen Randborsten. Hinterleib blaugrün. Hypopyg schwarz mit zwei gelbbraunen, an der Spitze gebogenen, wenig belsarten stab. förmigen Anbängen. Beine mit allen Hüften schwarz, vordere Schienen und Metatarsen gelb, Hinterschienen rötlichbrann. Vorderschienen anf der Außenseite mit fünf längeren Borsten, Tarsen nackt. Mitte]schienen anf der Ober- und Außenseite mit drei und zwei Borsten in zwei Reihen. Mittelmetatasus anf der AnBenseite mit einer Reihe etwas breitgedrïckter, schmal blattförmiger Borsten oder Sebuppen; unten zwischen der feinen Behaarung stehen einige längere Eiuzelborsten. Äbnlichkeit in der Bewimperung ist mit der Art deficiens vorhanden, die Wimpern sind hier aber linger und baben eine andere Form. Hinterschienen und Tarsen sind auber der gewölnnlichen ratuen Beharung olne charakteristiselıe Beborstung; die Tarsen haben die Stärke der Scbiene und die drei letzten Glieder sind etwas breitgedrtickt. - Vordertarsen un $1 \%$ liinger als ilne Schiene, diese 
reichlich so lang wie der Metatarsus und letzterer un $1 \frac{1}{s}$ linger als die vier folgenden Glieder zusammen. Mittelmetatarsus so lang wie die Sehicne. Ilintertarsen um $1 \frac{1}{8}$, kiïrzer als die Schiene, diese doppelt so lang wie der Mctatarsus, letzterer etwas lïnger als die folgenden vier Glieder zusammen. Die Bräiunng der Fliigelbinden hat ungefiihr dic gleiche Ausdelnnng wic bei der vorigen Art igmoratus. i $m$ m lang.

1 ठै aus Brasilien, Theresopolis. Sammlnng des Ungarischen Nationalmuseums.

57 impatiens n. sp. oך . . . . . . . . . . . . Venezuela

Kopf von gewöhnlicher Form nnd Färhung. Fïbler schwarz mit anffallend langon Randborsten am zweiten Gliede, anch die schwarzen Taster sind lang behaart. Schwinger sebwarzbrann. Hinterleibsringe mit breiten schwarzbramen Vorderandsbinden. Hypopyg klein schwarz mit dreicekig verlïngerten beharten schwarzen iußeren Lamellen. Beine nebst Hiiften ganz schwarz. Die Schenkel haben auf ihrer Unterseite eine

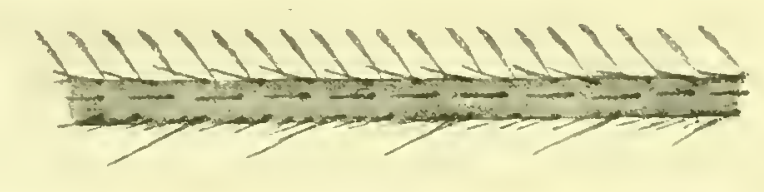

Fig. 118. Cundylostylus ignotus Beck. O'. Nittelmetatarsus. 45: ].

lange, an den Vorderbeinen aneh dichte Beharung, die zum großen 'l'eil sehwarz ist. Die Vorderschienen und deren Tarsen sind ganz borstenlos und fast nackt, jm Gegensatz zu melami) us Lw. (siehe die A mmerkung unten), bei der die Vordersehienen lange Einzelborsten tragen und deren Metatarsus auel beborstet ist. - Die Mittelsehienen tragen nur wenige kurze Einzelborsten, die nicht reihenweise georlnet siml; ilr Metatarsus ist anf seiner AnBenseite sebr fein, aber nul verhältnismäirg kurz bewimpert, ihnlich wie bei meiner Art difficilis. Die Hinterschienen siud ctwas raul, die Hinterschenkel unterseits besonders lang reilienförmig hohart: die Tarsen bleiben in der gleichen Dicke wie die sehicnen und ohne Verbreiterung ihrer letzten Glieder. Die Vordertarsen sind $1 \frac{1}{2}$ mal, die Mitteltarsen $1 \frac{1}{4}$ mal so lang wie ihre Schicne, die Hintertarsen kỉizer. Fliigel nit zwei braunen, nicht seharf begrenzten Qnerbinden, die am Vorderrande bis zm. dritten Läingsader verbunden sind; Gabelader nuter $75^{\circ}$ nach rickwiirts abzweigend. $6 \mathrm{~mm}$ lang.

4 O’, 1 q ans Veneznela [Lindig] (1864). Sammlung des Wienel Hofmuseums.

Anmerkung. Diese Fxemplare wuden ron sehiner als melamme Lw. he-

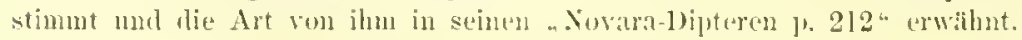


58 imperator Aldr. ơ. Trausact. Amer. Ent. Soc. XXX 281, 283 [Psilopodinus] (1901) . . . . . . . . S. Amerika

Nach Aldrich's Bestimmungstabelle wird man nicht ohne weiteres anf imperator hingeführt, da cr von den Wimpern der tegulae sagt, daß sie weißlich, nu oben schwarz scien. Bei den Exemplaren, dic ich untersuchen konnte, habe ich nur schwarze Wimpern gesehen.

万. - Eine große, prichtig gefärbte Art. Thoraxriicken nul Schildchen blan, rorne etwas gran bereift, mit nur vier Paar Dorsozentral- und drei Paar Akrostikalborsten. Schwinger hell gelbbraun, Schiippchen gelblich mit dunklem Saum nnd schwarzen Wimpern. Fiibler klein schwarz, das zweite Glied nur sehr kurz beborstet, das dritte Glied mit smbapikaler Borste. Riissel und Taster rostgelb. Hinterleib: die ersten beiden Ringe sind blau, die anderen goldgrỉn nit langer Randbeborstung, vorne am zweiten Ringe liegt eine weißgrall bestiubte Binde, auf den iibrigen Pingen sind die Vorderränder dunkel purpurfärbig. Hypopyg klein, schwarz mit liinglich dreieckigen, fast stabförmig nach

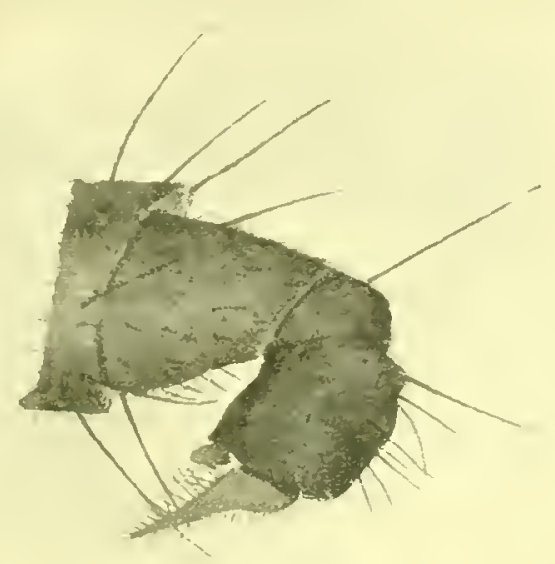

Pign. 119. Condylostylus imperator Alir. Hypopyg. $24: 1$.

vorne ausgestreckten behauten schwarzen äuferen Anhängen. Beine nebst den Vorderhiiften rotgelb, Hinterschienen an der Spitze braun, Hintertarsen schwarz, Mitteltarsen ganz, Vordertarsen roul zweiten Gliede an braun. Alle Schenkel nuterseits sehr zart weilj behaart. Vorderschienen auf der Vorderscite mit drei kleinen Einzelborsten, auf den iilorigen Sciten auler der feinen Grundbeharung: ohne bemerkenswerte Börstchen. Vordermetatarsus anf der Unterseite mit ungefähr acht mikroskopisch kleincn, aber nit der Lupe noch bemerkbaren, gleichmäßig verteilten Börstchen; Endglied der Vordertarsen unterseits mit kurzen schwarzen Borsten. Mittelschicnen auf der Außenseite mit drei, oberseits mit zwei bis drei Einzelborsten; Netatarsus ihnlich wie bei den Vorderbeinen auf der Unterseite mit zehn kleinen Börstchen. Hinterschienen unterseits ziemlicb dentlich bewimpert, oberseits mit zwei bis drei Einzelborsten; Netatarsus ohne besondere Beborstung. Die Vordertarsen haben annähernd dic dopprelte 
Liinge der Schiene, diese ist $1 \%$ mal klizer als der Metatarsus und letzterer $13 / 4$ mal linger als die vier folgenden Glieder zusammen. Die Mitteltarsen sind 1 m $1.6 \mathrm{mal}$ linger als die Schiene, diese ist fast so lang wie der Metatarsus und letzterer 1.85 mat linger als die vier folgenden Glieder zusammen. Hintertarsen ktir"zer als die Schiene, diese $13 / 4$ mal lingel als der Metatarsus. - Fliigel mit den iblichen bramen, am Vorderrande bis zur dritten Lingsader verbundenen, sonst aber etwas unterbrochenen Binden, die den Hinterand und die Spritze des Fliigels nicht ganz beriihren. Spitze der Vordermandzelle braun. Die Gabelader zweigt spitzwiuklig nach riickwärts ab, auf der Mitte fast rechtwinklig. $7.5 \mathrm{~mm}$ lang.

๑. - Keine wesentlichen Unterschiede rom $\sigma^{7}$

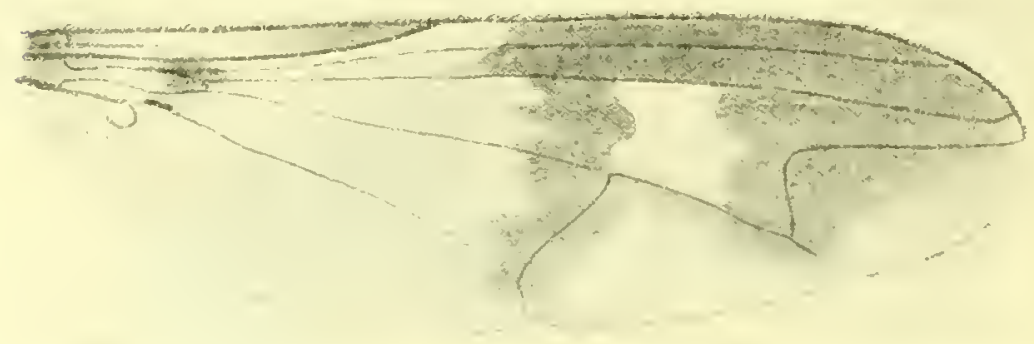

Fig. 120. Condylostylus imperator Aldr. of. Flïgel. 16:1.

18,39 ans Bolivia-Mapiri, 10. 111. 1903, Sarampioni $700 \mathrm{~m}$ hoch. - Aus Perı $150 \mathrm{~m}$ hoeh an der Pachiteamtindung, 2. XI. 1903 [Schnuse]. Sammlung des Dresdner Museums.

Einige Exemplare aus Pelu, Callanga in der Sammlung des Dentsehen Entomologischen Museums.

59 impreralis Fbr. o Syst. Antliat. 267. 4 [Dolichopus] (1805). Brasilia (Nec Wied., nee Schin.)

Nach Fabricius ist es eine größere Art mit ungefleckten Fliigeln, rotgelben Beinen und mit einer Verdiekung an der Spitze der Fihhlerborste. Wiedemann, der die Type in Kopenhagen gesehen hat, nenut die Fligel zwal glashell, fiigt aber hinzu, daß die erste nud die zweite Liingsader an der Spitze braun gesäumt seien; hinsichtlich der Fiihlerborste aubert sich Wiedemannn etwas absprechend iiber Fabricius' Beobachtung und Beschreibung, er glaubt, Fabricius habe ein Staubkorn an der Fiiblerborste fur eine Verdiekung derselben angesehen, und bestreitet das Vor handensein letzterer. Diese versehiedene Darstellung gab mir Veranlassung, der 'l'ype etwas genauer nachznforschen. Herr Dr. Wilh. Lmmbeck rom zoologischen Museum in Kopenbagen latte die Frenudlichkeit, mir iber die Fabricins'sche Type folgendes 
mitzuteilen: Die dorsale Fijhlerborste lat dieht vor der Spitze eine palettenartige Verbreiternng, wie Fabricius dies angegeben; Wiedemann's Äufernug bleibt vollkommen unverstiindlieb; man kann vielleieht annebmen, daß er entweder ein Weibehen, bei dem die Verdiekung der Fiihlerborste fehlt, oder iiberhanpt eine andere Art seiner Beobachtung und Kritik untergelegt hat. - Somit waire also die Art imperialis Fbr. (nee Wied.) gesiehert, da in dieser Gruppe keine andere Art mit soleber Filhlerborste konkuriert. - Aber auch Sehiner, der in seinen Novara-Dipteren dieser Art Erwäbnung tut und sie aus flihrlich beschreibt, ist mit seiner Auftassung wahrseheinlieh ebenfalls in's Wiedemanu'sehe Fahrwasser eingeliufen; er besehreibt eine ganz andere Art als imperiatis, seine Art hat eine einfache aber apikale Fiillerborste und Fliigel mit zwei brannen Qnerbinden und breitem Saum am Vorderande bis zur zweiten Lïngsader. Sehiner's 'Type ist ein $\sigma^{7}$ aus Venezuela [Lindig] (1864) im Wienel Hofmuseum. Da diese 'Type aber sehr defekt ist (es fehlt der ganze Hinterleib, ein Teil der Fliagel und die Vordertursen), so lälit sie sieh nicht mehr einwandfrei besehreiben und habe iel daranf verzichtet. Diese Art mit apikaler Fiblerborste gehört anch niebt zur Gattung Condylostylus. incisuralis Maeq. ㅇ, Dipt. exot. supplem. 1. 120.21 tab. XX Fig. 6 [Psilopus] (1846) . . . . . . . . . . . . . Mexico

Ein Weibehen mit gelben Beinen, zwei brannen, beiderseits verbundenen Fliigelbinden. $\overline{5} \mathrm{~mm}$ lang. Die Art bleibt zweifelhaft. inficitus Walk. = patibulatus Say.

60 infumatus Aldr. O", Biolog. Centr. Amer. Dipt. I 365. 2 [Gnamptopsilopus] (1901) . . . . . . . . . . . . . . . . Mexieo

5. - Fỉhler sehwarz, Sehiippehen sehwarz bewimpert. Sebwinger gelb. Hypopyg mit kleinen bramnen laarigen Anbingen. Sehenkel, Sehienen mud die Vorderhiften gelb, letztere mit drei sehwarzen Borsten an der Spitze. Fligel mit einem braunen Querbande rom Vorderraude bis zun hinteren Ende der Qnerader. Der Flïgelrorderrand ist bewimpert, namentlich am Ende der zweiten Längsalder. $3-4$ min lang.

A nmerkung. Iclı kenne diese Art nur ans der Besehreibung; sie scheint sich hinsichtlich der Flïgelzeichnmng an die Arten dimidiatus Lw, macula Wied. und medianus $m$. anzuschließen. Mldrinh hat sie trotzder schwarzen Wimpern an den śchüppehen zn seiner Gattnng Gnamptopsilopus = Sciopus Zell. gestellt: rielleicht ist die Sehilubelorstung etwas seliwitcher als gewöhlich, woriher er sicls allerdings nieht weiter ansspricht. Wir haben hier wohl wiplor eine tor C̈hergangsformen; wohin man diese stcllen will, ist schlieblich Ansichtssache: rine besondere frattung rechtfertigt sich nicht; ieh stelle sie wit den iilorigen 201 Condylostylus.

61 inornatus Aldr. $\sigma^{7}$, Biol. Centr. Am. Dipt. 1356.7 [Psilopus] (1901). Mexico 万. - Kleine dnukle Alt mit gebänderten Fliigeln. Sehwinger schwarz; Fïhler ebenso, zweites Glied mit vielen langen Endborsten. 
Hypolpyg klein, schwar mit zwei kn'zen zylindrisehen schwarzen Aubaingen und mit zalhl'eiehen schwarzen Haaren. Beine sehwarz, fist ohne lBorsten, Yorderschienen gelblich; Hintertarseuglieder anf (lel Mitte etwas breiter. Fligel mit zwei Jraunen Binden, die anch an der vierten Längsader etwas verbunden sind. Gabelader auf der Mitte rechtwinklig gebogen. $4-5.2 \mathrm{~nm}$ lang.

૧. - Sebwinger gelb. (Naeh Aldrich.)

62 insularis Aldr. o", Trans. Eutom. Soe. London 344. 4 [Psiloms] (1896).

America centr.

Ђ. - Fiihler sehwarz. Sehwinger gelb. Hypopyg klein, selıwarz init zwei dunkelgranen zangenförmigen Organen. Beine nebst Vorderluilten ganz gelb. Mittelmetatarsus am oberen Ende mit ein wenig gebogenen Wimpern. Hintersehienen ungewöhnlich stark haarig. Fliigel glashell olme Bindenzeichnung; Gabelader spitzwinklig nael riickwärts abzweigend. 4-5 mm lang.

Q. - Dem ơ gleich, jedoch der Mittelmetatarsus ohne Zilien. (Naeh Aldrich.)

63 interceptus Aldr. 57, Biolog. Centr. Amer. Dipt. 1 363. 25 [Psilopus] (1901) . . . . . . . . . . . . . Mexico

ठै. - Fiilılel sehwarz, das zweite Glied mit wenigen kurzen Börstehen. Schwinger bräunlich. Hypopyg schwarz mit zwei runden schwarzen Lamellen und kleinen fadenförmigen Anläingen. Iliften und Hiftgelenise alle schwarz, Sehenkel und Schienen gelb, letztere mit nur vereinzelten Borsten. Der Vordermetatarsus $1 \frac{1}{2}$ mal so lang wie die Schiene, an der Spitze veiß, die anderen vier Glieder schwarz, das vierte auf der Oberseite sehwarz bewimpert, das finfte-weil behaart. Fliggel an del Wurzel gelb mit braunen Querbinden, die am Vorderrande bis zur zweiten Längsader niteinander verbunden sind. $7 \mathrm{~mm}$ lang. (Nach Aldrich.)

64 jucumlus Lw. 万’. N. Beitr. V111 87. (1861). - Monogr. Amer. Dipt. 11 258. (1864) [Psilomus] . . . . . . . . . Brasilia Antillae

万. - Fïhler sehwarz, zweites Glied nieht hesonders lang beborstet. Hypopyg mu kleiu, schwirzlieh mit sehr sehmalen kleinen Lanellen. Beine mit Hiften und Schenkeln schwarz. Torder- und Mittelschienen gelb, Hintersehienen dunkelbraun. Vorderschienen und Vordermetatarsus auf der Hinterseite (?) mit drei langen Borsten. Fltigel mit zwei braunen Querbinden, Gabelader in einem Wiukel von $70^{\circ}$ abzweigend.

Anmerkung. Loew sagt: auf der II interseite der Tordersehienen und des Metatarsus stande eine Reihe von drei lingeren Borsten. Ob diese Ansdrucksweise in "nnserem" Sinne richtig ist, möchte ich bezweileln; wahrseheinlieh ist es lie $A$ u $B$ enseite"; auf Aieser stehen nimlich bei sehr vielen Arten Borstenreihen. an der IIinter- wler Lnterseite wenigstens bei den Metatarsen keine. Ist das Vorderlein mit seiner natürlichen Stellung (nach rorne ausgestreckt) 1 m $90^{\circ}$ zur Seite gebugen. su daß das Bein senkreeht zur Laungsachse des Körpers gerichtet ist, dann stehen die AuBenborsten su, Iab sie nach hinten gerichtet sind. Vielleicht hat 
Loew diese zufällige Stellung des Beines für seine Darstellhng lonützt, ohne aul' eine natiirliche Stellung Rüicksicht zn nehmen. - Diese lovew'sehe Art ist wahe verwamlt mit den von uir beschriebenen Arten ignoratus nul simplicitarsis; sie wirl nicht mit einer von dieven identisch sein, ieh kann sie aber ohne Typenvergleiehung in meiner Tabelle jenen gegentiber nieht spezieller charakterisieren.

laetus n. sp. $\sigma^{7}$. . . . . . . . . . . . Ameriea merid.

$0^{7}$. - Thoraxriicken azurblan. Schwinger hellgelb. Kopf mit den gewöhnlichen schwarzen Fïllern. Hinterleib grlinblau mit selmualen mattsehwarzen Querbinden und gewöhnlieher Beborstung; das kleine seliwarze IIypojyg hat ebenfalls kleine schwarze, dreieckig zugespitzte, etwas behaarte Anallamellen. Beine nnd Hïften sehwarz, Vorder-und Vittelschienen nebst den Vordermetatarsen rostgelb; Hinterschienen selıwarz, nur an der Wurzelhälfte rotbrann. Vorderschienen auf der Wurzelhälfte ihrer Anßenseite mit drei längeren Borstenharen; Metatarsus unten mit etwa fünf Linzelbörstchen, ron denen die letzte die längste ist. Mittelsehienen ebenso wie die Vorderbeine anf der AuBenseite mit drei etwas kilueren Borsten, ilu Metatarsus unten mit etwa acht bis neun kurzen Einzelbörsteheu. Hinterschienen und Tarsen etwas rauh behanıt, letztere so diek wie die Sehiene und die letaten Glieder etwas verbreitert. - Vordertarsen etwa $1 \frac{1}{2}$ mal, Mitteltarsen 1\% mal so lang wie ihre Schienen. - Fligel grau mit am Vorderrande bis zur dritten Lïngsader velbundenen Qnerbinden, aneh längrs der vierten Längsader zeigt sich eine sehwache Bräunung; Gabelader sehr spitzwinklig, hernach fast rechtwinklig bogenförmig abbiegend; lintere Querader rechtwinklig, nm $1^{1} /$, ilner eigenen Lainge von der Gabelader entfernt. $4.5 \mathrm{~mm}$ lang.

10 aus Slidamerika, Guarino [Petersen] Nr. 8255 der Sammlung des Berliner Museums. - $13 \delta^{7}, 3$ a aus Peru und Bolivia in der Simmlung Schmuse im Dresdner zoologischen Museum.

Anmerkung. Die lixemplare der Schnuse'schen Sammlng haben eino kriftigere und etwas ansgebreitetere Fligelzeichnung, so daß ein rollkommener Fensterfleck entstrlit. Maßgelvend für die Beurteilung der Zugehörigkeit zu einer bestimmten Art bleibt in erster Linie stots die Behorstung der Beine, welche hipr vollkoumen übereinstimmt.

60 lepidus Walk. $\sigma^{7}$, Ins. Saunders. Dipt. I 207 [Psilopus] (1852).

Mexieo, Venezuela

$\sigma^{7}$. - Fỉhler und Beine schwarz, Fligel mit zwei braunen Binden. $5-6 \mathrm{~mm}$ lang.

Die Beschreibung ist so eharakterlos wie möglich. Loew erklärte, denn arch schon eine Deuturg fïr ummöglieh. Schinel dagegen hatte den Jnt, einige Weibehen aus der Novara-Sammlung fiir lepidus Walk. anzuspreehen. Eine siehere Deutmg der Art ist damit natlilieh nieht gegeben.

2 of ars Venezmela in der Sammlung des Wiener naturhistorischen Hofmusenms. 
67 Lemieuri Macq. O־, Dipt. exot. II 119.12 tab. XX Fig. 5 [Psilopus] (1842) .

Brasilia

Fiihler schwarz, das zweite Glied sehr kurz belaart. Bcine gelb, Hinterschienen und Tarsen sehwarz. Schwinger gelb. Fltigel mit zwei sebl breiten braunen Querbinden, die vorne bis zur dritten Liingsader verbunden sind. Gabelader spitzwinklig abbiegend. 3 Linien lang.

Die Art wird nicht festzustellen sein, da iber die Analanhänge und die Beinbeborstung nichts gesagt ist.

- longicornis Fbr., Syst. Entomol. 783.52 [Mfusca] (1775). Antillae Brasilia

万. - Fihhler schwar, drittes Fuhlerglied kegelförmig und schaufelförmig in einc lange Borste olne merkliche Trenunng libergehend, so lang wie der ganze Körper. Gesicht ohne Quercindruck. Schüppchen weiß bewimpert. Schildelen mit zwei starken Borsten. Beine schwarz; die Vorder- und Mittelschienen sowic die Wurzel der Hinterschienen rostgelb. Flïgel wasserklar ohne Binden; die Gabelader geht rechtwinklig abzwcigend in einen einzigen stumplwinkligen Bogen zur Flïgelspitze; die hintere Querader liegt sehr schrïge, fast parallel zum Flïgelhinterrande. Hypolyg mit dentlich zangenförmigen Anlängcn und langer Penisscheide. Körperlïnge olne Fühlerborste. $6 \mathrm{~mm}$ lang.

$1 \sigma^{\pi}$ aus Brasilien in der alten Sammlung des naturhistorisclien Hofmuseums in Wien als Type bezcichnet.

Diese Art ist ebcnfalls von Wiedemann beschrichen, hier ist aber eine Vermischung und Verwechselung typischer Exemplare rorgckommen. Diese Wiener 'Type steckte zwischen fünf anderen oberflächlich ähnlich ausschauenden Tieren der Art chrysoprasins Walk., Loew., die alle wahrscheinlich als von Wiedemam bestimmt geltcn können nnd mit Wiedemann's Beschreibung libereinstimmen; auch das Fabricius'sche Exemplar des Kopenhagener Musenms, ans der 'Tönder-Lund-Sehestedt'schen Sammlung, das wahrscheinlich ron Fabricius bestimmt ist, hat sich als chrysomasius Walk. erwiesen (Herr Dr. W. Lundbeck latte die Giite, mil die Art vorzulegen). - Loew in den N. Beitr. V1II 78 und spaiter in den Jlonogr. 231 kommt zu der Ansicht, daß die Wiedemann'sche Beschreibung anf chrysomasius Walk hinweise, daß aber die langen Fiilller der von Fabricins beschriebenen Art nicht gut mit chrysoprasius ibereinstimmten. Loew erwithnt dann noch, daß in der Winthem schen Sammlung eine Type von Wiedemamn als longicornis bezeichnet stecke, die gleich chrysomrasius sei. Das ist richtig; Loew muB also die Winthem'sche Sammlung untersucht liaben, hierbei muß ihm aber die ron mil vorgefundene, wohl allein richtige Type von longicornis Fbr. entgangen sein. Wer die Konfusion und Vermischung der beiden Arten longicornis und clrysoprasius rorgenommen hat, wird sich mit Sicherheit kaum mehr feststellen lassen. Vielleicht und wahrscheinlich hat bereits Fabricins diese eingeleitet; Tatsache ist, daß beide Arten nuter den Wiedemann'schen Exemplaren von longi- 
cornis Fbr. in der Wiener Sammlung rorhanden sind, daß Wiedemaun aber seine Besehreibung nach chrysoprasius Walk., nieht aber nach der riehtigen Type gefertigt hat. Da nun letztere, die ich aufgefunden, der Beschreibung des Fabricius durehaus entspricht, so glaube ieh, begehen wir keine Voreiligkeit und Unriehtigkeit, sie als Type anzusehen und zu behandeln. Das Originalexemplar wird woul in Kiel mit den ubrigen Typen zugrunde gegangen sein.

Wegen der besonderen Form des dritten Fihlergliedes und der langen apikalen Borste, anch wegen der weiß bewimperten tegulae gehört diese Art nieht zur Gattung Condylostylus, sonderu zn Megistostylus (1859), die Bigot mit del Type crinicomis Wierl. aufgestellt lat; auch die siidamerikanische Art longisetosus Wulp. mit ihren luell be-

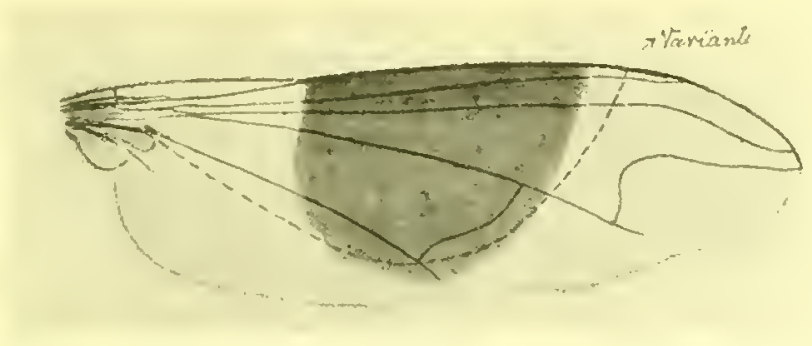

Fig. 121. Condylostylus mediumus Beek. ठౌ. Flïgel. 12 : 1.

wimperten tegulue gebört in diesen Kreis. Siehe das Weitere bei dieser Gattung.

longicormis Wied. (nee Fbr.) = chrysoprasius Walk.

68 longiseta Coquill, Journ. N. York Ent. Soe. X 14 [Sciopus] (1902). Mexieo

б. - Finhler schwar"z, zweites Glied mit sehr laugen Randborsten. Sehwinger gelb. Beine nebst Hiiften und Sehenkeln sehwarz, Sebienen gelb. Vordersehienen mit drei liugeren Borsten auf der ,inneren Hinterseite", erstes Gliel del Vordertarsen mit zwei Borsten; die letzten beiden Hintertarsenglieder etwas verbreitert. Fligel glashell mit zwei braunen Querbinden. $4 \mathrm{~mm}$ lang.

Anmerkung. Coquillett vergleicht lliese Art mit seiner breciseta und geturaucht lier wieder wie bei breviseta bei Angabe der Beinhorstenstelhung die fiur micht nicht ohne weiters verständlichen Ausdruicke: "inner-posterior side", wif ,outeranterior side" und inner-anterior". Ieh vermag die Art meiner Tabelle nicht einzureilien.

mediamus n. sp. Peru

0. - Messinggelb, Sehildehen und der erste Hinterleibsring etwas blau, Brustseiten silbergrau. Schwinger braun. Sehildehen auffillenderweise nm mit zwei starken Borsten und zwei kaum bemerkbaren Nebenhärchen; dabei sind die Wimpern dem Gattungseharakter entspreebend sehwarz und krạftig entwickelt, so daß wir hier in der ge- 
ringeren Schildehenbeborstung nur eine Ausnalune vou der Regel erblicken kïnnen. Fiihler sehwarz. Hinterleibsringe ohne mattsehwarze Querbindeu. Hypopyg sehr klein, sehwarz mit kurzen sehwarzen, etwas kugelförmig zugespitzten behaarten Lamellen. Beine: Hüften und Schenkel sehwarz, alle Schienen und 'Farsen, letztere am Ende briunlieh; die Beine sind auffallenderweise borstenlos, nur mit kurzer Pubeszenz, aneh auf der Unterseite der Sehenkel findet man keine Haare; die Beine sind aucl sehr sehlank, selbst die Hintertarsen sind nael dem Ende hin ebenso verjingt wie die Vordertarsen; diese sind $13 / 4$ mal so lang wie ihre Schiene, die Mitteltarsen etwa $1 \frac{1}{2}$ mal so lang; die Hintertarsen haben nur $3 / 4$ der Länge ibrer Sehiene. - Fliigel glashell mit einem großen schwarzbramen Fleeken anf der Mitte. Das mittlere Drittel des Vorderrandes bildet die Basis dieses Fleekens, der am Ende der ersten Liingsader beginnt, die hintere Qnerader in sich anfnimmt, um parallel mit ih" in einem großen Bogen zum Vorderrand zu verlanfen; die dritte Längsader ist dieht ror der Spitze dentlieh gebogen; die hintere Qnerader rerliuft schlank Sformig und im ganzen etwas schrige; die Gabelader zweigt spitzwinklig ab im Gegensatz zu Sciapus macula Wied., die reehtwinklig ansetzt (s. Figul 121). $45 \mathrm{~mm}$ lang.

1 Exemplar aus Peru, Callanga. Sammlung des Ungarisehen Nationalmuseums.

Yariant". leh fand in ler luew'schen sammlung im Berliner Huseum 10 dieser Art ans Colmubien, Cortilteren, terra templada [Thieme S.]; es gleielst unseres Art durchans in GröBe, Färbung, Nack theit der Brine, Hypopgo und Flïgeladerung. anch hinsichtlich der Beborstming des sichildchens, nur der branne Fliigelteck hat pine uröBere Ausdelmung amrenommen und bedeckt auch den soust hellen Wurzelteil des Fliigcts. lch labe auf der Figur 121 die Begrenzung des bramen lileckens durell eine junktierte linie angedentet.

70 melampus Lw. \% , Berl. Ent. Zeitseh1. V1 215 ['silopus] (186:) Mexico o. - Blangriin. l'ibler sehwarz, zweites Glied lang behorstet. Schwinger seliwarbram. Hinterleib mit breiten mattsehwarzen Vorderrandsbinden. Hypopyg schwarz mit kleinen dunklen Anhängen. Beine ganz scbwarz; Schenkel auf der Unterseite mit sehr langen weißen und auch schwarzen Haaren. Vordersehienen auf der Aubenseite mit 4-5 liingeren Borsten, Metatarsen ebenda mit 7-10 liingeren Borsten bewehrt. Mittelsehienen oberseits mit einigen gewöhmliehen, etwas längeren llaren wimperartig besetzt, aulerdem noch nnit einigen mäßig langen Borsten; Metatursus oberseits sehr kurz bewimpert. Fliigel glashell mit zwei am Vorderrande bis zur dritten Lingsader verbundenen braunen Querbinden; der Vorderrand ist deutlich, wenn auch nielıt lang, bewimpert. Hintere Querader in mäßig selırägel Lage. 5-6 mm lang.

Q. - Ebenfalls ganz schwar wie das ob, an den Beinen mit wesentlich kuirzeren Haaren; Hinterleibsbinden sind fist ganz verschwunden. Schwingerknopf gell,. Randader nackt. 
10 57, 13 o aus Mexico in der Sammlung des Dentschen Entomologischen Nusenms in Berlin-Dahlem nnd im Berliner zoolngischen Insenm.

mexicunus Aldr., Biolog. Centr. Amer. Dipt. I 365 [Gmamptopsitomus] (1901) . . . . . . . . . . . . . . Mexico

Gehört nach Aldrich's Beschreibung zur Gattung Sciopus.

71 mundus Wied., AuBeremrop. zweifl. Ins. II 227. 30 [Psilomus] (1830)

Brasilia et America sept.

ciliatus Lw., N. Beitr. VIIl 88. 6 [Psilopus] (1861).

Eine scluwarzbeinige Art mit ungefleckten Fligelu. Im Wiener Inseum befinden sich zwei männliche Typen ron Wiedemann, von ilım selbst bestimmt, die mit der Beschreibung iibereinstimmen. Die Beine sind charakteristisch beborstet und behart; ror allem sind die

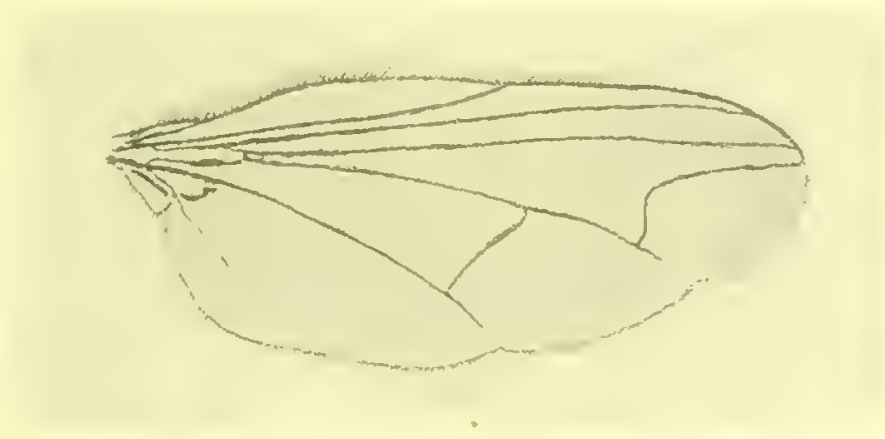

Fig. 122. Condylostylus mundus Wied. Of. Niigel. 12:1.

Flügel durch die ausgebanchte und lang bewimperte Vorderrandsader ausgezeichnet. Wiedemann hat diese auffallenden Merkmale merkwürdigerweise nicht gesehen oder nicht beachtet. Loew sprach schon die Vermutung aus, daß seine Art ciliatus wohl mit mudus iabereiustimmen kömme. Dats ist richtig, auch Aldrich hat dies schon friblier bestiitigt.

ơ. - Glänzend schwarzblau; Schwinger gelb. Fialller schwarz. Beine ganz schwarz. Vorderschienen und Tarsen ziemlich lang behart, der Metatarsus am stiirksten, das zweite Glied selır kurz, nicht länger als breit. Mittelsehienen auBen und unten mit je $2-3$ stärkeren Einzelborsten. Fliigel glashell obne Fleckung; erste Längsader sehr lang, iiber die Fliigelmitte hinausgehend, wach anßen gebogen, die Vorderrandader sehr fein und lang bewimpert. 5 mm lang.

$2 \sigma^{7}$ ans Brasilien in Wintluem's Sammlung. Wiener Musenu.

nigripes Macq. Dipt. exot. II 2. 121. 16 [Psilomes] (1St2) Chile

Ein Hännchen mit schwarzen Beinen und glashellen farblosen Fltigeln, zwei Linien lang ohne weitere naihere Angaben. Die Ait bleibt ganz zweifelhaft. 
72 nobilissimus Aldr. Biolog. Centr. Amer. Dipt. I 360 . Is tab. VI fig. 23 ['siloms] (1901) . . . . . . . . . . . Mexieo

б’. - Fiihler sehwarz, Borste subapikal, sehr dick an der Wurzel und so lang wie der ganze Körper, an der Spitze lamellenartig verbreitert. Sehwinger gelb. Hinterleibsborsten lang, Anallamellen mit langen, wellenförmig gehogenen Borsten, groß, selımal und gelb. Hïften und Sehenkel sehwarz, Kuiee und Schienen gelb. Vordersehienen an der Anßenseite mit ungefälu sieben Borsten in wachsender Lainge; Mittelsebienen mit 2-3 solcher Borsten. Vordertarsen weilieb, Mitteltarsen an den beiden letzten Gliedeln mit silberfarbenen Haaren. Flibel wasserklar mit sehwacher Briunung an den drei läingsaderu. Gabelader spitzwinkelig abzweigend; hintere Querader scluäge. 4-5 nm lang. - (Nach Aldrieh.)

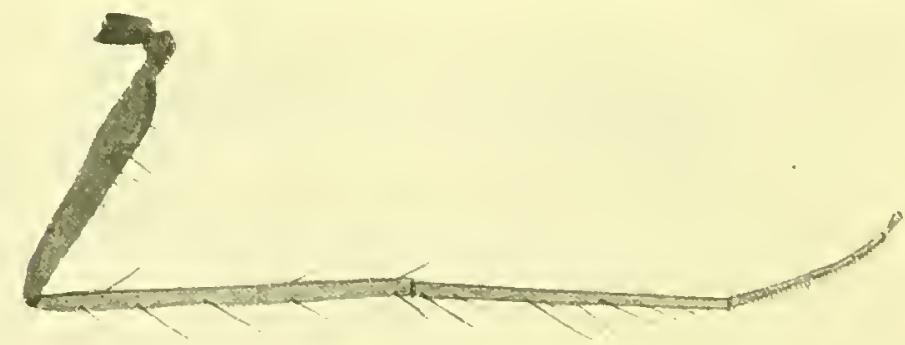

Fig. 123. Condylostylus mubeculus Beck. ON. Nittelbein 16:1.

73 nubeculus 11. sp. $\sigma^{\top}$. 2 Figuren . . . . . . . . Columbia 3. - 'Thor'ax und Sebildehen rein azurblan, Brustseiten aseligran; Schwinger gelb; die sehwarzen Wimperu an den Seliippehen ron besonderer Linge. Stirne und Gesieht breit, blau, unterer Gesichtsteil etwas gelbgrau bestaiubt; Ruissel, Taster und Fiihler sehwarz, das zweite Fuhlerglied unten lang beborstet; Fiihlerborste subapikal und verläugert, so lang wie Kopf und Thorax zusammen. Hinterleib sehwarzgrtin, letzter Ring mit einigen sehr langen und feinen Borsten. Hypopygimm klein, sehwarz, mit etwas lappigen, nach unten umgebogenen schwarzen Anbängen, die an ihrer Wurzel eine domartige Abzweigung zeigen. - Beine nebst allen Iliften schwarz; Vorder- nud Mittelsehienen gelb, Hinterschienen rotbrann. Vordersehienen mit 3-5 längeren Haaren ant der Oberseite, Metatarsus oberseits ebenfalls mit 9-10 lingeren Haaren, von denen die letrte an der Spitze am längsten ist; die iibrigen Tarsenglieder lıaben an ihrer Spitze gleichfalls ein längeres Haar. Mittelsebienen mit den gewölmliehen Borsten $3+3$ in zwei Reihen; der Metitarsus oberseits mit einer Reihe von $7-8$ mäßig langen Haaren, an den daranf folgenden 'Tarsengliedern ist die Oberseite fein und 
kurz bewimpert (s. Figur 123). Die Hinterbeine sind ganz einfach gebildet, auch die letzten Glieder sind nicht rerbreitert. Vordertarsen $\mathrm{mm}^{3 / 4}$. mal länger als die Sehiene, diese so lang wie der Metatarsus und letzterer um $1 \frac{1}{3}$ mal lainger als die folgenden vier Glieder zusammen. Mitteltarsen $n \mathrm{~m} 1 \frac{1}{3}$ so lang wie die Sehiene, diese um $1 \frac{1}{8}$ länger als der Metatarsus und letzterer wiederum um $1 \frac{2}{3}$ liinger als die iibrigen Glieder. Hintertarsen kiirzer als die Schiene; diese fast $11 / 2$ mal so lang und $3 \frac{1}{2}$ mal länger als ihr Metatarsus, letzterer $11 \mathrm{~m} 1 \frac{1}{5}$ mal kiirzer als die iibrigen Glieder zusammen. - Fliigel wasserklar mit einem wenig bemerkbaren, grau rerwaschenen Sehattenflecken ror dem Ende der ersten Läingsader am Flïgelvorderrande. Die Gabelader zweigt spitzwinklig ab, die hintere Querader steht sehr seluäge. $4 \mathrm{~mm}$ lang.

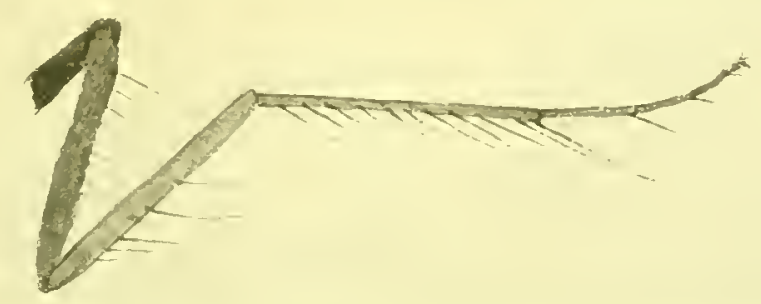

Fig. 124. Condylostylus nubeculus Beck. of. Vorderbein. 16:1

$1 \sigma^{7}, 6$ ans Columbia, Aracabaca II 1902, Ujhelgi. Sammlung des Ungariscben Nationalmuseums.

nudipes n. sp. ठे . . . . . . . . . America merid.

o. - Griingold bis blan. Sehwinger gelb. Kopf mit den gewöhnlichen schwarzen Fiihlern. Stirne ziemlieh deutlich weib bestainbt. Hinterleib mit deutlichen mattsclıwarzen Vorderrandbinden. Hypopyg klein, sehwarz, mit zwei kleinen fadenförmigen, schwach beharten schwarzen Anhäingen. - Beine mit allen Hiiften blaßgelb. Mittelschienen mit Ausnabme ibrer Wurzel, Hinterschienen und alle Tarsen sehwarzbraun bis schwarz. Schenkel unten fast nackt. Vorclerschienen und Tarsen ebenfalls nackt und letztere selu lang. Ich messe bei zwölftacher Vergröferung die Längen wie folgt: Sehiene $42 \mathrm{~mm}$, Metatarsus $67 \mathrm{~mm}$, die iibrigen Gliedel zusammen $33 \mathrm{~mm}$; die Tarsen sind also fast $2 \frac{1}{2}$ mal so lang wie die Sehiene. Mittelschienen ebenfalls gauz kahl, die Längen letragen: Sehiene $61 \mathrm{~mm}$, Mctatarsus $55 \mathrm{~mm}$, die iibrigen vier Glieder $27 \mathrm{~mm}$; die Tarsen sind also $11 / 2$ mal so lang wie die Sehiene. Hinterschienen und Tarsen sind etwis stärker behart; letztere um $1 / 4$ kiirzer als die Sehiene; die Tarsen bleiben so stark wie die Schiene und dic beiden letzten Glieder sind Abhandl. d. zool. -botan. Ges Bd. XIII, Heft 1. 
etwas rerbreitert. - Fligel ron sehwach gelbbriunlicher Firbung nit zwei bramen, am Vorderrande nur bis zu. zweiten Laingsader miteinander verbundenen Querbinden, deren Begrenzung nicht seharf, viehmebr verwaschen ist; die dritte Liingsader ist an der Spitze ziemlich stark gebogen, so daß ihr Endpunkt dem der vierten Língader sehr nahe kommt; die Gabelader zweigt spitzwinklig ab und verliuft hermach reebtwinklig, kurz bogenförmig abbiegend; hintere Querader senkleeht zur vierten längsader, so 1 aß sie un das $1 \frac{1}{2}$ fache ihrer eigenen Liinge ron der Gabelader entfernt bleibt. $5 \mathrm{~mm}$ lang.

1 ot aus Paramaribo [Miehaëlis] Sammlung des Wiener naturhistorisehen Hofmusenms.

4 q a $\mathrm{s}$ Peru, Callauga Sammlung des Ungarisehen Nationalmuseums.

Die kurzen Finzelbörstchen der Mittelschienen treten etwas deutlieher herror als beim $\sigma^{\gamma}$, desgleichen ist die Stirne auch etwas kiöftiger weil bestäubt, sonst kein Untersehied.

75 Oedipus n. sp. $\sigma^{7}$.

Brasilia.

Eine gröliere, dunkel gefärbte Art.

๑๋. - Thorax blan; kopf wie gewöhnlich mit selswarzen Ftihlern. Hinterleib goldgriin olne deutliche Querbinden. Hypopyg klein, schwarz; Analanlänge bandförmig in Gabelform, am Ende etwas verbreitert und selwwach behaart. F'iße mit allen Hiften ganz schwarz, alle Teile olne nenuenswerte Borsten. Vordertarsen doppelt so lang wie die Schiene, die beiden letzten Glieder dureh einseitig angeorduete kinnmartige dichte Beborstung verbreitert. Mitteltarsen $1 \frac{1}{4}$ mal so lang wie die Sehiene und bis zum Ende so dick wie die Sehiene selbst. llintertarsen erheblich kijrzer als die Schiene und ebenfalls bis zum Endgliede annilhernd in gleicher Dieke fortlanfend, an der Spitze ein wenig breiter. - Nligel mit zwei sebr breiten bramen Querbinden, die fist den ganzen Fliigel rom Ende der ersten Liingsader an gerechnet eimehmen; es bleibt nur ein schmaler Zwischenranm wie gewölnlich ron der dritten Liingsader beginnend iibrig, ebenso wie ein sehmaler Saum am Hinterrande. $7 \cdot 5 \mathrm{~mm}$ lang.

$1 \sigma^{7}$ aus Brasilien, Blumenau [Lothar Matschke] Sammlung des Wiener naturhistorischen Hofmusenms

pampoecilus Big. $\sigma^{\gamma}$. . . . . . . . . . America cents.

万े. - Fiihler dunkelbraun. Sehringer und Beine lıellgelb. Vorderschenkel an der Wurzel breit schwarz. Fliigel glashell. $5 \mathrm{~mm}$ lang. Aus Haiti.

Andere Angaben außer diesen nud denen der gewöhnlichen Fär. bung werden nieht gegeben, die Art ist daher nicht geniigend charakterisiert und bleibt uns fremd.

7i) patellitarsis n. sp. ठ7\%, 4 Figuren . . . . . . America merid.

б. - Thoraxricken goldgriin bis veilehenblau, gliuzend ohne Bestäubung. Schwinger blaßgelb. Kopf mit sehwarzen Fiilıleru, Rtissel rost. 
gelb. Hinterleib goldgriu unit breiten purpurfurbenen Vorderandsbinden an allen Ringen und verhältnismäßig kur\% schwarz behart nnd beborstet. Hypopyg schwarz mit braunen längeren zugespitzten, schwarz behairten äußeren Anhängen. Beine nebst allen Hiiften blaßgelb. Vordertarsen reichlich doppelt so lang wie die Schiene; der Metatarsus fast $1 \frac{1}{2}$ mal so lang wie die ubrigen vier Alieder zusammen; er ist sehr dium nud ohne Beborstung, das zweite Glied ist anf beiden Seiten dentlich seluwarz bewimpert und trägt anf einer Seite zwei längere Borsten, das dritte Glied ist schwächer behaart oder berimpert, ebenso lang wie das zweite mit vier liingeren, an der Spitze blattartig verbreiterten Einzelborsten; das vierte und fünte Glied sind beiderseitig fein behalart, das fiinfte Glied ist außerdem an der Spitze etwas rerbreitert nud schwarz (s. Figur 127). Die Mitteltarsen sind 1.4 mal so lang wie die Schiene, der Metatarsus reichlicb doppelt so lang wie die ibrigen vier Glieder zusanmen;

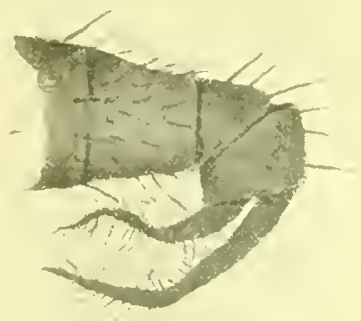

lige. 1'55. C'ondylust. patcllitarsis lieck. o'. 1lypolyg. 24: 1.

alle Tarsenglieder sind einfach ohne besondere Beborstnng', nur die Schienen zeigen anf der Oberseite zwei kleine Einzelborsten. Die Hintertarsen sind kiirzer als die Schiene, diese ist um $1 \frac{1}{3}$ lïnger; der Metatarsus ist um 1.4 mal länger als die vier anderen Glieder, las zweite ist etwas rerdiinnt nud so lang wie die folgenden drei

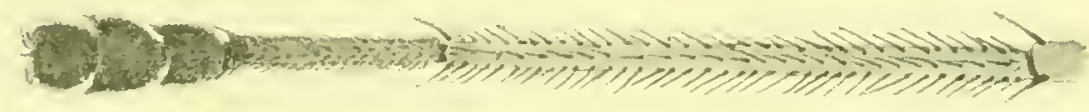

Tig. 126. (ondylostylus patellatarsis Berk. O'. Hintertarsen. 24: 1.

zusammen, letztere sind unter sich gleich lang, etwas verbreitert und schwarz (s. Figur 126). Schienen und Metatarsus sind etwas rauh bewimpert. Alle Schenkel auf der Unterseite nackt, Vorderhiiften desgleichen, jedoeh tragen sie vorue drei schwarze Borsten. Die Fligel sind farblos, jedoch mit schwaeher Andeutung der iiblichen zwei Querbinden versehen; der lielle trenuende Zwischenranm reicht hier bis zur zweiten Längsader; beide Binden sind auch etwas unvollkommen (s. Figur 128). $55 \mathrm{~mm}$ lang.

Q. - Bei dem Weibehen sind Stirne und Gesicht ganz dicht 
weißgrau bestäubt, während bei dem Månnchen nur der untere Teil des Gesichtes weiß bestainjt ist; andere Untersehiede außer der im weiblichen Geschlecht stets kibrzer gehaltenen Beine sind nicht vorhanden.

20,1 ans Bolivia-Mapiri, 15. I. 1903 Chimate 650 m hoch, aus Peru, Meshagua, 30. IX. 1903 Urubam-

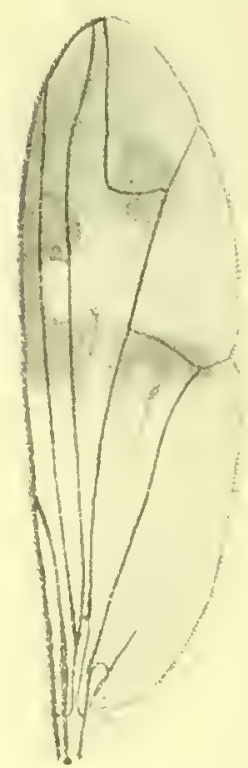
bafi [Schnuse] Sammlung des Dresdner Museums. Variante $4.20,2$ \& als l'eru-Callanga. Sammlung des Ing:arischen Nationillunse.ums.

Dir Minnehen haben eine ähnliche Verzierung der Vurdertursen, die nur in Finzelheiten abweicht (vol. d. ligur 129); auch das $7 \mathrm{y}$ pulyge weicht in der Form seiner Analanliange etwas al, insufern, als letztere, chenfalls schwarz, nur etwa latlh so lang sind; andere Ahweidhungen sind nicht whanten; ich veruag hierin vine andere Art nicht zu (m)licken.

Yariante b ebenfalls aus l'eru-Callanga. Sammlung des l'ugarisehen Nationalmusenms

Fin. 128. Condylostylus Ein $\sigma^{7}$. Hice ist die patellitarsis Beck. on. Flitgel. It : 1 . beinverziermo die gleiche wie lee der llamptform, jo doch die wimpelförmigen Analanhiange sind etwas linger und von gelber, nicht schwarzer Fübung. In: hiermit die Untersehiede erscheipft sind, bin ich such hier der Ansicht, dab keine nete Art, vielmelu eine Lekalasse vorliegt.

VI 168. 2(182 J) Brasilia, Am. centr. et sept. rmatus Walk, List. Dipt. Brit. Mus. III 648 zweite Fiihlerglied nit langen Randborsten. Ge-

Fig. 127. Condylustylus patellitarsis lieck. of Vurdertarsen. 24:1. sicht lang weiß beharrt. Schwinger sehwarz. Hypopyg klein, sehwarz mit ebenfalls kleinen schwarzen Lamellen. Beine mit allen Hiiften 
sehwarz. Sehenkel unten mit der gewöhnlichen weißen Behaarung; Sehienen nur mit wenigen Einzelborsten, die nicht reihenweise geordnet sind. Vordermetatarsus so lang wie die Sehiene und doppelt so lang. wie die ulurigen vier Glieder, an der Spitze mit selwwarzen Borsten; das zweite und dritte Glied sind gleieh kurz, zusammen nieht linger als das vierte Glied. Mittelmetatarsus an der Vorderseite mit einer sehwachen wimperartigen l'ubeszenz. Fliigel mit zwei braunen Querbinden, die an Vorderande bis zur dritten Läugsader verbunden sind. $5 \mathrm{~mm}$ lang.

૧. - Mit einfachen Beinen und gelben Sehwingeru, sonst dem $\sigma^{\overrightarrow{ }}$ gleieh. 1 Exemplar aus Brasilieu im Wiener Museun.

Anmerkung. Durehans : ihnlieh mul verwanit nit der Art melampus 1.w. Loew hat beide Arten ausfihrliell heselnieben. patibulatus hat ein behaartes, melampus ein nacktes Gesicht. (Nach Loew.)

78 pectinatus 11. sp. бo. 1 Figur. . . Bolivia

ot. - Thoraxrieken sehwilrblau, nur vorne am Halse etwas grau bestaiubt; je fuinf Dorsozentral- nnd je vier Akrostikalborsten. Sehwinger dunkelbraun. Kopf mit sehwarzen Fiilılern. Hinterleib stalıblan mit mattseluwarzen Vorderrandsbinden. Hypopyg seliwarz mit zwei kleinen schwarzen beharten Lamellen. Sehenkel rotbraun bis sehwarz, Sehienen und Tarsen gelb. Torderhiften rotbraun, hintere Hiften sehwarz. Vordertarsen 1.6 mal länger als die Sehiene, Jetatarsus reichlich $1.5 \mathrm{mal}$ so lang wie die iibrigen Glieder znsammen; die Vordersehienen sind auf ihrer Außenseite mit 6-7 längeren, in gleiehem Abstande stehenden Borsten besetzt. Mitteltarsen reiehlieb $1.3 \mathrm{mal}$ so lang wie die Sehiene, der Mletatarsus sehr Jang, etwas länger als die Sehiene und iiber 25 mal so lang wie die iibrigen Glieder zusammen; die Schienen sind auf ihrer gauzen Außenseite kräftig, kurz kammartig mit gleiel langen Borsten besetzt, der lietatarsus und das zweite Glied ebenfalls, aber die Borsten stehen weit dichter und sind sebr fein, in gewissen Abständeu stehen stärkere Borsten dazwischen (s. Figur 130); dies ist allerdings uur scheinbar, denn diese

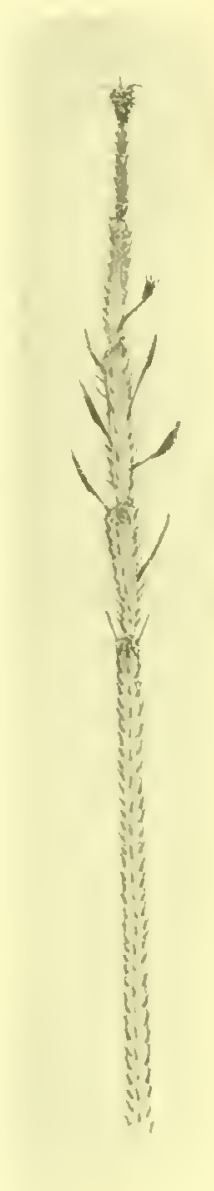

Fig. 129. Condylostylus patellitarsis var. Beck. o. Vurlertarsen. $24: 1$. stiirkeren Einzelborsten stehen in einer anderen, um etwa $45^{\circ} \mathrm{rel}-$ schobenen Reihe. An den Hinterbeinen sind die Sehienen nur wenig länger als die 'Tarsen; der Metatarsus ist um 1.75 länger als die iibrigen Glieder zusammen, die Schienen sind auf iłner Unterseite kurz bewimpert: die Tarsen sind nicht dinner als die Schicue und 
die letzten Tarsenglieder etwas verbreitert. - Fliigel farblos, groh und lang; die elste Läingsader reicht fast bis zur Mitte, die Gabclader biegt sppitzwinklig zuriick und ebenfalls spitzwinklig wieder nach vorwärts, an ihrem Kniekpunkte sieht man einen kurzen riieklaufenden Aderast. Liinge les Körpers und der Fligel $6 \mathrm{~mm}$.

૧. - Dem o goleieh, jedoch mit einfaeben Nittelbeinen; die llintertarsen sind aber auch ebenso stark verdickt.

107,1 q ans Bolivia-Mapiri, 30. IV. nud 12. Y. 1903, Lorenzoprata [Sehnuse] Sammlung des Dresdner Juseums.

Anmerkung. Alurieh hat in dere Biolug. Centr. Amer. Dipt. I und in seinen: Diptera ol St. Vincent 344 eine ähnliche Art insularis beschrielen, die aher gellue Beine hat und bei der nur der Mittelmetatarsus unit Zilien besetzt ist: cine

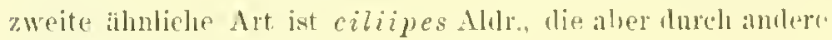
Gabelader und Beinfirthng abweicht.

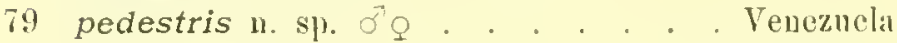
equestris Schin. (nee Fabr.) Novara-Reisc, Bipt. 209. 2 [Psilomus] (1868).

Fabricins beschreibt bei equestris ein o mit schwarzen beinen. Wiedemann erzïhlt (1830), er habe in der Samulung von Fabrieius nur ein $q$ gefunden mit rotgelben Beinen. Sehiner beschreibt in den Novala-Diptereren ein Pärehen mit rotgelben Beinen: vielleicht hat Sehiner angenommen, da die weibliche Type von Fabricius gelbe Beine habe, misse dies :meh beim of der Fall sein. Diese Schluffolgermug ist nieht immer richtig, da wir viele Arten kenuen, bei denen die Mimmehen dunklere Beine haben als dic Weibehen, iiberdies sagt Fabrieius dentlich: "pedes nigri".

o. - Firbung wie gewöhnlieh. Fithler schwarz, zweites Glied sehwaeh beborstet und die Fihlerborste von gewöhulieher Läinge. Sehwinger hellgelb. Hyropyg mit braunen, nicht schr groben zugespitzten Lamellen. Beine hellgelb. Huiften und Hittgelenke sehwarzgrau, Vorderhiiften an der Spitze gelb, Tarsen allmïlilich verdunkelt. Schenkel und Schienen ohme besondere Beborstung oder Bewimperung, nur die Mittelsehienen auf der Außenseite und Endhälfte mit weitlïufiger Bewimperung nud die Vordertarsen von besonderer Bildung: das erste Glied ist selır lang, reichlich doppett so lang wie dic folgenden vier Glieder

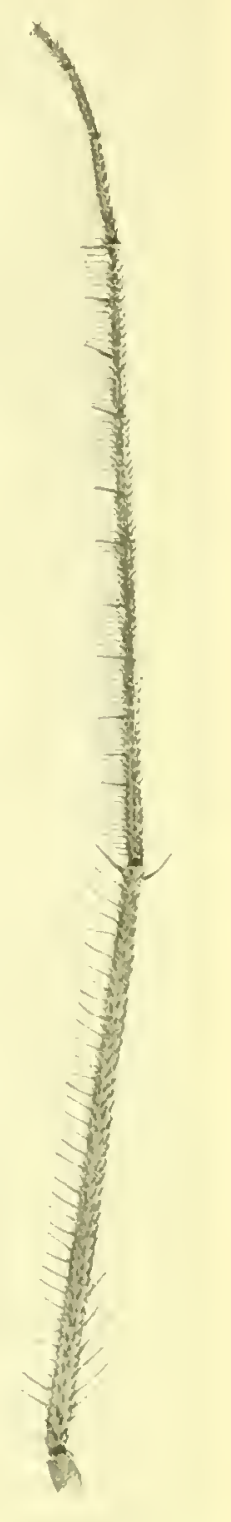

r'ig. 130. Condylostylus pectinatus Beck. ot. Mittelherill. $24: 1$. 
zusammen, an der Spitze ein wenig crweitert und unterseits mit einigen stärkeren Borsten; das zweite und dritte Glied kurz und fast gleielı lang, das vierte Glied etwas lïnger als $2+3$, allc drei auf der Unterseite mit einigen kurzen stumpfen Dornen beset\%t. Fliigel mit den gewönliehen brannen Querbinden, die am Vorderrande bis zur dritten Längsader ver. bunden sind. $7-8$ mm lang. (S. Figur 131.)

1 Piireben aus Venezuela 1864 [Lindig] ron Scliner als equestris bestimmt. Sammlung des Wiener Hofmuseums. - 2 Pirehen in der Samm. lung des Ungarischen Nationalmuseums.

penicilliger Enderl., Zool. Jahrb. Suppl. XV

Band 1 [Psilopus] 398 (1912) . . . Brasilia

5. - Der mir vorliegenden Type fehlen leider das Hypopyg mud die Mitteltarsen; an den Mittelschienen sieht man aber an der Spitze der Unterseite eine lange, senkrecht abstehende Borste, anch der helle Zwisehenraum zwisehen beiden Flïgclbinden erstreekt sieh nieht wic gewölnnlieh bis zur dritten, sondern nur bis zur zweiten Längsader; die Beine nebst Vorderlüiften sind hell rotgelb. Ieh kenne mit diesen Eigen schaften drei versehiedene Arten: flagellatus, flagellipodex und subcorlatus iu., Enderlein's Art gehört in die näebste Nibe dieser drei Arten. Alle drei genannten Arten laben nuit Ausnahme von flagellatus ganz einfuche Tarsen und annäbernd gleiehe Längenverbältnisse der Beine, aneh die Briunung am Vorkerrande der Fliigel beginut sehon etwas vol der Miundung der ersten Lüingsader nnd eine lielle Stelle sieht man meist anch in der ersten Hinterrandzelle innerhalb der Spitzenquerbinde; die allgemeine Körperfürbung und Gröbe ist schließlich anuähernd die gleiche; unterselıeiden tun sich alle drei Arten sehr deutlich durch lingere, bei flagellatus und flagellipodex sogar sehr lange

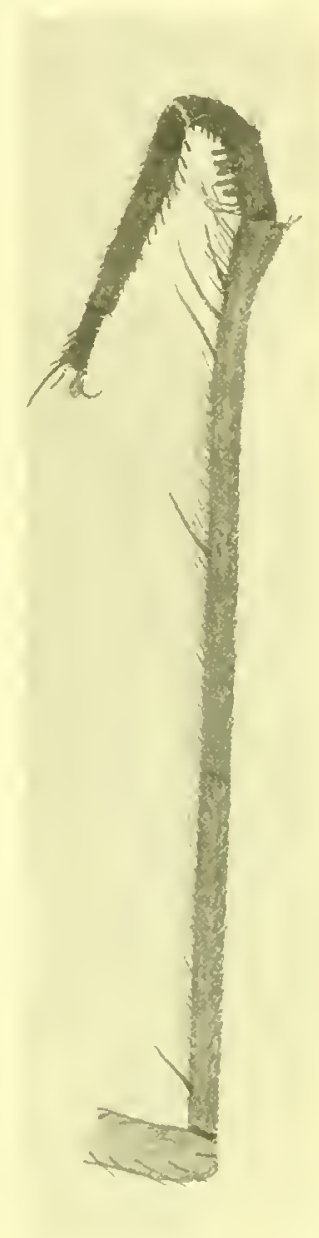

Fig. 131. Condylostylus pedestris beck. o". Vor dertarsen. 24:1. geißelförmige behaarte Analanbänge (s. meine F'iguren). Enderleiu's Art penicilliger ist höchst wahrseheinlich identiseh mit einer von diesen drei Arten; da aber das Hyporyg fehlt, so lïit sieh dieselbe mit Sieberheit niebt bestimmen und bewerten.

1 Exemplar aus Siidbrasilien, S. Catharina in Stettiner Musenm.

Anmerkung. Enderlein vergleicht seine Art mit flaviroxa Alar.; diese ist

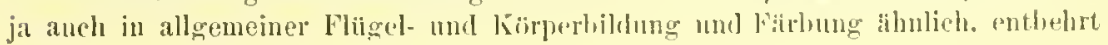


aber der charakteristischen Burste an der spitze der Mittelschienen, die Enderlein ïhersehen laben mag.

81 pennifer Aldr., Biolog. C'entr. Amer. Dipt. I 363 [Psilopus] (1901)

Mexico et Peru

3. - 'Thoraxrieken gringold bis blan, etwas matt, je fiinf Dorsozentral- und vier Akrostikalborsten. Schwinger dunkelbraun. Stirne und Gesicht reilehenblan, letzteres unten gelbgrau bestäubt, sonst ohne Reif. Fiihler selwar\%, zweites Glied mit langen Randborsten. Hinterleib blau bis grijn, glïnend mit mattsehwarzen Vorderraudsbinden, spïrlieh behaart und nur mit kurzen Randborsten. Hypolyg schwarz, die brannselwarzen anBeren Anhiinge wimpelförmig wie bei der Art patellitarsis; die inneren Organe sind nu klein und lassen sich bei dem einzigen Exemplar nicht genan feststellen. - Beine: Hiiften und IIiftgelenke sehwarzgran; Sehenkel und Sehienen rofgelb, Hintertarsen und die Endglieder der vorderen 'Tarsen schwarz bis braun. Beine ganz einfach. Beharmng der Sehenkel sehwach. Vorderschienen mit je einem kleinen Börstehen auf der Vorder- und Außenseite. Mittelschienen mit einer desgleichen auf der Vorder- und zwei auf der Außenseite. Hinterschienen sehr zart borstlich bekleidet. Vordertarsen $1.5 \mathrm{mal}$ so lang wie die Sehiene, Metatarsus $1.75 \mathrm{mal}$ so lang wie die iibrigen Tarsenglieder zusammen und linger als die Sehiene. Mitteltarsen um 1.25 mal linger als die Schiene, Metatarsus um 1.75mal lïnger als die ibrigen Glieder. Hintersebienen um 1.3 mal länger als die Tarsen, der Metatarsus um 1.25 mal lainger als die vier End. glieder. - Fliigel fast farblos nit Bindenzeichnung wie bei der Art flagellatus (s. Figur), nur ist namentlich die Spitzenbinde schwiicher und läßt den Hinterrand etwas mehr trei. $5 \mathrm{~mm}$ lang.

$1 \sigma^{7}$ aus Pern 1. 1904. Pichis-TVeg [Selnuse] Sammlung des Dresdner Insenms.

- practus Walk. Transat. Ent. Soc. London. n. S. V. 287 [I'silopus] (1860) . . . . . . . . . . . . . Hexico

Ein Weibehen ohne Angabe branchbarer Merkmale.

- permodicus Walk. O', Transatet. Ent. Soe. Lonilon. n. S. V. 288 [Psilopus] (1860). . . . . . . . . . Mexico

Ein Mammehen, das auch nach Loew's Ansicht unkenntlieb lueschrieben ist.

s.2 perspicuns n. sp. ơ.

Brasilia

ठౌ. - Dunkel blaugriun; Schwinger gelbbrann. Kopf mit sehwarzen Fiihlern. Hinterleib unit mattsehwarzen Vorderrandsbinden und kräftiger Beborstung. Hypopyg groli, nackt, schwar, trompetenähnlich mit aufgerichteten, seheinbal lalppigen Anhängen. Beine mit allen Hüften schwarz, mr die Vorderschienen an der Endhilfte etwas rostbraun. Vordersehienen mit etwa drei Einzelborsten an der Aufenseite und melureren anderen vorue. Tarsen kaum linger als die Sehiene, Meta- 
tarsus unten mit zwei kurzen Einzelbörstchen. Mittelschienen einfach, mit einigen Einzelbörstchen, Tarsen ungefäbr $1 \frac{1}{2}$ mal so lang, der Metatarsus nebst den beiden folgenden Gliederu anf der Unterseite selır weitläufig borstlich bewimpert. Hinterschienen rauh behaart, länger als die Tarsen, diese an den letzten drei Gliedern rerbreitert. Fligel mit zwei ziemlich breiten, aber schwach entwickelten brannen Qucrbinden, die am Vorderrande bis zur dritten Laingsader und anch noch alı der vicrten Längsader verbunden sind, so daß ein Fensterfleck entstcht; die erste Längsader erreicht nicht ganz die Fliigelmitte; Gabelader spitzwinklig abzweigend, hernach rechtwinklig bogenförmig abbiegend; hintere Querader etwas sclurïge zur vierten Liangsader; die Briiunung am Vorderrande beginnt am Ende der ersten Liingsader. $4 \mathrm{~mm}$ lang.

.. - - Mit ganz einfachen Beinen, sonst dem o gleieb.

$2 \sigma^{\top}, 2 \&$ ans Brasilien, Sammlung des Wiener Hofmuseums.

83 pilipes Macq. $ᄋ$, Dipt. exot. II. 2 117. S tab. XXI fig. 6 [Psilopus] (1942) . . . . . . . . . . . . Brasilia

९. - Fiihler schwarz, zweites Glied mit langen Randborsten, drittes Glied mit langer Ruckenborste. Schenkel schwarz, Schienen rotgelb. Schenkel und Schienen der Vorder- und Mittelbeine oberseits stark behaurt. Schwinger gelb. Fliigel mit Schattenfleck am Vorderrande und schwacher Bräunung au den Queradern. 2 Linien lang.

Diese Beschreibung reicht nicht ans, die Art zu charakterisieren. 84 pilosus Loew. o'. N. B. VIII S6 (1861) et. Monogr. Il 256 (1864).

Central-Amer.

$\sigma^{7}$. - Thorax in der gewöhnlichen Fairbung. Schwinger schwarz, Schiippchen breit schwarz gerandet mit langen sehwarzen Wimperu. Kopf wie gewöhnlich, Taster und Fiilıler schwarz. Hinterleib olıne besondere Abweichung von der gewöhulichen Gestaltung; das Hypopyg ist klein, schwarz mit kleinen schwarzen iußeren Lamellen. Beine und alle Hiiften schwarz, nur die Vorderschienen und der Metatarsus der Mittelbeine sind gelbbriunlich. Vorderschiene auf der Anßenseitc unit einigen lïngeren schwarzen Borsten, Vordertarsen ohne besondere lieborstung. Mittelschienen auf der Vorderscite der ganzen Länge nach gewimpert, an der Spitze noch mit einigen laingeren Borsten besetzt; der Metatarsus ist oberseits ebenfalls bewimpert. Minterschienen und Tarsen sind lediglich etwas rauh behaart, die letzten drei 'Tarsenglieder verbreitert und plattgedriickt. Die Vordertarsen sind fast doppelt so lang wie die Schiene, die Mitteltarsen doppelt so lang und die Hintertarsen viel kiirzer. Fliigel glashell mit den gewöhulichen zwei brannen, an Vorderande verbundenen Querbinden, die nicht besonders breit sind; die Gabelader zweigt fast rechtwinklig a], und geht auf ihrer Jitte in einem stumpfwinkligen Bogen zur Fliigclspitze; die lintere Querader liegt schiefwinklig nnd ist etwas geschwungen. $6-7 \mathrm{~mm}$ lang. 
Ieh lienne diese Art nieht aus eigener Ansclauung; sie hat sehr große Ähnlichkeit mit posticutus Wied. hinsiehtlich der Bewimperung der Mittelbeine und der Form der Hintertarsen, aber die Sehienen sind hier alle gelb; die Schwinger ebenfalis gelb. Die Tarsen sind bei posticatus ktirzer, an den Vorderbeinen und Mittelbeinen, nur etwa $1 \frac{1}{2}$ mal so lang wie die Sehienen; am Hypopyg sind die äußeren Anhïinge größer und rostgelb. Damn ist die Aderung an den Fligeln eine andere; die Gabeladel zweigt spitzwinklig $\left(50-60^{\circ}\right)$ ab und macht auf der Mitte ebenfalls eine spitzwinklige Biegung bis zur Fligelspitze. Damit sind die Untersehiede ersehöpft, sie sind aber ausreichend, um die Selbstïndigkeit der Art zu begrtinden.

- polychromus Big. o". Annal. Soe. Ent. Fr. Série 6. X 289. 2 [Psiloms] (1890) .

America centr.

o. - Fiihler sehwarz, Schwinger gelblich. Beine hellgelb, Hiften und Sehenkel, letztere an der Wurzel braun. Fligel glashell. 4 mm laug.

Ohne weitere eharakteristisehe Merkmale - unkenntlich.

- portoricensis Maeq., S. à Bufti. I 450.7 [Psilopus] (1834). America centr.

๑. - Fiihler sehwarz, die Fihlerborste soll an der Wurzel behart sein. Beine gelb. 21/2 Linien lang; sonst kein Merkmal.

s5 posticatus Wied. $\sigma_{f}$, Außereurop. zweitl. Ins. II 217. 7 [Psilopus]

(1830) . . . . . . . . . . . . . . Brasilia

In der Wiener naturhistorischen Sammlung des Hofmuseums befindet sieh eine mäinnliche 'Type olne Kopf, allerdings sehr verfilzt und nur notdïrftig keuntlich.

ङ. - Thoraxricken griinblan mit je fünf Dorsozentral- nud vier Akrostikalborsten. Schwinger hellgelb. Kopf mit schwaren Filulern. llinterleib blan bis messinggelb mit matt purpurfarbenen Vorderandbinden und mäßig langen Randborsten. Hypopyg glänzend blauschwarz unit flach "keulförmigen gelbbräunliehen äuBeren Anhängen, deren vorderer Rand mit krallenartigen Borsten besetzt ist (s. Figur 132). Penisscheide röhrenförmig. - Beine: Hüften und Sehenkel sehwarz, Schienen und vordere Knice rostgelb; an den Hinterselienen ist die Wurel nnd Spitze, letztere im Anschluß an die Tarsen sehwarz; an den vorderen Beineu sind die Metatarsen gelb, die ibrigen Tarsen braun bis sehwarz. Schenkel unterseits weif behaart. Vordersehienen an! der Außenseite mit fuinf bis sechs Einzelborsten, der Metatarsus nackt. Vordertarsen nur $1 \frac{1}{2}$ mal so lang wie die Schiene, der Metatarsus etwa so lang wie diese und fast $1 \frac{1}{2}$ mal länger als die vier folgenden Glieder zusammen. Die Mittelsehienen sind auf ihrer Außenseite grob borstlich bewimpert; die Metatarsen haben eine Borsten- und Harreihe: feine Haare stehen reibenförmig fast anf ihrer Oberseite, weitliufig gereihte kurze stumpfe Börstehen anf der Anßenseite. Die feine Bewimperung reicht anch noch his zum Ende des Metatarsus. Mitteltarsen $1.6 \mathrm{mal}$ linger als die Schiene, der Vletatarsus so lang wie 
letztere und fast doppelt so lang wie die iibrigen Tarsenglieder. Hintertarsen kül'zel' als die Sehiene, letztere $1.25 \mathrm{mal}$ so lang wie erstcre, Metatarsus halb so lang wie die Sehiene und 1.5 mal so lang wie die tibrigen Tarsenglieder. Die Hintertursen sind an den Ietzten drei Gliedern, die annähernd gleieh kurz sind, verbreitert, und zwar das vierte Glied etwas mehr als die anderen, ähnlich wie bei der Art patellitarsis (s. Fig. 125); IIintersehienen und Metatarsus sind etwas borstlich bewimpert. - Fligel fast wasserkla mit zwei braunen, vornc bis zu dritten Liingsader verbundenen Querbinden, von lenen die iiber der hinteren Querader liegende sehmal ist, wïhrend die andere den Hinterrand des Fltigels nicht ganz erreicht. Gabelader sehr spitz abbiegend. $6 \mathrm{~mm}$ lang.

Q.- Bei den

Weibchen sind die beiden Fliigelquerbinden unter der vierten Lïngsader etwas verbunden; die Beine sind einfach, die Hinterschienenganzgelb. Vorderschienen aluf der Vorderund AuBenseite mit je zwei bis drei Borstenpaaren und der Metatarsus unten mit fünf gleichmäßig rerteilten kleinen Börstelien. Nittelschienen ohen und

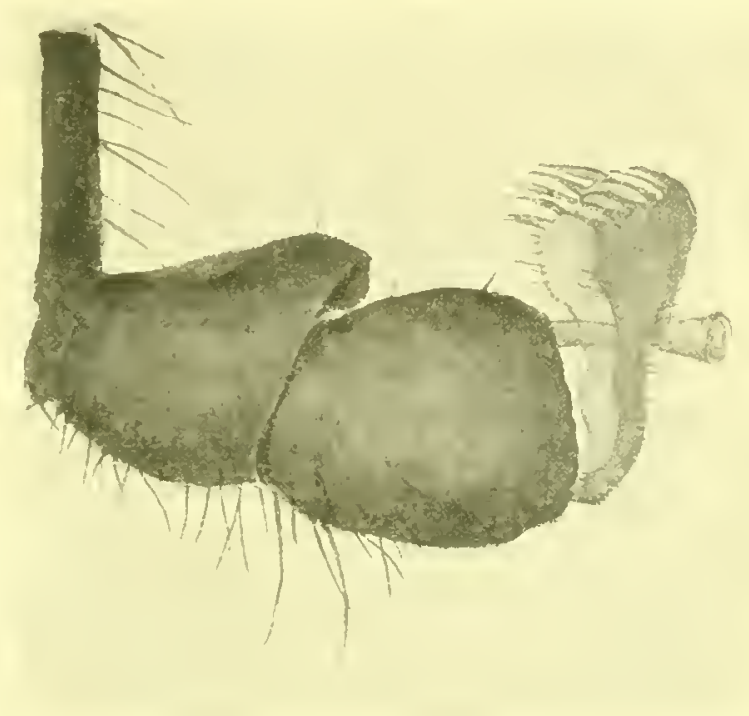

l"ig. 132. Condylustylus posticutus Wiert. ơ. 11yporyg. $24: 1$. außen mit je zwei Einzelbörstehen, der Metatarsus ahnlich wie del Vordermetatarsus sebr kurz bcborstet. Schwinger gelb.

$25 \%, 5$ qus Bolivia-Mapiri 30. I. 1903, Sarampioni $700 \mathrm{~m}$ hoeh; aus Peru 11. I. 1904. Chanchemayo; aus Peru, Madre de dios und ans dem Ladrostal 14. VIII. 1903, 2000-3000 m hoch [Sehnuse] Sanmlung des Dresdner Musenums.

5 o ans Argentinien, Tueuman XI. $190 \overline{5}$ und ans Brasilien, Theresopolis [Vezényi] Sammlung des Ungarischen Nationalmuseums.

Variante $\sigma$. lu der Firbung dunkter: clie llinterschienu sind ganz verdumkelt, desgleichen sind aueh die gelbbraunen Analanhỉnge schwarzbram greworden.

1 त ans Peru 12. I. 1904, Chanchemayo [Schnuse]. 
S6 maestans Aldr., Biolog. Centr. Amer. Lipt. I 354. 3 [Psilomus] (1901)

Mexico

б. - Fiihler schwarz, zweites Glied nur kur\% belaart, Borste kurz. Schwinger dunkelgelb. Ifypopygium klein, sehwarz mit zwei großen selıwarzen bandförmigen Anlängen. Beine ganz schwarz. Mittel- und Hintertarsen etwas diek, namentlieh an dritten bis fuinften Gliede. Fligel mit zwei bramen Binden, deren vordere Verbindung bis zur dritten Laingsader reicht. $6-7 \mathrm{~mm}$ lang.

- metiosus Walk., List. Dipt. British Mus. I]I 648 [Psilopus] (1849) Brasilia

Ohne Angabe des Gesellleclits nur mit den stets sich wiederholenden und greich bleibenden Angaben tiber allgemeine Firbung. $21 / 4$ Linien.

Die Beschreilung ist unbranchbar.

- psittacims Lw., N. Beitr. VIII 96 (1861) und Monogr. 11281 tab. V11 fig. 44 h. (1864) . . . . . . . . America centr. et sept.

Gebört zur Gattung Sciopus Zell.

87 micher Wied. \& AnBereurop. zweifl. Ins.II 224[Psilopus](1830) Brasilia

q. - Selwarze Fiihler, mit rotgelben Beinen, ganz einfachen Schienen und Tarsen, mit bram gebinderten Fligeln, bei denen ein leller Fensterfleck sichtbar wird. $5 \mathrm{~mm}$ lang.

Zwei Weibelsen der Kollektion Winthem, die der Wiedenamn'selıen Besehreibung entspreehen, wit dem Fundort Brasilien; auch aus Paragnay.

88 pulchripes n. sp. $\sigma^{7}$. . . . . . . . . . . . . . Brasilia

ơ. - Azublan, Schwinger gelh. Kopf mit sehwarzen Fiblılern. Ilinterleib mit mattscluwarzen Vorderrandsbinden und ziemlich kraiftiger Beborstung. Hypopyg klein, sclıvarz, nußförmig mit kurzen fadenförmigen beharten dunklen Anläingen. - Beine mit allen Hüften sehwarz, Schienen und die Metatarsen der beiden vorderen Beine gelb. Vorderselienen auf der Wu'zelhälfte der Anßenseite mit drei lingeren Einzelborsten; ferner anf der Außenseite ebenso wie der Metatarsus kurz und fein bewimpert, letzterer ebenda noch mit ein bis zwei Einzelborsten, die zweite laurz ror del Spitze. Mittelselienen olne Wimperung, nur mit ungefalı vier Einzelborsten auf der Wurzelbiilfte der Außenseite; Tarsen einfach. Hinterschienen nol Tarsen raul behaart, die letzten drei Glieder der Tarsen ein wenig verbreitert. Fligel mit zwei braunen, am Vorderande bis zur dritten Lüingsader miteinander verbundenen Querbinden; Fligeladerung wie gewöhnlich. $55-6 \mathrm{~mm}$ lang.

$2 \sigma^{*}$ ans Brasilien. Sammlung des Wiener Hofmusenms.

S9 mummatus Aldr. ơ, Biolog. Centr. Amer. Dipt. I 358. 12 [Psilopus] (1901) . . . . . . . . . . . . . . Мexico

$\sigma^{7}$. Fiihlel selwwar, zweites Glied mit nu wenigen kn"\%en Borsten. Schwinger blaßgell. Hypopygimm klein, sehwarz, mit zwei 
kleinen sehwarzen gegabelten Anhängen. IIiften und Selienkel schwarzgriiu, Schienen gelb, Hinterschienen alhühlich nach der Spitze hiu braun werdend. Vordersehienen mit mehreren Borsten an der Wruel der Hinterseite. Mittelsehienen mit Einzelborsten, die mit Ausnahme derer an der Oberseite vereinzelt, nicht reihenförmig gestellt sind. Hintertarsen nicht verdickt. Fliigel mit zwei braunen Binden, die volne bis zur dritten Längsader verbunden sind. $6 \mathrm{~mm}$ lang. (Nach Aldrich.)

90 purmereus Aldr. O’Q, Biolog. Centr. Amer. Dipt. I 362. 22 [Y'silopus] (1901) . . . . . . . . . . . . . Mexico

Hiiften, Sehenkel wud luinterc Schienen schwarz. Schwinger selwairzlich. Hypopyg mit großen gelben Anhängen. Vorderschienen mit einer Reihe ron Borsten anf der Außenseite. Mittelschienen mit nul wenigen Einzelborsten. Hintertarsen mit lïngeren Borsten auf der Aufenseite und kiirzeren auf der Innenseite. Fliigel glashell. $4-4.5 \mathrm{~mm}$ lang.

quadricolor Walk., List Dipt. Brit. Mus. III 649 [Psilopus] (1849) Brasilia

Beschreibung ohne Angabe des Gesehlechts nnd ohne besondere Nerkmale. $1^{3} / 4$ Linien lang.

91 radians Maeq. Suit. it Buffon, I 450. 6 [Psiloms] (1834)

Ameriea merid. et sept.

Diese Art soll nach Loew N. Beitr. VIIl S0. 13 (1861) mit longicornis Fbr. identiseh scin, das ist aber nicht gut möglich. Maequart sagt, die Fliagel vou radians hiitten an der Spitze eine Briunung; von dieser ist an der in Wiener Museum befindlichen Type von longicomis Fbr. nichts zu sehen. Daß Wiedemann iibrigens und walıseheinlieh anch sehon Eabricius diese Art mit der ïußerlich äbulich aussehenden Art chrysoprasius Walk. vermiseht haben, geht aus der in Kopenhagen noch befindichen Type des Fabricius (chrysoprasius) und den Wiedemaunschen Exemplaren des Wiener linseums hervor; siehe das Nïhere iaber longicornis Fbr. bei dieser Art. Loew's Ansielıt über die Synonymie dieser Art steht jedenfalls auf viel zu sehwachen Fiißen, als daß wir sie mangels jeden Beweises anuehmen könnten; wir miissen die Art rentians Haeq. als eine nieht meln deutbare Art bezeichnen.

92 Schnusei n. sp. бㅇ . . . . . . . . . . . America meril.

Eine dureh lange Beborstung besonders ansgezeichnete Art.

ơ. - Thoraxrïcken griu bis veileheublau mit je fiunf Dorsozentral- und vier Aklostikalborsten; Brustseiten sclıwarzgran; Schwinger gelb, Sehiippelien braun. Stirne und Gesicht glinzend blaugriin, die nntele Gesichtshälfte kaum etwas braungran bereift. Riissel, Tastel nnd Fibler schwarz. Hinterleib intensis blangriiu mit sehr langen Randborsten, die sieh am unteren Rancle des sechsten Ringes ganz besonders verläingern; auch der siebente lange und diinne Ringabschnitt ist laug behart. Hypopygium schwarz, kclchförmig mit gelben lappig nud spitz 
endigenden Anläingen, die am unteren Teil behantt, an der Spitze bisschelförmig helaart sind und in einen stachelförmigen Dorn auslaufen (s. Figur. 133). Beine und Hiiften schwarz, Selienen und Metatarsen gelb, letzte Tarsenglieder brann. Hiiften und Unterseite der Sclienliel lang weif behart. Vordersehienen auf der Oberseite mit drei bis rier langen Borsten; Tarsen besonders diinn, Metatarsus fast naekt. Mittelselienen auf der Oberseite mit drei, außen mit zwei Einzelborsten; die beiden letzten Tarsenglieder mit mikroskopisel kleinen Hauseböpfen, die einen bellen Schimmer haben. Hintersehienen und Metatarsus rauh und knl'z beborstet. Vordertarsen doppelt so lang wie die Scliene,

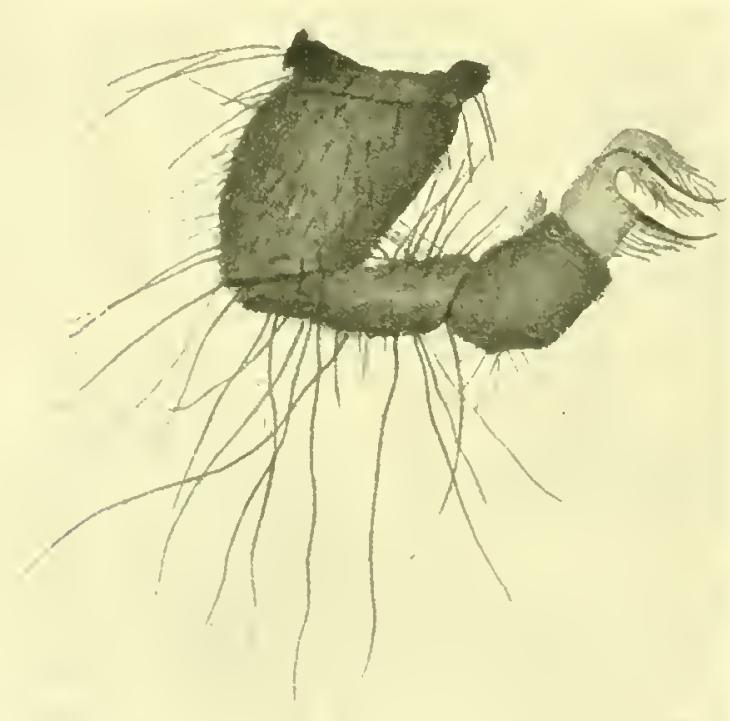

Fig. 133. Condylostylus Schmesi Beck. of. 11ypong. 24. I. diese wenig kiirzel als der Netatiu'sus und letzterer nur wenig liinger als die vier letzten Glieder zusammen. Mitteltarsen fast $1 \%$ mal so ling wie die Sehiene, diese ein wenig liinger als der Hetiltarsus und letzterer $13 / 4$ mal so lang wie die letzten viel Glieder. Hintertarsen wenig kiirzel als die Schiene, diese fast doppelt so lang wie derMetatarsus; Hintertarsenglieder nicht verbreitert.

- Fliigel mit zwei nur sehr sehwael entwiekelten Querbinden mit verwaschener Begrenzung; die Verbindung zwisehen beiden am Vorderrande reicht bis zur dlitten Jaingsader; die Binden erselıeinen liäufig nur als graubraune Flecken iiber der hinteren Querader, der Gabelader und an Vorderrande, olne Zusammenhang, oder die ganze Fltigelbriumung besehriinkt sich anf einen Schattenfleek am Vorderrande. $4.5-5 \mathrm{~mm}$ lang.

Q. - Bei den Weibchen ist der Charakter der Beinbeborstung der gleiehe; die aufderOberseite der Sehienen stehenden Bor'sten an denVorder. und Mittelbeinen sind noeh etwas lianger, a ueh an den Hinterschienen sieht man eine Reihe ron drei bis vier kirzeren Borsten. Die Flijgelfleekung seheint im allgemeinen noeh schwächer zu sein, im iabrigen kein lTntersehied. 
zangenförmigen Lamellen, die auf einer Seite bejorstet sind. Sehenkel und Hiiften schwarz, Schienen rostbram, Tarsen schwarz. Vorderschienen auf der Außenseite mit fünf lïngeren Borsten, die in gleichen Abständen stehen, der Metatarsus unterseits außer der feinen anliegenden Behaarmg mit zwei kleinen abstehenden Einzelbörstehen. Mittelsehienen auf ihrer Außenseite mit 16-1S gleich langen, kammartig, gereihten Borsten grob bewimpert, der Metatarsus arf seiner Unterseite ebenfalls mit etwa drei kurzen Börstehen. Hinterschenkel mit knrzen, diclıt gestellten IBörstelıen; Tarsen so dick wie ihre Schiene, Endglieder kanm verbreitert. Vordertarsen $1 \%$ mal so lang wie die Schiene, diese mm $1 \frac{1}{3}$ mal länger als der Metatarsus und letzterer um $1 \frac{1}{5}$ mal lïnger als die vier folgenden Glieder zusammen. Mitteltarsen $12 / 5$ mal so lang wie die Schiene, diese $10 \mathrm{~m} \mathrm{1/4}$ mal lïnger als der Metatarsus und letztere $1 \mathrm{~m} 1^{1 / 4}$ mal länger als die folgender Glieder. Hintertarsen nur wenig kirzer als die Seliene, diese reichlich doppelt so lang wie der Metatarsus und letzterer ungefihr so lang wie die vier letzten Glieder. - Fliigel etwas graulich getriibt, aber ohne deutliche Flecken oder Binden; die Gabelader zweigt an ihrer Basis nnd ebenfalls auf ilner Mitte spitzwinklig ab. Fast $4 \mathrm{~mm}$ lang.

․ - Schienen rostgelb bis braun; Mittelschienen einfach, nur nit wenigen Einzebörstchen, sonst dem $\delta$ gleich. -

2 б, 6 q alus Bolivia-Mapiri, 3. I. 1903. S. Carlos $800 \mathrm{~m}$ hoch. aus Peru, I. 190t. Pachis Weg; aus Pern, Meshagua, 2ち. IX 1903. Urubambafi [Schnuse] Sammlung des Dresdner Museums.

Mit den roten Beinen, wegen der Flirgelzeichnung und der längeren band-oder fadenförmigen Analanbänge verwandt mit subcordatus, flagellatus und flagellipodex m., abweichend aber durch die Form der Analanhänge.

万. - Azurblau; Sehwinger sehwarzbraun. Fühler schwarz, drittes Glied sebr klein, mit mïßig langer Borste, das zweite Glied mit km'zen Randborsten. Hinterleib mit sehmalen mattbraunen Querbinden und langen Randborsten. Iypopyg klein, selrwarz mit ebenso gefuirbten fadenförmigen belatarten Anliingen, die an der Wurzel etwas breiter sind; die Aualanhänge sind reichlich doppelt so lang wie das Hypopyg und laufen in eine einfache gerarle Spitze ans. Beine nebst den Vorderlififten hell lotgelb, Hintertarsen bram; Hinterschenkel an der Spitze, Hinterschienen an del Wurmel bram. Unterseite der Sehenkel nur schwacl weiß behart. Vorderschienen und Tirsen ohne Beborstung, fast natekt. Tarsen ungefäln $1^{1 / 2}$ mal so lang wie die Sehiene. Mittelschiene an del Spitze mit etwas stiirkerel Borste, im ibrigen nur mit 2-3 Einzelbörstehen (Tarsen fehleu). Hintertarsen nicht verbreitert. Flïgel lang mit zwei undentlielien braunen Binden, die rolne nur his zur zweiten liangsader verbunden sind. Der Vorderrand ist bis 
iiber die erste Längader himans braun, aueh die kleine Querader ist etwas fleekenartig gebräunt. Gabelader spitzwinklig abzweigend, hermach reehtwinklig bogenförmig; hintere Querader nur wenig sebrïge, um das $1 \frac{1}{2}$ faehe ihrer eigenen lainge von der Gabelader entfernt. $7 \mathrm{~mm}$ lang.

¡. - Hintersehenkel und Sehiene an Spitze nnd Wurzel niebt gebräunt. Mittelsehienen auf der Wurzelhïlfte ihrer Außen- und Oberseite nur mit je zwei kleinen Einzelhorsten.

1 б, 3 q ans Brasilien in der Wiener Sammlnng, wo ieh sie unter den als "sipho Say" bestimmten Tieren fand. -31 o aus PeruLaristhal, 9. VIII. 1903, 2000_-3000 m hoeh [Sehnuse] Dresdner Insenm.

9 similis Aldr. Ơ, Biolog. Centr. Amer. I Dipt. 35!) 14 [Psilopus] (1901).

Mexieo, Brasilia.

Ђ. - Firbung wie gewöhnlieh; Kopf ohne abweiehende Merkmale; Schwinger hellgelb. Hinterleib mit schwarzen Querbinden; IIypopyg selwarz, klein mit dreieekig zugespitzten etwas beharten Anhingen. Beine nit allen Hiiften sehwar, Sehienen und die vorderen Uetatarsen gelb. Vorlersehienen auf der Außenseite mit drei langen Linzelborsten, von denen die letzte, die etwas jenseits der Sehienenmitte steht, am längrsten ist: die Unterseite der Sehiene ist ebenso wie die des Netatarsus sehr zart und wenig aufiillig wimperartig behart, letzterer zeigt unterseits nahe der Spitze noch eine Einzelborste. Die Vordertarsen sind reiehlich $1 \frac{1}{2}$ mal so lang wie die Sehiene. Mittelbeine ohne jeglielıe Besonderheit; die Sehienen tragen einige kmre Einzelbörstchen, sind aber im iibrigen wie die Tarsen nackt; letztel'e sinul reiehlieh $1 \frac{1}{4}$ mal so lang wie ihre Sehiene. Die Hinterbeine sind ganz einfaeh, aueh die Tarsen sind nieht verbreitert. - Fliigel mit zwei bramen Querbinden, die an Vorderande noeh etwas iber die dritte lingsader hiuaus miteinauder verbunden sind, fermer anch noch längs der vierten Liingsader, so daß der helle Fleck zwisehen den Binden wie ein Fensterfleek erselıeint. Gabelader unter etwa 70 Grad nach riiekwairts abzweigend; hintere Querader zienlich steil und gerade. $4 \cdot 5-5 \mathrm{~mm}$ lang.

- Torderhtiften, Schenkel und Sehienen gelb. Vorderbeine nackt; Mittelschieven mit einigen winzigen Einzelbörstehen, Hinterschienen auf ler Oberseite ebenfalls mit $2-3$ kleinen Börstehen, sonst dem or gleich.

$1 \sigma^{\sigma}, 2$ a a Brasilien in der Wiener Sammlung, die als jucundus Lw. gedentet waren. Ieh kenne Loew's Art zwar nieht aus Anschaunng, aber die Beschreibung weieht in mehreren Punkten erluebliel ab: so sollen die Hintersehienen sehwarzbrann sein und sind hier gelh, der Vordermetatarsus soll wach Loew nicht ganz so lang sein wie die Schiene, ist lier erheblich länger; die Schwinger sollen schmutzig- 
braun sein $\left(\sigma^{*}\right)$ und sind hier blaßgelb; dann sind bei jucundus Loew aneh die Fliggelbinden nicht an der vierten Längsader miteinander verbunden. Aus diesen Grinden kann man eine Identitait mit jucundus Lw, nicht anssprechen, dalingegen paßt Aldrich's Besehreibung roll staindig.

An nerkung. In Loew's Bescheibung von jucundus X. Beitr. YllI. 87 befindet sich ein sinnentsteltenter Druckfehler. p 88 , Zeile 3 ron ohen muß es anstatt: "das erste Glied derselben" heißen: "das erste Glied der Mittelfiiße".

Eine Reihe von Exemplaren in der Sammlung von Sehnuse und des Ungarischen Nationalmuseums.

Eine durch helle Vorderschenkel von den üibrigen abweichende Art.

o'. - Tholax riicken azurblau; Brustseiten silberweiß schimmernd, Sehwinger gelb. Fiibler selnwarz. Hinterleib blau bis messinggrin. 1 ypopyg $^{\circ}$ lilein sehwarz mit linglieh dreieekigen, zugespitzten beharten schwarzen Lamellen. Beine: Vorderbeine mit Hiffen bis auf die etwas bramen Tarsengliedel ganz rotgelb. Mittel- nud Hintersehenkel nebst Hiaften schwarz: Sehienen mud Metatarsus rotgelb. Die Beborstung der Beine ist schl zart. Vorderschienen unten weitlänfig bewimpert, anf del. Oberseite mit zrei Borsten, Metatarsus unterseits mit $2-4$ kleinen Börstehen. Mittelschienen außen mit zwei, oben mit drei zarten Börstehen, Metatarsus fast nackt. Hinterschienen nebst Tarsen selwach, aber etwas rauh behart und beborstet. Vordertarsen um $1 \frac{1}{2}$ mal länger als die Sehiene; diese $1 \frac{1}{4}$ mal lainger als der Metatarsus und letaterer $1 \% 1 / 4$ mal länger als die vier nächsten Glieder yusammen. Nitteltursen $11 / 3$ mal linger als die Schiene, diese $n$ m $1 \frac{1}{3}$ mal liinger als der Metatarsus und letzterer $1 \frac{1}{2}$ mal so lang wie die nächsten vier Glieder. Hintertarsen kiirzer als die Schiene; diese um $1 \frac{1}{3}$ mal linger als die Tarsen und $21 / 3$ mal läinger als der Metatarsus, letzterer um $1 \frac{1}{3}$ mal länger als die vier Endglieder. Fliigel glashell mit nur schmalen, blaß braun gefäbten, vorne bis zur dritten Längsader miteinander verbundenen Querbinden. $4 \mathrm{~mm}$ lang.

$2 \sigma^{7}$ aus Perm, Pachitea-Hindung, $150 \mathrm{~m}$ hoch. 25. Xl. 1903 [Schnuse] Sammlung des Dresdner Museums.

A nmerkung. Wollte man die besondere helle Furbung der Vorderschenkel nicht als Artmerkmal, sondern nur als Vabemraritä ansehen, so käme man nach inserer Tabelle auf die Arten atrolamellatus und depressus Aldr. deren Besclureibung aber uicht itbereinstimmt.

Ein Exemplar olne Kopf, sonst ziemlich gut erhalten, in der alten Sammlung des Wiener zoologischen Museums aus Venezuela [lindig] 1864 als smaragdulus Wied. bestimmt; letztere ist eine ganz andere Art und synonym mit caudatus Wied., wie ich dies nach gewiesen habe. S. bei caudatus. 
б. - Thoraxricken griingold, Schildchen blau, mit zwei sehr langen und zwei etwas kürzeren Randborsten. Schwinger blaßgelb. Hinterleib azurblau, fast ohne selowarze Querbiuden und mit ziemlich langer Behorstung. Das Hypopyg ist schwarz mit zwei langen stieloder bandformigen behaarten gelblichen Anhängen, die an der Wurzel etwas rerdickt und im zweiten Drittel gegabelt sind; im iibrigen haben sie auffallende Ähnliclıeit mit denen der Art flagellatus m. (s. dort die Figur). Beine nebst Hüften ganz blaßgelb, jedocls sind

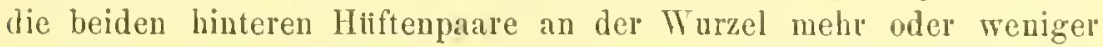
grau; Schienen und Tarsen sind nicht verdunkelt. Die Schenkel haben unterseits nur spärliche Behaarung, jedoch sind die Vorderschenkel durch drei schwarze Borsten ansgezeichnet, die vor der Spitze an der Außenseite dicht gedrängt zusammenstehen; auch die Vorderschienen sind ausgezeichnet, einmal dureh eine leichte Anschwellung auf der Wurzelhälfte der Unterseite, sodann durch feine dichte liewimperung der Unterseite. Tarsen einfach, fast uackt, sie sind fast doppelt so lang wie die Sehiene; Mittel- und Hinterbeine einfach, fast nackt. - Fligel farblos mit gelben Aderu ohne Fleeken; die dritte Längsader ist an der Spitze mäbig gebogen; die Gabelader zweigt rechtwinklig ab und biegt in einem stumpfwinkligen Bogen auf ihrer Mitte zur Fligelspitze ab: die hintere Querader steht senkrecht zur vierten Liingsadel und ist fast $u$ m das $1 \frac{1}{2}$ fache ihrer eigenen Länge ron der Gabeladel entfernt. $3 \cdot 5-4 \mathrm{~mm}$ lang.

$1 \sigma^{7}$ wie oben angegeben.

simuatus Macq. Dipt. exot. II 2. 120.13 tab. XX fig. 4 [Psilomus] (1842)

Brasilia

Eine Art mit gebänderten Fliggeln und stark riickwảits gebogener Gabelader. Beine gelb, Hintersehenkel an der Spitze braun. $6 \mathrm{~mm}$ lang.

Obne Geschlechtsangabe und niihere Merkmale nnerkennbar.

sipho Macq. (nec Say) = jucundus Lw. (teste Loew.)

sipho Say, Journ. Acad. Nat. Se. Philadelpbia III 84 [Dotichopus]

(1823). Lw., N. B. VIII 181861 et Monogr. Il 232 et 247 (1864).

5. - Thorax und Hinterleib griingold bis messingfarbig, Sehildchen and der erste Hinterleibsring blau. Sehwinger gelb. Das weißbestaiubte Untergesicht ist ziemlich brejt. Filhler sehwar"z, das zweite Glied ohne hervortretende Randborsten. Fiihlerborste ron gewöhnlieher Länge, Riissel gelb, 'Taster gelhbriunlich. Hinterleib nur kurz belaart nud beborstet; Hypopyg klein, schwarz, äußere Analanhänge linglich dreieckig, schwarz, kurz behart. Beine nebst Torderhiliften rotgelb, Hintertarsen und die vier letzten Glieder der vorderen Beine braunschwarz. Alle Sehenkel unterseits deutlich etwas weili behaart. Volderschienen auf der Außenseite außer der kuren Beharung mit t-6 Einzelborsten, Metatarsus auf der Unterseite mit $3-4$ schwachen Borsten, erheblich läuger als die ibrigen vier Glieder zusammen; 
die Vordertarsen etwa $1 \frac{1}{2} \mathrm{mal}$ so lang wie ihre Sehiene. Mittelsehienen auf der Anßenseite mit einigen Borsten, anßerdem sehon halb anf der Unterseite der ganzen Liange nach mit grober Bewimperung; der Hetatarsus ebenda mol auf seiner Wurzelhälfte mit $4-5$ kleinen Einzelborsten; die Mitteltasen siud ebenfalls ungefillu $1 \%$ mal so lang wie ihre Schiene. Hintersehienen und Tarsen haben anßer ihrer etwas rabheren Beharmug keine Borsten; die Tarsen sind kiirzer als die Schiene. - Fligel glashell mit den gewöhnliehen braunen Querbinden, die am Vorderrande bis zur dritten Längsader niteinander verbunden sind; die binden haben weder eine gröfere Breite, noeh eine dunklere Färbung. Die erste Längsader reieht bis oder fast bis zur Mitte des Fligels; die Gabelader zweigt ab in einem Winkel von 70- $80^{\circ}$ nach riickwirts und zeigt auf seiner Mitte nur eine kurze Isiegung. $6 \mathrm{~mm}$ lang.

Q. - Dem o gleiel an allgemeiner Färbung. Die Tarsen sind iu Verhailtnis zur Sehienenlinge etwas kiirzer. Schienen nnd Tarsen nur mit den gewöhnlichen Einzelborsten, ohne charakteristische Reilienbeborstnng. 5) $\mathrm{mm}$ lang.

Vorkommen in Nordamerika, Mexico und auf Cuba. Sammlungen des Berliner nud Wiener Musenms; typisehe Exemplare in der Winthem'selien Sammlung, anch von Sehiner eine Reilıe von Exemplaren als nsupertus Wied." bestimmt.

smaragdulus Wied. $=$ caudatus Wied.

- solidus Walk., Trans. Entom. Soc. London n. Serie V. 287 [Psilopus] $(1860)$.

๑. - Unkenntlich beselırielıen.

100 squamifer 11. sp. 2 Fignren Hexieo gelpriunten Fligeln.

ア. - Thoraxriicken sehwarz, Schildehen blausehwarz, Brustseiten selwargrau; Sehwingerknopf dunkelbrann, Stime azurblan, Gesielit schwalrz, nur weniggraugelb bestiulut. Riissel, Taster und Fiihler sehwarz. Hinterleib nit selwarzen Analanbingen, die selmmal, stab-bis zangenfirming vorgestreekt sind. - lieine nebst. Hiiften ganz sehwal'z, nul die vorderen Schienen brannschwarz. Sehenkel unterseits deutlich weiß behart, Vordersehienen anf ihrel Außenseite mit sieben längeren Borsten, Metatursus mit einigen wenigen Einzelborsten anf der Unterseite. Mittclschienen anBen der ganzen Länge nach kräftig kammartig bewimpert (etwa $2 x$ Borsten), die Oberseite, aber un anf ilurer Wrurzelhailfte mit etwa sieben lïngeren feineren Haren; der Netatarsus und ein Teil des zweiten Gliedes sind, halb anßen, halb hinten, ebenfalts etwas weitliufig gekimmt mit Borsten, deren Spitzen blattartig verhreitert sind; diese Bürstehen stehen in den gleichen Zwischenrïnmen roneinander wie die anf der Schiene; in einer zweiten Reilse stehen hier dam noch etwa zehn stumpfe Borsten (s. die Figur 134). Hinter- 
schienen und Tarsen etwas ranh und dicht borstlieh bekleidet, sie sind bis zur Śpitze ebenso diek wie die Sehiene. Pordertarsen 1\% mal so lang wie die Scliene: diese etwas länger als der Mletatarsus mul letzterer $1.5 \mathrm{mal}$ so lang wie die letzten vier Glieder zusammen. Mittel tarsen 1.3 mal länger als die Schiene; diese um ein geringes kirzer als der Metatarsus, letzterer fast viermal linger als die vier tolgenden Glieder zusammen. Hinterschienen $1.2 \mathrm{mal}$ lïnger als die T'ursen und

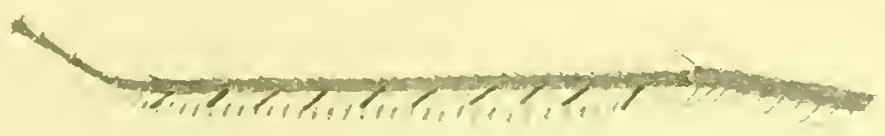

Fig. 134. Condylustylus squamifer Beck. O'. Mitteltalsecis. 10:1.

fast doppelt so lang wie der Metatarsus, letzterer 1 's mal so lang wie die folgenden vier Glieder. - Die branne Bindenzeichuung der Flitgel ist iiber die ganze Flaiche ausgelneitet und derartig zusammengeflossen, daß nu der Hinterrand und ein kleiner runder Fensterfleck in der ersten Hinterrandzelle frei bleiht. $5 \mathrm{~mm}$ lang. S. Figur 135.

1 ans Peru-Urubaubafi. 9. IX. 1903. Umahuankilia [Felunuse] Sammlung des Dresdner Museums.

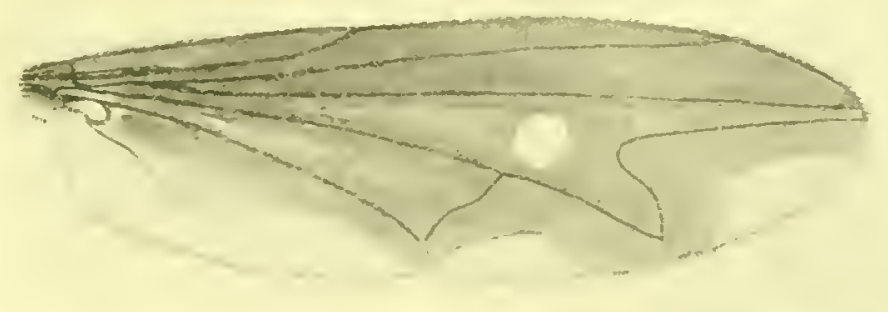

l'ig. 135. Condylustylus stpumifer lieck. O. Flügel. 16:1.

2 ó ans Columbia, Aracataca 11 1912 [Ujhelyi] Sammlung des Ungarischen Nationalmuseums.

stigma Wied. (nec. Fbr.) @. Aufereuropäische zreifl. Ins. II 2I6; [Psilopus $](1836)$. . . . . . . . . . . America merid.

Diese Art ist von Romlani als synonym ron guttipemis Rond. bezeiehnet worden und ging diese Synonymie somit in den Katalog Kértesz Vl 179 aiber. Vergleiclıe dagegen meine Bemerkungen bei der folgenden Art stigma Fbr. Die Art stigma bleibt vorliautig eine species incoguita. 
101 stigma Fbr. Q, Sys. Antl. 263. S [Dolichopus] (1805) America merid. guttipemis Rond. ơ 9 , in Truqui Studii Entomol. 1. 87. 46. tal). III

fig. 7 bis [P'sitopus] (1848).

testacipes Rond. o in Truqui Studii Entomol. I. 88 (IN48).

Zur Synonymie ron guttipennis Rond. mobte ieb zmnäehst folgendes bemerken: Rondani beschreibt seine Art gullipennis im mänulichen Gesehleeht mit sehwarzen, im weibliehen Geseblecht mit rotgelben Sehenkeln und selıwarzen Fiblern. Die Flijgel sind mit Ausnahme der iußersten basis und des Hinterrandes bramsehwar mit hellen Flecken in der ersten IIinterandzelle auf der Mitte des liigels; die Gabelader ist spitzwinkelig naeh innen geloggen und zeigt in der Figur (tab. 11 fig. 7) an der mittleren Biegung einen rijeklanfenden Aderast. - Rondani ist der Ansieht, daß seine Art mit stigma Wied. (nec. Fbr.) identisch sei; zu dieser Auffassung mag er gekommen sein dureh die Erkenntnis, daß stigma Wied, nieht dieselbe Art scin könue wie stigma Fbr., was zutreffend ist, danu aber sieher auch noels dadureb, laß er angenommen hat, Wiedemann's l'Besehreibung sei auf ein $\delta^{\top}$ mit dunklen Schenkeln gegrindet, wie el das bei gullipennis festgestellt habe, währeud die $\rho$ rotgelbe Sehenkel zeigten; letztere Aulfassung lat sieh aber als irrig herausgestellt insofern, als die Wiedemann'sche Type ein Weibchen mit sehwarzen Beinen darstellt.

In der Fabrieius'schen Sammlung in Kopenlagen befinden sich untel dem Altuamen stigma zwei Weibehen; das eine hat rotgelbe Beine und klitgel, so wie Rodani sie bei guttipennis besehrieben, dies ist die Type; das andere Weibehen, welebes Wiedemann zu seiner Beschreibung benutzt hat, bat schwarze Sehenkel und briunliehe Sehienen; der helle Fligelfleek ist nieht eingesehlossen, sondern zu einer Querstrieme erweitert, wie dies bei den meisten dieser Arten der Fall ist, nnd dieser helle Streifen reicht bis an die dritte Längsaler; ein solehes Weibehen hat natiolieh nichts mit der Fabricius'schen Art zu tun, stellt vielmehr eine andere Art dar, deren Hïnchen unter den vielen :ihnlieh gefäbten Arten noeh nieht erkarnt worden ist. Hierdureh ist aber anch erwiesen, daf gullipemis Ront. ebenfalls nieht uit stigma Wied. ifbereinstimmen kann. Rondani hat also diese Synonymie zu Unrecht ausges]rochen. Man kann vielmebr zu der entgegengesetzten Auffissung gelangen, daf guttipemis Rond. synonym ron stigma Fbr. sein miisse. Daf die Hïmnchen dunklere Beine laben als die Weibehen, ist eine in dieser Gattung sehr häufig rorkommende Erseheinung; auch Rondani gibt ja seinem Weibehen die helleren Beine, wie l'abricins sie besehreibt; die Fligelfärbung stimmt ebenfalls iiberein. Aneh Rondani ist diese Ähnlichkeit nieht entgangen; der cinzige Umstand, das Fabricius von seinem Weibchen sagt, der Hinterleib sei mngefleekt, wiilmend Rondani auf dem Hinterleibe Binden feststellt, ist fiir Rondani hestimmend gewesen, diẹse Synonymie nicht 
anzumehmen. Ich miehte auf dies Merkmal nicht allzuviel Gewicht legen; allerdings ist die mattsehwarze Bindenzeichnung auf den Hinterleibsringen bei den meisten Arten vorbanden, wenigstens bei den Männehen, bei den Weibchen ist sie al)er sehwäier, l'ehlt anch bisweilen ganz; sie kann bei älteren Exempluren aber auch abgerieben und verloren gegangen sein. lis ist daher nieht unwalrseheinliel, daß Rondani's Art guttipennis mit stigma Fbr. zusammenfällt. leh nehme diese Synonymie, die viel Wahrscheinliehkeit fiir sich hat, an; die Wiedemann'sehe Art stigna Wied. (nee. Fbr.) vermag ieh zurzeit nicht zu deuten.

Da die Fliigelbinden bei guttipennis Rond. ganz rusammen. geflossen sind und nur in der ersten Hinterranlzelle ein kreisrunder Fleek zu sehen ist, so gibt es bei dieser Flügel- und leinfairbung nicht viele Arten, die man mit Rondani's Art velgleiehen könnte. Iel habe u. a. eine Art squamifer besehrieben, die eventuell mit guttipennis zusammenfallen könnte; leider macht liondani keine An. gaben über die Körpergrüße und iiber die Beborstung der Beine. Sollten die Mittelsehienen ohne kammartige Beborstung sein, was wahrscheinlich ist, dam wiirden beide Arten sieher nieht zusammenfillen. Sollte jedoch die Größe ibereinstimmen, Mittelsehienen nud Tarsen dentlich reihenförmig bewimpert sein ( $\mathrm{vgl}$. die Zeichnung bei squamifer), was sich spüter mit Hilfe meiner Besehreibung wird feststellen lassen, so künnte es sein, dal\} mein Name squamifer eingezogen werden miifte; bis dahin muß ieh denselben jedoch aufreeht erhalten. suavium Walk., List Dipt. Brit. Mus. III 645 [Psilonus] (1849)

Ameriea centr.

Besehreibung ohne Gesehlechtsangabe und ohne brauchbare Merkmale.

subcordatus n. sp. $\sigma^{7}$. . . . . . . . . America merid.

Ђ. - Thoraxtiicken azurblau. Schwinger gelb. Kopf mit den gewöhnlichen sehwarzen Fïhlern. Hinterleib griugold mit breiten mattschwarzen Vorderrandsbinden nud kräftigen Raudborsten. Hypopyg klein, schwarz; Analanhänge gelbloriunlich, stielförmig, aufrecht gerichtet, an der Spitze hakenförmig nach unten nmgebogen und nur zart behaart, so lang wie das Hyponygimm selbst. - Beine mit den Vorderhüften blaßgelb; Schenkelbehaarung auf der Unterseite spärlich. Vorderschienen auf der Außenseite nur mit zwei kleinen Einzelbürstchen, sonst uackt wie die Tarsen. Mittelsehienen nieht eigentlich bewimpert, aber doch auf der Anßenseite kurz und fein behaart; die gewöhnliche Einzelbeborstung ist aueh hier sehr schwach, dagegen sielit man an der Spitze der Unterseite eine starke S fourmig gebogene elarakteristisehe Borste, die vielleieht nur dureh Zufall diese Krimmung erhalten haben mag; Tarsen naekt. Hintersehienen und Tarsen ohne jede besondere leborstung. - Fliigel mit zwei bramen, am Vorder- 
lande nur bis zur zweiten Lỉngsader miteinander verbundenen Quer. binden; die Briunng an Forderande beginnt hier schon etwas vor der Mindung der ersten Liingsader; Gabelader nach r'ickwairts spitzwinklig abzweigend, hernach fast unter einem rechten Winkel zur Spitze abbiegend; hintere Querader nur wenig schräge gestellt. $6 \mathrm{~mm}$ lang.

$1 \sigma^{7}$ ans Brasilien. Lollektion Winthem im Wiener zoologisehen Hofmuseum.

103 smperbus Wied. Oे AuBereurop. zweifl. Ins. II. 223. 21 [Psilopus] (1830) . . . . . . . . . . . . . America merid.

o. - Veilchenblau, auch das Gesicht kamn etwas bereift. Fïhler schwarz, das zweite Glied mit starken Randborsten. Schwingerknopf dunkelbraun. Hinterleib mit deutliehen mattschwarzen Querbinken. Hypopyg sehwarz mit vorgestreckten dunkelbraunen, an der Spitze blattformig rerbreiterten Anhängen. Beine mit allen Hiitten schwarz, Vorder- und Mittelschienen gelb. Vorderschienen anf der Anßenseite mit zwei bis drei langen Borstenharen; Tarsen ohne besondere Borsten. Mittelsehienen nur mit einigen knrzen Einzelborsten, Tarsen einfach. Hintersehienen und Tarsen ohne besondere Merkmale, letztere naeh der Spitze zu allmihlich diuner werdend. - Fliigel wasserklar mit zwei nur schwach ausgebildeten braunen Querbinden, deren Zusammenbang hin und wjeder etwas unterbrochen ist; ihre Verbiudung am Vorderrande reicht nur bis zur zweiten Lingsader; die Vorderrandader ist fein bewimpert. $5 \mathrm{~mm}$ lang.

Einige Exemplare (Typen) in der Winthem'schen Samulung des Wiener Hofmuseums aus Montevideo.

Im Berliner zoologisehen Musenm befinden sich ebenfalls vier Exemplare unter Nr.3100, die den Wiener Exemplaren vollkommen entsprecheu.

$10 t$ superflus Sehin. STo, Norara-Reise Dipt. J10 [Psilopus] (1868).

Eine große Art mit dunklen Beinen; Vorder- und Vittelschienen rostgelb. Fliigel mit brannen Binden. Mlttelsehienen und deren Metatarsus sehr fein gewimpert.

$0^{x}$. - Blangriin, Schwinger hellgelb. Fiihler schwar, Hinterleib goldgriin mit dentlichen mattschwarzen Vorderrandbinden und naißislangen Randborsten. Hypolyg schwarz; iußere Anhinge klein dreieckig. sclıw:1"\% mit lingerer Beborstung, an der Basis mit Borstenmansehette; Penisscheide röhrenförmig mit trompetenförniger Endigung. Beine und lliften schwarz, die heiden vorderen Schienenparre nebst ihren Knieen rostgelb his braum. Vorderschienen auf der AnBenseite mit einer Reihe von rier feinen Borsten. Nittelschienen nebst dem ersten Tarsengliede anf ihrer Oberseite sehr fein bewimpert; diese Bewimperung ist bei der Schiene ansnahmsweise ebenso dicht mod fein wie bei dem Metatarsus; die Schienen zeigen dann auf ihrer Unter- 
seite, aber halb nach anlien gewendet, eine zweite gröbcre und weitliufiger gestellte Reihe von ungefihr 14 Borsten; unter dem Mikroskop sieht man danu noch halb auf der Unterseite eine dritte Reihe stumpfer, an der Spitze etwas verdiekter Börstchen. Auch Allrich bat eine Art triseriatus mit drei Borstenreihen an den Mittelsehienen beschrieben, die abel nicht mit nuserer Art identisch, viehmehr in Fliigelzeiehnung nul Beinfirlumg abweichend gebildet ist. Hinterbeine etwas rauh behart, die Tarsen sind so dick wie die Schiene und behalten diese Dieke gleichmïßig bis zum Ende bei, ohne daß die letzten Glieder breiter werden. - Vordertarsen $1^{2 / 3} \mathrm{mal}$ so lang wie die Sehiene; de Metutarsus etwas linger als die Sehiene und reiehlich $1 \frac{1}{2}$ mal so lang wie die tibrigen vier Glieder. Mitteltursen $1 \frac{1}{3}$ mal so lang wie die Sehiene; der Metatarsus etwas

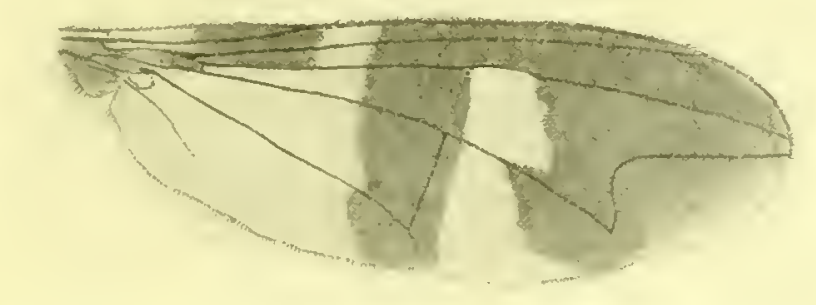

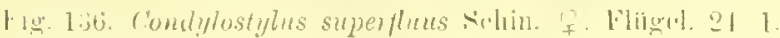

kiirzer als seine Schiene, aber $21 / 4$ mal liager als die vier iibrigen Glieder zusammen. Hintertarsen kiirzel als die Schiene; der Ietatarsus mehr als doppelt so kur wie die Schiene und fast $1 \%$ mal so lang wie die vier ïbrigen 'Tarsenglieder. - Kligel wasserklal' mit zwei brannen, vorne bis zur dritten Längsader verbnndenen Querbinden, die an del vierten Liingsader eine unvollkommene oder unterhrochene Verbindung zeigen; ein brauncr Randfleck liegt ferner an der Fligelbasis iiber der ersten Lüngsader und der kleinen Querader (s. Figur 136). $7 \mathrm{~mm}$ lang.

7. - Vorderschienen oben mit zwei, außen unit drei Einzelborsten. Mittelschienen oben und anßen mit je drei Einzelborsten. Hinterschienen rauh borstlieh. 6-7 $\mathrm{mm}$ lang.

307,11 ans Peru, Chanehemayo 11. I. 1904 ans Pern Meshagna, Uruhambafi [Sehnuse] Sammlung des Dresdner zoologischen II useums.

Anmerkung. Diese Art fand ich auber in der Scliner'schen simmlung anch in ale ron Sclunse; letztro Exemplare sehr gut phalten, sind kritiger gelairht als die sichiner'sche Tyle, die schun ibber 50 , lahre alt ist: dies tritt

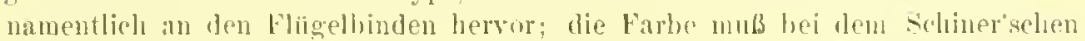

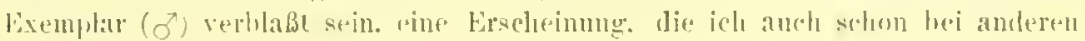


Arten melirfach beohachten konnte. schiner spricht noch besonders ron einer Bbännng der Mediastinalzelle; diese ist bei seinem Lxenplar kaum noch bemerkbar, währent sie bei den Exemplaren ron Schmuse deutlich hervortritt. Wem nicht die voltkommene Gleiehheit in der Bewimperung, Beborstung sowie Lïnge der Beine nebst Hypopygialanlaiugen rorliegen wïrte, kömnte man die l'rischeren. dunklergel'ithten Exemplare der Schnuse'sehen sammlung fiir einn besonilere Art ansehen.

○. Azurblan, Schwinger gelbbraun, Fiihler schwarz. llinterleib mit Querbinden. Hypopyg klein mit gelben bis brannen beharten, anf der inneren Seite gespaltenen Anhäingen. Beine nebst Hiiften schwarz, alle Schienen und die vorderen Tarsen gelb. Vorderschienen auf ihrel Außenseite mit fün Borsten, Tarsen borstenlos, $1 \frac{1}{4}$ mal länger als ihre Schiene. Mittelschienen auf der Unterseite mit vier bis fünf kurzen linzelborsten; Metatarsus anf der Anßenseite fein und dicht hell bewimpert, anf seiner Unterseite mit einer weitlinfigen Reihe vou sicben bis acht schwarzen Einzelborsten; Tarsen etwas länger als die Schienen. Hintertarsen ron $4 / 5$ der Schienenlänge; die Tarsen so dick wie die Schiene, die letzten Glieder noch etwas verbreitert. - Fliigel mit zwei etwas verschwommenen, an Vorderramle bis zur dritten Längsader und auch lïngs der vierten etwas verbundenen Querbinden, so daß der helle Fleck in der ersten Hinterrandzelle als undentlicher Fensterfleck erscheint; anch am Vorderrand des Fliigels setzt sich die Bräunung bis zum Ende der ersten Liingsader fort. Gabelader spitz abzweigend, lernach bogenförmig und rechtwinklig abbiegend; hintere Querader fast rechtwinklig zur vierten Lïngsader. $5-5.5 \mathrm{~mm}$ ling.

$1 \delta^{7}$ aus Peru, Callanga. Sammlung des Ungarischen Nationalmuseums.

106 terminalis 11. sp. $\sigma^{\circ}$. . . . . . . . . . Argentinia

万. - Azurblan, Schwinger gelb. Kopf mit schwarzen Fühleru, zweites Glied unten mit langen Borsten. Hinterleib mit braunschwarzen Qnerbinden; der siebente Hypopygialring mit zwei langen bisschelartigen schwarzen Haarsträhuen; Hypopyg klein sehwarz, mit stielförmig vorgestreckten selwwarzen Anliaingen, die an der Spitze nmgebogen nnd battförmig verbreitert sind. - Beine mit allen Hüften schwarz; Vorderschienen, Metatarsus, Mittelschienen und die Wurzellialfte der Hinterschienen gelb. Keine charakteristische Behorstung der Beine. Vorderschienen nur mit wenigen Einzelborsten, Mittelschienen desgleichen; T'arsen einfach. Die Tarsen sind verhältnismäßig sebr kurz. Vordertarsen $1 \frac{1}{4}$ mal länger, Mitteltarsen nur wenig länger als ilıre Schiene, Hintertarsen kiirıcr. - Fligel glashell olıne Bräunnng; Gabelader rechtwinklig ansetzend und in kurzem Bogen sehr stumpfwinklig zur Spitze abbiegend; hintere Querader ziemlich steil. 3-3.5 mu lang. 
3 ऽ aus N. Argentinien, Provinz Teeuman, Salta $1200 \mathrm{~m}$ hoeh [Steinbaeh]. Sammlung des Berliner zoologischen Museums. testaceipes Rond. = guttipemis Rond.. .

o. - Kopf ron gewölınlicher Form und Fürbung. Fiihler sehwar\%. zweites CHied nur mit wenigen lïngeren Randbolsten, drittes Glied mit subapikaler Flihlerborste, die etwas länger als gewölnnliel ist. Schwingerknopf hellgelb mit etwas dunklerem Stiel. Hinterleib mit schmalen schwarzen Querbinden; Hypopygium schwarz mit braunen gebogenen Lamellen, die mit einer starken Staehelborste besetzt sind. Beine mit allen Hiften sehwarz, alle Sehienen und Tarsen gelb, nur die Hintertarsen braun. Vordersehienen auf der Oberseite mit drei bis vier Einzelborsten, von denen die letzte etwas linter der Sehienen mitte die lïngste ist; der sehr diinne Metatarsus ist auf seiner AuBenseite mit newn gleiehmälig verteilten selıwarzen Börstehen beset»t. Die Mittelsehienen sind äbnlich wie die Vordersehienen anf ihrer Oberseite mit vier längeren Einzelborsten besetzt, die sieh gleichmäßig iuber die ganze Länge verteilen; Tarsen einfach. IIinterschienen und 'l'arsen obne besondere Beborstung', nur etwas stälkel' behart als die vorderen Beine, aneh die Hintertarsen sind nicht verdickt. nehmen vielmehr nach der Spitze hin allmählich an Dicke ab. Fligel ganz wasserklar ohne Zeichnnng; die erste Längsader reieht nielıt ganz bis zur Fliigelmitte; Gabelader spitzwinklig, mit 60-70 Grad naelı riickwärts abzweigend, auf der Hitte mit knrzer Biegung reehtwinklig bis nahe ror der Spitze miudend; hintere Querader zienlieh sehräge. $4: 5 \mathrm{~mm}$ lang.

$1 \sigma^{7}$ (Type) aus Antigua, Coll. Winthem. Wiener zoologisehes Hofmusenm.

10 tonsus Aldr. O. Biolog. Centr. Amer. Dipt. I 36t [Psitopus](1901). Mexieo

$\sigma^{7}$. - Fiiller schwarz, zweites Glied mit nur wenigen laingeren Hatren; Sehwinger hellgelb. Hypopygium sehwarz, Anhänge (?) leine gelb; Mittel - und Hinterliuften und die hinteren Hiftgelenke schwar; Hintersehenkel an der Spitze braun. Beine olne besondere Beborstung. Fliigel fast glashell olne Zeiehnung, Aderung wie bei eaudatus Wied. $4 \mathrm{~mm}$ lang.

trichosoma Big., Ann. Soc. Ent. Fr. Série 6. X 250. 4 [Psilonus]

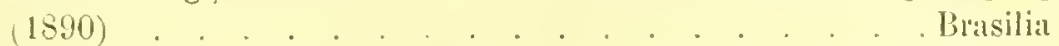

Ђ. - Fiihler sehwarz. Sehwinger briiunlich. Huiten und Sehenkel seluwarz, Selienen gelb bis braun, Tarsen bram. Fligel fast farblos. (6) mu lang.

Die Art lißßt sich hiemach nieht feststellen.

109 triseriutus Aldr. O'. Biolog. Centr. Amer. Dipt. I 356.8 [T'silopus] (1!101).

Uexico. Brasilien 
3. - Fiihler sehwarz, zweites Glied mit einigen langen Borstenhaaren; Sehwinger briululich. IJypopyg klein sehwarz, mit seln kleinen gelbbranneu Aubingen. Hiften und Schenkel schwarz; Schienen und der Wurzelteil der Vordermetatarsen gelh, IIinterschienen braun. Vordersehienen an der Aubenseite mit einer Borstenreihe. Mittelschienen anf der Vorderseite mit nenn dieken Borsten; der Mittelmetatarsus ist an der Volderseite mit Wimpern besetzt und auf der Unterseite ebenso, aher kiirzer und auf der Oberseite eine dritte Reihe, aber nicht senkrecht abstehend. Fligel fast glashell mit Qnerbinden, die vorne bis zur dritten Längsader, a ber anch an der vierten Längsader miteinander verbunden sind. 4-5 $\mathrm{mm}$ lang. (Naeh Aldrich.) triseriatus Enderl. (nee Aldrich) $=$ dimimans Beck.

Eine durch verzierte Vordertarsen ausgezeichnete Art.

๑. - Thoraxticken blangriun; Sehwinger hellgelb. Taster und Fiihler schwarz, zweites Fiihlerglied unten mit langer Borste. Ilinterleib griu, etwas grau bestiulst mit dunkelbrannen Vorderrandsbinden. Beine: Schenkel und hintere lliften schwarz; Vorderhiiften, Schienen und Tarsen rostgelb, Hintertarsen am Ende schwarz. Selienkel nuten wenig oder gar nicht behaart. Yorderschienen mit mehreren Einzelborsteu der Vorder- und Außenseite; Tarsen verziert: Metatarsus selur lang, unterseits mit melleren Einzelborsten, die iibrigen Glieler an der Spitze leicht verdickt, das zweite Glied außerdem anf einer geringen Anselıwellung mit einer Reihe kurzer, krallenförmig gebogener Borsten. Miftelschienen auf der Auben- und hnenseite mit je einer Reilıe rou vier Einzelborsten; Metatarsus unten mit fiuf bis sechs kurzen Einzelbörstehen. Hintersehienen und Tarsen ohne besondere lieborstung, so dick wie die Sehiene, die drei letzten Glieder sehr kur und dentlich etwas verbreitert. - Vordertarsen um 1.6 mal lainger als die Schiene, diese nur wenig länger als der Metatarsus und letzterer um 1.S mal lainger als die ibrigen vier Glieder znsammen. Mitteltarsen $1.5 \mathrm{mal}$ so lang wie die Schiene, diese ebenso lang wie der Metatarsus und letzterer nieht ganz doppelt so lang wie die vier folgenden Ghieder zusammen. Hintertarsen so lang wie die Sehiene, diese un 1.6 mal länger als der Metatarsus, letzterer $1 \frac{3}{4}$ mal so lang wie die ibbrigen Tarsenglieder. - Fliigel wasserklar obne Zeichnung; Gabelader spitzwinklig, hernach rechtwinklig und kurz bogenfölnigg abbiegend; lintere Querader ziemlich senkrecht zur vierten Längsader.

$10^{7}$ aus Peru, Pachita-Miindung, $150 \mathrm{~m}$ hoch. 18. X1. 1903 [Schnnse] Sammlung des Dresdner IIusenms.

Anmerkung. Diese Arl acheint der coxalis Alul. nalie zu strhen. ist aliel Anrch lielle Vorlerhitten und andere Buinbebustumg abweichend gebilidet.

unifasciatus Say = Sciopus genus 
111 uniseriatus n. sp. ơf. 2 Figuren . . . . Peru, Bolivia

ơ. - Thoraxricken blangriin. Schwinger schwarzbraun. Taster, liiissel und Fiihler selowarz. Hinterleib schwarzblau bis messinggelh: Hypopyg klein, schwarz; äufere Organe lamellenförmig, zart behaart.

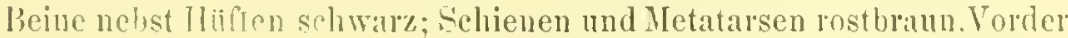
schienen auf der A ulienseite mit sechs bis neun längeren

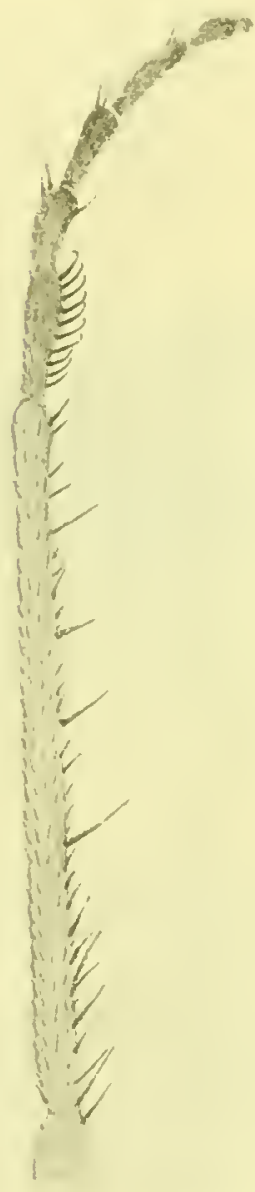

Fig. 1:37. Cundylostmhs muguines Beek. of. Tordertasen. 2.1 : 1 . Vorsten: Voudermetatarsus unten mit vier ljis funf kurzen Börstchen. Mittel. selienen auf der dußenseite der ganzen Lünge nacl mit steifen Borsten, grob gewimpert, Metatarsus hall, al ulen, latlb unten mit einer lieihe you etwa zwölf weit liutig gestellten Einzelborsten (s. Figur 13í). Die feine liewimperung, wie sie bei einer Reihe von Arten rorkommt, wie z. I), bei superfluus Schin, fehlt hier, anstatt deren sicht man, allerdings erst bei 00 facliel Vergriblerung, ganz kurze, fast knopfartige dicke borstenabiange in eincr lieilıe mehr nach unten, die sich als blattfürmig verbleiterte sehuppenförmige Organe darstellen. Hinterschienen und Tarsen fein und etwas ratub behart; letatere so dick wie die Sehiene nnd lic letaten drei Glieder. etwas verbreitert. Vorder tursen reichlich $1.5 \mathrm{mal}$ so lang wie die Schiene; Wetatarus ctwas läncer als

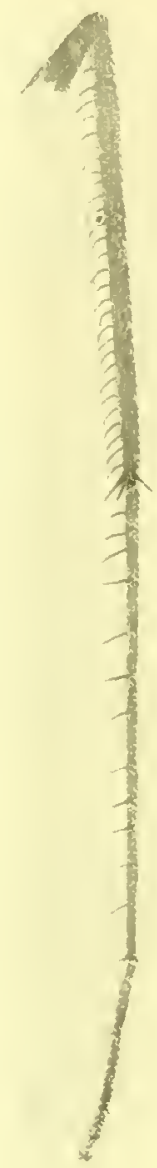

Fier 13: (int7ylout. whiseriatus lieck.

Mitteltrin. 41

diese und mehr als doppelt so lang wie die vier tibrigen Glieder zusammen. Mittelmetatarsus so lang wie die Sehiene und reichlich doppelt so lang wie die ibrigen Glieder. Hintertarsen kiil'zel als die Schiene, diese $1.8 \mathrm{mal}$ so lang wie del Metatarsus. - Ntigel mit Jer gewöhnlichen lramen bindenzeichnung: 
die beiden Binden, die vorne bis zur dritten Längsader verbunden sind, gruppieren sieb als breite Adereinfassungen und sind soweit zusammengeflossen, da $B$ in der ersten Hinterrandszelle ein rundlicher Fensterfleek iibrig bleibt, der weder die dritte noch vierte Läng cs. ader bertihrt; die Gabelader zeigt in ihrer Biegung spitze Winkel; die Querader steht nur wenig schräge. $6.5 \mathrm{~mm}$ lang. (S. Figm 139).

\&. - Alle Schienen, aueh die Hinterschienen sind gelb; die Beinbeborstung ist der des $\sigma^{7}$ ahnlich, nur die Mittelschienen haben anstatt der Borstenreihe der Außenseite einige Einzelborsten.

12 б, 32 q aus Bolivia-Mapiri, 31. X11. 1902. S. Carlos $800 \mathrm{~m}$ boeh; Peru, Chanchemayo, 15. I. 1904 [Schnuse] Sammlung des Dresdner Muselums.

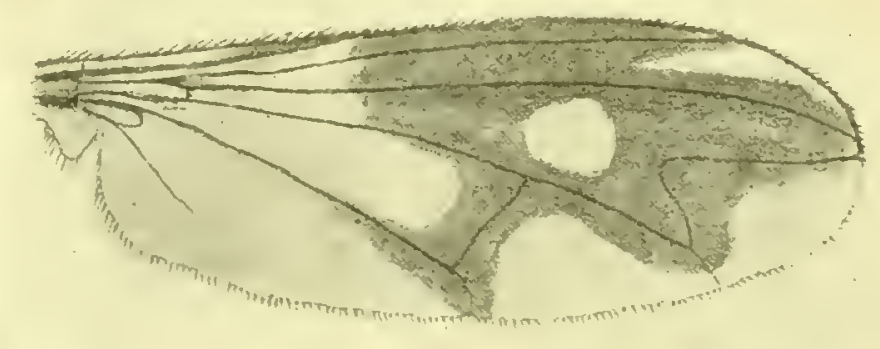

Fig. 139. Condylostylus uniscriatus Beck. ơ. Flügd. 12:1.

111 a C. uniseta n. sp. o.

Diese Art zeiehnet sich im männlichen Geschlecht dadurch aus, daß der Vordermetatarsus anf seiner Unterseite eine stäkere Einzelborste triigt.

o. - Thoraxidicken und Schildchen ron der gewöhnlichen blaugrimen Fỉrlung und Beborstung. Kopf: Stime glinzend griu, fast messingfarbig. Fiihler schwarz mit Borste ron gewöhnlicher Liinge. - Hinterleib metalliseh griin ohne besondere Abweichungen in Farbe und Beborstung. Hypopyg metallisch schwaz mit zwei kurzen schwarzbraunen stabförnigen, horizontal vorgestreckten Anhängen. - Beine: Hiiften und Schenkel schwarz, jedoch sind die Vorderhiiften an ihrer Spitze gelb; Schenkeispitze, Schienen nelst Metatarsen der vorderen Beine gelb. Alle Schenkel sind anf ihrer Unterseite ziemlich weithufig weiß behart; Vorderschienen auf ihrer Außenseite mit drei Einzelborsten, die an deu ersten Zweidritteilen ler Schienenlinge gleichmißig verteilt stehen; der Vordermetatarsus trägt auf seiner Unterseite im letzten Viertel eine deutliche Einzel. borste. Mittel- und llintersehienen sind weder eharakteristisch be- 
wimpert noeh beborstet. - Fligel mit zwei braunen bis zur dritten Lïngsader reichenden Querbinden; die rierte Lïngsader ist anch etwas braun umsäunt, so daß in del ersten Ilinterrandszelle ein heller eingeschlossener Fleck entsteht. Die Randader hat eive deutliel abstehende kurze Bewimperung. $5-6$ mm lang.

Sammlnug des Deutsehen entomologisehen Instituts Berlin-Dahlem.

112 vagans n. sp. $\sigma^{\top}$. . . . . . . . . . America merid.

\%. - Thoraxriieken und Schildeben blau. Selnwinger bram. Kopf mit sehwarzen lłihlern; das zweite Finhlerglied lang beborstet, Fühlerborste subapikal, nicht lïnger als der Thorax. Hinterleib bronzefarbig mit sehmalen mattsehwaren Querbinden. Hypopyg schwarz, annäbernd von gleielrer Größe und Form wie bei nubeculus mit langen schwarzen Haaren am letzten Ringe und am Banche in der Gegend des vierten Stemits. Beine und Hiften fast ganz schwarz, nur die vorderen Schienen rostrot. Vordersehienen auf der Vorderoder Oberseite mit drei bis vier langen Borstenlataren, Vordertarsen nackt. Hittelschienen mit einigen wenigen Borsten an mehreren Seiten, die aber nur sehwach und nieht reihentörmig entwiekelt sind, Metatarsus nackt. Hintersehienen außer der kurzen Beharung nit drei his viel" liingeren Haaren, Endglieder der Tar'sen nieht verbreitert. Vordertarsen um 1.7 mal länger als die Scliene, diese fast solang wie der Metatarsus und letzterer um 1.75 mal länger als die vier folgenden Glieder zusammen. Hitteltarsen fast $1.5 \mathrm{mal}$ länger als die Sebiene, diese etwas liinger als der Metatarsus und letzterer um 1.4 mal länger als die iibrigen Glieder. Hintertarsen so lang wie die Scliene, diese um 1.8 mal länger als der Metatarsus und letzterer um 1.25 mal länger als die vier folgenden Glieder. - Fliigel glashell mit schwachen Selattenflecken an der Spitze des Vorderrandes ibnlich wie bei mbeculus.

2 o aus Costa Rica, Sarubres nud Higuito-San Mateo [Schild]. Sammlnng des Ungariselsen Nationalmusenms. variegatus Lw., N. Beitr. VIII 95 (1861) et Monogr. II 278 (1864).

Ist nach einem Exemplar del Winthem schen Sammlung ein Sciopus.

113 veliformis n. sp. of . . . . . . . . . . Pelll

5. - Thoraxirieken und Sehildehen rein veilehenblan. Schminger hellgelb. Riissel, Taster und Fühlel schwarz, das zweite Fiihlerglied mit langen Randborsten, Fiblerborste etwas subapikal. Hinterleib blau mit dunklen Querbinden und langen Randborsten. Hypopyg klein, scbwarzbraun mit einigen sehr langen Borstenharen; äuljere Anhïnge gelb, kelchförmig zusammengesehlossen, auf einer Seite beborstet. Beine: Schenkel mit Hiiften schwar, Schienen mud Tarsen gelb, Ilintertarsen etwas brann. Vordersehienen auf der Vorder-oder Oberseite mit drei bis vier sehr langen Borsten; der Metatarsus ist bei 
grofer Länge im gewöhnliehen Sinne des Wortes (unter der Lupe beselıen) nackt, nimmt man aber das llikroskop zur Hand, so sielit man aul del Unterseite eine selı feine und kurze Bewimperung wie den Antanw eines Schleiergewebes (s. ligur 140). Mittelsehienen mit zwei bis drei kraftigen Borsten auf der Oberseite. Hinterschienen und Borsten fast nackt. Vordertarsen $n$ m 24 mal linger als die Schiene, diese um 1:3") mal

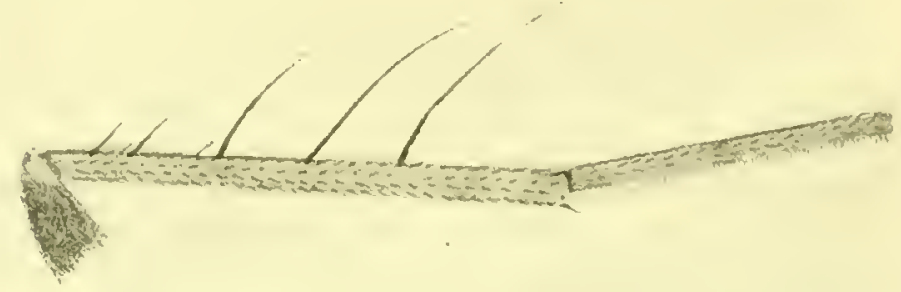

lig. 140. Condylostylus valiformis Beck. OF. Vondershiene. 24:1.

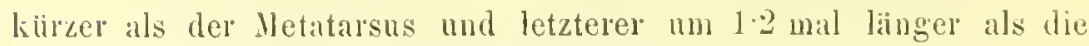
vier folgenden Glieder zusammen. Mitteltarsen kanm länger als die Schiene, diese dopjelt so lang wie der Metatarsus und letaterer so lang wie die vier folgenden Glieder. Hinterschienen lang (Tarsen zum Teil abgebrochen). Fligel wasserklar ohne Fleekung; erste Iäingsader bis zur liligelmitte reielend; Gabelader spitzwinklig

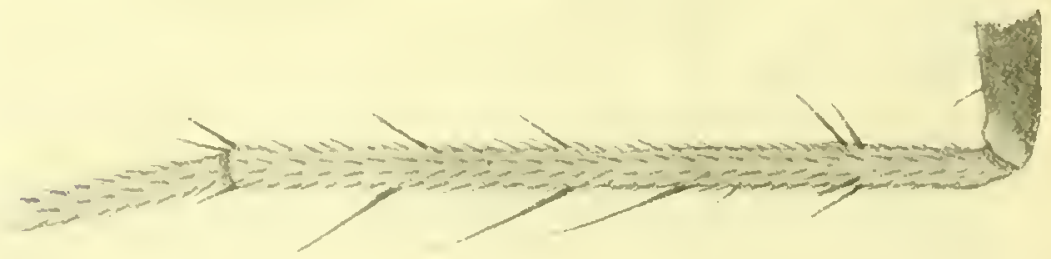

Fig. 141. Condylostylus reliformis Beck. O7. Mittelsehiene. 24: 1

(nngelähr nu $60^{\circ}$ ) aluzweigend, nachher reehtwinklig bogenförmign zur Spitze lanfend. 4 mu lang.

Q. - Die Behorstung der Beine ist der des ơ durchaus aihnlich; das Gesielıt ist gan\% gram bestiubt, sonst keine Untersehiede.

8 8, 7 q aus Pern, Pachita-1lindung $150 \mathrm{~m}$ loch 18. XJ. 1903; ans Peru, lleshagna, Urubambafi, 3. X. 1903 [Schnuse] Sammlnng des Dresdner Museums. 
vigilans 11 . \$p).

Brasilia

Eine der busiluris Wied. nalse stehende Art, aber kleiner und mit anderer Fligelzeichnung sowic Hintertarsen.

O. - Thorax stahlblan; Sebrvinger blaßgelb, Brustseiten aschgrall. Kople mit gelben Fiihlern. Stime und Gesicht asehgrau bestiubt, letzteres verlältnismäßig schmal. Ilinterleib metallisch schwarzgrin mit granen llinterrandsbinden. Ilypopyg klein, selawarz mit ziemlieh gleich breiten linglichen, schwirzlichen behaarten Anhingen. Beine und alle Hiiften blaligelb, einfach ohne besondere Beborstung; Hintertarsen sowie die Endglieder der vurderen sehwarz. Vordertarsen $1 \%$ mal so lang wie die Sebiene; Mitteltarsen ungefihl von gleicher Lïnge wie ihre Schiene; Hintertarsen erheblich kiirzer, letztere sind ron gleicher Dicke wie die Schiene und ihre letzten Glieder noch ein wenig verbreitert. - Fligel ron schwach gelbbraunlicher Triilıng' mit zwei selu schwach ausgebildeten bramnen Querbinden, die au Vorderande nur bis zur zweiten Lingsader mit einander verbunden sind. 5 mm lang.

1 o aus Brasilien, Blumenau [Lothar Hetsehko]. Aammlung des Wiener zoologisehen Hofmuseums.

violuceus Hacq. O", Dipt, exot. II. 2.118.10 tab. XX fig. 3 [Psilomes] $(19+2)$

૧. - Schwarze Fihhler und Beine. Schwinger gells. Flitgel mit ansgedehnter Briiunung an Vorderrande unl in Verbindung lamit breite Sïnmung der Liings- und Queratern, so dall die Bindenzeiehnung der Figur nach nicht dentlich zum Auschnck gelangt. $2 \cdot 1$ Linien lang.

Die Art ist zum Erkenuen ungenijgend charakterisiert. virgo Wied. क, Aubereurop. zweifl. Ins. II 224. 24 [Psilonus] (1530)

Ameriea

Diese nur in einem Weibchen von Wiedemann beschriebene Art ist höchst wahrscheinlieh identisch mit candatus Wied; siche meine Bemerkungen bei comdutus.

115 biseta $11.81 \% \cdot 0^{7}$

5. - Thoraxriieken und Schildchen metallised griin bis blan unit fiuf Paar Dorsozentral- und drei Paal Akrostikalborsten. Schwinger, Schiippehen schwarzbram, letztere mit starken sehwarzen Wimpern. - Kopf blau, Gesicht weif. Fiihlel licin, schwarz, zweites Glied unten lang beborstet, Fühleriorste so lang' wie del 'Thorax. Rüissel und Taster rostbram. - Hinterleils gringold mit mattsehwarzen Vorderrandshinden, mailige lang schwarz behart und beborstet. Iypolyg sehwallzbraun, die außeren Organe in zwei große, am Rande hehat te Sehafeln auslaufend, welehe spitz endigen. - lieine mit allen Hiiften schwar, nur die Vorder- wie die Vlittelschienen sind rostgelb bis rosthraun. Die Schenkel sind auf ihrer Unterseite etwas 
weitlianfig kannuartig schwar" und weib belaart. Vorderschienne anf der Ober- und Unterseite mit etwa zwei zarten Einzelbörstehen. Vordermetatarsus so lang wie die Schiene, auf der Außenseite außer einer zarten Borste an der Basis mit zwei Einzelhorsten auf ilırer Mitte; das zweite Tarsenglied ist nieht länger als das dritte nud unterseits kurz kammartig hewimpert. Mittelsehienen mit melreren doppelt gestellten Einzelhorsten. Hinterselienen außer der Bewiunperung ohne Einzelborsten. - Fliigel etwas grall mit zwei am Vorderrande verbundenen, sehwaeh ansgebildeten nud nieht seharf begrenzten ranehgranen Querbinden; Galelader spitzwinklig nach riiekwïrts, lernach knieförmigg abbiegend und zur Fligelspitze lanfend; hintere Querader gerade und nur wenig sehrige zur vierten Liingsader gestelit. $4 \mathrm{~mm}$ lang.

10 von den Cordilleren ans Columbien, terra ealiente [Thieme S.] Sammlung des lierliner zoologiselıen Museums. 


\section{Nearktische Region.}

\section{Condylostylus Big. (1859).}

Als ich diese Gattung in der neotropischen Region behandelte, hatte ich, nu die Schwierigkeiten der Ordnnng angesichts des Artenreichtums nieht zu vermehren, die nearktischen Arten ausgesehieden und labe letrtere daher noeh besonders zu behandeh, was naehstehend erfolgen soll. Man ersielıt aus dereu geringen Anzahl im Verhältnis zu den neotropisehen, dalf diese Gattung ganz eigentlich tropisehen Ul'sprungs ist.

\section{Artverzeichnis.}

albicoxa Wakk. ơ List Dipt. Brit. Mus. III (65) [Psilopus] (1841).

Die Besclueibung ist unkemntlieh.

1 calcaratus Lw. of, N. Heitr. N11I 93. 10 (1861) et Monogr. Dipt.

N. Amer. II 27:. 13 [Psilopus] (1864).

Hijften und Sehenkel sehwarz, vordere Kniee und Sehienen gelb. Spitze der Mittelschienen mit langer spornatigel Borste; Mittelmetatarsus nicht mit gekriimmten Borsten auf der Unterseite, sondern nu* mit einigen wenigen geraden Börstehen. Gesicht lang behart. Fliigel wasserklar ohne Fleckung. $3-3.5 \mathrm{~mm}$ lang.

Anmerkung. In der ,caudatus -Gruppe am nächsten der Art scobinator; lie Unterschietle bestehen in anderer lewehrung des Mittehmetatarsus.

curatiniensis Big., Ann. Soc. Entom. Fr. sér. 6. VIll Bull. XXIS

[Psilopodinus] (1S68).

Unkenntlieh besebrieben.

2 coudatus Wied. OTQ, AnRereurop. zweifl. Ins. 11 224. 23 (1830).

Siebe die Besehreibung und 'l'abelle fiar die neotropisehe Region.

3 chysopretsius Walk. ơ, List Dipt. Brit. Mus. III 646 (1849).

ciliipes Aldr., Biolog. Centr. Amer. Dipt. I :355. 6. tab. VI fig. 22

(1901).

ciliipes $=$ chrysoprasius Walk. var.

3 comatus Lw. ơ , N. Beitr. VIII. 89. 7 [P'silopus] (1861).

Siche Besehreibung und Tabelle bei Behandlung der Gattung innerhalb der neotropisehen Region.

5 crinitus Aldr. O’?, Trans Amer. Ent. Soe. Pliilapelphia XXX 281, 283

[Psilopodinus] (1904). 
Alle IJiften und Sehenkel selıwarz; Schienen mit Ansualune der Spitze der Hintersehienen gelb; Hintertarsen ganz selıwar\%, die vorderen bräiulich. Vordersehienen sehr lang; Vordermetatarsus mit langen Haaren anf der Oberseite. Flügel wasserklar, jedoch mit einer sehwachen Verdunkelung an der Spitze des Vorderrandes. llintere Querader selur schriage gestellt. $4-4.5 \mathrm{~mm}$ lang.

(i) debilis n. sp. o

Mit hirsutus m. verwandt, aber dureh kiirzere und weit sehwieliere beharmng und Beborstung an Beinen und IInterleib sowie durch andere Anallamellen und kirzere T'arsen abweichend gebildet.

o". - Thorax mit der gewöhnlichen Färbung. Stirn und Gesicht glänzend hau, sehr breit; letzteres stark gewölbt, nackt, nur der unterc dureh eine Querfurehe al)gegrenzte 'Teil ist etwas weif bestäubt. Fiiller und Taster sehwarz. - Ilinterleib nelı grimlich mit Randborsten nicht lïnger als die Ringe dick. Hypopyginn klein mit etwas dieken bräunlichen Anliängen, deren Form bei dem einzigen vorliegemlen Exemplar nicht deutlich erkenulsa ist, jedoch sielıt man mit ilmen verbunden zwei starke, krumme, dornartige Borsten; die langen Iaaro :m IIypopygium wie hei hirsutus fehlen. - Beine: Jiuften und Sehenkel selwarzbraun, Kniee, Sehienen und 'arsen bis auf die Endglieder der Hinterbeine ganz gell). Die Schenliel haben auf der Unterseite nur eine schwache weiße heharung. Vorderscbienen auf der (Oberseite mit vier allmällilich lïnger werdenden Borsten, von denen die letate im zweiten Drittel die lingste ist. Vordertarsen $1 \frac{1}{2}$ mal so lang wie ihre Schiene; Metatarsus oherseits mit sieben bis acht weitlautig gestellten Jorsten; die iibrigen 'Tarsenglieder sind olne Beborstung. Mittelsebienen oberseits ebenfalls nit drei bis vier Borsten in gleiclier Anorinung wie an den Vorterbeinen. Mitteltarsen 1\% mal su lang wie ille Sehiene. Hintersehienen nul sehr zart hehart und beborstet. - Fliigel farblos; Randaler olne lingere Viupern; die elste längsader reicht fast bis zur. Mitte; Gabelader und lintere Queraler genan so im Verlanfe wie bei hirsulus, die ich ans Brasilien besehrieben. $4.5 \mathrm{~mm}$ lang.

1 Exemplar aus Gengia [Horrisun] in der Sammlung des Wiener Jofunsenms.

- delicutus Walk. q, list Dipt. Brit. Mus. 11 I 645 (1849).

Unkenntlich besehrieben.

7 diffusus Wied. ơ, AuBereurop. zweill. Ins. II 2201. 17 (1830).

Siehe Beselureibung und Tabelle bei Behandlung der Gattung innerhali der neotropisehen liegion.

- femoratus Say o", Journ. Acad. Nat. Sei. I'hiladelphia III S6. 5 [Molichopus] (1823).

Diese Art konnte bislang nicht gedentet werden. Loew iunert siclı iiber Say's Besehreibung in den N. Beitr. VIIl 79 (1861); er stellt 
diese Art wegen der schwarzen Sehenkel des o und ller grelben Schenkel

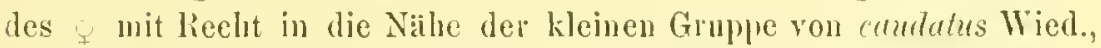
scobinator Lw. u. a. und meint, daß sie ohne Entdeekung einel mämnlichen Type in Wiedemann's Sammlung zweifellaft bleiben misse. In Wiedemann's Sammlung stecken vier kxemplare, aberalles Weibchen mit gelben lieinen, naeh denen Wiedemann offenbar seine liesehreibung gefertigt hat. Da wir also auch hier eine weitere Aufkliurung nicht erhalten, bleibt die Ant femorutus nach wie vol zweitellaft.

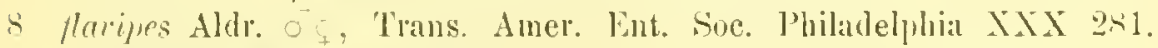
$28+$ [Psilopodinus] (1904).

Vorderhiiften, Sehenkel, Sehienen und rordere Metatarsen gelh. llintertarsen und Spilze der Hintersehienen schwärzlieh; letztere mit cinerstarkeu Borste ror der Mitte der Oberseite. Gesieht mit lingeren weißen IIatren. Hliigel wasserklar, Adernng wie bei caulutus Wied. $3 \cdot 6$ mm lang.

9 inemis Lw. Ơ, N. Beitr. VIII 98. 11 [7'sitopus] (1861).

Gesicht hehaat. Hiiften und Sehenkel sehwar, Spitze der vorderen Sehenkel und die Sehienen gelb; Spitze der Hintersehienen und Tarsen mit Ausnahme der vorderen Metatarsen schwarzbrinnlieh. Mittelsehienc ohne senkreeht abstehende Endborste, Metatarsus einfach. Fltigel wasserklar. $4 \mathrm{~mm}$ ling:

10 melumpus Iw. Oో f, Berlin. Lntom. Zeitsehr. V1215. 69 [Psilopus] (1862).

Siehe Beschreibung und 'Tabelle bei liehandlung' der Gattung imerbill, der neotropisehen Region.

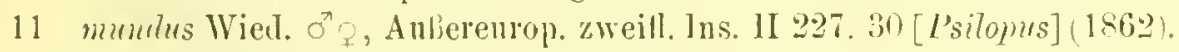

Siche lieselneibung wie vor.

nigrifemoratus Walk., List Dipt. Brit. Mns. 111650 (1849).

Der lieschreibung nach unkeuntlich.

necirlentrilis ligig., Ann. Soe. Ent. Fr. sér. 6 V'Hll Bull. XX]X [I'siloportimus] (1884).

Der Besehreilıng nach unkenntlich.

pallescens Big. o7, Aun. Sue. Entom. Fr. sér. 6 VIll bull. XXIX ['silnparlinus] (1858).

Unzureichend heschrieben.

12 putibulatus Say, Jomm. Acad. Nat. Aci. philadelphia III 87.7 [Holichopus] $1823 \%$

Siehe Beschreibung und Tabelle bei Behandlong der Gattung: imnerhalb der neotropiseben Region.

13 pilicomis Aldr. ơ 'Trans. Amer. lint. Soe. Philarlelphia XXX 279.

282 [Psiloporlinus] (1904).

Beine ganz sehwarz; Vordertarsen linger als die Sehiene: Vortermetatursus linger als die vier folgenden Glieder zusammen mit einer Reihe zarter Hare auf der loterseite und nalle der Spitze mit einigen kleinen borsten an dep Anlienseite, nnten an her Spitze mit emer 
kleinen Verbreiterung; das zweite und dritte Glied kur\%, gleich lang und unten ebentalls verhreitert. Mittelmetatarsus so lang wie die Sehiene, auf der Oberseite mit einer Reibe sebr zarter aufrecht stehender Haare, vornehmlich an der Wurzel. Fliigel mit zwei braunen Querbinden. 4-5̃ mm laug.

-- radians Macq. S. à Buff. I 450. 6 (1831).

Nicht melr zu denten, siehe meine Bemerkungen bei Behandlung der Gattung innerhaib der neotropisclien Region.

14 scuber Lw. O’, N. Beitr. VIII 85̄. 2 (1861).

Der Art sipho Say nahe verwandt; siehe die Unterschiede in der Bestimmungstabelle.

I5 scobinator Lw. Oै, N. Beitr. VIII 91.9 [Psitoms] (1S61).

Siehe Beschreibung' und 'Tabelle bei der neotropischen Region sowie die nachfolgende Bestimnungstabelle.

li; sipho Say, Journ. Acad. Nat. Sci. Philadelphia 11I. 84 [Dolichomus] (15:3).

Siehe Besehreibung und Tabelle bei der neotropiselien Region.

- ungulicena Walk., Trans. Entom. Soe. London n. ser. IV. 149 (1857).

Unzureichend bescbrieben.

- virgo Wied. Außeremop. zweifl. Ins. I1. 224. 24. (18:30).

Diese Art ist höchstwalurscheinlich das Weibchen ron camdutus Wied. ठౌ.

17 rividicoxa Aldr. ơ, Trans. Amer. Entom. Soc. Philadelphia XXX 281. 284 [Psitopodimus] (190j).

Vorderiliften schwïrlichgran, nur die Spitzen gelb. Sehenkel und Schienen gelb, Vorder- und Mitteltarsen von der Spitze des ersten Gliedes an gebriunt; Hintertarsen ganz bran. Vorderschienen an der Außenseite (Hinterseite) mit einer Reihe ron fün his sechs kleinen Borsten. 6.4 $\mathrm{mm}$ lang.

Restimmungstabelle fïir die neatrktischen Arten der (iattung" Condylostylus liig.

1 Schenkel alle rotgelb . . . . . . . . . . . . . . 2

- Schenkel alle schwarz . . . . . . . . . . . . . . 7

2 Flitgel glashell ohne Flecken. . . . . . . . . . . . . a

- Fligel mit zwei bramen, am Vorderrande verbundenen Querbinden 4

3 Gesicht mit längeren weifen Haaren. Hinterschienen anf der Oberseite dielit ror der Mitte mit einer stiirkeren Borste. 35 nm lang.

flacipes Aldr. O?

4 Gesicht nackt. Fliggelquerbinden am Vorderande bis zur dritten Längs ader verbunden.

5. Vorderliuften gelb 
- Vorderbiften schwïmlich. Vordersehienen an der Außenseitc mit einer lieihe ron finf bis sechs kurzen Borsten. $6.4 \mathrm{~mm}$ lang.

riridicoxa Aldr. Ofo

6 Mittehmetatarsus mit einer lieihe anfrecht stchender Ilaare auf der Obesseite. $6 \mathrm{~mm}$ lang . . . . . . . . . . . . scaber Lw. 0

-- Mittelusetatarsus einfach. $6 \mathrm{~mm}$ lang . . . . . . sipho Say o

7 Flïgel ganz glashell ohne Flcckung oder Zeichnung . . . . 8

- Fliigel glashell, aber mit einem granen Schattenflecken an der Spitze des Vorderrandes . . . . . . . . . . . . . . $1 \%$

- Fiigel mit zwei braunen, am Vorderrande bis zur dritten Längsader verbundenen Querbinden . . . . . . . . . . 15

\& Gesicht lang behaart . . . . . . . . . . . . . . 9

- Gesicht naclit . . . . . . . . . . . . . . . . 12

9 Mittelschienen an der Spitze der Unterseite mit einer langen, senkipeht abstehenden Borste . . . . . . . . . . . . 10

-- Mittelschiene ohne solehe Borste. Mittelmetatarsus einfach inermis Lw. o’ $q$

10 Mittelmetatarsus auf seiner Unterseite mit zwei Reihen gekrimmiter Borsten . . . . . . . . . . . . . . . . 11

_- Mittelmetatarsus auf seiner Unterseite nur mit wenigen geraden Börstchen. $3-3.5 \mathrm{~mm}$ lang . . . . . . . . . calcuratus Lw. O’

11 Letzter Hinterleihsring am Rande mit schirmartig gereihten langen Borsten. $3 \mathrm{~mm}$ lang . . . . . . . . caudatus Wied. o

Letzter Hinterleibsring obne lïngere Borsten. $4 \mathrm{~mm}$ lang scobinator Lw. Or

12 Vorder'andzelle des Fliggels lang, bauchig vortretend, die ganze Vorderrandsader lang und fein bewimpert. Yordersehienen und Vordertarsen lang bchaart; zweites Glied der Vordertarsen selı ku\%, nicht lïnger als breit. $5 \mathrm{~mm}$ langr . . . . . . . mundus Wied. o

Vorderandzelle fast bis zur Fligelmitte reiebend, einfach. Torderrandsader ohne längele Wimpern. İlittelschienen und Metatarsus einlach. Vorderschienen und Metatarsus anf ihrer Oberseite mit vier, bezüglich sieben bis acht lingereu Borsten. $4.5 \mathrm{~mm}$ lang . debilis $11.51 . \sigma^{7}$ Vorderrandzelle kurz, einfach: die Fliigehandader nicht lang bewimpert. Mittelschienen außen mit finfzehn bis sechzehn Borsten kammartig besetzt. Mittelmetatelsus nebst dem zweiten Gliede fein kammartig bewimpert. 4-5 mm lang. . . . . . . chrysoprasius Walk. of

13 Nittelschienen anßen kammartig beborstet. Mittelmetatarsus und das zweite Glied fein kammartig bewimpert. $4-5 \mathrm{~mm}$ lang

clerysoprasius Walk. val. citiines Aldr. O

Mittelschienen nicht kammartig beborstet. Vordermetatarsus oberseits mit etwa 10 langen Borsten... . . . . . . . . 14

14 Auch del Mittelmetatarsus oberseits lang beborstet. 4 mm lang comatus Lw. ơ? Mittelmetatarsus mackt.. 4-4.5 $\mathrm{nm}$ lang . . . rrinitus Aldr. of

1) Beine ganz schwarz . . . . . . . . . . . . . . . 16 
- lieine schwar\%, Vorderschienen und 'Tascu rustgelb. Yorder- und Mittelsehienen anf ihrer Oberseite mit lingeren Borsten beserzt. $6 \mathrm{~mm}$ lang . . . . . . . . . . diffusus $\sigma_{+}$. Wierl.

16 Gesicht nackt . . . . . . . . . . . . . . . 17

- Gesicht lang behary. Sohienen nur mit Einzelhorsten, nicht reihenfirmig beborstet. Vordermetatarsus an der Spitze mit schwirzen liorsten. 5 mm lang . . . . . . . . putibulatus Sily o

17 Flitgelrorderrand nicht sehr lang; aber deutlich fein bewimpert. Vorderschienen anßen mit vier bis linf, Vordermetatarsus anßen mit sieben bis zehn langen Borsten. 5-6 mm lang . . Melumpus Lw. OTf

- Fliigelvorderrant olme hesondere Bewimperung; zweites Fiihlerglied besonders lang und stark leborstet. Vordermetatarsus nuterseits lang behart und an der Spitze etwas verbreitert; zweites nud drittes Tarsenglied kurz, weich lang mol anch etwas verbreitert. 4-5) mu lang. . . . . . . . . . . pritirornis Aldr.

\title{
Sciopmis Zeller.
}

\author{
Ixis .1 I 8:1. 14 (1842).
}

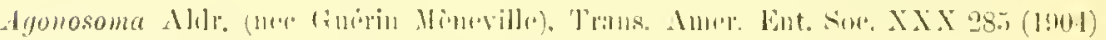
(.) ('it:al. (I905).

Amblypsilonus lig., Amı. Sire. Ent. I'r. 269 (18:0).

Ginemptopsilopus Alilr., Linssis l'nis. Guart. II IS (1893).

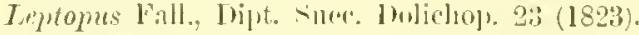

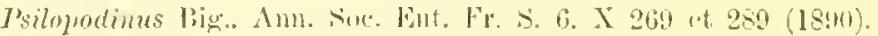

I'silopedius Rund., Mijut. Ital. I'rentr. IV. II (1801).

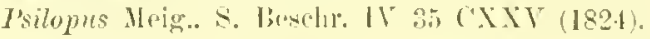

Die Gattung Scimms, die in der paliarktischen Region als einzigster Gattungsvertreter der Gruppe der Grysosomatinae stelat, scheint iilrer die ganze $W^{r}$ elt, wem auch in verschiedener Ausdelınung und Anzahl verbreitet zu sein. In der nearktischen Region ist sie neben der sidamerikanisclen Gattung. Comlylostylus Big: immerhin noch die dominierende Gattung. In Siidanerika besteht das umgekehrte Veshiilunis. Aldrieh in der biolog. Centr. Amer. Dipt. 1901 fijhrt mus 15 Arten ron seciopns ror, die in Zentral-, Nord- und Sildamerika bis dahin gefunden worden; eine 1 li. flaricomis beschrieb er allerdings nur als Weibchen ans St. Vincent hereits iu Jahre 1896. Was ich in ten rerschiedenen Sammlungen sonst noeh halue entdecken kimmen, ist nicht allzuviel.

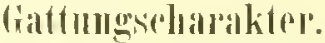

Wir wissen ans den Frörternngen tiber diese Gattung innerhalh der paliarktischen Region, daß sic eharakterisiert ist anßer dureh besondere Lopffom und llabitus zum Unterschiede von den anderen Gattungen dieser Gruppe durble eine dorsale Fibhlerhorste, mit nur zwei Sohildborsten und 
dureh weiße Wimpern der Schiippehen. In dep paläarlitischen Zone simd diese Merkmale durehaus konstaut, nieht ganz so in der nearktischen und neotropischen Region; die Faibung ler Wimpern und die Anzahl der Sehildborsten erleiden Schwankungen mod Ausuahmen, mit denen wir uns abzufinden haben. lis sind Ubergangsformen, die wir als sulche bewerten missen, besondere Gattungen dalaus zu bilden wiile mangebracht.

\section{Bestimmunnestalloelle.}

1 Fiihler ganz sehwarz, Schenkel gelb . . . . . . . . . . o Fiihler ganz gelb, wenigstens die beiden ersten Glieder gelh . . 5

2 Fligelvorderiand bewimpert, Randader verdickt, an knde der \%weiten Lïngader mit einem Haken und Einsehnitt und hier mit eingen lïngeren Haaren. Hinterleil, an der Basis gelb. licine nnd Hiffen gelb, nur die Vittelhiiften an den Seiten grau. $3-t$ mm lang custulis Aldr. of

Fligelyorderand nieht bewimpert. Hinterleib an der Basis nicht geelb :3

3 beine mit allen Hiaften gan\% blaßgelb; Vorderbeine sehr diinn; Vurdertarsen dreimal so lang wie dic sehiene; viertes 'T'arsenglied an der Endhilfte weiß, das fünte sehwar nnd rerlueitert. 230 mu lang . . . . . . . . . crpillimanus Enderl. ơ

Beine mit Vorderhisften gelb, Mittel- und Ilinterhiffen grau . . +

+ Fltigel mit einem großen am Vorderande liegenden schwarbramen Flecken, dessen Grenze bogenfirmig und parallel zur hinteren Querader verlïuft. $6 \mathrm{~mm}$ lang . . . . . . . muculu Wied. ठ

Fligel theckenlos, Gabelader reehtwinklig abzweigend. $: 5 \overline{0}-4 \cdot \overline{5}$ mm lang o. . . . . . . scintillens liv.

Fligel mit zwei brannen, an Vorderande verbundenen Querbinden. llinterschenkel und llintersehienenspit\%e nicht gebriant, Hintersehienen olue branne Binde. $5-5.5 \mathrm{~mm}$ lang gratiosus u. sp.

Fligel mit zwei hramen, nicht rerbudenen Querbinden. Hinterschenkel :In der Spitze, ein liing an den Hinterschienen und die Spitzenhiilfte derselhen lram. $t$ mm lang. . . . . . lectus n. sp.

5) Thoraxrielsen gelt) mit eineu hlangriinen Mittelstreifen . . . i Thoraxrieken ganz ron metallischer liabmog . . . . . . . 7

(i) Mittelschiene und Metatarsus mit zwej Reihen anfrecht stehender Wimperu. Tordersehenkel unterseits an der Basis mit sechs km\%en dornartigen borsten. Vordertarsen fast 3 mal so lang wie die Sehicue. $4-5 \mathrm{~mm}$ lang. . . . . . . . . . flacidus Aldr.

Torderschicne oberseits an der basis mit einor Einzelborste; Metatursus nebst den folgenden Gliedern oberseits bewimpert; drittes, viertes und finftes Gallied mit einer Endhorste. $3 \%$ mm lang

$$
\text { strintionllis n. sp. }
$$


Alle Sehienen und Tarsen ohne hesondere Bewimperung und Beborstung dorsalis Lw. on

7 Eligelvorderrandsader ausgebuebtet und wit einer rortretenden Eeke an Ende der "zweiten Läugsader . . . . psitlacinus Lw. O’

- Fligelvorderrandsaler nicht ansgebuchtet und ohne vortretende Eeke, aber bewimpert .

- Fligelvorderrandsader einfach, nielit bewimpert

is Hinterleib metallisel gefirlbt, olme gelbe Ringe oder Flecken. Mittelund Hinterhiiften grau. $4 \mathrm{~mm}$ lang . . . . castus Lw. O

- Der zweite Hintelleibsring an den Seiten gello. Mittel- und IIinterhitiften gelb. $6 \mathrm{~mm}$ lang . . . . . . . variegatus Lw. o

9) llttel- und Hinterlibften grau. Ilinterleib ohne gelb gefleckte Ringe 10

- Mle Hiften gell. Hinterleib mit mehr orler weniger gelb gefleckten lingen . . . . . . . . . . . . . . . . 11

10) Zweites Filhlerglied mit gelben Börstehen. Sehienen besonders lang, fadenförmig. li-7 mm lang. . . . . . . . . filipes $\mathrm{Lw}$.

- Zweites Fiblerglied mit sehwarzen Börstehen. Thoraxrielien matt bestäubt. Mittelschienen mit kurzen abstehenden Börstehen. 4-5 $\mathrm{mm}$ lang . . . . . . . . . . . . . pallens Wied. o’

11 Alle drei liblerglieder gelb . . . . . . . . . . . . 12

Drittes Fiblerglied bram bis schwarz . . . . . . . . . 14

12 Selır kleine Art von 1.5 mm Länge . . . . flacicornis Aldr. of

- Gröbere Arten von 5 mm Lïnge . . . . . . . . . . . 1:

13 Vordertarsen dreimal so lang wie ihre Schiene antennatus n. sp. ठ

- Vordertarsen nu etwa 1.6jual so lang . . . . unifusciutus Say. o

14 Vordersehenkel unten an der Wurzel mit drei gelben Borsten. 4 mm lang . . . . . . . . . . . tener Lw. $\sigma^{7}$

- Vorderschenkel unten ohne borsten . . . . . . . . . . 15

15) IInterleib an den ersten vier Ringen ibberwiegend gelb, nur mit schwachen grinen llinterandsïumen, die beiden letzten Ringe ganz metalliseh gefiirbt. Mittelschienen mit schwachen Wimperbörstchen. $34 \mathrm{~mm}$ lang . . . . . . . . . . rotundicens Aldr.

- Hinterleib iberwiegend metalliseh gefarbt, nur am ersten und zweiten Ringe gelb. . . . . . . . . . . . . . 16

16 Baneh und der erste llinterteibsring gelb. Beine borsteulos, aber die Hittelsehienen mit etwas abstehenden Börstehen; Fußgelenke del Nittelbeine etwas gebräunt und verdiekt. Gabelader in weitem Abstande von der dritten Laingsader und fast parallel verlaufend. $4.5 \mathrm{~mm}$ lang . . . . . . . . . noditarsis n. sp. o

Die beiden ersten linge nit selben Seitenflecken, Mittelbeine einfach; Gabelader wie gewiilnulich konvergierend. $4 \% 5$ mm lang. 
- Beide ersten Hinterleibstinge zum 'Teil gelb Beine einfach. Yor= dertarsen reiehlieh $1 \%$ mal so lang wie ihre Sehiene; dritte Läingsader rorne stark gebogen; hintere Qneraler sehräge und S-förnign gebogen. $5 \mathrm{~mm}$ lang . . . . . . . unifusciutus Sily. ô

\section{Artrerzeichnis, symonymie mud leschreibungen.}

angustatus Enderl. $q=$ scintillans Lw.

antennatus $11 . \mathrm{s} p .07 \%$ Peru

б. - 'Thoraxrijeken azurblau, nur vorne etwas bereift; vier' Dorsozentralborsten und nur zwei starke Gchildborsten ohne Nebenbörstehen. Seltippehen mud Schwinger gelb, erstere braun gesäumt, zum 'leil mit hellgelben, zum 'Teil braunen Wimpern. Riissel, 'Tistel' und Fiihler gelb. Hinterleib goldgriin mit etwas dunkleren Vorderrandsiamen und sehwachen liandborsten; der erste Ring blau mit längeren Borsten; zweiter ling an den Seiten und am Banelie gelb. Hypopyg mit sehmalen stielförmigen, an der Spitze linger behaaten gelbbrannen Anhängen. Beine nebst Hiiften ganz gell, ohne besondere Borsten, Tarsen nach der Spitze zu allmilhlich verdunkelt. 'T'u'sen der Vorderbeine sebr lang. Teh messe hei zwïlfficher Vergrößerung die Liingen wie folgt:

Vordersehiene 30, Metatarsus 55, die ijbrigen Glieder $35 \mathrm{~mm}$. Verhiiltnis der 'Tarsen zar Sehiene wie $3: 1$.

Mittelschiene 52, Metatarsus 44, die iibrigen Glieder $30 \mathrm{~mm}$.

Dic Mitteltarsen sind also niebt ganz $1 \frac{1}{2} \mathrm{mal}$ so lang wie ihre Schiene. - An den Fliggeln zweigt die Gabelader reehtwinklig ab, um anf der Vitte eine stmmpfwinklige Biegung anzunehmen; die hintere Querader liegt schrige, nm ihre eigene Lainge ron der Gabelader entfernt. $5 \mathrm{~mm}$ lang.

Anmerkung. Ínsere Art lat zweilethos grobe Ähnlielakeit mit unifasciatus Say, aber al,gesehen ron der wesentlich alweichenden köperfirbung sind the Lingenvrhibiltnisse der Beine ganz andere, da die Tarsen an den Vorderhinen

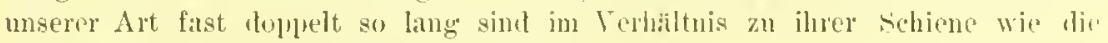
Turdertarten bei unifresciatus. $4.5 \mathrm{~mm}$ lang.

bicolor Lw. $q=$ unifusciatus Say.

2 capillimanus Enderl. O', Zoolog. Jahrb. Suppl. XV, 1. Band [L'sitopus] 40.2. tig. $B,(1, I)(1812)$. . . . . . . . . . . . Brasilia

Auf dem Schildchen stehen dentlieh nur zwei starlse landborsten und die Wimpern der Sehitppehen sind weib, die Art gehört also zur Gattung Séciopus Zell.

రౌ. - Sehwarzblau. Fibller sehwar\%. Hinterleib schwarzgriin, sehr schwach beborstet. Analanbïnge gelb, schlank, zangenfömig znSamnengrebogen. Jeine mit allen lJiften blaßgelb, nackt, die drei letzten 'Tarsenglieder loraun. Vorderbeine selı' diinn unt Jang; die 
'latsen sind dreimal so lang wie die Schiene, der Metatarsus zweimal so lang wie diese nud anch wie die vier ïbrigen Glieder zusammen; das vierte Glied ist an der Eudhällte weih, das fünfte schwar und rerheitert (s. die Fig. (' bei Enderlein I. e.). Bei zwölfacher Vergrößerung messe ich die Lingenverhiltnisse an den Beinen wie folgt:

Vorderschiene 40, Metatarsus 80, lie iihrigen vier Glieder $40 \mathrm{~mm}$. Verlialtuis wie $40:(80+40)=1: \therefore$.

Mittelschiene 50, Netatalsus 50, die iibrigen vier Glieder 40 mm. Verhailnis wie $50:(50+40)=1: 1 \cdot 8$.

Hinterschiene 74 , Metatarsus 40 , die iibrigen Glieder $40 \mathrm{~mm}$. Verhïltuis wie $74:(40+40)=1: 1 \cdot 1$.

Flügel glashell. keilformig, Gabelarler reehtwinklig abzweigend (s. Fig. I) bei Enderlein l. c.) Körperliingen $2 \cdot 3$, Fliigellänge $2 \cdot 5 \mathrm{~mm}$.

1 Exemplar (Type) ans S. Cathariua, Brasilien [Liiderwaldt] im zoologisehen Insenm Stettin.

3 custus Lw. o, lierl. Ent. Zeitsehr. IX 180. 84 ['silopus] (1865) Cuba

Oे. - Von der gewihnlichen metallisehen lärbnng. Die beiden ersten Fiihlerglieler gelb, das dritte schwarz. Hinterleib griublau olne gelbe Fleeken udel linge. Beine nebst Vorderlibiften gelb, 'Tarsen bram, ulue besondere behaarung. Vorderindader der ghashellen Fliigel hewimpert. $4 \mathrm{~mm}$ lang.

4 costulis Ahl. o* Transact. Amer. Ent. Sore. Philadelphia XXX 286 [Alyonosoma $](1904)$. . . . . . . . . Americal sejt.

Diese Art ist sehon in ler [Biolog. Centr. Aner. Diptera (1901) von Allrich als bekannt aufgefiihrt, die lieschreibung ist aber von ihm erst 1904 gegeben.

o. - liihler sehwar\%. Schwinger und die Wimpern der Schiippchen gelb. Hinterleib am ersten linge und an Banche gelb. Hypoby gimm mit kleinen sehwarzen Inhingen. Beine nud llitten gelb, nur die Mittelhiiften zur Hälfte grau. Vorlerschienen ohue borsten, nur mit einer kleinen Einzelborste an der Wurzel. 'Tarsen nackt, nit Ansnalme des ersten Gliedes braun. Fligel etwas gelblich getriibt; die Randater etwas verdickt und bewimpert, namentlich an Ende der zweiten Iaingsader; lier ist ein Einsehnitt mit einem Ilaken in der liandader bemerkenswert, fler mit mehreren langen Harren besetzt ist. :- + mm lang.

- - Einfache Beine und rlitgel.

5 Arratis Lw. O', Berl. Ent. Zeitschr. IX 180. 85] [I'sitopus] (1865) Cuba

$\sigma^{3}$. - Die beiden ersten Fihlergrieder sind gelb. Thorax gelb, auf den Rijeken mit netallisehhlaner oder sriner läingsstrieme. Hinterleib gelb, der erste, zweite, dritte mul vierte ling mit schmalen metalliseh gefirloten Hinteraudsänmen, die allmällieh naeh hinten zu

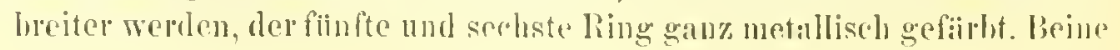


mit allen lliften gelb, mackt, ohme Hatre oder borsten ron irgend einer Bedeutung. Fltigel schwach graulich mit zart bewiuperter liandader. 5 mm lamg.

(i filipes Lw. 5, N. Beitr. VIII 99 (1861) et Vunngr. bipt. N. Amer. Il 2815. 21 tab. VIl fig. 44 a [l'silopus] (186t) . . America sept.

6. - Die beiden ersten Fühlerglieder sind gelh, das zweite falied anch gelb beborstet ju Gegensatz zu pallens Wied., die hier schwarz behorstet ist. Hinterleib uhne gelbe Binden. Beine unit Vorderhiffen ech, Mistel- mal Hinterlibfen schwirzlich. Schienen borstenlos. Yurdertursen $12 / 3$ mal so lang wie die Sehiene; an den Nitfelfiilien sind die Sehienen sehı lang, farlenfirmig. Fliigel lang und schmal, Gabelader stumpfwinklig abzweigend, in flachem Bogen weiterlatend; lintere Querader mäßig selurige gestellt. 6-7 mm lang. Fiche Luew's ausfilurliche Beschreilung.

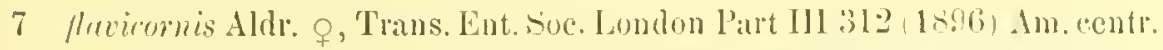

Wiedemamn hat bereits cinen P'sitopus /latromis beschrieben, aher seine drt stammt aus Sumatra, ist cin Weibehen und hat mach Mitfeilung rou Dr. Lundbeck in Kopenhagen. wo sich dic 'Yype hefindet, cine apikite liihlerborste. Aldrich's Alt gehört also wieht der orientalischen Gattung an und kamn fïglich ihren Namen weiterfibren.

Was die Ant selbst betrifit, so entnimmt man ans Aldrich"s licschreibung, dab es eine seln likine, metallisch gelairbte Art ist, hei der beide ersten Fibhlerglieder, der Bauch und die liasis des Hinterleibes sowic lieine nebst allen Iliiften gelb sind; die Gabelader zweigt rechtwinklig als. $1.8 \mathrm{~mm}$ lang.

Vielleicht ist die seringe Größe geeignet, spuiter das zugehörige Jïnnchen anlizufiuden.

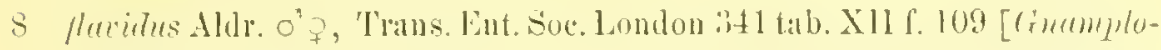
psilopus] (L896) et Trans. Aner. Ent. Fine. Philadelphia XXX 285 [Afonosome $](1904)$. . . . . . . . America centr. $2^{7}$. - Fiihler ganz gelb. Thorax gelb mit blangriuem llittelstreifen und Schildehen. Hetanotum gelb. Hinterleih gelb; die ersten vier Ringe nit griublauen Ilinteräindern, der fünfte und sechste fist gam\% netallisch gefarbt; liandborsten lang. IIypopyg gell, mit zwei gelben behatrten lamellenartigen Anlängen. beine mit allen Jlitten gelb. Vordersehenkel unten an der lasis mit drei bis vier lorsten. Vorlertarsen annälernd dremal so lang wie die Schiene. Mittelschienen nebst den Metatarsen mit eine Doppelreihe dicht gestellted Wimperuhare, sonst ohme liorsten Fliigel grashell, rlie liandader bewimpert. $45 \mathrm{~mm}$ lang.

7. - Die Dornen der Vordersebenkel sind kriftiencer. lieine und l'liigel cintach.

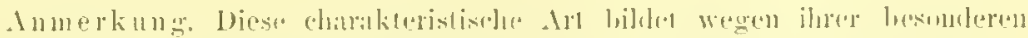

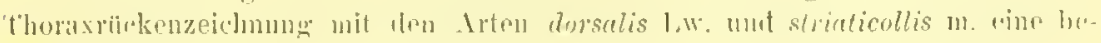
sunclere kleine (irujpe. 
9 gilvines Enderl. 2, Zool. Jalnb. Supplem. XV 1. Band [I'silopus] 404 $(1912)$

․ - Thorax blan. Selıwinger rostgelb, Schiappehen gell, blaßgelb bewimpert. Fiihler schwar, Gesielat nackt. Hinterleib grimliehblar oline gelbe Ringe oder Fleeken. Beine mit allon Hiiften blaligelb, nackt. Schenkel nnterseits ohne Behaarung. Fliigel farblos. Dritte Liingsader im Endteil nach unten gebogen; Gabelader nach rickwirts etras spitzwiuklig abzweigend, anf der Mitte rechtwinklig geloggen. $35 \overline{-}-4$ mm lang.

1 Exemplar (Type) ans S. Catharina, Brasilien in der Sammlnng des zoologischen IIuseums in Stettin.

Anmerkung. Diese Art gteicht sehr Her angustutus Enıl. = scintillans Lw. und unterseheirlet sich nur durch die gelben Mittel- und Hinterhüften.

ot. - Thoraxriieken und Schildchen metallisel blan auf del. Mittellinie nuessingrelb ohne dentliehe Streifung. Fünf Paar Dorso"sentral- und drei par: Akrostikalborsten. Schwinger gelb, Schiippelien klein, weiß mit sehwarem Sanme nud zarten weißen Wimpern. Kopf: Stirne glïnzend blan, Gesicht weiß. Riissel und 'Taster rostrot, lettatere selıwarz beborstet. Fỉlıler selıwaz, Borste kurz. - Hinterleib blaugriin mit mattschwarzen Tordermandsljinden; Hypopyg selwarz mit kolbig endigenden Organen, deren Zusammensetzung ich nicht näilier anzugeben velmag. Behaarung und Beborstnug des Hinterleibes mäßig. - Leine nelst Vorderliiften rotgelb; letztere zart weiß behart, an der Spitze mit einigen weißen Borsten. Sehenkel nnterseits schwaeh weili behant. Sehienen fast borstenlos. Mittelmetatersus und das folgende Glied an der Spitze mit je zwei längeren Borsten, die beiden letzten Glieder der Mitteltarsen alstehend behaart. - Fligel farblos uit zwei am Vorderrande bis zur dritten Längsader verbundenen brannen Querbinden, welehe den Ilinterraud nieht ganz erreichen und weiter als gewöhnlicl voneinander getrennt siud; Gabelader rechtwinklig im Bogen abzweigend; hintere Querader gerade und katum etwas sehraige gestellt, mu etwas mehr als die eigene Lïnge ron der Gabelader entfernt. 5- 5 כ mm lang.

2 วै, 37 ans Brasilien in der Loew'sehen Sammlung des Berliner zoologiselien Musenms.

11 lectus 11. sp. C?.

万. - Thoraxriteken und Schildehen metalliseh blangriin mit vier Paar Dorsozentral- und zwei Par Akrostikalborsten. Sehwinger gelb, Sehijplehen weiß mit schwarzem Rande und weißen Vimpern. - Koprf blau, Gesieht und der untere Teil der Stirne weiß bestiubt. litissel und T'ister rostrot; Fiilıler schwarz mit kurzer Rijekenborste. - Hinterleib blangriin, die Ringe dentlich abgesetzt mit selur schmalen schwarzen Einschnitten und selwacher Beharung und Be- 
borstung. Hypopyg sehwarz mit ainßeren Organen von der Länge des Hypopygs selbst, schmal, dreieckig zugespitzt und deutlieh behart. - Beine mit den Vorderhtiften rotgelb; letztere weiß behart, an del Spitze einige weiße und schwarze Borsten. Schenkel unterseits fast naekt. Schienen fast borstenlos. Mitteltarsen ebenso beborstet wie die vorige Art gratiosus. Hintersehenkel an der Spitze braun gefleckt; Hinterschienen anf der Endhaifte gebriiunt mit einem braunen Ringe in der Nähe der Basis; die äufersten Spitzen der anderen Schienen, die Hintertarsen bran. - Fligel glashell mit zwei nicht miteinander verbundenen brannen Querbinden von geringer Ausdehnung; Gabelader rechtwinklig abzweigend; hintere Querader gerade und wenig sehr:ige gestellt. $4 \mathrm{~mm}$ lang.

1 Exemplar unter Loew's amerikanischer Sammlung ohne spezielle Herkunftsangabe. Berliner Museum.

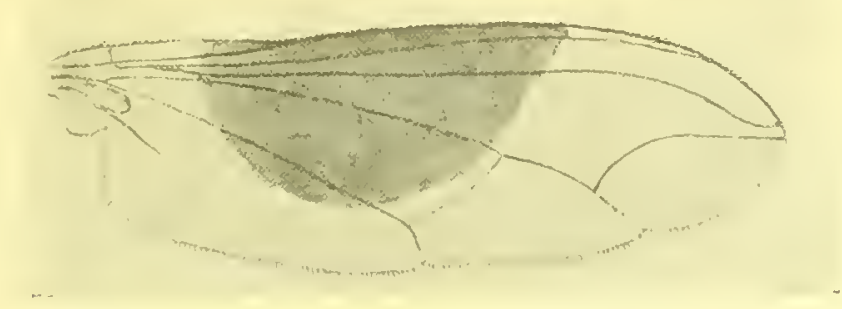

Fig. 142. Sciopus macula Wienlem. O l'ligel. 12:1.

12 macula Wied. A Aufereurop. zweill. Ius. II 219 [Psitopus] (1830)

America centr.

Q. - Fiihler schwarz. Beine wit Vorderhiiften gelb, Hinterschienen und Fibe allmaihlich braun werdend. Wimpern der tegulat gelblich. Vier gleich starke Sehildborsten. Fliggel wasserklar mit einem großen, an Vorderrande liegenden schwarzhraunen Flecken, der bogenförmig in die Flïgelfäiche einschneidet; er beginnt an der kleinen Qnerader, liBt die hintere Querader unberïhrt, indem die Begrenzung parallel zu dieser in den Vorderrand einbiegt (s. Fig. 142). Kïrperlänge 6 mm.

1 Weibehen ('Type) in Museum zu Kopenhagen.

Anuerkung. ldiese bisher nu im weiblielıen Gesclulecht bekannte Art macula Wied. steht wegen ihrer besonderen Flügelzelehnug in allernichster besziehung zu Condylost!lus dimidiatus lw. und medianus Beck (s. lort die Foguren). Diese erhebliche Abweichung in der Fliigelliatumg luat aber anch noch andere Anderungen in Gefolge. Wie bereits in I'oxt leci dimidiatus lw hemerlit. lat diese Art wie liei der Gatung Sciopus nur zwei stake silublborsten, labei sind die Iriupurn der tegulae deutlich schwarz; ganz dieselbe Erscheinung sehen wir bei medianus beek; bei mserer Art macula Wied. aber ist es umgekehrt:

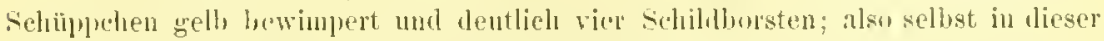

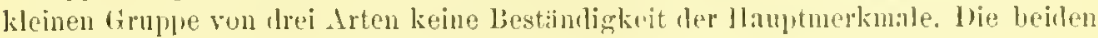
hauptsächliehsten ['uterscheidungsmerkmale zwisehen Condylostylus big. mat 


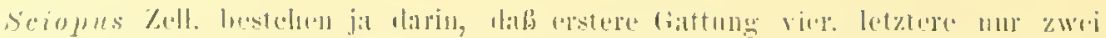

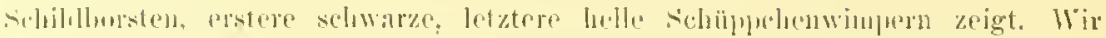

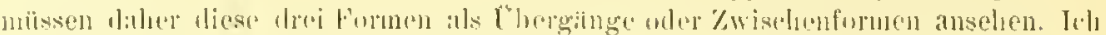

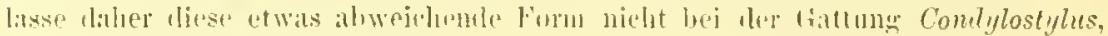
suntern stellar sie zo Sciopus.

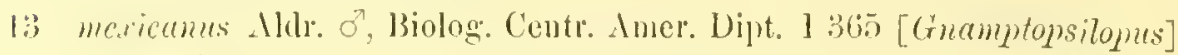
$(1001)$. Iexico

$\therefore$ - Die ersten beden Fibllerglieder sind gelh, das dritte Imann, schwinger gelb. Ilinterleib mit gelben dreicekigen Seitenflecken anf den ersten beiden Ringen. Ilypopyg mit gelben bandförmigen kleinen behaarten Anhängen. Beine mit allen Hiiften gell, Mintertarsen vom zweiten Gliede an sehwarhaun. Fligel farblos olne besondere Bewimperung der Torder'andader; lintere Querader schlank S-fömig gebogen. 4.4 mm lang (nach Aldrich.

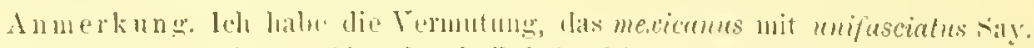

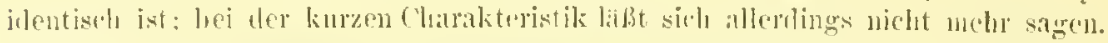

14 noditarsis 11 . sp.

Brasilia

o. - Thorax und Schildelien glänzend ammblan, an Vorder- und Seitenrande etwas gelbgrau bestiubt. Vier Dorsozentralborsten, Akrostikabiirstehen nicht sichtbar; nur zwei Sehihlborsten ohne Nebenbörstehen. Seluwinger und schiippehenbewimperung blabgelb. Stirne blan, unbestäuht. Gesicht breit, blan, unteu grau bestäulu, liiissel, 'Taster und Fiihler gelb, Arites Glied bram. Hinterleil, blangrỉn, bauch und erster ling gelb, Behorstung nur am elsten línge, sonst schwaeh. 1]ypryyg schwarz mit gelben Anluangen, jedoch ist die Form nicht sicher zu erkennen. Beine nebst allen lliiften gelh ohne jegliche Beborstung, llintertarsen braun; an den Mittelsehienen ist die sonst fust auliegende kurze l'nbeszenz etwas struppiga abstelend und die Tarsengelenke erscheinen etwas dunkler und gesehwollen. Die Beinlängen sind bei zwölffacher Vergrößerung wie nachstehend:

Vorlerschiene 2!, Metatarsus 24 , die ibrigen Glieder 19 mm.

Verhailtuis der Tarsen zu den Schienen wie 15:1.

Mittelschiene 39 , Metatarsus 26 , die iilnrigen vier Glieder 26 mm.

Verhälnis der Tarsen zu dea Schienen wie 1.33:1.

Fliigel fablos; die crste Längsaler kum, zweite lang, dritte an der Spitze wenig gebogen; Gabelader etwas spitzwinklig abzweigend, auf der Nitte rechtwinklig gebogen mud mit der dritten Liingsader wenig konvergierend, fast parallel zu libelspitze lanfend; lintere Querader fast rechtwinklig zur vierten Längsader, un ilıe eigene liange ron der Gabelader entfernt. 4.5 $\mathrm{mm}$ lang.

- - Aueh das dritte liihlerglied ist ganz gelb; die Beine sind wie gewöhnlich einfach nul kirmer; an Ilinterleibe zeigen mitnnter aneh der dritte und rierte llinterleibsring gelbe lieeken, sonst dem of gleich. 
1 б', 3 q aus Blumenan, Brasilien [Lothar Hetsehko] und von der Brasilianischen Expedition Wittstein, Young Iguape in der Sammlung. des Wiener Hofmusenms.

Anmerkung. Während sonst gewönlich die Gabelader sich der dritten Längsader an Fliggelrand selır nähert und mit ihr stark konveryiert, bleibt hier die Gabelader weit enternt; der Alsstand ber beiden Adern an Flïgelrande ist last so lang wie die halbe hintere Querader; an dieser Aderstellung ist anch das Weibchen leicht zu erkennen.

15 pallens Wied. $\sigma^{7}$, Außereurop. zweifl. Ins. II 219.11 (1830)

Ameriea sept. et Europa

Siehe meine Beschreibung bei den paläarktischen Sciopus-Arten (nach Aldriels).

16 psittacims Lw. ơ \&, N. Beitr. VIII 96. 16 (1861) et Monogr. Dipt. N. Amer.

II. 281 Taf. VII fig. 44 lı (1864) . . . Portorico et America sept.

Nach Angaben des Herm v. Röder ist diese nordamerikanische Art auch in Portorico beobachtet worden.

$\sigma^{7}$. - Die ersten beiden Fühlerglieder gelb; Schwinger hellgelb. Hinterleib am ersten, zweiten und dritten Ringe zum Teil gelb. An hiinge des llypopygs bramn. Beine mit Hiiften gelb, Nittelhïften an der Wurzel grau. Selienen ohne besondere Beborstung. Vordertarsen fast doppelt so lang wie die Sehiene, Mitteltarsen $11 / 2$ mal so lang. Fliigelvorderrand ausgebuehtet, mit einer vortretenden Eeke am Ende der zweiten Lïngsader abgestumpft und bis dahin bervimpert. $4-5 \mathrm{~mm}$ lang.

․ - Hinterrand der Brustseiten gelb; Fliigelrorderrand einfach. Siebe die ansfiihrliche Beschreibung bei Loew.

17 rotundiceps Aldr. б, Trans. Amer. Ent. Soc. Philadelphia XXX 285 et 286 [Agonosoma] (1904) . . . . . . . America sept.

$\sigma^{\nearrow}$. - Gesicht schmal, die beiden ersten Fiihlerglieder gelb, das dritte braun; die Stirme ist dicht weiß bestäubt. Hinterleib gelb mit grinen Vorderrandbinden, die nach hinten zu immer breiter werden und die beiden letzten Ringe ganz eimnehmen. Hypopyg mit gelben Anhängen. Beine mit allen Hiiften gelb; Mittelsehjenen mit ziemlich dentlichen Wimperbörstchen; Vorderhiiften mit gelben Borsten an der Spitze. Fliigel glashell, Vorderrand ohne Wimpern. $3.4 \mathrm{~mm}$ lang.

Anmerkung. Adrich spricht die Vermutung aus, daß seine Art vielleicht das of der von ihm 1896 beschriebenen flavicornis $q$ sein könne. Ich stimme ilm hierin bei und glaube, daß mau mit der größten Walırscheinlichkeit dies behaupten kann.

18 scintillans Lw. ơㅇ, N. Beitr. VIII 94. 13 (1861) et Monogr. Dipt.

N. Amer. II 273. 15 tab. VIl f. 44 d [Psilopus] (1864)

angustatus Enderl. o, Zoolog. Jahrb. Supplem. XV 1. Band [Psilopus] 405 (1912) . . . . . . . Brasilia, Ameriea sept.

๑. - Fïhler ganz schwarz, Taster desgleiehen. Hinterleil, goldgriin. Hypopygialanhiinge sehwarz. Beine nebst Vorderhiiften blaßgelb, Mittel- und Hinterhiiften sehwarz. Sehienen borstenlos, au den MittelAbbandl. der zool.-bot. Ges. Band. XIIT, Heft 1. 
schienen ist die kn'me Pubeszenz ctwas ahstehend angcordnet. Vordertarsen $1 \frac{2}{3}$ mal so lang wie die Schiene, Mitteltarsen $1 \frac{1}{2}$ mal so lang, Hintertarsen anuäherud so lang. Sehwinger hellgelb. Gabelader reehtwinklig abzweigend; auf der Mitte etwas stumpfwinklig aufbiegend; hintere Qnerader etwas sehrige liegend. $35-4.5 \mathrm{~mm}$ lang.

Die Beschreibnng der Art angustatus Enderl. \& deekt sich vollständig mit der Loew'sehen, so daß man mit großcr Wahrscheinlichkeit von dieser Synonymie sprechen kann.

Sayi Wied. = unifasciatus Say.

19 striaticollis n. sp. ठ․ Figur 143 Brasilia

Eine kleine gelbe Art, die in näehster Nähe ron dorsalis Lw. und flavidus Aldr. steht, aber in den Längenverluailnissen der Bcine und in ihrer Bebarung alsweicht.

ठ․ - Thorax gelb, kaum etwas glïnzend, auf del Mitte des Rickens ein blauer, metallisch glänzender Mittelstreifen, der den Raum zwiseben den vier Dorsozentralborstenparen ausfiillt, die hier näher als gewöhulich aneinander stehen, Akrostikalbürstehen sind nicht sichtbar. Schildeben metallisch griublau. Brustseiten, Schwinger und Sehiiplpchen blaßgelb, letztere gelb bewimpert; nur zwei starke Schildborsten. Kopf: Stime glinzend blau, Gesicht dicht weiß bestiubt. Riussel, Taster, Fïhler gelb. Metanotum und Hinterleilo gelb; der erste Ring ist an beiden hinteren Seitenecken metallisch verdunkelt, der zweite, dritte und vierte Ring mit blanen Hinterandsïumen, fünfter und sechster Ring sind ganz blan. Hypopyg metallisch gefärbt mit zwei gclben schmalen verliingerten behaarten Lamellen; die Rïinder der Ringe sind spärlicb aber lang beborstet. Beine und Hiiften blaßgelb, nur die Hintertarsen gebriiunt. Die Beine entbehren fast jeder Beborstung, immerhin sind die Vorderbeine in gewisser Weise durch Beharung ausgezeichnet: Vorderschienen mit einer Einzelborste an der Basis der Vorder- oder Oberseite, sonst kabl; Vordermetatarsus und die iibrigen Glieder in abnehmender Lainge ziemlich lang oberseits bewimpert, am Ende des dritten, vierten nnd fünften Gliedes steht je eiue Einzelborste; die Mittel- und Hinterbeine sind außer ilurer kurzen, fast anliegenden Pubeszenz olne längere Haare oder Borsten. Die Längenverhältnisse der Schienen und ihrer Tarsen sind bei 12 facher Vergrößerung unter den Mikroskope wie folgt:

Vordersehiene 25, Metatarsus $33 \cdot 5$, die ibrigen Glieder $22 \cdot 5 \mathrm{~mm}$. Längenverhailtnis wie $25:(33 \cdot 5+22 \cdot 5)=1: 2 \cdot 1$.

Mittelsehiene 36, Metatarsus 29, die iibrigen Glieder $29 \mathrm{~mm}$. Längenverbïltuis wie $36:(29+29)=1: 1 \cdot 16$.

Hinterschiene 54, Metatísus 26, die ibrigen Glieder $24 \mathrm{~mm}$.

Längenverhältnis wie $54:(26+24) 1: 099$.

Fligel sehr zart gelblich mit gelben Adern; die dritte Liangsader ist an der Spitze zicmlich gebogen; die Gabelader nach rickwirts 
etwas spitzwinklig abzweigend, auf der Mitte reehtwinklig gebogen; die hintere Querader nur wenig selıräge, schlank S-förmig, um jhre eigene Läinge von der Gabelader entfernt. Die Randader zeigt unter dem Mikroskope eine dentliche, aber selı. feine Bewimperung. Körperlïnge $35 \mathrm{~mm}$.

10 त der Berliner Sammlung Nr. 3121 aus Brasilien. Die Unterschiede ron den ahulich organisierten Arten dorsalis Lw. und flavidus Aldr. sind in der Bestimmungstabelle angegeben.

20 tener Lw. $\sigma^{7} q$, Berlin. Ent. Zeitschr. VI 217. 71 [T'silopus] (1862) et Monogr.

Dipt. N. Amer. II 284. 20 (1864)

Ameriea sept. et merid.

Ich fand ein unbestimmtes $\sigma^{7}$ im Wiener Hofmuseum aus Siidamerika, das ich nach Loew's ausfiihrlicher Beschreibung fiir diese Art halten muß. Färbung; Beinlängen und Fliigeladerung stimmen genall tiberein.

$\sigma^{7}$. - Die beiden ersten Fiilılerglieder, Hinterleils an der Wurzel und Beine mit allen Hiiften gelb. Hypopygialanhänge blafgelb. Vorderschenkel unterseits an der Basis mit drei bis vier gelben Borsten. Die Beinlängen lei 12 facher Vergrößerung gemessen sind die folgenden:

Vorderschiene 31, Metatarsus 40, die iibrigen Tarsenglieder $27 \mathrm{~mm}$.

Verhältnis der Tarsen zu der Schiene wie $67: 31=2 \cdot 1: 1$.

Mittelsehiene 53, Metatarsus 59, die iibrigen Tarsenglieder $29 \mathrm{~mm}$.

Verbältnis der Tarsen zn den Scbienen wie $88: 53=1 \cdot 6: 1$.

Flitgel lang und schmal, Gabelader in einem flachen Bogen abzweigend; hintere Querader sclurige gestellt: an der Fliigclwurzel steht oben auf der Raudader eine sehwarze, dicke dornähnliche Borste. $4.5 \mathrm{~mm}$ lang.

q. - Hinterleib gelb.

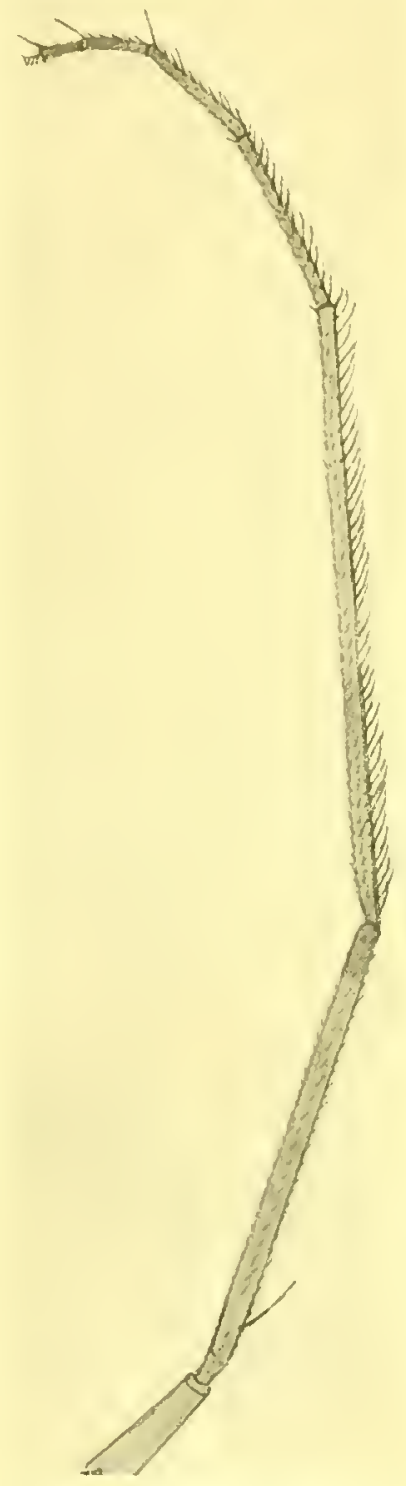

Fig. 143. Sciopus striaticollis Beck. ot. Torderbein. 24: 1 .

$1 \sigma^{x}$ ans Siidamerika in der Kollektion Winthen, Wien.

Anmerkung. Loew macht an Schlusse seiner Beschreibung in den Monogr. 1864 I. e. anfmerksam auf ein besonderes Iterkmal des o'; er sagt: an der Basis 
der l'ligel stehe auf der Unterseite (under side) ein dicker krummer schwarzer Dorn. Dieser Dorn ist vorhanden, man wird ihn aber vergeblich auf der I'nterseite suchen, er steht auf der Oberseite; es muß daher im Text heißen: n1pper side.

21 mifasciatus Say, Joun. Acad. Nat. Se. Philadelphia III 85. 2 [Dolichopus] (1823) . . . . . . . . . America sept. et centr. bicolor Lw., N. Beitr. VI1I. 96. 15 [Psilopus] (1861).

Sayi Wied., Auberenrop. zweifl. Ins. II 219. 13 [Psilopus] (1830).

In der Berliner Sammlung steckt unter Nr. 3114 ein of ans Nordamerika, das von Keitel als mifasciatus bestimmt wnrde, ferner fand ich ein zweites Exemplar unter Nr. 3120 ans Portorico; beide passen sehr gut auf die etwas allgemein gehaltene Beschreibung von Say und Wiedemann: das dritte Fiihlerglied ist aber brann, nicht gelb, wie Loew ans dem Fehlen des dritten Gliedes an der Type glaubt folgern zu miissen; der Hinterleib ist am ersten und zweiten Ringe gelb, Beine und alle Hiiften sind gelb und die dritte Lingsader ist am Ende stark gebogen, wie Say dies angibt. Ich bin iberzengt, daß diese beiden Exemplare die Say'sehe Art darstellen. Sie ist damn aber auch sicher versehieden ron meiner Art antematus, und zwar vor allem deutlich durch die weit kiirzeren Vordertarsen; diese messe ich bei 12 facher Vergrößerung: Vorderschiene 35, Metatarsus 30, die iibrigen Glierler zusammen $24 \mathrm{~mm}$; das Verhältnis der Tarsen zu ihrer Schicne ist also mu 1.6:1, während ieh dieses bei antematus wie $3: 1$ feststellte; hieraus allein sehon muß man die Verschiedenheiten beider Arten annehmen.

variegatus Lw. ơๆ, N. Beitr. VIII 95 [Psilopus] (1861)

America sept., centr. et merid.

ऽ. - Die ersten beiden Fühlerglieder gelb. Schildehen außer den zwei Hauptborsten noeh zwei kleine Nebenbörstehen. Schiippehen weif bewimpert. Hinterer Rand der Brustseiten gelb. Der erste Hinterleibsring, der zweite an der Wurzel und an den Seiten gelb. Beine und alle Hiiften gelb, die Mittelhiiften jedoel an den Seiten grau. Beine fast borstenlos; Mittelsehienen mit einer Einzelborste an der Basis der Oberseite. Vordertarsen $1 \frac{2}{3}$ mal so lang wie die Sehiene, Mitteltarsen $11 / 2$ mal so laug. Fliigel farblos; dritte Längsader an der Spitze deutlich gebogen; Gabelader nach riekwärts gerichtet spitzwinklig abzweigend, daun auf der Mitte reehtwinklig bogenförmign aufbiegend. $5-6 \mathrm{~mm}$ lang.

Loew beschrieb diese Art uach Exemplaren aus Florida. Ich fand ein Exemplar aus Rio grande in der Sammlnng des Ungarisehen Nationalmusenms. 


\section{Megistost!lurs.}

Big., Ann. Soe. Ent. France 215 (I859).

Type: Psilopus crinicomis Wier., Analecta Entomol. 39.68 [Dolichopus] (I824) et AnBereurop. zweith. Ins. II 222. 20 (1830). Jara.

Mlegistoftylus Big., Ann. Soe. Ent. Fr. Bull. XXIV (ISs8).

Megystostylus Big., Ann. Soc. Fnt. Fr. 222 (1859).

Die typisehe Art dieser Gattung ist nach Bigot erinicomis Wied. von der Insel Java Wiedemann spricht 1824 in seiner Beschreibung ron cinem Weibchen in Westermann's Sammung, nacls welchem die nrspringliche Beschreibung ron 1824 gefertigt sei. Das Exemplar in Westermann's Sammlung im Kopenhagener Musenm ist aber, wie mir Dr. Will. Lundbeck mitteilte, ein Jänuchen mit apikaler langer Fiihlerborste, die mit dem dritten kegelförmigen Gliede verwachsen ist; es entspricht auch durchaus Wiedemanu's zweiter Beschreibung rom Jahre 1830 . Das männliche Exemplar, von welchem Wiedemamn hier spricht, habe ich geselıen, es befindet sich nach wie vor in Wiedemann's Sammlung in Wien zusammen mit mehreren anderen Exemp]aren [Dolescha]] aus Amboina.

Die Gattung Megistostylus (s. hieriiber anch Enderlein, Zoolog. Jahrb. Suppl. XV 1. Band 369, 1912) ist Bewoluerin der äthiopischen Regionen, kommt aber anch in Siidamerika vor, wie die Beschreibungen von longicornis Fbr. nud longisetosus v. d. Wulp beweisen; aus den Beschreibungen geht dentlich hervor, daß das dritte Fiihlerglied die gleiche charakteristische Form und dasselbe glatte glinzende Aussehen hat, das selbst Fabricius anfgefillen ist, der es mit dem Ausdruck ,acneo nitens" belegt. Die Beschreibungen sind so ibereinstimmend an Größe und Färbung, daß die Vermutung sofort rege wird, es könnte dieselbe Art hier dreimal beschrieben sein. Ich fand denn auch bei der Vergleichung der typischen Excmplare ron crinicornis Wied. nnd der Type von longicomis Fbr., von der ein $\sigma^{7}$ aus Brasilien in der alten Sammlung des Wiener Hofmusenms sich befindet, daB Unterschiede nicht vorhanden sind. Die Fliigel sind wasserklar, zeigen aber bei mehr ausgereiften Exemplaren einen zarten bräunlichen Schattenflecken an der Spitze der Vorderrandader. Die 'Type von longisetosus v. d. Wulp habe ich zwar nicht gesehen, aber ich finde in der langen Besehreibung fast alles iibereinstimmend, nur geringe Abweichungen in der Firbung der vorderen Beine, so daß man die Synonymie mit grober Wahrseheinlichkeit aussprechen kaun.

\section{Gattungscharakter.}

Netallisch blan his griingold gefürbte Arten vom allgemeinen SciopusTypus. Kopf flach halbkugelig, hinten ausgehöhlt. Stirne eingesattelt mit höckerartig erhobenen Punktangen, zwei nach vorne gericliteten sturken Borsten neben denselben und zwei Scheitelborsten. Postvertikale fchlend. 
Gesicht mäßig breit mit flacher Querfalte. Riissel und Taster usłedeutend. Fiihler: erstes Glied kugelig verdickt, nach unten etwas banchig vortretend ohne Beharnug; das zweite Glied ist unbedentend, von der Form eiuer kuren Mansehette mit kurzen Randbïrchen und einem lingeren Haar anf ler Unterseite; drittes Glied kegelförmig in eine lange Borste iibergehend ohne sichtbaren Borstenansatz; die obere Seite dieses dritten Gliedes ist abgeflacht oder etwas ausgehöhlt, gliinzend wie poliert, lie Unterseite an der Basis nur mikroskopisch schwach pubeszent, im iibrigen erscheint die Borste anch bei 100 facher Vergröferung ganz nackt. Die Fiihler sind lang und im ganzen fast halbkreisformig nach oben gebogen (s. Figur 144). Thoraxriicken mit drei Dorsozentralborsten, zwei hinten und eine vol der Quernalit; drei starke Akrostikalborstenpaare. Schildehen mit zwei starken Borsten und zwei kleinen Nebenbörstehen. Schiippehen weiß bewimpert. - Ilinterleib mit sechs dentlichen Ringeu; Hypopyginm mit dem siebenten Ringstick scharf geknickt unter den Banch geschlagen; in der Form hat das Hypopygium einige Ähnlichkeit mit dem der Gattung Sciopus. Beiue lang, Flïgel desgleichen; die erste Längsader reicht ungefäbr bis zur Fliigehnitte; die Gabel der vierten Längsader zweigt rechtwinklig ab und wendet sich in flachem Bogen zur Spitze; hintere Querader im ganzen schriige liegend, meist deutlich S-fimnig gebogen.

1 longicomis Fbr., Sỵst. Entom. 783. 52 [Musca].

Fbr. Syst. Antliat. 269. 14 [Dolichopus] (1805). Antillae. Amer. merid. India, Philippinae

crinicornis Wied., Analecta Entom. 39.68 [Dolichopus] (1824).

Außeremrop. zweifl. Ins. II 222. 20 (1830).

filifer Walk., Linn. Soe. London IV 114 [Psilopus] (1860).

longicornis Dolesh., Naturk. Tijdschr. Neder. Ind. ser. 4 III (XVII) 94. 34 [Psilopus] (1858).

longisetosus v. d. Wulp, Tịdschr. r. Entomol. XXV 120. 3 tab. X fig. 7 [ Psilopus] (1882).

§’. - Thorax von schöner azurblaner Farbe. Schwingerknopf schwarzbraun. Kopf: Stime nnd Gesicht blan, nur auf dem nnteren Teil des Gesichts mit weißer Bereifung; Taster und Fiihler schwarz, letztere wie in der Gattungsbeschreibung angegeben (s. Figur 144). Kinnbart weif. - Hinterleib blau mit deutlichen mattschwarzen Vorderrandbinden und Randborsten, welche so lang sind wie der Hinterleib dick. Hypopyg mit schmalen gelbbraunen bis schwarzen äuBeren Anhïingen. Beine: Hiiften und Schenkel schwarz; Hinterschienen uul deren Tarsen desgleichen; vordere Schienen nebst deren Tarsen, letztere zum 'Teil gelb. Eine besondere Beborstnng der Beine ist nicht vorhanden, sie sind fast borstenlos; iie Sehenkel sind auf ilner Unterseite auch nur spärlich weiß behart. Flïgel ohne Flecken und 
Binden, zart gelbbrïunlieh bis wasserklar mit zarten dunklen Adern; die Gabelader biegt reehtwinklig in Kreisbogenform ab. 5-6 mm lang.

Joew kannte diese Art nieht; er muß die Type in Wien iibersehen haben, da el sie nur mit chrysoprasius Walk. vergleieht, einer Art, die ich im Wiener Musemm. mit der Type von longicomis zusammengesteckt vorfand. Coquillett erwïlnt die Art aus Porto Rieo; ob sic aber mit longicornis Wied. identiseh ist, bleibt fraglieh, da Aldrieh sie in seinem Katalog mit comatus Loew identifiziert, die eine cntfernte Ähnliebkeit anfweist, obgleieh sie cine abweiebendc Fligeladerung hat und wegen ihrer anderen Fiibleransbildmng ciner anderen Gattung angehört.

ㅇ. - Das Weibehen ist noeh unbekannt.

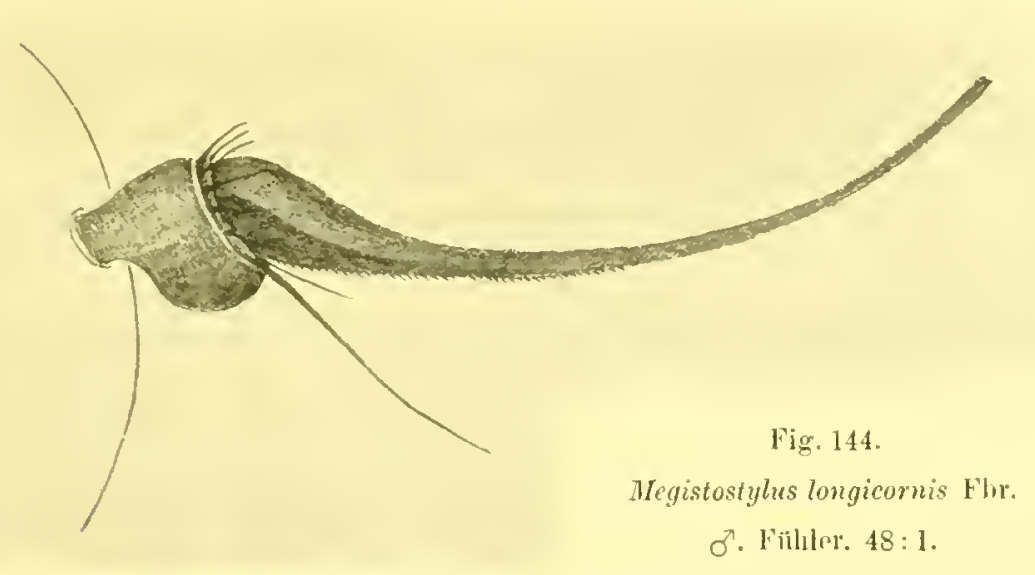

2 longisetosus v. d. Wulp ơ, Tijdselur. v. Entomol. XXV 120. 3 tab. X fig. 7 [Psilopus] (1882) . . . . . . . . . . . . . Brasilia

8. - Blaugriin, Sehwinger dunkel rotgelb. Fiihler" sehwarz, drittes Fïhlerglied lang kegelförmig, zu ciner langen Borste ohne Trennung ausgezogen. Beiue sehwalz; Sehienen gelb, Hintersehienen mal alle Tarsen schwarzbrann. Fliigel glashell mit einem Sehattenfleek an der Spitze des Vorderrandes. Sehiippchen weiß bewimpert. $6 \mathrm{~mm}$ lang. (Nach v. d. Wulp.)

Anmerkung. Die Unterschiede von longicornis Fbr. beruhen in der etwas anderen F'trbung der Tarsen und in der Fleckung der Fliggel; da letztere sehs schwach ist und bei weniger gut entwickelten Exemplaren auch ganz verschwinden kann, so ist es nicht nnmöglich, daß longisetosus mit longiconnis zusammenfällt, da die etwas hellere Fiarbung der vorderen Tarsen allein kaum eine liesondere Art wird begrïnden kömnen; eine Bestätigung diestr meiner lermutung könnte jedoch erst durch Verylejehung der Typen miteinander erbracht werten. 


\section{Mesorhaga.}

Schin., Novara-Reise, Dipt. 217 (1868).

Aptorthus Aldr., Kansas I'nir. Quart. 1148 (1898).

Type: Mesorthaga tristis Schin.

\section{Gattungscharaliter.}

Was diese Gattung zunächst vor allen anderen dieser Gruppe auszeiehnet, ist die Fliigeladerung, bei der die vierte Längsader in ilurem letzten Abschnitte eine doppelte, mitunter fast reehtwinklige Biegung macht, obne eine geradlinige Verlingerung iiber die erste Biegung hinaus zu finden; diese Fliigeladerung erinnert lebhaft an die der Gattung Orthoceratium Schrank. Das Sehildehen lat nur zwei Hauptborsten, denen siel allerdings zwei unbedeutende Nebenbörstehen zugesellen. Ferner ist abweichend von den iibrigen Gattungen die Borstenlosigkeit der Beine und des Hinterleibes; letzterer hat mit Ansnahme des ersten Ringes so unbedentende Randborsten, daß man sie von der iibrigen Haarbekleidung kanm untersebeiden kann; als besonderes unterseheidendes IIerkmal erscheint mir aber zu sein, daß diese Arten nur seels Hinterleibsringe, also einen weniger als die Gattungen Sciopus, Condylostylus, Chrysosoma und Megistostylus haben. An den Beinen sieht man außer einer kleinen Sehienenendborste keinerlei herrortretende Borsten. Die Farbe der Wimpern der tegulae ist nielit ganz ibbereinstimmend; von den seebs amerikanischen Arten haben fuinf weiße Zilien, eine, und zwar die typische Art tristis Sehin., sehwarze; letztere ist anch in anderer Hinsieht etwas abweichend gebildet, liibt sich aber bei iibereinstimmender Fliigeladerung doeh nicht von den iibrigen tremnen.

\section{Bestimmungstabelle für die fattumg Mesorhaga Schin.}

1 Sehiippehen weiß bewimpert, Schwinger hellgelb . . . . . . 2

- Sehiippchen sehwarz berwimpert, Sehwinger sehwarzbraun. Beine ganz schwarz. Hypopyg schwarz, Analanhänge dunkelbraun, bandförmig. Fligel graulich. $5-55 \mathrm{~mm}$ ling . . . . . . tristis Schin. of

2 Sehenkel und alle Hiiften schwarz . . . . . . . . . . . 3

- Sehenkel und die Vorderhiften gell. . . . . . . . . . . 4

3 Vorder- und Vittelsebienen gelb, ltintersehienen bram. Analanliinge klein, gelb. Fliggel glashell. $4 \mathrm{~mm}$ lang . . albiciliata Aldr. $\sigma^{7} 0$.

- Kniee und Vordersehienen gelb, Nittel. nud Hinterschienes brann. Fliigel glashell. $4 \mathrm{~mm}$ lang . . . . . . . . migripes Aldr. o.

4 Vorderhiiften ganz gelb . . . . . . . . . . . . . . . 5

- Vorderbtiften an der Wurzel breit blansehwarz. Hintertarsen so breit wie die Sehiene, die drei letzten Glieder gleieh lang und etwas stärker verbreitert. Fltigel glashell; die vierte Lïngsader im letzten 
Abschnitt mit einer stumpfwinkligen Aufbiegung. Borsten des Schildehens schwarz. Gesicht braungrau bestäubt. $25-4 \mathrm{~mm}$ lang. jucunda n. sp. o".

5 Borsten des Schildehens und an den Thoraxseiten gelh bis gelbbraun. Fligel glashell. Gesicht weiß bestiubt. $4 \mathrm{~mm}$ lang.

Townseneli Aldr. Q.

- Borsten am Schildchen und am Thoraxriicken ganz schwarz. Hintertarsen nicht verbreitert. Hypopygium schwarz. Anallamellen klein, oval, briunlich. Fligel mit einem granen Schattenflecken iiber der zweiten und dritten Längsader an der Fligelspitze; letzter Abschnitt der vierten Längsader zweimal rechtwinklig gebogen. Gesicht gelblich bestiubt. $4 \mathrm{~mm}$ lang . . . . . laeta n. sp. o

\section{Verzeichnis mul Arfbeschreilumg.}

1 alliciliate Aldr. O’o, Kansas, Unir. Quart. II. 48 [Aptorthers] (1893) America sept.

o. - Thorax blaugriin, Borsten alle schwarz anch an Schildehen. Schlippchen weiß wit schwarzer Spitze und mit langen weißgelben Zilien. Seluwinger gelb. - Gesicht breit, gelb hestäubt, Stirne glänzend griin. Fibler klein, schwarz nit gelben Haaren an zweiten Fihlergliede. Riissel und Taster gelb. Hinterkopfzilien unten weiß. Hinterleib blaugribn, am ersten Ring mit längeren gelben Ha:ıren. Hypupyg schwarz mit kleinen gelben Auallamellen. - Hiiften und Schenkel schwärzlich griin; Kniee, Vorder- und Mittelschienen gelb, Hinterschieneu braun; alle Tarsen vom Ende des ersten Gliedes an allmählich gebräunt. Vorder- und Mitteltarsen deutlieh länger als ilıre Schiene. Fliigel glashell. $4 \mathrm{~mm}$ lang.

‥ - Gesicht weiß; die Haare an den Stirnseiten, die bein $\sigma^{7}$ weiß sind, braum. Hinterschienen auch gelb.

Von Aldrich aus Westrille in N. Yersey beschrieben.

1 o aus der Savannah in der Berliner Sammlung, bislıer als Psilopes femoratus Say gedeutet.

2 borealis Aldr. \&, Kansas, Univ. Quart. If 49 [Aptorthus] (1893).

Dies Weibchen soll sich von dem Weibchen ron albiciliata dureh gelbe, an der Wurzel braune Vorderhliften unterscheiden und durch geringere Auzahl von Stirnhiaren. Die Art ist hiedureh sebr dirftig charakterisiert; ich kenne sic nicht.

б. - Thoraxiticken und Schildchen hlau, mit zartem granen Reife iibergossen; je fiinf Dorsozentralborsten und dentlich zwei Reihen vou Akrostikalbörstehen. Sehildehen mit zwei starken und zwei schwachen Randborsten. Brustseiten grau. Schwinger und Schippluehen weißlich, letztere nur mit schmalem braunen Saume und vielen langen 
weißgelben gebogenen Wimperhaaren. - Kopl: Stirne und Gesiebt blan; Stirne nur leicht, Gesicbt dicht granbraun bestäubt. Taster nnd litissel gelb, Fiihler sehwarzbranu, drittes Glied selır klein, das zweite Glied unten mit gelben Borsten; Fiihlerborste nur kurz, sehwarz, nackt. Borsten auf dem Punktaugenhöeker sebwarz, am seitlichen Stirnrande gelb. Postokularilien unten weif, am oberen Augenrande stehen gar keine Borsten, er ist naekt. - Hypopyg glïnend blangriin, schwarz behaart, auch die längeren Seitenhatre des ersten Ringes sind schwarz. Das Hypopyg ist bei dieser Art lang rorgestreekt, krebsschwanzartig unter den Banch gesehlagen, ziemlich stumpf endigend mit lïngeren gelbbrannen dreieckigen beharten Anhängen. - Beine nebst Vorderhitiften gelb, letatere

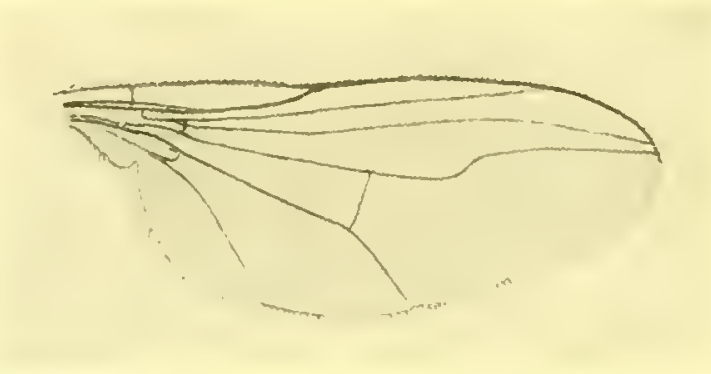

Fig. 145. Mesorhaga jucunda n, sp. б’. Flïgel. 12:1. :In der iußersten Basis schwarz, die hinteren Hiiften :u der Spitze gelb, letzte 'Tarsenglieder braun. Die Hintertarsen bleiben bis zum Ende mindestens so breit wie die Schiene, die drei letzten Glieder sind gleich lang und noch etwas stiirker verbreitert; der Metatarsus kamm etwas lïnger als das zweite Glied. Die Beine sind alueb bei dieser Art borstenlos. - Fligel glaslıell mit feinen schwarzen Adern; die vierte Laingsader macht im letzten Absehnitt nur eine stumpfwinklige Biegung und miindet, mit der dritten kouvergierend, erheblich vol Jer Fltigelspitze in die Randader; die hintere Querader steht reehtwinklig zur vierten Längsader. $35 \mathrm{~mm}$ lang.

Q. - Das vorliegende Exemplar entspricht durehaus dem $\sigma^{7}$, ist aber erheblieb kleiner. $2.5 \mathrm{~mm}$ lang.

Anmerkung. leh kann nicht glauben, daß das vorliegende Mbinnchen als das noch unbekannte Minnchen der Art Townsendi Allr. anzuselien ist; zunachst sind die Schild- und seitlichen Thoraxhursten nicht gelb wie bei Towusendi, sundern ganz schwarz; damn aber hat unser of ein dicht graubrann bestiubtes Gesicht, was mit dem weiB bestäubten Gesicht des $O$ ron Townsendi nicht harmoniert, lenn stets laben die Blimmehen eine etwas hellere, reinere fresichtslarbe als die Weibchen, nicht aber umgekehrt.

107,1 o aus Paraguay, Asuneion 1904 [Vezényi] Sammlnng des Ungarischen Nationalmuseums. - 1 q aus Georgia, N. Amer. [Morrison] Berliner zoologisehes Museum Nr. 7962.

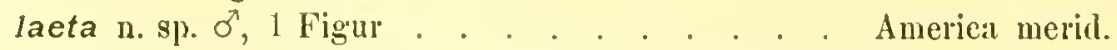

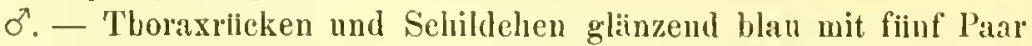
Dorsozentralborsten. Sehildehen mit zwei starken Seitenborsten und 
zwei feinen Härchen danebeu. Brustseiten aschgran. Schwinger und Schiippehen blaßgelb, letztere mit breitem braunen Saum und langen zahlreichen blaßgelben Wimperu. - Kopf: Stirne und Gesicht goldgriin, aber durch gelbliche Bestäubung fast ganz unatt; die Borsten auf dem Punktangenhöcker sind schwarz, die Häirchen am Stirnrande gelblich. Fühler schwarzbrann, das zweite Glied nur mit mäßiger Beborstung; Rtissel und Taster gelb; Hinterkopfzilien weiß. - Hinterleib schwarzgrlin, glinzend, schwarz behart, an den Seiten des ersten linges lange, gelbbraune Borstenhaare; der sechste Ring ist sehr kurz und nur als Tergit noch unter dem fünften zul seben. - Dis Hypojyg wächst ans dem Hinterleib direkt als Verliingerung bervor, ist unter dem Bauch gebogen und nur von geringem Umfange; außer

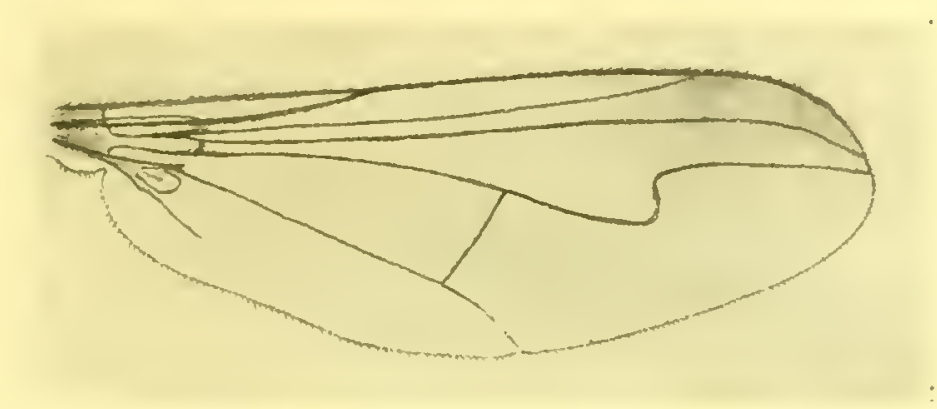

Fig. 146. Mesorhaga laeta 11, sp. ठౌ. Flïgel. $16: 1$.

dem diinnen Penis sind noch zwei braune bandförmige Verlängerıngen und zwei branne ovale Lamellen sichthar. - Beine nebst Vorderhtifte bell rotgelb, die Enden der Tarsen, namentlich au den Hinterbeinen braun; anßer einigen zarten Sehienenendbörstehen ist keine Borste an den Beinen zu sehen, viehmehr nur die gewöbuliche anliegende mikroskopische Behaarnng. - Fliigel wasserklar mit einer starken doppelten rechtwinkligen Biegung der vierten Längsader; hintere Querader ziemlich steil und lang; am Spitzenrande in der Nähe der dritten und zweiten Längsader liegt ein grauer Sehattenfleck. $4 \mathrm{~mm}$ lang.

$10^{7}$ ans Paragualy [Fiebrig]. Sammlung des Ungarischen Nationalmuseums.

5 nigripes Aldr. 9 , Kansas, Univ. Quart. II 49 [Aptorthus] (1893).

․ - Thoraxriicken blaugrïn mit sehwarzen Borsten anch am Schildchen. Schwinger und Schïppchen gelb, letztere mit langen gelben Wimpern. - Kopf: Gesicht weiß bereift. Filhler schwarz, schwarz behaart; an den Stirnseiten einige hellere Haare. Hinterleib gliinzend blangriin, sehwarz behart. Hüften und Schenkel sehwarz; 
Kniee und Vorderschienen gelb, Mittel- und Hintersehienen braun, Tarsen fast ganz braun. Fligel wasserklar. $4 \mathrm{~mm}$ lang.

Aldrieh besebrieb ein Weibehen aus Kalifornien.

6 Tomnsendi Aldr. ㅇ, Kansas, Univ. Quart. II 50 [Aptorthus] (1893).

․ - Thoraxrieken glinzend und griin, zart weiß bereift; die Sehildborsten sind gell und die seitliehen Ritekenborsten gellsbraun, anf der Mitte mehr schwirzlich. - Kopf: Gesieht weiß bercift, Stirne gliuzend griü; die Borsten auf den Ozellen und die Seitenhare der Stirn gelblich. Augenhinterrandborsten weißlich. Sehwinger und Schiippehen wie bei den iibrigen Arten, letztere mit weißen Wimperu. - Hinterleib goldgriin, gelb behaart. - Beine nebst Torderhüften gelb, die Enden der 'Tarsen gelırinut; Behaaruug del Beine gelblich. Fliigel wasserhell. $4 \mathrm{~mm}$ liug.

Aldrich besehrieb das Weibehen nach einem Exemplar ans Arizona.

7 tristis Sehin. O', Novara-Reise, Dipt. 217. 21 (1868). America sejt.

o. - Thoraxrïieken

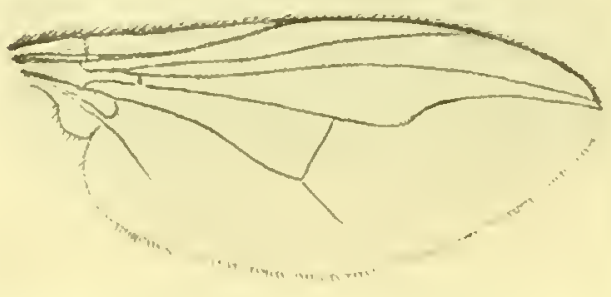

Fig. 147. Mesorkaga Tounsendi Aldr. જ’. Fliigel. $12: 1$. griingold, Sehildehen blan; 'T'luoraxborsten ziemlich lang, schwarz, anch die Akrostikalbörstehen sind von ansehulielier Länge und Stärke, Schwinger sehwarzbraun,Sehtippehen hellbraun mit vielen langen, schwarzen Wimperu. Kopf metalliseb gritin, das breite Gesicbt kaum etwas weißlich schimmernd.Filh-

ler und Taster sehwarz; alle Kopfborsten sehwarz, an Scheitel eine Reilıe langer feiner Frontorbitalborsten. Hinterleib glänzend griun, schwarz behart; aw ersten Ringe seitwiirts stelien lange schwarze Borsten; Hypopygium sehwarz, mit g]eiehfarbigen bandförmigen anßeren Anhängen; die Borsten an den Ringrindern sind efwas länger als bei den iibrigen Arten. - Beine ganz sehwarz und borstenlos; die Schenkel anf iluer Unterseite mit längeren feinen Haaren. Fligel mit etwas brännlieher 'Triubung namentlieh an Vorderrande; der Aderverlauf last genan wie bei laeta (s. Figur 146). $5 \mathrm{lmm}$ lang.

$2 \sigma^{7}$ ans Columbien in Sehiner's Sammlung des Wiener Hofmuseums.

$1 \sigma^{\pi}$ aus den Cordilleren rou Columbia, terra fria [Thieme S.] Sammlung des Berliner zoologischen Musenus. 


\section{Leptorletum.}

Aldr., Kansas Univ. Qunart. II 50 (1893).

\section{liattungscharakter (nach Aldrich).}

Kopf breiter als der Thorax; Gesicht lang und selumal; Fiihler wie bei Sciopus, Ftihlerborste dorsal; Stime kaum etwas vertieft; die seitliehen Borsten klein. Akrostikalborsten in zwei Reilıen. Sehildelıen mit zwei großen inneren und zwei kleinen äıßeren Borsten. Hinterleib des of etwas keulenförmig; das Hypopyginn olıne Stiel, wenig sichtbar. Fliigel an der Basis versehmälert, seehste Längsader fehlend; dritte Läingsadel nach der Spitze hin gebogen, vierte wie bei Sciopus gegabelt.

1 angustatum Aldr. ot, Kansas Univ. Quart. II 50 (1893) et Trans Entom. Soe. London 345. 1 tab. XII fig. 108 (1896) . . . . . Antillate

ot. - Thoraxrieken glänzend grtin. Selıwinger, Sehiippehen und deren Wimpern gelb. - Kopf: Gesielıt sehr schmal, weiß, die Augen beriiluren sich fast auf der Mitte; Stirne glänzend griin. Fiihler klein, gelb, Borste dorsal. Hinterleib gelb mit metallisch griuen Hinterrandbinden der Ringe. Hypopygium klein, sehwairzlieh mit kleinen vorgestreekten weißliehen Lamellen. Beine mit allen Hiiften gelb; Tarsen nur wenig dunkler. Vordermetatarsus länger als seine Sehiene. Mittelsehiene etwas diek, anf der Mitte der Oberseite mit einer deutlichen Borste; der Metatarsus ist etwas länger als die Sehiene, anf der Unterseite (Außenseite?) mit einer weitlïufig stehenden Reilıe kleiner Borsten, die nach der Spitze hin mehr zusammengedriugt stehen; die iibrigen Glieder sind einfach. Hinterbeine olne besondere Beborstung. Fliigel wasserklar, Adermg durehaus im Charakter der Sciopus-Arten. $2 \mathrm{~mm}$ lang. 


\section{Genus incertae sedis.}

\section{Anchinewra.}

Thoms., Eugenies Resa, I)ipt. 506 (1869).

Diese Gattung ist von Thomson auf ein Weibehen der Gallopagosinseln gegrindet worden; er hat sie als eine Psiloms Meig. nabestehende Gattung aufgefaßt und bezeichnet, nieht gerade mit Gliiek; unserem Velstiindnis ist sie dureh Zeichnung und Beschreibung, noel dazu als Weibehen, kaum nïher gebracht worden; man könnte sogar die nicht unbegriindete Vermutung aussprechen, daß diese Fliege iberbaupt nicht zur Familie del Dolichopodidae gehöre, wenn nicht Coquillett in den Proeeed. of Washington Acad. Se. III 374 (1901), Papers from the Hopkins Stanford Galopagos Expedition Results (2) Diptera, dieser ron Thounson beselriebenen Art tibialis ebenfalls Erwähnung getan hätte, der man entnebmen nuf, daß er diese Art selbst gesehen, also gekannt bat. Leider ist Coquillett anf die teils widerspruchsvolle, teils auffällig lautende Beschreibung von Thomson nicht näher eingegangen und hat diese Gattung nicht näiber charakterisiert.

Widerspruehsvoll ist Thomson's Besehreibung insoferm, als er an zwei Stellew derselben von der Fiiblerborste sagt: "Antenuae seta dorsali“ und "seta porreeta dorso instrueta", wähend die auf Tafel IX fig. 8 alggebildete Fliege eine dentlich apikale Borste zeigt, desgleichen die fig. $8 \mathrm{~b}$, in der die Ftihler vergrößert dargestellt werden. Wie ich vom Professor Aurivillius in Stoekholm erfahre, der so liebeuswiirdig war, meine Anfrage zu beantworten, ist die Fiiblerborste der Type von tibialis der Beschreibung entspreehend dorsal und in der Zeiehuung nur infolge ungtinstiger Stellung als eine apikale anders ausgefallen.

Anffïllig fuir einen Gattungsvertreter der Gruppe der Chrysosomatiuae ist die Randaderbildung. Thomson sagt dariber: "nervo eostali longe aute apicem desinente", l. h. also wohl, die Randader reicht nur bis zur dritten Längsader, denn die vierte mtindet sehr dentlieb hinter der Fliigelspitze aus; auch aus der Bezeichnung und Längenangabe der einzelnen Randaderabsehnitte geht hervor, daß die Randader am Ende der dritten Liingsader ebenfalls ibr Ende findet. Herr Professor Aurivillius bestätigte mir denn anch die Riehtigkeit meiner aus der Besehreibung abgeleiteten Auffassung. Die vierte Längsader biegt der Zeiehnung nach nieht wie gewölnlich, an der Flïgelbente anf, zweigt hier keine Gabelader zur dritten Laingsader hin ab, sondern gelat gerad- 
linig verlanfend und mit der dritten divergierend hinter der Fligelspitze in den Flitgelrand. Diese Zeiehnung entsprieht aber nicht ganz der Wirkliehkeit, wie mir Herr Professor Aurivillius mitteilte: die vierte Längsader geht nieht ganz geradlinig weiter, sondern macht, entspreelend den meisten Fligehn der Dolichopodidae, an der Fligelbenle einen stumpfen Winkel.

Nur in einem Punkte, wo Thomson von dem ausgehöllten Scheitel und dem erhobenen Punktangenhöeker sprielt, wird man an eine der Gattung Sciopus :ihnliche Kopfbildung erinnert; alle iibrigen von Thomson anfgefiihrten Einzelheiten sind fiir clie Beurteilung der Gattung und ihrer Siellung ohne Belang. Ich glaube trotzdem nicht, daß wir es mit einer Chrysosomatine zu tun haben, sondern mit einer besonderen Gattung aus einer der tibrigen Gruppen; zur Beurteilung ist die Lenntnis des Mämuehens unbedingt erforderlich und tun wir gut, nit unserer Stellungnabme zu dieser Gattung so lang zu warten, bis das Benrteilungsmaterial vollständig vorhanden sein wird.

1 tibialis Thoms. o, Eugenies Resa, Dijtera 307. 105 tab. IX fig. 8 [Psitopus] (1869) . . . . . . . . . . . . . I. Gallopagos 


\section{Verzeichnis der Gattungen und ihrer Synonyme}

(alphabetisch greordnet).

\begin{tabular}{|c|c|c|c|c|c|}
\hline & & Seit & & & \\
\hline Achrelcus lw. (1857). . & . & . 157 & Hydrophorus Fall. (1823). . & & \\
\hline Achradocera Beck. n. g. & . . & - . 207 & Hygroccleuthus Lw. (1857). & . & \\
\hline Aedipsilopus Big. (1859) . & & .251 & Hypocharassus Mlik. (1878). & & \\
\hline Agonosoma Aldr. (nec. Gurr.) & $(19$ & 5) .360 & IIyptiochacta Beck. n. g.. . & & \\
\hline Amblypsilopnes Big. (1890). . & . . & . .360 & Iphis Meig. (1800) . . . . . & & \\
\hline bates Stann. (1831). . & - & . $\quad 77$ & Leptocorypha Aldr. (1896). & & \\
\hline Anchineura Thous. (1869) & . . & . 382 & Leptopus Fall (1823) . . . . & & \\
\hline Anepsiomyia Bezzi (1902) & . & - 248 & Leptopus Halid. (1832) . & . & \\
\hline ins Lw. (1857) . . . & . & . 248 & Leptorhetum Ahls. (1869). & & \\
\hline Anglcaria Carl. (1835) . . & . & .148 & Leucostola luw. (1857) . . & & \\
\hline Aphantotimus Wheel. (1890). & . . & . 144 & Liancalus Lw. (1857). . & . & \\
\hline & & 97). 127 & Lyroneurus Lw. (1857). & & \\
\hline 550 . & . & . . 104 & Macellocerus llik. (1878). & & \\
\hline hus Aldr. (1893) . . . & . & .376 & ch. (1819) . . & . & \\
\hline 34) . . & • & $\cdot 2$ & is Big. (1859). & . & \\
\hline 69). . . & . & . 204 & Megistotylus Bigr. (1888) . . & & \\
\hline actus 1 & . . & . 247 & Megystostylus Big. (1559). & - & \\
\hline (1851) & ). & . 220 & Selin. (18 & . & \\
\hline 32) . & . . & . 220 & (1893) & . & \\
\hline$C h r$ & . & . 248 & 6) . & . & \\
\hline 857) & . . & . 248 & l. $(1899)$. & . & \\
\hline 24) . & . & - 187 & Big. (1859) . . . & . & \\
\hline 896) & . & 212 & Latr. (1809) & & \\
\hline Condilotylus B & . & . 951 & us Pigr. (1859). . . . & . & \\
\hline$(1859)$ & . & .251 & $(1890)$ & . & \\
\hline 3). . & . & & R. 11. sulog. & •. & \\
\hline upsilopus $\mathrm{B}$ & . & . 251 & $(1899)$ & . & \\
\hline horus Meig. (1824). . & - & . 164 & Parhyclrophores Wh & & \\
\hline stracus l,w. (1861). & - & 121 & . $(1861)$ & . & \\
\hline$u s \mathrm{I}$ & . & 9 & es Itheel. (1890). & & \\
\hline Urepanomyia Whecl. (1898). & . & . 121 & T'eodes 1w. (1857). . . . . & & \\
\hline Drymonoefa Beck. (1907). . & - & . 155 & Perethinus llalid. (1832). . & - & \\
\hline Lit L & . & 155 & Phylarchus Ahr. (1901) & & \\
\hline ptopsilopus A & . & . 360 & Plagioneurus Lw. (1857). & . & \\
\hline k. 11. g. . & . & 98 & Plectropus Ilalidi (1832) . . & . & \\
\hline Gymnoceromyia Big. (1890) . & - & 251 & Polymedon 0. Sack. (1877) & . & \\
\hline Gymnopternus Lw. (1857). . & & - 31 & Porphyrops Meig. (1824). & . & \\
\hline Hammobates Rond. (1857). . & & & Psilischium Beck. n. g.. . & . & - \\
\hline IIercostomus Lw. (1857). & & & Psilopodinus Big. (1890) : & & \\
\hline Hydrochus Fall. (1823) . . . & & & Psilopodimus Allr. (nec. Big.) (1 & & \\
\hline
\end{tabular}




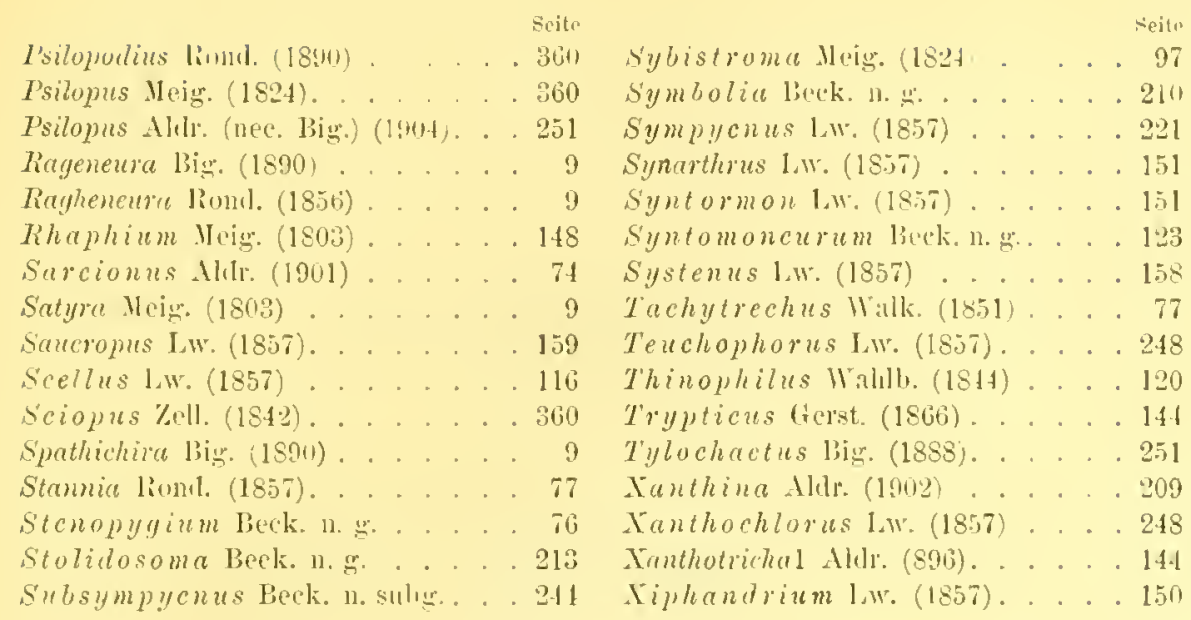




\section{Zusammenstellung der Arten}

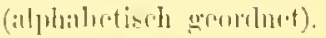

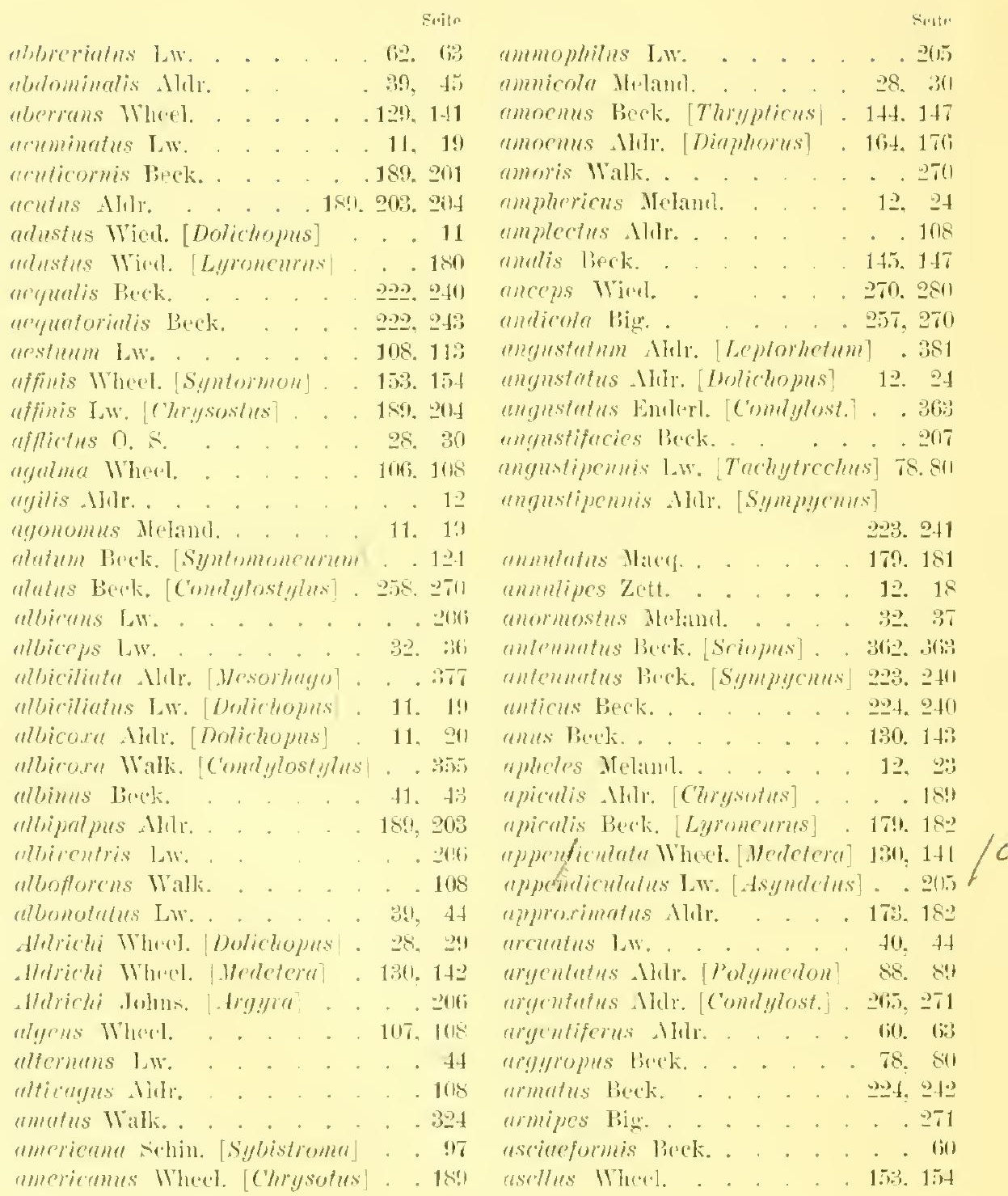


usterquinus lije. . . . . . . . 279 utricuulu. slilr. . . . . . . 262. 972 ulrolumellalus 1]11. . . . 263. 272 ntroir Brek. . . . . . . 258. 278 auretus Alilr. [Macellocemes] . . . 93 murutus 1w. [Clorysotus] . . 190, 304 aurifacics dlur. . . . . 1:. 20 anrifer Thoms. . . . . . . . 32 anrieituta Wlonel. . . . 130.143 arielus l.w. . . . . . . . 117

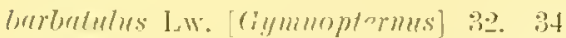

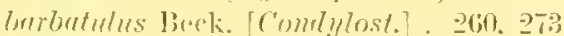
barbatus Lw, [chrysolus] . . 190, 203 burbatus 1hlr. [Chrysotimus] . . 248

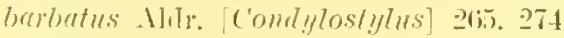
laryenpmus roquil].

12. 29 basilaris Wied. [Comblylostylus] 254. 27t

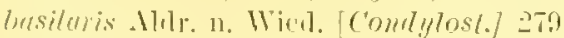
butillifer l, w.

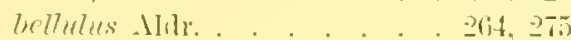
bellus .1111. . . . . 4. 4. 48 bicolon Lu.

30

lifidus lierok. . . . . . . 235. 2310

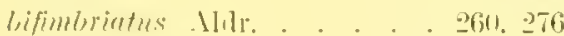

bifeactus 1,w. . . . . . . 1.9. 1

bifmoms Wialk......... . . 64

bigeminatus Slall. . . . . . 5.! tit

bigultutus beck. . . . . . 50, 6it

binodutus l.w. . . . . . . 92, 92

bimenctutus Mare. [Dolirhopus] . 12

bipunctutus Mace. Turhytrechus]. St

bispta lierk. . . . . . 35:

bisprinosus Mlili. . . . . . 180. 187

lituberculatus Mary. . . . . 294. 970

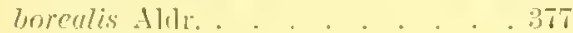

masilicnsis Fchun. . . . . . . . 37 . .

brevimamus Lw. [Doliclu(n) ns] . 1-2, 201

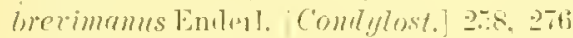
hreripennis Mriu. . . . . . . . 1. lireris lieck. . . . . . . . . . 278

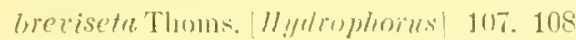

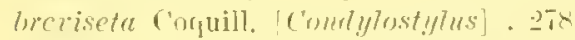
brevitursis Beck. . . . . 2.25. 240 brumneus llikr. . . . . 12. 23)

crarsar Bricki.

$.711 .2-19$

alnimes Mlatinal,

$12, \quad 19$

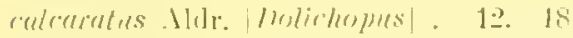

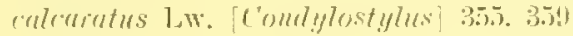
inleeritu Lw.

$2(16)$ calritrans I,w.

- 210

califormirnsis When. . . . 130. 14:8

callosus lieck. . . . . . . 89, lis

ronaliculatus Thoms. . . . 12. 20

camescens Whirel. . . . . 1616. 10)

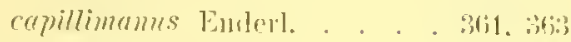

carbonifert Lw. . . . . . 15!!. 1601

curoliniensis Big. . . . . . . . .5.5

custus Lw. [Sciopus] . . . . 869. 364

castus Whed. [Polymerlou] . . RS, 90

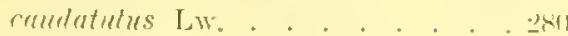

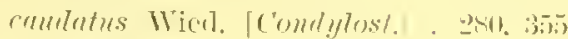

courlutus dlile. [Achalrus] . . . . 157

remtius Lw. . . . . . . . Jofi, 1019

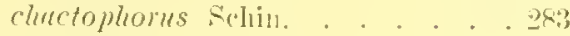

rhalcochrus Lw. . . . . . . 3. 34

clulybacus r. Riml. . . . . . . 180

chamacleon Berli. . . . . 16.5, 176

rhorirus Wheel. . . . . . 1!11, -211

rliysolyyus Walk. . . . . 117. [11!

chrysoprosins llatk. . . . . 283.30 .

rhrysostomus Lw. . . . . 12.

ciliatus Beck. [sympyrmus]. , 2026, 2-24-2

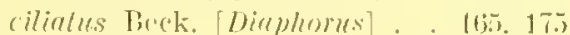

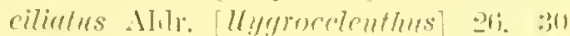

ciliforus linek. . . . . . 40. 45

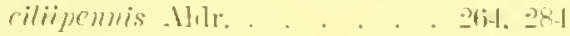

riliipes Alilr. . . . . . . . . .85

cilitursis $\mathbb{W u l}_{1}$. . . . . . . . . . . . . .

cinerriventris Lw. . . . . 1\%3, 1.5

rinereus Ponis . . . . . . 11:3

cingulata Lw. . . . . . . . . 207

rlenthretus Macr. . . . . . . . . . .

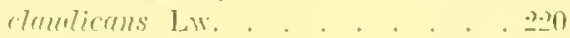

raviculalus Lw. . . . 4. 41. 46

rlarigerellus llherel. . . . . . .

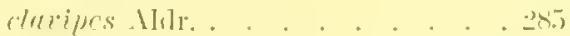

rlunulis Coquill. . . . . . . . 28.

cochlearis Buck. . . . . . 2-25.

coerulesecus 1,W. . . . TH(1. 1S.

cogmatus I,w. . . . . . till, (ii)

collinus Plilippi . . . . . . 10

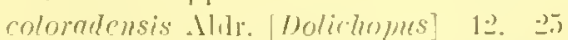

comatus 1,w. Dolichopus]. …20

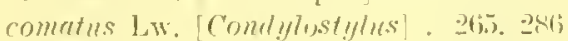

completus Beck. . . . . . 250, 207

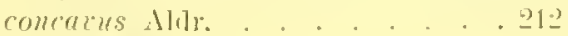

ronrinmarius say . . . . . . 1:41

roncolor l'hilipipi . . . . . . 10

confluens lieck. . . . . . 26011. 20-4

comstuguineus ltherel. . . . 28. 30 
consobrimes zott. . . . . . . . 149

contigmes Alir. . . . . 168. 176

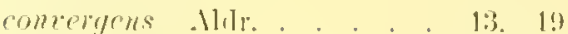

converm lierk. . . . . . 24ti

compllletti Mllr. . . . 13. 2.5

corex Lit. . . . . . . 13, 18

corculum Wilk.

cormutus lw.

costalis Al]1. [Sriopus.

costulis l,w. [Chmysotus].

rostulis biack. [Puruclins.]

correlis Lw. [Gignmoplermus].

coprelis Alell'. Symmygenus

corulis dlitr. [Comblyfostylus].

reressimmilu Lw.

remotus 11.8

reinicumis Wherol.

crimipes lineli

crinitus Nlilr.

ctrmomes buderl.

rupress say.

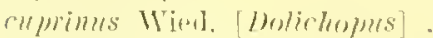

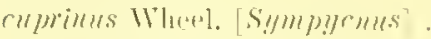

cupalifer Mlatr.

cynurem lieck.

rymenss WTu,

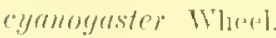

cylintrien Las.

dukotensis Alit.

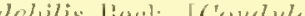

lebilis Jow. [llerenstomas] . . "3: 36

teceptims. Mlal.

decom dlate.

decorizess lieck.

degener moen.

drlicutus Walk. ['ommlylost.

drlieutus Lw. ['brysotimus]

depressus Alitr.

derempte Walk.

despicutus Lw.

verersus Lit.

dichomatas bige.

rifficilis Lw. Herecostomms.

nifficilis lieck. [lementiess].

diffusns Wiedem.

digitulus liack.

$\left.266^{2}\right)$

rlilututer biock

diminliuta Lw. [.Ventogone].

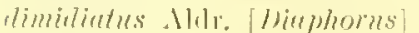

dimidiulus Lw. [Comdylostylus
$19(1,2 n 4$

361.341

190. 2014

40. $46 \mathrm{i}$

$9.07,040$

- $(i 1$.

3‥ 80

-2. 30

874

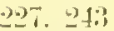

35.5. 351

2.5? 989

, $1:$

13.

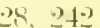

45. 117

$-15.9$

(i).

I31. 140

0616

13, 21

166. 179

15). 180

$-3460 .-3641$

$$
\text { . }
$$

, :ints

- $\because 48$

나.) 39.91

- . $1(10)$

32 .

1i.) 19

. 124

30.805

t?. 47

(i.) (it)

1:31. 111

15!) $16(61$

$.17 i$

$238.29 !$ diminurus Jieck.

situ

259.98

11\%. 109

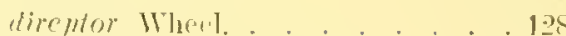

discifer Mlatr. [P'amelins] . 41. 10

discefer Stann.| Dotichomes] . 13. 15

eliscolor Zett. [forphymespes] . . . 150

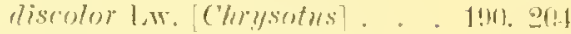

discolor Big. Xiphementum . . . 1.00

dissimitis Whece. . . . . (i2.) 6 if

dirersipes liock. . . . 251. 294

dorsalis Lw. [Comblylustylus. . . .994

dersentis Lw. [Scionus] . . 369.361

doryerems liw. . . . 18. 18

mabioses Pliliuni. . . . . 10

dubins Mldr. . . . 16iti. 175

detplicatus Slik. . . . . . 13. 25

der. Wied. . . . . . . . 204

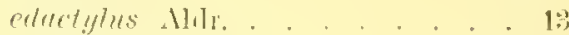

effituthes Wherel. . . . . . . 1,00

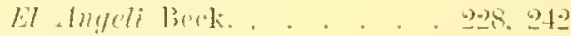

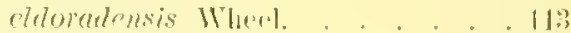

clectus Walk. . . . . . . . . .94

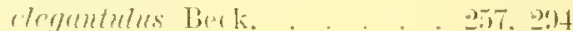

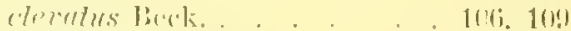

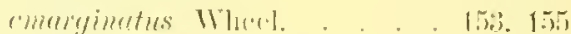

e'nigme lloland. . . . . . 19. 19

cymes lw. EEntursus!. . . . 155

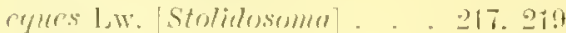

cuncestris For. . . . . . 205

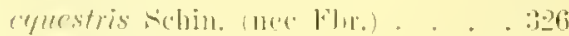

crectus beck. . . . . . .

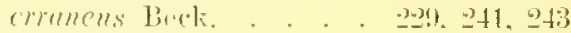

creductylus LW. . . . 13. 11i. 21

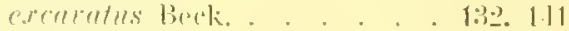

erceplus lieck. . . . . 1!(1) 2010

ercipiens linets. . . . 133.141

ercisus Hell. . . . 1511 2014

eremtus Walk. . . . . .

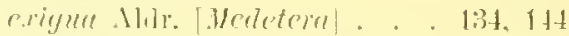

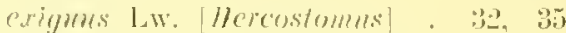

crilis T'milippi [Dotichopes'] . . 10

erilis LW. [Hereostommis] . . :

cryulisitus Walk. . . . . . . . 297

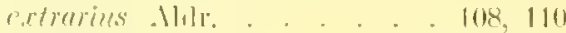

commuis Thoms. . . . . 166, 178

cerustus Malk...... . 117

fucinlis Beck. . . . . 41, t8

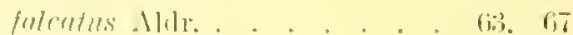

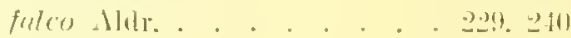

fuscintus v. Risil. . . . tit. 
frlir Peck. . . . . . . . 207. 2989 irmoralis Buck. L'anadins. . 41, t8

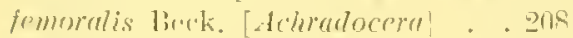
femmortus Big. [Chrysotus] . . . . 1!1 frmerretus say comblylostylus . . Bati

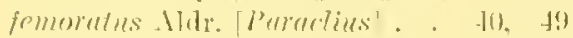
femorrtus Walls. [Dirmhores] . . 16ti festinans rompill. . . . . 13. 16 fitifer I,w. Seollus. . . . . . 117 filifer Alar. Prandius . . t.2, 49 filifer Walk, [leyistostulus| . . 37t filiferus Ahl. . . . . . . . . 117 filiformis Becl. . . . . . 256, 298 filizenicillutus timlert. . . . 257,300 filimes 1, . . . . . . . 362,365 fimbriatus LW. . . . . . . 32.36

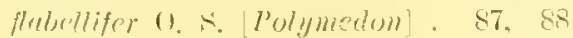
flubellifern liseck. [holetern] . 134, 1t? flugellutus beck. . . . . . 25i), 300 fluyelliportex lieck. . . . 255, 301

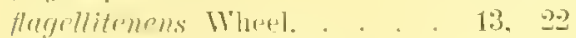
flucicomis Aldr. [Sciopus . . 362, 365 flarirornis Aldr. [Comfylostylus] . 302 fluricomis Buck. [Horleteru] 135. 143 flaricora Alle. [Comlylostylus . . 3(B3

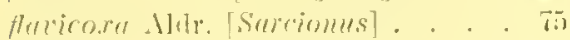
flurilles Alur. Comblylostylus] . .3083

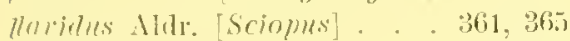
flurifrons Thilipri. . . . . . . 10 flureilumellutus livek. . . . . 251), 368 flurimanes liace. . . . . . . . 304 flripipes MH1: [Diapherus] . . 167. 175 fluripes schin. [Pelastowrurus] 61. 67

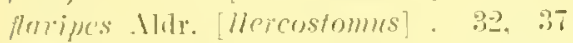

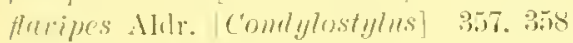
florus 1,w. |llercostomms] . 9.2, 84 flu1 us . Ihir. [Chysotus] . . . . 1!11 flomidoms Wherl. . . . (51. 67 floridensis Alil. foriduln Wheel. 78,81 159 foripipates Itir.

$26 \mathrm{t}, \mathrm{BOH}$ .247 fortumalus Whend. frutellus Alur. [Asymictus]. . . 08
fratellus Buck. [Lymoncurus] . 18i). 183 frater Ild1: . . . . . . 20?, 240

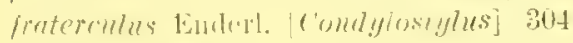
fraterculus Whon. [Thryllirms] 145, 147 frequens Lw. $32, \quad 3.5$ Hontulis $1, \mathrm{~m}$. . 347 fullipes 1 w. fumipemis Lw. 13. 21 . $11 !$ fundilor LW

11. 95

furcifer Lw. . . . . . . 93. 67

fusrirmis Allu. . . . . . 40, 4! fusifomis link. . . . . . f!. 4 !)

gemimms Brok.

2015. 2016 yemmifor Walk. . . . . . . . 3nt yemualis Lw. [bianculus] . . . . 11! gemulis Alir. [Condylostylus] E(b), :301 germamis Whenl. . . . . 11. 25 giluipes Endert. [Comlylostylus] . . 30.) gileipes Enrlerl. [Sciomes] . . . . 366; ylalintor Mik. . . . . . . . . 12-3 globulilursis Bock. . . . . . 230. 24:3 yracilis Mllr. [Dolichopus] . . 14, 21 yracilis Aldr. Comdylostylus] 206.2.305 gracilipes Mlitr. . . . . . . . . 1.59 yrandis . Mlr. . . . . . 11, o6

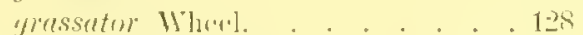
gratiosus Alir. [IIyllophorus] 10., 111 gratiosus Beck. [Sciopms] . . Btil, Bui yratus bw. . . . . . . . 18 yriseirmllis bieck. . . . . . . - t griscoprasins 1101 1. . . . . . .305 grocnlumlicus Zott. . . . . 11, 18

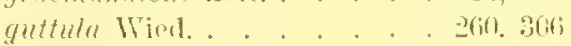
gntimenis Romal. . . . . . . . 305 guncumensis Macul. . . . . . . Buri

herectina Walk. . . . . . . . 3hi mematus lieck. [Sympyemes . 231, 241

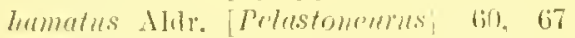
lumifrumis liock. . . . . . 258 306 lustutus Lw. . . . . . 14. 20 lellims lw. . . . . . . . . 18 Henshani Whem. . . . . 11 . 15 leteronemres Mat.r. . . . . . 50 lleyleni Tierl. . . . . . . . 1.1 limmlus Whoel. . . . . . 15i3, 15: hirsutus Beck. Tomblylustylus gati. 307 liersulus 1hlr. [Chrysotus] . 191. 2014 lirtipes Ahlr. [Condylostylus] zhio.:304 hirtipes lw. Stympychns] . . . . . 2010 hirtulus liju. . . . . . . . . . . . . . . . . . horticula Philipji . . . . . . . 10 memeralis Mlur. . . . . U1. 50 humilis Lw. . . . . . 32, 3:5 hybrilus Mrland. . . . . 4. 50 highlrophilus dlil. . . . . . . 119 idulünsis Mblt. . . . . . . 29?. :01 
inmolitis Burk.

$26: 308$

iefuerretus linek

-263, 309

ignootus biock.

26. 309

imituter Pacels.

191. 208

203.910

957. 311

imererrtor Alll.

257, 319

imperiolis Flor.

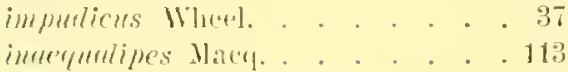

incertus Walk. . . . . . . . . 192

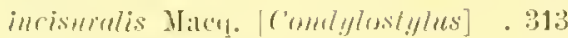

incismalis Tw. [Dolichomes] . 11, 98

incomernens Wheol.

14. 18

inermis Allr. [chrysotus] . . 192. 204

inermis Lw. (comlylostylus]. 357, 359

infiritus Wall. . . . . . . . 313

infumatus lluls. . . . . . 2.01, 898

infuscalus lige. . . . . . . . 111

immolutus Lw. . . . . . . 118. 111

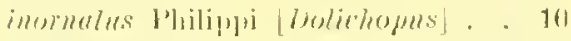

immontus Jlar. |fomdylostylus] 2063, 313

imsularis Mlll. . . . . . 977. 814

intrger Buck. . . . . . . 23:2, 241

intentus Malant. |bolirhorms 11, 1s

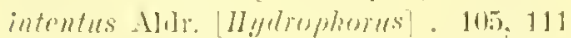

intereptus lletr. . . . . .55, 314

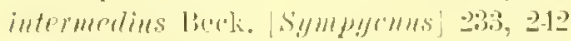

intermedius Buck. |Torhytrerh.| TE, \&1

interreptus Lw. . . . . . 2015, 206

irrasus Walk. . . . . . . 6 67

Johnsoni Aldr. [Dolichopus] . 14. 17

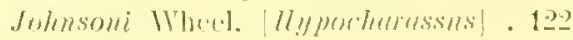

jurnurlus law. . . . . . . . 814

jumetus Conaill.

7!) 80

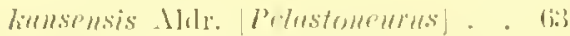
limusensis Alir. Doulichopus: 11, 19

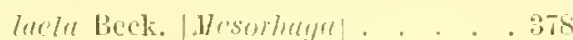

luetus Lw. [condylostylus\}. . . . 315

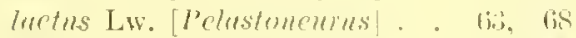

latus Berk. |Lyromeums| . 179, 18:3

lusvigutum lieck. Irsilichimm . . 90

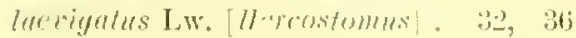

lapeis Beck. . . . . . 43, 51

Incinatus Buck. . . . . . 15, $20 \% 3$

lergotis Where. . . . . 153, 154

lumellatus Lw. L'elustoncums 60, 68

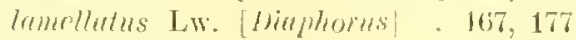

lamellicomis Tlonus. . . . . . . "?!!

lum urostcthus l'hilipul . . . . 10 luterulis siay. . . . . Jo9. 1601 laticurnis link. [Mydrophorns 101. 111

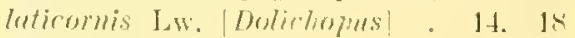
lulifuries liculi. . . . . . li3. 51

Intipemis J, . . . . . . . . 21

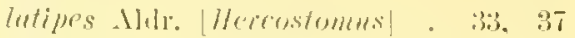

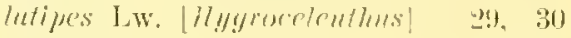

lutitusis lincli. . . . . . 70, 8? lectus Pieck. . . . . . . . 361, stiti

lepidus Wallk. [Comlylustylus] . . 315

Lepricari Hacer. . . . . . . . 3lli

leucurpilus LW. . . . . . 41, 50

lemostomus T.w. . . . . . 167, 177

liemusu Where. . . . . 159, 161

limearis dlill. . . . . . . . 248

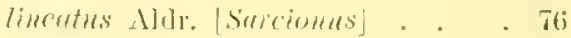

limentus Lw. $\{$ Sigmpmemsis]. . 234,241

litorms Fall . . . . . . . 11:3

lebrtus Lw. . . . . . 11, -4

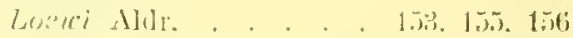

longirmule lw. . . . . . (i.2, 68

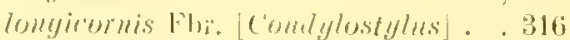

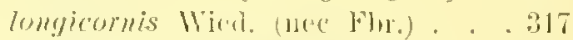

longiermis Tolush. [1/egisfostylus] . 374

lomyiromis Flor. [Megistostylus] . . 374

lompifaries lieck. . . . . . 88, 90 longimames Lw. [Tolychepus]. 14: ?n

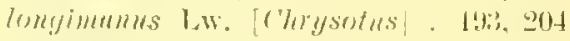
longivenlmes dhis. . . . 19:3, $20-1$ longipemis Lw. . . . . . . 14 longipes Lw. [forphyresps] . . . 1:01

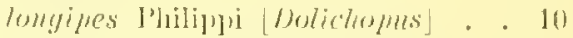
lomyiselu compill. [comblylostylus] . 317 longisetoses llul]. [Heyistontylus]. . :T. lueirlum licek. . . . . . 214, 219 lugnlor Lw. lihnphimm . . . . . 14s lugulvig Lw. [Prlusfoncuins]. (ii), bs lnnifer Lw. . . . . . . 3; :3) lutepormis 1.4. . . . . . 14

muculu Wincl. . . . . . . 361, 367 inaculipes 11 all. . . . . . . 6 . . Magdalenae Wholl. . . . 107. 112 mercides What. . . . . . 234. 041 merginalis Borels. . . . . . 1801, 184

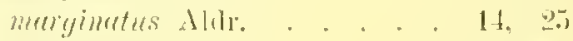

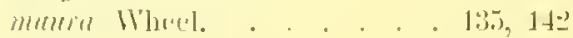

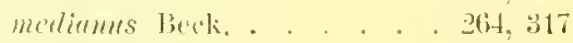
medintinctus lieck. . . . . 168, 176 molumples 1.w. . . . . . . . 1.8 Melumbli bick. . . . . . . 1.5, 203 
melanocerus Lw. . . . . . 15, 83 meniscus L,W. . . . . . . 3is, 35 merilliomalis lifeck. . . . . . . 208 metalliun Berk. . . . . 19.5, 144 metatursalis Thoms. . . . . 33, 37 inctutursutus Beck. . . . . 194, 203 mericanus Ahlr. [Comblylostylus] . 319 mericamus Mhr. [Sriopus\} . . . 368 mericamus litin. [Pelastomenras] . . 68 miner Aldy. [Thrypticus] . . 145, 147 minor Berk. [Meletera] . . 136, 149 mimuta Lw. [Aryyra] . . . . . . 206 mimutus Lw. Ilercostumusi . 30. 36 mirificus Heland. . . . . . 38. 3.5 misellus Helant. . . . . . . . 15 moechus Lw. . . . . . . 9. 9. monstruosus 11. . . . . . . 117 monlicolus bick. . . . . 234. 241 montivagus Wherl. . . . . 153, 155 mundus Wiod. [Comdyluslylus] 215, 319 mendus 1.w. Diaphoms| . . 169.175 myosota 1. …. . . . 15. 19 mystirus lieck. . . . . . . 39, 5-3

meylectus Where. [Thimophilus] . . 120 neglectus wherl. [Pelastememus] 60, 68 nemoralis Plilippii . . . . . . 10 nertosus Beck. . . . . . 107, 117 niyer Aldr. . . . . . . . 194, 204

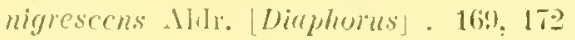
migrescens Wheel. [7'plustrneur.] 67, 68 niyribarbus Lw. . . . . . 33, 36 nigricams Nsig. . . . . . 169, 176 witgricitiutus lieck. . . . . - 235,243 niyricornis Mlrig. . . . . . 15, 23 nigricora law. [Porplyrups] . . 149 nigricorte liock. [Sympycules]. . . 2355 niyrifemorutus Walk. . . . . . .857 nigripes Mace. [Comelylustylus . . 319 niqripes Aln?". [Mesmlunn] . . . . 379 nigripes l.w. Aryyru| . . . . 206 nigripes LW. Mndetera]. . 10:5, 143 niqripes Al]r. [Parartius] . . 40, 53 nimius All1. . . . . . . . 88, 89 nobilissimus 1lill. . . . . . 264,320 molatus I.w. . . . . . . . . 247 noditarsis buck. . . . . . \$32, 368 nubeculum licek. [Rhaphium]. . . 76 mubeculus linck. [("onlylest. Dot, 320 mbilus šlt. . . . . . . . 194 medipes linel.

25.5. 3201

mulus I.w. .

1.3. $\geq 1$

aleordatus Alitr.

15. 21. 24

whiqums Lw. 194, $2013,-2(14$ obscurus say. ubteclus linck. uceamus Matey.

. : : :;)

79. $\quad 8 \%$

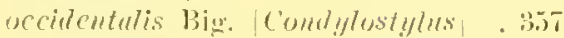
uccilentulis Alur. [Dolicherpus 1.5. occidentulis Whasel. Pelastonourus]

(i1. 68 occidentalis silu. Bedetera 135. 141 occidentulis Alur. Ssyntormmen 1.53, 1.54 occultus lieck. . . . . . 181, 185 ochiracen Berk. . . . . . . . . 211

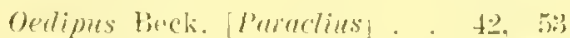

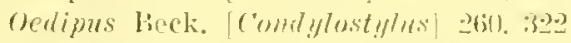

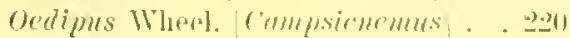
Olga Alil.. . . . . . . . . . 1ə1 Olympiar Aldr. . . . . . !:\$ $! 4$ opaces l.w. Dinuhurns . . . . . 16!!

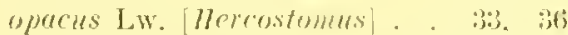
orbicularis lipek. . . . 15!) 160. 16:2 Oreas Wheel. . . . . . . . 947 seutes tw. . . . . 15. 1!

juchycnemus L.W. . . . . . 1.5. 201 paluestricus lw. . . . . . 15, 21 pallens Wiod. Sriojus' . . $366^{-2}, 360$ mallescens Big. . . . . . . . . . . . prillipes 1.w. . . . . . 191, 201, 2014 palmuris 1. . . . . . 153. 1.44 palparis lieck. . . . . . 194. $2(1)$ pulpiger Where. . . . . . 170, 177 puluster Moland. . . . . . 15, 28 pantomimus $11 \mathrm{m.}$. . . . . 15, paraloxus 1lik.. . . 195. 201. 2014 partitus Mel. . . . . . . 15, 18 purrecornis Lw. . . . . . . 33, 36 parculus All1. [Liaphoras] . . . . 170 parculus Alin. [chrysutus] . 195. zol

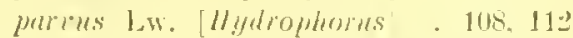

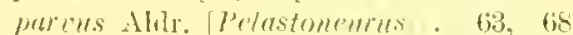
patellitursis lieck. [sympmenus 236ti. 243

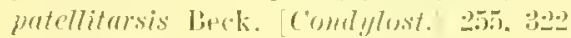

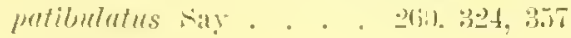
P'aulsoni Hhilip.. . . . . . . 148 late dill. . . . . . . . . . .8 pectimutus linel. . . . . . Etiti. : :-5 pertinifer llhwel. . . . . . . 120 


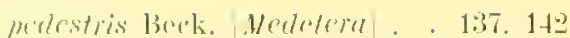
pedestris beck. [romlylustylus] 256,326 monilliger Endrol. mmifor Aldu. prhsus . Mllr. perartus Malk. jermorlins Vialk. permutums Bunk. . pernir Mll. .327 permmus liveck. jerspirmus Beck. petulea Whanel. phibocteles llated. philombrims Wheel. philtrmm Maland. uhore Mlis. -3.5, 328 108, 112 . 328 .398 $-17.219$ 15. 23 41,43 213,328 $13 ! 3,145$

- 230

107,119

19.5, 107,112 33. (35) 195, 2(14 6으. fis 19.5, 2(1)?

41. 4. 357,360 - . 320 2.96. 243

militarsis lineck. pilasicormis Malli. pilosus law. . 68 $25 ! 9,320$ 1117,119

14. 15

platyprosomus 14w. matypus linek.

plumberns dlit phomiremalu bllle. plumipes secopl. unmitarsis Fall. jhomosns didr. promitems Whenel. poliongaster 1'hil. politus l,w. . poller 1). polychromus lije. portoriensusis Dlacy. posticutus Virinl. . precorer T,chms.

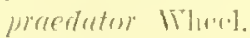
proestans Dlly. proeustus 1.w. masimas 1,w. matimende Where. pretiosus IValk. menceps Wheel. procerns Wheed.

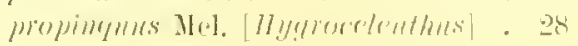

$287,2-18$

$1(15,113$

. . 910

15,29

15, 93

15. 25

. 33

. 117

ii.i. 36

1...

.330

.380

23). 330

1116. 119

. 128

2(ii, 331

15, 94

121

.331

(3), 143

23
$1116 ; .214$

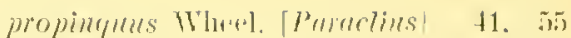

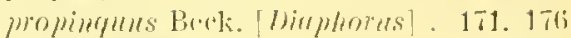
motrerns Mr.

79. 8. manosus Wharel. . . . . . . 129

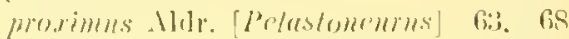
morimms Mlle. [Chrysotus] - 196, 204 psittarims L.w. . . . . . . .60. 860 peroperlus sichin. . . . . . 7!?. 85 purjil $\mathrm{L}$. $\lceil$ Dolichomms? . . 15. 20

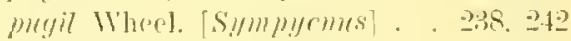
pulcher lviol. . . . . . . . 331 pulchrimmens lig. . . . . . . 15 palchipes lieck. . . . . . 2062, 331 pamilir Lw. . . . . . . 411. пи punctiger l'hilipul . . . . . . 111 munclipennis Sia . . . . . . 61

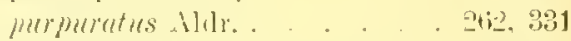
mommens Allr. . . . . . 266,993

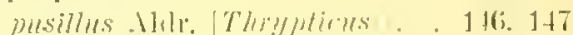
pusillus Macr. J'monclins . . . 55

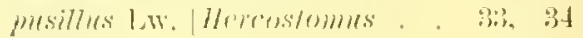
mesie Lw. . . . . . . . . 948

yuartratus Alile.

15i). 15

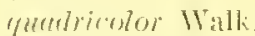
. 8333 renalrilumellatus 1,w. . . . 16. 95 cundrinelutus Mlll. . . . 4:3. 5.)

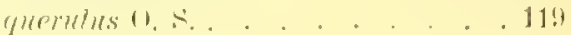

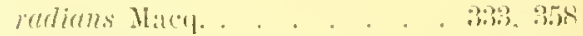
rmmifor Lw. . . . . . . . 16, 21

inptor link. . . . . . . 158

Remientrogi when. . . . 171, 177

whertus blin. . . . . . 16, 202

weyntromis linek. . . . . 116i, 114

jemipes Wlilles. . . . . . . 16

ipmilestrus Vi.1. . . . 16, 23

robustus licek. . . . . . 40, 5.

motundierps Lw. L'orphypops|. . . 149

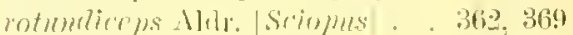
rabellu l,w. . . . . . . 159. 161

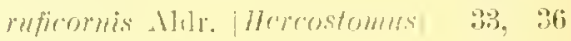

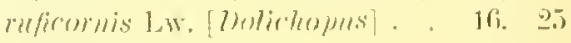
rilprestris Halirl. . . . . . . . 13

smlad Whome. . . . . . . . . . . .

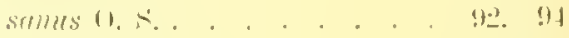
sarotes Ln. . . . . . 16. 16

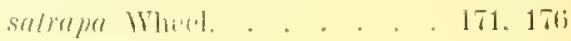
Sumi Wierl. . . . . . . . . 370 
screber Lw: 3.5. 3.5

16. 2 ?ti srapularis I,

Srhunsei Beck.

-361. 264. 3939

Selünherri Boh. sciutillus I, .

*i1. 360

$3(0,33 \%$

16.

83. 34

(i) $\quad 09$

17. 176

$$
\text { . } 266
$$

semuiuter Burct.

325

$60, \quad 69$

.56 .336

16. $9 ?$

16. 23

16. 27 150

15.?. 160

161. 114

. 119

․ㅗ․ 240

269.937

180. 180

-25. 398

10. - 11

$14 f i$

ำ-7. 938

. $1 ., 6$

3.39

$3: 39$

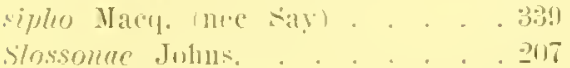

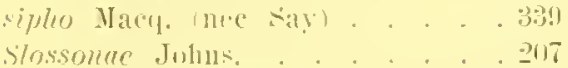

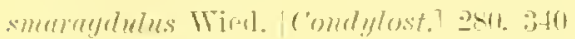

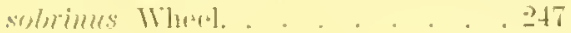
socius Lw. . . . . . . 1‥ 19 somalis Lw. Dirphorms] . . 172, 175 sordulis Whese fllydropherust 10\%. 114 sestertus burek.

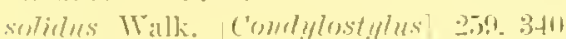

smdidus Alil. . . . . . . . . 1.57

spectubilis Lw. Hinplems . 173. 176

spectabilis ],w. [llercostamms :3is. 34

sulecristes liruw. . . . 16.

splemdimlus lw.

16. 21

spinimmmus Zitt.

sumemifer lieck.

sligmat Flit. Cimelylostylus

stigme Wivel. (110" lohr.) .

strutreegus Wherel.

Srinticullis Bork. stylatus beck.

snrtis L.W.

snarimm Walk.

smbapiratis linel.

smbeilintus Lw.

suberordatus lierk.

subrosfatus l,w.

subulilatatus 1.w.

sulopubescens lines.

17,175

subututus low

smperbiens 1.w. . . . . . . . 15!

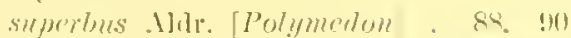

superlus wierl. [condylost. . 2061, : 44

superfluns schin. . . . . 3til. 34t

syntormoildes Wheel. . . . . . . . tit

turniatus lierk. . . . . . 61. 71

temypus Lw. . . . . . . 1.j. 16

teapums Alals. . . . . . . . . I!s

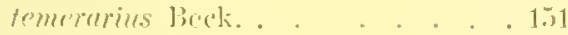

tener 1,w. [Sriopus] . . . . 36; : :3

tener Lw, Dolichorpus . . . 11i. פ1

temuipes Mde. Dolirhomms] . . . 16i

temuipes Btek. [Symmycmss]. 235. 241

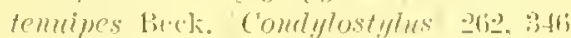

temuis lw. . . . . . 15!) 16t1

ferminulis Beck. 'Comlylust.) . 26ti, stti

tominulis Lw. Dolicler)mss] . 16.

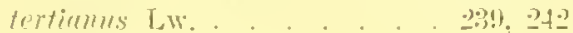

testurripes liomi. . . . . . . . . . . . . .

trtrints Lw. . . . . . 1ii. 1s

Thersites Whesel. . . . . . . . . . . 1

Memacious Plilipui . . . . . 198

tibiolis Wien]. [Comlylustylus] 266, ist7

fibialis Thoms. [Anchinewa . . . 3.3

Titicre"t buek. . . . . 116i. 114

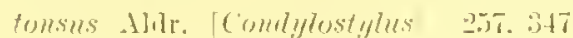

tomsus Lw. [Holichomes] _. . 1:

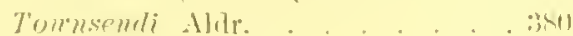

traperailes Beck. . . . . til. II

trimuguluris Alul. . . . . . \$s.

trirlessomen big. . . . . . . 347

tripurtitus Alit. . . . . . . 12ti

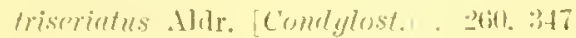

triseriatus Enderl. (nes Mloli.) . .

tristis law. [Hercostomust . . 33. :3

tristis sohin. Vesmharga . . . . Bst

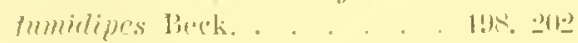

turbilus bock. . . . (jo). it

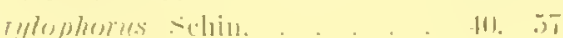


mulnipictus linck. . . . . 59. 79

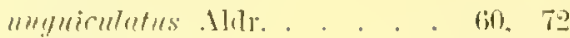

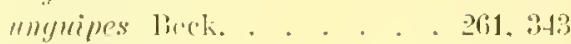

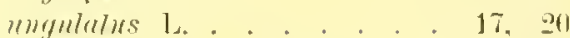

numulirena Walk. . . . . . 358

nniculor Berek. [Metetern] . 139, 143

unicolor Lw. [Herrostomuts] . 33, 37

umifosciutus say . . . . 362, 372

uniscrintus beck. . . . . 259, 349

muisetn Brek... . . . . . . 201, ח.

mivitutus LW. . . . . . . 116

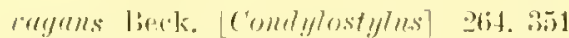

rayans Lw. P'etastonearus] , fi1. 78

inlitus law. . . . . . . . .

raripes corpull. . . . . . 17.

rariolutis 1,w. . . . 17. 21

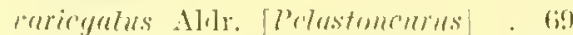

rariegatus lav. [Comlylustylus] . . 351

rmicgatus luw. [Sriomes] . 31iz,

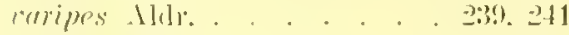

rarims Walk. . . . . . . . wh

rerrem linek, . . . . . . 95

respotus lWherl. . . . . . . 247

reles law. . . . . 189. 1 to

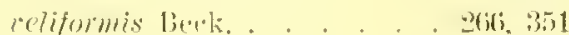

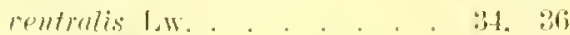

remastus dlite. . . . 4. 57

retitns bleland. . . . . 34. 37

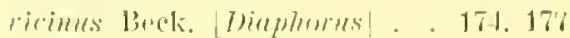

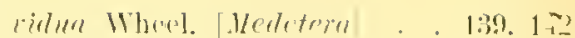

villua beck. [Linncalus] . . . . 118

rigil 0. . . . . . . . . . 117

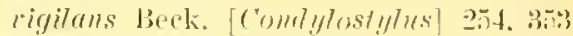

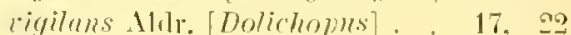

ciolucezs Hacl. . . . . . . .838

virago Alilr. . . . . . . . . . 117

virgo Wied. . . . . 280.333, 358

virilicolor linek. . . . . . 139. 14 :

riraticora dlit. . . . . . 358, 35s

ririflifemore Мa"r. . . . . . gno

viriliflos Walk. . . . . . 110

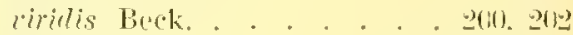

villalus Lw. . . . . 17, 17.96

vividus LW. . . . . 201. 2010

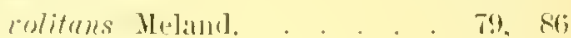

romerer law. 78.80

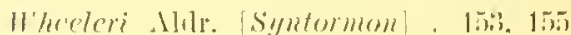

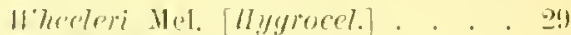

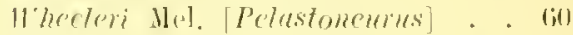

Irillistoni Wheel. [Thypticus $\rceil$ 146, 117

H'illistomi Aldr. [Dolichopus] 17. 27

miscontenensis Whewl. . . . 2011. g04

andhorremus Lw. . . . . 17, 1!

menthotricha Beck. . . . . . 140

rerophitu Whete. . . . . 141, 144

ripheres Wherl. . . . . . . 101

\section{Druckfeliler.}

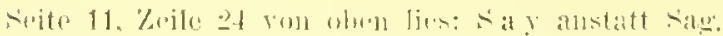

suite 19, Zeile 13 von ohen lies: t). s. anstatt Lw.

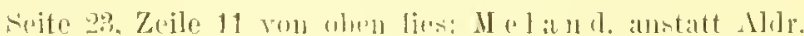

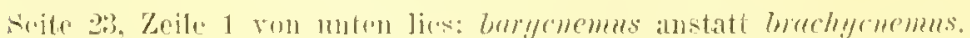

soite 89, Zeile

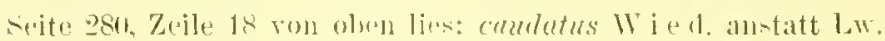




\section{Schlußbemerkung und Nachtrag.}

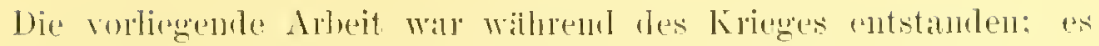
wal natiolieh nicht möglich gewesen, lïr diese die anslämdischo Literatur

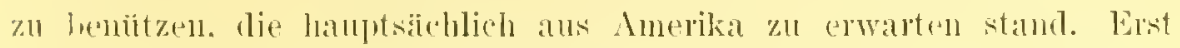

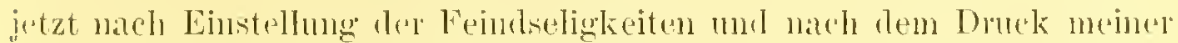
Arbeit fließen mir die von amerikanisehen Frenulen gesanten Arbeiten

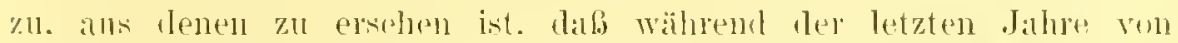

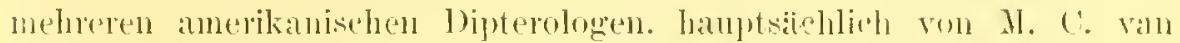

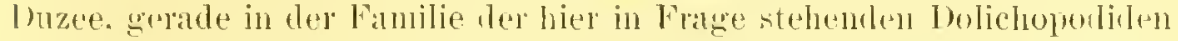
Wertrolles geleistet worlen ist, das nuter anderen I'mstimblen mberlingt

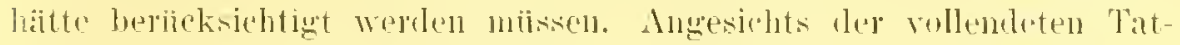
saldene will ioh mun wenigrstens im Nachtrage die in Fralge kommenden neneren Arbeiten. someit sir mil besannt geworlen sind. ihrem Titel zinl luhalt nald angeben. wie folgt:

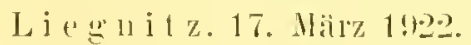

Th. Becker. 


\section{Amerikanische Literatur.}

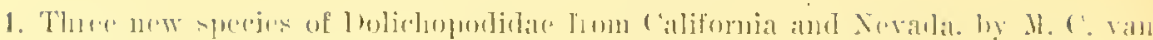

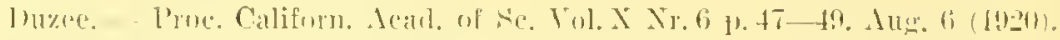

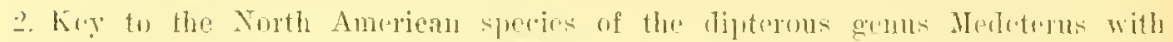

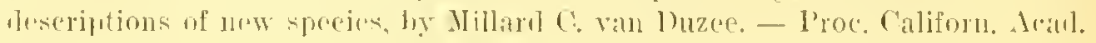

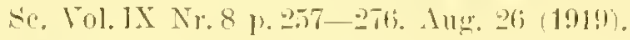

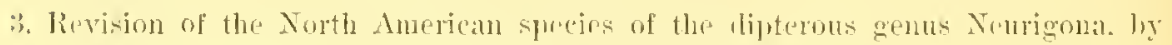

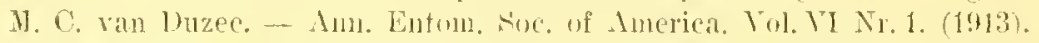

4. Biolngieal Recommasisane of thr okefonckee swamp region in Fenrgia. The

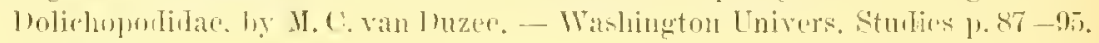
? (1912).

5. Synoptieal Table of the Nonth Anerican sincedes of the Dipterous cicnus sym-

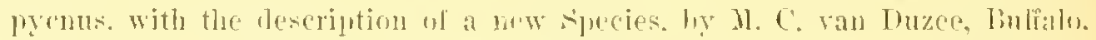
Xew York. - Entomological New. Tol. XXI p. 269-292. June (1913).

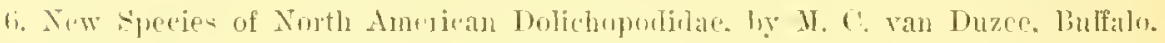
New Iork. - Entomol. News Tol. XXY p. tht-flli. Xov. (1914).

7. New species of North Ameriean Dolinhomdidat, ly M. C. van Dume, Buffalo, New York. - Estomol. News Tol. XXY 1. 193-143. 1)'z. (1914).

8. Derriptions of thee now species of the bipterons gems scialpus with a key

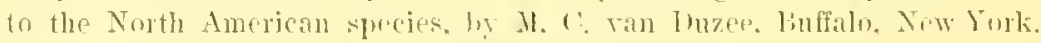

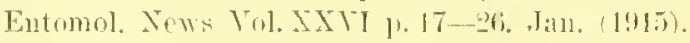

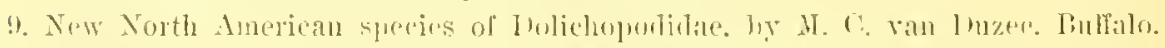

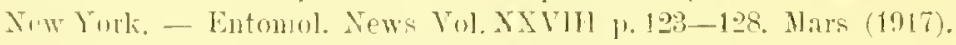

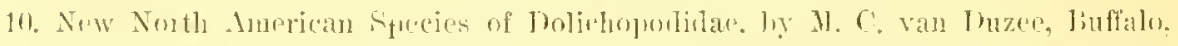

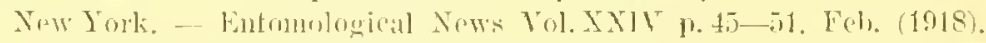

11. Two New Asyndetus with a Tallo of the North American Speries. Dy M. C. van luzer, Julfalo. New Yurk. - Entumul. Xews ]. 248-250. Nor. 1919).

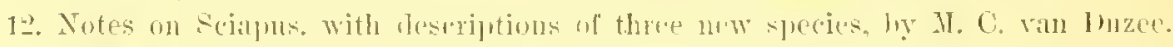

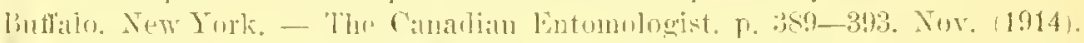

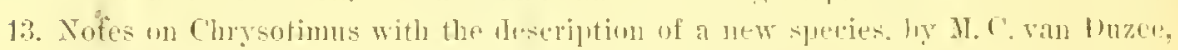

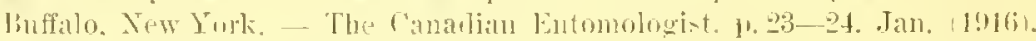

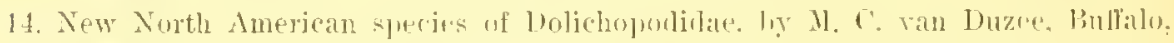

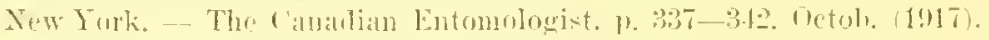

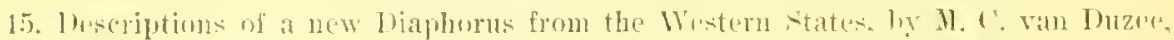

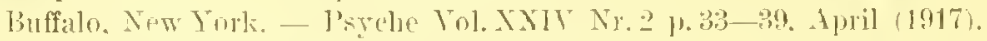

16. Tilhe of males of the North Ameriean species of the genus Asmotutus will

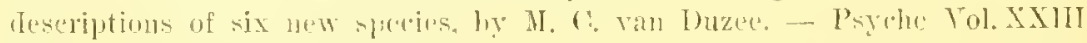

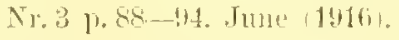

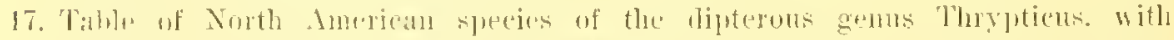

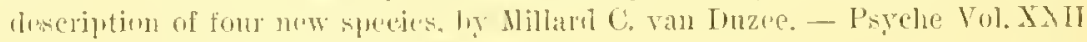
$\mathrm{Nr}, 3$ p. 84-88. Junc 11915$)$.

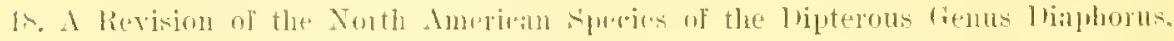

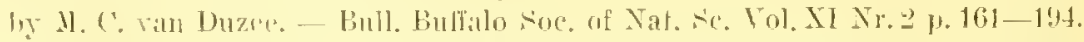

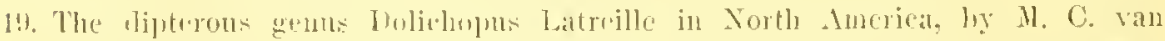
Huzer, F. R. Gole and I. M. Ahrich. - Sulthemian Institution, Lnited states

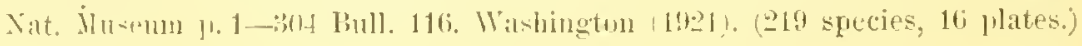







SMITHSONIAN INSTITUTION LIBRARIES 